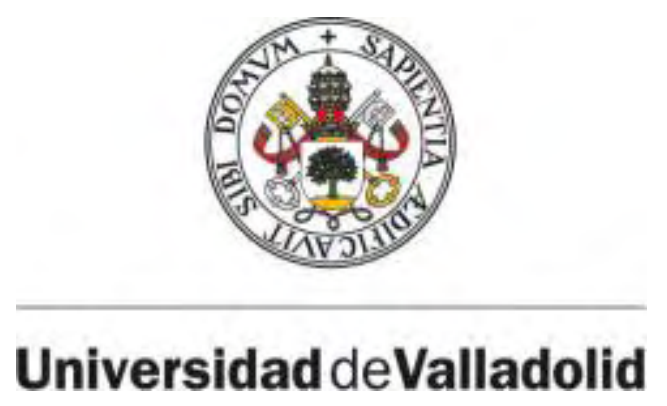

\author{
ESCUELA DE INGENIERÍAS INDUSTRIALES \\ DEPARTAMENTO DE INGENIERÍA ENERGÉTICA Y \\ FLUIDOMECÁNICA
}

TESIS DOCTORAL:

\title{
COMBUSTIÓN DE MEZCLAS DE GASÓLEO Y ACEITES VEGETALES PARA \\ SU USO COMO COMBUSTIBLE EN \\ CALDERAS DE BAJA POTENCIA
}

Presentada por Ismael Gobernado Arribas para optar al grado dedoctor por la Universidad de Valladolid

\section{Dirigida por:}

Dr. Julio San José Alonso

Dr. Fco. Javier Rey Martínez 


\section{CONTENIDO}

\section{CAPITULO 1}

ANTECEDENTES, JUSTIFICACIÓN Y OBJETIVOS

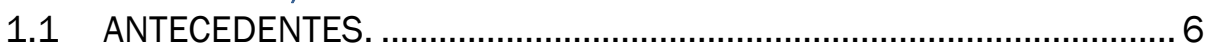

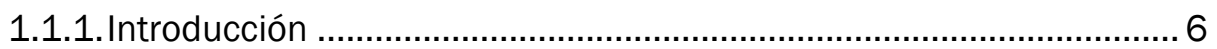

1.1.2. Escenarios energéticos. ............................................................. 9

1.1.2.1. Factores económicos............................................................. 9

1.1.2.2. Factores medioambientales................................................... 12

1.1.2.3. Limitaciones tecnológicas. ...................................................... 14

1.1.3. La biomasa en el contexto energético................................................16

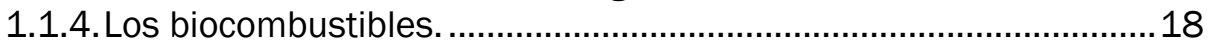

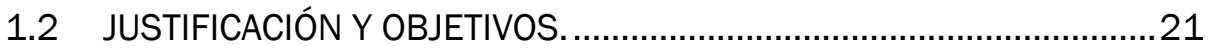

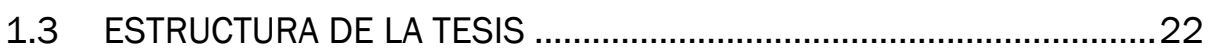

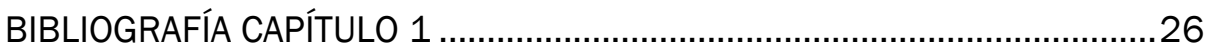

\section{CAPITULO 2}

\section{POTENCIAL DE BIOMASA EN CASTILLA Y LEÓN}

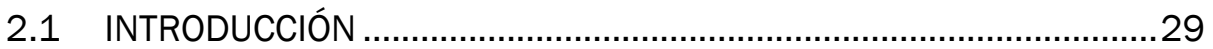

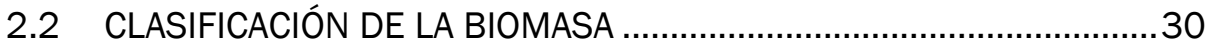

2.2.1. Clasificación de la biomasa por su origen ...........................................30

2.2.2. Clasificación de los biocombustibles según su estado .....................32

2.3 VALORACIÓN DE LOS POTENCIALES DE BIOMASA. ….......................33

2.4 DISPONIBILIDAD DE BIOMASA EN CASTILLA Y LEÓN. ........................35

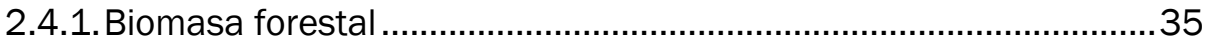

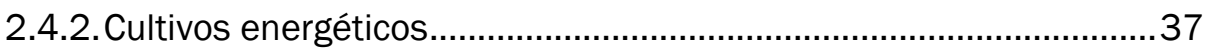

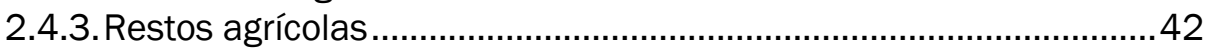

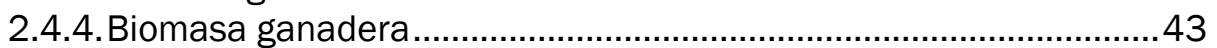

2.4.5. Restos de la industria de la madera....................................................4

2.4.5. Biomasa de origen urbano y de otras industrias..............................48

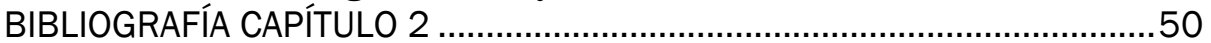

\section{CAPITULO 3}

COMBUSTIBLES

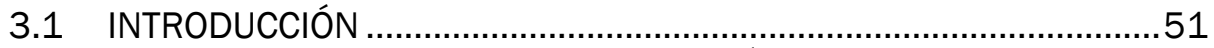

3.2 NATURALEZA DE LOS COMBUSTIBLES LÍQUIDOS .............................52

3.2.1.El aceite vegetal ...........................................................................5

3.3 CARACTERÍSTICAS FÍSICAS DE LOS COMBUSTIBLES. .....................57

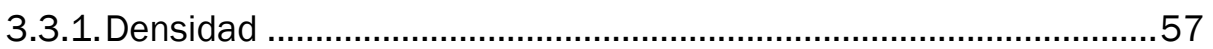

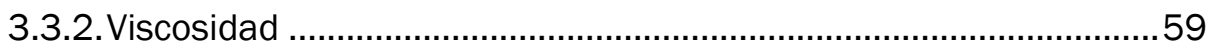

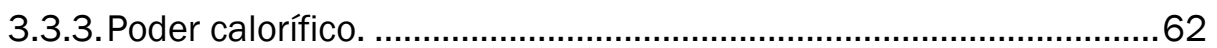

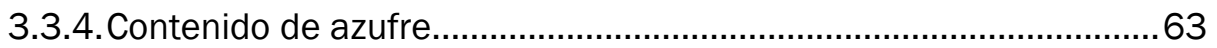

3.4. CARACTERIZACIÓN DE LAS MUESTRAS DE COMBUSTIBLES A

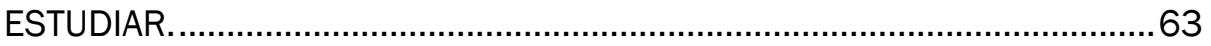

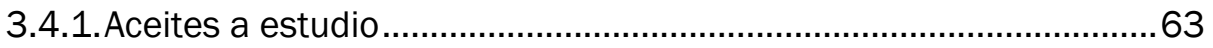

3.4.2. Caracterización de los aceites como combustibles............................68 
3.5. MISCIBILIDAD Y/O SOLUBILIDAD DE ACEITES EN GASÓLEO. 69

3.5.1. Caracterización de las mezclas....................................................... 71

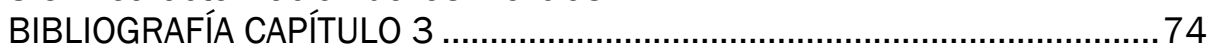

CAPITULO 4

COMBUSTION

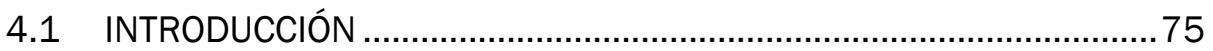

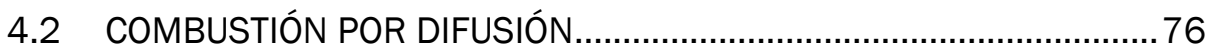

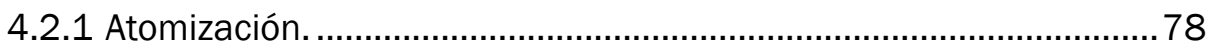

4.2.2 Atomizador de presión con rotación (PSN) utilizado .........................8 87

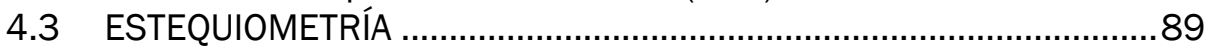

4.3.1 Determinación del aire de combustión ..............................................90

4.3.2 Determinación de los productos de la combustión ...........................92

4.4 HOJA DE CÁLCULO PARA EL ANÁLISIS DE LA COMBUSTIÓN DE LAS

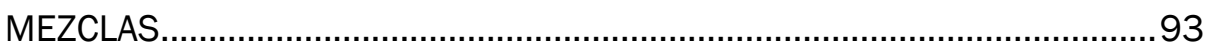

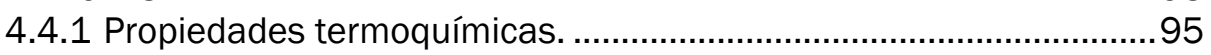

4.4.2 Poder calorífico de las muestras. ......................................................96

4.4.3 Rendimiento de la combustión .........................................................96

4.5 EMISIONES DE GASES DE COMBUSTIÓN ……..................................99

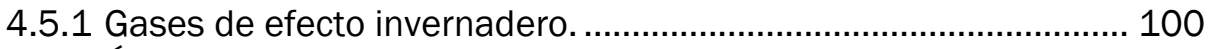

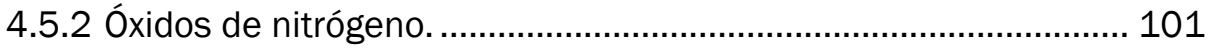

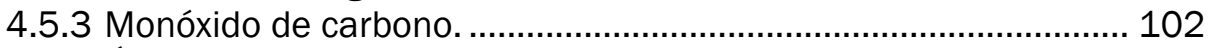

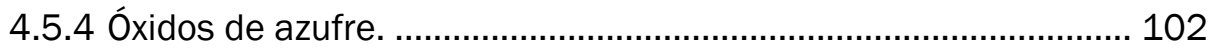

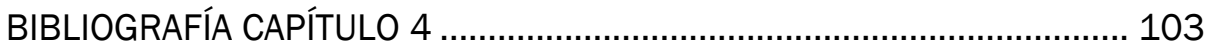

CAPITULO 5

INSTALACIÓN EXPERIMENTAL

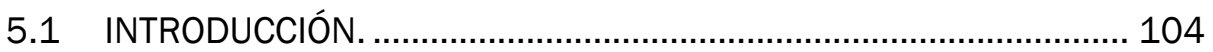

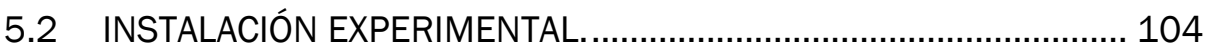

5.2.1 Sistema de alimentación de la mezcla.......................................... 105

5.2.2 Conjunto quemador-caldera......................................................... 108

5.2.3 Instalación de disipación............................................................. 114

5.2.4 Sistema de control y medida........................................................ 114

5.3 METODOLOGÍA DE ENSAYO..................................................... 116

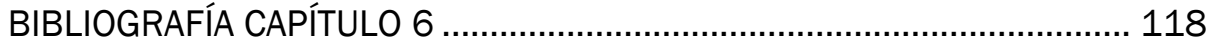

CAPITULO 6

DISEÑO DE EXPERIMENTOS

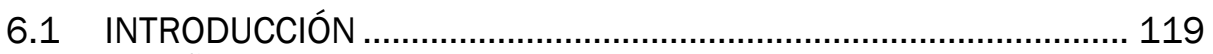

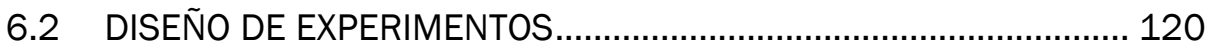

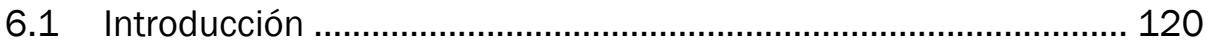

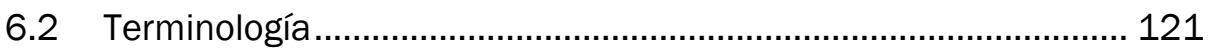

6.3 Técnicas de diseño de experimentos .......................................... 122

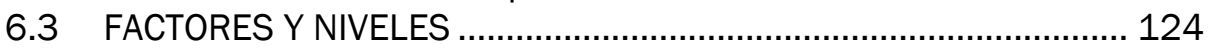

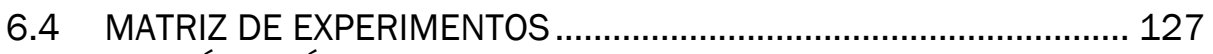

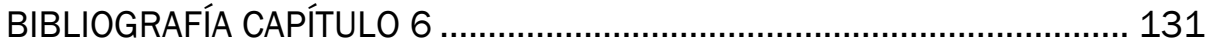




\section{CAPITULO 7}

\section{MEDIDAS EXPERIMENTALES}

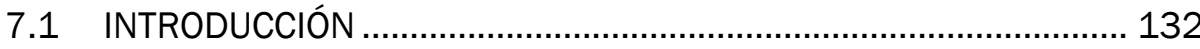

7.2 PROCESO DE ENSAYOS ............................................................. 133

7.3 PROBLEMÁTICA EN LA FASE DE EXPERIMENTACIÓN DE LOS

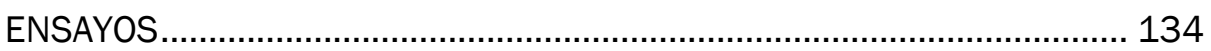

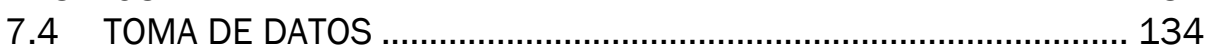

7.5 ANÁLISIS DE COMBUSTIÓN ........................................................... 135

7.5.1.Emisiones de gases contaminantes ........................................... 135

7.5.2. Eficiencia de la combustión ......................................................... 136

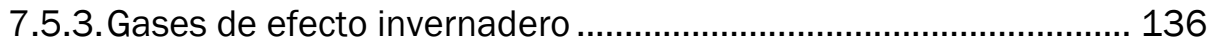

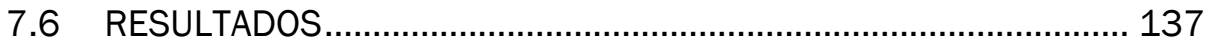

CAPITULO 8

ANÁLISIS DE RESULTADOS

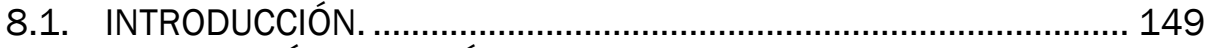

8.2. DESCRIPCIÓN DEL ANÁLISIS ANOVA ............................................ 150

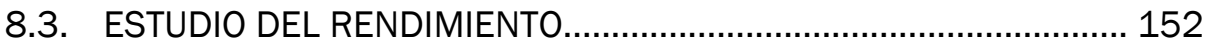

8.3.1. Análisis del rendimiento para $p=10$ bar...................................... 152

8.3.2. Análisis del rendimiento para $p=12$ bar....................................... 168

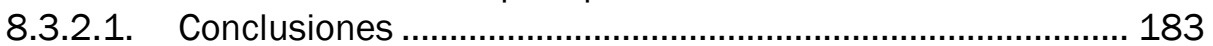

8.5.1.Análisis del rendimiento para $p=14$ bar...................................... 184

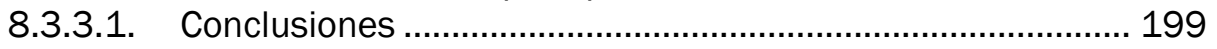

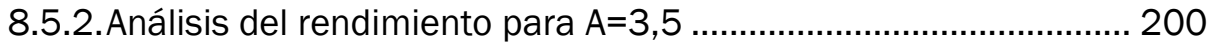

8.3.4.1. Conclusiones ................................................................. 214

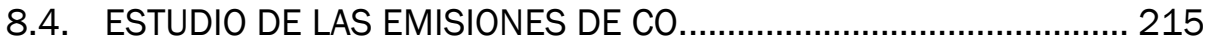

8.5.1. Análisis a de las emisiones de $\mathrm{CO}$ a $\mathrm{P}=10 \mathrm{BAR}$........................... 215

8.4.1.1. Conclusiones ..................................................................... 230

8.5.2. Análisis a de las emisiones de CO a P=12 BAR .............................. 231

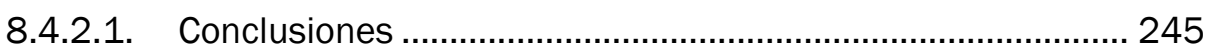

8.5.3. Análisis de las emisiones de CO a P=14 BAR ............................... 246

8.4.3.1. Conclusiones .................................................................. 261

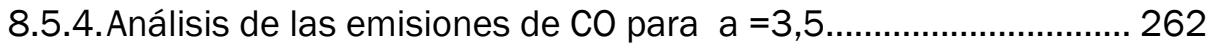

8.4.4.1. Conclusiones .................................................................... 277

8.5. ESTUDIO DE LAS EMISIONES DE NOx...................................... 278

8.5.1. Análisis de las emisiones de NOx para $\mathrm{P}=10$ bar ............................ 278

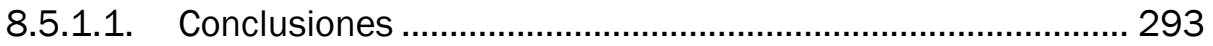

8.5.2. Análisis a de las emisiones de NOxa $P=12$ BAR ............................ 294

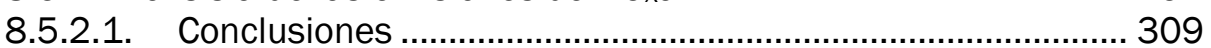

8.5.3. Análisis de las emisiones de NOxa P=14 BAR .............................. 310

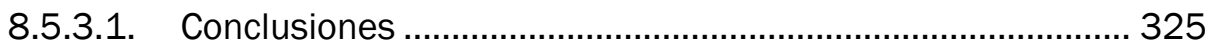

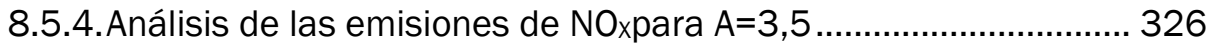

8.5.4.1. Conclusiones ................................................................ 341 
CAPITULO 9

CONCLUSIONES

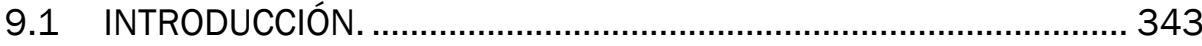

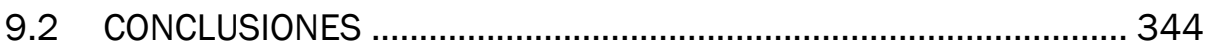

9.2.1. Los biocombustibles como recurso energético. ............................ 344

9.2.2. Caracterización de los biocmbustibles .......................................... 344

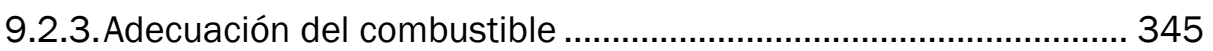

9.2.4. Combustión de las mezclas ........................................................... 345

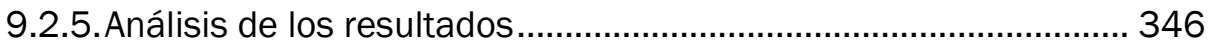

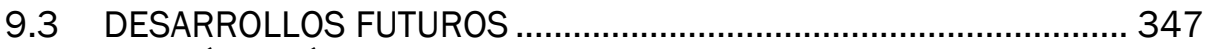

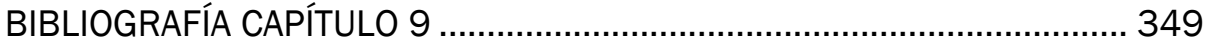

ANEXOS

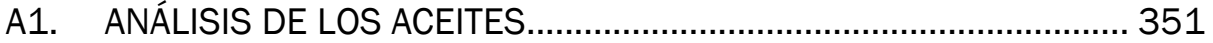

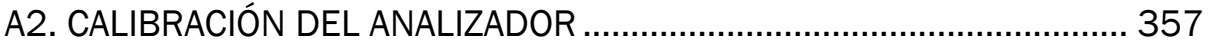




\section{$1.1 \quad$ ANTECEDENTES.}

\subsubsection{Introducción}

En el siglo XX la evolución de la sociedad ha estado estrechamente relacionado con la innovación tecnológica, que ha obligado a la explotación cada vez más intensa de las fuentes de energía ${ }^{1}$, esto ha dado protagonismo a las fuentes de energía y a su repercusión sobre el medio ambiente? ${ }^{2}$.

Este problema se espera se agrave durante el siglo XXI, debido al acceso al desarrollo económico y tecnológico de nuevas áreas geográficas del planeta, además las primeras etapas de desarrollo económico de los países vienen caracterizados por fuertes consumos de energía 3 .

El modelo actual puede clasificarse de injusto, limitado e insostenible económica y medioambientalmente. El desequilibrio entre países pobres y ricos, productores y consumidores es fuente de inestabilidad y conflictos.

1 Price, David, Energy and human evolution. Population and environment: a journal of interdisciplinary studies, vol. 16, Num. 4 (1995).

2 Robert A. Hefner, the grand energy transition: the rise of energy gases, sustainable life and growth, and the next great economic expansion, John Wiley \& Sons. (2009).

3 Dopazo, Cesar, Tendencias en el Sector Energético, Congreso la Energía, un Sector en transformación: Retos y Oportunidades, Valladolid (2010) 
El modelo energético por otra parte es decisivo para el crecimiento económico. 4

En este contexto, el modelo energético de los países desarrollados fija como estrategias: i) disponibilidad a medio y largo plazo, ii) confiabilidad, iii) coste y iv) impacto ambiental. Este nuevo enfoque se inscribe dentro del concepto de desarrollo sostenible. El término desarrollo sostenible se aplica al desarrollo socio-económico y fue formulado por primera vez en el documento conocido como Informe Brundtland5 (1987) fruto de los trabajos de la Comisión Mundial de Medio Ambiente y Desarrollo de las Naciones Unidas en 1983. El concepto de desarrollo sostenible se asumiría en el Principio $3^{\circ}$ de la Declaración de Rio sobre el Medio Ambiente y el Desarrollo (1992).

La preocupación por el agotamiento progresivo de las energías fósiles, junto con los problemas de cambio climático causados por el uso de dichas energíasy el principio de sostenibilidad, requieren un nuevo escenario energético.

La política energética europea aborda este nuevo escenario sobre tres conceptos: diversificación energética, eficiencia energética y sostenibilidad, la diversificaciónsigue siendo uno de los criterios fundamentales a la hora del planteamiento de una estrategia energética asumible, al tener obligatoriamente que seguir utilizando a medio plazo las fuentes fósiles e ir incrementando otras fuentes de origen renovable y energía nuclear ${ }^{6}$.

La eficiencia energética a escala de país se valora como la relación entre la energía primaria y el P.I.B. España presenta un ratio más desfavorables que el resto de la Unión Europea, la Intensidad energética es de las más altas, aunque también en los últimos años ha bajado. Aún así se sitúa muy por encima de los valores medios europeos, baste señalar, que España es el país europeo que menos mercancías transporta por ferrocarril aún siendo éste más eficiente que el transporte por carretera. ${ }^{7}$ Como se puede ver en la gráfica 1.1.

La sostenibilidad energética representada por el uso de energías renovables no presenta en España tampoco perspectivas económicas demasiado estables. Se han modificando primas con carácter retroactivo, recientemente se han suspendido temporalmente las primas a las

\footnotetext{
${ }^{4}$ Eurostat, Sustainable development indicators, Web Eurostat (2005).

${ }^{5} \mathrm{H}$. Brundtland, Informe "Our Commom Future", ONU (1987).

6 Becerril, Carmen, Opciones energéticas para la década 2010-2020: el lugar de las energías renovables, Congreso la Energía, un Sector en transformación: Retos y Oportunidades, Valladolid (2010)

${ }^{7}$ Club español de la energía, Conceptos de ahorro y eficiencia energética: Evolución y oportunidades, (2010).
} 
renovables para generación eléctricapor lo que se ha creado un marco de inseguridad que aleja posibles inversiones en ese campo al reducirse la rentabilidad y como consecuencia se producirán retrasos en alcanzar los objetivos ${ }^{8}$.

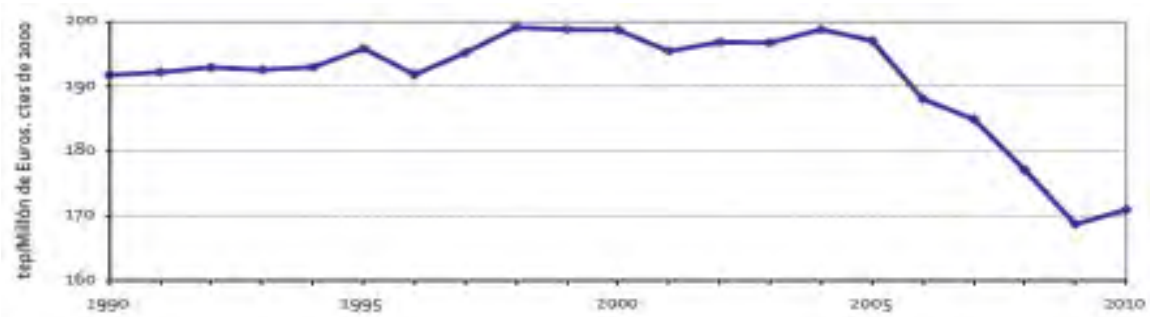

Gráfica 1.1: Intensidad energética en España (energía primaria/PIB)9

La evolución de la incidencia de las energías renovables en P.I.B. de España se presenta en la tabla 1.1.

Tabla 1.1: Contribución directa al P.I.B. por tecnologías en millones de euros 10

\begin{tabular}{|l|c|c|c|c|c|c|}
\hline Millones de $€$ & 2005 & 2006 & 2007 & 2008 & 2009 & 2010 \\
\hline Biocarburantes & 71,4 & 81,7 & 87,5 & 90,2 & 2009,1 & 334,8 \\
\hline Biomasa & 665,6 & 657,5 & 668,3 & 698,6 & 661,3 & 702,9 \\
\hline Eólica & $1.444,1$ & $1.728,3$ & $1.933,1$ & $2.311,0$ & $1.953,0$ & $1.813,3$ \\
\hline Geotermia alta temp. & 3,8 & 6,4 & 8,0 & 10,7 & 12,0 & 13,6 \\
\hline Geotermia baja temp. & 1,2 & 1,5 & 2,1 & 4,0 & 8,0 & 14,4 \\
\hline Minihidráulica & 351,2 & 403,4 & 328,6 & 375,4 & 348,2 & 406,4 \\
\hline Marina & 2,6 & 3,6 & 4,4 & 5,0 & 6,0 & 7,7 \\
\hline Minieólica & 30,1 & 26,1 & 29,4 & 32,8 & 33,8 & 39,0 \\
\hline Solar fotovoltaica & 228,7 & 253,1 & 300,2 & $1.216,6$ & $2.716,9$ & $2.774,9$ \\
\hline Solar termoeléctrica & --- & 3,9 & 34,9 & 61,1 & 212,2 & 637,1 \\
\hline $\begin{array}{l}\text { Contribución directa al } \\
\text { PIB }\end{array}$ & $2.798,7$ & $3.165,7$ & $3.396,4$ & $4.805,4$ & $6.170,5$ & $6.744,0$ \\
\hline
\end{tabular}

La respuesta Europea desde el tratado de Lisboa es utilizar la política energética y las energías renovables como la locomotora del desarrollo

\footnotetext{
8 Secretaría de Estado de energía, Ministerio de Industria, Turismo y Comercio, Informe de Sostenibilidad Ambiental del Plan de Energías Renovables 2011-2020Gobierno de España 2011.

9 Secretaría de Estado de Energía Ministerio de Industria, Turismo y Comercio, Energía en España 2010, Gobierno de España (2011).

10 APPA Estudio del impacto Macroeconómico de las energías renovables en España, año 2010, Madrid, 2010
} 
económico, La Directiva 2009/28/CE del Parlamento Europeo y del Consejo, de 23 de abril de 2009, el SET Plan (EuropeanStrategicEnergyTechnology Plan) marcan los objetivos de la política energética comunitaria y establecen los objetivos que deberán cumplirse en los próximos años ${ }^{11}$.

\subsubsection{Escenarios energéticos.}

Cualquier escenario energético debe responder a tres retos: el económico, el medioambiental y el tecnológico, aunque en muchos casos no es fácil la separación de los campos por las interrelaciones entre ellos.

\subsubsection{Factores económicos.}

La crisis energética de los años 1973 y 1974 hizo que los países industrializados orientaran sus políticas energéticas hacia escenarios de menor consumo relativo de energía y a una mayor seguridad en los suministros. Casi cincuenta años después los países desarrollados siguen buscando tanto la estabilidad en el consumo energético como la seguridad de los suministros de energía ${ }^{12}$. Baste observar la gráfica 1.2de precios del petróleo crudo Brent en los últimos 30 años en dólares por barril para observar la poca estabilidad del mismo.

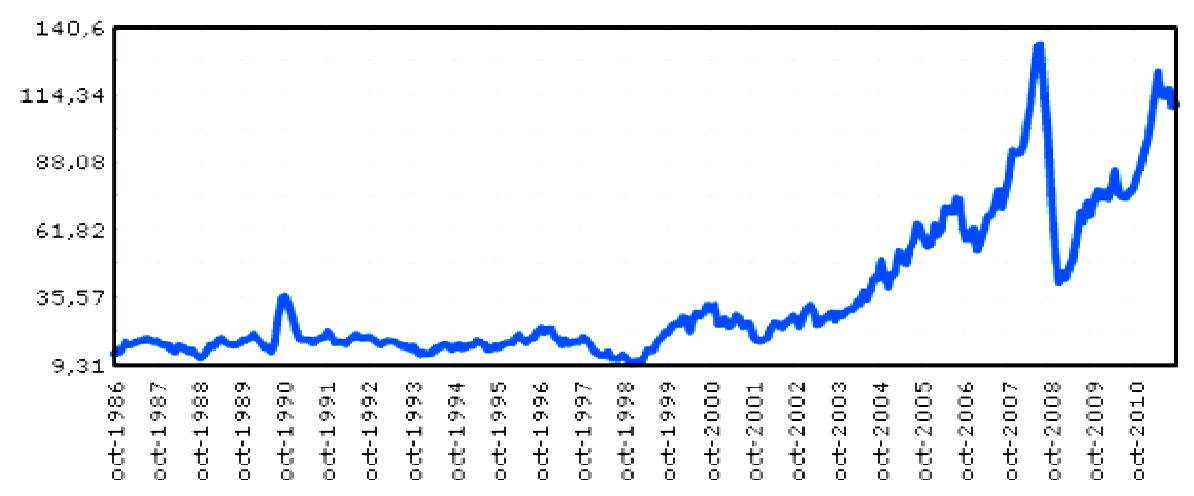

Gráfica 1.2: Evolución del precio del petróleo crudo Brend. Fuente: US EnergylnformationAdministration ${ }^{13}$.

Sería fácil identificar por las fechas de los repuntes del precio las distintas crisis mundiales, Guerra entre Irán e Irak, Invasión de Irak a Kuwait, Crisis de Irán, etc.

\footnotetext{
${ }_{11}$ Diario Oficial de la Unión Europea C 306, de 17/12/2007 “Tratado de Lisboa" 2007.

12 Club español de la energía, Política energético y medioambiental en la Unión Europea. Situación y perspectivas, 2009.

13 http://www.platts.com
} 
Estos problemas se ven agravados por la forma tan heterogénea en que los recursos están repartidos en el planeta, lo que provoca que existan países con un alto consumo energético sin reservas energéticas y viceversa, en la figura 1.1 se puede observar cómo se distribuyen las diferentes fuentes fósiles en el planeta. ${ }^{14}$

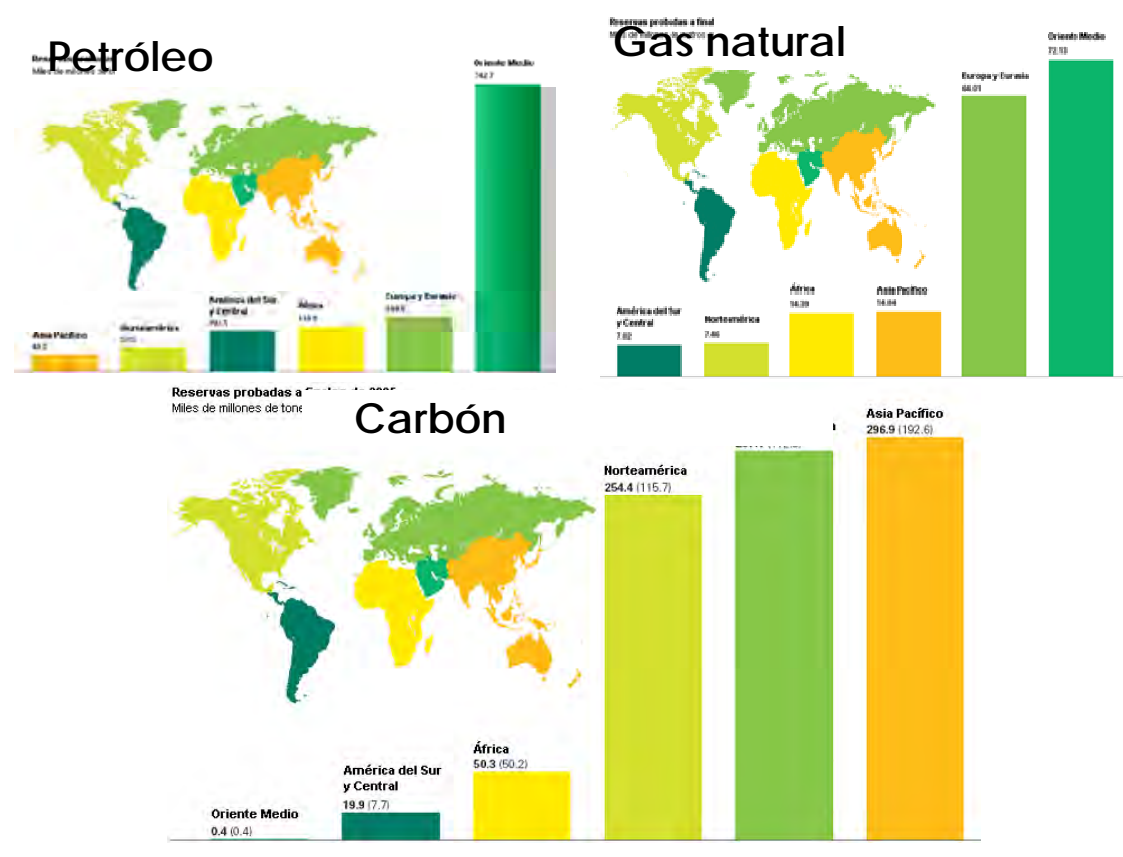

Figura 1.1: Localización geográfica de las reservas en el planeta.

La elevada dependencia energética es una constante en los países de la OCDE, España se sitúa entre los de cabeza con una dependencia sobre el $80 \%$. La dependencia ha bajado en los últimos años debido a la reducción del consumo total lo que hace que la contribución de las energías renovables aumentara y disminuyera la dependencia, se puede observar en la tabla $1.2^{15}$.

${ }^{14}$ BP Statistical Review of World Energy 2006.

15 IDAE, Ministerio de Industria, Turismo y Comercio, Observatorio de energías renovables, julio 2010. 
Tabla 1.2: Evolución de la energía primaria en España. ${ }^{16}$

\begin{tabular}{|c|c|c|c|c|c|}
\hline \multirow{2}{*}{$\begin{array}{c}\text { Energía } \\
\text { primaria }\end{array}$} & \multicolumn{2}{|c|}{2008} & \multicolumn{2}{c|}{2009} & \multirow{2}{*}{$\begin{array}{c}\text { Variación } \\
08 / 09\end{array}$} \\
\cline { 2 - 5 } & ktep & Estruct. & ktep & Estruct. & \\
\hline Carbón & 13.983 & $9,8 \%$ & 10.353 & $7,9 \%$ & $-26,0 \%$ \\
\hline Petróleo & 68.182 & $47,9 \%$ & 63.673 & $48,8 \%$ & $-6,6 \%$ \\
\hline Gas natural & 34.782 & $24,4 \%$ & 31.104 & $23,8 \%$ & $-10,6 \%$ \\
\hline Nuclear & 15.368 & $10,8 \%$ & 13.750 & $10,5 \%$ & $-10,5 \%$ \\
\hline $\begin{array}{c}\text { Energías } \\
\text { renovables }\end{array}$ & 10.942 & $7,7 \%$ & 12.325 & $9,4 \%$ & $12,6 \%$ \\
\hline $\begin{array}{c}\text { Saldo } \\
\text { eléctrico }\end{array}$ & -949 & & -697 & & \\
\hline Total & 142.308 & & 130.508 & & $-8,3 \%$ \\
\hline
\end{tabular}

En el año 2010 las importaciones de petróleo y gas por valor de 34.500 M€ ha supuesto el $66 \%$ del déficit comercial total, lareducción de consumo y el cambio de las fuentes de energía fósiles por renovables se hace inevitable a corto plazo.

A todo lo anterior hay que añadir, el agotamiento de las fuentes de energías fósiles debido a la sobre explotación durante todo el siglo XX, existen multitud de estudios que fijan un periodo de máximo consumo y después prevén la desaparición de estas fuentes, si bien el incremento decostes provoca que año tras año se incrementan las reservas energéticas, en la figura 1.2, se observa una de estas previsiones. ${ }^{17}$

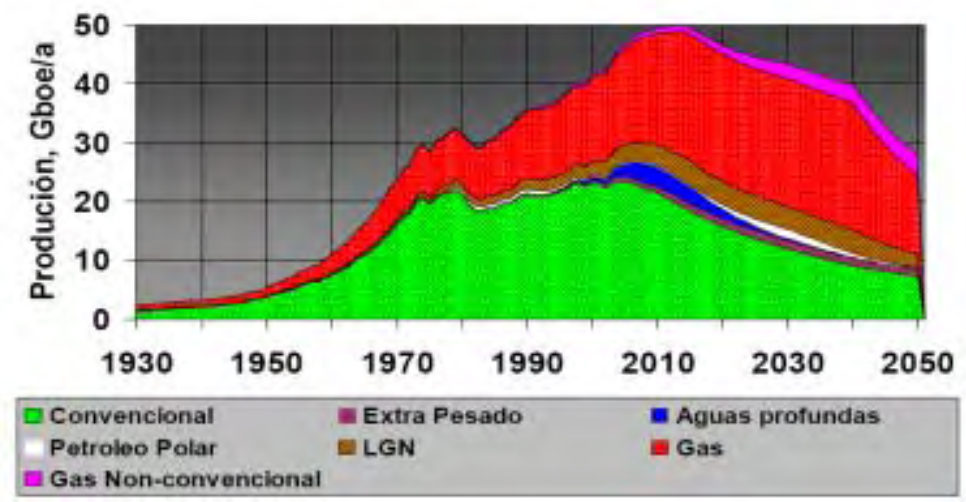

Figura 1.2: Evolución de la producción de combustibles en el mundo

16 APPA, Estudio del Impacto Macroeconómico de las Energías Renovables en España, año 2010, Madrid 2010.

${ }^{17} \mathrm{G}$. Wolff, ¿Se puede prescindir de los combustibles derivados del petróleo? Jornadas Retos y problemas de combustibles actuales, Universidad de Valladolid, noviembre 2009. 
Las energías fósiles presentan los siguientes problemas: i) la inestabilidad y aumento de los precios, ii) la excesiva dependencia de un recurso distribuido de forma heterogénea en el planeta y iii) la previsión de agotamiento de las fuentes. Estas amenazas han provocado que desde 1991 el Consejo Europeo hiciera el primer programa europea de ahorro y eficiencia energético conocido como SAVE ("SpecificActionsforVigorousEnergyEfficiency"), que sucesivamente ha ido actualizando hasta el actual programa Energía Inteligente- Europa (20072013). ${ }^{18}$

El Consejo Europeo ha adoptado unos objetivos ambiciosos para el 2020: los objetivos 20-20-20, que representan: reducir el consumo previsto para el 2020 en un $20 \%$, reducción al menos un $20 \%$ las emisiones de efecto invernadero de 2020 en comparación con 1990 y lograr que las energías renovables representen el 20\% del consumo energético de la EU en 2020. Estos objetivos se recogen en el Libro Verde sobre la estrategia europea para la energía, que perfila la nueva política energética europea, 19 y la Comunicación de la comisión "Dos veces 20 para el 2020 - El Cambio Climático una oportunidad para Europa” 20.

\subsubsection{Factores medioambientales.}

Las estrategias energéticas y medioambientales de los países desarrollados van encaminadas a la reducción del consumo de energía y a la reducción del impacto ambiental que generan sobre todo el empleo de combustibles fósiles.

El protocolo de Kioto, vencido recientemente (2012) y prorrogado en la cumbre de Durban hasta 2015, los compromisos de la Cumbre de Bali de diciembre de 2007 y los de la Cumbre de Copenhague, diciembre de 2009 , fijan objetivos hasta el año 2020, aunque dichos compromisos no son vinculantes marcan una tendencia de fuerte reducción de las emisiones para que la temperatura media del planeta no supere los $2^{\circ} \mathrm{C}^{21}$.

En el caso de la Unión Europea, junto con la disminución de emisiones de GEI se plantean retos en la política energética respecto a la seguridad del

\footnotetext{
18 R. Sánchez Durán, Marco legal Europeo y Español, Conceptos de ahorro y eficiencia energética: Evolución y oportunidades, Club Español de la energía (2010).

19 Superficies y producciones de cultivos agrícolas de tipo herbáceo en Castilla y León. Instituto Tecnológico Agrícola de Castilla y León (ITACYL), 2005- 2007

20 DIRECTIVA 2003/30/CE DEL PARLAMENTO EUROPEO Y DEL CONSEJO de 8 de mayo de 2003 relativa al fomento del uso de biocarburantes u otros combustibles renovables en el transporte 2003 ${ }^{21}$ Report of the Conference of the Parties on its fifteenth session, held in Copenhagen from 7 to 19 December 2009.
} 
suministro y a la dependencia exterior de sus fuentes de energía ya recogidos en el Libro Verde ${ }^{22}$ del año 2001.

El Consejo Europeo en la "Comunicación de la Comisión al Parlamento Europeo, al Consejo, al Comité Económico y Social y al Comité de las Regiones", dos veces 20 para el 2020, El cambio Climático, una oportunidad para Europa, fija los dos objetivos fundamentales 23 :

- Reducción de al menos un $20 \%$ de emisiones de GEI.

- La aportación al consumo de energía de la UE en 2020 de lasenergías renovables sea de un $20 \%$.

Para el cumplimiento de este último objetivo la UE articula la Directiva 2009/28/CE del Parlamento Europeo y del Consejo, de 23 de abril de 2009 con el objetivo del fomento de las energías renovables.

La transposición a la legislación española se realiza a través del Artículo 78 de la Ley 2/2011 de 4 de Marzo, de Economía Sostenible donde se fijan los objetivos nacionales en materia de ahorro y eficiencia energética y energías renovables. Reconoce esta Ley la necesidad de orientar las políticas y los incentivos públicos al desarrollo de las diversas fuentes de energía y a la mejora de la eficiencia energética. Las medidas concretas se recogen el PANER ${ }^{24}$ (Plan de Acción nacional de energías renovables) y en el PER

Estos objetivos en resumen, suponen un 20 por ciento de participación en el consumo de energía final de las energías renovables, incluyendo una participación en todos los tipos de transportes de un mínimo equivalente al $10 \%$ del consumo total de energía del sector transporte.

Al mismo tiempo fija un objetivo general de reducción de demanda de energía primaria de acuerdo con el objetivo de la Unión Europea del $20 \%$ en 2020.

Para dar cumplimiento a la Directiva 2009/28/CE sobre la adopción por cada estado miembro de un plan de acción en materia de energía renovable se aprueba el PANER 2011-2020 (Plan de Acción Nacional de Energías Renovables) desarrollado según los requerimientos y la metodología de la Directiva Europea, recogiendo en él las aportaciones de las distintas Comunidades Autónomas.

\footnotetext{
${ }^{22} \mathrm{Hacia}$ una estrategia Europea de seguridad del abastecimiento energético. (2001).

${ }^{23}$ Comunicación de la Comisión al Parlamento Europeo, al Consejo, al Comité Económico y Social Europeo y al Comité de las Regiones, “Dos veces 20 para el 2020 El cambio climático, una oportunidad para Europa"Bruselas, 23.1.2008 COM 2008

24 Plan de Acción nacional de energías renovables 2011-2020 (30 de Junio 2010)
} 
El PER, (Plan de energías renovables) pendiente de su aprobación, desarrolla los elementos esenciales del PANER junto con análisis adicionales no contemplados en él y un estudio por sectores conteniendo las perspectivas de evolución tecnológica y la evolución esperada en costes.

\subsubsection{Limitaciones tecnológicas.}

La tecnología es elemento fundamental en la mejora de la eficiencia energética y en el aprovechamiento de las energías renovables, la utilización de tecnologías inadecuadas produce: reducción en la eficiencia del sistema, incremento de costes e incrementa el impacto medioambiental. Así la inversión requerida por las instalaciones de producción de energía final hace que, en general, el coste total de producción de un kWh de electricidad sea alrededor del doble del coste que supone ahorrar ese kWh. Desde este punto de vista, las inversiones en la mejora de la eficiencia energética tienen casi siempre un efecto positivo en el empleo. ${ }^{25}$

La clasificación de las tecnologías se realiza atendiendo a la cadena de valor de la energía. Así se distingue entre tecnología de: oferta, demanda y consumo.

Dentro de las tecnologías de oferta se incluirán aquellas que transforman la energía primaria en final, es decir las referidas a la transformación de la energía.

Las tecnologías de demanda se refieren a la utilización a la que está destinada la energía como las del sector servicios: rendimiento de generadores térmicos, sistemas de control de la instalación, etc.

Las tecnologías de consumo se refieren al estilo de vida, ocio, hábitos, así, las que ofrecen alternativas a los hábitos de uso permiten un consumo más racional y por tanto un comportamiento eficiente. Éstas tienen un efecto multiplicador ya que evitan producirla y, por tanto, también se evita las consiguientes pérdidas en transformación y su distribución para el consumo.

La tecnología de oferta se ve influenciada por el origen de la fuente primaria y la energía final a obtener, existiendo una gran variedad de posibilidades y tecnologías asociadas, la situación actual se puede resumir en la figura 1.3.

${ }^{25}$ SAVE study, ACE, UK. National and local employment impacts of energy efficiency investment programmers, (2000). 


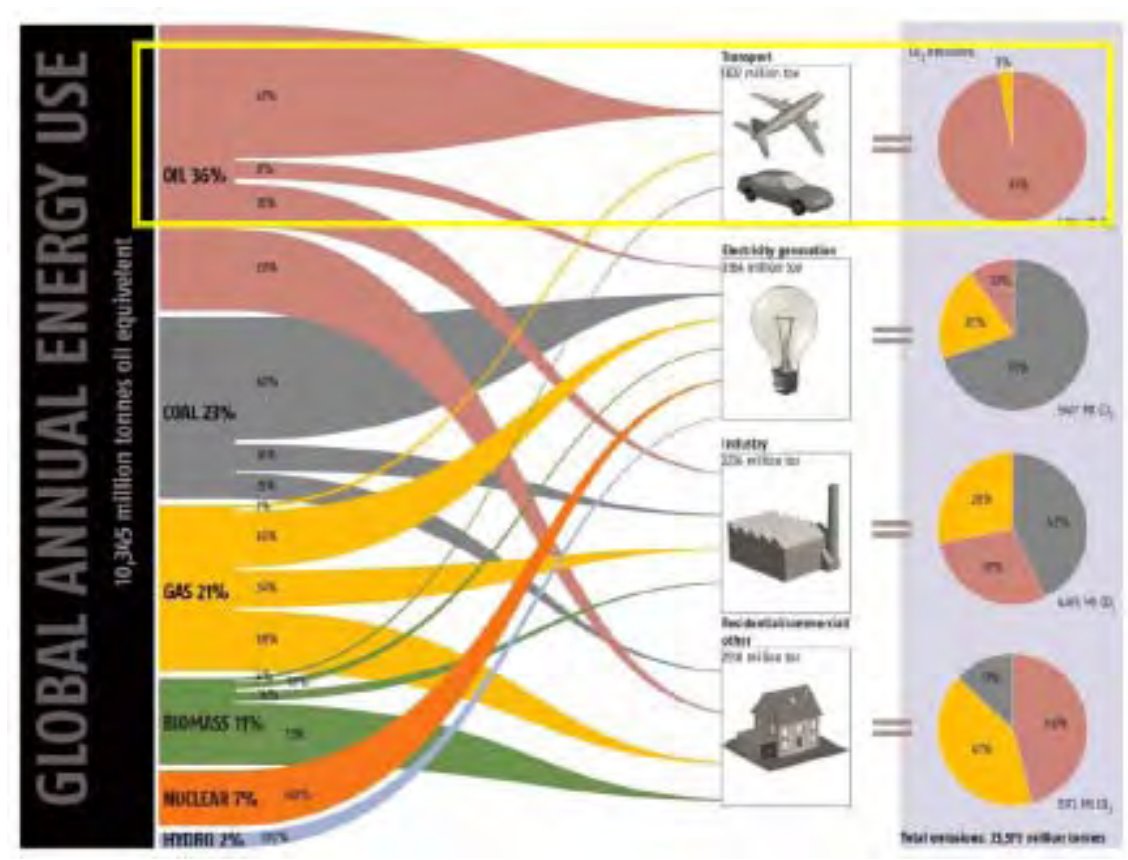

Figura 1.3: relación entre fuente de energía primaria y fuente de energía final. 26

El desarrollo de la presente tesis se basa en el estudio de la combustión de mezclas de aceites vegetales con gasóleo, incide por lo tanto directamente en el empleo de biomasa aunque de forma complementaria al uso de combustible fósil, al objeto de aprovechar la tecnología desarrollada y existente para estos combustibles.

La utilización de la biomasa requiere un análisis detallado del tipo de biomasa y el proceso de transformación más adecuado. En la tabla 1.3 se presenta la tecnología más adecuada según el origen de la biomasa, Tinaut ${ }^{27}$.

La biomasa puede tener que ser transformada en un producto energético intermedio (biocombustibles, pellets, etc.); este proceso debe ser lo más simple posible, repetitivo y que no incida excesivamente en el precio final de la energía. El uso final de la biomasa o de su producto intermedio puede ser obtener energía mecánica u obtener energía térmica. La obtención de energía mecánica requiere de motores térmicos, los cuales han llegado a un punto de ajuste, que obliga a los biocarburantes a poseer unas propiedades con límites muy estrechos, que requiere de

${ }^{26}$ EIQ. Energy International Quarterly Mayo/Junio 2010

${ }^{27}$ Tinaut F., "Biomasa: la energía renovable con mayor potencial", Jornadas sobre Energías Renovables, Cátedra de Energías Renovables de la Universidad de Valladolid, Abril de (2004). 
elevados controles en toda la cadena de valor de los biocarburantes ${ }^{28}$, lo que encarece el producto. La obtención de energía térmica permite muchas más posibilidades, aunque el valor de esta energía es inferior.

\begin{tabular}{|c|c|c|c|c|c|c|c|}
\hline \multirow[b]{3}{*}{ Tipo de Biomasa } & \multicolumn{7}{|c|}{ Tecnología más adecuada } \\
\hline & \multicolumn{3}{|c|}{ Termoquímicas } & \multicolumn{3}{|c|}{$\begin{array}{l}\text { Químicas y } \\
\text { biológicas }\end{array}$} & \multirow{2}{*}{ 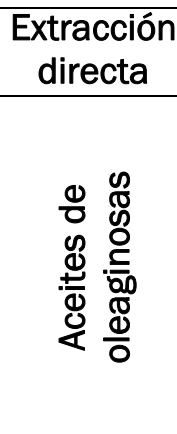 } \\
\hline & 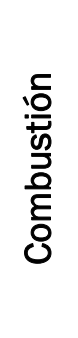 & 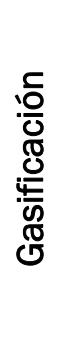 & $\frac{\frac{\infty}{0}}{\frac{0}{0}}$ & 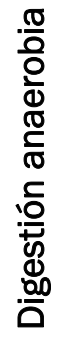 & 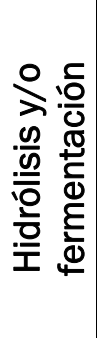 & 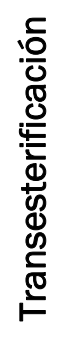 & \\
\hline $\begin{array}{l}\text { Residuos } \\
\text { forestales }\end{array}$ & & & & & & & \\
\hline Residuos agrícolas & & & & & & & \\
\hline $\begin{array}{l}\text { Cultivos } \\
\text { energéticos }\end{array}$ & & & & & & & \\
\hline $\begin{array}{l}\text { Residuos } \\
\text { ganaderos }\end{array}$ & & & & & & & \\
\hline $\begin{array}{l}\text { Industria } \\
\text { agroforestal } \\
\text { alimentaria }\end{array}$ & & & & & & & \\
\hline
\end{tabular}

Tabla 1.3: Tecnología más adecuada según el origen de la biomasa.

\subsubsection{La biomasa en el contexto energético.}

El uso de la biomasa con fines energéticos hoy día tiene dos limitaciones: la sostenibilidad de la biomasa 29 y no ser usada otros fines ${ }^{30}$, especialmente alimentarios, con estas restricciones la definición de biomasa sería el conjunto de materia orgánica renovable, de origen vegetal o animal no utilizable para consumo humano o industrial y que mediante procesos fisicoquímicos o bioquímicos puede transformarse en energía.

\footnotetext{
${ }^{28}$ European Norm 14214, Automotive fuels - Fatty Acid Methyl Esters (FAME) for Diesel Engines, Requirements and Test Methods, EU, 2009.

29 Directive 2009/28/EC of the European Parliament and of the councilof 23 April 2009.

30 Organización de las Naciones Unidas para la Agricultura y la Alimentación, "El estado mundial de la agricultura y la alimentación 2008", Roma 2008.
} 
La reserva de biomasa es enorme, aunque la valoración del potencial energético presenta serias dificultades por la diversidad de su origen y por las múltiples formas de aprovechamiento, hay cierto consenso entre los criterios de instituciones internacionales AIE, ONU y sus órganos encargados el medio ambiente, la UE, etc. en que la biomasa representa la de mayor peso, con un objetivo para el 2020 del 60\% de las energías renovables y el $12-15 \%$ del consumo total de energía primaria. Estos valores varían sustancialmente de unos países a otros, en la actualidad constituye un 3\% de la demanda total de energía primaria en los países desarrollados, un $4 \%$ en la UE, frente a un 30-35\% en países subdesarrollados 31 .

Las sociedades desarrolladas no solo se caracterizan por el enorme consumo energético sino que también son generadores de una gran cantidad de residuos, muchos de ellos orgánicos, con un contenido elevado de energía y de materias primas. Es necesario el desarrollo de técnicas de valorización de dichos residuos como fuente de energía y de materias primas y que al mismo tiempo den solución a la acumulación de residuos, en el caso de los orgánicos son fuente de generación de Gases de Efecto Invernadero, GEl de gran Potencial de Calentamiento Global, PCG, como el caso del Metano, con un índice de PCG de 62. Otros residuos son causa de otros problemas, como el caso de los residuos forestales que pueden ser fuentes de incendios forestales 32 .

La biomasa puede también provenir de cultivos específicos para producción de combustibles, a modo general las plantas pueden ser fermentables como los cereales o la caña de azúcar, que dan origen a alcoholes o plantas oleaginosas para producción de aceites como colza, girasol, soja, etc. que pueden ser utilizados directamente como combustibles en calderas o mediante procesos como la transesterificación para su uso como biodiesel.

La política de desarrollo de la biomasa debe seguir estrictos criterios de sostenibilidad, desde organizaciones como la Food and Agriculture Organization de Naciones Unidas FAO en la Conferencia de Alto Nivel sobre Seguridad Alimentaria Mundial se alerta sobre la incidencia en los precios de los alimentos por el aumento de cultivos energéticos ${ }^{33}$.

Las políticas energéticas a las que estamos sujetos en nuestro ámbito próximo emanan de las Directivas de la CE que dejan la consecución de los objetivos globales a los distintos Estados miembros y son estos

31 D.L. Klass, Biomass for renewable energy, fuels, and chemicals, ISBN 10:0-12-410950-0 Londres 1998.

$32 \mathrm{M}$. Lauer, Current terrestrial methods and activities for biomass potential assessment in Europe, 17th European Biomass Conference \& Exhibition, Hamburg 2009.

${ }^{33}$ Organización de las Naciones Unidas para la Agricultura y la Alimentación, "El estado mundial de la agricultura y la alimentación 2008", Roma 2008. 
últimos los que han de establecer la cuota de energía procedente de fuentes renovables.

La Comunidad establece a través de la Directiva 2009/28/CE los mecanismos de supervisión, control y procedimientos y criterios de valoración, cálculo de parámetros, criterios de sostenibilidad, métodos de cálculo de emisiones de $\mathrm{GEI}$, etc ${ }^{34}$.

En el PANER se recoge la estimación de la contribución total previsible de cada tecnología de energía renovable en España al cumplimiento de los objetivos vinculantes para 2020 y trayectoria indicativa correspondientes a las cuotas de energía procedentes de recursos renovables en los distintos sectores 35 .

\subsubsection{Los biocombustibles.}

Los denominados biocombustibles son todos aquellos combustibles líquidos obtenidos a partir de productos agrícolas, grasas animales y plantas marítimas. Como criterio general, se considera cualquier biocombustible líquido, aquel que pueda ser utilizado en una central térmica en sustitución de combustibles fósiles. ${ }^{36}$

Los aceites vegetales y animales han sido empleados comúnmente por el hombre como combustible para iluminación. Se datan lámparas de terracota de 7.000 a 8.000 A.C. encontradas en las planicies de Mesopotamia. Las colecciones de lámparas de aceite de todos los materiales y estilos constituyen piezas habituales en todos los museos arqueológicos.

Todas las culturas han utilizado aceites para las lámparas, junto con las velas y se han esforzado en aumentar la eficiencia de la iluminación, Hero de Alejandría en el siglo I D.C. inventó una lámpara alimentada por una columna de aceite en la que la presión de la columna alimentaba la mecha, Leonardo Da Vinci perfeccionó el invento añadiendo una lente de cristal. Las aportaciones continuaron consiguiendo lámparas con iluminación constante y de gran eficacia.

En el año 1830 Reichenbach y el Dr. Christiandescubrieron el queroseno y el uso de las lámparas de petróleo y queroseno se universalizaron desplazando al aceite al producir mejor iluminación.

34DIRECTIVA 2009/28/CE DEL PARLAMENTO EUROPEO Y DEL CONSEJO

de 23 de abril de 2009relativa al fomento del uso de energía procedente de fuentes renovables y por la que se modifican y se derogan las Directivas 2001/77/CE y 2003/30/CE

35Plan de Acción Nacional de Energías Renovables de España (PANER) 2011 - 2020 , 30 de Junio de 2010

36European Biodiesel Board General Assembly, Annual Report 2006-07, p. 73, Nov. 2007. 
En la actualidad el empleo de biomasa para usos térmicos está muy extendido y constituye una de las herramientas para hacer frente a la dependencia energética de los combustibles fósiles, a la reducción de la emisión de GEl y para contribuir al desarrollo agrario.

Obermberger I. realiza una exhaustiva revisión sobre las tecnologías asociadas a cada tipo de biomasa para su combustión con fines térmicos, estableciendo sus pros y sus contras ${ }^{37}$, los trabajos realizados en el Centro de Investigación de Recursos y Consumos Energéticos (CIRCE) de la Universidad de Zaragoza sobre la Co-combustión 38 y la revisión bibliográfica realizada por Spliethoff 39

Existen trabajos sobre el aprovechamiento de la biomasa con fines térmicos, Batey 40 realiza estudios sobre la combustión de biodiesel y mezclas de aceite y gasóleo en instalaciones residenciales de combustión, Vanlaningham ${ }^{41}$ estudia la combustión con fines térmicos del aceite de semilla de soja, San Josét2que estudia la combustión de mezclas de aceite de soja, colza y girasol con gasóleo en diferentes proporciones y con diferentes parámetros de combustión en un quemador de pulverización mecánica por presión y también estudia la combustión de biodiesel que no cumple con las especificaciones para biocarburante ${ }^{43}$.

Respecto al uso de grasas animales existen poca bibliografía, entre la que cabe destacar los trabajos realizados en la Universidad de Budapest el Dr. FerencLezsovits ${ }^{44}$ utilizó la grasa animal para investigar acerca de su utilización en generadores de vapor industriales que trabajaban originalmente con gasóleo o gas natural. La utilización de este subproducto se hizo no sólo con el propósito de deshacerse y eliminar estos residuos, sino también con el de utilizar un combustible no fósil.

\footnotetext{
37 I. Obernberger, Reached developments of biomass combustion technologies and future outlook, $17^{\text {th }}$ European Biomass Conference and Exhibition, Hamburgo 2009.

38 J. Royo, D. García, F. Sebastián y P. Canalís, La co-combustión: una alternativa para incrementar la contribución de la biomasa en el mercado eléctrico español. Centro de Investigación de Recursos y consumo Energéticos (CIRCE) (Universidad de Zaragoza), 2004.

${ }^{39}$ Spliethoff, H.; Hein, K.R.G. "Co-combustión of coal and Biomass. Suitability of Combustion Systems and State of the Art".IVD, University of Stuttgart. Symposium Co-combustion and Gbiofuels, Nijmegen/NL, 8-9 November 1995.

${ }^{40}$ Batey J., Combustión testing of a bio-diesel fuel oil blend in residential oil burning equipment, Tech. rep., Energy Research Center, prepared for: Massachusetts Oil hest Council \& National Oil heat Research Alliance,2003.

${ }^{41}$ Vanlaningham N., Gibson H., Kaufman B., "Evaluatión of soyben heating oil blends for use in residential applications", no. 046082, ASAE Paper,annual meeting held on August 23-24, 2004.

42 San José Alonso J.F, LópezSastre J.A., Romero-Avila C., "A note on the combustion of blends of diesel and soya, sunflower and rapeseed vegetable oils in a light boiler", Biomass \& Bioenergy 32880-886, 2008.

43 San José J., Awf Al-Kassir, LópezSastre J.A., Gañán J. “Analysis of biodiesel combustion in a boiler with a pressure operated mechanical pulverization burner",Fuel Processing Technology 92 271-277, 2011.

${ }^{44}$ Lezsovits F., Könczöl S., Sagát L..“Animal-fat firing investigation and realization in industrial steam generators".16th European Biomass Conference \&Exhibtion. Valencia 2008.
} 
Para aplicar esta tecnología fue necesario realizar una clasificación en función de las propiedades de cada grasa (por ejemplo, la evolución de la viscosidad y de la densidad con la temperatura). Posteriormente se comparó el funcionamiento de los generadores de vapor con dichas grasas con el de los combustibles de trabajo originales; se obtuvieron unos resultados prometedores pero hubo ciertos problemas en la regulación de potencia así como en el abastecimiento del combustible debido a la reducción de la vida útil de algunos elementos del quemador. Finalmente se modificaron los quemadores por otros rotatorios e integrados en la caldera, satisfaciendo así todos los requisitos, incluidos los ambientales.

En Alemania F. Pfab45 realizó un tratamiento y una posterior combustión de la grasa animal, proveniente de las plantas de transformación, para la generación de vapor en una caldera tubular. Antes de introducir la grasa en el quemador debe ser limpiada utilizando un decantador y un separador. La innovación introducida en la tecnología de este estudio fue realizar la combustión de la grasa animal con una presión de inyección por debajo de los 10 bar, comparada con la presión convencional de 30 bar; esto fue posible gracias a inyecciones adicionales de vapor. Esta variación permitió reducir el desgaste de elementos como la bomba de combustible y la boquilla de inyección, a la vez que se redujeron las emisiones de NOx gracias a la disminución de temperaturas en la reacción. De esta forma se alcanzaron los valores límite de emisiones permitidas y se redujeron los costes de operación al mismo tiempo que se fueron ampliando las posibilidades de generación de vapor con combustible no fósil. Esta tecnología se ha desarrollado comercialmente con más de 12 sistemas instalados y operando en plantas de transformación.

J. San José46, realizó varios estudios sobre la combustión de manteca de cerdo en un quemador comercial y sobre la miscibilidad de la manteca de cerdo en gasóleo, estos estudios planteaban un importante campo de trabajo en la caracterización de grasas animales y su utilización como combustibles en instalaciones convencionales de gasóleo.

El profesor AfshinGhorbani de la Universidad Tecnológica del Petróleo de Irán ha realizado múltiples estudios comparativos de la eficiencia y emisiones de combustión de biodiesel y aceites vegetales ${ }^{47}$, los estudios

\footnotetext{
45 Pfab F. "Processing and combustion of animal fat from animal waste rendering plants for steam generation in a smoke tube boiler". 2nd World Conference on Biomass for Energy, Industry and Climate Protection.Roma 2004.

46 San José J., López J.A., Romero-Ávila C. y San José L.M., “Combustion of Animal Fat and Diesel Mixtures in a Mechanical Pulverization Burner", 5 th Annual Symposium on Environment EnvironmentalEngineering and Sustainability. Atenas 2010.

${ }^{47}$ AfshinGhorbani, Combustion Performance and Emissions of Methyl Ester of Some Vegetable Oils in a Water-Cooled Furnace, Society of Petroleum Engineers, ISBN: 978-1-55563-260-1, 2009.
} 
del profesor N. Vanlaningham y otros sobre la evaluación de la combustión de mezclas de soja gasóleo en generadores térmicos para climatización 48 y los trabajos realizados por Bemtgen sobre la combinación en la combustión de biomasa y combustibles fósiles ${ }^{49}$.

\subsection{JUSTIFICACIÓN Y OBJETIVOS.}

En la actualidad, los mayores esfuerzos en el uso de combustibles procedentes de biomasa están siendo dirigidos al empleo de biocombustibles para la obtención de energía mecánica. Los fuertes compromisos en este sentido limitan el uso de biolíquidos para otros usos como la obtención de energía térmica.

En el contexto internacional, europeo, nacional y regional se sigue apostando por la biomasa como una energía que posee gran potencial lo que justifica investigaciones y estudios sobre desarrollos de nuevas alternativas energéticas.

La tecnología utilizada, combustión directa de biolíquido en calderas de baja potencia, es una tecnología ampliamente desarrollada y usada para combustibles fósiles, sobre todo en zonas rurales sin acceso al gas natural, que utilizan como combustible el gasóleo, lo que permite poder utilizar directamente los equipos de generación sin ninguna transformación dando a las instalaciones una flexibilidad de uso en función de los condiciones sociales, económicas y políticas.

Al poderse usar los biolíquidos sin ninguna transformación, salvo el filtrado y el precalentamiento, con poca incidencia del transporte, se genera una mejora importante en los índices de sostenibilidad obtenidos a partir de la reducción de los GEI.

Las menores exigencias en cuanto a las especificaciones de los combustibles para uso térmico frente a las de uso mecánico, la posibilidad de valoración de residuos como aceites usados, grasas animales y subproductos de difícil reciclaje como biodiesel, abren una puerta a su uso y justifican el estudio de la combustión directa de dichos productos como combustibles líquidos. Es frecuente el uso en centrales térmicas de carbón y de fuel, así como en los hornos de plantas cementeras el uso de co-combustión con combustibles procedentes de

48 N. Vanlaningham, h. Gibson, B. Kaufman, Evaluation of soybean heating oil blens for use in residential applications, no. 0460082, ASAE Paper, annual Meeting held on August 23-24, 2004.

${ }^{49}$ Bemtgen, J.M.; Hein, K.R.G., Minchener, A.J. "Combined combustion of Biomass/Sewage Sludge and Coal. Volume II: Final Reports" IVD, University of Stuttgart, 1995. ISBN 3-928123-16-5. 
residuos de distintos orígenes, más que para valorizar dichos residuos para deshacerse de ellos.

Frente a los biolíquidos, la técnica de obtención de biodiesel partiendo de aceites vegetales como colza, soja o girasol es la reacción de transesterificación que es la obtención de metilésteres o ésteres ligeros de los ácidos grasos, obtenidos por reacción de los aceites con metanol, produciéndose glicerina como subproducto, están ampliamente desarrolladas a nivel industrial, en la actualidad en España la capacidad de producción de biodiesel supera tanto la demanda como la producción de materia prima, lo que implica necesidad de importar aceite y exportar biodiesel. Los rechazos procedentes de dicha transformación industrial son fácilmente reconducibles a su uso como biolíquido para la obtención de energía térmica.

La combustión de mezclas de gasóleo y aceites vegetales se inscribe dentro de la nuevo escenario energético al utilizar energía renovable lo que logra una reducción de la dependencia energética, una reducción de emisiones y asegura el uso de los excedentes agrícolas, sin exigir inversión alguna, al no tener que transformar el aceite en biocombustible y no requerir instalaciones específicas para su utilización.

El objetivo general de la tesis es el estudio de la combustión de mezclas de aceites vegetales con gasóleo en un generador con una cámara de combustión a presión constante, con un quemador de pulverización mecánica por presión. Se buscará los parámetros que permitan obtener una combustión estable y eficiente y que reduzca las emisiones de gases de efecto invernadero y de contaminantes.

\subsection{ESTRUCTURA DE LA TESIS}

Para la consecución del objetivo general la tesis desarrolla los siguientes apartados:

$\left.1^{\circ}\right)$ Realización de un estudio, desarrollado en el Capítulo 2, de los recursos disponibles en Castilla y León, con el fin de establecer el alcance que podría llegar a tener la combustión con fines térmicos de los aceites vegetales.

$2^{\circ}$ ) Estudio de los combustibles en el Capítulo 3, comenzando con el acopio de muestras, el aceite vegetal usado se ha solicitado a una empresa de transformación de aceites vegetal usado en biodiesel, que tiene como materia prima el aceite vegetal usado, que les suministran los 
gestores de aceites usados y como subproducto del proceso de la planta se obtiene glicerina. Las muestras llegaron al laboratorio el día 18 de noviembre de 2009, en garrafas de 5 litros de capacidad y suministraron glicerina y aceite vegetal usado, se nos facilita algunos datos de las muestras.

Los aceites vegetales de soja, girasol y colza se han solicitado al Grupo SOS Aceites IbéricosAcisa a la factoría de Andújar (Jaén), la cual nos suministra el producto elaborado.

Las muestras llegaron al laboratorio el día 20 de noviembre de 2009 en garrafas de 5 litros de capacidad y suministraron Aceite de soja crudo y refinado, aceite de girasol crudo y refinado y aceite de colza crudo.

Se determinan de las propiedades físico-químicas de las muestras, especialmente en lo referente a su utilización como combustible, puesto que lo que se pretende es hacer una sustitución de un combustible fósil por biocombustibles. Las principales características físico-químicas que se deben tener en cuenta en las muestras son: composición elemental, densidad, viscosidad, y poder calorífico inferior. Así se calcularán las propiedades físicas y químicas de mayor importancia en su aplicación como combustibles en calderas.

$\left.3^{\circ}\right)$ Realización de un estudio de la combustión en el Capítulo 4 de las mezclas de los aceites con gasóleo, este estudio permite determinar los límites de miscibilidad y las condiciones en que se debe mantener la mezcla para que la misma sea homogénea, buscar las propiedades termoquímicas de dichas mezclas, la estequiometría de la combustión así como las emisiones de los gases de combustión

$4^{\circ}$ ) En el Capítulo 5 se describe el diseño y montaje de una instalación que permita: la alimentación de las diferentes mezclas en las condiciones fijadas en el estudio de miscibilidad, regular los parámetros decombustión y realizar el análisis de los productos de la combustión para lo que se requiere:

a) Diseño y montaje de un sistema de mezclado y mantenimiento de la homogeneidad de la mezcla de aceite con gasóleo, para ello se requiere disponer de un sistema de alimentación que permita cambiar de combustible sin tener que detener el quemador, para conseguir un régimen estacionario sea logrado sin necesidad de utilizar grandes cantidades de mezclas.

b) Introducción de sensores de medida en el quemador de pulverización mecánica por presión, que permitan conocer las condiciones de funcionamiento del equipo y poder 
modificar las, estas variables sirven para poder realizar un plan de ensayos

c) Establecer los parámetros necesarios para caracterizar los productos de la combustión de las muestras y el proceso de medida que se realizará en cada ensayo.

$5^{\circ}$ ) Elaborar el plan de ensayos a realizar, recogido en el Capítulo 6, que permita analizar los resultados de la combustión de las diferentes muestras y comparar los resultados obtenidos, lo que se conseguirá mediante:

a) Análisis de las principales variables a considerar en la combustión de cada muestra y se fijan el número de mezclas a ensayar, los parámetros a controlar durante los ensayos y los datos a medir en cada ensayo.

b) Determinación del número de ensayos a realizar: definidos el número de mezclas a ensayar, los parámetros a variar en cada experimento se fija el número total de ensayos, que permitirían caracterizar la combustión de estas mezclas.

c) Realización de un análisis estadístico sobre el número de ensayos, que incluye el diseño de parámetros, los factores y niveles, para determinar si el número obtenido anteriormente es necesario para caracterizar los ensayos.

$\left.6^{\circ}\right)$ En el Capítulo 7 se recogen los datos experimentales, siguiendo un protocolo para la preparación de la instalación, la preparación de las mezclas, la realización de la combustión de las diferentes mezclas, el control de variables de la instalación y la adquisición de datos.

a) Se determinan las condiciones que debe tener la instalación en los ensayos, por lo que requerirá de un ajuste previo, una puesta en funcionamiento y estabilización y finalmente un ajuste de parámetros.

b) Las mezclas deben ser preparadas conforme a unos porcentajes previamente definidos y homogenizadas antes de ser introducidas en el quemador.

c) Realización de la combustión de las muestras conforme a las especificaciones del ensayo, controlando la estabilidad del proceso.

d) Se realiza el análisis de los productos de la combustión, la toma de datos y su almacenamiento..

$7^{\circ}$ ) En el Capítulo 8 se procede al análisis de los resultados obtenidos, se pretende realizar una caracterización energética del proceso de combustión de las muestras y evaluar las emisiones de gases de efecto 
invernadero y por último analizar las emisiones contaminantes del proceso.

a) La caracterización energética de la combustión se realiza mediante la determinación de la eficiencia de combustión, evaluando las pérdidas por calor sensible en humos y los inquemados del proceso.

b) La medición de las emisiones de gases de efecto invernadero se realizará mediante el porcentaje de $\mathrm{CO}_{2}$ en humos, que se verá influenciado por el tipo de grasa y el porcentaje de mezcla.

c) Las emisiones serán evaluadas para cada grasa y porcentaje.

d) Se realizará un estudio estadístico de los resultados medidos en función de las variables de control y un estudio multivariable, este estudio permite obtener la tendencia en los procesos de combustión.

$\left.8^{\circ}\right)$ Finalmente en el Capítulo 9 se presentanlas conclusiones y los desarrollos futuros, con toda la experiencia adquirida se está en condiciones de extraer y elaborar un resumen donde se pongan de manifiesto los conocimientos adquiridos en el desarrollo de los trabajos realizados y proponer líneas que sería interesante estudiar y ampliar en posibles trabajos futuros. 


\section{BIBLIOGRAFÍA CAPÍTULO 1}

) Price, David, Energy and human evolution. Population and environment: a journal of interdisciplinary studies, vol. 16, Num. 4 (1995).

2) Robert A. Hefner, the grand energy transition: the rise of energy gases, sustainable life and growth, and the next great economic expansion, John Wiley \& Sons. (2009).

3) Dopazo, Cesar, Tendencias en el Sector Energético, Congreso la Energía, un Sector en transformación: Retos y Oportunidades, Valladolid (2010)

4) Eurostat, Sustainable development indicators, Web Eurostat (2005).

5) H. Brundtland, Informe "Our Commom Future", ONU (1987).

6) Becerril, Carmen, Opciones energéticas para la década 2010-2020: el lugar de las energías renovables, Congreso la Energía, un Sector en transformación: Retos y Oportunidades, Valladolid (2010)

7) Club español de la energía, Conceptos de ahorro y eficiencia energética: Evolución y oportunidades, (2010).

8) Secretaría de Estado de energía, Ministerio de Industria, Turismo y Comercio, Informe de Sostenibilidad Ambiental del Plan de Energías Renovables 2011-2020Gobierno de España 2011.

9) Secretaría de Estado de Energía Ministerio de Industria, Turismo y Comercio, Energía en España 2010, Gobierno de España (2011).

10) APPA Estudio del impacto Macroeconómico de las energías renovables en España, año 2010, Madrid, 2010

11) Diario Oficial de la Unión Europea C 306, de 17/12/2007 “Tratado de Lisboa" 2007.

12) Club español de la energía, Política energético y medioambiental en la Unión Europea. Situación y perspectivas, 2009.

13) http://www.platts.com

14) BP Statistical Review of World Energy 2006.

15) IDAE, Ministerio de Industria, Turismo y Comercio, Observatorio de energías renovables, julio 2010.

16) APPA, Estudio del Impacto Macroeconómico de las Energías Renovables en España, año 2010, Madrid 2010.

17) G. Wolff, ¿Se puede prescindir de los combustibles derivados del petróleo? Jornadas Retos y problemas de combustibles actuales, Universidad de Valladolid, noviembre 2009.

18) R. Sánchez Durán, Marco legal Europeo y Español, Conceptos de ahorro y eficiencia energética: Evolución y oportunidades, Club Español de la energía (2010).

19) Superficies y producciones de cultivos agrícolas de tipo herbáceo en Castilla y León. Instituto Tecnológico Agrícola de Castilla y León (ITACYL), 2005- 2007 
20) DIRECTIVA 2003/30/CE DEL PARLAMENTO EUROPEO Y DEL CONSEJO de 8 de mayo de 2003 relativa al fomento del uso de biocarburantes $u$ otros combustibles renovables en el transporte 2003

21) Report of the Conference of the Parties on its fifteenth session, held in Copenhagen from 7 to 19 December 2009.

22) Hacia una estrategia Europea de seguridad del abastecimiento energético. (2001).

23) Comunicación de la Comisión al Parlamento Europeo, al Consejo, al Comité Económico y Social Europeo y al Comité de las Regiones, "Dos veces 20 para el 2020 El cambio climático, una oportunidad para Europa" Bruselas, 23.1.2008 COM 2008

24) Plan de Acción nacional de energías renovables 2011-2020 (30 de Junio 2010)

25) SAVE study, ACE, UK. National and local employment impacts of energy efficiency investment programmers, (2000).

26) EIQ. Energy International Quarterly Mayo/Junio 2010

27) Tinaut F., "Biomasa: la energía renovable con mayor potencial", Jornadas sobre Energías Renovables, Cátedra de Energías Renovables de la Universidad de Valladolid, Abril de (2004).

28) European Norm 14214, Automotive fuels - Fatty Acid Methyl Esters (FAME) for Diesel Engines, Requirements and Test Methods, EU, 2009

29) Directive 2009/28/EC of the European Parliament and of the council of 23 April 2009.

30) Organización de las Naciones Unidas para la Agricultura y la Alimentación, "El estado mundial de la agricultura y la alimentación 2008", Roma 2008.

31) D.L. Klass, Biomass for renewable energy, fuels, and chemicals, ISBN 10:0-12-410950-0 Londres 1998.

32) M. Lauer, Current terrestrial methods and activities for biomass potential assessment in Europe, 17th European Biomass Conference \& Exhibition, Hamburg 2009.

33) Organización de las Naciones Unidas para la Agricultura y la Alimentación, "El estado mundial de la agricultura y la alimentación 2008", Roma 2008.

34) DIRECTIVA 2009/28/CE DEL PARLAMENTO EUROPEO Y DEL CONSEJO de 23 de abril de 2009relativa al fomento del uso de energía procedente de fuentes renovables y por la que se modifican y se derogan las Directivas 2001/77/CE y 2003/30/CE

35) Plan de Acción Nacional de Energías Renovables de España (PANER) 2011 - 2020 , 30 de Junio de 2010

36) European Biodiesel Board General Assembly, Annual Report 2006-07, p. 73, Nov. 2007.

37) I. Obernberger, Reached developments of biomass combustion technologies and future outlook, 17th European Biomass Conference and Exhibition, Hamburgo 2009.

38) J. Royo, D. García, F. Sebastián y P. Canalís, La co-combustión: una alternativa para incrementar la contribución de la biomasa en el mercado 
eléctrico español. Centro de Investigación de Recursos y consumo Energéticos (CIRCE) (Universidad de Zaragoza), 2004.

39) Spliethoff, H.; Hein, K.R.G. "Co-combustión of coal and Biomass. Suitability of Combustion Systems and State of the Art".IVD, University of Stuttgart. Symposium Co-combustion and Gbiofuels, Nijmegen/NL, 8-9 November 1995.

40) Batey J., Combustión testing of a bio-diesel fuel oil blend in residential oil burning equipment, Tech. rep., Energy Research Center, prepared for: Massachusetts Oil hest Council \& National Oil heat Research Alliance,2003.

41) Vanlaningham N., Gibson H., Kaufman B., "Evaluatión of soyben heating oil blends for use in residential applications", no. 046082, ASAE Paper,annual meeting held on August 23-24, 2004.

42) San José Alonso J.F, LópezSastre J.A., Romero-Avila C., "A note on the combustion of blends of diesel and soya, sunflower and rapeseed vegetable oils in a light boiler", Biomass \& Bioenergy 32880-886, 2008.

43) San José J., Awf Al-Kassir, LópezSastre J.A., Gañán J. "Analysis of biodiesel combustion in a boiler with a pressure operated mechanical pulverization burner",Fuel Processing Technology 92 271-277, 2011.

44) Lezsovits F., Könczöl S., Sagát L..."Animal-fat firing investigation and realization in industrial steam generators".16 ${ }^{\text {th }}$ European Biomass Conference \&Exhibtion. Valencia 2008.

45) Pfab F. "Processing and combustion of animal fat from animal waste rendering plants for steam generation in a smoke tube boiler". 2nd World Conference on Biomass for Energy, Industry and Climate Protection.Roma 2004.

46) San José J., López J.A., Romero-Ávila C. y San José L.M., "Combustion of Animal Fat and Diesel Mixtures in a Mechanical Pulverization Burner", 5 th Annual Symposium on Environment Environmental Engineering and Sustainability. Atenas 2010.

47) Afshin Ghorbani, Combustion Performance and Emissions of Methyl Ester of Some Vegetable Oils in a Water-Cooled Furnace, Society of Petroleum Engineers, ISBN: 978-1-55563-260-1, 2009.

48) N. Vanlaningham, h. Gibson, B. Kaufman, Evaluation of soybean heating oil blens for use in residential applications, no. 0460082, ASAE Paper, annual Meeting held on August 23-24, 2004.

49) Bemtgen, J.M.; Hein, K.R.G., Minchener, A.J. "Combined combustion of Biomass/Sewage Sludge and Coal. Volume II: Final Reports" IVD, University of Stuttgart, 1995. ISBN 3-928123-16-5. 
CAPITULO 2

POTENCIAL DE BIOMASA EN CASTILLA Y LEÓN

\section{$2.1 \quad$ INTRODUCCIÓN}

La Agencia Internacional de la Energía AIE50 ha valorado las previsiones de potencial de biomasa a largo plazo en seis tipos de recursos: restos forestales, cultivos energéticos biomasa en terrenos marginales, restos agrícolas, residuos ganaderos y residuos urbanos orgánicos ${ }^{51}$.

Los escenarios geográficos para el análisis de los potenciales de biomasa interesan que sean localistas, los datos globales sobre generación y consumo de bioenergía a nivel mundial e incluso a nivel nacional carecen de precisión, encontrándonos valores muy distintos según las fuentes consultadas.

Usando la definición establecida por la Unified Bioenergy Terminology, UBET, la FAO y el Comité Europeo de Estandarización CEN, la biomasa es el material de origen biológico excluido el procedente de formaciones

50 Agencia Internacional de la Energía,Renewable Energy: Policy Considerations for Deploying Renewables, París 2011.

51 Especificación Técnica Europea CEN/TS 14961:(Clasificación y especificaciones). 
geológicas y que se ha fosilizado. El combustible elaborado directa o indirectamente a partir de biomasa es biocombustible y su energía la bioenergía 52 .

\subsection{CLASIFICACIÓN DE LA BIOMASA}

En la actualidad existe una cierta desarmonización en las definiciones, términos, unidades que usamos en la bioenergía. Los datos estadísticos facilitados por distintas agencias, instituciones o administraciones no corresponden a criterios uniformes por lo que las comparaciones no son fiables. Existe una necesidad de unificación de la terminología, recogida por la FAO en la IBEP53a través de la UBET54 en colaboración con otras agencias (AIE, UNSO, EUROSTAT, CEPE, etc.).

\subsubsection{Clasificación de la biomasa por su origen}

Según el Plan de la Bioenergía en Castilla y León (PBCyL) la clasificación de biomasa por su origen es como sigue:

Tabla 2.1: Biomasa forestal

\begin{tabular}{|l|l|}
\hline \multirow{4}{*}{ Fracción leñosa } & Restos de tratamientos silvícolas \\
\cline { 2 - 2 } & $\begin{array}{l}\text { Restos de aprovechamiento por el sistema } \\
\text { tradicional }\end{array}$ \\
\cline { 2 - 2 } & Copas aprovechadas de forma integrada \\
\hline \multirow{2}{*}{ Fracción maderable } & Coníferas \\
\cline { 2 - 2 } & Frondosas \\
\hline
\end{tabular}

Tabla 2.2: Biomasa agrícola

\begin{tabular}{|c|l|}
\hline \multirow{3}{*}{ Cultivo energético } & Herbáceo de regadío \\
\cline { 2 - 2 } & Herbáceo de secano \\
\cline { 2 - 2 } & Leñoso \\
\hline \multirow{3}{*}{ Resto agrícola } & Resto agrícola herbáceo de regadío \\
\cline { 2 - 2 } & Resto herbáceo de secano \\
\cline { 2 - 2 } & Resto agrícola leñoso \\
\hline
\end{tabular}

52 Especificación Técnica Europea CEN/TS 14588(Definición de los biocombustibles).

53 Departamento Forestal de la FAO, Terminología unificada sobra la bioenergía, TUB,Organización de las Naciones Unidas para la agricultura y la alimentación Diciembre 2004.

54 Organización de las Naciones Unidas para la Agricultura y la Alimentación,Presentación de la Plataforma Internacional de Bioenergía, ROMA, 2006 
Tabla 2.3: Biomasa ganadera

Estiércol vacuno

Purín

Gallinaza

Tabla 2.4:Biomasa industrial

\begin{tabular}{|l|l|}
\hline \multirow{3}{*}{ Industria de la madera } & Subproducto de la madera \\
\cline { 2 - 2 } & Corteza \\
\cline { 2 - 2 } & Legía negra \\
\hline \multirow{3}{*}{ Industria agroalimentaria } & Residuo y subproducto de origen vegetal \\
\cline { 2 - 2 } & Subproducto animal \\
\cline { 2 - 2 } & Lodo de EDAR industrial \\
\hline
\end{tabular}

Tabla 2.5: Biomasa urbana

\begin{tabular}{|l|l|}
\hline Fracción orgánica de residuos urbanos \\
\hline Aceite vegetal usado \\
\hline Lodo de EDAR urbanas \\
\hline \multirow{4}{*}{ Madera recuperada } & Residuos de envases de madera \\
\cline { 2 - 2 } & Residuo de construcción y demolición \\
\cline { 2 - 2 } & Madera de podas en calles, parques y jardines \\
\cline { 2 - 2 } & Residuo voluminoso de madera \\
\hline
\end{tabular}

Tabla 2.6:Biomasa acuática

Alga

Fitoplancton

Con los criterios de la UBET se establece una clasificación de la biomasa atendiendo a la naturaleza básica de cada material:

- WOODY BM Biomasa leñosa

- HERBACEOUS BM Biomasa herbácea.

- BM FROM FRUITS AND SEED Biomasa de frutos y semillas.

- OTHERS/MIXTURES Otras y Mezclas 


\subsubsection{Clasificación de los biocombustibles según su estado}

En el documento, Plan Regional de Ámbito Sectorial de la Bioenergía de Castilla y León55 se encuentra una comparación entre ambas clasificaciones.

Tabla 2.7:Biocombustible sólido

\begin{tabular}{|l|l|}
\hline \multirow{4}{*}{ Grado de transformación bajo } & Leña \\
\cline { 2 - 2 } & Paja \\
\cline { 2 - 2 } & Fruto o similar \\
\cline { 2 - 2 } Grado de transformación medio & Cáscara o similar \\
\hline \multirow{4}{*}{ Grado de transformación alto } & Astilla \\
\cline { 2 - 2 } & Hebra \\
\cline { 2 - 2 } & Paca \\
\cline { 2 - 2 } & Harina \\
\cline { 2 - 2 } & Pélet \\
\cline { 2 - 2 } & Cariqueta \\
\hline Otros & \\
\hline
\end{tabular}

Tabla 2.8: Biocombustible líquido

\begin{tabular}{|c|l|}
\hline \multirow{2}{*}{$\begin{array}{c}\text { Sin transformación industrial } \\
\text { bioenergétrica per se }\end{array}$} & Aceite vegetal puro \\
\cline { 2 - 2 } $\begin{array}{c}\text { Producto principal de una transformación } \\
\text { industrial bioenergética }\end{array}$ & Legía negra \\
\cline { 2 - 2 } & Biodiesel \\
\cline { 2 - 2 } $\begin{array}{c}\text { Subroducto de una transformación } \\
\text { industrial bioenergética }\end{array}$ & Biometanol \\
\cline { 2 - 2 } & Bio-EFBE \\
\cline { 2 - 2 } & Bio-DME \\
\cline { 2 - 2 } & Otros carburantes sintéticos \\
\cline { 2 - 2 } & Líquido piroleñoso \\
\hline Otros & \\
\hline
\end{tabular}

55 Plan Regional de Ámbito Sectorial de la Bioenergía de Castilla y León (Decreto 2/2011, de 20 de enero, BOCyL $n^{\circ} 17$ de 26 de enero de 2011). 
Tabla 2.9: Biocombustible gaseoso

\begin{tabular}{|l|l|}
\hline \multirow{2}{*}{ Digestión anaerobia } & Gas de vertedero \\
\cline { 2 - 2 } & Gas de tratamiento biológico \\
\hline \multirow{2}{*}{ Otros procesos } & Gas de tratamiento termoquímico \\
& Biohidrógeno \\
& Otros gases sintéticos \\
\hline Otros & \\
\hline
\end{tabular}

Con los criterios de la UBET se establece una clasificación de los biocombustibles

- WOODFUELS Biocombustibles leñosos

- AGROFUELS Agrocombustibles.

- MUNICIPAL BY-PRODUCTS Subproductos municipales

- OTHERS/MIXTURES Otras y Mezclas

\subsection{VALORACIÓN DE LOS POTENCIALES DE BIOMASA.}

La valoración de los potenciales de biomasa presenta una gran complejidad en cualquier escenario y para cualquiera de los tipos de recursos considerados.

Desde el año 2007 para los recursos de biomasa forestal en Castilla y León se está procediendo a la aplicación de la metodología WISDOM ${ }^{56}$ que es una herramienta espacial creada por la Organización de Naciones Unidas para la Agricultura y la Alimentación, basada en Sistemas de Información Geográfica (SIG).

Fue desarrollada por la FAO junto con el Instituto de Ecología de las Universidad Nacional de México (UNAM) y hasta la fecha se ha aplicado a nivel Supranacional en la Costa Oriental de los países de África Central, Sudeste Asiático, a nivel Nacional en Eslovenia (2006), Italia, México, Mozambique y Senegal y a nivel sub-nacional en la Comunidad Autónoma de Castilla y León y Emilia Romagna de Italia.

${ }^{56}$ Food and Agriculture Organization of the Units Nations, Methodology WISDOM: Woodfuel Integrated Supply/Demand Overview mapping. 
Esta metodología permite la integración de información estadística y espacial de la producción y del consumo de dendrocombustibles, permitiendo la modelización con lo que podemos generar distintos escenarios de decisión.

Es por lo tanto una herramienta de planificación energética que facilita el análisis espacial de la oferta y demanda de combustibles leñosos con la resolución deseada, local, regional o nacional.

Estos modelos son especialmente útiles en la valoración de la biomasa forestal, para la que fueron creados, trabajando con datos reales de inventario, zonas de abastecimiento, competencia con otras industrias y los costes de aprovechamiento específicos de una zona permite, aplicando los modelos correspondientes, calcular los resultados para cada parcela y al mismo tiempo permite la inclusión en los análisis espaciales de variables como carreteras, ferrocarriles, espacios protegidos, etc. que pudieran tener significación en el aprovechamiento o los costes de explotación.

La metodología WISDOM, creada específicamente para la programación y desarrollo de la dendroenergía, está siendo aplicada a otras fuentes de bioenergía, por ejemplo en el INTA ${ }^{57}$ en proyectos sobre biocombustibles PNEG141158, se valora la eficiencia energética de los distintos combustibles, la idoneidad de los cultivos para su producción, sistema agrícola más eficiente, implicaciones socio-ambientales, valoración de residuos, etc.

Para el cálculo de la oferta forestal se han desarrollado aplicaciones específicas para la evaluación de recursos biomásicos que partiendo de datos de inventario permiten conocer las existencias de biomasa y sus aprovechamiento sostenible, zonas de abastecimiento, competencia con otras industrias y los costes de aprovechamiento específicos de una zona.

Este tipo de herramientas está permitiendo generar modelos de gestión integrados tanto para el sector energético como para el sector agrícola.

\footnotetext{
57 INTA: Instituto Nacional de Ingeniería Agropecuaria (Argentina),Análisis del Balance de Energía derivada de Biomasa en Argentina - WISDOM Argentina - Buenos aire 2009.

58 INTA: Instituto Nacional de Ingeniería Agropecuaria (Argentina),Programa Nacional de Bioenergía del INTA, PNEG1411Residuos y cultivos agrícolas para la producción de bioenergía, Resoluciones consejo directivo 2008/09.
} 


\subsection{DISPONIBILIDAD DE BIOMASA EN CASTILLA $Y$ LEÓN.}

La metodología antes expuesta está proporcionando datos cada vez más fiables sobre los recursos existentes.

La Junta de Castilla y León a través del Plan de Ámbito Sectorial de la Bioenergía de Castilla y León (PBCyL) proporciona los valores estimados en biomasa del aprovechamiento actual y las previsiones para los próximos años.

Se incluye para cada sector los costes de obtención y los mercados competidores para cada una de las distintas formas de biomasa: forestal, cultivos energéticos, restos agrícolas, biomasa ganadera, biomasa de la industria agroalimentaria, restos de la industria de la madera y biomasa de origen urbano y de otras industrias.

\subsubsection{Biomasa forestal}

Se entiende por biomasa forestal cualquier vegetal procedente de terrenos forestales que sea apto para generar energía, quedan incluidos árboles completos, parte de ellos, tocones y matas.

Atendiendo a la forma de extracción el PBCyL clasifica la biomasa forestal en producto forestal o en subproducto. En Castilla y León el $52 \%$ del territorio es forestal y el 32\% corresponde a superficie arbolada59.Se entiende por biomasa forestal potencial el crecimiento anual total de los montes de Castilla y León, en la tabal 2.10 se recogen los recursos forestales de Castilla y León.

59 Plan Regional de Ámbito Sectorial de la Bioenergía de Castilla y León (Decreto 2/2011, de 20 de enero, BOCyL $n^{\circ} 17$ de 26 de enero de 2011). 
Tabla 2.10: Previsiones de biomasa forestal potencial en Castilla y León

\begin{tabular}{|c|c|c|c|c|c|c|c|c|c|c|}
\hline & & & & 2009 & 2011 & 2013 & 2015 & 2020 & 2025 & 2030 \\
\hline \multirow{3}{*}{ 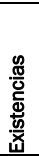 } & \multicolumn{3}{|c|}{$\begin{array}{l}\text { Volumen maderable } \\
\left(10^{3} \times \mathrm{m}^{3} / \text { año cc }\right)\end{array}$} & 167.551 & 175.286 & 180.556 & 186.556 & 199.790 & 211.103 & 222.202 \\
\hline & \multirow{2}{*}{$\begin{array}{l}\text { Biomasa } \\
\text { Total }\end{array}$} & \multicolumn{2}{|c|}{$\begin{array}{l}\text { Material anhidra } \\
\left(10^{3} \times \mathrm{t} / \mathrm{año}\right)\end{array}$} & 219.563 & 229.699 & 237.083 & 244.809 & 261.809 & 276.634 & 291.179 \\
\hline & & \multicolumn{2}{|c|}{$\begin{array}{l}\text { Material Verde } \\
\left(10^{3} \times \text { t/año }\right)\end{array}$} & 439.125 & 459.397 & 474.165 & 488.934 & 523.618 & 553.267 & 582.357 \\
\hline \multirow{5}{*}{ 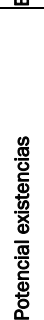 } & \multicolumn{3}{|c|}{$\begin{array}{l}\text { Crecimiento medio de volumen } \\
\text { maderable }\left(10^{3} \times \mathrm{m}^{3} / \text { año cc }\right)\end{array}$} & 7.850 & 8.212 & 8.476 & 8.740 & 9.360 & 9.890 & 10.410 \\
\hline & \multirow{4}{*}{$\begin{array}{l}\text { Biomasa } \\
\text { potencial } \\
\text { Total }\end{array}$} & \multirow{2}{*}{$\begin{array}{l}\text { Material } \\
\text { anhidra }\end{array}$} & $\begin{array}{ll}10^{3} & x \\
\text { t/año }\end{array}$ & 10.287 & 10.762 & 11.108 & 11.454 & 12.266 & 12.961 & 13.642 \\
\hline & & & ktep/año & 4.700 & 4.900 & 5.000 & 5.200 & 5.600 & 5.900 & 6.200 \\
\hline & & \multirow{2}{*}{$\begin{array}{l}\text { Material } \\
\text { Verde }\end{array}$} & $\begin{array}{ll}10^{3} & x \\
t / a n ̃ o & \end{array}$ & 20.573 & 21.523 & 22.215 & 22.907 & 24.532 & 25.921 & 27.284 \\
\hline & & & ktep/año & 4.200 & 4.400 & 4.500 & 4.600 & 5.000 & 5.200 & 5.500 \\
\hline
\end{tabular}

La cantidad de biomasa fácilmente valorizable, estimando un escenario realista se muestra en la tabla 2.11:

Tabla 2.11: Previsiones de biomasa forestal fácilmente valorizable en Castilla y León

\begin{tabular}{|c|c|c|c|c|c|c|c|c|c|}
\hline & & & 2009 & 2011 & 2013 & 2015 & 2020 & 2025 & 2030 \\
\hline \multirow{8}{*}{ 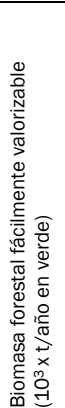 } & \multirow{7}{*}{$\begin{array}{l}\text { Fracción } \\
\text { leñosa }\end{array}$} & $\begin{array}{lll}\text { Restos } & \text { de } & \text { tratamientos } \\
\text { selvicolas }\end{array}$ & 12 & 29 & 39 & 48 & 60 & 60 & 60 \\
\hline & & $\begin{array}{l}\text { Restos de aprovechamiento por } \\
\text { el sistema tradicional }\end{array}$ & 57 & 72 & 84 & 95 & 124 & 123 & 133 \\
\hline & & $\begin{array}{l}\text { Copas aprovechables de forma } \\
\text { integrada }\end{array}$ & 225 & 288 & 336 & 380 & 494 & 490 & 529 \\
\hline & & total & 291 & 389 & 159 & 523 & 678 & 673 & 722 \\
\hline & & Coníferas & 0 & 73 & 206 & 306 & 474 & 632 & 829 \\
\hline & & Frondosas & 439 & 652 & 706 & 837 & 1.025 & 1.135 & 1.223 \\
\hline & & Total & 439 & 725 & 912 & 1.143 & 1.499 & 1.767 & 2.052 \\
\hline & \multicolumn{2}{|l|}{ TOTAL } & 733 & 1.114 & 1.371 & 1.666 & 2.177 & 2.440 & 2.774 \\
\hline \multirow{8}{*}{ 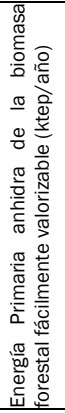 } & \multirow{4}{*}{$\begin{array}{l}\text { Fracción } \\
\text { leñosa }\end{array}$} & $\begin{array}{lll}\begin{array}{l}\text { Restos } \\
\text { selvicolas }\end{array} & \text { de } & \text { tratamientos } \\
\end{array}$ & 3 & 6 & 9 & 11 & 14 & 14 & 14 \\
\hline & & $\begin{array}{l}\text { Restos de aprovechamiento por } \\
\text { el sistema tradicional }\end{array}$ & 13 & 16 & 19 & 21 & 28 & 28 & 30 \\
\hline & & $\begin{array}{l}\text { Copas aprovechables de forma } \\
\text { integrada }\end{array}$ & 53 & 55 & 75 & 85 & 111 & 110 & 119 \\
\hline & & Total & 70 & 87 & 103 & 117 & 153 & 152 & 153 \\
\hline & \multirow{3}{*}{$\begin{array}{l}\text { Fracción } \\
\text { maderable }\end{array}$} & Coníferas & 59 & 69 & 98 & 121 & 159 & 194 & 230 \\
\hline & & Frondosas & 44 & 94 & 107 & 117 & 178 & 203 & 223 \\
\hline & & Total & 102 & 163 & 205 & 257 & 337 & 397 & 452 \\
\hline & \multicolumn{2}{|l|}{ TOTAL } & 172 & 250 & 308 & 374 & 490 & 549 & 625 \\
\hline
\end{tabular}

Los costes son difíciles de conocer, la extracción y el transporte tienen una influencia importante en la valoración final del producto, la viabilidad varía en función del uso final, es decir, de la oferta del demandante y de las posibles bonificaciones existentes. Como valor de referencia en euros 
por tonelada seca puesta en fábrica se estima entre 30 y $60 € / t$ con radios de transporte a planta de menos de $30 \mathrm{Km}$.

En cuanto a los mercados competidores están constituidos por los aserraderos, fábrica de tableros, y fábricas de pasta de papel.

Las características de los recursos de los distintos sectores son variados desde la industria el desenrollo con diámetros mayores de $35 \mathrm{~cm}$ a la industria de desintegración con diámetros de hasta $5 \mathrm{~cm}$.

La incorporación del sector bioenergético en el mercado puede producir un aumento de precios de la materia prima y como consecuencia un desabastecimiento para la industria de la madera, industria muy consolidada en la región con importante transcendencia económica y de puestos de trabajo.

Es necesario que el desarrollo de la biomasa forestal se haga de forma progresiva, cuidando que la política de ayudas no cause efectos desfavorables en el resto de la industria.

\subsubsection{Cultivos energéticos}

Utilizando la definición que se establece en la Directiva 2003/30 CE60 entendemos por cultivos energéticos aquellos cultivos no alimentarios destinados a la producción de energía que se utilizan fundamentalmente en la producción de biocarburantes o energía térmica y eléctrica producida a partir de la biomasa. Se pueden clasificar los cultivos energéticos con diferentes criterios, siguiendo el criterio del aprovechamiento final del cultivo distinguimos entre:

Cultivos herbáceos. Se trata de cultivos de especies herbáceas de ciclo anual. Se pueden dividir en:

Oleaginosos: obtención de biodiesel a partir de semillas de plantas oleaginosas como son el girasol y la colza.

Amiláceos: obtención de bioetanol a partir de semillas con grandes concentraciones de almidón, como son las de los cereales, trigo y cebada.

Oligosacáridos: Obtención de bioetanol a partir de materia rica en inulina y azúcares simples como la remolacha o la pataca.

60 Directiva 2003/30/CE del Parlamento Europeo y del Consejo, relativa al fomento del uso de biocarburantes u otros combustibles renovables en el transporte, de 8 de mayo de 2003. 
Lignocelulósicos: Obtención de bioetanol o directamente producción de calor y electricidad a partir de cultivos con alta concentración de celulosa, como el sorgo papelero.

Cultivos leñosos de corta rotación. Se trata de cultivos de especies leñosas de crecimiento rápido capaces de rebrotar de cepa en turnos cortos (normalmente de 3 a 5 años). Son cultivos de especies forestales gestionados bajo un sistema agrícola, como el chopo, sauce, pawlonia y eucalipto.

Los cultivos energéticos en Castilla y León son principalmente las oleaginosas (colza y girasol) o cereales (cebada y trigo) orientados a la producción de grano para la elaboración de biocarburantes sustitutivos del gasóleo.

Cultivos como la remolacha, patata, etc. tradicionales en Castilla y León, y que podrían dedicarse a la producción de bioetanol y etilterbutileter por fermentación de azúcares no se producen en la comunidad más que para fines alimentarios.

Los cultivos energéticos leñosos de corta duración son, salvo alguna excepción de carácter experimental, inexistentes en Castilla y León. También existen a nivel experimental otros cultivos herbáceos, como cardo, pataca, etc.

La evolución de los cultivos energéticos desde el año 2005 en el que el FEGA61 distribuye en España las ayudas del PAC62 viene reflejada en la tabla 2.12 relativa a las superficies en ha que han recibido las ayudas, estas superficies se refieren a terrenos de retirada.

${ }^{61}$ FEGA: Fondo Español de Garantía Agraria, CAMPAÑA 2005/2006 (Cosecha 2005) Ayuda a los cultivos energéticos Capítulo 5 del TíTULO IV del R(CE) 1782/2003 Art. 44 del R(CE) 1973/2004: superficies definitivas de la campaña

62 PAC Política Agraria Común, ayudas concedidas, desde 1997,

http://www.fega.es/PwfGcp/es/financiacion_de_la_pac 
Tabla 2.12: Ayudas del PAC a los cultivos energéticos en Castilla y León de 2005 a 2009(Fuente FEGA).

\begin{tabular}{|c|c|c|c|c|c|c|}
\hline & & 2005 & 2006 & 2007 & 2008 & 2009 \\
\hline \multirow{3}{*}{$\begin{array}{l}\text { Oleaginosas } \\
\text { (ha) }\end{array}$} & Colza & & 570,83 & $3.607,00$ & $2.996,76$ & $5.319,51$ \\
\hline & Girasol & $1.605,18$ & $26.717,69$ & $31.957,09$ & $2.613,23$ & $14.985,46$ \\
\hline & Cárcamo & & & & & 816,76 \\
\hline \multirow{7}{*}{$\begin{array}{l}\text { Cereales } \\
\text { (ha) }\end{array}$} & Trigo & 788,29 & $22.661,41$ & 717,93 & 14,74 & \\
\hline & Cebada & $1.911,14$ & $35.929,78$ & $2.206,33$ & 17,46 & \\
\hline & Avena & & & & 7,75 & 15,68 \\
\hline & Centeno & & & & 102,53 & 37,72 \\
\hline & Triticale & & & & 7,82 & 13,00 \\
\hline & Sorgo & & & & & \\
\hline & Maíz & & & & & \\
\hline Otras & & & & & 36,77 & 138,50 \\
\hline Total & & $4.304,61$ & $85.879,71$ & $38.488,35$ & $5.797,06$ & $21.026,63$ \\
\hline $\begin{array}{c}\text { Total } \\
\text { España }\end{array}$ & & $26.510,24$ & $216.269,47$ & $108.079,12$ & $9.782,23$ & $35.591,32$ \\
\hline
\end{tabular}

La ayuda a los cultivos energéticos se estableció en el Capítulo 5 del Título IV del Reglamento (CE) 1782/2003, del Consejo. Este reglamento ha sido derogado por el Reglamento (CE) 73/2009. Aunque en este último se establece que en el año 2009 seguiría siendo de aplicación, por lo que la campaña 2009/2010 sería la última en estar en vigor dicha ayuda.

El aumento de los precios de los cereales en el mercado internacional ha hecho que los agricultores dediquen la superficie de cultivo a la producción para consumo humano en detrimento de los cultivos energéticos.

Las continuas modificaciones en las normativas agrícolas comunitarias, reforma del PAC, modificación de los mecanismos de pago, la poca adaptación de algunos de los cultivos a las condiciones edafoclimáticas de la región, la falta de tradición y el desconocimiento de los nuevos cultivos por parte de los agricultores, la competencia del mercado alimentario y sobre todo la baja rentabilidad de los cultivos hacen que estos no tenga el desarrollo previsto.

Para la determinación de la producción potencial energética de los cultivos es necesaria la estimación del rendimiento del cultivo (t/ha) en cada zona, y la valoración del rendimiento del proceso de transformación para su conversión en biocombustible.

Han sido tan variables las superficies de cultivo en los últimos años que las estimaciones basadas en tendencias no puedan aplicarse de una forma fiable. 
Desde el lado de la demanda, con la capacidad de generación de biodiesel de las plantas instaladas en la actualidad y las que pronto estarán en funcionamiento, las necesidades de superficie de cultivo para suministro de materia prima de dichas plantas se aproxima a 0,9 millones de ha en la Comunidad de los 2,3 millones de ha de la superficie total dedicada a tales cultivos 63 .

Considerando la producción potencial como la que podría aportar la superficie agrícola de Castilla y León, de secano y regadío, que actualmente se usa para cultivos cuya semilla o biomasa podría usarse para fines energéticos, más el barbecho cuyas características edáficas son adecuadas y la producción fácilmente valorizable como la producción obtenida con este tipo de cultivos a partir de una superficie agrícola realista y bastante conservadora.

La estimación de la producción potencial unitaria para cada tipo de cultivo en secano y regadío es recogida en la tabla 2.13 para el año 2.008

Tabla 2.13: Producción potencial de cultivos energéticos herbáceos en Castilla y León de 2008 (Fuente: PBCyL)

\begin{tabular}{|c|c|c|c|c|c|c|c|}
\hline & & $\begin{array}{l}\text { Superficie } \\
\text { (ha) }\end{array}$ & $\begin{array}{l}\text { Producción } \\
\text { semilla en } \\
\text { verde(t/año) }\end{array}$ & $\begin{array}{l}\text { Producción } \\
\text { potencial en } \\
\text { verde(t/año) }\end{array}$ & $\begin{array}{l}\text { Humedad en } \\
\text { origen(\%) }\end{array}$ & $\begin{array}{l}\text { Producción } \\
\text { potencial } \\
\text { restos an- } \\
\text { hidro(t/año) }\end{array}$ & $\begin{array}{l}\text { Energía } \\
\text { primaria } \\
\text { (ktep/año) }\end{array}$ \\
\hline \multirow{10}{*}{ 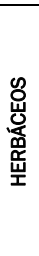 } & Cereal & 1.684 .834 & 2 & 3.369 .668 & 13 & 2.931 .611 & 1.173 \\
\hline & Girasol & 243.614 & 1 & 243.614 & 9 & 221.689 & 89 \\
\hline & Leguminosas & 134.583 & 0.7 & 94.208 & 10 & 84.787 & 34 \\
\hline & Colza & 6.852 & 3,2 & 14.720 & 9 & 13.395 & 5 \\
\hline & TOTAL SECANO & 2.069 .883 & - & 3.722 .210 & - & 3.251 .482 & 1.301 \\
\hline & Maiz & 103.299 & 10 & 1.008 .903 & 14 & 867.657 & 347 \\
\hline & Remolacha & 34.262 & 90,5 & 3.100 .711 & 25 & 2.325 .533 & 930 \\
\hline & Cereal & 179.180 & 4 & 716.720 & 13 & 623.546 & 249 \\
\hline & Patata & 23.237 & 44,6 & 1.035 .758 & 30 & 725.031 & 290 \\
\hline & TOTAL REGADÍO & 339.978 & - & 5.862 .092 & - & 5.541 .767 & 1.816 \\
\hline \multicolumn{2}{|c|}{ TOTAL BARBECHO } & 745.934 & 1,5 & 1.118 .901 & 13 & 973.444 & 389 \\
\hline \multicolumn{2}{|c|}{ TOTAL SEMILLA } & 3.155 .795 & 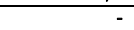 & 10.703 .203 & - & 8.766 .693 & 3.506 \\
\hline
\end{tabular}

Sirve de base para la estimación de las superficies y producción de energía hasta el año 2.030 que se recoge en la tabla 2.14 .

63 Los cultivos energéticos en Castilla y León Fdo. Rodríguez López y J. Ignacio Sánchez Macías. Universidad de Salamanca 
Tabla 2.14: Previsiones de cultivos energéticos herbáceos fácilmente valorizables en Castilla y León (Fuente: PBCyL)

\begin{tabular}{|c|c|c|c|c|c|c|c|c|c|}
\hline \multicolumn{3}{|c|}{ Origen de la producción } & 2009 & 2011 & 2013 & 2015 & 2020 & 2025 & 2030 \\
\hline \multirow[b]{6}{*}{ 食 } & \multicolumn{2}{|c|}{$\begin{array}{l}\text { Superficie secano potencial } \\
\text { (barbecho incluido) }\end{array}$} & \multicolumn{7}{|c|}{2.897 .347} \\
\hline & \multirow{5}{*}{$\begin{array}{l}\text { Fácilmente } \\
\text { valorizable }\end{array}$} & $\begin{array}{l}\% \text { fácilmente } \\
\text { valorizable }\end{array}$ & $0,5 \%$ & $5 \%$ & $8 \%$ & $11 \%$ & $15 \%$ & $16 \%$ & $17 \%$ \\
\hline & & $\begin{array}{l}\text { Superficie de } \\
\text { secano(ha) }\end{array}$ & 14.487 & 144.867 & 231.788 & 318.708 & 434.802 & 483.576 & 492.549 \\
\hline & & $\begin{array}{l}\text { Producción } \\
\text { en verde } \\
\text { (t/año) }\end{array}$ & 34.044 & 340.438 & 544.701 & 748.964 & 1.021 .315 & 1.089 .402 & 1.157 .490 \\
\hline & & $\begin{array}{l}\text { Producción } \\
\text { anhidra } \\
\text { (t/año) }\end{array}$ & 29.818 & 295.181 & 473.890 & 851.599 & 888.544 & 947.780 & 1.007 .016 \\
\hline & & $\begin{array}{l}\text { E. primaria } \\
\text { anhidra } \\
\text { (ktep/año) }\end{array}$ & 12 & 118 & 190 & 261 & 356 & 379 & 403 \\
\hline \multirow[b]{6}{*}{$\begin{array}{l}\text { 음 } \\
\text { 㥕 } \\
\text { 㟧 }\end{array}$} & \multicolumn{2}{|c|}{$\begin{array}{l}\text { Superficie regadío potencial } \\
\text { (ha) }\end{array}$} & 476.823 & 480.000 & \multicolumn{5}{|l|}{510.000} \\
\hline & \multirow{5}{*}{$\begin{array}{l}\text { Fácilmente } \\
\text { valorizable }\end{array}$} & $\begin{array}{l}\% \text { fácilmente } \\
\text { valorizable }\end{array}$ & $0 \%$ & $2 \%$ & $4 \%$ & $4,5 \%$ & $8 \%$ & $9 \%$ & $11 \%$ \\
\hline & & $\begin{array}{l}\text { Superficie de } \\
\text { regadío(ha) }\end{array}$ & 0 & 10.200 & 20.400 & 22.950 & 40.800 & 45.900 & 56.100 \\
\hline & & $\begin{array}{l}\text { Producción } \\
\text { en } \\
\text { verde(t/año) }\end{array}$ & 0 & 51.100 & 102.000 & 114.750 & 204.000 & 229.500 & 280.500 \\
\hline & & $\begin{array}{l}\text { Producción } \\
\text { anhidra } \\
\text { (t/año) }\end{array}$ & 0 & 44.370 & 88.740 & 99.833 & 177.480 & 199.665 & 244.035 \\
\hline & & $\begin{array}{l}\text { E. primaria } \\
\text { anhidra } \\
\text { (ktep/año) }\end{array}$ & 0 & 18 & 35 & 40 & 71 & 80 & 98 \\
\hline \multirow{3}{*}{\multicolumn{2}{|c|}{ TOTAL }} & $\begin{array}{l}\text { Superficie } \\
\text { (ha) }\end{array}$ & 14.487 & 155.067 & 252.188 & 341.658 & 475.402 & 509.476 & 548.649 \\
\hline & & $\begin{array}{l}\text { Producción } \\
\text { (t/año) }\end{array}$ & 29.618 & 340.551 & 562.630 & 751.431 & 1.066 .024 & 1.147 .445 & 1.251 .051 \\
\hline & & $\begin{array}{l}\text { E. primaria } \\
\text { anhidra } \\
\text { (ktep/año) }\end{array}$ & 12 & 136 & 225 & 301 & 426 & 459 & 501 \\
\hline
\end{tabular}

El mercado agrícola y el cerealista en particular es un mercado muy sensible y con un desequilibrio creciente entre oferta y demanda creado fundamentalmente por cosechas más bajas, consecuencia de sequías y otros fenómenos climáticos, junto con la creciente demanda de las economías emergentes como China e India.

El incremento de los precios agrícolas favorece un aumento de rentas en el sector agrícola y una pérdida de competitividad del sector de los biocarburantes.

El importante consumo de cereal, cerca del 90\%, para alimentación animal en Castilla y León, hace que difícilmente se dedique esta producción a otros usos como los biocombustibles, esta dificultad se agrava al haber aumentado el precio del cereal para alimentación en los últimos años.

El agricultor dispone de un mercado adicional, el energético, para colocar sus productos al mismo tiempo al aumentar la demanda aumentará el 
precio lo que permitirá en ambos casos un mayor desarrollo agrario en la región.

La competencia del resto de los mercados agrícolas hace que las ayudas por superficie cultivada, con independencia de la producción, sea una ventaja competitiva en Castilla y León con unos rendimientos productivos por debajo de la media de la UE.

Estas ayudas de $45 € /$ ha para los cultivos energéticos han desaparecido para la campaña 2010/2011, lo que crea una gran incertidumbre, se espera en breve una nueva modificación del PAC con nuevas ayudas específicas para cultivos energéticos.

En el momento que redacto estas líneas los borradores de la reforma de la PAC prevén ayudas de hasta $400 € /$ ha, lo que puede modificar sustancialmente el panorama sobre determinados cultivos de tipo leñoso

\subsubsection{Restos agrícolas}

Se incluyen en esta categoría de biomasa los residuos agrícolas procedentes de cultivos herbáceos como la paja del cereal, los cañotes de maíz, etc., como los precedentes de cultivos leñosos como la vid, los frutales, el olivo.

La cuantificación de los potenciales energéticos viene definida por la de los cultivos de los que proceden. La estimación potencial viene reflejada en la tabla 2.15: 
Tabla 2.15:Previsiones de restos agrícolas en Castilla y León (Fuente: PBCyL)

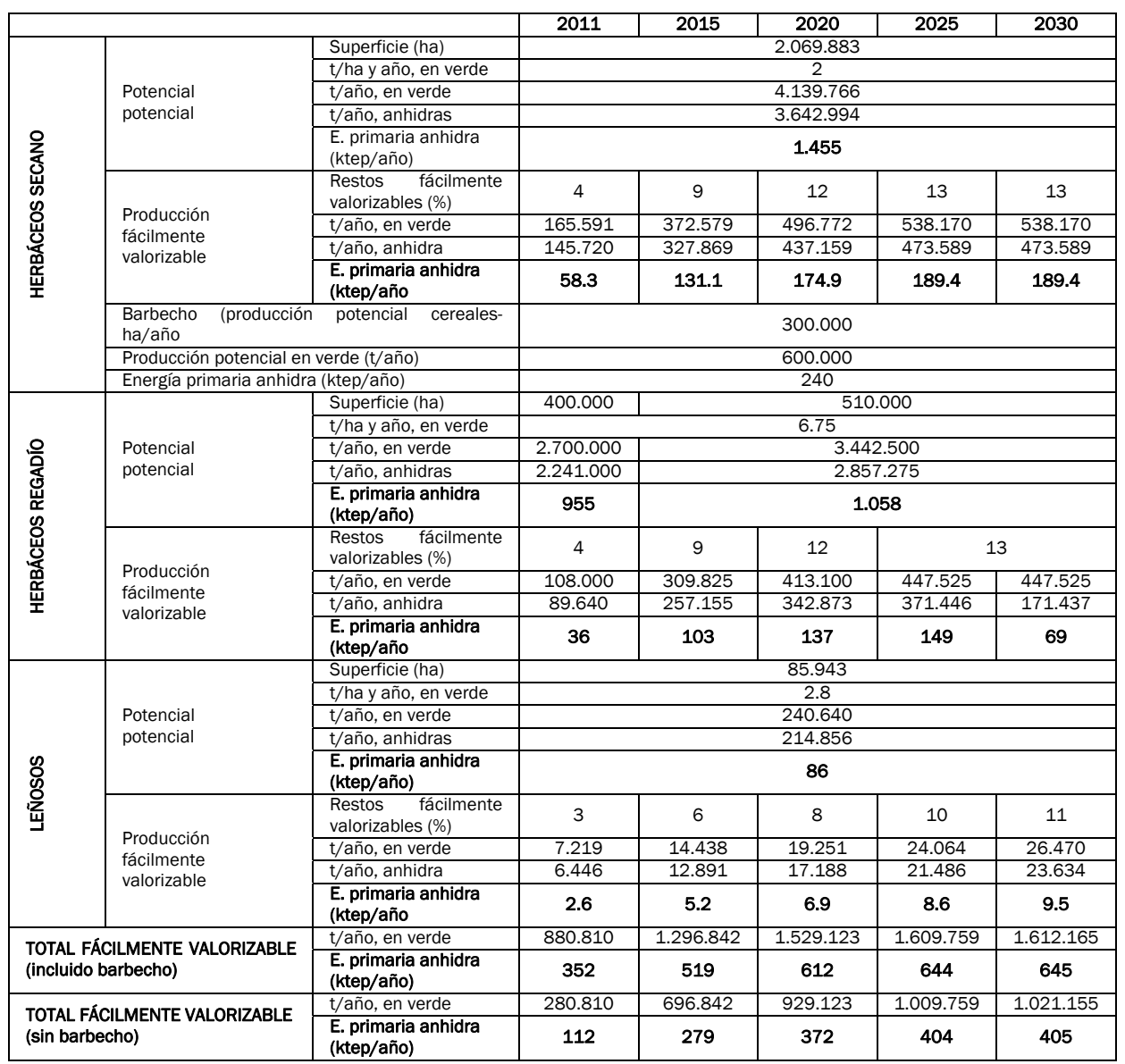

Los mercados competidores para estos restos agrícolas son en el caso de la paja de los cereales el mercado ganadero que lo utiliza de alimento y como cama para ganado.

En cuanto a los restos leñosos su aprovechamiento es en calderas y chimeneas domésticas y en el caso de los sarmientos para elaboración de platos típicos en gastronomía.

\subsubsection{Biomasa ganadera}

La biomasa ganadera está constituida por todos aquellos restos orgánicos procedentes de las explotaciones ganaderas intensivas y de las industrias de transformación de alimentos de origen animal que podrían ser susceptibles de valoración energética. Son subproductos animales no destinados al consumo humano (SANDACH). 
En las explotaciones ganaderas podemos diferenciar distintos subproductos:

- Purín. Residuo formado por las deyecciones líquidas y las aguas de limpieza de establos.

- Gallinaza. Residuo compuesto por deyecciones sólidas y líquidas, restos de alimentos, plumas y huevos rotos en las granjas avícolas.

- Estiércol. Residuo originado por las deyecciones líquidas y sólidas con material de las camas del ganado y aguas de limpieza.

Subproductos en la industria agroalimentaria clasificados por la industria que los genera:

- Residuos de la industria láctea.

- Residuos y subproductos animales de la industria cárnica.

- Residuos de la industria vitivinícola.

- Residuos de la industria de panificadora.

- Residuos de la industria molinera.

- Residuos de la industria de conservas vegetales.

- Residuos de la industria de alimentación animal.

Con el censo actual de las cabañas y los ratios medios de producción de subproductos animales se obtiene la producción total de biomasa generada en las explotaciones ganaderas intensivas que se presenta en la tabla 2.16.

Tabla 2.16: Producción actual de residuos ganaderos en explotaciones en Castilla y León (Fuente: PBCyL)

\begin{tabular}{|c|c|c|c|c|}
\hline $\begin{array}{l}\text { CABAÑA } \\
\text { GANADERA }\end{array}$ & \multicolumn{2}{|c|}{$\begin{array}{l}N^{\circ} \text { DE CABEZAS DE GANADO } \\
\text { POR TIPO DE ANIMALES }\end{array}$} & $\begin{array}{l}\text { TIPO DE } \\
\text { BIOMASA }\end{array}$ & $\begin{array}{l}\text { BIOMASA } \\
\text { PRODUCIDA } \\
\text { (t/año. Humedad }\end{array}$ \\
\hline \multirow{3}{*}{ Bovino } & Carne & 889.761 & \multirow{3}{*}{ Estiércol bovino } & \multirow{3}{*}{5.790 .947} \\
\hline & Cebo & 212.174 & & \\
\hline & Leche & 201.446 & & \\
\hline \multirow{2}{*}{ Porcino } & Reproductores & 475.827 & \multirow{2}{*}{ Purines } & \multirow{2}{*}{10.6372299} \\
\hline & Cebo & 3.546 .503 & & \\
\hline \multirow{2}{*}{ Avícola } & Pollos & 10.877 .765 & \multirow{2}{*}{ Gallinaza } & \multirow{2}{*}{604.449} \\
\hline & Ponedoras & 13.410 .328 & & \\
\hline \multicolumn{2}{|l|}{ Ovino } & & Estiércol ovino & 3.965 .359 \\
\hline \multicolumn{4}{|l|}{ TOTAL } & 20.998 .054 \\
\hline
\end{tabular}

En cuanto a las previsiones de biomasa ganadera en explotaciones se presenta la tabla 2,17. 
Tabla 2.17: Previsiones de biomasa ganadera en explotaciones en Castilla y León (Fuente: PBCyL).

\begin{tabular}{|c|c|c|c|c|c|c|c|}
\hline & & & 2011 & 2015 & 2020 & 2025 & 2030 \\
\hline \multirow{5}{*}{ 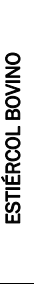 } & \multirow[t]{2}{*}{ Potencial } & $\begin{array}{l}\text { Producción total anual } \\
\text { (t/año humedad en } \\
\text { origen) }\end{array}$ & 5.804 .859 & 5.814 .153 & 5.825 .490 & 5.837 .451 & 5.849 .135 \\
\hline & & $\begin{array}{c}\begin{array}{c}\text { Energía primaria anhidra } \\
\text { (ktep/año) }\end{array} \\
\end{array}$ & 488 & 488 & 489 & 490 & 491 \\
\hline & \multirow{3}{*}{$\begin{array}{l}\text { Fácilmente } \\
\text { valorizable }\end{array}$} & \% fácilmente valorizable & 8 & 12 & 14 & 15 & 16 \\
\hline & & $\begin{array}{c}\text { Producción total anual } \\
\text { (t/año humedad en } \\
\text { origen) } \\
\end{array}$ & 464.389 & 697.698 & 815.611 & 875.618 & 935.862 \\
\hline & & $\begin{array}{c}\text { Energía primaria anhidra } \\
\text { (ktep/año) }\end{array}$ & 39 & 59 & 68 & 74 & 79 \\
\hline \multirow{5}{*}{ 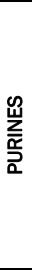 } & \multirow[t]{2}{*}{ Potencial } & $\begin{array}{l}\text { Producción total anual } \\
\text { (t/año humedad en } \\
\text { origen) }\end{array}$ & 11.867 .021 & 12.764 .837 & 13.983.221 & 15.317 .898 & 16.779 .968 \\
\hline & & $\begin{array}{c}\text { Energía primaria anhidra } \\
\text { (ktep/año) }\end{array}$ & 184 & 198 & 217 & 237 & 260 \\
\hline & \multirow{3}{*}{$\begin{array}{l}\text { Fácilmente } \\
\text { valorizable }\end{array}$} & \% fácilmente valorizable & 16 & 18 & 19 & 20 & 21 \\
\hline & & $\begin{array}{c}\text { Producción total anual } \\
\text { (t/año humedad en } \\
\text { origen) } \\
\end{array}$ & 1.898 .723 & 2.297 .671 & 2.656 .812 & 3.063 .580 & 3.523 .793 \\
\hline & & $\begin{array}{c}\text { Energía primaria anhidra } \\
\text { (ktep/año) }\end{array}$ & 29 & 36 & 41 & 48 & 55 \\
\hline \multirow{5}{*}{ 离 } & \multirow[t]{2}{*}{ Potencial } & $\begin{array}{c}\text { Producción total anual } \\
\text { (t/año humedad en } \\
\text { origen) } \\
\end{array}$ & 680.708 & 736.820 & 813.509 & 898.179 & 991.663 \\
\hline & & $\begin{array}{c}\text { Energía primaria anhidra } \\
\text { (ktep/año) }\end{array}$ & 52 & 56 & 62 & 68 & 75 \\
\hline & \multirow{3}{*}{$\begin{array}{l}\text { Fácilmente } \\
\text { valorizable }\end{array}$} & \% fácilmente valorizable & 13 & 17 & 19 & 20 & 21 \\
\hline & & $\begin{array}{c}\text { Producción total anual } \\
\text { (t/año humedad en } \\
\text { origen) } \\
\end{array}$ & 88.492 & 125.259 & 154.567 & 179.636 & 208.249 \\
\hline & & $\begin{array}{c}\begin{array}{c}\text { Energía primaria anhidra } \\
\text { (ktep/año) }\end{array} \\
\end{array}$ & 7 & 10 & 12 & 14 & 16 \\
\hline \multirow{5}{*}{ 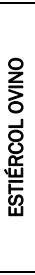 } & \multirow[t]{2}{*}{ Potencial } & $\begin{array}{c}\text { Producción total anual } \\
\text { (t/año humedad en } \\
\text { origen) }\end{array}$ & \multicolumn{5}{|c|}{4.005 .013} \\
\hline & & $\begin{array}{c}\text { Energía primaria anhidra } \\
\text { (ktep/año) }\end{array}$ & \multicolumn{5}{|c|}{307} \\
\hline & \multirow{3}{*}{$\begin{array}{l}\text { Fácilmente } \\
\text { valorizable }\end{array}$} & \% fácilmente valorizable & \multicolumn{5}{|c|}{0} \\
\hline & & $\begin{array}{c}\text { Producción total anual } \\
\text { (t/año humedad en } \\
\text { origen) }\end{array}$ & \multicolumn{5}{|c|}{0} \\
\hline & & $\begin{array}{c}\text { Energía primaria anhidra } \\
\text { (ktep/año) }\end{array}$ & \multicolumn{5}{|c|}{0} \\
\hline \multirow{2}{*}{\multicolumn{2}{|c|}{$\begin{array}{c}\text { TOTAL } \\
\text { FÁCILMENTE } \\
\text { VALORIZABLE } \\
\end{array}$}} & t/año humedad en origen & 2.451 .604 & 3.120 .628 & 3.262 .990 & 4.118 .833 & 4.667 .904 \\
\hline & & $\begin{array}{c}\begin{array}{c}\text { Energía primaria anhidra } \\
\text { (ktep/año) }\end{array} \\
\end{array}$ & 75 & 105 & 121 & 135 & 149 \\
\hline
\end{tabular}

Para la cuantificación de la producción media de las explotaciones de la industria agroalimentaria utilizamos los valores unitarios de la tabla 2.18. 
Tabla 2.18: Producción media de biomasa de industria agroalimentaria en Castilla y León (Fuente: PBCyL).

\begin{tabular}{|c|c|c|}
\hline TIPO DE INDUSTRIA & $\begin{array}{l}\text { TIPO DE } \\
\text { BIOMASA }\end{array}$ & $\begin{array}{l}\text { PRODUCCIÓN } \\
\text { UNITARIA }\end{array}$ \\
\hline Láctea & $\begin{array}{l}\text { Sólidos no conformados, suero } \\
\text { lácteo }\end{array}$ & $\begin{array}{l}20-0,15 \mathrm{~kg} / \mathrm{t} \text { leche recibida. Valor medio } \\
10 \mathrm{Kg} / \mathrm{t}\end{array}$ \\
\hline Cárnica & Sólidos cárnicos & $41 \%$ de las toneladas de producto final \\
\hline \multirow[b]{2}{*}{ Vitivinícola } & Vegetales & $251 \mathrm{~kg} / \mathrm{ha}$ de viñedo \\
\hline & $\begin{array}{l}\text { Residuos prensado bodega. } \\
\text { Vegetales }\end{array}$ & $2.088 \mathrm{~kg} / \mathrm{ha}$ de viñedo \\
\hline $\begin{array}{lll}\text { Pan, bollería } & \text { y } \\
\text { galletas } & & \\
\end{array}$ & Sólidos & $11 \%$ de las toneladas de producto final \\
\hline Molinería & Sólidos & $5 \%$ de las toneladas de producto final \\
\hline Conservas vegetales & Sólidos orgánicos & $20 \%$ de las toneladas de producto final \\
\hline Alimentación animal & Sólidos & $5 \%$ de la producción final \\
\hline
\end{tabular}

Con la producción unitaria de la tabla anterior se puede establecer la cuantificación de biomasa actual y las previsiones de biomasa de la industria agroalimentaria:

Tabla 2.19: Producción total de biomasa de industria agroalimentaria en Castilla y León (Fuente: PBCyL)

\begin{tabular}{|c|c|c|c|}
\hline TIPO DE INDUSTRIA & TIPO DE BIOMASA & $\begin{array}{l}\text { PRODUCTO } \\
\text { PRINCIPAL (t/año) }\end{array}$ & $\begin{array}{l}\text { BIOMASA } \\
\text { FRESCA (t/año) }\end{array}$ \\
\hline Láctea & $\begin{array}{l}\text { Sólidos no conformados, } \\
\text { suero lácteo }\end{array}$ & $1.425 .000 .000 *$ & 14.687 \\
\hline Cárnica & Sólidos cárnicos & 560.000 & 229.600 \\
\hline \multirow[b]{2}{*}{ Vitivinícola } & Vegetales & \multirow[b]{2}{*}{$200.000 .000 *$} & 17.969 \\
\hline & $\begin{array}{l}\text { Residuos prensado bodega. } \\
\text { Vegetales }\end{array}$ & & 149.482 \\
\hline $\begin{array}{l}\text { Pan, bollería y } \\
\text { galletas }\end{array}$ & Sólidos & 205.000 & 20.705 \\
\hline Molinería & Sólidos & 456.845 & 22.842 \\
\hline $\begin{array}{l}\text { Conservas } \\
\text { vegetales }\end{array}$ & Sólidos orgánicos & 1.836 .000 & 367.200 \\
\hline $\begin{array}{l}\text { Alimentación } \\
\text { animal }\end{array}$ & Sólidos & 1.997 .804 & 99.890 \\
\hline \multicolumn{2}{|l|}{ TOTAL } & & 922.366 \\
\hline
\end{tabular}

*Valor expresado en litros

Las previsiones para producciones de biomasa fácilmente valorizables vienen expresadas en la tabla 2:20: 
Tabla 2.20: Previsiones de producción fácilmente valorizable de biomasa agroalimentaria en Castilla y León (Fuente: PBCyL)

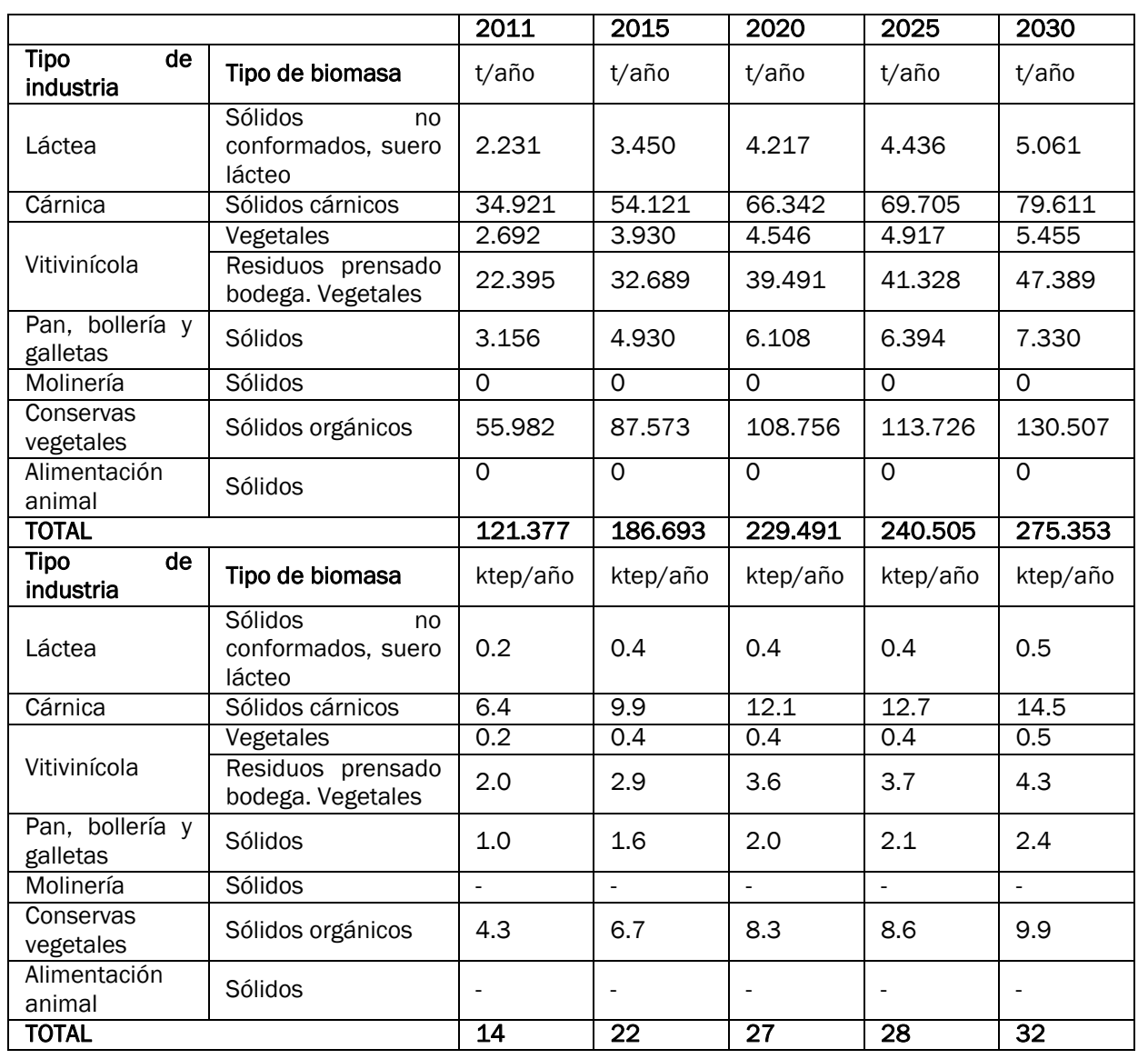

\subsubsection{Restos de la industria de la madera.}

La biomasa procedente de la industria de la madera son los residuos y subproductos que se generan en el desarrollo de la actividad industrial y que pueden ser valorizados energéticamente. Estos restos pueden ser procedentes de la industria de primera transformación como aserraderos, industria del desenrollo y fábricas de tableros y está constituida por madera. También consideramos los residuos de la industria de segunda transformación, industria de carpintería y ebanistería.

Se incluye en la biomasa como resto los residuos procedentes de la industria de la pasta de papel como las legías negras que se generan en el proceso productivo. 
Los restos procedentes de la segunda transformación no se valoran, por su menor relevancia frente a los restos de la primera y por la existencia de barnices y otras sustancias que normalmente contienen estos restos.

Partiendo de los datos de volumen de madera de las cortas realizadas en Castilla y León que se adjuntan en la tabla 2.21.

Tabla 2.21: Flujo actual de madera en Castilla y León (Fuente: PBCyL)

\begin{tabular}{|c|c|c|c|c|c|c|c|c|}
\hline \multirow{3}{*}{$\begin{array}{l}\text { Destino de } \\
\text { La madera }\end{array}$} & \multicolumn{8}{|c|}{ FLUJO DE MADERA (m³/año sc) } \\
\hline & \multicolumn{3}{|c|}{ MADERA EN ROLLO } & \multicolumn{3}{|c|}{ MADERA RECICLADA } & \multirow[b]{2}{*}{ SUBP } & \multirow[b]{2}{*}{ TOTAL } \\
\hline & $\begin{array}{c}\text { Cortas } \\
\text { CyL }\end{array}$ & Import & Export & Región & Import & Export & & \\
\hline $\begin{array}{ll}\text { Aserrío } & \text { y } \\
\text { traviesas } & \end{array}$ & 358.000 & 520.000 & 50.000 & 0 & 0 & 0 & 290.000 & 1.118 .000 \\
\hline $\begin{array}{l}\text { Desenrollo } \\
\text { (chapas) }\end{array}$ & 201.000 & 4.000 & 120.000 & 0 & 0 & 0 & 24.000 & 109.000 \\
\hline $\begin{array}{ll}\text { Apeas, } & \\
\text { postes } & \text { y } \\
\text { estacas } & \end{array}$ & 29.000 & 80.000 & 10.000 & 0 & 0 & 0 & 24.000 & 123.000 \\
\hline $\begin{array}{ll}\text { Trituración } & \\
\text { (tablero } & 0 \\
\text { pasta) } & \\
\end{array}$ & 327.000 & 396.000 & 20.000 & 40.000 & 280.000 & 0 & $\begin{array}{l}244 . \\
000\end{array}$ & 1.267 .000 \\
\hline $\begin{array}{l}\text { Otros usos } \\
\text { industriales }\end{array}$ & 25.000 & 0 & 0 & 0 & 0 & 0 & 1.000 & 26.000 \\
\hline Bioenergía & 80.000 & 0 & 0 & 0 & 0 & 0 & 131.000 & 191.000 \\
\hline TOTAL & 1.000 .000 & 1.000 .000 & 200.000 & 40.000 & 280.000 & 0 & 714.000 & 2.834 .000 \\
\hline
\end{tabular}

Para estimar el potencial fácilmente valorizable hay que precisar que la gran mayoría del material que se genera es autoconsumido como subproductos para su incorporación al proceso productivo y para su uso energético por lo que el margen para la producción de restos es muy estrecho.

En el PBCyL se hace una estimación para los años 2010/2030 con unas hipótesis de crecimiento del sector maderero, aumento de las cortas en los montes de Castilla y León y una reducción de importaciones tanto de madera en rollo como de madera reciclada.

Estas estimaciones pueden sufrir un significativo vuelco como consecuencia de las previsiones de ayudas del PAC a los cultivos leñosos de ciclo corto lo que modificaría al alza las estimaciones residuos susceptibles de valoración energética.

\subsubsection{Biomasa de origen urbano y de otras industrias.}

Constituye la biomasa de origen urbano todos aquellos residuos catalogados como urbanos y que por su contenido orgánico pueden ser valorizables energéticamente. Se incluyen en este grupo residuos industriales no peligrosos, biodegradables no procedentes de la industria 
de la madera ni de la agroalimentaria, como son lodos de plantas depuradoras, madera de construcción y demolición y residuos de envases de madera.

Podemos clasificar dichos restos agrupándoles en:

- Grupo A: Fracción orgánica de restos sólidos urbanos, FORU, residuos biodegradables generados en cocinas, restaurantes, residuos de mercados y similares.

- Grupo B: Aceites vegetales usados. Aceites y grasas comestibles generados en domicilios particulares o en actividades de servicios.

- Grupo C: Lodos de plantas de depuración de aguas residuales, EDAR urbanas o industriales.

- Grupo D: Residuos de envases de madera, madera procedente de construcción y demolición, restos de poda y jardinería urbanos y residuos voluminosos de madera. 


\section{BIBLIOGRAFÍA CAPÍTULO 2}

50) Agencia Internacional de la Energía, Renewable Energy: Policy Considerations for Deploying Renewables, París 2011.

51) Especificación Técnica Europea CEN/TS 14961:(Clasificación y especificaciones).

52) Especificación Técnica Europea CEN/TS 14588(Definición de los biocombustibles).

53) Departamento Forestal de la FAO, Terminología unificada sobra la bioenergía, TUB, Organización de las Naciones Unidas para la agricultura y la alimentación Diciembre 2004.

54) Organización de las Naciones Unidas para la Agricultura y la Alimentación, Presentación de la Plataforma Internacional de Bioenergía, ROMA, 2006

55) Plan Regional de Ámbito Sectorial de la Bioenergía de Castilla y León (Decreto 2/2011, de 20 de enero, BOCyL nº 17 de 26 de enero de 2011).

56) Food and Agriculture Organization of the Units Nations, Methodology WISDOM: Woodfuel Integrated Supply/Demand Overview mapping.

57) INTA: Instituto Nacional de Ingeniería Agropecuaria (Argentina), Análisis del Balance de Energía derivada de Biomasa en Argentina WISDOM Argentina - Buenos aire 2009.

58) INTA: Instituto Nacional de Ingeniería Agropecuaria (Argentina), Programa Nacional de Bioenergía del INTA, PNEG1411Residuos y cultivos agrícolas para la producción de bioenergía, Resoluciones consejo directivo 2008/09.

59) Plan Regional de Ámbito Sectorial de la Bioenergía de Castilla y León (Decreto 2/2011, de 20 de enero, BOCyL n 17 de 26 de enero de 2011).

60) Directiva 2003/30/CE del Parlamento Europeo y del Consejo, relativa al fomento del uso de biocarburantes $u$ otros combustibles renovables en el transporte, de 8 de mayo de 2003.

61) FEGA: Fondo Español de Garantía Agraria, CAMPAÑA 2005/2006 (Cosecha 2005) Ayuda a los cultivos energéticos Capítulo 5 del TíTULO IV del R(CE) 1782/2003 Art. 44 del R(CE) 1973/2004: superficies definitivas de la campaña

62) PAC Política Agraria Común, ayudas concedidas, desde 1997, http://www.fega.es/PwfGcp/es/financiacion_de_la_pac

63) Los cultivos energéticos en Castilla y León Fdo. Rodríguez López y J. Ignacio Sánchez Macías. Universidad de Salamanca. 
CAPITULO 3 COMBUSTIBLES

\section{$3.1 \quad$ INTRODUCCIÓN}

Interesa conocer las características físicas y químicas de los combustibles que se van a utilizar, sobre todo aquellas características que intervienen en los procesos de mezcla y los de combustión.

Para las características de los combustibles de origen fósil (gasóleo) utilizaremos las especificaciones que se fijan en el RD 61/2006 de 31 de Enero donde se transponen las exigencias de calidad de la Directiva Europea 2003/17/CE relativas a la calidad de la gasolina y el gasóleo64.

Se recogen en este capítulo también las propiedades de distintos aceites y grasas caracterizados en el Laboratorio Regional de Combustibles de Castilla y León.

Se estudia el proceso de mezcla al objeto de obtener una disolución estable y homogénea necesaria para una combustión así mismo estable.

Se estudian aquellas propiedades de las mezclas que intervienen en el proceso de combustión como la miscibilidad y la viscosidad.

${ }^{64}$ Council Directive no 2003/17/CE "relating to the quality of petrol and diesel fuels". 


\subsection{NATURALEZA DE LOS COMBUSTIBLES LÍQUIDOS}

La composición de los combustibles líquidos de origen fósil están formados por hidrocarburos, los hidrocarburos se clasifican en65:

- Hidrocarburos alifáticos

- Hidrocarburos saturados. Posen solamente enlaces simples

- Alcanos

- Lineales: $\mathrm{CH}_{3} \mathrm{CH}_{3}$ etano; $\mathrm{CH}_{3} \mathrm{CH}_{2} \mathrm{CH}_{3}$, propano;

- Ramificados: $\mathrm{CH}_{3} \mathrm{CHCH}_{3}$, 2-metilpropano

I

$\mathrm{CH}_{3}$

- Cicloalcanos:

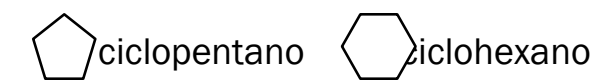

- Hidrocarburos insaturados. Posen enlaces dobles o triples.

- Alquenos: $\mathrm{H}_{2} \mathrm{C}=\mathrm{CH}_{2}$ eteno; $\mathrm{H}_{2} \mathrm{C}=\mathrm{CH}_{2} \mathrm{CH}_{3}$ propeno

- Alquinos: $\mathrm{H}-\mathrm{C} \equiv \mathrm{CCH}_{3}$ propino

- Hidrocarburos aromáticos

- Benceno, tolueno y naftaleno.

Es también frecuente clasificar los hidrocarburos por la forma de su cadena en hidrocarburos de cadena abierta o cerrada.

Es interesante resaltar que en los hidrocarburos saturados la relación $\mathrm{C} / \mathrm{H}$ es más pequeña que en los insaturados y menos aún que en los aromáticos.

De los combustibles líquidos el más usado tanto para transporte como para usos térmicos es el gasóleo que es un derivado del petróleo compuesto por una mezcla de hidrocarburos cuyo número de átomos de carbono está comprendido entre C14 y C20 lo que caracteriza tanto su poder calorífico como otras propiedades como su temperatura de inflamación, viscosidad, etc ${ }^{66}$.

${ }^{65}$ Lapuerta M. y Hernández J.J., Lapuerta Amigo M. y Hernández Adrover J.J.. "Tecnologías de la combustión. Capítulo 2. Caracterización de los combustibles”, Ediciones de la Universidad de Castilla - La Mancha. pp 39 - 66, 1998.

66 REAL DECRETO 61/2006, de 31 de enero, por el que se determinan las especificaciones de gasolinas, gasóleos, fuelóleos y gases licuados del petróleo y se regula el uso de determinados biocarburantes. Ministerio de Industria, Turismo y Comercio, 2006 


\subsubsection{El aceite vegetal}

El aceite vegetal se extrae por un método usado desde la antigüedad, sin embargo, ampliamente mejorado y mucho más eficiente. Además, hoy el proceso de extracción de aceite se emplean solventes orgánicos para obtener virtualmente el $100 \%$ de aceite contenido en las semillas. El proceso no se detiene con la extracción del aceite vegetal, sino que luego es refinado para remover los ácidos grasos y otras impurezas que están adicionadas y que produce que el aceite tenga olores y una apariencia desagradables y que puede en algunos casos ser peligroso para la salud.

El proceso de elaboración de aceites para uso alimenticio comienza por el cultivo de las semillas y termina con la puesta en el mercado del aceite. En todo el proceso hay diferentes criterios de actuación los cuales sin lugar a duda determinaran la calidad final del aceite. La legislación Europea permite diferentes posibilidades para la puesta en el mercado de los aceites de semillas.

\section{Proceso de obtención del aceite:}

El método usado para extraer el aceite de las semillas comienza con una separación de restos de metales, pequeñas piedras y arenillas, que haya sido mezclada con las semillas desde la granja antes del descascarillado, seguido de las siguientes fases, en la figura 3.1 se puede ver un diagrama del proceso de obtención del aceite.

Preparación de las semillas. Descascarillado, separación de cáscaras, limpieza por criba, aplastado del grano mediante molino de cilindros.

Calentamiento de las semillas. Se calientan mediante el paso por tubos de vapor a temperatura $>100^{\circ}$.

Prensado. Obtención del aceite mediante presión en prensa sinfín de gran potencia. El líquido resultante suele superar los $60^{\circ}$ de temperatura, Se suele producir que a partir de $45^{\circ}$ la molécula de los ácidos grasos insaturados se altera de su forma natural "Cis" a su forma "Trans".

Filtro por centrifugado, se obtiene aceite en bruto de presión. Los restos del prensado (la torta), son mezclados con disolventes (Hexano). Resulta una mezcla de aceite + Hexano que es destilada y pasada a través de vapor. Se obtiene aceite en bruto de extracción.

Mezclado del aceite en bruto. Se mezcla el aceite en bruto de extracción con el de presión. 


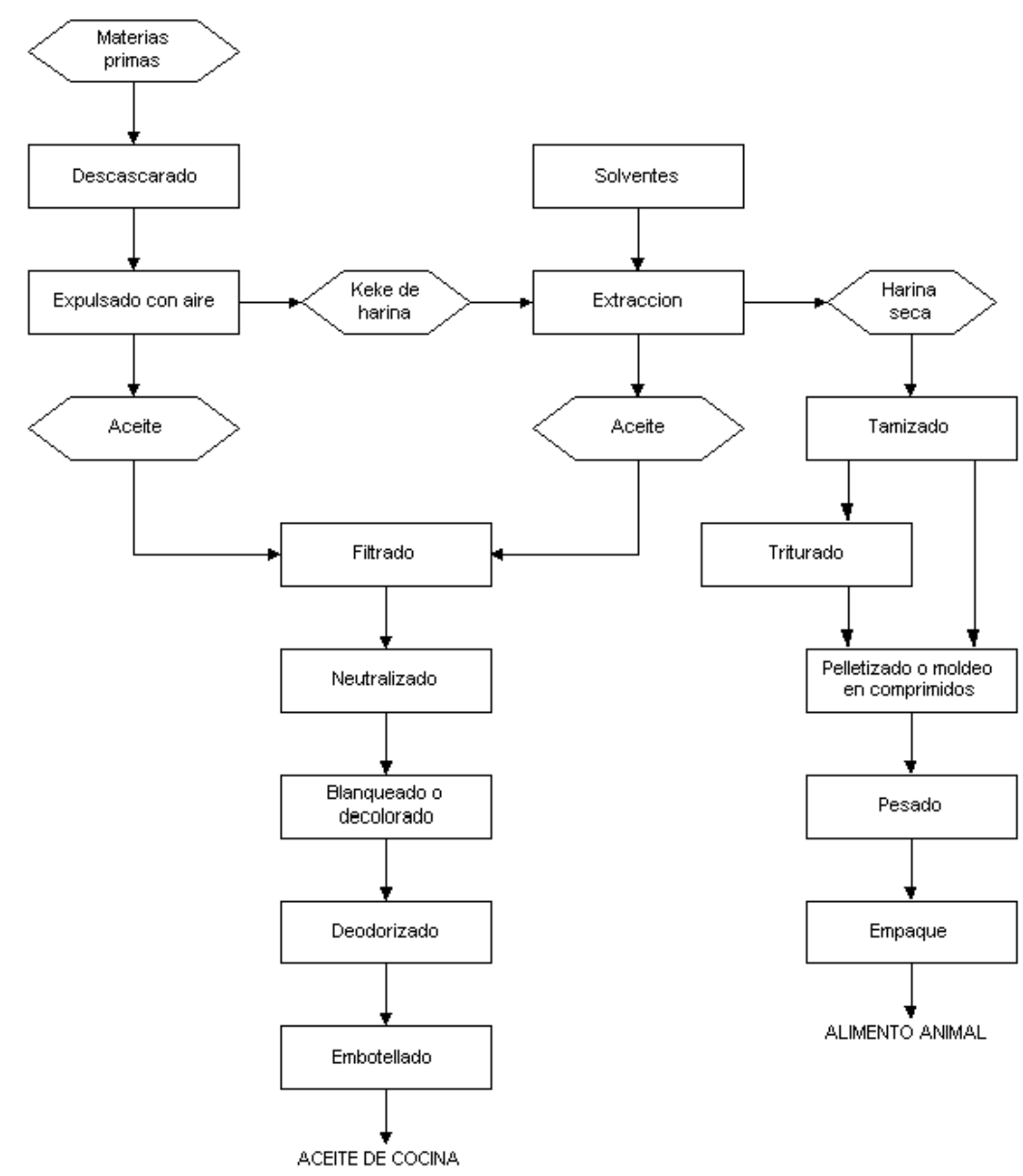

Figura 2.1. Esquema de principio de obtención de aceite de semillas.

Desmucilaginación. Mediante sales inorgánicas o ácidos diluidos.

Neutralización. El aceite resultante es sometido a la neutralización mediante lejías acuosas alcalinas y el uso de ciertas substancias jabonosas.

Lavado y secado. El aceite neutro obtenido es lavado en agua, quedando restos de substancias jabonosas.

Decoloración. Se decolora el aceite mediante el uso de tierras decolorantes y carbón activo. 
Filtrado. Se filtra mediante el paso a través de tierras usadas y pigmentadas obteniéndose un aceite neutro y claro.

Eliminación de ceras. Este proceso no es obligatorio.

Desodorización. Mediante la inyección de vapor $\left(180^{\circ}\right.$ a $\left.200^{\circ}\right)$ al vacío se elimina las substancias volátiles.

\section{Composición del aceite vegetal}

Los aceites y las grasas están formados por ésteres de la glicerina (triglicéridos) y ácidos grasos saturados o insaturados. Los aceites contienen mayor proporción de ácidos no saturados que las grasas por lo que presentan un punto de fusión más bajo.

Los tres ácidos que más frecuentemente se encuentran en las grasas y aceites son el palmítico, esteárico y oleico, los dos primeros a temperatura ambiente son sólidos y el tercero es líquido.

La nomenclatura utilizada para nombrar a los distintos ácidos grasos varía según su campo de aplicación, distinguiéndose:

- La nomenclatura sistemática de Ginebra67. Muy específica pero escasamente utilizada por los técnicos por su complejidad aunque en algunos casos es la única posible para ácidos grasos escasamente difundidos en la naturaleza. Consiste fundamentalmente para nombrar al ácido graso elegir como función principal la función ácido considerando entre todas las cadenas posibles la cadena lineal con mayor $\mathrm{n}^{\circ}$ de átomos de carbono que contiene a la función ácido.

- Nombre común. Utilizado tanto por científicos como técnicos del campo de los aceites y las grasas y menos difundida fuera de ese campo. El nombre generalmente impuesto por el descubridor deriva en muchos casos de la planta donde se descubrió.

- Nomenclatura abreviada. Se indica en primer lugar el $n^{\circ}$ de átomos de carbono de la cadena más larga con el grupo carboxílico seguido por ":" y el $n^{\circ}$ de enlaces diferentes a C-C de la misma. A continuación entre paréntesis y separados por comas se expresa la posición en la cadena del primer átomo de carbono con una función distinta al enlace saturado y la naturaleza de dichos enlaces distintos (enlaces cis "c" y enlaces trans "t" y triple enlace "a").

Relación de algunos ácidos grasos más comunes entre grasas y aceites en sus distintas nomenclaturas se recogen en la tabla 3.1:

67 International Union of Pure and Applied Chemistry, “The Congress of Chemistry, Ginebra 1892. 
Tabla 3.1: Ácidos grasos más comunes. ${ }^{68}$

\begin{tabular}{|c|c|c|c|}
\hline NOMBRE COMÚN & $\begin{array}{l}\text { NOMENCLATURA } \\
\text { SISTEMÁTICA } \\
\end{array}$ & $\begin{array}{c}\text { NOMENCLATURA } \\
\text { ABREVIADA } \\
\end{array}$ & PROCEDENCIA \\
\hline \multicolumn{4}{|c|}{ Ácidos grasos saturados } \\
\hline Butírico & Butanoico & $4: 0$ & Leche de rumiantes \\
\hline Caproico & Hexanoico & $6: 0$ & $\begin{array}{l}\text { Leche de rumiantes y } \\
\text { palmáceas. }\end{array}$ \\
\hline Caprílico & Octanoico & $8: 0$ & $\begin{array}{c}\text { Leche de rumiantes y } \\
\text { palmáceas }\end{array}$ \\
\hline Láurico & Dodecanoico & $12: 0$ & $\begin{array}{l}\text { Laureáceas,coco y } \\
\text { palmiste }\end{array}$ \\
\hline Mirístico & Tetradecanoico & 14:0 & $\begin{array}{l}\text { Miristáceas, coco y } \\
\text { palmiste }\end{array}$ \\
\hline Palmítico & Hexadecanoico & $14: 0$ & Todas las grasas \\
\hline \multicolumn{4}{|c|}{ Ácidos grasos monoinsaturados } \\
\hline Palmitoleico & Hexadec-9c-enoico & $16: 1(9 c)$ & $\begin{array}{c}\text { Grasas y aceites } \\
\text { animales, vegetales, } \\
\text { marinas }\end{array}$ \\
\hline Oleico & Octadec-9c-enoico & $18: 1(9 c)$ & Todas las grasas \\
\hline Vaccénico & $\begin{array}{l}\text { Ontadec-11t- } \\
\text { enoico }\end{array}$ & $18: 1(11 t)$ & Mantequilla \\
\hline \multicolumn{4}{|c|}{ Ácidos grasos poliinsaturados } \\
\hline Linoleico & $\begin{array}{l}\text { Octadeca-9c, 12c- } \\
\text { dienoico }\end{array}$ & $18: 2(9 c, 12 c)$ & Todas las grasas \\
\hline Linolénico & Octadeca-6c,9c & 18:3(9c, 12c, 15c) & Todas las grasas \\
\hline
\end{tabular}

El número de ácidos grasos distintos es bastante elevado hay caracterizados en la actualidad más de cuatrocientos ácidos grasos distintos.

A continuación se exponen para las grasas y los aceites más usuales su composición media en ácidos grasos, esta composición en algunos casos es muy variada dependiendo de la variedad de semilla, de las técnicas de cultivo y de la edafología.

68 Enrique Graciani Constante, Los aceites y grasas: composición y propiedades. Editor, AMV, 2006 
Tabla 3.2: Composición en Ácidos grasos de los aceites y grasas más comunes.

\begin{tabular}{|l|l|l|l|l|l|l|}
\hline & $\begin{array}{l}\text { Manteca de } \\
\text { cerdo }\end{array}$ & $\begin{array}{l}\text { Sebo de } \\
\text { Vacuno }\end{array}$ & $\begin{array}{l}\text { Aceite } \\
\text { de soja }\end{array}$ & Aceite & $\begin{array}{l}\text { Aceite de } \\
\text { Girasol }\end{array}$ & $\begin{array}{l}\text { Aceite } \\
\text { de Oliva }\end{array}$ \\
\hline Mirístico & & 1,1 & & & & \\
\hline Palmítico & 28,3 & 24,6 & $7,0-14,0$ & 2,8 & $3,0-10,0$ & 6,9 \\
\hline Esteárico & 11,9 & 30,5 & $1,5-5,5$ & 1,1 & $1,0-10,0$ & \\
\hline Oleico & 47,5 & 36,0 & $19,0-30,0$ & 10,9 & $14,0-65,0$ & 84,4 \\
\hline Linoleico & 6,0 & 4,3 & $44,0-62,0$ & 11,6 & $20,0-75,0$ & 4,6 \\
\hline Linolénico & & & $4,0-11,0$ & 9,9 & & 34,1 \\
\hline Araquídico & & & & 1,2 & & \\
\hline Gadolénico & & & & 9,5 & & \\
\hline Erúcíd & & & & 51,6 & & \\
\hline O & & & & 5 & & \\
\hline
\end{tabular}

\subsection{CARACTERÍSTICAS FÍSICAS DE LOS COMBUSTIBLES.}

En los procesos de combustión junto con las características químicas del combustible, sobre todo su composición, es importante el conocimiento de algunas características físicas.

\subsubsection{Densidad}

La densidad de una sustancia a una temperatura se define como el cociente entre su masa y su volumen a dicha temperatura, en el S.I. la densidad se mide en $\mathrm{Kg} / \mathrm{m}^{3}$.

La dependencia de la densidad con la presión se considera despreciable.

Es muy usual utilizar el concepto de densidad relativa frente al de densidad absoluta que es el anterior. La densidad relativa es el cociente entre la densidad absoluta de una sustancia a una temperatura y la densidad a esa misma temperatura de una sustancia de referencia, en el caso de líquidos la sustancia de referencia suele ser el agua. La densidad relativa es una variable adimensional. 
Es frecuente en hidrocarburos utilizar para la medida de la densidad relativa los grados API de sus siglas en inglés American Petroleum Institute, definidos como:

$$
{ }^{\circ} \mathrm{API}=\frac{141,5}{\mathrm{sp} \cdot \mathrm{gr} 60 / 60^{\circ} \mathrm{F}}-131,5
$$

En la que: sp.gr60/60 ${ }^{\circ} \mathrm{F}$ es la densidad relativa del hidrocarburo respecto del agua a $60^{\circ} \mathrm{F}\left(15,56^{\circ} \mathrm{C}\right)$.

Para la determinación de la densidad de un combustible existen distintos métodos como la Norma UNE 5115669 y ASTM70 D4052-96

La figura 3.2 permite obtener la densidad relativa cuando variamos la temperatura, tomando como base la densidad a $15,56^{\circ} \mathrm{C}\left(60^{\circ} \mathrm{F}\right)$.

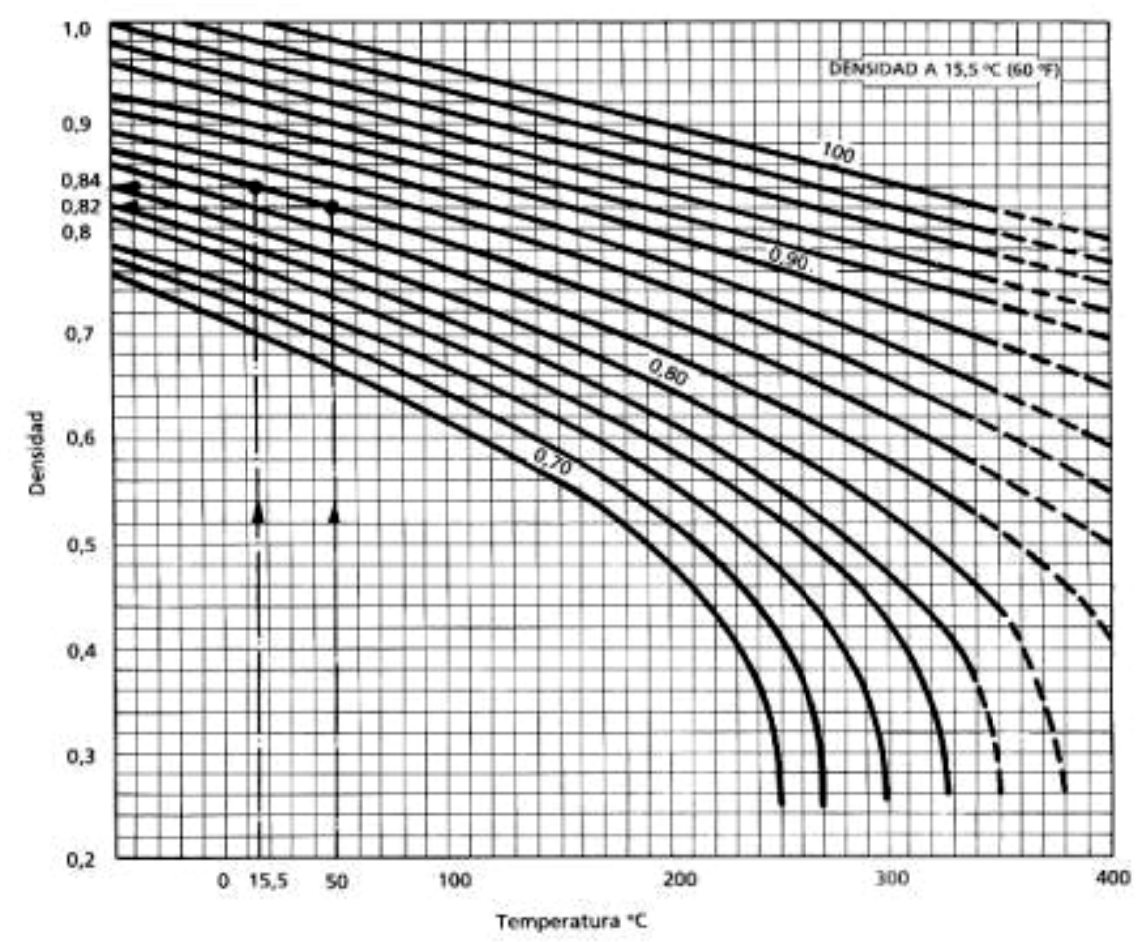

Figura 3.2:Variación de la densidad relativa con la temperatura ${ }^{71}$.

69 Norma UNE 51116, de 15 de septiembre de 1998. Petróleos crudos y productos petrolíferos líquidos. Determinación de la densidad y de la densidad relativa en el laboratorio. Método del areómetro, 1998.

70 ASTM D4052 - 96, 2002.)e1 Standard Test Method for Density and Relative Density of Liquids by Digital Density Meter, 2002. 


\subsubsection{Viscosidad}

La viscosidad es la resistencia que ofrece internamente un fluido cuando se le aplica una fuerza exterior. A causa de la viscosidad es necesario aplicar una fuerza para obligar a una capa de fluido a deslizar sobre otra.

La fuerza que hay que aplicar es proporcional al gradiente de velocidad, el coeficiente de proporcionalidad es la viscosidad dinámica o absoluta y se mide en Poises. (En el S.I. se mide en Pa.s)

La viscosidad es consecuencia de las fuerzas de cohesión entre las moléculas del fluido, en los líquidos, las fuerzas de cohesión son mucho más grandes que en los gases, al igual que la viscosidad. Los efectos de la temperatura sobre la cohesión y sobre la viscosidad en el caso de líquidos es disminuir notablemente con el aumento de la misma. Las variaciones de presión no tienen apenas influencia en la viscosidad de líquidos.

La viscosidad y la adherencia son factores muy importantes en el uso de combustibles líquidos, para su trasiego, y para la pulverización en quemadores.

En las especificaciones se suele emplear la viscosidad cinemática que es el cociente entre la viscosidad dinámica y la densidad. La unidad empleada es el Stoke. (En el S.I. m²/s).

Es frecuente la utilización en Europa de los grados Engler $\left({ }^{\circ} \mathrm{E}\right)$ medida experimental tomada del aparato de medida Ilamado viscosímetro Engler. En la técnica de aceites lubricantes se utiliza para el grado de viscosidad el número SAE (Society of Automotive Engieneers).

La variación de la viscosidad con la temperatura en un aceite genérico tiene una gráfica similar a la figura 3.3:

${ }^{71}$ ASTM D4052 - 96, 2002.)e1 Standard Test Method for Density and Relative Density of Liquids by Digital Density Meter, 2002. 


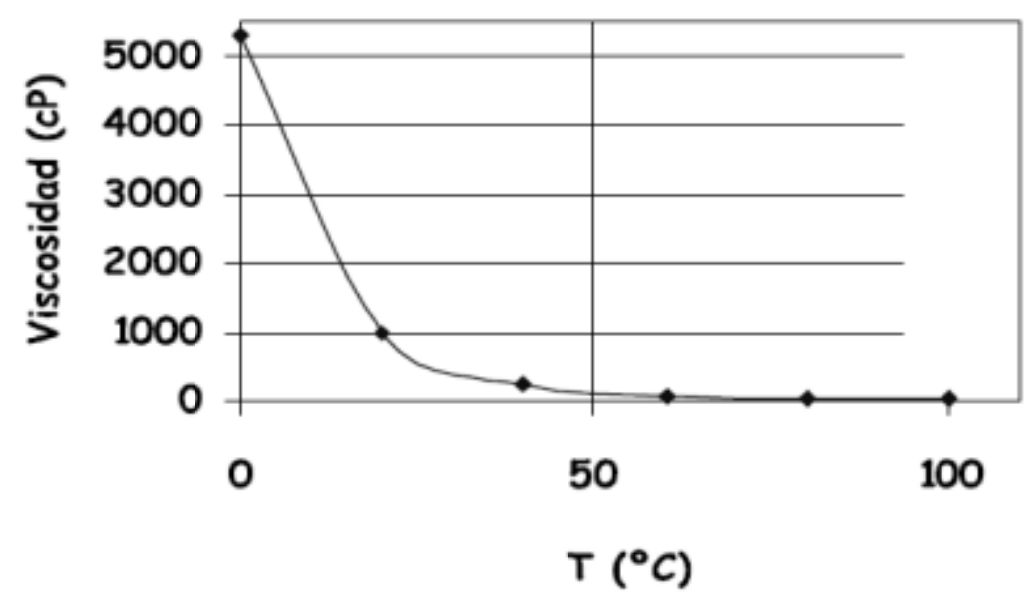

Figura 3.3: Típica variación de la viscosidad con la temperatura en aceites

Es frecuente la utilización de escalas logarítmicas para representar la variación de viscosidad con la temperatura de forma que la representación sea una recta.

En la figura 3.4 podemos observar la variación de la viscosidad con la temperatura de distintos tipos de combustibles comerciales con sus valores límites de uso para verano e invierno y la clasificación de dichos combustibles por su viscosidad.

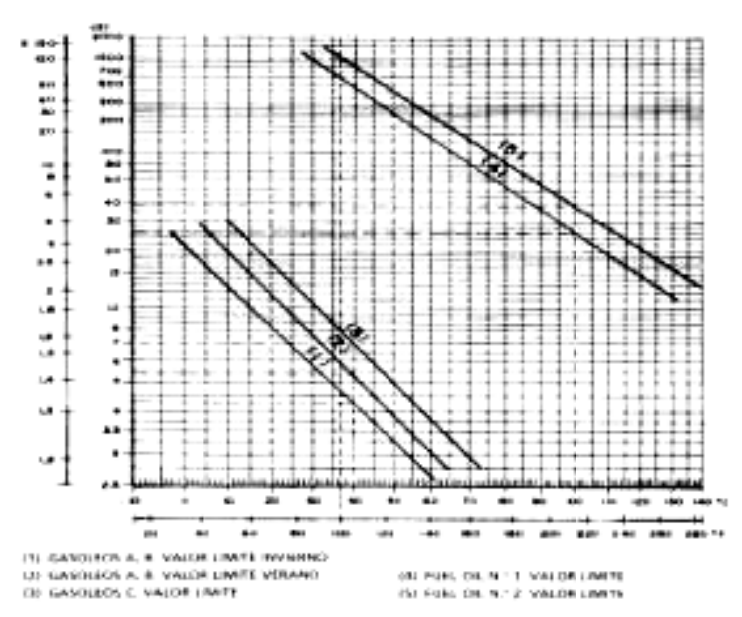

Figura 3.4: Variación de la viscosidad con la temperatura72.

72 Norma UNE 51108, de 15 de marzo de 1983. Productos petrolíferos. Determinación de la viscosidad cinemática y cálculo de la viscosidad dinámica. líquidos opacos y transparentes, 1983. 
Para determinar la viscosidad de la mezcla de dos combustibles distintos podemos utilizar la figura 3.5 en función de los porcentajes de mezcla. Así mismo la gráfica nos permite determinar los porcentajes para alcanzar una determinada viscosidad.

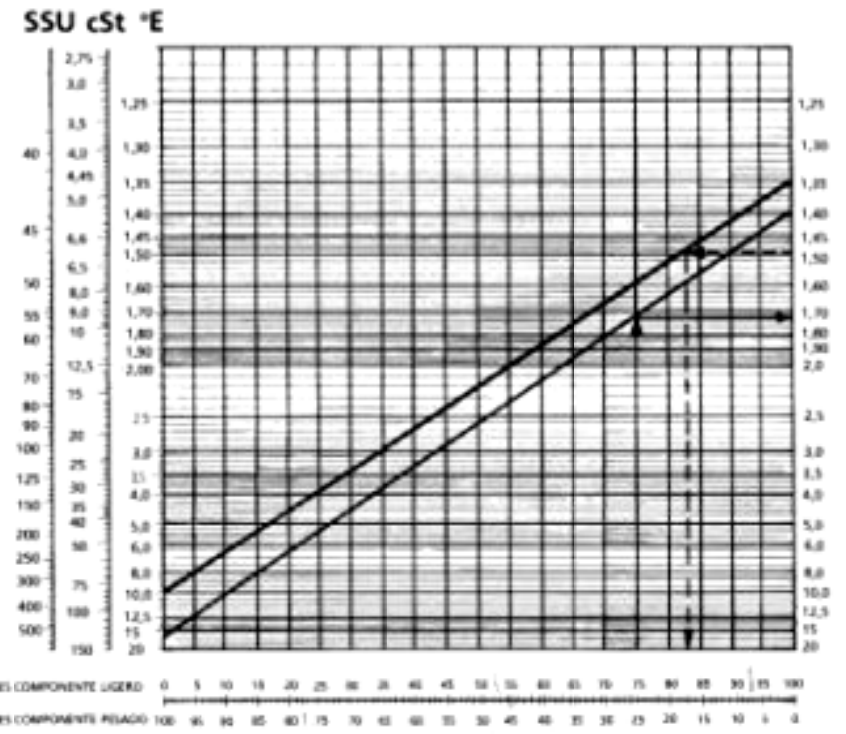

Figura 3.5: Viscosidad de la mezcla de dos combustibles ${ }^{73}$.

En la gráfica anterior se representan las viscosidades de los dos componentes, a la derecha el ligero y a la izquierda el pesado, en el eje de abscisas se representa los porcentajes de cada uno de los componentes.

La determinación de la viscosidad de una determinada mezcla se consigue trazando la recta que une los puntos de viscosidad e ambos componentes, llevando los porcentajes de la mezcla en una vertical hasta cortar a la anterior, trazándola horizontal nos determina la viscosidad de la mezcla.

Así mismo podemos determinar partiendo de una determinada viscosidad los porcentajes de mezcla para conseguirla.

En el gráfico están determinados la mezcla de $75 \%$ y $25 \%$ de dos combustibles de viscosidad a $50^{\circ} \mathrm{C}$ de $1,4^{\circ} \mathrm{E}$ y $17^{\circ} \mathrm{E}$. La viscosidad resultante es de $1,74^{\circ} \mathrm{E}$.

${ }^{73}$ ASTM D341 - 09 Standard Practices for Viscosity-Temperature Charts for Liquid Petroleum Products, 2009. 
Para la determinación del porcentaje de mezcla usamos combustibles de viscosidad $1,35^{\circ} \mathrm{E}$ y $10^{\circ} \mathrm{E}$, queriendo obtener una viscosidad de mezcla de $1,5^{\circ} \mathrm{E}$, siguiendo el procedimiento anterior determinamos los porcentajes de mezcla, siendo $83 \%$ y $17 \%$.

\subsubsection{Poder calorífico.}

El poder calorífico representa la energía específica liberada como consecuencia de la reacción de combustión completa, en la que se forman como productos de la combustión $\mathrm{CO}_{2}$ y $\mathrm{H}_{2} \mathrm{O}$. En condiciones estándar se considera al combustible en estado líquido, a una temperatura de $25^{\circ} \mathrm{C}$, el aire y los productos de la combustión se consideran a esa misma temperatura.

Cabe distinguir entre el Poder Calorífico Inferior (PCl) y el Poder Calorífico superior (PCS) dependiendo de que el agua formada en la combustión esté en fase líquida o gaseosa.

La determinación del Poder calorífico se hace en laboratorio utilizando una bomba calorimétrica. La combustión de una muestra de carburante en atmósfera de oxígeno en un recipiente sumergido en agua permite la determinación de la energía liberada por el incremento de temperatura del agua, corregido con las características calóricas del dispositivo.

Los dispositivos calorimétricos proporcionan el PCS del combustible, para la determinación del PCl es necesario conocer el contenido de hidrógeno del combustible. La masa de agua producida por la combustión de un kg de comburente cuyo contenido másico de hidrógeno es $M_{H}$ puede expresarse como:

$$
M_{H_{2 O}}=\frac{M_{H}}{100} * \frac{18}{2}
$$

Como la entalpía de vaporización del agua a $25^{\circ} \mathrm{C}$ es de $2.443 \mathrm{~kJ} / \mathrm{kg}$ obtenemos:

$$
\mathrm{PCl}=\mathrm{PCS}-220 * \mathrm{MH}_{\mathrm{H}}
$$

Con PCl y PCS expresados en $\mathrm{kJ} / \mathrm{kg}$. 
Existen correlaciones para la determinación del PCI en función de ciertos parámetros, por ejemplo en la formula de Sirtori74:

$P C l_{m}=4,18 *(106,38 *$ Parafinas $+105,76 *$ Olefinas $+95,55 *$ Aromáticos $)$

El PCl medido en $\mathrm{kJ} / \mathrm{kg}$ y Parafinas, Olefinas y aromáticos el tanto por ciento en peso de estos compuestos en el combustible.

\subsubsection{Contenido de azufre}

El contenido de azufre, característico de los derivados del petróleo se determina mediante la Norma ASTM 155275, su presencia en los combustibles es fuente de contaminación ambiental y de problemas de corrosión.

Los problemas de corrosión pueden originarse a baja temperatura por condensación del ácido sulfúrico al alcanzar los humos el punto de rocío ácido o a alta temperatura produciendo en turbinas y calderas con alto grado de recalentamiento corrosión por sulfatos de metales alcalinos.

Las cantidades máximas de azufre en los combustibles comerciales se han ido reduciendo drásticamente en los últimos años.

\subsection{CARACTERIZACIÓN DE LAS MUESTRAS DE COMBUSTIBLES A ESTUDIAR.}

Las muestras de combustibles que se van a estudiar son mezclas de aceite vegetal y gasóleo en diferentes proporciones, para caracterizar las mezclas se comienza con la caracterización cada aceite vegetal y el gasóleo, de forma independiente, para luego poder determinar las propiedades de las diferentes mezclas

\subsubsection{Aceites a estudio}

Los aceites vegetales de soja, girasol y colza se han solicitado al Grupo SOS Aceites Ibericos Acisa a la factoría de Andujar (Jaén), la cual nos suministra el producto elaborado.

\footnotetext{
${ }^{74}$ Sirtori, S., Garibaldi P. y Vicenzetto F.A., "Prediction of the combustion properties of gasoline from the analysis of their composition". SAE paper n. 74-1058, International automobile Engineering and Manufacturing Meeting. Toronto, Ontario, 1974.

75 ASTM D1552 - 08 Standard Test Method for Sulfur in Petroleum Products (High-Temperature Method), 2008.
} 
Aceite de colza

El aspecto que presenta el aceite de colza se muestra en la foto 3.1:

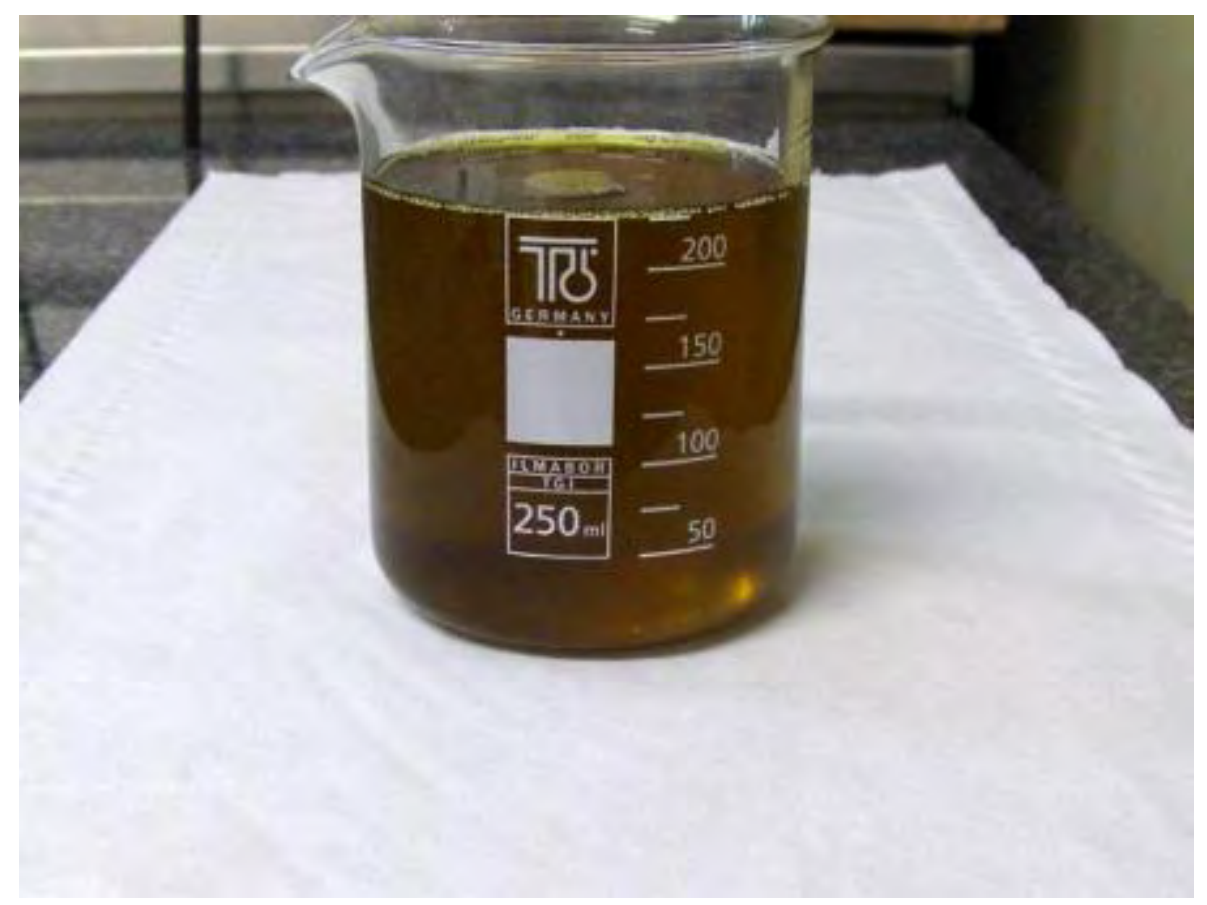

Foto 3.1: Aceite de colza, según ha sido recibido.

Apariencia de la muestra de aceite de colza recibido se recoge en la tabla 3.3:

Tabla 3.3: Apariencia de la muestra de aceite de colza.

\begin{tabular}{|l|l|}
\hline CARACTERIZACIÓN & \\
\hline Estado de agregación & Líquido \\
\hline Apariencia & Homogénea \\
\hline Olor & Aceite sintético \\
\hline Impurezas & Presenta \\
\hline Estratificación & No presenta \\
\hline Color & Dorado y transparente \\
\hline
\end{tabular}




\section{Aceite de soja}

El aspecto que presenta el aceite de soja refinado se muestra en la foto 3.2:

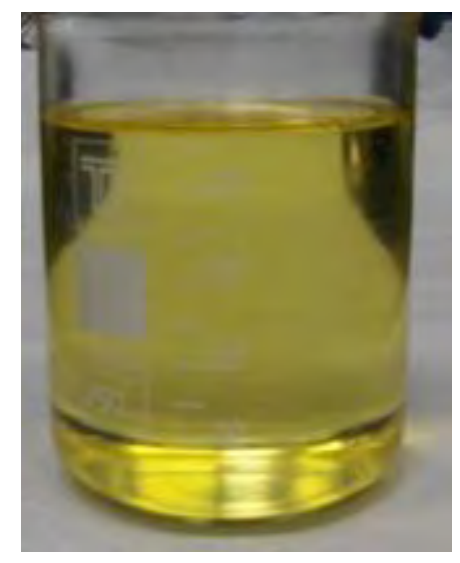

Foto 3.2: Aceite soja, según ha sido recibido.

Apariencia de la muestra de aceite de soja recibido se recoge en la tabla 3.4:

Tabla 3.4: Apariencia de la muestra de aceite de soja.

\begin{tabular}{|l|l|}
\hline CARACTERIZACIÓN & \\
\hline Estado de agregación & Líquido \\
\hline Apariencia & Homogénea \\
\hline Olor & Inapreciable \\
\hline Impurezas & No presenta \\
\hline Estratificación & No presenta \\
\hline Color & Dorado y transparente \\
\hline
\end{tabular}

Datos que nos facilita el suministrador:

- $\quad$ Acidez

- $\quad$ Color Lovibond (5 1/4 “)
o UU Rojas
1,5
o UU Amarillas
15

- Composición de ácidos grasos:
o C 14:0 Mirístico (\%)
0,08
o C 16:0 Palmitico (\%)
10,91
o C16:1 Palmitoleico (\%)
0,09
o C18:0 Esteárico (\%)
3,00
o C18:1 Oleico (\%)
24.90 
o C18:2 Linoleico(\%)

o C18:3 Linolénico (\%)

o C20:0 Aráquico (\%)

o C20:1 Gadoleico (\%)

o C22:0 Behénico (\%)
54,23

5,42

0,32

0,25

0,45

\section{Aceite de girasol}

El aspecto que presenta el aceite de girasol refinado se muestra en la foto 3.3:

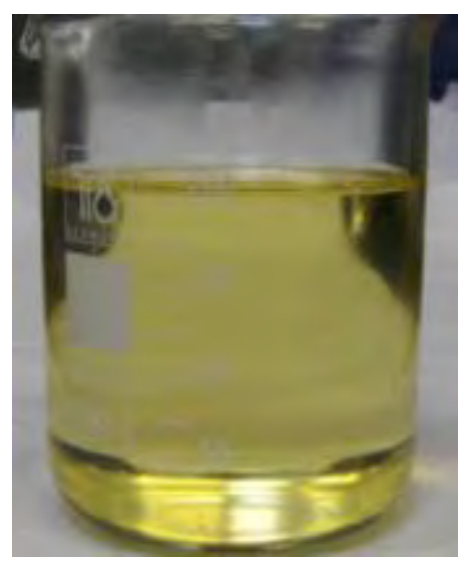

Foto 3.3: Aceite girasol, según ha sido recibido.

Apariencia de la muestra de aceite girasol recibido se recoge en la tabla 3.4:

Tabla 3.4: Apariencia de la muestra de aceite girasol.

\begin{tabular}{|l|l|}
\hline CARACTERIZACIÓN & Líquido \\
\hline Estado de agregación & Homogénea \\
\hline Apariencia & Pipas tostadas \\
\hline Olor & No presenta \\
\hline Impurezas & No presenta \\
\hline Estratificación & amarillo y transparente \\
\hline Color &
\end{tabular}


Datos que nos facilita el suministrador:

- Acidez

- Color Lovibond (5 1/4 “)
o UU Rojas
o UU Amarillas

- Composición de ácidos grasos:

$\begin{array}{lll}\text { o } & \text { C 14:0 Mirístico (\%) } & 0,08 \\ \text { o } & \text { C 16:0 Palmitico (\%) } & 6,61 \\ \text { o } & \text { C16:1 Palmitoleico (\%) } & 0,18 \\ \text { o } & \text { C18:0 Esteárico (\%) } & 3,80 \\ \text { o } & \text { C18:1 Oleico (\%) } & 30,53 \\ \text { o } & \text { C18:2 Linoleico(\%) } & 57,17 \\ \text { o } & \text { C18:3 Linolénico (\%) } & 0,07 \\ \text { o } & \text { C20:0 Aráquico (\%) } & 0,28 \\ \text { o } & \text { C20:1 Gadoleico (\%) } & 0,15 \\ \text { o } & \text { C22:0 Behénico (\%) } & 0,72\end{array}$

\section{Aceite vegetal usado}

el aceite vegetal usado se han solicitado a una empresa de transformación de aceites vegetal usado en biodiesel, que tiene como materia prima el aceite vegetal usado, que les suministran los gestores de aceites usados y como subproducto del proceso de la planta se obtiene glicerina.

El aspecto que presenta el aceite vegetal usado se muestra en la foto 3.4:

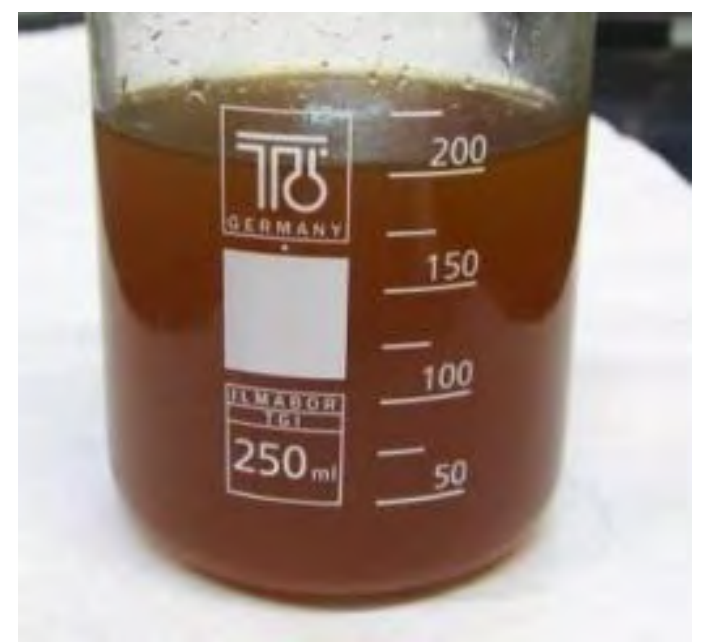

Foto 3.4: Aceite vegetal usado, según ha sido recibido. 
Las característicasaparentes de la muestra de aceite vegetal usado que se recibido se recoge en la tabla 3.5:

Tabla 3.5: Características aparentes de la muestra de aceite vegetal usado.

\begin{tabular}{|l|l|}
\hline CARACTERIZACIÓN & Líquido \\
\hline Estado de agregación & Homogénea \\
\hline Apariencia & Frito \\
\hline Olor & No presenta \\
\hline Impurezas & No presenta \\
\hline Estratificación & Dorado y transparente \\
\hline Color &
\end{tabular}

Datos que nos facilita el suministrador:

- Agua

600 PPM

- Acidez

$$
\text { 2,55 mg KH/g }
$$

\subsubsection{Caracterización de los aceites como combustibles}

El estudio se realiza sobre seis aceites vegetales:

- Aceite vegetal de colza crudo.

- Aceite vegetal de soja crudo.

- Aceite vegetal de soja refinado

- Aceite vegetal de girasol crudo.

- Aceite vegetal de girasol refinado.

- Aceite vegetal usado.

La caracterización como combustible de los aceites y el gasóleo de forma independiente se ha realizado en el Laboratorio Regional de Combustibles LARECOM, en la Tabla 3.7 se puede observar las características de los aceites y del gasóleo. (En el Anexo 2 se recogen todos los análisis). 
Tabla 3.7: Características de los aceites y el gasóleo.

\begin{tabular}{|c|c|c|c|c|c|c|c|}
\hline & 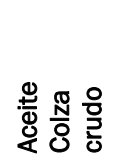 & 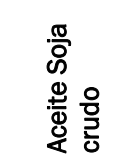 & 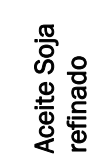 & 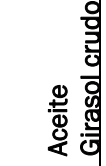 & 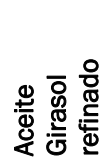 & 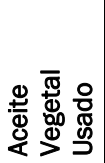 & 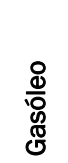 \\
\hline Densidad a $15^{\circ} \mathrm{C}\left(\mathrm{kg} / \mathrm{m}^{3}\right)$ & 919,5 & 922,5 & 922,5 & 923 & 922,5 & 920 & 848 \\
\hline Densidad a $35^{\circ} \mathrm{C}\left(\mathrm{kg} / \mathrm{m}^{3}\right)$ & 906,5 & 909,5 & 910 & 910 & 909,5 & 907,5 & 635 \\
\hline $\begin{array}{l}\begin{array}{l}\text { Viscosidad cinemática a } 40{ }^{\circ} \mathrm{C} \\
\left(\mathrm{mm}^{2} / \mathrm{s}\right)\end{array}\end{array}$ & 35,45 & 31,96 & 32,52 & 33,7 & 33,68 & 41,22 & 2,7 \\
\hline $\begin{array}{l}\text { Viscosidad cinemática a } 100{ }^{\circ} \mathrm{C} \\
\left(\mathrm{mm}^{2} / \mathrm{s}\right)\end{array}$ & 8,24 & 7,67 & 7,95 & 7,98 & 8,25 & 8,87 & 1,2 \\
\hline$\%$ S en masa & $<0,02$ & $<0,02$ & $<0,02$ & $<0,02$ & 0,03 & $<0,02$ & 0,07 \\
\hline \% C en masa & 77,5 & 77,4 & 77,4 & 78,0 & 77,5 & 77,3 & 86,6 \\
\hline$\% \mathrm{H}$ en masa & 11,7 & 11,5 & 11,6 & 11,5 & 11,5 & 11,3 & 12,3 \\
\hline$\%$ O en masa & 10,8 & 11,0 & 10,9 & 10,4 & 10,9 & 11,3 & 1,03 \\
\hline$\% \mathrm{~N}$ en masa & $<0,05$ & $<0,05$ & $<0,05$ & $<0,05$ & $<0,05$ & $<0,05$ & ---- \\
\hline Cenizas & 0,025 & & 0,002 & & $<0,001$ & 0,012 & ---- \\
\hline P.C.S. (MJ/kg) & 39,4 & 39,3 & 39,3 & 39,42 & 39,2 & 39,3 & 44,9 \\
\hline P.C.I. (MJ/kg) & 36,9 & 36,9 & 36,8 & 37,0 & 36,7 & 36,9 & 42,3 \\
\hline
\end{tabular}

En las características de las diferentes sustancias, que aparecen en la Tabla 3.7, se puede observar que los aceites poseen características muy similares. Las diferencias más significativas de estas con el gasóleo, corresponden a características como viscosidad y el porcentaje de oxigeno, de lo que se puede concluir que para el proceso de combustión se debe de emplear un quemador especifico para este tipo de combustible, esto para el caso de la viscosidad y en cuanto al oxigeno, se debe trabajar con un índice de oxigeno más bajo.

\subsection{MISCIBILIDAD Y/O SOLUBILIDAD DE ACEITES EN GASÓLEO.}

Los aceites y las grasas a temperaturas superiores a su temperatura de fusión son totalmente miscibles con los disolventes orgánicos, la solubilidad aumenta con la temperatura ${ }^{76}$. Existen algunas inmiscibilidades concretas como la del aceite de ricino, que no es completamente miscible con los hidrocarburos de cadena larga.

Con condiciones supercríticas se presentan así mismo situaciones de inmiscibilidad por lo que esta característica puede ser empleada para fraccionarlos en una extracción líquido-líquido.

${ }^{76}$ Formo M-W. Jungermmann E., Norris F.A., Sonntag N.O. "Bailey`s industrial oil and fat products" Eds. Swern D.Edn $4^{\text {th }}$ Vol.1 ed. John Wileey and Sons. New York, USA, 1997 
Los metilesteres de los aceites vegetales posen características físicoquímicas muy similares a las del gasóleo con el que pueden mezclarse en cualquier proporción no alterando muy significativamente las propiedades del gasoil como su poder calorífico o el índice de cetano. ${ }^{77}$

\section{Proceso de mezcla.}

El estudio de mezcla permite concluir que para tener una mezcla homogénea de aceite y gasóleo no se puede pasar del $60 \%$ de mezcla, cada mezcla tiene un código de identificación. El código consta de tres letras y dos números:

- Las letras:

- $\quad$ ACC Aceite de colza crudo

- $\quad$ ASC Aceite de soja crudo.

- $\quad$ ASR Aceite de soja refinado

- $\quad$ AGC Aceite girasol crudo

- $\quad$ AGR Aceite girasol refinado

- $\quad$ AVU Aceite vegetal usado

- Los números representan el porcentaje (\%) de aceite empleada en la mezcla. Se preparan cuatro mezclas por cada tipo de grasa en diferentes porcentajes $(10,20,30,40 \%)$.

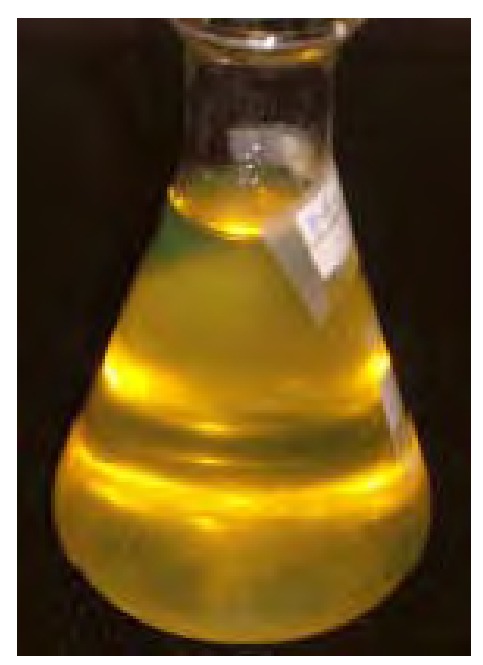

Foto 3.5: Aceite de colza crudo mezclado con gasóleo.

\footnotetext{
${ }^{77}$ Guía completa de la biomasa y los biocombustibles. José $M^{a}$ Fernández Salgado. AMV Ediciones2010 (1 $1^{\text {a }}$ Edición). ISBN: 978-84-96709-62-1.
} 


\subsubsection{Caracterización de las mezclas.}

La caracterización de cada una de las mezclas se realiza:

i) a partir del conocimiento de las propiedades de los componentes puros que forman la mezcla (teóricas), mediante la regla de la aditividad con respecto a una propiedad física:

$$
P_{m t}(T)=x_{a}{ }^{*} P_{a}(T)+\left(1-x_{a}\right)^{*} P_{d}(T)
$$

Donde: $\mathrm{P}_{\mathrm{mt}}(\mathrm{T})$ es la propiedad física de la mezcla teórica a la temperatura $T, x_{a}$ es la fracción molar de la grasa en la mezcla, $P_{a}(T)$ y $P_{d}(T)$ son la propiedades físicas de la grasa y el gasóleo.

ii) a partir de medidas de laboratorio (empíricas), como es el caso de la viscosidad, la reología la ciencia de la deformación y del flujo de la materia en el caso de los aceites es extremadamente complicada, al no poder ser considerados fluidos Newtonianos ${ }^{78}$, la viscosidad de cada una de las mezclas determinada en el LARECOM, presentan una gran desviación de la calculada partiendo de los valores de los compuestos de origen y su porcentaje.

En la Tabla 3.8, se presentan los resultados de las mezclas de aceite de colza crudo y gasóleo en diferentes proporciones.

Tabla 3.8:Características de las mezclas de aceite de colza y gasóleo.

\begin{tabular}{|c|c|c|c|c|c|c|c|}
\hline Nombre & $\% \mathrm{C}$ & $\% \mathrm{H}$ & $\% \mathrm{O}$ & $\% \mathrm{~S}$ & $\begin{array}{c}\text { Densidad } \\
\left(15^{\circ} \mathrm{C}\right) \\
\left(\mathrm{kg} / \mathrm{m}^{3}\right)\end{array}$ & $\begin{array}{c}\text { Viscosidad } \\
\left(100^{\circ} \mathrm{C}\right) \\
\left(\mathrm{mm}^{2} / \mathrm{s}\right)\end{array}$ & $\begin{array}{c}\text { P.C.I. } \\
(\mathrm{MJ} / \mathrm{kg})\end{array}$ \\
\hline ACC-00 & 86,6 & 12,3 & -- & 0,07 & 848 & 1,2 & 42,3 \\
\hline ACC-10 & 85,7 & 12,2 & 1,1 & 0,065 & 855,4 & 1,9 & 41,8 \\
\hline ACC-20 & 84,8 & 12,1 & 2,2 & 0,060 & 862,7 & 2,6 & 41,2 \\
\hline ACC-30 & 83,9 & 12,0 & 3,3 & 0,055 & 870,1 & 3,2 & 40,7 \\
\hline ACC-40 & 83,0 & 11,9 & 4,4 & 0,050 & 877,4 & 3,9 & 40,2 \\
\hline ACC-50 & 82,1 & 11,9 & 5,6 & 0,045 & 884,8 & 4,6 & 39,7 \\
\hline ACC-100 & 79,0 & 11,5 & 10,4 & $<0,02$ & 923 & 7,98 & 36.2 \\
\hline
\end{tabular}

En la Tabla 3.9, se presentan los resultados de las mezclas de aceite de soja crudo y gasóleo en diferentes proporciones.

78 Flores Luque V., Gómez Herrera C., Tabernero de la Linde P. Grasas y aceites. 26:216-220, 1975. 
Tabla 3.9: Características de las mezclas de aceite soja crudo y gasóleo.

\begin{tabular}{|c|c|c|c|c|c|c|c|}
\hline Nombre & $\% \mathrm{C}$ & $\% \mathrm{H}$ & $\% \mathrm{O}$ & $\% \mathrm{~S}$ & $\begin{array}{c}\text { Densidad } \\
\left(15^{\circ} \mathrm{C}\right) \\
(\mathrm{kg} / \mathrm{m} 3)\end{array}$ & $\begin{array}{c}\text { Viscosidad } \\
\left(100{ }^{\circ} \mathrm{C}\right) \\
(\mathrm{mm} / \mathrm{s})\end{array}$ & $\begin{array}{c}\text { P.C.I. } \\
(\mathrm{MJ} / \mathrm{kg})\end{array}$ \\
\hline ASC-00 & 86,6 & 12,3 & -- & 0,07 & 848 & 1,2 & 42,3 \\
\hline ASC-10 & 85,7 & 12,2 & 1,1 & 0,065 & 855,5 & 1,8 & 41,8 \\
\hline ASC-20 & 84,8 & 12,1 & 2,2 & 0,060 & 862,9 & 2,5 & 41,2 \\
\hline ASC-30 & 83,8 & 12,1 & 3,3 & 0,055 & 870,4 & 3,1 & 40,7 \\
\hline ASC-40 & 82,9 & 12,0 & 4,4 & 0,050 & 877,8 & 3,8 & 40,1 \\
\hline ASC-50 & 82,0 & 11,9 & 5,5 & 0,045 & 885,3 & 4,4 & 39,6 \\
\hline ASC-100 & 77,4 & 11,5 & 11,0 & $<0,02$ & 922,5 & 7,67 & 36,9 \\
\hline
\end{tabular}

En la Tabla 3.10: se presentan los resultados de las mezclas de aceite de soja refinado y gasóleo en diferentes proporciones.

Tabla 3.10: Características de las mezclas de aceite de soja refinado y gasóleo.

\begin{tabular}{|c|c|c|c|c|c|c|c|}
\hline Nombre & $\% \mathrm{C}$ & $\% \mathrm{H}$ & $\% \mathrm{O}$ & $\% \mathrm{~S}$ & $\begin{array}{c}\text { Densidad (15 } \\
\left.{ }^{\circ} \mathrm{C}\right) \\
(\mathrm{kg} / \mathrm{m} 3)\end{array}$ & $\begin{array}{c}\text { Viscosidad } \\
\left(100{ }^{\circ} \mathrm{C}\right) \\
(\mathrm{mm} 2 / \mathrm{s})\end{array}$ & $\begin{array}{c}\text { P.C.I. } \\
(\mathrm{MJ} / \mathrm{kg})\end{array}$ \\
\hline ASR-00 & 86,6 & 12,3 & -- & 0,07 & 848 & 1,2 & 42,3 \\
\hline ASR-10 & 85,7 & 12,2 & 1,1 & 0,065 & 855,5 & 1,9 & 41,8 \\
\hline ASR-20 & 84,8 & 12,2 & 2,2 & 0,060 & 862,9 & 2,6 & 41,2 \\
\hline ASR-30 & 83,8 & 12,1 & 3,3 & 0,055 & 870,4 & 3,2 & 40,7 \\
\hline ASR-40 & 82,9 & 12,0 & 4,4 & 0,050 & 877,8 & 3,9 & 40,1 \\
\hline ASR-50 & 82,0 & 12,0 & 5,5 & 0,045 & 885,3 & 4,6 & 39,6 \\
\hline ASR-100 & 77,4 & 11,6 & 10,9 & $<0,02$ & 922,5 & 7,95 & 36,8 \\
\hline
\end{tabular}

En la Tabla 3.11: se presentan los resultados de las mezclas de aceite de girasol crudo y gasóleo en diferentes proporciones.

Tabla 3.11: Características de las mezclas de aceite de girasol crudo y gasóleo.

\begin{tabular}{|c|c|c|c|c|c|c|c|}
\hline Nombre & $\% \mathrm{C}$ & $\% \mathrm{H}$ & $\% \mathrm{O}$ & $\% \mathrm{~S}$ & $\begin{array}{c}\text { Densidad } \\
\left(15^{\circ} \mathrm{C}\right) \\
(\mathrm{kg} / \mathrm{m} 3)\end{array}$ & $\begin{array}{c}\text { Viscosidad } \\
\left(100{ }^{\circ} \mathrm{C}\right) \\
(\mathrm{mm} / \mathrm{s})\end{array}$ & $\begin{array}{c}\text { P.C.I. } \\
(\mathrm{MJ} / \mathrm{kg})\end{array}$ \\
\hline AGC-00 & 86,6 & 12,3 & -- & 0,07 & 848 & 1,2 & 42,3 \\
\hline AGC-10 & 85,7 & 12,2 & 1,0 & 0,065 & 855,5 & 1,9 & 41,8 \\
\hline AGC-20 & 84,9 & 12,2 & 2,1 & 0,060 & 863,0 & 2,6 & 41,2 \\
\hline AGC-30 & 84,0 & 12,1 & 3,1 & 0,055 & 870,5 & 3,2 & 40,7 \\
\hline AGC-40 & 83,2 & 12,0 & 4,2 & 0,050 & 878,0 & 3,9 & 40,2 \\
\hline AGC-50 & 82,3 & 12,0 & 5,2 & 0,045 & 885,5 & 4,6 & 39,7 \\
\hline AGC-100 & 78,0 & 11,6 & 10,4 & $<0,02$ & 923 & 7,98 & 37,0 \\
\hline
\end{tabular}

En la Tabla 3.12: se presentan los resultados de las mezclas de aceite de girasol refinado y gasóleo en diferentes proporciones. 
Tabla 3.12: Características de las mezclas de aceite de girasol refinado y gasóleo.

\begin{tabular}{|l|c|c|c|c|c|c|c|}
\hline Nombre & $\% \mathrm{C}$ & $\% \mathrm{H}$ & $\% \mathrm{O}$ & $\% \mathrm{~S}$ & $\begin{array}{c}\text { Densidad } \\
\left(15^{\circ} \mathrm{C}\right) \\
(\mathrm{kg} / \mathrm{m} 3)\end{array}$ & $\begin{array}{c}\text { Viscosidad } \\
\left(100^{\circ} \mathrm{C}\right) \\
(\mathrm{mm} 2 / \mathrm{s})\end{array}$ & $\begin{array}{c}\text { P.C.I. } \\
(\mathrm{MJ} / \mathrm{kg})\end{array}$ \\
\hline AGR-00 & 86,6 & 12,3 & -- & 0,07 & 848 & 1,2 & 42,3 \\
\hline AGR-10 & 85,7 & 12,2 & 1,1 & 0,066 & 855,5 & 1,9 & 41,7 \\
\hline AGR-20 & 84,8 & 12,1 & 2,2 & 0,062 & 862,9 & 2,6 & 41,2 \\
\hline AGR-30 & 83,9 & 12,1 & 3,3 & 0,058 & 870,4 & 3,3 & 40,6 \\
\hline AGR-40 & 83,0 & 12,0 & 4,4 & 0,054 & 877,8 & 4,0 & 40,1 \\
\hline AGR-50 & 82,1 & 11,9 & 5,5 & 0,050 & 885,3 & 4,7 & 39,5 \\
\hline AGR-100 & 77,5 & 11,5 & 10,9 & 0,03 & 922,5 & 8,25 & 36,7 \\
\hline
\end{tabular}

En la Tabla 3.13: se presentan los resultados de las mezclas de aceite vegetal usado y gasóleo en diferentes proporciones.

Tabla 3.13: Características de las mezclas de aceite vegetal usado y gasóleo.

\begin{tabular}{|l|l|l|l|l|c|c|c|}
\hline Nombre & $\% \mathrm{C}$ & $\% \mathrm{H}$ & $\% \mathrm{O}$ & $\% \mathrm{~S}$ & $\begin{array}{c}\text { Densidad } \\
\left(15^{\circ} \mathrm{C}\right) \\
(\mathrm{kg} / \mathrm{m3})\end{array}$ & $\begin{array}{c}\text { Viscosidad } \\
\left(100{ }^{\circ} \mathrm{C}\right) \\
(\mathrm{mm} / \mathrm{s})\end{array}$ & $\begin{array}{c}\text { P.C.I. } \\
(\mathrm{MJ} / \mathrm{kg})\end{array}$ \\
\hline AVU-00 & 86,6 & 12,3 & - & 0,07 & 848 & 1,2 & 42,3 \\
\hline AVU-10 & 85,7 & 12,2 & 1,1 & 0,065 & 855,2 & 2,0 & 41,8 \\
\hline AVU-20 & 84,7 & 12,1 & 2,3 & 0,060 & 862,4 & 2,7 & 41,2 \\
\hline AVU-30 & 83,8 & 12,0 & 3,4 & 0,055 & 869,6 & 3,5 & 40,7 \\
\hline AVU-40 & 82,9 & 11,9 & 4,5 & 0,050 & 876,8 & 4,3 & 40,1 \\
\hline AVU-50 & 82,0 & 11,8 & 5,7 & 0,045 & 884,0 & 5,0 & 39,6 \\
\hline AVU-100 & 77,3 & 11,3 & 11,3 & $<0,02$ & 920 & 8,87 & 36,9 \\
\hline
\end{tabular}




\section{BIBLIOGRAFÍA CAPÍTULO 3}

64) Council Directive no 2003/17/CE "relating to the quality of petrol and diesel fuels".

65) Lapuerta M. y Hernández J.J., Lapuerta Amigo M. y Hernández Adrover J.J.. "Tecnologías de la combustión. Capítulo 2. Caracterización de los combustibles", Ediciones de la Universidad de Castilla - La Mancha. pp 39 - 66, 1998.

66) REAL DECRETO 61/2006, de 31 de enero, por el que se determinan las especificaciones de gasolinas, gasóleos, fuelóleos y gases licuados del petróleo y se regula el uso de determinados biocarburantes. Ministerio de Industria, Turismo y Comercio, 2006

67) International Union of Pure and Applied Chemistry, "The Congress of Chemistry, Ginebra 1892.

68) Enrique Graciani Constante, Los aceites y grasas: composición y propiedades. Editor, AMV, 2006.

69) Norma UNE 51116, de 15 de septiembre de 1998. Petróleos crudos y productos petrolíferos líquidos. Determinación de la densidad y de la densidad relativa en el laboratorio. Método del areómetro, 1998.

70) ASTM D4052 - 96, 2002.)e1 Standard Test Method for Density and Relative Density of Liquids by Digital Density Meter, 2002.

72) Norma UNE 51108, de 15 de marzo de 1983. Productos petrolíferos. Determinación de la viscosidad cinemática y cálculo de la viscosidad dinámica. líquidos opacos y transparentes, 1983.

73) ASTM D341 - 09 Standard Practices for Viscosity-Temperature Charts for Liquid Petroleum Products, 2009.

74) Sirtori, S., Garibaldi P. y Vicenzetto F.A., "Prediction of the combustion properties of gasoline from the analysis of their composition". SAE paper n. 74-1058, International automobile Engineering and Manufacturing Meeting. Toronto, Ontario, 1974.

75) ASTM D1552 - 08 Standard Test Method for Sulfur in Petroleum Products (High-Temperature Method), 2008.

76) Formo M-W. Jungermmann E., Norris F.A., Sonntag N.O. "Bailey`s industrial oil and fat products" Eds. Swern D.Edn $4^{\text {th }}$ Vol.1 ed. John Wileey and Sons. New York, USA, 1997

77) Guía completa de la biomasa y los biocombustibles. José $M^{a}$ Fernández Salgado. AMV Ediciones2010 (1ª Edición). ISBN: 978-8496709-62-1.

78) Flores Luque V., Gómez Herrera C., Tabernero de la Linde P. Grasas y aceites. 26:216-220, 1975. 


\subsection{INTRODUCCIÓN}

El presente capítulo establece los fenómenos que influyen en el proceso de combustión de instalaciones térmicas convencionales, al objeto de poder seleccionar el proceso optimo de combustión para las mezclas de aceite y gasóleo.

Los fenómenos implicados en la combustión son de distintos tipos, en primer lugar se estudiará los fenómenos de transporte asociados a la pulverización y a la evaporación del combustible, procesos previos a la combustión pero que influyen de forma fundamental en el proceso. Se hace una revisión de los principales trabajos sobre el tema, recogiendo los parámetros adimensionales más importantes que influyen en el proceso de pulverización.

La estequiometria de la reacción de combustión permite establecer las necesidades de aire y los caudales y composición de los humos de las mezclas de combustible. Se ha desarrollado una hoja de cálculo para determinar en función de los porcentajes de mezcla ensayados la composición elemental en tanto por uno de la mezcla así como las propiedades físicas de la misma.

Los procesos de combustión se analizan en función de tres aspectos, el rendimiento de la combustión de las diferentes mezclas de aceite vegetal 
gasóleo, la reducción de las emisiones de gases de efecto invernadero y las emisiones de gases contaminantes, asociados al proceso de combustión y que limitan la posibilidad de usar dichas mezclas por aspectos medioambientales.

Para la determinación de los rendimientos de la combustión se utiliza el método indirecto, usual en este tipo de instalaciones, determinando el PC del combustible y las pérdidas en el proceso, que suelen ser: pérdidas sensibles por humos y pérdidas por inquemados.

Los gases de efecto invernadero se cuantifican en función de la cantidad de $\mathrm{CO}_{2}$, que aparece en los humos de origen fósil.

El análisis de las emisiones contaminantes más importantes asociadas al proceso de combustión, se realiza en función de la legislación en materia de emisiones para comprobar que los resultados están dentro de los límites establecidos en la citada legislación para el uso de generación térmica.

\subsection{COMBUSTIÓN POR DIFUSIÓN}

Los procesos de combustión se caracterizan atendiendo a distintos criterios: por su continuidad o discontinuidad tanto espacial como temporal; por la forma en que se realiza la mezcla de combustiblecomburente; según la fase inicial del combustible y por el tipo de flujo del combustible y del comburente.

En la tabla 4.1, se ve las distintas clasificaciones de los procesos de combustión: 
Tabla 4.1 Tipos de procesos de combustión.

\begin{tabular}{|c|c|c|c|c|}
\hline Temporal & Espacial & $\begin{array}{l}\text { Formación de } \\
\text { la mezcla }\end{array}$ & $\begin{array}{l}\text { Fase del } \\
\text { combustible }\end{array}$ & Tipo de flujo \\
\hline \multirow{4}{*}{$\begin{array}{l}\text { Localizada } \\
\text { (Continuidad) }\end{array}$} & \multirow{3}{*}{$\begin{array}{l}\text { Deflagración } \\
\text { (Discontinuidad de T) }\end{array}$} & \multirow{2}{*}{ Difusión } & Gas/Gas & $\begin{array}{l}\text { Laminar } \\
\text { Turbulento }\end{array}$ \\
\hline & & & Líquido/Gas & $\begin{array}{l}\text { Laminar } \\
\text { Turbulento }\end{array}$ \\
\hline & & Premezcla & & $\begin{array}{l}\text { Laminar } \\
\text { Turbulento }\end{array}$ \\
\hline & $\begin{array}{l}\text { Detonación } \\
\text { (Discontinuidad de P) }\end{array}$ & & & \\
\hline $\begin{array}{l}\text { Autoencendido } \\
\text { (Discontinuidad) }\end{array}$ & & & & \\
\hline
\end{tabular}

Los procesos de combustión que se van a experimentar en esta tesis son procesos continuos en el tiempo (combustión localizada) discontinuos en temperatura (deflagración), siendo la mezcla de combustible y comburente por difusión líquido /gas en régimen turbulento. El combustible, finamente atomizado se evapora absorbiendo calor, se mezcla con el aire y se produce la combustión.

En el proceso de combustión la etapa más lenta es la que controla el proceso, en nuestro caso, usando quemadores de pulverización por presión, es la evaporación la etapa que controla la combustión. Las gotas de combustible absorben calor por convección y fundamentalmente por radiación dada la alta temperatura existente en el hogar y en el frente de llama. Parte del líquido se vaporiza, alcanza la superficie de la gota donde existe una zona de vapor saturado y se difunde hacia el exterior.

Experimentalmente se ha comprobado que el diámetro de la gota decrece linealmente con el tiempo según la ley conocida como "ley d2":

$$
\frac{d\left(d_{g}^{2}\right)}{d t}=-K_{v}
$$

En la que $\mathrm{K}_{v}$ es la constante de vaporización. Esa constante es función de las propiedades físico-químicas del líquido y del gas circundante. Spalding 79 determinó la constante de vaporización resolviendo las ecuaciones de la energía y de las especies bajo ciertas hipótesis encontrando la expresión:

79 Spalding D. Brian, Combustión y transferencia de masa, CECSA 1.979 


$$
K_{v}=8 * \frac{\rho_{s}}{\rho_{f}} * D_{s} * \ln (1+B)
$$

Donde $\rho_{s}$ y $\rho_{f}$ son las densidades del aire y del líquido respectivamente, $D_{s}$ es la difusividad másica y $B$ se determina resolviendo un sistema de ecuaciones formado por la igualdad de números de transferencia, la ley de Dalton y la ecuación de Clausius-Clapeyron.

Admitiendo que la gota es esférica, inicialmente su masa será:

$$
m_{g}=\frac{\pi}{6} * \rho_{f} * d_{g}^{3}
$$

La velocidad con que su masa líquida se transforma en vapor:

$$
m_{e v}=-\frac{d m_{g}}{d t}=\frac{\pi}{6} \rho_{f} \frac{d\left(d_{g}^{3}\right)}{d t}=-\frac{\pi}{6} \rho_{f} \frac{d\left[\left(d_{g}^{2}\right)^{1,5}\right]}{d t}=\frac{\pi}{4} \rho_{f} d_{g} K_{v}
$$

\subsubsection{Atomización.}

Para poder estimar el caudal de vapor generado es necesario determinar el número de gotas presentes en el chorro, su diámetro y las condiciones del ambiente que rodea a cada gota, es necesario estudiar el proceso de atomización, que es la desintegración de un caudal de líquido que se transforma en una dispersión de pequeños fragmentos o gotas.

La atomización es un proceso complejo en el que intervienen numerosos fenómenos físicos y en el que influyen parámetros relativos a la geometría del atomizador, a las propiedades del fluido atomizado y las del medio donde se atomiza. La vena fluida se disgrega por efecto de fuerzas centrífugas y aerodinámicas convirtiéndose en gotas o ligamentos, llamándose a este proceso atomización primaria, posteriormente las gotas se disgregan en gotas más pequeñas en el proceso llamado de atomización secundaria.

La mayoría de los atomizadores basan su funcionamiento en conseguir una alta velocidad relativa entre el líquido y el gas que lo rodea. En el tipo de atomizador que vamos a usar el líquido es descargado a alta velocidad sobre aire en reposo, este tipo de atomizador denominado de presión logra una mayor efectividad haciendo pasar el líquido por un pequeño orificio, cuando el líquido sale del atomizador al ambiente exterior solo está contenido por las fuerzas de tensión superficial, cuando estas fuerzas, por efecto centrífugo o aerodinámico son superadas se desfragmenta. 
La energía en forma de presión suministrada al líquido se convierte en energía cinética al pasar por la tobera de dimensiones reducidas y el fluido se pulveriza en la expansión.

Otros métodos de atomización serían los de atomización con fluido auxiliar, generalmente aire o vapor, y la atomización mediante fuerza centrífuga. La combinación de distintos métodos de atomización, mejoran la eficiencia y flexibilidad de los atomizadores al tiempo que hacen su diseño más complejo.

Los atomizadores de presión pueden ser de chorro en los que la velocidad de salida es paralela al eje del atomizador y los de rotación en los que una componente rotacional hace que el fluido salga con una trayectoria helicoidal.

En los atomizadores de presión con rotación, el fluido pasa por unas ranuras que le proporcionan una elevada velocidad de rotación. La geometría de la tobera permite modelar la forma espacial del espray, si bien este tipo de atomizador es poco flexible no permitiendo más que límites de regulación muy pequeños, por lo que son utilizados en instalaciones de caudal constante.

Los atomizadores de presión con componente rotacional proporcionan una lámina cilíndrica en el interior del atomizador, la lámina se pega a las paredes y al abandonar el inyector la lámina se convierte en cónica, por lo que habitualmente se denominan de cono hueco, este tipo de atomizador suele denominarse PSN (pressureswirlnozzles) 80.

En la figura 4.1 puede observarse el diseño básico de un atomizador de presión con rotación. Los distintos fabricantes introducen modificaciones para mejorar la eficiencia de los mismos.

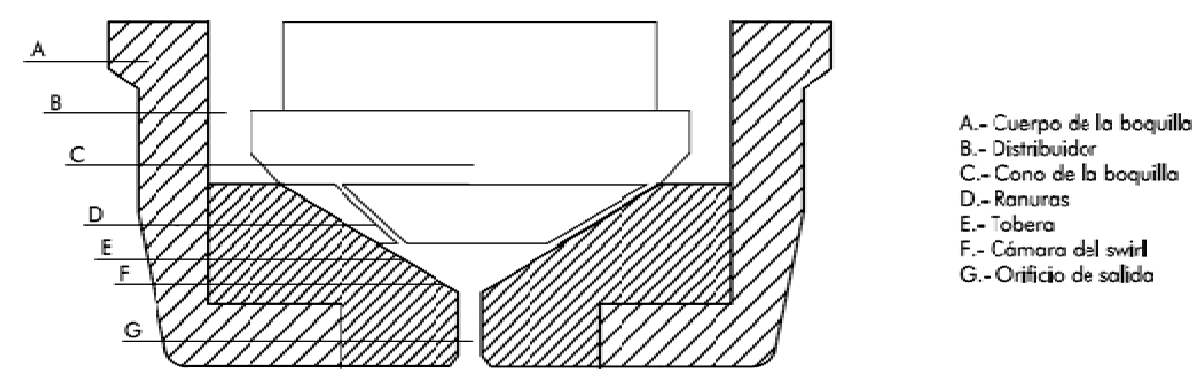

80 Méndez C., "Modelado numérico de un chorro atomizado no estacionario", tesis doctoral, Universidad de Valladolid 2003. 
Figura 4.1 Atomizador de presión con rotación (PSN)

Se va a caracterizar los parámetros geométricos que intervienen en la atomización

Parámetros geométricos:

$\mathrm{d}_{\mathrm{o}}$ : diámetro orificio de salida.

$\mathrm{d}_{\mathrm{d}}$ : diámetro vías tangenciales.

ds: diámetro de la cámara

lo: longitud orificio de salida.

Id: longitud vías tangenciales.

ls: longitud de la cámara

Ao: área orificio de salida.

$A_{d}$ : área de vías tangenciales.

$\mathrm{N}$ : número de vías tangenciales

$\varphi$ : ángulo vías tangenciales.

$€$ : rugosidad de las superficies

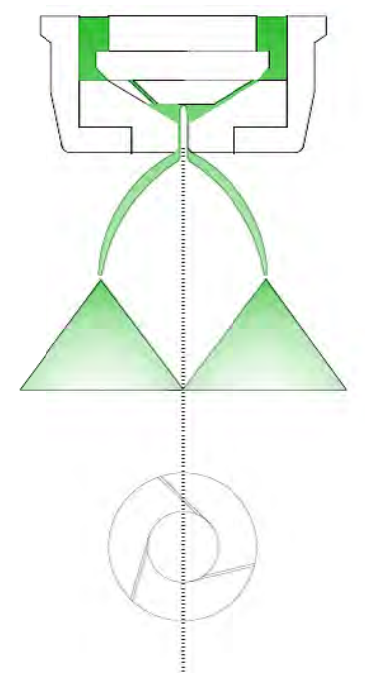

Figura 4.2 Atomizador con flujo (PSN)

Agrupando los parámetros geométricos característicos de los PSN formamos los grupos adimensionales que se muestran en la tabla 4.2:

Tabla 4.2 Grupos adimensionales geométricos (PSN)

Grupos adimensionales formados con los parámetros geométricos

\begin{tabular}{|c|c|c|c|c|c|c|}
\hline $\mathrm{K}=\frac{\mathrm{N} \mathrm{A}_{\mathrm{d}}}{\mathrm{d}_{\mathrm{s}} \mathrm{d}_{0}}$ & $\frac{\mathrm{I}_{\mathrm{d}}}{\mathrm{d}_{0}}$ & $\frac{\mathrm{d}_{0}}{\mathrm{~d}_{\mathrm{s}}}$ & $\frac{\mathrm{I}_{\mathrm{d}}}{\mathrm{d}_{\mathrm{d}}}$ & $\frac{\mathrm{I}_{\mathrm{s}}}{\mathrm{d}_{\mathrm{s}}}$ & $\frac{\epsilon}{\mathrm{d}_{0}}$ & $\mathrm{~N}_{\mathrm{s}}=\frac{\pi \mathrm{d}_{0} \mathrm{~d}_{\mathrm{s}} \cos \varphi}{4 N A_{d}}$ \\
\hline
\end{tabular}

Debido a la excentricidad de las ranuras por las que circula el líquido y a la tobera que forman las paredes de la cámara del swirl el líquido se pega a las paredes del orificio de salida por lo que en su interior existe una 
cámara de aire, denominándose por ello a este tipo de boquilla de cono hueco.

A la entrada de la cámara del swirl, las componentes de la velocidad del fluido serán 81 :

- $\quad \mathrm{U}_{\mathrm{ts}}=$ velocidad de rotación. (tangencial)

- $\mathrm{U}_{\mathrm{xs}}=$ velocidad axial.

- $\mathrm{U}_{\mathrm{s}}=$ módulo de velocidad.

- $U_{\mathrm{bs}}=$ velocidad media.

- $\mathrm{U}_{\mathrm{bs}}=\frac{\mathrm{Q}}{\mathrm{N} \cdot \mathrm{A}_{\mathrm{d}}}$

A la salida del orificio las componentes de la velocidad del fluido serán:

- $\mathrm{U}_{\mathrm{to}}=$ velocidad de rotación. (tangencial)

- $\mathrm{U}_{\mathrm{xo}}=$ velocidad axial.

- $\mathrm{U}_{0}=$ módulo de velocidad.

- $\mathrm{U}_{\mathrm{b}}=$ velocidad media con orificio lleno.

- $\mathrm{U}_{\mathrm{b}}=\frac{\mathrm{Q}}{\mathrm{A}_{\mathrm{o}}}$

Siendo Q el líquido inyectado.

Los procesos hidrodinámicos que se desarrollan en el interior de los atomizadores son muy complejos, en los análisis más simples se considera fluido no viscoso y el movimiento un vórtice libre al que se superpone un flujo axial.

La conservación del momento angular exige que se cumpla la ecuación siguiente:

$$
\mathrm{U}_{\mathrm{ts} .} \mathrm{r}_{\mathrm{s}}=\mathrm{U}_{\mathrm{to}} . \mathrm{r}_{\mathrm{o}}
$$

Cuando la viscosidad no es despreciable se producen modificaciones importantes en el flujo interno como consecuencia del desarrollo de la capa límite. En trabajos recientes de simulación Dumouchel et al.82 Realizan el cálculo con fluido viscoso y considerando simetría axial y a la salida el orificio lleno de líquido. A pesar de las aproximaciones llegan a determinar los parámetros característicos del flujo en la salida como el ángulo de cono y el coeficiente de descarga.

81 Ruiz, F. y Chigier, N.A., Parametric experiments on liquid jet atomization spray angle, Atomization and Sprays, 1, 23-45, 1991.

82 Dumouchel C. Ledoux M. Bhor M.I.G. ,The design of pressure swirl atomizers, ASME International Gas Turbine Aeroengine Congress Exhibition 43 rd Stockholm Sweden (1998) 
Consideraciones posteriores, Yule ${ }^{83}$, ponen de manifiesto la existencia de flujo recirculante en las paredes de la cámara del swirl, así como diferentes perturbaciones en la superficie de la interface líquido-aire en la que aparecen ondas de pequeña amplitud que se propagan hacia la salida, influyendo en el desarrollo de la lámina y en su rotura.

Los parámetros característicos del flujo a la salida se reagrupan en los siguientes números adimensionales, tabla 4.3:

Tabla 4.3 Grupos adimensionales geométricos (PSN)

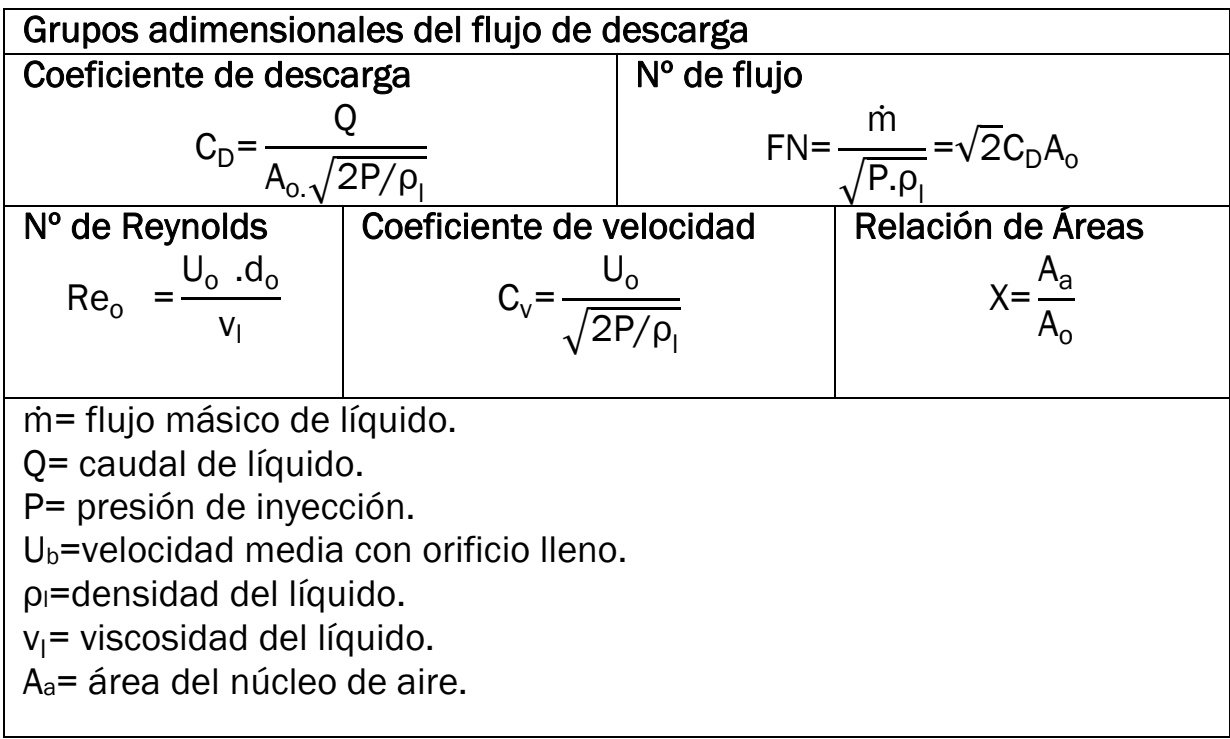

El coeficiente de descarga $C_{D}$ relaciona el caudal inyectado con el caudal teórico de descarga considerando el orificio lleno y sin pérdidas.

El coeficiente de velocidad $C_{v}$ expresa la reducción en la velocidad de descarga debido a las pérdidas internas del atomizador.

La geometría del flujo de salida se caracteriza por el ángulo de cono " $\alpha$ " y el espesor de la lámina.

Para la determinación de dichos parámetros se debe utilizan correlaciones empíricas más o menos complejas relacionadas con las características geométricas del atomizador, con las condiciones de la inyección $(\mathrm{P}, \mathrm{T})$ y con las propiedades del fluido.

${ }^{83}$ Yule A.J. Chinn J.J., The internal flow and exit conditions of pressure swirl atomizers, Atomization and Sprays, vol.10, no. 2, pp.121-146, 2000. 
En la tabla 4.4, se recogen algunas de las correlaciones más importantes para caracterizar el flujo de salida:

Tabla 4.4 Parámetros característicos del flujo de salida

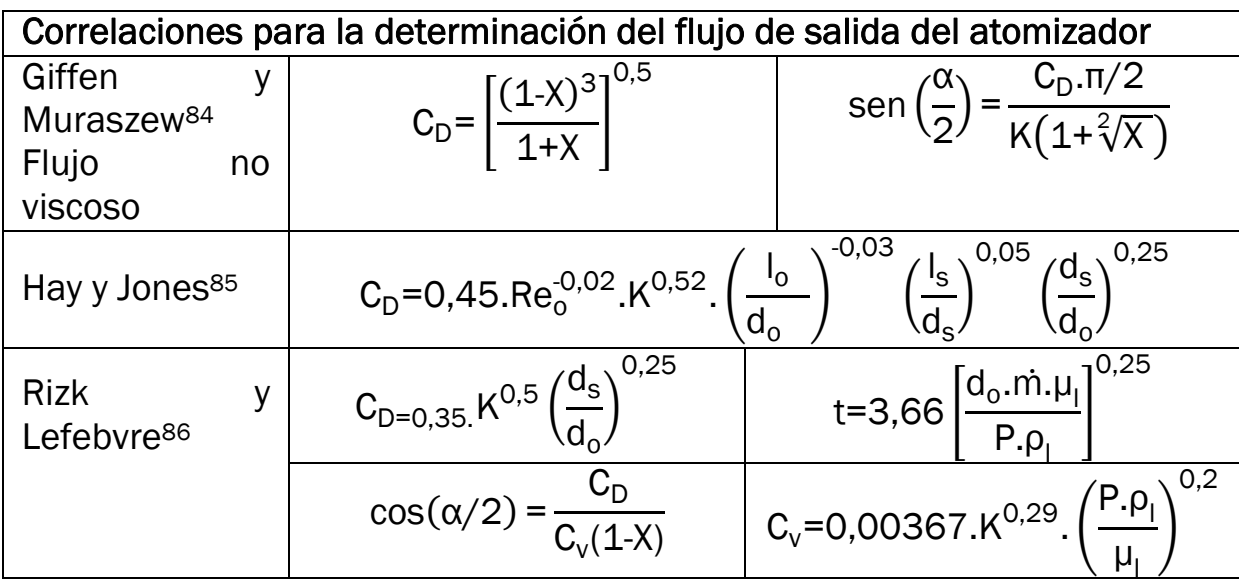

La viscosidad tiene más influencia en los atomizadores de pequeño tamaño, al aumentar la viscosidad aumenta el espesor de la película de líquido.

En los atomizadores de pequeño caudal es necesario para un comportamiento estable alcanzar una presión de inyección mínima. Los parámetros de la descarga, ángulo de cono y coeficiente de descarga son independientes de la presión, es la zona de uso el atomizador. La presión de inyección mínima aumenta con la viscosidad del líquido.

El aumento del número de Reynolds, genera una disminución del $C_{D}$, pero a partir de un determinado valor se mantiene constante, en el trabajo de Ramamurthi87, este valor marca la transición entre los diferentes tipos de lámina, al aumentar Reynolds se reduce el espesor de la lámina de líquido.

El número de rotación $\mathrm{N}_{\mathrm{s}}$ influye sobre las características de la descarga, de forma que al aumentar $N_{s}$ aumenta el ángulo de cono " $\alpha$ ” y el $C_{D}$ disminuye.

\footnotetext{
${ }^{84}$ Edmund Giffen, A. Muraszew, The atomisation of liquid fuels, Chapman \& Hall, 1953.

85 Hay N. y Jones PL "Comparison of the various correlations for spray penetration". SAE, Paper 7207761982.

86 Rizk, N. K. and Lefebvre, A. H., Internal flow characteristics of simplex swirl atomizers. Journal of Propulsion and Power, 1, 193-199. 1985.

87 Ramamurthi K. Tharakan T.J. , Atomization characteristics of swirled annular liquid sheets, AIP Phycs of Fluids, 1997.
} 
Alcanzado el orificio de salida, el líquido adquiere la forma cónica como puede verse en la figura 4.3.

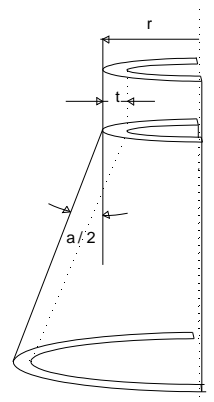

Figura 4.3 Geometría del flujo de salida.

El proceso de atomización pasa por la desintegración de las láminas, para convertirse en ligamentos o gotas y posteriormente en gotas más pequeñas.

La desintegración de láminas cónicas con elevada velocidad de rotación está influida por la presión de inyección, Lefevre ${ }^{88}$ describe las distintas configuraciones que se muestran en la figura 4.4:

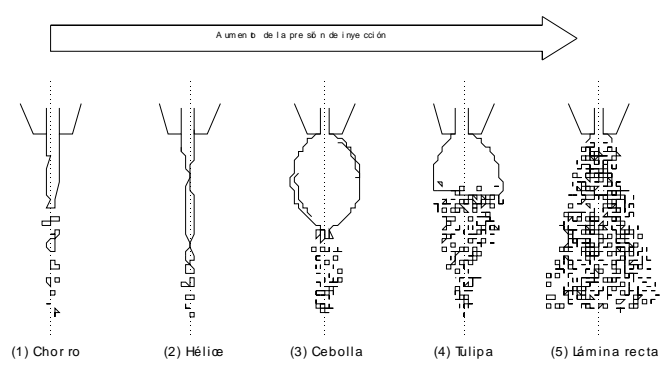

Figura 4.4 Influencia de la presión de inyección sobre el flujo.

88 Lefebvre A.H. Atomization and Spray.Hemisphere Pub.Corp., 1989. 
Al ir aumentando la presión de inyección, el flujo de descarga va pasando por las etapas siguientes:

1. Chorro que se desintegra según el régimen de Rayleigh89 (baja velocidad).

2. Formación de estructuras helicoidales de líquido unidas por finas películas.

3. Tipo cebolla, la lámina se expande inicialmente pero se colapsa y adopta esa forma.

4. Tipo tulipa, la lámina tiende a cerrarse pero se rompe antes de colapsar.

5. Lámina cónica recta, las oscilaciones causan la rotura dela lámina a una distancia cada vez menor de la salida.

El objetivo de obtener un diámetro de gota y un número de gotas que aparecen en el chorro de atomización es solamente alcanzable determinando el diámetro medio de las gotas. Para este valor medio pueden tomarse distintos valores medios que responden a la expresión general:

$$
D_{p q}=\frac{\sum_{i=1}^{\mathrm{i}=N_{c l}} N_{i} D_{i}^{p}}{\sum_{i=1}^{\mathrm{i}=N_{c l}} N_{i} D_{i}^{q}}
$$

En la tabla 4.5, puede verse los valores medios según el criterio elegido:

Tabla 4.5: Diámetros medios.

\begin{tabular}{|l|l|}
\hline \multicolumn{2}{|l|}{ Diámetro medio } \\
\hline $\mathrm{D}_{10}$ & Diámetro de la distribución numérica \\
\hline $\mathrm{D}_{20}$ & $\begin{array}{l}\text { Diámetro de una gota cuya superficie es el promedio de las } \\
\text { superficies de todas las gotas del spray }\end{array}$ \\
\hline $\mathrm{D}_{30}$ & $\begin{array}{l}\text { Diámetro de una gota cuyo volumen es el volumen medio de } \\
\text { todas las gotas del spray. }\end{array}$ \\
\hline $\mathrm{D}_{32}$ & $\begin{array}{l}\text { Diámetro de una gota cuya relación de superficie-volumen sea } \\
\text { igual a la de toda la distribución }\end{array}$ \\
\hline $\mathrm{D}_{43}$ & Diámetro medio de la distribución de volúmenes \\
\hline $\mathrm{D}_{50 \%}$ & $\begin{array}{l}\text { Diámetro de gota tal que el } 50 \% \text { de las gotas del spray tengan } \\
\text { un diámetro inferior }\end{array}$ \\
\hline
\end{tabular}

89 Rayleigh Lord, on the instability of yet, Proc. London Math. Soc. (1878) 
El diámetro $D_{32}$ (DMS) llamado el diámetro de Sauter junto con el $D_{50 \%}$ (DMV), son los valores más usados en la práctica.

En la tabla 4.6, se puede ver distintas correlaciones empíricas para la determinación del diámetro de Sauter en sprays generados con PSN, recopiladas por Lefebvre.

Tabla 4.6: Diámetro de Sauter generado con PSN

\begin{tabular}{|l|c|}
\hline \multicolumn{2}{|l|}{ Diámetro medio de Sauter } \\
\hline Jauja & $D_{32}=4,4 \sigma_{1}^{0,6} u_{1}^{0,16} m^{0,22} p^{-0,43}$ \\
\hline Lefebvre & $D_{32}=2,25 \sigma_{1}^{0,25} \mu_{1}^{0,25} m^{0,25} p^{-0,5} \rho_{g}^{-0,25}$ \\
\hline $\begin{array}{l}\text { Wang } \\
\text { Lefebvre }\end{array}$ & $D_{32}=4,52\left[\frac{\sigma_{1} \cdot \mu_{1}^{2}}{\rho_{\mathrm{g}} \cdot P^{2}}\right]^{0,25}(\operatorname{t.cos}(\alpha / 2))^{0,25}+0,39\left[\frac{\sigma_{1} \cdot \rho_{1}}{\rho_{\mathrm{g}} \cdot P^{2}}\right]^{2} \quad$ t.cos \\
\hline
\end{tabular}

La desintegración de la lámina de líquido genera un flujo bifásico gotasaire entre los que se desarrolla una interacción mutua con acciones aerodinámicas, generación de turbulencias, de forma quela distribución de tamaños puede verse alterada por otros fenómenos no contemplados hasta ahora como son.

- La rotura secundaria por interacción aerodinámica.

- Colisiones entre gotas que pueden producir coalescencia o fragmentación múltiple.

- Evaporación y condensación.

Los fenómenos de evaporación tienen mucha relevancia cuando las temperaturas son elevadas, como es el caso de los hogares donde están colocados los atomizadores.

En nuestros ensayos vamos a utilizar una boquilla comercial y los rangos de las propiedades de la mezcla y las condiciones de flujo que se desarrollen van a estar dentro del rango de los valores de uso de dicha boquilla recomendados por el fabricante., Al hacer el estudio de la instalación experimental se incluirán las características de la boquilla atomizadora empleada.

En forma de síntesis se incluye la tabla 4.7 con la influencia de los principales parámetros en la atomización para una boquilla dada: 
Tabla 4.7: Influencia de la presión, viscosidad y densidad del combustible en la atomización.

\begin{tabular}{|c|c|c|c|}
\hline & Presión & Viscosidad & Densidad \\
\hline Caudal & $\begin{array}{l}\text { Al crecer la } \\
\text { presión el caudal } \\
\text { crece proporcional } \\
\text { a la raíz cuadrada }\end{array}$ & $\begin{array}{ll}\text { Al crecer la } \\
\text { viscosidad } & \text { el } \\
\text { caudal decrece } & \end{array}$ & $\begin{array}{l}\text { Si la densidad } \\
\text { crece el caudal } \\
\text { crece } \\
\text { directamente } \\
\text { proporcional a la } \\
\text { densidad }\end{array}$ \\
\hline Ángulo & \begin{tabular}{lr}
\multicolumn{2}{l}{ Si la presión crece } \\
el & ángulo \\
disminuye y la \\
llama se alarga, \\
con ángulos más \\
abiertos & los \\
diámetros & de \\
gotas & son \\
mayores &
\end{tabular} & $\begin{array}{ll}\text { Si crece la } & \text { las } \\
\text { viscosidad } & \text { el } \\
\text { ángulo disminuye } \\
\text { al disminuir la } \\
\text { velocidad } & \\
\text { tangencial } & \end{array}$ & No tiene efecto \\
\hline Diámetro & $\begin{array}{l}\text { Al aumentar la } \\
\text { presión disminuye } \\
\text { ligeramente la } \\
\text { gota }\end{array}$ & $\begin{array}{ll}\text { Al aumentar la } \\
\text { viscosidad } & \text { el } \\
\text { diámetro tiende a } \\
\text { crecer }\end{array}$ & No tiene efecto \\
\hline
\end{tabular}

\subsubsection{Atomizador de presión con rotación (PSN) utilizado}

La boquilla de inyección seleccionada es comercial de la casa DANFOSS de $0,5 \mathrm{GPH}$, que ha sido caracterizada con un combustible de densidad $820 \mathrm{~kg} / \mathrm{m}^{3}$, viscosidad $3,4 \mathrm{~mm}^{2} / \mathrm{s}$ y que ha sido inyectado a una presión de 7 bar, una representación de la misma se muestra en la Figura 4.5. La determinación del caudal inyectado para el gasóleo y a otras presiones los proporciona el fabricante y se presentan en la Tabla 4.8.

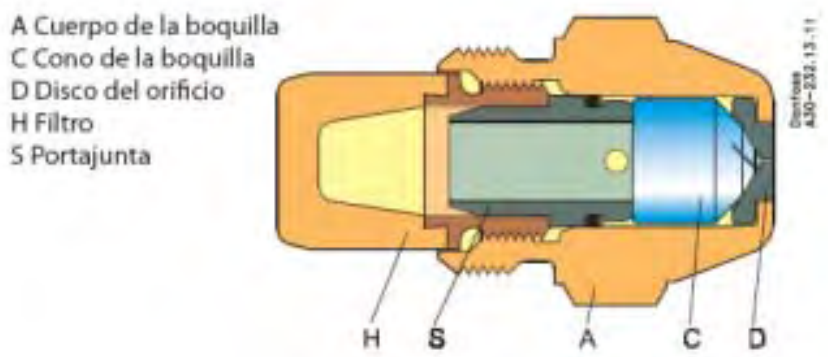

Tamaños de 0,65 a 35,00 USgal/h con rosca inferior 
Figura 4.5: Boquilla de pulverización.

Tabla 4.8: Caudales de pulverización en función de la presión de inyección para un combustible de densidad $0,84.90$

\begin{tabular}{|c|c|c|c|c|c|c|c|c|c|c|}
\hline \multicolumn{11}{|c|}{ Presión de inyección en kg/cm² } \\
\hline \multirow{2}{*}{$\begin{array}{l}\text { Caudal } \\
\text { nominal } \\
\text { en GPH }\end{array}$} & \multicolumn{2}{|c|}{7} & \multicolumn{2}{|c|}{8} & \multicolumn{2}{|c|}{10} & \multicolumn{2}{|c|}{12} & \multicolumn{2}{|c|}{14} \\
\hline & $\mathrm{l} / \mathrm{h}$ & $\mathrm{Kg} / \mathrm{h}$ & $l / h$ & $\mathrm{Kg} / \mathrm{h}$ & $\mathrm{l} / \mathrm{h}$ & $\mathrm{Kg} / \mathrm{h}$ & $\mathrm{l} / \mathrm{h}$ & $\mathrm{Kg} / \mathrm{h}$ & $\mathrm{l} / \mathrm{h}$ & $\mathrm{Kg} / \mathrm{h}$ \\
\hline 0,40 & 1,5 & 1,3 & 1,7 & 1,4 & 1,8 & 1,5 & 1,9 & 1,6 & 2,0 & 1,7 \\
\hline 0,50 & 1,9 & 1,6 & 2,0 & 1,7 & 2,3 & 1,9 & 2,5 & 2,1 & 2,7 & 2,3 \\
\hline 0,60 & 2,3 & 1,9 & 2,4 & 2,0 & 2,7 & 2,3 & 3,0 & 2,5 & 3,2 & 2,7 \\
\hline 0,65 & 2,5 & 2,1 & 2,6 & 2,2 & 2,9 & 2,4 & 3,3 & 2,7 & 3,4 & 2,9 \\
\hline 0,75 & 2,8 & 2,4 & 3,1 & 2,6 & 3,5 & 2,9 & 3,8 & 3,2 & 4,0 & 3,4 \\
\hline 0,85 & 3,2 & 2,7 & 3,4 & 2,9 & 3,8 & 3,2 & 4,0 & 3,6 & 4,5 & 3,8 \\
\hline 1,00 & 3,8 & 3,2 & 4,0 & 3,4 & 4,5 & 3,8 & 5,2 & 4,2 & 5,2 & 4,4 \\
\hline 1,10 & 4,1 & 3,4 & 4,3 & 3,6 & 4,8 & 4,5 & 5,7 & 4,5 & 5,7 & 4,8 \\
\hline 1,20 & 4,5 & 3,8 & 4,9 & 4,1 & 5,5 & 4,8 & 6,3 & 5,0 & 6,3 & 5,3 \\
\hline
\end{tabular}

En los quemadores de pulverización mecánica la combustión está caracterizada por la evaporación y pulverización del combustible, al utilizar una boquilla comercial los grupos adimensionales de la Tabla 4.2 deben estar dentro de un rango próximos a los que el fabricante recomienda para su utilización.

Los parámetros geométricos de la boquilla son fijos y los parámetros que dependen de las propiedades de las mezclas, viscosidad y densidad, se mantienen en un rango semejante al gasóleo; es la razón por la que no se queman las grasas directamente, sino mezcladas con gasóleo para mantener las propiedades dentro de los rangos de uso de la boquilla y las condiciones de funcionamiento de boquilla se varían en tres presiones de inyección diferentes 10, 12 y 14 bar, rango que recomienda el fabricante de la boquilla.

Este criterio de mantener en un rango de variación las propiedades del fluido y las condiciones de funcionamiento, permite suponer que el proceso de evaporación y pulverización para este tipo de boquillas sea homogéneo.

90 Danfoss, “Practical tips Oil nozzles” burner.danfoss.com, 2010. 


\subsection{ESTEQUIOMETRÍA}

La aplicación del principio de conservación de la masa a los componentes de las reacciones químicas se denomina estequiometria.

El ajuste de las ecuaciones permite determinar las cantidades de reactivos y de productos que participan en la reacción. En la reacción de combustión, permite, conocida la composición del combustible y la composición del aire comburente, determinar en el caso ideal, combustión completa, las cantidades de productos generados.

La ecuación de la combustión del carbono es:

$$
\mathrm{C}+\mathrm{O}_{2}=\mathrm{CO}_{2}
$$

El balance de materia de dicha reacción será:

$$
1 \mathrm{kmol} \mathrm{C}+1 \mathrm{kmolO}_{2}=1 \mathrm{kmolCO}_{2}
$$

Sustituyendo los valores de sus masas molares:

$$
12,01 \mathrm{~kg} \mathrm{C}+32 \mathrm{~kg} \mathrm{O}=44,01 \mathrm{~kg} \mathrm{CO} 2
$$

Por cada kg de carbono que se quema:

$$
1 \mathrm{~kg} \mathrm{C}+2,664 \mathrm{~kg} \mathrm{O}_{2}=3,664 \mathrm{~kg} \mathrm{CO} 2
$$

Las reacciones básicas de la combustión son a parte de la combustión del carbono:

$$
\begin{gathered}
\mathrm{H}_{2}+1 / 2 \mathrm{O}_{2}=\mathrm{H}_{2} \mathrm{O} \\
\mathrm{S}+\mathrm{O}_{2}=\mathrm{SO}_{2}
\end{gathered}
$$

En las que el balance de masas será:

$1 \mathrm{~kg} \mathrm{H}+7,937 \mathrm{~kg} \mathrm{O}_{2}=8,937 \mathrm{~kg} \mathrm{H}_{2} \mathrm{O}$

$1 \mathrm{~kg} \mathrm{~S}+0,998 \mathrm{~kg} \mathrm{O}_{2}=1,998 \mathrm{~kg} \mathrm{SO}_{2}$ 


\subsubsection{Determinación del aire de combustión}

Para determinar la cantidad de oxígeno necesaria para la combustión completa de un combustible se suman las cantidades necesarias para cada uno de los elementos que participan y re resta la cantidad de oxígeno presente en el combustible.

Conocida la cantidad de oxígeno mínima se determina la cantidad de aire mínima, llamada también estequiométrica. Se utiliza para ello una composición estándar del aire que se incluye en la siguiente tabla 4.9.

Tabla 4.9. Composición estándar del aire.

\begin{tabular}{|l|l|l|l|l|}
\hline \multirow{2}{*}{ Aire } & \% en volumen & \% en peso \\
\cline { 2 - 5 } & Real & Uso & Real & Uso \\
\hline Nitrógeno & 78,03 & 79 & 75,45 & 76,8 \\
\hline Oxígeno & 20,99 & 21 & 23,2 & 23,2 \\
\hline Argón & 0,94 & 0 & 1,3 & 0 \\
\hline $\mathrm{CO}_{2}$ & 0,030 & 0 & 0,05 & 0 \\
\hline Otros & 0,001 & 0 & despreciable & 0 \\
\hline Peso molecular (kg/kmol) & $\mathbf{2 8 , 9 6 7}$ & \\
\hline
\end{tabular}

Utilizando el análisis elemental del combustible en tanto por uno, con la nomenclatura usual:

\section{$\mathrm{C}+\mathrm{H}+\mathrm{S}+\mathrm{O}+\mathrm{N}+\mathrm{W}+\mathrm{A}=1$}

Determinamos que la cantidad de oxígeno mínimo será en kg de Oxigeno por kg de combustible:

$$
\mathrm{O}_{\text {min }}=2,664 \mathrm{C}+7,937 \mathrm{H}+0,998 \mathrm{~S}-\mathrm{O}
$$

Y el consumo mínimo de aire seco (estequiométrico):

$$
I_{\min }=\frac{O_{\min }}{0,232}
$$

Para que una reacción de combustión sea completa, es decir todos los productos de la combustión están en el máximo estado de oxidación, es necesario que el aire utilizado I sea superior al estrictamente necesario, es decir al estequiométrico $I_{\min }$ a la relación entre ambos:

$$
\lambda=\frac{\mathrm{I}}{\mathrm{I}_{\min }}
$$


Se le denomina exceso de aire, o dosado relativo. El dosado se llama al cociente entre las masas de aire y combustible, la relación entre el dosado absoluto y el estequiométrico es el dosado relativo.

La composición de los humos se resume en la tabla 4.10, dada en kg de /kg de combustible de composición elemental conocida:

Tabla 4.10: Composición de humos en kg/kg de combustible.

\begin{tabular}{|l|l|l|l|}
\hline Componente & $\begin{array}{l}\text { Se forma } \\
\text { por } \\
\text { combustión }\end{array}$ & $\begin{array}{l}\text { En composición } \\
\text { del combustible }\end{array}$ & $\begin{array}{l}\text { Del aire introducido } \\
\text { para la combustión }\end{array}$ \\
\hline $\mathrm{CO}_{2}$ & $3,664 . \mathrm{C}$ & - & - \\
\hline $\mathrm{H}_{2} \mathrm{O}$ & $8,937 . \mathrm{B}$ & W & seco \\
\hline $\mathrm{SO}_{2}$ & $1,998 . \mathrm{S}$ & & - \\
\hline $\mathrm{O}_{2}$ & - & & $0,232(\lambda-1) I_{\min }$ \\
\hline $\mathrm{N}_{2}$ & - & $\mathrm{N}$ & $0,768 \lambda \mathrm{I}_{\min }$ \\
\hline
\end{tabular}

En la tabla 4.11 se presentan las expresiones para la determinación de la masa y el volumen de aire seco y húmedo en la combustión estequiométrica:

Tabla 4.11: Aire de combustión estequiométrica.

\begin{tabular}{|c|c|}
\hline $\begin{array}{l}\text { Masa de } \mathrm{O}_{2}\left(\mathrm{Mo}_{2}\right) \text { necesaria } \\
\text { para la combustión por } \mathrm{kg} \text { de } \\
\text { combustible. }(\mathrm{kg} / \mathrm{kg}) \text {. }\end{array}$ & $M_{02}=2,666 \mathrm{C}+8 \mathrm{H}+\mathrm{S}-0$ \\
\hline $\begin{array}{l}\text { Masa de aire seco }\left(\mathrm{M}_{\mathrm{A}} \mathrm{O}\right) \\
\text { necesario para la combustión } \\
\text { por kg de combustible. } \\
\text { (kg/kg). }\end{array}$ & $\mathrm{M}_{\mathrm{A}} \mathrm{0}=11,52 \mathrm{C}+34,56 \mathrm{H}+4,32 \mathrm{~S}-4,32 \mathrm{O}$ \\
\hline $\begin{array}{lcr}\text { Volumen de aire seco } & \left(\mathrm{V}_{\mathrm{A}} \mathrm{O}\right) \\
\text { necesario } & \text { para } & \text { la } \\
\text { combustión. }\left(\mathrm{m}^{3} \mathrm{~N} / \mathrm{kg}\right) & \end{array}$ & $\begin{array}{l}V_{A} 0=8,885 C+26,656 H+3,332 S- \\
3,3320\end{array}$ \\
\hline $\begin{array}{l}\text { Masa de aire húmedo }\left(\mathrm{M}_{\mathrm{Ax}} \mathrm{O}\right) \\
\text { necesario para la combustión } \\
\text { por kg de combustible. } \\
(\mathrm{kg} / \mathrm{kg}) \text {. }\end{array}$ & $\begin{array}{l}M_{A x} 0=M_{A} 0+V_{A}^{0} \cdot x \\
x=\text { humedad específica del aire } \\
\text { (kgagua } / m^{3} \text { de aire seco) }\end{array}$ \\
\hline $\begin{array}{l}\text { Volumen de aire húmedo } \\
\left(\mathrm{V}_{\mathrm{Ax}}{ }^{0}\right) \text { necesario para la } \\
\text { combustión. }\left(\mathrm{m}^{3} \mathrm{~N} / \mathrm{kg}\right) .\end{array}$ & $V_{A x} 0=V_{A}^{0}+1,244 V_{A}^{0} \cdot x$ \\
\hline
\end{tabular}




\subsubsection{Determinación de los productos de la combustión}

Los productos de la combustión que se generan cuando no hay exceso de aire se recogen en la tabla 4.12:

Tabla 4.12: Productos de la combustión estequiométrica.

\begin{tabular}{|c|c|}
\hline $\begin{array}{l}\text { Masa total de gases secos } \\
\left(\mathrm{M}_{\mathrm{Hs}}{ }^{0}\right) \text { generados por } \mathrm{kg} \text { de } \\
\text { combustible. }(\mathrm{kg} / \mathrm{kg}) \text {. }\end{array}$ & $\begin{array}{l}\mathrm{M}_{H s} 0=12,52 \mathrm{C}+26,56 \mathrm{H}+5,32 \mathrm{~S}+\mathrm{N}-3,32 \\
\mathrm{O}\end{array}$ \\
\hline $\begin{array}{l}\text { Volumen total de gases } \\
\text { secos }\left(\mathrm{V}_{\mathrm{Hs}}{ }^{0}\right) \text { generados por } \mathrm{kg} \\
\text { de combustible }\left(\mathrm{m}^{3} \mathrm{~N} / \mathrm{kg}\right) .\end{array}$ & $\begin{array}{l}\mathrm{V}_{\mathrm{Hs}}{ }^{0}=8,89 \mathrm{C}+21,07 \mathrm{H}+3,33 \mathrm{~S}+0,8 \mathrm{~N}-2,63 \\
\mathrm{O}\end{array}$ \\
\hline $\begin{array}{l}\text { Masa total de gases } \\
\text { húmedos }\left(\mathrm{M}^{0}\right) \text { generados } \\
\text { por kg de combustible } \\
(\mathrm{kg} / \mathrm{kg}) .\end{array}$ & $\mathrm{M}_{\mathrm{H}^{0}}=\mathrm{M}_{\mathrm{Hs}} \mathrm{O}+9 \mathrm{H}+\mathrm{W}+\mathrm{V}_{\mathrm{A}} \mathrm{O} \cdot \mathrm{x}$ \\
\hline $\begin{array}{l}\text { Volumen total de gases } \\
\text { húmedos }\left(\mathrm{V}_{\mathrm{H}^{0}}\right) \text { generados por } \\
\mathrm{kg} \text { de combustible }\left(\mathrm{m}^{3} \mathrm{~N} / \mathrm{kg}\right) .\end{array}$ & $V_{H} 0=V_{H s} 0+11,2 H+1,224\left(W+V_{A} 0 . x\right)$ \\
\hline
\end{tabular}

Cuando la combustión se hace con exceso de aire $(\lambda)$ las masas y volúmenes de gases secos y húmedos se recogen en la tabla 4.13:

Tabla 4.13: Productos de la combustión con exceso de aire.

\begin{tabular}{|c|c|}
\hline $\begin{array}{l}\text { Masa total de gases secos }\left(\mathrm{MHs}^{1}\right) \text { generados } \\
\text { con exceso de aire por } \mathrm{kg} \text { de } \\
\text { combustible. }(\mathrm{kg} / \mathrm{kg}) \text {. }\end{array}$ & $\mathrm{MHs}_{\mathrm{H}}^{1}=\mathrm{M}_{\mathrm{Hs}}{ }^{0}+\mathrm{M}_{\mathrm{A}} \mathrm{O}(\lambda-1)$ \\
\hline $\begin{array}{l}\text { Volumen total de gases secos }\left(\mathrm{V}_{\mathrm{Hs}^{1}}\right) \text { generados } \\
\text { con exceso de aire por } \mathrm{kg} \text { de combustible } \\
\left(\mathrm{m}^{3} \mathrm{~N} / \mathrm{kg}\right) \text {. }\end{array}$ & $\mathrm{V}_{\mathrm{HS}^{1}}=\mathrm{V}_{\mathrm{Hs}^{0}}{ }+\mathrm{V}_{\mathrm{A}} \mathrm{O}(\lambda-1)$ \\
\hline $\begin{array}{l}\text { Masa total de gases húmedos }\left(\mathrm{M}_{\mathrm{H}^{1}}\right) \text { generados } \\
\text { con exceso de aire por } \mathrm{kg} \text { de combustible } \\
(\mathrm{kg} / \mathrm{kg}) \text {. }\end{array}$ & $\mathrm{M}_{H^{1}}=\mathrm{M}_{H^{0}}+\mathrm{M}_{\mathrm{Ax}}{ }^{0}(\lambda-1)$ \\
\hline $\begin{array}{l}\text { Volumen total de gases húmedos } \\
\left(\mathrm{V}_{\mathrm{H}^{1}}\right) \text { generados con exceso de aire por } \mathrm{kg} \text { de } \\
\text { combustible }\left(\mathrm{m}^{3} \mathrm{~N} / \mathrm{kg}\right) \text {. }\end{array}$ & $V_{H^{1}}=V_{H^{0}}+V_{A x} x^{0}(\lambda-1)$ \\
\hline
\end{tabular}

Conocida la composición elemental del combustible nos permite determinar los parámetros de la combustión y mediante un análisis elemental de humos estimar el coeficiente de exceso de aire. 


\subsection{HOJA DE CÁLCULO PARA EL ANÁLISIS DE LA COMBUSTIÓN DE LAS MEZCLAS}

Los analizadores de humos tienen una base de datos de los combustibles comerciales, con la que el analizador calcula los productos de la combustión al medir la concentración de oxígeno en humos. El problema aparece cuando los humos que tratamos de analizar provienen de un combustible que no está caracterizado en la base de datos del analizador y no es capaz de determinar todos los productos de la combustión.

Para la determinación de la composición de la mezcla necesitamos conocer y caracterizar a los distintos aceites que vamos a usar, esta caracterización se hace en laboratorio, las muestras de los aceites son enviadas al Laboratorio Regional de Combustibles de Castilla y León (LARECOM), los datos de los distintos análisis se adjuntan en el Anexo "1" de la tesis.

Como alternativa a los métodos experimentales para la obtención de las propiedades físico-químicas de los combustibles existen métodos estimativos que se basan en la resolución de ecuaciones teóricas como Clasius-Clapeyron,o semiempíricas como Grumberg-Nissan.

Se ha desarrollado una hoja Excel que nos permite determinar la composición elemental de la mezcla conocida la composición elemental de los componentes y el porcentaje de mezcla, al mismo tiempo usamos la hoja para la determinación de las características termoquímicas de la mezcla y para la determinación del rendimiento de la combustión.

La primera pantalla de la hoja de cálculo nos solicita las características de los combustibles que forman la mezcla y el porcentaje de mezcla, y determina: i) Las propiedades de la mezcla a estudio, ii) el caudal de aire necesario estequiométrico y iii) la composición y caudal humos estequiométricos. La figura 4.6 reproduce la mezcla al 10\% de la mezcla de aceites vegetales al 33\% y gasóleo al 90\%.

El analizador de gases de combustión analiza los gases y determina el contenido de $\mathrm{O}_{2}$ en los humos con lo que se puede calcular el exceso de aire o dosado relativo de la combustión:

$$
(\lambda-1)=\frac{0_{2}}{V_{A}^{0} \cdot 0,21}
$$


A partir del conocimiento del exceso de aire nos permite determinar la masa y el volumen de humos secos por masa de combustible:

$$
\mathrm{M}_{\mathrm{Hs}}^{1}=\mathrm{M}_{\mathrm{Hs}}^{0}+\mathrm{M}_{\mathrm{A}}^{0} *(\lambda-1) \mathrm{y} \mathrm{V}_{\mathrm{Hs}}^{1}=\mathrm{MV}_{\mathrm{Hs}}^{0}+\mathrm{MV}_{\mathrm{A}}^{0} *(\lambda-1)
$$

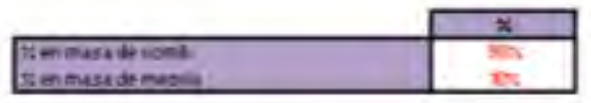

\begin{tabular}{|c|c|c|c|c|}
\hline \multirow{2}{*}{\multicolumn{5}{|c|}{ COMPOSICIOM QUNACA OEI COMBUSTIEIE }} \\
\hline Elenenato & Sielpalo & Conb. & Aceite & \\
\hline Critono & c & Q50000 & Q77me & aist? \\
\hline Heablonos & H & $0, m 00$ & entase & in \\
\hline Atovire & s & Q.906060 & enten & gis \\
\hline Nundgrmo & N & aperee & anceep & asen \\
\hline Origent & 0 & 0,00000 & 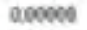 & 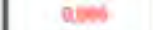 \\
\hline Agou & MO & 00500 & acocece & aost \\
\hline Censas & & 000150 & 000600 & 000 \\
\hline
\end{tabular}

\begin{tabular}{|c|c|c|}
\hline \multicolumn{3}{|c|}{ PEACTrVOS (eombastión mstequionítrica) } \\
\hline 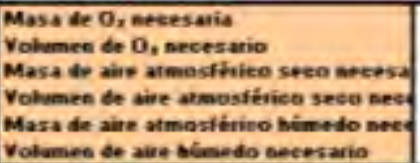 & 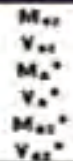 & 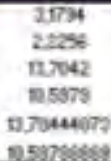 \\
\hline
\end{tabular}

Ig be 0,9 g be vont

in' be ovg be ocme.

'g oe als seccotg a comb

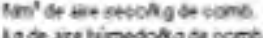

Ig de are himedokg os ocmb.

Nim' do ues kimedotig de nomb.

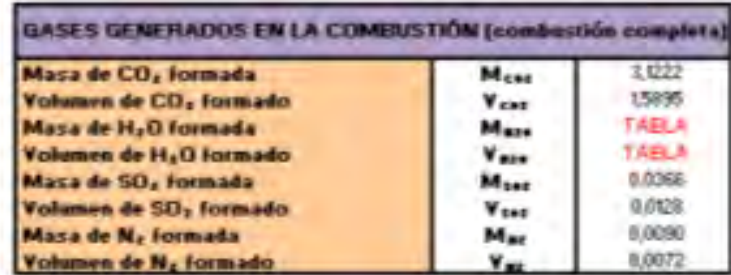

Igdecong to ocmb $\mathrm{Nm}$ ' de covig se somt laservokg o oomb. Nmit de Hoig de somb. ig se sojag de some. Nin' a songs secome. ig de Natg de comb.

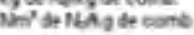

ias geves spoosag be cont Man' de geiel stbask g be bomb Ig oe gasus himedoskig so some Nm' de gases HimedooA g de comb

late geses stocosh g be vomb. Nm' de getes sttogk g te somb.

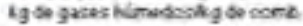

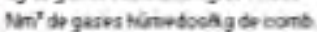

Figura 4.6: Pantalla para la introducción de datos del combustible a estudio. 


\subsubsection{Propiedades termoquímicas.}

Para la determinación de la energía liberada en el proceso de combustión se aplican las leyes de Lavoassiare -Laplace y la de Hess que son consecuencia del primer principio de la termodinámica.

La ley de Lavoassiare y Laplace dice que: "el cambio energético que acompaña a una reacción química es de magnitud exactamente igual pero de signo opuesto al que va asociado a la misma reacción cuando se realiza en sentido opuesto"

Y la ley de Hess que "el cambio energético que acompaña a una reacción química a $\mathrm{P}$ o $\mathrm{V}$ constante, es independiente de si la reacción se produce en una o en varias etapas".

Para el cálculo de la energía liberada en una combustión consideramos que el aire y el combustible, entran en la cámara de combustión en condiciones de presión y temperatura determinadas, los productos de la combustión, supuesta completa y con exceso de aire, abandonan la cámara la misma presión pero a temperatura distinta, suponiendo despreciable las variaciones de energía cinética y potencial para un sistema abierto el balance de energía es:

$$
\mathrm{Q}_{\mathrm{n}}=\sum \mathrm{H}_{\text {productos }}\left(\mathrm{t}_{2}, \mathrm{p}\right)-\sum \mathrm{H}_{\text {reactivos }}\left(\mathrm{t}_{1}, \mathrm{p}\right)
$$

La variación de entalpía es igual al calor de reacción a presión constante y se puede determinar partiendo de valores tabulados de otras reacciones.

Los combustibles son una mezcla de sustancias, en el que el análisis químico de las sustancias que componen los reactivos no es conocido, por lo que la variación de entalpía se determina experimentalmente mediante un equipo llamado calorímetro ${ }^{91}$.

El poder calorífico de un combustible, es la energía por unidad de masa del combustible que se libera cuando éste se somete al proceso de combustión y los productos obtenidos llegan a su estado final de oxidación, estando los reactivos y los productos a la temperatura y presión de referencia estándar y se expresa por unidad de masa de combustible quemado en $\mathrm{kJ} / \mathrm{kg}$, en un combustible se distingue dos poderes caloríficos: 92

${ }^{91}$ Ca selles M.J ., Gómez M.R., Molero M. y Sardá J ., 2004. “Químic a a plic a da a la ingeniería. Capítulo 6. Temodinámica química", UNED. pp 231-245, 2004.

92Noma UNE 9205:1987. Cálculos relativos a la combustión. AENOR, octubre 1987. 
- Poder calorífico superior (P.C.S.). Es la cantidad total de calor de un combustible, incluyendo el calor latente del agua formada por la combustión del hidrógeno contenido en dicho combustible.

- Poder calorífico inferior (P.C.I.). Es la cantidad de calor que resulta al restar del poder calorífico superior el calor latente del agua formada por la combustión del hidrógeno contenido en el combustible.

\subsubsection{Poder calorífico de las muestras.}

Conocidos los valores del P.C.I y del P.C.E. por métodos experimentales, dadas las grandes diferencias que se pueden presentar en la composición de los aceites naturales por la variedad de semilla, método de cultivo,y de la edafología, se procede a determinar los valores de las mezclas en función de la distinta composición de la mezcla.Para el PCl.:

$$
\left.\left.\mathrm{PCl}_{\text {combustible(mezcla) }}=\mathrm{PCl}_{\text {aceite }} * \text { (\% aceite }\right)+\mathrm{PCl} \text { gasóleo } \text { (\% gasóleo }\right)
$$

Los valores experimentales se determinan en el Laboratorio Regional de Combustibles de Castilla y León (LARECOM). El método experimental que se aplica sigue las especificaciones técnicas recogidas en la Norma internacional ASTM D-24093.

\subsubsection{Rendimiento de la combustión}

El rendimiento de la combustión viene dado por la relación entre el calor útil de la combustión y el calor nominal del combustible. El rendimiento representaría la cantidad de calor que obtenemos, frente a la máxima cantidad que podríamos obtener si no hubiese pérdidas.

Los métodos para la determinación del rendimiento son el método directo $y$ el indirecto.

En el método directo, evaluamos el calor útil suministrado por la combustión, como sería la cantidad de calor entregada al fluido caloportador, por cantidad de combustible consumida, es necesario conocer los balances de masa de los fluidos que participan referidos a la masa de combustible, para el cálculo el rendimiento por el método indirecto es necesario estimar las pérdidas. En ambos casos la expresión del rendimiento viene dada por:

93 Noma ASTM-240.Procedimientos, equipos y correcc iones termoquímic as para el calor de combustión. Abril de 2002 


$$
\eta=\frac{\mathrm{Q}_{\mathrm{u}}}{\mathrm{Q}_{\mathrm{n}}}=\frac{\mathrm{Q}_{\mathrm{n}}-\sum \text { Pérdidas }}{\mathrm{Q}_{\mathrm{n}}}
$$

En la que Ques el calor útil de la combustión en $\mathrm{kJ} / \mathrm{kg}$ y $\mathrm{Q}_{n}$ es el calor nominal del combustible en $\mathrm{kJ} / \mathrm{kg}$.

Las pérdidas de calor provienen de varias causas:

- Pérdidas por humos. Los gases evacuados lo hacen a alta temperatura. $\left(P_{s}\right)$

- Pérdidas por inquemados. Parte del material combustible no llega a oxidarse por completo por lo que no llega a generarse una parte del calor. $\left(\mathrm{Pi}_{\mathrm{i}}\right)$

Podemos expresar el rendimiento de la combustión como:

$$
\eta=\frac{\text { P.C.I. }-P_{s}-P_{i}}{\text { P.C.I. }}
$$

Las pérdidas por humos $\left(P_{s}\right)$ corresponden al calor que se ha utilizado para calentar los humos hasta la temperatura a la que abandonan la chimenea. Por debajo de dicha temperatura o no es posible aprovechar ese calor por baja temperatura o no interesa por condensación de ciertos productos. Estas pérdidas aumentan al aumentar la temperatura y al aumentar la cantidad de gases por lo que un mayor exceso de aire aumenta las pérdidas por humos.

Las pérdidas por humos se calculan en función de la energía interna de los humos respecto a la temperatura de entrada de los productos de la combustión, expresado en tanto por ciento:

$$
P_{S}=\frac{M_{H}^{1} * C p_{H} *\left(T_{H^{-}} T_{\text {ref }}\right)}{\text { P.C.I. }} * 100
$$

En la que $\mathrm{M}_{\mathrm{H}}^{1}$ es la masa de humos húmedos no estequiométricos por kg de combustible $\mathrm{kg} / \mathrm{kg}_{\text {comb. }} \mathrm{Cp}_{\mathrm{H}}$ es el calor específico de los humos en $\mathrm{kJ} / \mathrm{kg}^{\circ} \mathrm{C}$, que se determina de acuerdo con la norma UNE 9205:198794. $\mathrm{T}_{\mathrm{H}}$, temperatura de los humos a la salida en $\left({ }^{\circ} \mathrm{C}\right)$ y $\mathrm{T}_{\text {ref, }}$, temperatura de referencia o de entrada de los productos a la combustión en $\left({ }^{\circ} \mathrm{C}\right)$.

94 Noma UNE 9205: 1987 .Cálculos relativos a la combustión. AENOR. Octubre de 1.987 
El calor específico $\mathrm{Cp}_{\mathrm{H}}$ de los humos se calculan, a partir del calor específico de cada componente que aparece en los humos, multiplicado por su porcentaje en tanto por uno en los humos.

Las pérdidas por inquemados corresponden a la energía química de los productos de la combustión que no ha sido liberado, por no haber sufrido la oxidación total. Se presentan en los casos de combustión incompleta, siendo más altas las pérdidas cuanto mayor sean la cantidad de inquemados. En el caso de la oxidación parcial del carbono, el producto que caracteriza las pérdidas por inquemados es la concentración de CO en los humos que se determina por:

$$
\mathrm{P}_{\mathrm{i}}=\frac{\mathrm{V}_{\mathrm{Hs}}^{1} *(\mathrm{CO}) * \rho_{\mathrm{CO}} * \mathrm{PCl}_{\mathrm{CO}}}{100 * \mathrm{PCl}}
$$

En la que $\mathrm{V}_{\mathrm{Hs}}^{1}$ es el volumen de los humos secos en $\mathrm{m}^{3} \mathrm{~N} / \mathrm{kg}$, (CO) es el porcentaje de $\mathrm{CO}$ en los humos de combustión, $\rho_{\mathrm{CO}}$ es la densidad del $\mathrm{CO}$ en condiciones normales en $\mathrm{kg} / \mathrm{m}^{3} \mathrm{~N}$ y PClco es el poder calorífico inferior del $\mathrm{CO}$ en $\mathrm{kJ} / \mathrm{kg}$.

Con los datos de temperatura de entrada del aire y el combustible, la temperatura de salida de los humos, el porcentaje de $\mathrm{CO}$ aplicados a las ecuaciones estequiométricas de la mezcla se determina mediante la hoja Excel el rendimiento de la combustión. La figura 4.7, muestra los resultados para un caso de estudio.

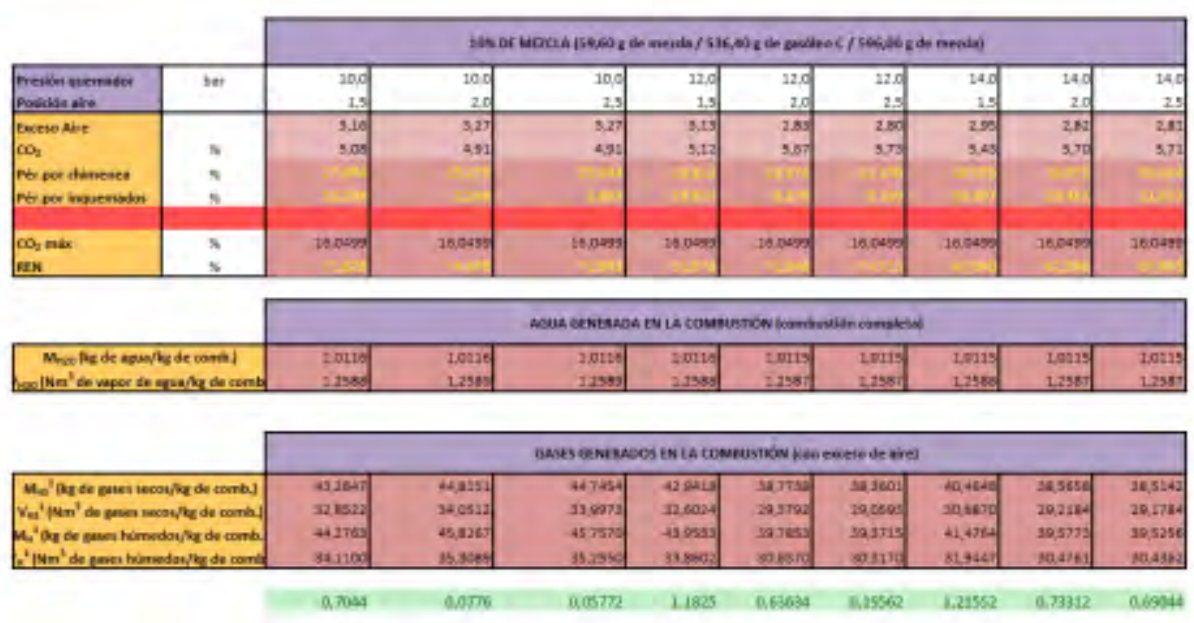

Pantalla 4.7: Pantalla donde se presenta los resultados de rendimiento de combustión. 


\subsection{EMISIONES DE GASES DE COMBUSTIÓN}

En el campo medioambiental se define las instalaciones de combustión como aquellas que queman cualquier tipo de combustible para la producción de electricidad, energía mecánica, fluido térmico (vapor, aceite, agua caliente), independientemente de su finalidad. Por lo tanto se deben incluir en la definición dispositivos para la generación eléctrica, cogeneradores, calderas, turbinas y motores.

La potencia térmica generada a considerar variará de 2 a $50 \mathrm{MWt}$, de modo que las grandes instalaciones de combustión, deberán cumplir la siguiente normativa:

- Real Decreto 646/1991, de 22 de abril, por el que se establecen nuevas normas sobre limitación a las emisiones a la atmósfera de determinados agentes contaminante procedentes de grandes instalaciones de combustión (BOE Num. 99, de 25 de abril de 1991). Aplicable hasta el 1 de enero de 2008, para nuevas instalaciones autorizadas antes de la entrada en vigor del Real Decreto 430/2004 de GICs.

- Orden de 26 de diciembre de 1995, para el desarrollo del Real Decreto 646/1991, sobre limitación de emisiones a la atmósfera de grandes instalaciones de combustión en determinados aspectos referentes a centrales termoeléctricas.

- $\quad$ Real Decreto 430/2004, de 12 de marzo, por el que se establecen nuevas normas sobre limitación de emisiones a la atmósfera de determinados agentes contaminantes procedentes de grandes instalaciones de combustión, y se fijan ciertas condiciones para el control de las emisiones a la atmósfera de las refinerías de petróleo.

- $\quad$ En el caso de que la instalación fuera de calefacción, climatización o agua caliente sanitaria es necesario tener en cuenta lo dispuesto en el CTE HE-2 Reglamento de Instalaciones Térmicas en los Edificios (RITE) y sus Instrucciones Técnicas Complementarias (ITE).

- Para el caso del límite de emisiones de dioxinas y furanos en la quema de grasas animales se deberá tener en cuenta el Real Decreto 653/2003, de 30 de mayo, sobre la incineración de residuos hasta el 4 de marzo de 2011 de acuerdo con el Reglamento (CE) Num. 1069/2009 del Parlamento Europeo y del Consejo, de 21 de octubre de 2009, por el que se establecen las normas sanitarias aplicables a los subproductos animales y los productos derivados no destinados al consumo humano y por el que 
se deroga el Reglamento (CE) Num. 1774/2002 sobre subproductos animales.

El límite de emisiones contaminantes a la atmósfera de una instalación de combustión dependerá por tanto, de la potencia térmica suministrada por la misma. La normativa nos proporciona los valores límite para instalaciones con una potencia térmica que varía de $2 \mathrm{MWt}$ a $50 \mathrm{MWt}$ por lo que para instalaciones con una potencia inferior a la mínima el límite de emisión a cumplir es el mínimo requerido, es decir, para la potencia térmica de $2 \mathrm{MWt}$. Asimismo, también dependerá del combustible de partida que se esté introduciendo en el proceso, ya sea en forma líquida, sólida o gaseosa.

Por consiguiente, para una instalación de baja potencia térmica (inferior a la mínima de la normativa) operando con un combustible líquido, los límites atmosféricos de los contaminantes se recogen en la Tabla 4.14:

Tabla 4.14: Límites de contaminantes emitidos a la atmósfera en combustión.

\begin{tabular}{|l|l|}
\hline Compuesto & Límite \\
\hline Óxidos de azufre & $4300 \mathrm{mg} / \mathrm{nm}^{3}$ (fuel pesado) \\
& $2000 \mathrm{mg} / \mathrm{nm}^{3}$ (fuel BIA) \\
& $700 \mathrm{mg} / \mathrm{nm}^{3}$ (gasóleo) \\
\hline CO & $350 \mathrm{mg} / \mathrm{nm}^{3}$ \\
\hline Opacidad (Bacharach) & 2 \\
\hline
\end{tabular}

\subsubsection{Gases de efecto invernadero.}

Los gases de efecto invernadero son aquellos gases que permiten que la radiación solar penetre hasta la superficie terrestre, atrapando la radiación infrarroja ascendente emitida por la Tierra, que de otro modo escaparía al espacio.

Su concentración atmosférica es baja, pero tienen una importancia fundamental en el aumento de la temperatura del aire próximo al suelo, es por ello, que se debe evitar en la medida de lo posible su emisión.

Los principales gases de efecto invernadero se enumeran a continuación: dióxido de carbono $\left(\mathrm{CO}_{2}\right)$, metano $\left(\mathrm{CH}_{4}\right)$, óxido nitroso $\left(\mathrm{N}_{2} \mathrm{O}\right)$, hidrofluorocarbonos (HFC), perfluorocarbonos (PFC) y hexafluoruro de azufre $\left(\mathrm{SF}_{6}\right)$. 
En lo que concierne a esta tesis, el gas de efecto invernadero que se debería tener en cuenta es el dióxido de carbono $\left(\mathrm{CO}_{2}\right)$ puesto que el combustible que sería introducido en el quemador es una mezcla de gasóleo y un biocombustible, con una relación de hasta el $40 \%$ del mismo. Esto permite reducir las emisiones de gases de efecto invernadero de origen fósil al ser sustituidos por gases de efecto invernadero de origen renovable.

Los valores de los GEl como Óxidos de azufre están limitados por el contenido máximo de azufre del gasóleo, como se recoge en la Tabla 4.14.

\subsection{2 Óxidos de nitrógeno.}

Por $\mathrm{NO}_{x}$ se designa de forma genérica a los óxidos de nitrógeno, $\mathrm{NO}$ y $\mathrm{NO}_{2}$. En los sistemas de combustión se forma principalmente NO (su cinética química es dominante frente a la del $\mathrm{NO}_{2}$ ). En general, durante el proceso de combustión, se reconocen cuatro mecanismos químicos responsables de la formación de $\mathrm{NO}_{x} 95$ :

- Mecanismo térmico: descrito por Zeldovich, es el mecanismo dominante para altas temperaturas. La ruta cinética de formación se inicia con la disociación de las moléculas de oxígeno $\left(\mathrm{O}_{2}\right)$, que posteriormente reaccionan con las moléculas de nitrógeno, empezando así una reacción en cadena. Se puede decir, que el mecanismo térmico deja de ser importante a temperaturas inferiores a $1800 \mathrm{~K}$.

- Mecanismo súbito: descrito por Fenimore, es el mecanismo que se da en frentes de llama (con alta concentración de carbón, hidrocarburos sin quemar o parcialmente quemados) se produce una rápida formación de NO antes del mecanismo térmico, radica en el hecho de que radicales de hidrocarburos reaccionan con el nitrógeno molecular para formar aminas y compuestos $\mathrm{CN}$ o $\mathrm{HCN}$, que se convierten finalmente en NO. Este mecanismo está muy relacionado con la relación aire-combustible, siendo despreciables para reacciones con exceso de aire.

- Mecanismo vía $\mathrm{N}_{2} \mathrm{O}$ : este mecanismo es importante en mezclas con defecto de aire (inferiores a 0,8) para bajas temperaturas y elevadas presiones, es típica de combustiones con fines mecánicos como la turbina de gas.

- Mecanismo vía combustible: La formación del NO ocurre al reaccionar directamente el nitrógeno del combustible con el oxígeno del aire y depende de la cantidad de nitrógeno que tienen los

95 Schwerdt C., "Modelling NOx-formation in combustion processes", ISSN 0280-5316, Department of Automatic Control, Lund University, Junio 2006. 
combustibles utilizados, en los grasas no hay cantidades significativas de nitrógeno.

\subsubsection{Monóxido de carbono.}

La formación de $\mathrm{CO}$ es un paso intermedio fundamental en la oxidación de un hidrocarburo y está íntimamente ligado con índice de exceso de aire. Los mecanismos de formación de CO son:

- $\quad$ El CO es una de las especies contaminantes más importantes en procesos de combustión con defecto de aire (esto ocurre en motores que utilizan combustibles muy heterogéneos). También cabe destacar la gran contribución del quemado de biomasa.

- Disociación de las moléculas de $\mathrm{CO}_{2}$, teniendo ésta lugar a temperaturas elevadas (aproximadamente a partir de $2000 \mathrm{~K}$ ) que son las temperaturas locales típicas que se alcanzan en los procesos de combustión. La cantidad de CO generada por un equipo de combustión depende del balance entre proceso de formación (reacciones rápidas) y oxidación del mismo (reacciones lentas), siendo ambos muy activos a temperatura elevada. Por tanto, en procesos donde los tiempos de residencia son del orden de segundos, las reacciones del CO alcanzarían el equilibrio y la cantidad de $\mathrm{CO}$ en los humos es prácticamente nula.

- Es el apagado de llama en la pared debido a las bajas temperaturas.

En el proceso de difusión utilizado en los ensayos de combustión de esta tesis puede formarse $\mathrm{CO}$, por dos motivos: haber zonas con defecto de aire en el frente de llama o zonas con una mala mezcla de combustible y comburente, (Problemas de pulverización y del proceso de mezcla).

\subsection{4 Óxidos de azufre.}

En los procesos de combustión, todo el azufre contenido en el combustible aparece en forma de $\mathrm{SO}_{2} \mathrm{O}_{\mathrm{SO}_{3}}$ en los productos de la combustión, la combinación de ambos suele notarse por $\mathrm{SO}_{\mathrm{x}}$. Los resultados de emisiones de $\mathrm{SO}_{\mathrm{x}}$, en esta tesis no son considerados al contener concentraciones en tanto por uno prácticamente despreciables. 


\section{BIBLIOGRAFÍA CAPÍTULO 4}

79) Spalding D. Brian, Combustión y transferencia de masa, CECSA 1.979

80) Méndez C., "Modelado numérico de un chorro atomizado no estacionario", tesis doctoral, Universidad de Valladolid 2003.

81) Ruiz, F. y Chigier, N.A., Parametric experiments on liquid jet atomization spray angle, Atomization and Sprays, 1, 23-45, 1991.

82) Dumouchel C. Ledoux M. Bhor M.I.G. ,The design of pressure swirl atomizers, ASME International Gas Turbine Aeroengine Congress Exhibition 43 rd Stockholm Sweden (1998)

83) Yule A.J. Chinn J.J., The internal flow and exit conditions of pressure swirl atomizers, Atomization and Sprays, vol.10, no. 2, pp.121-146, 2000.

84) Edmund Giffen, A. Muraszew, The atomisation of liquid fuels, Chapman \& Hall, 1953.

85) Hay N. y Jones PL "Comparison of the various correlations for spray penetration". SAE, Paper 7207761982.

86) Rizk, N. K. and Lefebvre, A. H., Internal flow characteristics of simplex swirl atomizers. Journal of Propulsion and Power, 1, 193-199. 1985.

87) Ramamurthi K. Tharakan T.J. , Atomization characteristics of swirled annular liquid sheets, AIP Phycs of Fluids, 1997.

88) Lefebvre A.H. Atomization and Spray.Hemisphere Pub.Corp., 1989.

89) Rayleigh Lord, on the instability of yet, Proc. London Math. Soc. (1878)

90) Danfoss, "Practical tips Oil nozzles" burner.danfoss.com, 2010.

91) Caselles M.J., Gómez M.R., Molero M. y Sardá J., 2004. "Química aplicada a la ingeniería. Capítulo 6. Termodinámica química”, UNED. pp 231-245, 2004.

92) Norma UNE 9205:1987. Cálculos relativos a la combustión. AENOR, octubre 1987.

93) Norma ASTM-240 .Procedimientos, equipos y correcciones termoquímicas para el calor de combustión. Abril de 2002

94) Norma UNE 9205: 1987 .Cálculos relativos a la combustión. AENOR. Octubre de 1.987

95) Schwerdt C., "Modelling NOx-formation in combustion processes", ISSN 0280-5316, Department of Automatic Control, Lund University, Junio 2006. 


\section{CAPITULO 5 \\ INSTALACIÓN EXPERIMENTAL}

\section{$5.1 \quad$ INTRODUCCIÓN.}

El presente capítulo hace una descripción detallada de la instalación experimental utilizada en la combustión de las diferentes mezclas objeto de la presente tesis. Los elementos y equipos que componen la instalación experimental son elementos comerciales, que conforman una instalación convencional con pequeñas modificaciones, que permite reproducir diferentes situaciones reales de funcionamiento del equipo de combustión y al mismo tiempo caracterizar energéticamente la combustión y las emisiones de gases de efecto invernadero y contaminantes.

En este capítulo también se describe el procedimiento que se ha seguido en los ensayos experimentales y las condiciones de funcionamiento de la instalación para que los resultados de los ensayos puedan ser admitidos como válidos.

INSTALACIÓN EXPERIMENTAL.

La combustión de las mezclas que se han experimentado en esta tesis se han realizado en una instalación situada en el Laboratorio de Calor y Frío 
Industrial de la Escuela de Ingenierías Industriales, sede $\mathrm{P}^{\circ}$ del Cauce, de la Universidad de Valladolid.

La instalación experimental está compuesta por:

- $\quad$ Sistema de alimentación de combustible. El sistema permite la alimentación de gasóleo o mezcla de forma alternativa. El depósito de mezcla está acondicionado como baño termostático para aumentar la temperatura y dispone de un agitador para a asegurar la homogeneidad de la mezcla que llega al quemador. El retorno de la bomba de inyección no llega al depósito de mezclas para evitar contaminación de las mezclas.

- Conjunto quemador-caldera formado por una caldera modular de hierro fundido con hogar en sobrepresión y un quemador de gasóleo de pulverización mecánica por presión.

- Disipador de calor formado por una red bitubular con elementos de disipación a base de dos aerotermos, que permiten disipar el calor generado, tienen la característica de tener poca inercia de funcionamiento.

- Sistema de control y medida para mantener las condiciones de funcionamiento de la instalación y poder registrar los datos de la combustión.

Esquemáticamente la instalación experimental se representa en la siguiente figura 5.1:

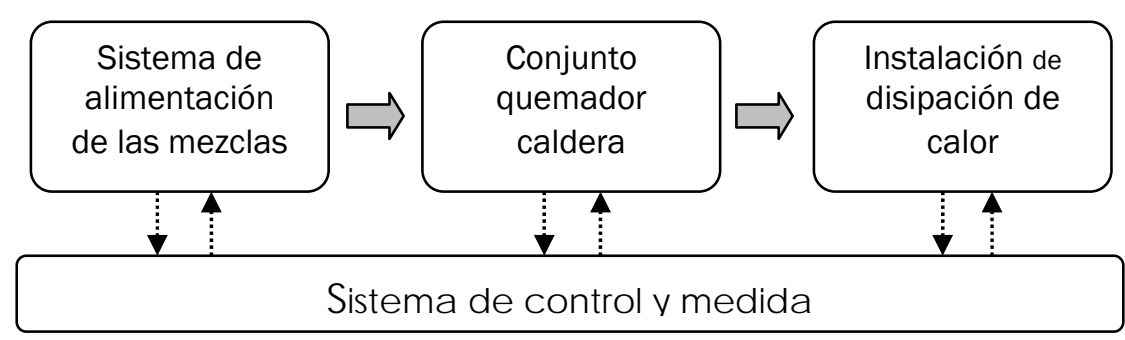

Figura 5.1 Esquema de la instalación experimental

\subsubsection{Sistema de alimentación de la mezcla.}

El sistema de alimentación está construido de forma que permita el uso de gasóleo puro y de mezcla, de forma alternativa. Tanto el arranque como la parada se realizan con gasóleo puro, evitando que en los conductos, bomba y caña del quemador, queden restos de mezcla. Una vez que se alcanzan los valores prefijados, que indican que la instalación está a régimen, se cambia de combustible para realizar el ensayo correspondiente. 
La temperatura de las mezclas para los ensayos se mantienen a temperatura ambiente al no presentar problemas de enturbiamiento este tipo de aceites, aunque es posible incrementar la temperatura por encina de la temperatura ambiente, con el sistema de calorifugado del depósitos de mezclas. El depósito de mezcla dispone de agitador para mantener la homogeneidad de dichas mezclas

El sistema cuenta con dos depósitos, uno de gasóleo, que cumple con las especificaciones generales de los depósitos de combustibles derivados del petróleo96, y el otro depósito para la muestra de ensayo cuenta con calorifugado y un sistema de agitación. Ambos depósitos permiten la conexión alternativa mediante válvulas que impidan la mezcla de ambos combustibles. En la siguiente figura 5.2, puede verse un esquema del conjunto del sistema de alimentación de combustible:

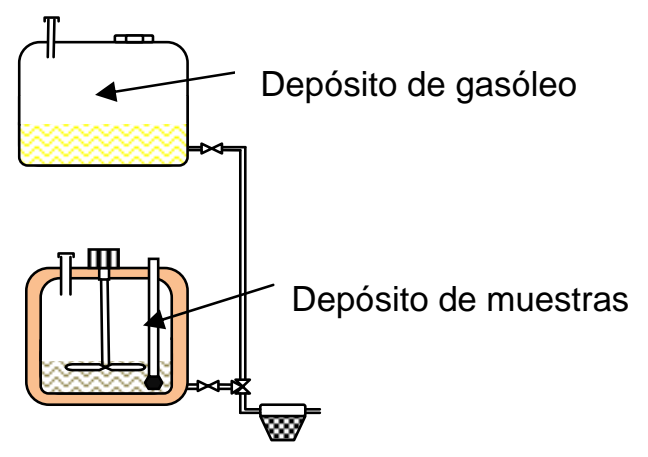

Figura 5.2 Esquema de la alimentación de combustible a la instalación.

Ambos depósitos cuentan con sensor para medida de temperatura. El depósitos de muestras es un depósito encamisado que dispone de un agitador eléctrico y un baño termostático de agua mantienen la temperatura y la homogeneidad de la muestra. En la figura 5.3, puede verse ambos sistemas:

96 ITC-MI-IP-03: Instalaciones petrolíferas para uso propio, instalaciones de almacenamiento para su consumo en la propia instalación, 1999 

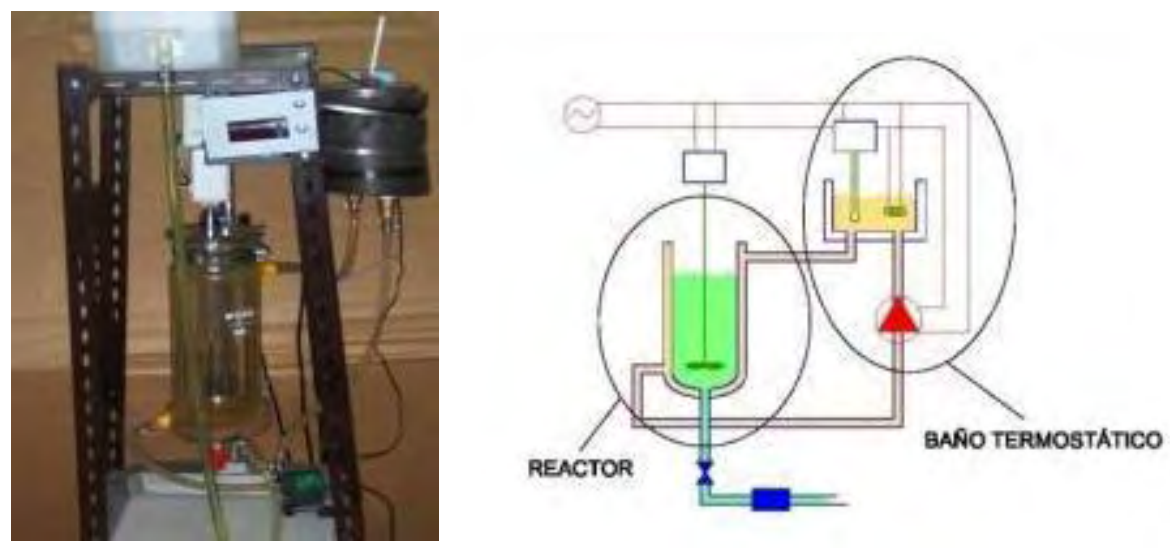

Figura 5.3 Alimentación de combustible a la instalación.

Las características del regulador de temperatura y de la bomba de circulación se recogen en las Tablas 5.1 y 5.2 respectivamente.

Tabla 5.1: Datos técnicos del regulador de temperatura AKO-14123.

\begin{tabular}{|l|l|}
\hline Rango de temperatura & $-50,0^{\circ} \mathrm{C}$ a $99,9^{\circ} \mathrm{C}$ \\
\hline Resolución y ajuste & $0,1^{\circ} \mathrm{C}$ \\
\hline Precisión & $1^{\circ} \mathrm{C}$ \\
\hline Tolerancia de la sonda a $25^{\circ} \mathrm{C}$ & $\pm 0,4^{\circ} \mathrm{C}$ \\
\hline Temperatura ambiente de trabajo & $5^{\circ} \mathrm{C}$ a $50^{\circ} \mathrm{C}$ \\
\hline Potencia máxima absorbida & $3 \mathrm{VA}$ \\
\hline
\end{tabular}

El agua se mueve mediante una bomba de la casa MAXI-JET modelo MJ500, cuyas características se recogen en la tabla 5.2:

Tabla 5.2: Datos de la bomba de circulación del agua:

\begin{tabular}{|c|c|c|}
\hline $\begin{array}{c}\text { Potencia absorbida } \\
(\mathrm{W})\end{array}$ & $\begin{array}{c}\text { Caudal máximo } \\
(\mathrm{l} / \mathrm{h})\end{array}$ & $\begin{array}{c}\text { Altura máxima } \\
(\mathrm{m})\end{array}$ \\
\hline 7,5 & 490 & 0,93 \\
\hline
\end{tabular}




\subsubsection{Conjunto quemador-caldera.}

El conjunto caldera-quemador es un equipo preparado para la combustión controlada y optimizada para un combustible concreto y para una cierta escala de potencia nominal, según el atomizador, la presión de atomización y la cantidad de aire que aportamos. Las operaciones que realiza la caldera se complementan con la cesión de la máxima cantidad de calor al circuito de disipación (aprovechamiento) y la expulsión de los productos de combustión a la atmósfera.

En el caso de combustibles líquidos, en el capítulo VI se desarrollo la necesidad de pulverizar y evaporar el combustible para poder obtener una buena combustión, los combustibles líquidos se queman en estado gaseoso, en la siguiente tabla 5.3 vemos los distintos quemadores en función de sus características fundamentales.

En la tabla 5.3 se incluye la energía auxiliar consumida en el proceso de atomización de cada uno de los sistemas y los tipos de combustible que se pueden quemar en función de la viscosidad del mismo.

El quemador que se ha utilizado en la presente tesis es un quemador de pulverización mecánica por presión directa. En este tipo de quemador el combustible a alta presión es obligado a pasar por un orificio apropiado produciendo la ruptura de su tensión superficial y obteniendo un cono completamente pulverizado. El esquema de este tipo de quemador y sus partes principales se incluyen en la figura 5.4: 
Tabla 5.3: Quemadores para combustibles líquidos y sus características ${ }^{97}$

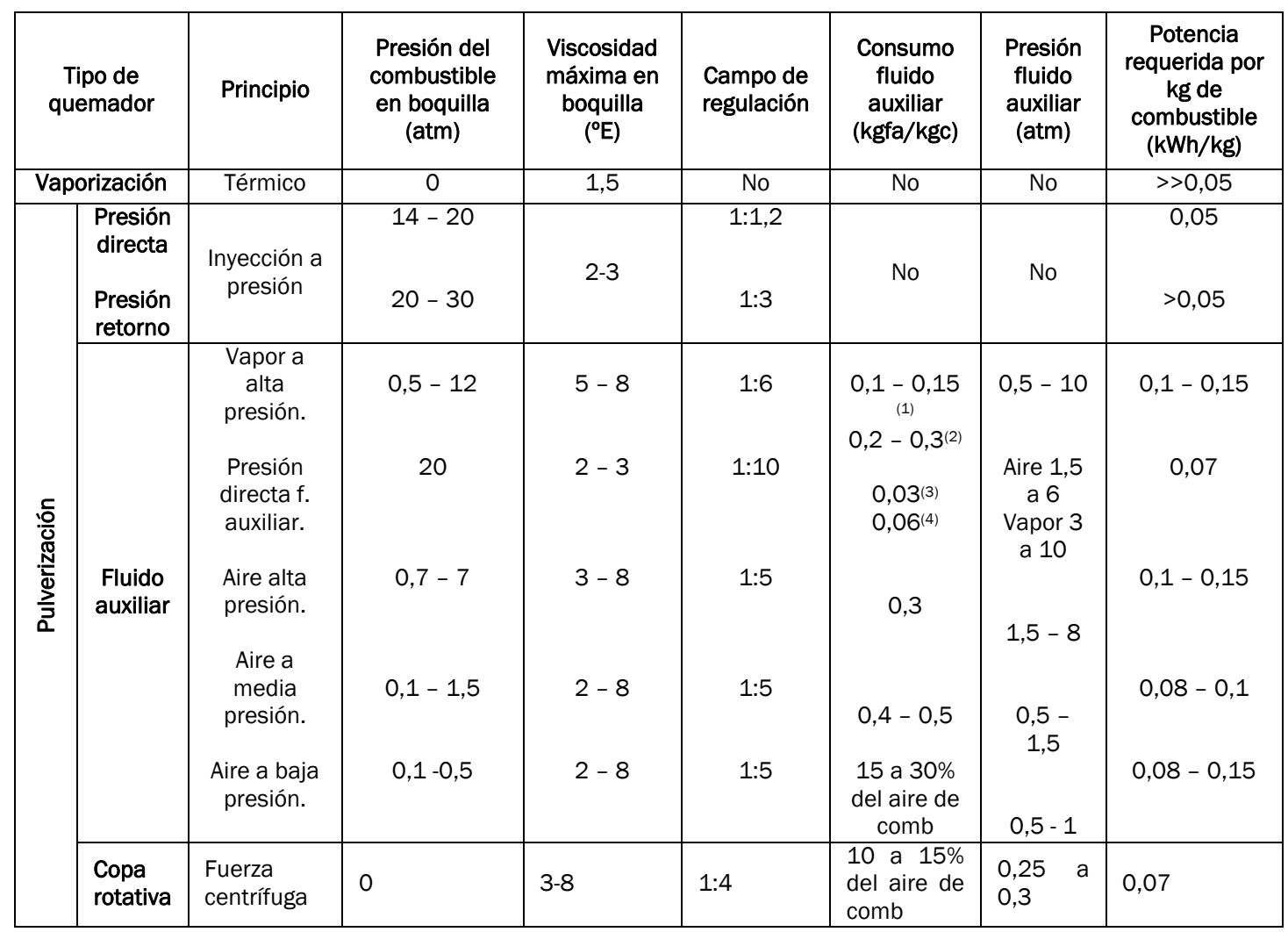

97 M.LapuertaM. Hernandez J.J. Tecnologías de la combustión. Ediciones de la Universidad Castilla-La Mancha, 1998. 


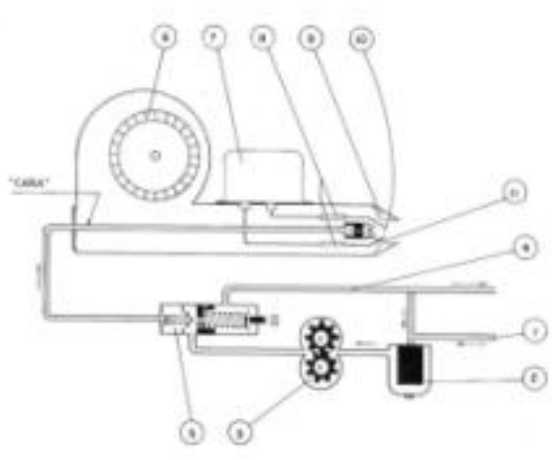

Bomba y circuito de combustible.

1 Alimentación de combustible

2 Filtro

3 Bomba

4 Retorno

5 Regulador de presión

11 Boquilla de pulverización

Ventilador y circuito de aire.

6 Ventilador

9 Distribución de aire

Cabeza de combustión.

10 Cabeza de combustión

Circuito de encendido.

7 Transformador

8 Electrodos de encendido

Figura 5.4: Esquema de quemador de pulverización mecánica por presión.

El quemador utilizado es un quemador comercial de la casa SANTA ANDREA modelo $\mathrm{OI}$, en que puede regularse la presión de inyección y el caudal de aire. Las características del quemador se recogen en la siguiente tabla 5.4:

Tabla 5.4: Características del quemador empleado den el ensayo.

\begin{tabular}{|l|l|l|}
\hline \multicolumn{3}{|l|}{ Quemador SANT'ANDREA modelo OI } \\
\hline Angulo & $\begin{array}{l}\text { Regulación presión de } \\
\text { inyección (bar) }\end{array}$ & $\begin{array}{l}\text { Regulación del caudal de aire } \\
\left(\mathrm{m}^{3} / \mathrm{h}\right)\end{array}$ \\
\hline $60^{\circ}$ & $8-16$ & $2,5-6,3$ \\
\hline
\end{tabular}

Respecto a la boquilla o atomizador empleado se trata de una boquilla Danfoss cuyas características se incluyen en la tabla 5.5: 
Tabla 5.5: Características de la boquilla empleada en el ensayo98.

\begin{tabular}{|l|l|}
\hline \multicolumn{2}{|c|}{ Boquilla Danfoss } \\
\hline Tipo & LN \\
\hline Código & $030 \mathrm{H} 6408$ \\
\hline Capacidad & $0.5 \mathrm{USgal} / \mathrm{h}$ \\
\hline Capacidad USgal/h & $7 \mathrm{bar}, 3.4 \mathrm{cSt}, 820 \mathrm{~kg} / \mathrm{m}^{3}$ \\
\hline Capacidad & $1.65 \mathrm{~kg} / \mathrm{h}$ \\
\hline Capacidad kg/h & $10 \mathrm{bar}, 2.0 \mathrm{cSt}, 820 \mathrm{~kg} / \mathrm{m}^{3}$ \\
\hline Angulo pulverización & $60^{\circ}$ \\
\hline Pulverización & $\mathrm{N}(\mathrm{semi}$ hueco especial) \\
\hline LE & Non \\
\hline Forma & Cónica \\
\hline Peso & 0.03 kilo \\
\hline
\end{tabular}

Para la regulación del aire de entrada, el quemador dispone de un sistema de regulación de aire mediante una clapeta que incrementa la pérdida de carga, tiene varias posiciones que permiten ajustar el aire que entra a la cámara de combustión.

Se ha caracterizado la relación caudal/posición del mecanismo mediante una tobera marca TECNER INGENIERÍA, tobera abierta serie TG-30 y el equipo multifunción KIMO AMI 300 que permite determinar presión diferencial. En la figura 5.5 se observa el montaje para caracterizar el ventilador centrífugo del quemador.

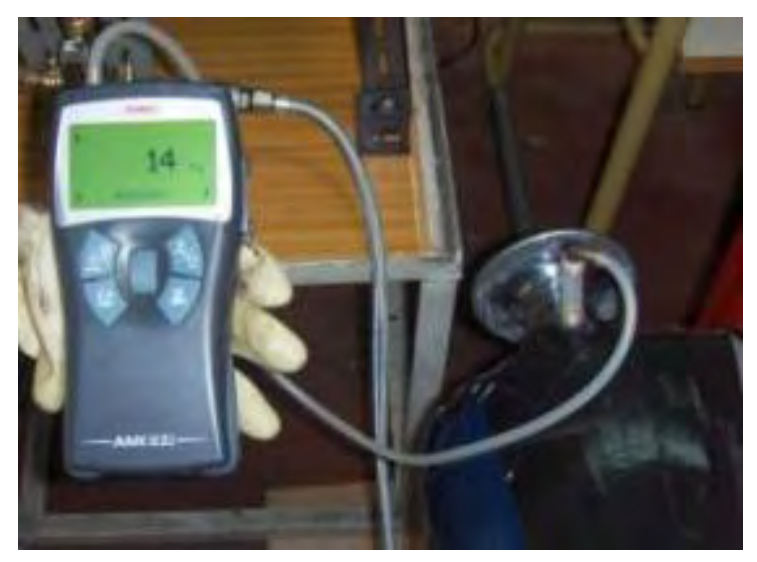

Figura 5.5: Medida del caudal de aire del ventilador en función de la posición del mecanismo de regulación de aire..

98 Danfoss Burner Components, Facts worth knowing about Oil nozzles, ref. $520 F 0019$ DKBG.PG.060.A8.02, 2009. 
La ecuación caudal-pérdida de carga en la tobera es:

$$
G_{V}=0,000265 * \sqrt{\frac{2 * \Delta P}{\rho}}
$$

En la que Gv representa el gasto volumétrico en $\mathrm{m}^{3} / \mathrm{s}, \Delta \mathrm{P}$ es la pérdida de presión en Pascales y $\rho$ la densidad del aire en $\mathrm{kg} / \mathrm{m}^{3}$ 99. Las medidas se realizaron con la instalación a régimen con una presión de inyección de combustible de 16 bar y un tiro en la chimenea entre 0,22 y 0,24 mbar, los resultados se representan en la gráfica siguiente:

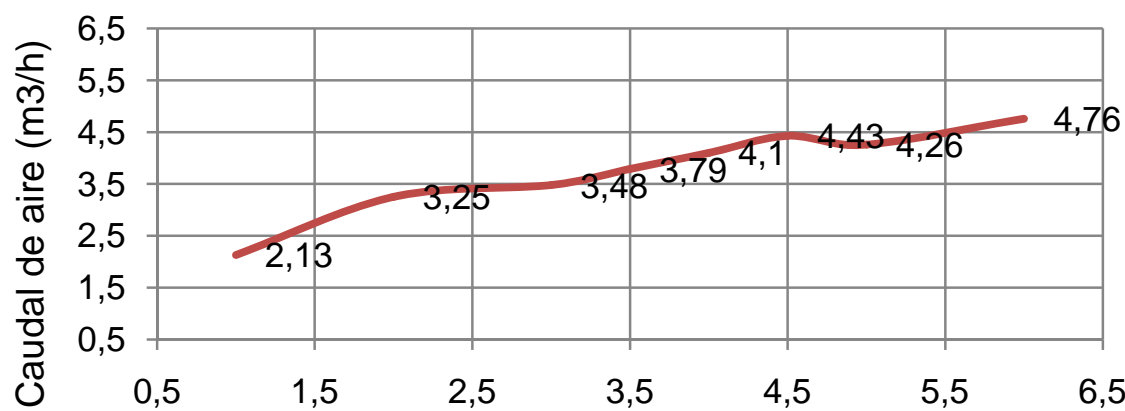

Posición mecanismo de regulación de aire

Gráfica 5.1: Caudal de aire en función de la posición mecanismo de regulación ( $P=16$ Bar)

Los ensayos se han realizado con distintas posiciones del mecanismo de regulación de aire. Las posiciones que se han adoptado para cada una de las presiones de inyección han sido 1,5; 2 y 2,5. Los caudales que corresponden se extraen de la gráfica anterior y corresponden a los datos siguientes:

Tabla 5.6: posición del mecanismo de regulación y caudal de aire al quemador. Coincide con otros capítulos

\begin{tabular}{|l|l|l|l|}
\hline Posición & 1,5 & 2 & 2,5 \\
\hline Caudal $\left(\mathrm{m}^{3} / \mathrm{h}\right)$ & 2.70 & 3,25 & 3,4 \\
\hline
\end{tabular}

Las pruebas a realizar para cada muestra corresponden a tres presiones de inyección (

99 TECNER Ingeniería. Toberas serie TG, Madrid 1999 
10,12 y 14 bar) y tres posiciones de aire para cada una de ellas $(1,5,2$ y 2,5).

Los caudales de aire para cada una de las presiones se indican en la tabla 5.7

Tabla 5.7: Caudales de aire en $\mathrm{m}^{3} / \mathrm{h}$

\begin{tabular}{|l|l|l|l|}
\hline POSICIÓN & \multicolumn{3}{|l|}{ PRESIÓN } \\
\cline { 2 - 4 } MANETA & 10bar & 12 bar & 14 bar \\
\hline 1,5 & 2,5 & 3,0 & 3,5 \\
\hline 2,0 & 3,0 & 3,5 & 4,0 \\
\hline 2,5 & 3.5 & 4,0 & 4,5 \\
\hline
\end{tabular}

La caldera es de cuerpo de hierro fundido, con hogar en sobrepresión. El esquema de la caldera se recoge en la figura 5.8 y las características en la tabla 5.8.
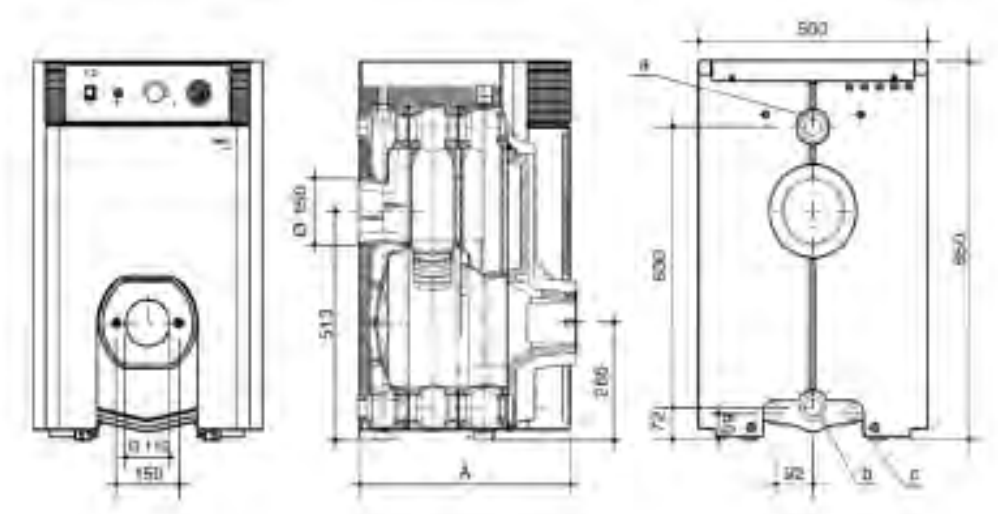

Figura 5.8: Caldera de la instalación experimental

Tabla 5.8: Características de la caldera 100

\begin{tabular}{|l|l|}
\hline Caldera modelo AR/25GT de ROCA \\
\hline Caldera tipo & Fundición \\
\hline Potencia calorífica & $26,7 \mathrm{~kW}$ \\
Capacidad de agua & 26 litros \\
Peso aproximado & $210 \mathrm{~kg}$ \\
Temperatura máxima de trabajo & $110^{\circ} \mathrm{C}$ \\
\hline
\end{tabular}

100 ROCA Catálogo electrónico calefacción 99. Barcelona 1999 


\subsubsection{Instalación de disipación}

La instalación de disipación de calor es una instalación bitubular de retorno directo con distintos elementos finales, para la realización de las medidas se ha escogido dos aerotermos que permiten disipar entre el 80 y $125 \%$ de la potencia nominal de la caldera y que permiten funcionar al quemador a régimen sin paradas en los ensayos cuando la caldera ha alcanzado las condiciones establecidas. El sistema de disipación posee muy poca inercia por lo que los tiempos de puesta a régimen son cortos.

El esquema de la instalación se representa en la figura siguiente:

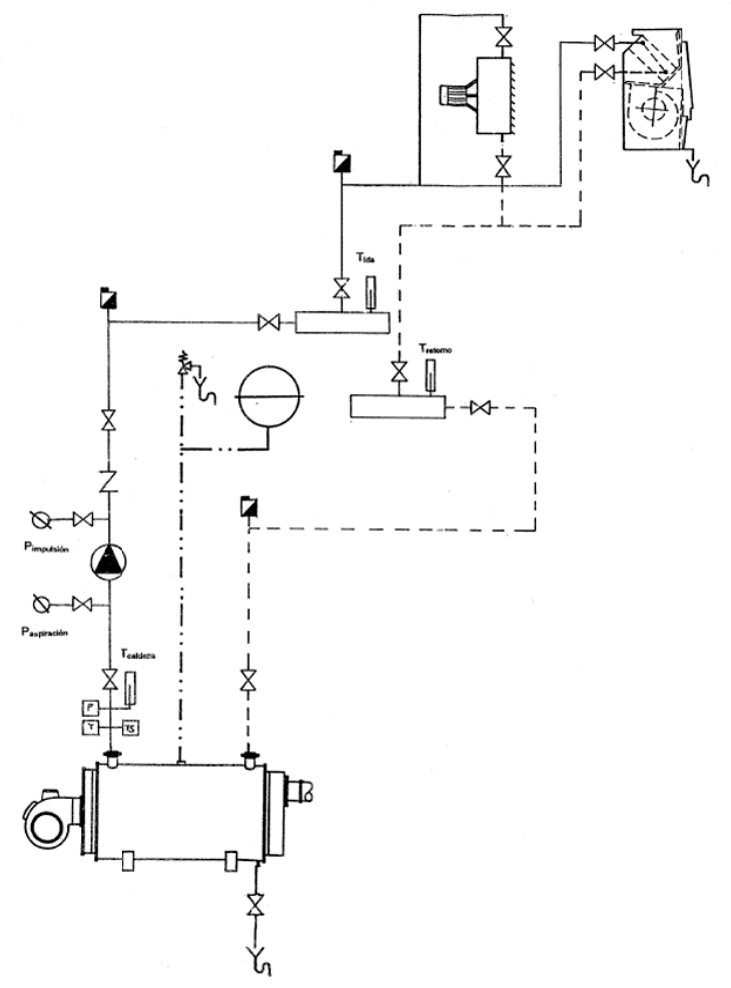

\begin{tabular}{|c|c|c|c|}
\hline \multicolumn{4}{|c|}{ LEYENDA } \\
\hline$-x$ & Válvula de corte & $\theta$ & Vaso de expansión cerrado \\
\hline$-N$ & Vấluula de retención & $\theta$ & Electrobomba de recirculacien de ag̣ua \\
\hline (1) & Purgador de aire & $\$$ & Temómetro \\
\hline 新 & Vâluula de seguridad & $Q$ & Manómetro \\
\hline 一固 & Termostato de seguridad & 阴 & Presostato \\
\hline- & Cireuito de ida & 마- & Termostato \\
\hline -- & Circuito de retorno & $h$ & Desagüe \\
\hline$-\cdots-$ & Cicuito de expansión & & \\
\hline
\end{tabular}

Figura 5.9: Esquema de la instalación de disipación

\subsubsection{Sistema de control y medida}

Las variables de control de la instalación son presiones y temperaturas de toda la instalación. Los valores que permiten mantener la instalación dentro del rango de funcionamiento estacionario se recogen en la tabla 5.9. Todos los ensayos deben realizarse en las mismas condiciones de régimen estacionario por lo que este debe ser alcanzado al comenzar cada serie de ensayos mediante el combustible convencional. 
Tabla 5.9: Parámetros de control de la instalación.

\begin{tabular}{|l|l|l|l|}
\hline Parámetro & Unidad & Error & Descripción \\
\hline Tida & ${ }^{\circ} \mathrm{C}$ & \pm 1 & $\begin{array}{l}\text { Representa la temperatura del agua } \\
\text { en el distribuidor situado en el } \\
\text { circuito de ida }\end{array}$ \\
\hline Tretorno & ${ }^{\circ} \mathrm{C}$ & \pm 1 & $\begin{array}{l}\text { Indica la temperatura del agua en el } \\
\text { colector del retorno, por donde } \\
\text { circula todo el agua antes de volver a } \\
\text { la caldera }\end{array}$ \\
\hline Pimpulsión & bar & $\pm 0,2$ & $\begin{array}{l}\text { Presión del agua en la impulsión en } \\
\text { el circuito principal, justo antes del } \\
\text { distribuidor. }\end{array}$ \\
\hline Paspiración & bar & $\pm 0,2$ & $\begin{array}{l}\text { Presión del agua en la aspiración de } \\
\text { la bomba del agua situada antes de } \\
\text { entrar en el distribuidor. }\end{array}$ \\
\hline Tcaldera & ${ }^{\circ} \mathrm{C}$ & \pm 1 & $\begin{array}{l}\text { Temperatura del agua a su paso por } \\
\text { la caldera. }\end{array}$ \\
\hline$T_{\text {Tamb }}$ & ${ }^{\circ} \mathrm{C}$ & \pm 1 & Temperatura ambiente. \\
\hline
\end{tabular}

Para el análisis de los productos de combustión se utiliza un analizador de gases de combustión, que permite medir la concentración en humos de: oxígeno, monóxido de carbono y óxidos de nitrógeno. El analizador permite así mismo medir presión de tiro en la chimenea y temperatura de humos. Estos datos junto con los datos de características de las muestras permiten el análisis del proceso de combustión.

El analizador de gases de combustión es de la casa TESTO modelo 342-3, este equipo cuenta con sonda de oxígeno, monóxido de carbono y óxidos de nitrógeno. En los anexos se incorpora hojas de calibración del equipo y de las sondas empleadas.

Las principales características del equipo de medición y sondas se recogen en la tabla 5.10. 
Tabla 5.10: Características equipo de medida TESTO modelo 342-3.

\begin{tabular}{|l|l|}
\hline \multicolumn{2}{|l|}{ Analizador de humos TESTO modelo 342-3 } \\
\hline Sonda de $\mathrm{O}_{2}$ electroquímica & Rango 0 \% a 21 \% \\
Sonda de CO (con compensación de & Rango 0 a $4.000 \mathrm{ppm}$. \\
$\mathrm{H})$ & Rango 0 a $3.000 \mathrm{ppm}$ \\
Sonda de NO celda electrolítica & $\mathrm{K}$ \\
\hline Sonda de temperatura (Cinco sondas) \\
\hline Termopar tipo & $-40^{\circ}$ a $1.000^{\circ} \mathrm{C} \pm 0,5^{\circ} \mathrm{C}$ \\
Intervalo de medida & Espiral \\
\hline Sonda de presión (cuatro sondas) & 1 a 40 bar precisión $1 \%$ \\
\hline Manómetros tipo & 0,2 a 1 bar precisión $1 \%$ \\
\hline Intervalo presión impulsión & Intervalo presión aspiración
\end{tabular}

\subsection{METODOLOGÍA DE ENSAYO.}

La primera fase es poner la instalación a régimen lo que se hace con gasóleo, encendida la instalación es necesario alcanzar la temperatura del agua de impulsión a $90^{\circ} \mathrm{C}$ y la de retorno a $70^{\circ} \mathrm{C}$. El calor se disipa en el sistema que se ha descrito anteriormente con los dos aerotermos que se conectan en cascada y en función de las condiciones climatológicas el tiempo medio de puesta a régimen es de unos 30 minutos.

Con la instalación a régimen se ponen las condiciones de presión y caudal de aire elegidas en el quemador y una vez que se ha estabilizado se hace el cambio de combustible de gasóleo a la mezcla correspondiente. Se hace funcionar al menos 120 segundos, tiempo que se considera suficiente para que el gasóleo de la instalación sea quemado y si la instalación está estable se comienza con el proceso de medida.

El proceso de medida se realiza durante 60 segundos, que es el periodo de equilibrio de la sonda de temperatura del analizador y en ese periodo se comprueba que las concentraciones en humos son estables y no hay variaciones bruscas.

Concluida la medida se extraen los datos del analizador mediante un cable con conexión USB al ordenador, se continúan con los ensayos para distintas presiones y posiciones de entrada de aire. Finalizada la serie con una muestra se vuelve al combustible convencional para 
asegurarnos de que al cambiar de mezcla no queda en la instalación rastros de la mezcla anterior. A continuación se cambia de mezcla y se prosigue el ensayo. El esquema de proceso se recoge en el diagrama de bloques de la figura 5.11 .

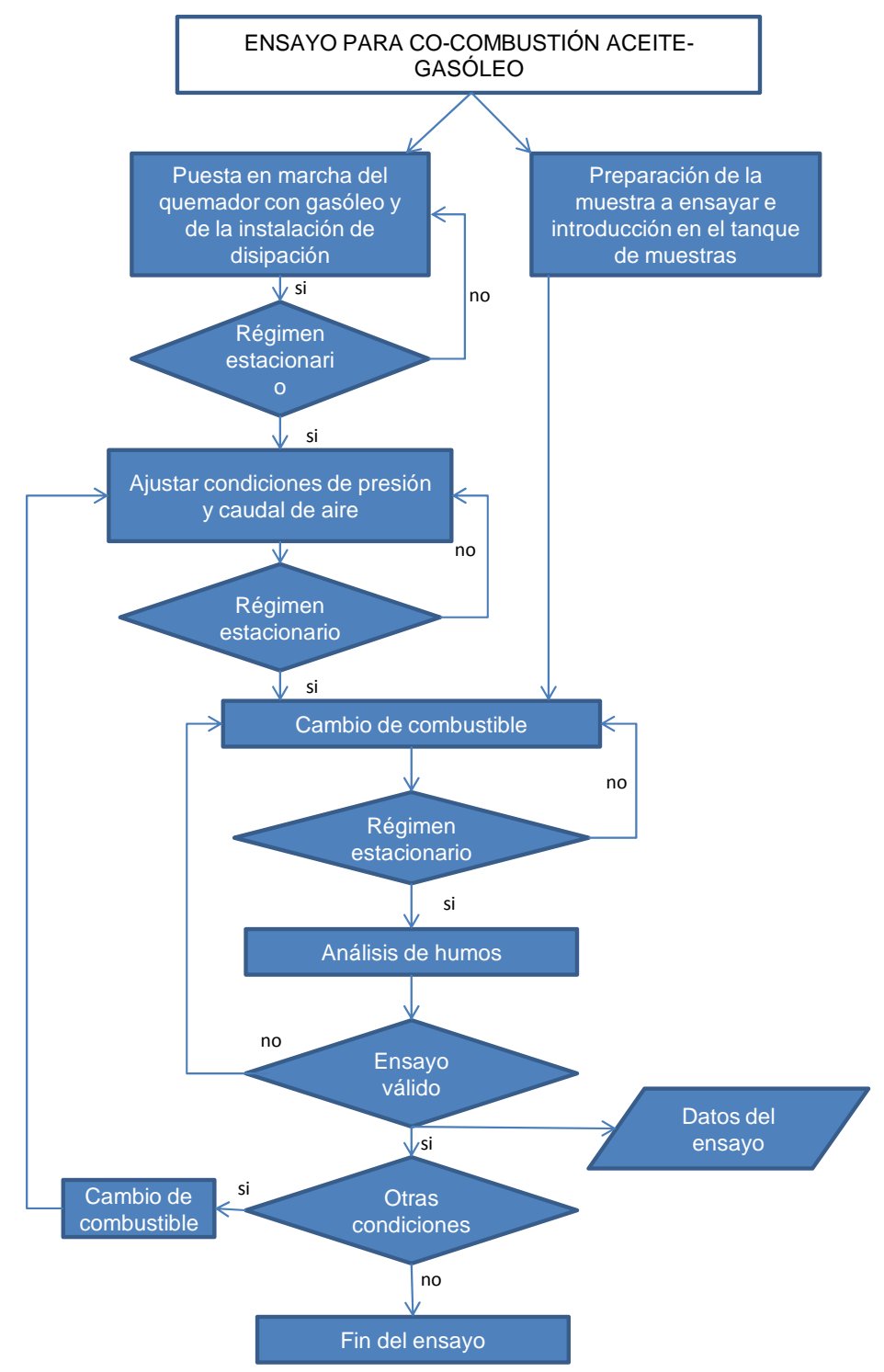

Figura 5.11: Diagrama de bloques del proceso de la metodología de ensayo. 


\section{BIBLIOGRAFÍA CAPÍTULO 6}

96) ITC-MI-IP-03: Instalaciones petrolíferaspara uso propio, instalaciones dealmacenamiento para su consumo en la propia instalación, 1999

97) M.LapuertaM. Hernandez J.J. Tecnologías de la combustión. Ediciones de la Universidad Castilla-La Mancha, 1998.

98) Danfoss Burner Components, Facts worth knowing about Oil nozzles, ref. 520F0019 - DKBG.PG.060.A8.02, 2009.

99) TECNER Ingeniería. Toberas serie TG, Madrid 1999

100) ROCA Catálogo electrónico calefacción 99. Barcelona 1999 


\section{$6.1 \quad$ INTRODUCCIÓN}

El análisis experimental trata de confirmar la influencia de determinados factores en un proceso.

Cualquier determinación experimental va acompañada de un grado de incertidumbre o variabilidad que se pone de manifiesto en la variación de los resultados obtenidos cuando repetimos la prueba experimental. La herramienta estadística trata no solo de medir el grado de incertidumbre, uso inicial de la estadística, sino del análisis e interpretación de los resultados de la experimentación.

La metodología aplicada en la experimentación es fundamental a la hora de obtener resultados concluyentes con el mínimo de pruebas. La experimentación en términos generales es un proceso con costes elevados por lo que es conveniente optimizar los experimentos. Las técnicas estadísticas del DOE (Design of Experiments) va más allá del análisis e interpretación de los resultados ya que nos ayuda a la planificación de los ensayos para que el tratamiento de la información que éstos nos proporcionan sea más consistente y las conclusiones más determinantes.

En términos generales, tratamos de ver la influencia de varios factores en una o varias variable de interés, cuando modificamos deliberadamente sus valores. 


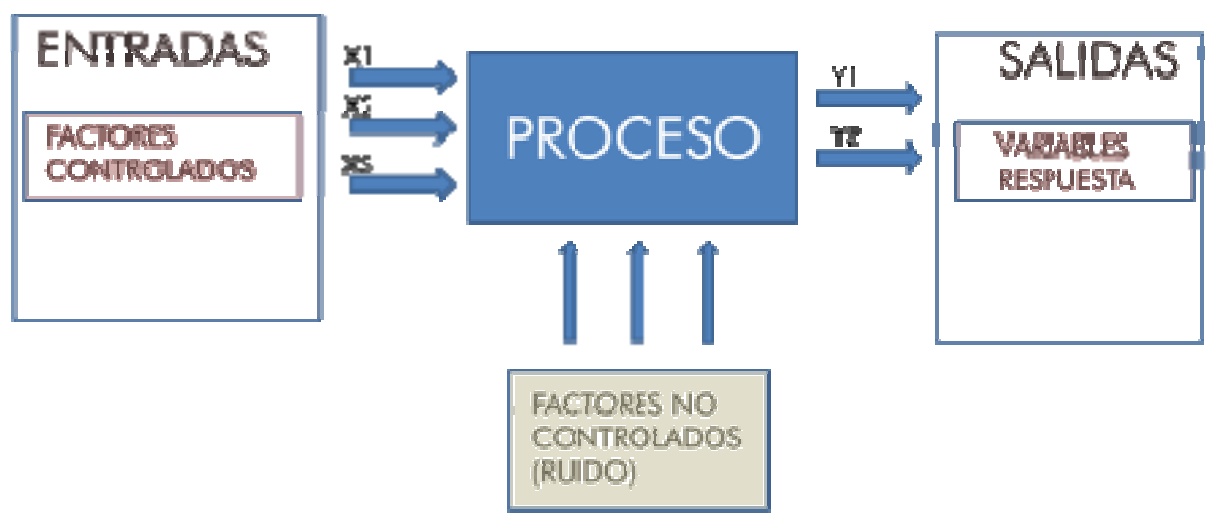

Figura 6.1 Organigrama genérico del DOE

Los objetivos de los experimentos diseñados son:

- Determinar cual son los factores que tienen mayor influencia en la variable respuesta.

- Determinar el mejor valor de los factores controlables (nivel)que proporcione el valor óptimo de la variable respuesta próximo al deseado.

- Determinar la mejor combinación de los valores de los factores controlables que proporcionen menor variabilidad en la respuesta.

- Determinar la combinación adecuada de factores controlados que ayuden a minimizar la influencia de los factores de ruido o incontrolados.

\subsection{DISEÑO DE EXPERIMENTOS}

\subsection{Introducción}

El desarrollo de los métodos del diseño de experimentos se deben a Fisher101 y sus colaboradores Yatesyy Kenneth Mather ${ }^{102} q u e$ desarrollaron los principios de la experimentación científica, el análisis de

101 Ronald A. Fisher. The Desing of Experinments 1935

102 Frank Yates and Kenneth Mather "Ronald Aylmer Fisher". BiographicalMemoirs of Fellows of the Royal Society of London 1963. 
varianza (ANOVA) y el diseño de experimentos(DOE), otros investigadores, han seguido desarrollando técnicas que mejoran y simplifican los modelos, Finney 103 que desarrolló los modelos de regresión de respuesta cualitativa, Cochran ${ }^{104}$ fundamentando matemáticamente el análisis de varianza, etc.

Son muchas las contribuciones en este campo pero la aplicación a los modelos de Calidad Total en la industria ha dado un fuerte impulso a estos métodos, trabajos como el de la metodología de superficies de respuesta (RSM) de Box ${ }^{105}$ y los trabajos de Taguchi ${ }^{106}$ desarrollando la "metodología Taguchi" basada en el concepto de función de pérdida de calidad y la metodología del diseño robusto (MDR) ${ }^{107}$ están evolucionando rápidamente y se aplican tanto en el campo de la Calidad Total en el sector industrial como en el campo científico, consiguiendo una optimización de los experimentos y un aumento en la calidad de los productos.

El desarrollo espectacular en los últimos años de estas técnicas estadísticas ha supuesto la aparición de Sofware informático muy desarrollado con aplicaciones gráficas y módulos específicos para distintas aplicaciones, baste señalar como ejemplos: el programa Minitab de Minitab ${ }^{\circledR}$ Statistical Software, Statgraphics-Centurión de Statgraphics.net, Inspéctor de CGG Soft, etc.

\subsection{Terminología}

En este apartado se resume la terminología que se emplea en los modelos de diseño de experimentos:

- Variable respuesta: es la variable que se desea estudiar y controlar su variabilidad. (Variable de interés o Característica).

o Factor: Variable independiente que puede afectar a la variabilidad de la variable de interés o respuesta.

o Factor de control: Factor controlable del que interesa conocer su influencia en la respuesta.

\footnotetext{
103 D.J.Finney: El método estadístico en el ensayo biológico. Charles Griffin \& Co., 1978

104 William GemmellCochran. Técnicas de muestreo. 1953

105 G.E.P.Box y M.R. Draper. EmpiricalModelBuilding and Response Surface. New York 1987

106 Taquchi, Genichi."IntroductiontoQualityEngineering: DesigningQualityInto

Products and Processes". AsianProductivityOrganization. Tokyo, 1986.

107 RobustEngineering: LearnHowtoBoostQualityWhileReducingCosts\& Time toMarket: por Taguchi, Genichi; Chowdhury, M Subir; Chowdhury 1953
} 
o Factor bloque: Factor controlable del que no interesa conocer su influencia en la respuesta pero si controlarlo para disminuir la variabilidad residual. (Nuisance)

o Factor de ruido: Factorno controlable durante la experimentación.

o Niveles: Cada uno de los valores que puede tomar un factor. Pueden ser de carácter cuantitativo o cualitativo.

o Efecto de un factor: Cambio en la respuesta cuando se modifica un factor.

o Interacción de factores: cuando el efecto de un nivel de un factor varía cuando se modifica el nivel de otro factor. Puede ser generalizado a mas de dos factores dándose interacciones de orden tres o superior.

o Nivel Óptimo: Conjunto de niveles de los factores que proporcionan el mejor resultado sobre la variable respuesta.

o Grado de libertad: número de comparaciones que deben realizarse para determinar el nivel óptimo de un factor. Es el $n^{\circ}$ de niveles menos uno.

o Ortogonalidad: Ensayo en que cada nivel de un factor se ensaya el mismo número de veces con todos los niveles del resto de los factores. Esta condición elimina el efecto sobre la media del resto de las observaciones.

\subsection{Técnicas de diseño de experimentos}

Cuando tratamos de ver el efecto en la respuesta de distintos factores podemos recurrir a distintas técnicas experimentales. Las principales técnicas se presentan a continuación:

\section{- Variar un factor cada vez. (VUFCV).}

Es el método más tradicional y consiste en variar un solo factor manteniendo los demás constantes. Determinado el mejor nivel de ese factor se experimenta con otro factor dejando fijos el resto y así hasta variar todos los factores. Este método no permite determinar la interacción entre factores y no permite determinar el valor óptimo pudiendo dar valores muy alejados de éste.

\section{- Diseño factorial completo.}

En este diseño de experimento se contemplan todas las combinaciones de niveles de los distintos factores de esta forma se obtiene información sobre la interacción de los distintos factores.

El $n^{\circ}$ de experimentos que se precisan es: 


$$
N^{\circ} \text { de experimentos }=\prod_{i=1}^{i=n} N_{i}
$$

Donde $\mathrm{N}_{\mathrm{i}}$ es el $\mathrm{n}^{\circ}$ de niveles del factor $\mathrm{i}$.

Las posibles interacciones entre factores vienen determinadas por el $n^{\circ}$ de combinaciones que se pueden realizar entre los factores. Solo se contemplan habitualmente las interacciones de orden 2 , entre dos factores, despreciándose las interacciones de orden 3 y superior.

La valoración de la interacción entre dos factores puede verse gráficamente, si suponemos un experimento en el que probamos el Factor $\mathrm{A}$ a dos niveles A1; A2 y el factor B para B1 y B2, representando la variable respuesta para estos valores obtenemos:

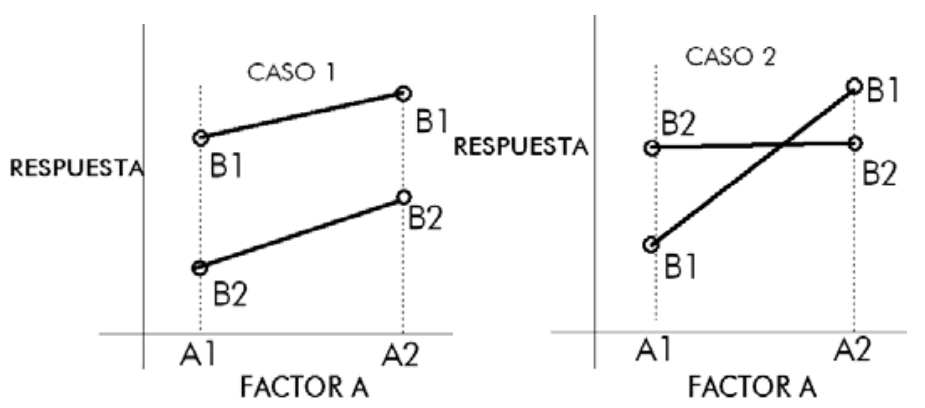

Gráfico 6.1: Posibles situaciones en los niveles de dos factores

En el Caso 1 de la anterior gráfica, la interacción de ambos factores A y B es prácticamente nula, cuanto más paralela sean las rectas menos interacción habrá entre ambas. En el Caso B en el que las rectas se cortan, la interacción es muy grande.

Al haberse hecho el ensayo para todas las combinaciones de factores a cada uno de los posibles niveles, el caso de mayor interacción se habrá contemplado en la experimentación.

\section{- Diseño ortogonal fraccional y arreglos ortogonales.}

El inconveniente de los diseños ortogonales es el elevado número de ensayos que es necesario realizar cuando el número de factores y niveles es elevado. 
El desarrollo de los diseños ortogonales fraccionales, trata de reducir el $n^{\circ}$ de ensayos no considerando las interacciones dobles entre factores por el conocimiento previo del proceso por el que se sabe que no van a ser relevantes en el resultado final.

Estas técnicas empleadas en la metodología Taguchi permiten la reducción del $\mathrm{n}^{\circ}$ de pruebas a realizar sin perder información simplemente determinando aquellas interacciones que van a ser menos significativas por el conocimiento y la experiencia sobre el proceso, son de aplicación cuando tanto el $n^{\circ}$ de factores como niveles es muy elevado apareciendo múltiples combinaciones de interacciones dobles. Las interacciones de orden superior no se consideran en ningún caso.

En la presente tesis doctoral, la reducida selección de los factores controlados y de sus niveles junto a que la experimentación es relativamente barata, vamos a realizar un diseño ortogonal completo corriendo todos los ensayos, asegurándonos que comprenden los experimentos óptimos.

\subsection{FACTORES Y NIVELES}

El objetivo de la presente tesis es el estudio de la combustión de distintos aceites vegetales con gasóleo con distintos porcentajes de mezcla entre ambos. Se quiere obtener la relación más apropiada de factores que proporcionen el mejor rendimiento de la combustión con condiciones medioambientales aceptables.

Establecemos dos tipos de factores:

Factores cualitativos: tipo de aceite empleado

Factores cuantitativos: porcentaje de mezcla; presión de inyección y caudal de aire.

\section{- Tipos de aceite:}

Los experimentos que se van a realizar de mezclas de gasóleo con distintos tipos de aceite, se van a realizar con los aceites vegetales más usuales en nuestro entorno, aceite de colza, aceite de soja crudo, aceite de soja refinado, aceite de girasol crudo, aceite de girasol refinado yaceite usado 
Este factor tiene 6 niveles, al ser cualitativo, no tiene ningún valor significativo salvo su identificación.

Tabla 6.1 Niveles de tipos de aceites vegetales

\begin{tabular}{|l|l|}
\hline NIVEL & IDENTIFICACIÓN \\
\hline Aceite de colza crudo & ACC \\
\hline Aceite de soja crudo & ASC \\
\hline Aceite de soja refinado & ASR \\
\hline Aceite de girasol crudo & AGC \\
\hline Aceite de girasol refinado & AGR \\
\hline Aceite vegetal usado & AVU \\
\hline
\end{tabular}

El factor es un factor controlable, elegido uno de los aceites se procede a realizar la serie completa de ensayos con ese aceite para evitar posibles contaminaciones en las mezclas.

\section{- Porcentaje de aceite vegetal.}

Los porcentajes en las mezclas con gasóleo se van a realizar desde un $10 \%$ hasta un valor máximo del $50 \%$, con incrementos del $10 \%$.

Identificamos la mezcla con el identificador, genéricamente XXX, del aceite de la tabla 6.1, seguido del \% de aceite en la mezcla.

Este factor es también controlable en el experimento y será realizado en orden creciente de porcentaje de mezcla. El valor 0\%, gasóleo puro, nos vale para poner la instalación a régimen aunque este valor no se considera un nivel del factor correspondiente.

Los niveles correspondientes a este factor son:

Tabla 6.2 Niveles de porcentaje de mezcla

\begin{tabular}{|l|l|}
\hline NIVEL & VALOR \\
\hline XXX-10 & $10 \%$ \\
\hline XXX-20 & $20 \%$ \\
\hline$X X X-30$ & $30 \%$ \\
\hline$X X X-40$ & $40 \%$ \\
\hline
\end{tabular}




\section{- Presión de inyección.}

La presión de inyección, como hemos visto en el capítulo IV, tiene influencia en el proceso de atomización del combustible, como la atomización también está relacionada con la viscosidad vamos a variar los valores de la presión de inyección para poder observar las consecuencias en la respuesta de este factor.

La presión de inyección nos modifica el caudal de combustible inyectado por lo que, para una misma boquilla, nos modifica las condiciones de aire mínimo que son controladas en el factor siguiente.

La selección de la presión se hace controlando manualmente en la bomba de inyección la válvula de retorno. La presión es medida por un manómetro y se varía también en orden creciente.

Los distintos niveles de este factor se caracterizan en la siguiente tabla:

Tabla 6.3 Niveles de presión de inyección.

\begin{tabular}{|l|l|}
\hline NIVEL & VALOR \\
\hline P-10 & 10 bar \\
\hline P-12 & 12 bar \\
\hline P-14 & 14 bar \\
\hline
\end{tabular}

\section{- Caudal de aire.}

El caudal de aire es el último factor a controlar. Los niveles seleccionados, en combinación con los del factor anterior, garantizan que la combustión se realice correctamente, es decir que por el índice de opacidad, el porcentaje de inquemados no sea elevado por falta de aire y que el aire en exceso no suponga una bajada importante del rendimiento de la combustión.

Optamos por tres niveles de posición de la maneta de aire para cada valor de la presión, que corresponden a los caudales de aire tasados que se expusieron en el capítulo V, las posiciones correspondientes originan los siguientes niveles para este factor:

Tabla 6.4 Niveles de caudal de aire

\begin{tabular}{|l|l|l|l|}
\hline NIVEL & 10Bar & 12Bar & 14Bar \\
\hline Q-1 & $2,50 m^{3} / \mathrm{h}$ & $3,00 m^{3} / \mathrm{h}$ & $3,50 m^{3} / \mathrm{h}$ \\
\hline Q-2 & $3,00 m^{3} / \mathrm{h}$ & $3,50 \mathrm{~m}^{3} / \mathrm{h}$ & $4,00 m^{3} / \mathrm{h}$ \\
\hline
\end{tabular}




\section{\begin{tabular}{|l|l|l|l|}
\hline Q-3 & $3,50 \mathrm{~m}^{3} / \mathrm{h}$ & $4,00 \mathrm{~m}^{3} / \mathrm{h}$ & $4,50 \mathrm{~m}^{3} / \mathrm{h}$ \\
\hline
\end{tabular}}

Como factor sustitutivo del caudal de aire, se podría haber seleccionado el índice de exceso de aire, pero el dispositivo experimental no permite trabajar con elevada precisión para fijar el caudal de aire necesario para las distintas mezclas y composición de aceites. Esta manera de operar permite desarrollar siempre los experimentos con el mínimo caudal, lo que no se podría asegurar si el factor elegido hubiese sido el índice de exceso de aire, aumentando el error asociado al desarrollo experimental.

Como podemos observar hemos fijado un orden para la ejecución de los ensayos, no hemos adoptado el criterio de aleatoriedad que se recomienda para el orden de ejecución de ensayos. La influencia de los factores no controlados o factores bloque y de los errores por factores no identificados quedan minimizados en este tipo de experimentos al conservar condiciones similares de ejecución para todos ellos. El haberlos en orden aleatorio además de un mayor tiempo de ejecución de los mismos comportaría mayor posibilidad de introducción de errores.

Otra característica de estos ensayos es que son únicos, es decir no se repite ninguno de ellos salvo el correspondiente a porcentaje $0 \%$ de aceite que no se usa como nivel en el factor \% de aceite lo utilizamos como referencia para alcanzar el estado permanente y valor de prueba confirmar el correcto estado de los componentes y elementos de control y medida.

\subsection{MATRIZ DE EXPERIMENTOS}

Determinados los factores a controlar y los niveles de cada uno de ellos podemos formar la matriz de experimentos, el diseño el experimento es ortogonal con lo que cada nivel de cada factor es ensayado el mismo $\mathrm{n}^{\circ}$ de veces con cada uno de los niveles de los factores restantes.

El conjunto de todos los factores controlados y sus respectivos niveles se muestra en la siguiente tabla:

Tabla 6.5 Factores y niveles de los experimentos.

\begin{tabular}{|l|l|l|l|}
\hline ACEITE & \%MEZCLA & P.inyección & Caudal de aire \\
\hline ACC & $10 \%$ & $10 \mathrm{bar}$ & Q1 \\
\hline ASC & $20 \%$ & $12 \mathrm{bar}$ & Q2 \\
\hline ASR & $30 \%$ & $14 \mathrm{bar}$ & Q3 \\
\hline
\end{tabular}




\begin{tabular}{|l|l|l|l|}
\hline AGC & $40 \%$ & & \\
\cline { 1 - 1 } AGR & & & \\
\cline { 1 - 1 } AVU & & & \\
\hline
\end{tabular}

Como se ha dicho anteriormente no se ha recurrido a establecer un orden aleatorio para la realización de los experimentos sino que se ha programado un orden secuencial, que facilita la ejecución de los mismos, garantizando el que los factores bloque y los factores ruido aportan una variabilidad mínima.

El orden de ejecución se hace de forma que la complejidad del cambio de experimento sea mínima:

- Se utiliza un tipo de aceite, realizando las mezclas en las distintas proporciones que se indican en los ensayos.

- Se varía la presión de inyección para cada uno de los tipos de mezcla.

- Se varía la posición de la maneta de aire para cada una de las presiones de inyección.

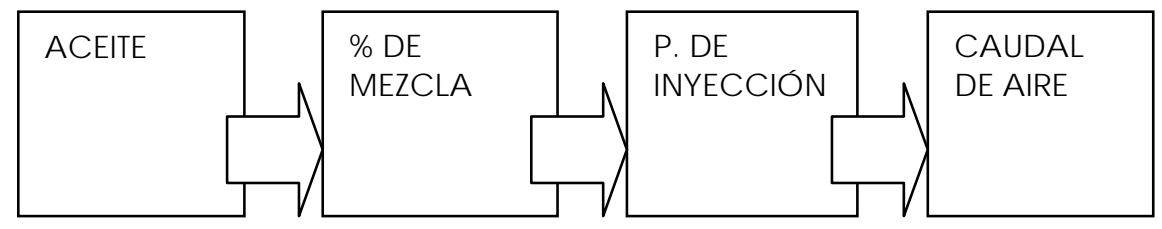

Figura 6.2: Secuencia de variación de factores

El número de experimentos a realizar para conservar la ortogonalidad será:

$$
6 \times 4 \times 3 \times 3=216
$$

La matriz de ensayos para todos los aceites será: 
Tabla 6.6: Matriz de ensayos a realizar para todos los aceites.

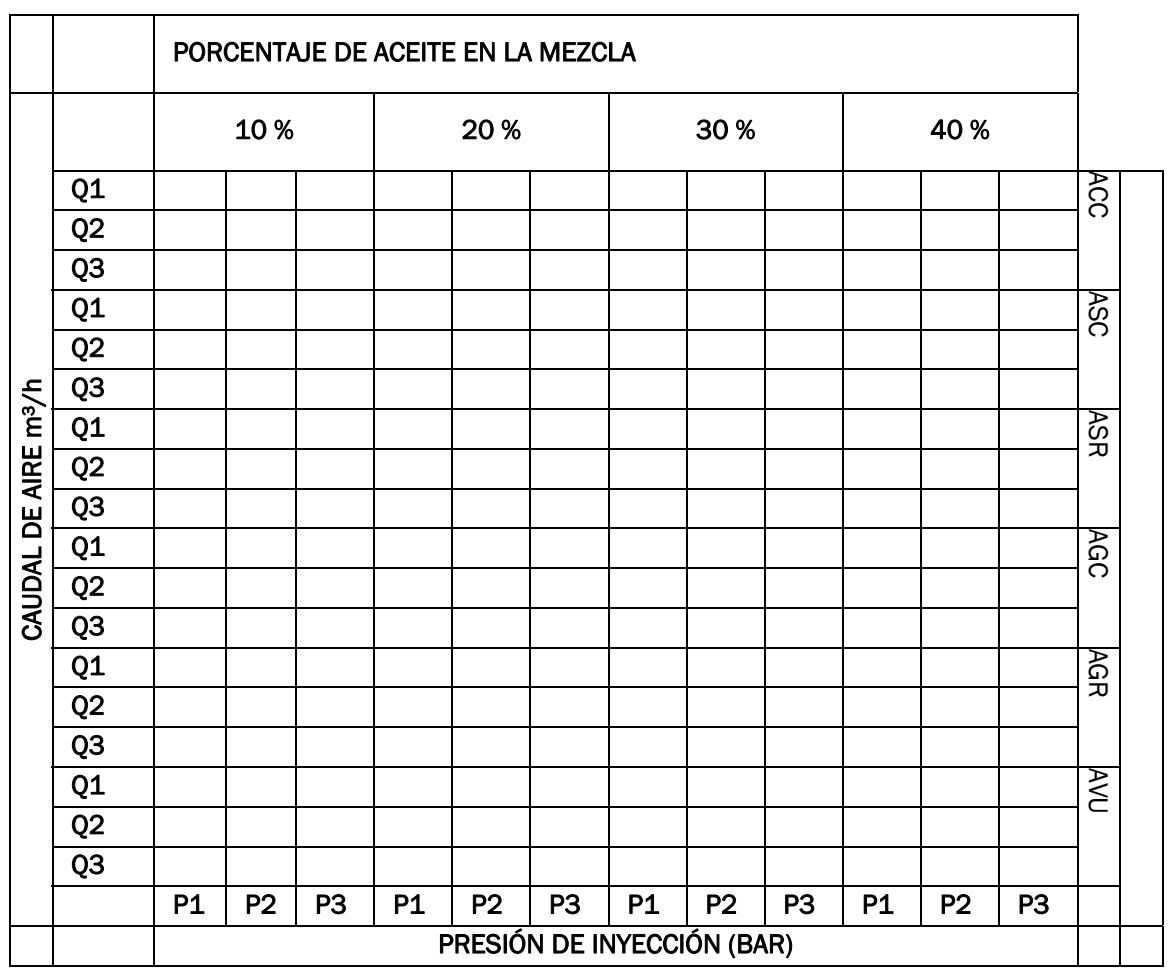

Los resultados que se han analizado en cada ensayo se recogen en la tabla siguiente: 
Tabla 6.7: Datos que se registran en cada ensayo.

\begin{tabular}{|l|}
\hline $\mathrm{O}_{2}$ \\
Exceso Aire \\
$\mathrm{CO}_{2}$ \\
$\mathrm{CO}$ \\
$\mathrm{NO}$ \\
$\mathrm{NO}_{2}$ \\
$\mathrm{NO}_{x}$ \\
$\mathrm{SO}_{2}$ \\
$\mathrm{CxH}_{\mathrm{H}}$ \\
$\mathrm{T}^{\mathrm{a}}$ Ambiente \\
$\mathrm{T}^{\mathrm{a}}$ Humos \\
Pér.por chimenea \\
\\
$\mathrm{H}_{2}$ \\
$\mathrm{O}_{2}$ ref (gasóleo C) \\
CO \\
máx (gasóleo \\
$\mathrm{C}$ ) \\
$\mathrm{Punto}$ rocío \\
$\mathrm{REN}$ \\
Escala Bacharat
\end{tabular}




\section{BIBLIOGRAFÍA CAPÍTULO 6}

101) Ronald A. Fisher. The Desing of Experinments 1935

102) Frank Yates and Kenneth Mather "Ronald Aylmer Fisher". Biographical Memoirs of Fellows of the Royal Society of London 1963.

103) D.J.Finney: El método estadístico en el ensayo biológico. Charles Griffin \& Co., 1978

104) William Gemmell Cochran. Técnicas de muestreo. 1953

105) G.E.P.Box y M.R. Draper. Empirical Model Building and Response Surface. New York 1987

106) Taquchi, Genichi."Introductionto Quality Engineering: Designing Qualitylnto

Products and Processes". Asian Productivity Organization. Tokyo, 1986.

107) RobustEngineering: Learn Howto Boost QualityWhile Reducing Costs\& Time to Market: por Taguchi, Genichi; Chowdhury, M Subir; Chowdhury 1953 


\section{CAPITULO 7 \\ MEDIDAS EXPERIMENTALES}

\subsection{INTRODUCCIÓN}

En este capítulo se presentan los resultados obtenidos en la parte experimental de esta tesis, que consiste en la combustión de las mezclas en diferentes condiciones de funcionamiento del quemador y el análisis de los humos resultantes de su combustión.

Se inicia estableciendo las condiciones de funcionamiento de la instalación, que permiten considerar régimen estacionario y los criterios aplicados en la recogida de datos.

Luego se presenta un análisis previo de los resultados en función de: las emisiones de gases contaminantes, en concreto del monóxido de carbono y los óxidos de nitrógeno; el rendimiento de combustión de las mezclas en diferentes condiciones de funcionamiento del quemador y finalmente, las emisiones de gases de efecto invernadero clasificadas según sean de origen fósil y de origen no fósil. 


\subsection{PROCESO DE ENSAYOS}

Los ensayos se realizan en régimen estacionario, para ello, las condiciones de funcionamiento de la instalación y del generador deben ser las mismas en todos los ensayos, estas condiciones han sido:

- $\quad$ Temperatura del cuerpo de caldera entre 85 y $90^{\circ} \mathrm{C}$.

- $\quad$ Temperatura del laboratorio entre 22 y $24^{\circ} \mathrm{C}$.

- $\quad$ El tiro de la chimenea $8 \mathrm{~mm}$ de c. a.

- $\quad$ El quemador debe funcionar de forma ininterrumpida.

El ensayo requiere un tiempo de arranque de la instalación, y que sea realizado con gasóleo, lo cual permite alcanzar a la instalación y al generador las condiciones adecuadas.

Durante ese tiempo, se prepara la mezcla con el tipo de grasa que corresponda y con el gasóleo como se ha descrito en el capítulo 4, para que sea una mezcla homogénea y una vez realizada la mezcla en el porcentaje de peso fijado se mantiene en agitación, que permite asegurar la homogeneidad de la mezcla.

A continuación se ajusta el caudal de aire de combustión y la presión de inyección de la mezcla para cada caso a estudio, mezcla de un aceite vegetal con gasóleo en un porcentaje determinado y se realiza la serie de ensayos para una muestra concreta.

El tiempo estimado para ensayar una mezcla de un tipo de aceite vegetal con gasóleo en un porcentaje determinado, para los tres caudales de aire y las tres presiones de inyección es de 90 minutos, donde el $88 \%$ es tiempo de estabilización del proceso de combustión, en esta tesis se han realizado tres ensayos por cada caso y sólo se han aceptado aquellos que estaban dentro del grado de error de los sensores respecto al valor medio de las medidas. En los ensayos el periodo menor para una mezcla fue de 90 minutos y el mayor fue de 120 minutos, al darse inestabilidades en los ensayos.

En cada ensayo se obtienen las siguientes variables de interés, mediante el analizador de humos descrito en el capítulo 5:

- 02 en humos (\% en volumen)

- CO en humos (ppm)

- Temperatura de humos (TH)

- Temperatura de entrada del aire ambiente (TA)

- NOx en humos (ppm) 
Concluidos los ensayos se realizaba una limpieza del tanque de alimentación y del circuito de combustible y se realizaban tres medidas de combustión de gasóleo puro para determinar si el inyector necesitaba ser cambiado o ajustar el plato difusor del quemador.

\subsection{PROBLEMÁTICA EN LA FASE DE EXPERIMENTACIÓN DE LOS ENSAYOS}

Durante la realización de los ensayos preliminares se han observado ciertas dificultades, tal y como se predijo en el diseño de experimentos, ya que existen ciertas restricciones entre las variables de estudio que no permiten realizar correctamente todos los ensayos.

Debido al alto porcentaje de oxígeno que contienen los aceites vegetales ha resultado imposible la realización de los ensayos para porcentajes de aceites superiores al $40 \%$, ya que la combustión tenía un exceso de aire extremadamente alto que producía el apagado de la llama. Por ello se decide eliminar la realización de la experimentación para todos los aceites con porcentaje del $50 \%$.

En cuanto al resto de restricciones comentadas en el diseño de experimentos, se decidió no tenerlas en cuenta y realizar todos los ensayos, por lo que, los ensayos realizados han sido 216.

La obstrucción de filtros ha sido un grave problema que ha requerido realizar un filtrado previo a las muestras de aceite vegetal usado.

Otra limitación del proceso de ensayo es la homogeneidad en el tiro de la chimenea, que se ve influenciada por las condiciones climatológicas, si bien esta influencia no representa graves problemas en el proceso de combustión y ha obligado a aplazarlos procesos de ensayo.

\subsection{TOMA DE DATOS}

En las Tablas 7.2, 7.3, 7.4, 7.5, 7.6 y 7.7 se presentan los resultados de los 216 ensayos en los que se han cumplido las siguientes condiciones:

- Condiciones estacionarias de funcionamiento de la caldera. 
- $\quad$ Caudal de aire y presión de inyección del combustible ajustado al ensayo.

- Funcionamiento ininterrumpido de la instalación para cada mezcla.

- Los valores de cada ensayo están dentro de los límites del error del equipo de medida.

En las Tablas se especifica el tipo de aceite, el porcentaje de la mezcla aceite gasóleo, la presión de inyección de la mezcla en bares, la posición del mecanismo de regulación del caudal de aire, las partes por millón en humos de $\mathrm{CO}$, el porcentaje de oxígeno en humos, la temperatura de los humos, la temperatura ambiental o de referencia y la concentración de óxidos de nitrógeno en humos y el índice de opacidad de los humos.

\subsection{ANÁLISIS DE COMBUSTIÓN}

El análisis de los productos de la combustión se ha realizado sobre tres aspectos:

- Emisiones de gases contaminantes.

- Eficiencia de combustión

- $\quad$ Gases de efecto invernadero.

\subsubsection{Emisiones de gases contaminantes}

Respecto a las emisiones de gases contaminantes se estudia las emisiones de monóxido de carbono, óxidos de nitrógeno y opacidad y se considera aceptable aquellas combustiones en que la concentración en humos en ppm del CO y NOx y opacidad son inferiores a los valores de la Tabla 7.1, que son los límites impuestos por la normativa actual expuesta en el capítulo 4 de la tesis.

Tabla 7.1: Límites para considerar una combustión sin problemas de contaminación.

\begin{tabular}{|l|l|}
\hline Compuesto & Límite superior \\
\hline CO & $500 \mathrm{ppm}$ \\
\hline NOx & $300 \mathrm{ppm}$ \\
\hline Opacidad & 3 \\
\hline
\end{tabular}

Los valores experimentales que superan estos valores se han presentado sobre un fondo gris. Estas combustiones son inaceptables medioambientalmente por lo que habría que estudiar la forma de regular el quemador para disminuir el porcentaje en humos de $\mathrm{CO}$ y la opacidad. 


\subsubsection{Eficiencia de la combustión}

La eficiencia de combustión o rendimiento de combustión representa la cantidad de energía que se transfiere al sistema térmico.

Los valores del rendimiento de combustión se representan en las Tablas $7.8,7.9,7.10,7.11,7.12$ y 7.13 , para cada mezcla en función de la presión de inyección y el caudal de aire. El valor del rendimiento se ha calculado con la hoja Excel y las expresiones descritas en el capítulo 4.

Los resultados obtenidos son similares a los obtenidos con la combustión de gasóleo, hay que destacar que los aceites tienen un PCI menor que el gasóleo y por lo tanto la energía liberada por unidad de masa es menor en el proceso de combustión, sin embargo los aceites poseen en su composición un porcentaje mayor de oxígeno y por lo tanto requiere menor caudal de aire, lo que reduce las pérdidas por humos, estos dos fenómenos juntos justifican que los valores de rendimiento de las mezclas y el gasóleo sean similares.

\subsubsection{Gases de efecto invernadero}

Los gases de efecto invernadero considerados en esta tesis son las emisiones de $\mathrm{CO} 2$ asociadas a la combustión del gasóleo, al ser un combustible fósil, puesto que el generado por la combustión de los aceites es de origen renovable.

La valoración se ha realizado en función de la composición elemental del gasóleo y los aceites y el porcentaje de mezcla. Este valor se recoge en las tablas $7.8,7.9,7.10,7.11,7.12$ y 7.13 y se indica los $\mathrm{kg}$ de $\mathrm{CO} 2$ emitidos en una combustión completa por $\mathrm{kg}$ de combustible, diferenciando entre los originados por el gasóleo origen fósil y los originados por el aceite origen no fósil. 


\subsection{RESULTADOS}

Tabla 7.2: Análisis de combustión de la mezclas de gasóleo y aceite de colza

\begin{tabular}{|c|c|c|c|c|c|c|c|}
\hline Mezcla & $\begin{array}{l}\text { Presión de } \\
\text { inyección } \\
\text { (bar) }\end{array}$ & $\begin{array}{c}\text { Posición rejilla } \\
\text { de aire }\end{array}$ & CO (ppm) & $\begin{array}{l}02 \\
(\%)\end{array}$ & $\begin{array}{c}\text { NOx } \\
(\%)\end{array}$ & $\begin{array}{l}\text { Opcid. } \\
\text { (IB) }\end{array}$ & $\begin{array}{l}\text { Th } \\
\left({ }^{\circ} \mathrm{C}\right)\end{array}$ \\
\hline \multirow{9}{*}{ ACC-10 } & \multirow{3}{*}{10} & 2,5 & 229 & 10,3 & 26 & 7 & 209,6 \\
\hline & & 3,0 & 300 & 10,5 & 26 & 5 & 216,6 \\
\hline & & 3,5 & 380 & 10,8 & 24 & 3 & 227,4 \\
\hline & \multirow{3}{*}{12} & 3,0 & 156 & 9,8 & 30 & 5 & 225,0 \\
\hline & & 3,5 & 121 & 10 & 30 & 3 & 227,5 \\
\hline & & 4,0 & 178 & 10,4 & 26 & 1 & 226,5 \\
\hline & \multirow{3}{*}{14} & 3,5 & 66 & 9,5 & 33 & 3 & 234,6 \\
\hline & & 4,0 & 57 & 9,8 & 31 & 1 & 236,7 \\
\hline & & 4,5 & 84 & 10,2 & 28 & 0 & 238,6 \\
\hline \multirow{9}{*}{ ACC-20 } & \multirow{3}{*}{10} & 2,5 & 144 & 9,6 & 31 & 7 & 200,0 \\
\hline & & 3,0 & 208 & 10,1 & 28 & 5 & 211,0 \\
\hline & & 3,5 & 300 & 10,5 & 25 & 2 & 218,0 \\
\hline & \multirow{3}{*}{12} & 3,0 & 93 & 9,4 & 34 & 6 & 232,0 \\
\hline & & 3,5 & 87 & 9,8 & 33 & 3 & 229,0 \\
\hline & & 4,0 & 137 & 10,2 & 30 & 1 & 231,7 \\
\hline & \multirow{3}{*}{14} & 3,5 & 65 & 9,3 & 36 & 4 & 238,0 \\
\hline & & 4,0 & 46 & 9,7 & 34 & 2 & 240,0 \\
\hline & & 4,5 & 60 & 10,1 & 31 & 1 & 243,5 \\
\hline \multirow{9}{*}{ ACC-30 } & \multirow{3}{*}{10} & 2,5 & 210 & 9,7 & 29 & 6 & 223,0 \\
\hline & & 3,0 & 279 & 10,3 & 28 & 4 & 223,0 \\
\hline & & 3,5 & 324 & 10,4 & 24 & 2 & 229,0 \\
\hline & \multirow{3}{*}{12} & 3,0 & 53 & 9,1 & 38 & 5 & 224,0 \\
\hline & & 3,5 & 56 & 9,5 & 37 & 3 & 237,0 \\
\hline & & 4,0 & 81 & 9,9 & 34 & 1 & 239,0 \\
\hline & \multirow{3}{*}{14} & 3,5 & 44 & 9 & 39 & 4 & 244,0 \\
\hline & & 4,0 & 34 & 9,4 & 40 & 2 & 247,0 \\
\hline & & 4,5 & 46 & 9,9 & 36 & 0 & 250,0 \\
\hline \multirow{9}{*}{ ACC-40 } & \multirow{3}{*}{10} & 2,5 & 95 & 9,4 & 35 & 4 & 210,0 \\
\hline & & 3,0 & 125 & 9,9 & 33 & 6 & 220,0 \\
\hline & & 3,5 & 200 & 10,4 & 28 & 3 & 226,0 \\
\hline & \multirow{3}{*}{12} & 3,0 & 47 & 9,1 & 40 & 5 & 230,0 \\
\hline & & 3,5 & 39 & 9,4 & 38 & 2 & 238,0 \\
\hline & & 4,0 & 52 & 9,7 & 35 & 1 & 242,0 \\
\hline & \multirow{3}{*}{14} & 3,5 & 23 & 8,9 & 41 & 4 & 247,0 \\
\hline & & 4,0 & 22 & 9,3 & 40 & 2 & 250,0 \\
\hline & & 4,5 & 29 & 9,7 & 37 & 1 & 254,0 \\
\hline
\end{tabular}


Tabla 7.3: Análisis de combustión de la mezclas de gasóleo y aceite de soja crudo.

\begin{tabular}{|c|c|c|c|c|c|c|c|}
\hline Mezcla & $\begin{array}{l}\text { Presión de } \\
\text { inyección } \\
\text { (bar) }\end{array}$ & $\begin{array}{l}\text { Posición } \\
\text { rejilla de aire }\end{array}$ & $\begin{array}{c}\mathrm{CO} \\
(\mathrm{ppm})\end{array}$ & $\begin{array}{l}\mathrm{O}_{2} \\
(\%)\end{array}$ & $\begin{array}{l}\mathrm{NO}_{\mathrm{x}} \\
(\%)\end{array}$ & $\begin{array}{l}\text { Opcid. } \\
\text { (IB) }\end{array}$ & $\begin{array}{l}\text { Th } \\
\left({ }^{\circ} \mathrm{C}\right)\end{array}$ \\
\hline \multirow{9}{*}{ ASC-10 } & \multirow{3}{*}{10} & 2,5 & 26 & 9,8 & 22 & 7 & 210,0 \\
\hline & & 3,0 & 19 & 10,1 & 20 & 4 & 213,0 \\
\hline & & 3,5 & 17 & 10,6 & 18 & 2 & 217,0 \\
\hline & \multirow{3}{*}{12} & 3,0 & 44 & 9,6 & 25 & 5 & 229,0 \\
\hline & & 3,5 & 47 & 9,9 & 23 & 2 & 227,0 \\
\hline & & 4,0 & 44 & 10,3 & 20 & 1 & 228,0 \\
\hline & \multirow{3}{*}{14} & 3,5 & 55 & 9,5 & 26 & 3 & 234,0 \\
\hline & & 4,0 & 56 & 9,7 & 24 & 1 & 239,0 \\
\hline & & 4,5 & 53 & 10,1 & 21 & 0 & 240,0 \\
\hline \multirow{9}{*}{ ASC-20 } & \multirow{3}{*}{10} & 2,5 & 24 & 10,0 & 20 & 7 & 209,0 \\
\hline & & 3,0 & 25 & 10,5 & 18 & 4 & 217,0 \\
\hline & & 3,5 & 22 & 10,9 & 15 & 2 & 218,0 \\
\hline & \multirow{3}{*}{12} & 3,0 & 51 & 9,4 & 27 & 5 & 229,0 \\
\hline & & 3,5 & 61 & 9,9 & 25 & 2 & 228,0 \\
\hline & & 4,0 & 60 & 10,3 & 22 & 1 & 230,0 \\
\hline & \multirow{3}{*}{14} & 3,5 & 69 & 9,6 & 27 & 3 & 235,0 \\
\hline & & 4,0 & 69 & 9,9 & 25 & 1 & 238,0 \\
\hline & & 4,5 & 66 & 10,2 & 23 & 0 & 241,0 \\
\hline \multirow{9}{*}{ ASC-30 } & \multirow{3}{*}{10} & 2,5 & 42 & 10,0 & 23 & 7 & 208,0 \\
\hline & & 3,0 & 39 & 10,1 & 23 & 4 & 222,0 \\
\hline & & 3,5 & 37 & 10,4 & 20 & 1 & 226,0 \\
\hline & \multirow{3}{*}{12} & 3,0 & 48 & 9,4 & 28 & 4 & 235,0 \\
\hline & & 3,5 & 49 & 9,7 & 28 & 3 & 235,0 \\
\hline & & 4,0 & 47 & 10,0 & 25 & 1 & 236,0 \\
\hline & \multirow{3}{*}{14} & 3,5 & 50 & 9,2 & 31 & 3 & 241,0 \\
\hline & & 4,0 & 51 & 9,5 & 30 & 2 & 245,0 \\
\hline & & 4,5 & 49 & 9,9 & 28 & 1 & 246,0 \\
\hline \multirow{9}{*}{ ASC-40 } & \multirow{3}{*}{10} & 2,5 & 25 & 9,5 & 28 & 7 & 221,0 \\
\hline & & 3,0 & 24 & 9,7 & 26 & 4 & 230,0 \\
\hline & & 3,5 & 23 & 10,0 & 22 & 2 & 234,0 \\
\hline & \multirow{3}{*}{12} & 3,0 & 33 & 9,4 & 31 & 2 & 233,0 \\
\hline & & 3,5 & 35 & 9,5 & 29 & 1 & 241,0 \\
\hline & & 4,0 & 33 & 9,7 & 26 & 0 & 244,0 \\
\hline & \multirow{3}{*}{14} & 3,5 & 36 & 9,2 & 32 & 2 & 250,0 \\
\hline & & 4,0 & 35 & 9,4 & 32 & 1 & 253,0 \\
\hline & & 4,5 & 34 & 9,6 & 30 & 0 & 256,0 \\
\hline
\end{tabular}


Tabla 7.4: Análisis de combustión de la mezclas de gasóleo y aceite de soja refinado.

\begin{tabular}{|c|c|c|c|c|c|c|c|}
\hline Mezcla & $\begin{array}{l}\text { Presión de } \\
\text { inyección } \\
\text { (bar) }\end{array}$ & $\begin{array}{l}\text { Posición } \\
\text { rejilla de aire }\end{array}$ & $\begin{array}{c}\mathrm{CO} \\
(\mathrm{ppm})\end{array}$ & $\begin{array}{c}\mathrm{O}_{2} \\
(\%)\end{array}$ & $\begin{array}{l}\mathrm{NO}_{\mathrm{x}} \\
(\%)\end{array}$ & $\begin{array}{l}\text { Opcid. } \\
\text { (IB) }\end{array}$ & $\begin{array}{l}\text { Th } \\
\left({ }^{\circ} \mathrm{c}\right)\end{array}$ \\
\hline \multirow{9}{*}{ ASR-10 } & \multirow{3}{*}{10} & 2,5 & 2 & 9,8 & 28 & 7 & 206,0 \\
\hline & & 3,0 & 0 & 10,2 & 26 & 4 & 221,0 \\
\hline & & 3,5 & 0 & 10,6 & 23 & 2 & 221,0 \\
\hline & \multirow{3}{*}{12} & 3,0 & 4 & 9,7 & 30 & 5 & 229,0 \\
\hline & & 3,5 & 7 & 10,0 & 28 & 3 & 231,0 \\
\hline & & 4,0 & 6 & 10,2 & 27 & 1 & 233,0 \\
\hline & \multirow{3}{*}{14} & 3,5 & 13 & 9,6 & 32 & 3 & 236,0 \\
\hline & & 4,0 & 17 & 9,9 & 31 & 1 & 243,0 \\
\hline & & 4,5 & 15 & 10,2 & 28 & 0 & 245,0 \\
\hline \multirow{9}{*}{ ASR-O } & \multirow{3}{*}{10} & 2,5 & 2 & 9,9 & 28 & 7 & 217,0 \\
\hline & & 3,0 & 0 & 10,2 & 28 & 4 & 225,0 \\
\hline & & 3,5 & 0 & 10,6 & 25 & 2 & 226,0 \\
\hline & \multirow{3}{*}{12} & 3,0 & 13 & 9,8 & 32 & 6 & 231,0 \\
\hline & & 3,5 & 15 & 10,2 & 31 & 3 & 232,0 \\
\hline & & 4,0 & 13 & 10,4 & 28 & 1 & 235,0 \\
\hline & \multirow{3}{*}{14} & 3,5 & 22 & 9,5 & 35 & 3 & 240,0 \\
\hline & & 4,0 & 23 & 9,8 & 34 & 1 & 243,0 \\
\hline & & 4,5 & 21 & 10,2 & 33 & 0 & 245,0 \\
\hline \multirow{9}{*}{ ASR-30 } & \multirow{3}{*}{10} & 2,5 & 14 & 9,9 & 30 & 6 & 210,0 \\
\hline & & 3,0 & 12 & 10,2 & 31 & 4 & 214,0 \\
\hline & & 3,5 & 8 & 10,5 & 27 & 2 & 224,0 \\
\hline & \multirow{3}{*}{12} & 3,0 & 20 & 9,6 & 35 & 6 & 230,0 \\
\hline & & 3,5 & 23 & 9,9 & 34 & 2 & 234,0 \\
\hline & & 4,0 & 19 & 10,3 & 30 & 1 & 237,0 \\
\hline & \multirow{3}{*}{14} & 3,5 & 25 & 9,4 & 37 & 4 & 240,0 \\
\hline & & 4,0 & 28 & 9,8 & 36 & 2 & 243,0 \\
\hline & & 4,5 & 26 & 10,1 & 34 & 1 & 249,0 \\
\hline \multirow{9}{*}{ ASR-40 } & \multirow{3}{*}{10} & 2,5 & 17 & 9,7 & 34 & 6 & 211,0 \\
\hline & & 3,0 & 14 & 10,0 & 30 & 7 & 221,0 \\
\hline & & 3,5 & 18 & 10,2 & 32 & 6 & 226,0 \\
\hline & \multirow{3}{*}{12} & 3,0 & 29 & 9,1 & 39 & 4 & 237,0 \\
\hline & & 3,5 & 29 & 9,5 & 35 & 2 & 242,0 \\
\hline & & 4,0 & 25 & 9,8 & 30 & 0 & 246,0 \\
\hline & \multirow{3}{*}{14} & 3,5 & 31 & 9,2 & 40 & 2 & 248,0 \\
\hline & & 4,0 & 31 & 9,5 & 38 & 1 & 250,0 \\
\hline & & 4,5 & 29 & 9,9 & 34 & 0 & 253,0 \\
\hline
\end{tabular}


Tabla 7.5: Análisis de combustión de la mezclas de gasóleo y aceite de girasol crudo.

\begin{tabular}{|c|c|c|c|c|c|c|c|}
\hline Mezcla & $\begin{array}{l}\text { Presión de } \\
\text { inyección } \\
\text { (bar) }\end{array}$ & $\begin{array}{l}\text { Posición } \\
\text { rejilla de aire }\end{array}$ & $\begin{array}{c}\mathrm{CO} \\
(\mathrm{ppm})\end{array}$ & $\begin{array}{l}\mathrm{O}_{2} \\
(\%)\end{array}$ & $\begin{array}{l}\mathrm{NO}_{\mathrm{x}} \\
(\%)\end{array}$ & $\begin{array}{l}\text { Opcid. } \\
\text { (IB) }\end{array}$ & $\begin{array}{l}\text { Th } \\
\left({ }^{\circ} \mathrm{C}\right)\end{array}$ \\
\hline \multirow{9}{*}{ AGC-10 } & \multirow{3}{*}{10} & 2,5 & 170 & 10,8 & 22 & 7 & 205,0 \\
\hline & & 3,0 & 230 & 11,1 & 20 & 5 & 209,0 \\
\hline & & 3,5 & 321 & 11,4 & 17 & 2 & 212,0 \\
\hline & \multirow{3}{*}{12} & 3,0 & 90 & 10,6 & 25 & 6 & 219,8 \\
\hline & & 3,5 & 120 & 10,8 & 22 & 3 & 223,2 \\
\hline & & 4,0 & 216 & 11,1 & 19 & 1 & 226,4 \\
\hline & \multirow{3}{*}{14} & 3,5 & 65 & 10,5 & 23 & 2 & 230,7 \\
\hline & & 4,0 & 73 & 10,6 & 22 & 1 & 237,3 \\
\hline & & 4,5 & 133 & 10,8 & 20 & 1 & 239,4 \\
\hline \multirow{9}{*}{ AGC-20 } & \multirow{3}{*}{10} & 2,5 & 150 & 10,6 & 22 & 7 & 206,0 \\
\hline & & 3,0 & 201 & 11,1 & 20 & 5 & 209,0 \\
\hline & & 3,5 & 288 & 11,3 & 18 & 2 & 213,0 \\
\hline & \multirow{3}{*}{12} & 3,0 & 90 & 10,4 & 25 & 5 & 217,0 \\
\hline & & 3,5 & 91 & 10,7 & 23 & 3 & 220,0 \\
\hline & & 4,0 & 144 & 11,1 & 21 & 1 & 225,0 \\
\hline & \multirow{3}{*}{14} & 3,5 & 51 & 10,2 & 26 & 3 & 228,0 \\
\hline & & 4,0 & 50 & 10,5 & 24 & 1 & 234,0 \\
\hline & & 4,5 & 70 & 10,8 & 22 & 1 & 237,0 \\
\hline \multirow{9}{*}{ AGC-30 } & \multirow{3}{*}{10} & 2,5 & 99 & 10,2 & 22 & 7 & 206,0 \\
\hline & & 3,0 & 141 & 10,7 & 20 & 5 & 214,0 \\
\hline & & 3,5 & 254 & 11,0 & 16 & 2 & 224,0 \\
\hline & \multirow{3}{*}{12} & 3,0 & 90 & 10,1 & 25 & 5 & 224,0 \\
\hline & & 3,5 & 75 & 10,5 & 24 & 3 & 227,0 \\
\hline & & 4,0 & 128 & 10,8 & 21 & 1 & 230,0 \\
\hline & \multirow{3}{*}{14} & 3,5 & 38 & 10,1 & 27 & 4 & 234,0 \\
\hline & & 4,0 & 40 & 10,3 & 25 & 2 & 237,0 \\
\hline & & 4,5 & 63 & 10,6 & 24 & 1 & 242,3 \\
\hline \multirow{9}{*}{ AGC-40 } & \multirow{3}{*}{10} & 2,5 & 68 & 10,1 & 24 & 5 & 208,0 \\
\hline & & 3,0 & 64 & 10,4 & 23 & 3 & 216,0 \\
\hline & & 3,5 & 115 & 10,5 & 19 & 1 & 232,0 \\
\hline & \multirow{3}{*}{12} & 3,0 & 35 & 9,7 & 27 & 4 & 232,0 \\
\hline & & 3,5 & 30 & 10,1 & 25 & 2 & 237,0 \\
\hline & & 4,0 & 68 & 10,3 & 22 & 1 & 245,0 \\
\hline & \multirow{3}{*}{14} & 3,5 & 24 & 9,6 & 28 & 4 & 242,0 \\
\hline & & 4,0 & 21 & 9,9 & 27 & 2 & 246,0 \\
\hline & & 4,5 & 36 & 10,2 & 25 & 0 & 252,0 \\
\hline
\end{tabular}


Tabla 7.6: Análisis de combustión de la mezclas de gasóleo y aceite girasol refinado.

\begin{tabular}{|c|c|c|c|c|c|c|c|}
\hline Mezcla & $\begin{array}{l}\text { Presión de } \\
\text { inyección } \\
\text { (bar) }\end{array}$ & $\begin{array}{l}\text { Posición } \\
\text { rejilla de aire }\end{array}$ & $\begin{array}{c}\mathrm{CO} \\
(\mathrm{ppm})\end{array}$ & $\begin{array}{l}\mathrm{O}_{2} \\
(\%)\end{array}$ & $\begin{array}{l}\mathrm{NO}_{\mathrm{x}} \\
(\%)\end{array}$ & $\begin{array}{l}\text { Opcid. } \\
\text { (IB) }\end{array}$ & $\begin{array}{l}\text { Th } \\
\left({ }^{\circ} \mathrm{C}\right)\end{array}$ \\
\hline \multirow{9}{*}{ AGR-10 } & \multirow{3}{*}{10} & 2,5 & 187 & 10,3 & 22 & 6 & 205,0 \\
\hline & & 3,0 & 294 & 10,6 & 21 & 3 & 209,0 \\
\hline & & 3,5 & 450 & 10,8 & 18 & 1 & 212,0 \\
\hline & \multirow{3}{*}{12} & 3,0 & 117 & 9,8 & 27 & 4 & 219,8 \\
\hline & & 3,5 & 140 & 10,3 & 25 & 2 & 223,2 \\
\hline & & 4,0 & 244 & 10,6 & 20 & 1 & 226,4 \\
\hline & \multirow{3}{*}{14} & 3,5 & 70 & 9,8 & 28 & 3 & 230,7 \\
\hline & & 4,0 & 76 & 10,1 & 25 & 1 & 237,3 \\
\hline & & 4,5 & 123 & 10,4 & 23 & 0 & 239,4 \\
\hline \multirow{9}{*}{ AGR-20 } & \multirow{3}{*}{10} & 2,5 & 244 & 10,3 & 24 & 6 & 206,0 \\
\hline & & 3,0 & 384 & 10,8 & 22 & 3 & 209,0 \\
\hline & & 3,5 & 664 & 11,1 & 16 & 2 & 213,0 \\
\hline & \multirow{3}{*}{12} & 3,0 & 159 & 9,9 & 30 & 4 & 217,0 \\
\hline & & 3,5 & 158 & 10,4 & 27 & 3 & 220,0 \\
\hline & & 4,0 & 235 & 10,7 & 24 & 1 & 225,0 \\
\hline & \multirow{3}{*}{14} & 3,5 & 77 & 9,8 & 32 & 3 & 228,0 \\
\hline & & 4,0 & 79 & 10,2 & 28 & 1 & 234,0 \\
\hline & & 4,5 & 122 & 10,5 & 26 & 0 & 237,0 \\
\hline \multirow{9}{*}{ AGR-30 } & \multirow{3}{*}{10} & 2,5 & 252 & 10,1 & 27 & 4 & 206,0 \\
\hline & & 3,0 & 364 & 10,5 & 23 & 3 & 214,0 \\
\hline & & 3,5 & & & & & \\
\hline & \multirow{3}{*}{12} & 3,0 & 41 & 9,3 & 37 & 4 & 224,0 \\
\hline & & 3,5 & 64 & 9,8 & 35 & 2 & 227,0 \\
\hline & & 4,0 & 120 & 10,2 & 31 & 1 & 230,0 \\
\hline & \multirow{3}{*}{14} & 3,5 & 41 & 9,3 & 38 & 4 & 234,0 \\
\hline & & 4,0 & 46 & 9,6 & 36 & 2 & 237,0 \\
\hline & & 4,5 & 79 & 10,0 & 33 & 0 & 242,3 \\
\hline \multirow{9}{*}{ AGR-40 } & \multirow{3}{*}{10} & 2,5 & 96 & 9,7 & 32 & 7 & 208,0 \\
\hline & & 3,0 & 111 & 10,0 & 32 & 6 & 216,0 \\
\hline & & 3,5 & 120 & 10,1 & 33 & 3 & 232,0 \\
\hline & \multirow{3}{*}{12} & 3,0 & 37 & 9,1 & 37 & 6 & 232,0 \\
\hline & & 3,5 & 39 & 9,4 & 36 & 3 & 237,0 \\
\hline & & 4,0 & 77 & 9,6 & 33 & 1 & 245,0 \\
\hline & \multirow{3}{*}{14} & 3,5 & 26 & 9,0 & 40 & 5 & 242,0 \\
\hline & & 4,0 & 24 & 9,2 & 39 & 2 & 246,0 \\
\hline & & 4,5 & 38 & 9,5 & 37 & 1 & 252,0 \\
\hline
\end{tabular}


Tabla 7.7: Análisis de combustión de la mezclas de gasóleo y aceite vegetal usado.

\begin{tabular}{|c|c|c|c|c|c|c|c|}
\hline Mezcla & $\begin{array}{l}\text { Presión de } \\
\text { inyección } \\
\text { (bar) }\end{array}$ & $\begin{array}{l}\text { Posición } \\
\text { rejilla de aire }\end{array}$ & $\begin{array}{c}\mathrm{CO} \\
(\mathrm{ppm})\end{array}$ & $\begin{array}{l}\mathrm{O}_{2} \\
(\%)\end{array}$ & $\begin{array}{l}\mathrm{NO}_{\mathrm{x}} \\
(\%)\end{array}$ & $\begin{array}{l}\text { Opcid. } \\
\text { (IB) }\end{array}$ & $\begin{array}{l}\text { Th } \\
\left({ }^{\circ} \mathrm{C}\right)\end{array}$ \\
\hline \multirow{9}{*}{ AVU-10 } & \multirow{3}{*}{10} & 2,5 & 0 & 9,3 & 31 & 7 & 210,0 \\
\hline & & 3,0 & 0 & 9,7 & 30 & 5 & 223,0 \\
\hline & & 3,5 & 0 & 10,1 & 28 & 2 & 229,0 \\
\hline & \multirow{3}{*}{12} & 3,0 & 0 & 9,2 & 35 & 5 & 232,0 \\
\hline & & 3,5 & 0 & 9,6 & 33 & 2 & 234,0 \\
\hline & & 4,0 & 0 & 9,9 & 31 & 1 & 239,0 \\
\hline & \multirow{3}{*}{14} & 3,5 & 0 & 9,2 & 35 & 2 & 242,0 \\
\hline & & 4,0 & 3 & 9,4 & 35 & 1 & 246,0 \\
\hline & & 4,5 & 5 & 9,8 & 32 & 0 & 249,0 \\
\hline \multirow{9}{*}{ AVU-20 } & \multirow{3}{*}{10} & 2,5 & 0 & 10,0 & 26 & 7 & 210,0 \\
\hline & & 3,0 & 0 & 10,3 & 23 & 4 & 214,0 \\
\hline & & 3,5 & 0 & 10,2 & 30 & 2 & 222,0 \\
\hline & \multirow{3}{*}{12} & 3,0 & 12 & 9,3 & 36 & 5 & 226,0 \\
\hline & & 3,5 & 14 & 9,8 & 33 & 2 & 230,0 \\
\hline & & 4,0 & 8 & 10,2 & 30 & 1 & 233,0 \\
\hline & \multirow{3}{*}{14} & 3,5 & 20 & 9,4 & 37 & 2 & 235,0 \\
\hline & & 4,0 & 23 & 9,8 & 35 & 1 & 236,0 \\
\hline & & 4,5 & 20 & 10,1 & 32 & 0 & 238,0 \\
\hline \multirow{9}{*}{ AVU-30 } & \multirow{3}{*}{10} & 2,5 & 3 & 10,4 & 27 & 6 & 200,0 \\
\hline & & 3,0 & 12 & 9,9 & 30 & 2 & 211,0 \\
\hline & & 3,5 & & & & & \\
\hline & \multirow{3}{*}{12} & 3,0 & 24 & 9,0 & 39 & 5 & 220,0 \\
\hline & & 3,5 & 27 & 9,4 & 37 & 1 & 225,0 \\
\hline & & 4,0 & 25 & 9,9 & 32 & 1 & 231,0 \\
\hline & \multirow{3}{*}{14} & 3,5 & 30 & 9,1 & 40 & 3 & 236,0 \\
\hline & & 4,0 & 30 & 9,5 & 38 & 2 & 236,0 \\
\hline & & 4,5 & 29 & 9,8 & 35 & 0 & 239,0 \\
\hline \multirow{9}{*}{ AVU-40 } & \multirow{3}{*}{10} & 2,5 & 10 & 9,7 & 32 & 8 & 210,0 \\
\hline & & 3,0 & 15 & 10,0 & 27 & 7 & 220,0 \\
\hline & & 3,5 & & & & & \\
\hline & \multirow{3}{*}{12} & 3,0 & 28 & 9,2 & 36 & 6 & 228,0 \\
\hline & & 3,5 & 29 & 9,5 & 38 & 6 & 233,0 \\
\hline & & 4,0 & & & & & \\
\hline & \multirow{3}{*}{14} & 3,5 & 31 & 8,9 & 41 & 2 & 240,0 \\
\hline & & 4,0 & 31 & 9,2 & 40 & 1 & 246,0 \\
\hline & & 4,5 & & & & & \\
\hline
\end{tabular}


Tabla 7.8: Eficacia de combustión de mezclas de aceite de colza y gasóleo.

\begin{tabular}{|c|c|c|c|c|c|}
\hline Mezcla & $\begin{array}{l}\text { Presión de } \\
\text { inyección } \\
\text { (bar) }\end{array}$ & $\begin{array}{l}\text { Posición } \\
\text { rejilla de aire }\end{array}$ & $\begin{array}{c}\text { Eficiencia } \\
(\%)\end{array}$ & $\begin{array}{c}\mathrm{CO}_{2} \mathrm{Fósil} \\
\text { (kg/kg de } \\
\text { combustible) }\end{array}$ & $\begin{array}{c}\mathrm{CO}_{2} \text { no Fósil } \\
\text { (kg/kg de } \\
\text { combustible) }\end{array}$ \\
\hline \multirow{9}{*}{ ACC-10 } & \multirow{3}{*}{10} & 2,5 & 86,204 & 2,86 & 0,28 \\
\hline & & 3,0 & 85,392 & 2,86 & 0,28 \\
\hline & & 3,5 & 84,100 & 2,86 & 0,28 \\
\hline & \multirow{3}{*}{12} & 3,0 & 85,672 & 2,86 & 0,28 \\
\hline & & 3,5 & 85,254 & 2,86 & 0,28 \\
\hline & & 4,0 & 84,797 & 2,86 & 0,28 \\
\hline & \multirow{3}{*}{14} & 3,5 & 85,354 & 2,86 & 0,28 \\
\hline & & 4,0 & 84,839 & 2,86 & 0,28 \\
\hline & & 4,5 & 84,164 & 2,86 & 0,28 \\
\hline \multirow{9}{*}{ ACC-20 } & \multirow{3}{*}{10} & 2,5 & 87,686 & 2,54 & 0,57 \\
\hline & & 3,0 & 86,319 & 2,54 & 0,57 \\
\hline & & 3,5 & 85,258 & 2,54 & 0,57 \\
\hline & \multirow{3}{*}{12} & 3,0 & 85,624 & 2,54 & 0,57 \\
\hline & & 3,5 & 85,374 & 2,54 & 0,57 \\
\hline & & 4,0 & 84,650 & 2,54 & 0,57 \\
\hline & \multirow{3}{*}{14} & 3,5 & 85,318 & 2,54 & 0,57 \\
\hline & & 4,0 & 84,697 & 2,54 & 0,57 \\
\hline & & 4,5 & 83,906 & 2,54 & 0,57 \\
\hline \multirow{9}{*}{ ACC-30 } & \multirow{3}{*}{10} & 2,5 & 85,869 & 2,22 & 0,85 \\
\hline & & 3,0 & 85,113 & 2,22 & 0,85 \\
\hline & & 3,5 & 84,501 & 2,22 & 0,85 \\
\hline & \multirow{3}{*}{12} & 3,0 & 86,505 & 2,22 & 0,85 \\
\hline & & 3,5 & 85,131 & 2,22 & 0,85 \\
\hline & & 4,0 & 84,479 & 2,22 & 0,85 \\
\hline & \multirow{3}{*}{14} & 3,5 & 85,216 & 2,22 & 0,85 \\
\hline & & 4,0 & 84,533 & 2,22 & 0,85 \\
\hline & & 4,5 & 83,661 & 2,22 & 0,85 \\
\hline \multirow{9}{*}{ ACC-40 } & \multirow{3}{*}{10} & 2,5 & 87,146 & 1,91 & 1,14 \\
\hline & & 3,0 & 85,859 & 1,91 & 1,14 \\
\hline & & 3,5 & 84,749 & 1,91 & 1,14 \\
\hline & \multirow{3}{*}{12} & 3,0 & 86,061 & 1,91 & 1,14 \\
\hline & & 3,5 & 85,155 & 1,91 & 1,14 \\
\hline & & 4,0 & 84,492 & 1,91 & 1,14 \\
\hline & \multirow{3}{*}{14} & 3,5 & 85,097 & 1,91 & 1,14 \\
\hline & & 4,0 & 84,414 & 1,91 & 1,14 \\
\hline & & 4,5 & 83,606 & 1,91 & 1,14 \\
\hline
\end{tabular}


Tabla 7.9: Eficacia de combustión de mezclas de aceite de soja crudo y gasóleo.

\begin{tabular}{|c|c|c|c|c|c|}
\hline Mezcla & $\begin{array}{l}\text { Presión de } \\
\text { inyección } \\
\text { (bar) }\end{array}$ & $\begin{array}{l}\text { Posición } \\
\text { rejilla de aire }\end{array}$ & $\begin{array}{c}\text { Eficiencia } \\
(\%)\end{array}$ & $\begin{array}{c}\mathrm{CO}_{2} \text { Fósil } \\
\text { (kg/kg de } \\
\text { combustible) }\end{array}$ & $\begin{array}{c}\mathrm{CO}_{2} \text { no Fósil } \\
(\mathrm{kg} / \mathrm{kg} \text { de } \\
\text { combustible) }\end{array}$ \\
\hline \multirow{9}{*}{ ASC-10 } & \multirow{3}{*}{10} & 2,5 & 86,824 & 2,86 & 0,28 \\
\hline & & 3,0 & 86,265 & 2,86 & 0,28 \\
\hline & & 3,5 & 85,339 & 2,86 & 0,28 \\
\hline & \multirow{3}{*}{12} & 3,0 & 85,659 & 2,86 & 0,28 \\
\hline & & 3,5 & 85,449 & 2,86 & 0,28 \\
\hline & & 4,0 & 84,869 & 2,86 & 0,28 \\
\hline & \multirow{3}{*}{14} & 3,5 & 85,411 & 2,86 & 0,28 \\
\hline & & 4,0 & 84,804 & 2,86 & 0,28 \\
\hline & & 4,5 & 84,214 & 2,86 & 0,28 \\
\hline \multirow{9}{*}{ ASC-20 } & \multirow{3}{*}{10} & 2,5 & 86,664 & 2,54 & 0,57 \\
\hline & & 3,0 & 85,452 & 2,54 & 0,57 \\
\hline & & 3,5 & 84,837 & 2,54 & 0,57 \\
\hline & \multirow{3}{*}{12} & 3,0 & 85,871 & 2,54 & 0,57 \\
\hline & & 3,5 & 85,355 & 2,54 & 0,57 \\
\hline & & 4,0 & 84,695 & 2,54 & 0,57 \\
\hline & \multirow{3}{*}{14} & 3,5 & 85,200 & 2,54 & 0,57 \\
\hline & & 4,0 & 84,607 & 2,54 & 0,57 \\
\hline & & 4,5 & 83,981 & 2,54 & 0,57 \\
\hline \multirow{9}{*}{ ASC-30 } & \multirow{3}{*}{10} & 2,5 & 86,718 & 2,22 & 0,85 \\
\hline & & 3,0 & 85,553 & 2,22 & 0,85 \\
\hline & & 3,5 & 84,864 & 2,22 & 0,85 \\
\hline & \multirow{3}{*}{12} & 3,0 & 85,427 & 2,22 & 0,85 \\
\hline & & 3,5 & 85,070 & 2,22 & 0,85 \\
\hline & & 4,0 & 84,619 & 2,22 & 0,85 \\
\hline & \multirow{3}{*}{14} & 3,5 & 85,229 & 2,22 & 0,85 \\
\hline & & 4,0 & 84,583 & 2,22 & 0,85 \\
\hline & & 4,5 & 83,996 & 2,22 & 0,85 \\
\hline \multirow{9}{*}{ ASC-40 } & \multirow{3}{*}{10} & 2,5 & 86,313 & 1,91 & 1,14 \\
\hline & & 3,0 & 85,430 & 1,91 & 1,14 \\
\hline & & 3,5 & 84,762 & 1,91 & 1,14 \\
\hline & \multirow{3}{*}{12} & 3,0 & 85,559 & 1,91 & 1,14 \\
\hline & & 3,5 & 84,862 & 1,91 & 1,14 \\
\hline & & 4,0 & 84,394 & 1,91 & 1,14 \\
\hline & \multirow{3}{*}{14} & 3,5 & 84,576 & 1,91 & 1,14 \\
\hline & & 4,0 & 84,114 & 1,91 & 1,14 \\
\hline & & 4,5 & 83,636 & 1,91 & 1,14 \\
\hline
\end{tabular}


Tabla 7.10: Eficacia de combustión de mezclas de aceite de soja refinado y gasóleo.

\begin{tabular}{|c|c|c|c|c|c|}
\hline Mezcla & $\begin{array}{l}\text { Presión de } \\
\text { inyección } \\
\text { (bar) }\end{array}$ & $\begin{array}{l}\text { Posición } \\
\text { rejilla de aire }\end{array}$ & $\begin{array}{c}\text { Eficiencia } \\
(\%)\end{array}$ & $\begin{array}{c}\mathrm{CO}_{2} \text { Fósil } \\
(\mathrm{kg} / \mathrm{kg} \text { de } \\
\text { combustible) }\end{array}$ & $\begin{array}{c}\mathrm{CO}_{2} \text { no Fósil } \\
(\mathrm{kg} / \mathrm{kg} \text { de } \\
\text { combustible) }\end{array}$ \\
\hline \multirow{9}{*}{ ASR-10 } & \multirow{3}{*}{10} & 2,5 & 87,120 & 2,86 & 0,28 \\
\hline & & 3,0 & 85,542 & 2,86 & 0,28 \\
\hline & & 3,5 & 85,026 & 2,86 & 0,28 \\
\hline & \multirow{3}{*}{12} & 3,0 & 85,550 & 2,86 & 0,28 \\
\hline & & 3,5 & 85,035 & 2,86 & 0,28 \\
\hline & & 4,0 & 84,625 & 2,86 & 0,28 \\
\hline & \multirow{3}{*}{14} & 3,5 & 85,155 & 2,86 & 0,28 \\
\hline & & 4,0 & 84,259 & 2,86 & 0,28 \\
\hline & & 4,5 & 83,701 & 2,86 & 0,28 \\
\hline \multirow{9}{*}{ ASR-20 } & \multirow{3}{*}{10} & 2,5 & 86,183 & 2,54 & 0,57 \\
\hline & & 3,0 & 85,219 & 2,54 & 0,57 \\
\hline & & 3,5 & 84,613 & 2,54 & 0,57 \\
\hline & \multirow{3}{*}{12} & 3,0 & 85,261 & 2,54 & 0,57 \\
\hline & & 3,5 & 84,679 & 2,54 & 0,57 \\
\hline & & 4,0 & 84,178 & 2,54 & 0,57 \\
\hline & \multirow{3}{*}{14} & 3,5 & 84,963 & 2,54 & 0,57 \\
\hline & & 4,0 & 84,367 & 2,54 & 0,57 \\
\hline & & 4,5 & 83,679 & 2,54 & 0,57 \\
\hline \multirow{9}{*}{ ASR-30 } & \multirow{3}{*}{10} & 2,5 & 86,679 & 2,22 & 0,85 \\
\hline & & 3,0 & 86,034 & 2,22 & 0,85 \\
\hline & & 3,5 & 84,883 & 2,22 & 0,85 \\
\hline & \multirow{3}{*}{12} & 3,0 & 85,552 & 2,22 & 0,85 \\
\hline & & 3,5 & 84,891 & 2,22 & 0,85 \\
\hline & & 4,0 & 84,138 & 2,22 & 0,85 \\
\hline & \multirow{3}{*}{14} & 3,5 & 85,061 & 2,22 & 0,85 \\
\hline & & 4,0 & 84,345 & 2,22 & 0,85 \\
\hline & & 4,5 & 83,488 & 2,22 & 0,85 \\
\hline \multirow{9}{*}{ ASR-40 } & \multirow{3}{*}{10} & 2,5 & 86,806 & 1,91 & 1,14 \\
\hline & & 3,0 & 85,725 & 1,91 & 1,14 \\
\hline & & 3,5 & 85,097 & 1,91 & 1,14 \\
\hline & \multirow{3}{*}{12} & 3,0 & 85,598 & 1,91 & 1,14 \\
\hline & & 3,5 & 84,773 & 1,91 & 1,14 \\
\hline & & 4,0 & 84,100 & 1,91 & 1,14 \\
\hline & \multirow{3}{*}{14} & 3,5 & 84,702 & 1,91 & 1,14 \\
\hline & & 4,0 & 84,189 & 1,91 & 1,14 \\
\hline & & 4,5 & 83,438 & 1,91 & 1,14 \\
\hline
\end{tabular}


Tabla 7.11: Eficacia de combustión de mezclas de aceite de girasol crudo y gasóleo.

\begin{tabular}{|c|c|c|c|c|c|}
\hline Mezcla & $\begin{array}{l}\text { Presión de } \\
\text { inyección } \\
\text { (bar) }\end{array}$ & $\begin{array}{l}\text { Posición } \\
\text { rejilla de aire }\end{array}$ & $\begin{array}{c}\text { Eficiencia } \\
(\%)\end{array}$ & $\begin{array}{c}\mathrm{CO}_{2} \text { Fósil } \\
(\mathrm{kg} / \mathrm{kg} \text { de } \\
\text { combustible) }\end{array}$ & $\begin{array}{c}\mathrm{CO}_{2} \text { no Fósil } \\
\text { (kg/kg de } \\
\text { combustible) }\end{array}$ \\
\hline \multirow{9}{*}{ AGC-10 } & \multirow{3}{*}{10} & 2,5 & 85,965 & 2,86 & 0,29 \\
\hline & & 3,0 & 85,219 & 2,86 & 0,29 \\
\hline & & 3,5 & 84,500 & 2,86 & 0,29 \\
\hline & \multirow{3}{*}{12} & 3,0 & 85,087 & 2,86 & 0,29 \\
\hline & & 3,5 & 84,531 & 2,86 & 0,29 \\
\hline & & 4,0 & 83,796 & 2,86 & 0,29 \\
\hline & \multirow{3}{*}{14} & 3,5 & 84,375 & 2,86 & 0,29 \\
\hline & & 4,0 & 83,710 & 2,86 & 0,29 \\
\hline & & 4,5 & 83,222 & 2,86 & 0,29 \\
\hline \multirow{9}{*}{ AGC-20 } & \multirow{3}{*}{10} & 2,5 & 86,127 & 2,54 & 0,57 \\
\hline & & 3,0 & 85,209 & 2,54 & 0,57 \\
\hline & & 3,5 & 84,557 & 2,54 & 0,57 \\
\hline & \multirow{3}{*}{12} & 3,0 & 85,544 & 2,54 & 0,57 \\
\hline & & 3,5 & 84,914 & 2,54 & 0,57 \\
\hline & & 4,0 & 83,914 & 2,54 & 0,57 \\
\hline & \multirow{3}{*}{14} & 3,5 & 84,968 & 2,54 & 0,57 \\
\hline & & 4,0 & 84,099 & 2,54 & 0,57 \\
\hline & & 4,5 & 83,414 & 2,54 & 0,57 \\
\hline \multirow{9}{*}{ AGC-30 } & \multirow{3}{*}{10} & 2,5 & 85,997 & 2,22 & 0,86 \\
\hline & & 3,0 & 84,559 & 2,22 & 0,86 \\
\hline & & 3,5 & 84,084 & 2,22 & 0,86 \\
\hline & \multirow{3}{*}{12} & 3,0 & 85,364 & 2,22 & 0,86 \\
\hline & & 3,5 & 84,617 & 2,22 & 0,86 \\
\hline & & 4,0 & 83,936 & 2,22 & 0,86 \\
\hline & \multirow{3}{*}{14} & 3,5 & 84,622 & 2,22 & 0,86 \\
\hline & & 4,0 & 84,122 & 2,22 & 0,86 \\
\hline & & 4,5 & 83,267 & 2,22 & 0,86 \\
\hline \multirow{9}{*}{ AGC-40 } & \multirow{3}{*}{10} & 2,5 & 86,557 & 1,91 & 1,14 \\
\hline & & 3,0 & 85,587 & 1,91 & 1,14 \\
\hline & & 3,5 & 84,186 & 1,91 & 1,14 \\
\hline & \multirow{3}{*}{12} & 3,0 & 85,251 & 1,91 & 1,14 \\
\hline & & 3,5 & 84,372 & 1,91 & 1,14 \\
\hline & & 4,0 & 83,466 & 1,91 & 1,14 \\
\hline & \multirow{3}{*}{14} & 3,5 & 84,641 & 1,91 & 1,14 \\
\hline & & 4,0 & 83,957 & 1,91 & 1,14 \\
\hline & & 4,5 & 83,076 & 1,91 & 1,14 \\
\hline
\end{tabular}


Tabla 7.12: Eficacia de combustión de mezclas de aceite de girasol refinado y gasóleo.

\begin{tabular}{|c|c|c|c|c|c|}
\hline Mezcla & $\begin{array}{l}\text { Presión de } \\
\text { inyección } \\
\text { (bar) }\end{array}$ & $\begin{array}{l}\text { Posición } \\
\text { rejilla de aire }\end{array}$ & $\begin{array}{c}\text { Eficiencia } \\
(\%)\end{array}$ & $\begin{array}{l}\text { C02 Fósil } \\
\text { (kg/kg de } \\
\text { combustible) }\end{array}$ & $\begin{array}{l}\text { C02 no Fósil } \\
\text { (kg/kg de } \\
\text { combustible) }\end{array}$ \\
\hline \multirow{9}{*}{ AGR-10 } & \multirow{3}{*}{10} & 2,5 & 86,576 & 2,86 & 0,28 \\
\hline & & 3,0 & 85,866 & 2,86 & 0,28 \\
\hline & & 3,5 & 85,313 & 2,86 & 0,28 \\
\hline & \multirow{3}{*}{12} & 3,0 & 86,075 & 2,86 & 0,28 \\
\hline & & 3,5 & 85,204 & 2,86 & 0,28 \\
\hline & & 4,0 & 84,526 & 2,86 & 0,28 \\
\hline & \multirow{3}{*}{14} & 3,5 & 85,287 & 2,86 & 0,28 \\
\hline & & 4,0 & 84,410 & 2,86 & 0,28 \\
\hline & & 4,5 & 83,821 & 2,86 & 0,28 \\
\hline \multirow{9}{*}{ AGR-20 } & \multirow{3}{*}{10} & 2,5 & 86,466 & 2,54 & 0,57 \\
\hline & & 3,0 & 85,560 & 2,54 & 0,57 \\
\hline & & 3,5 & 84,728 & 2,54 & 0,57 \\
\hline & \multirow{3}{*}{12} & 3,0 & 86,211 & 2,54 & 0,57 \\
\hline & & 3,5 & 85,299 & 2,54 & 0,57 \\
\hline & & 4,0 & 84,478 & 2,54 & 0,57 \\
\hline & \multirow{3}{*}{14} & 3,5 & 85,468 & 2,54 & 0,57 \\
\hline & & 4,0 & 84,511 & 2,54 & 0,57 \\
\hline & & 4,5 & 83,850 & 2,54 & 0,57 \\
\hline \multirow{9}{*}{ AGR-30 } & \multirow{3}{*}{10} & 2,5 & 86,679 & 2,22 & 0,85 \\
\hline & & 3,0 & 85,548 & 2,22 & 0,85 \\
\hline & & 3,5 & & & \\
\hline & \multirow{3}{*}{12} & 3,0 & 86,321 & 2,22 & 0,85 \\
\hline & & 3,5 & 85,529 & 2,22 & 0,85 \\
\hline & & 4,0 & 84,786 & 2,22 & 0,85 \\
\hline & \multirow{3}{*}{14} & 3,5 & 85,610 & 2,22 & 0,85 \\
\hline & & 4,0 & 85,041 & 2,22 & 0,85 \\
\hline & & 4,5 & 84,127 & 2,22 & 0,85 \\
\hline \multirow{9}{*}{ AGR-40 } & \multirow{3}{*}{10} & 2,5 & 87,008 & 1,91 & 1,14 \\
\hline & & 3,0 & 86,078 & 1,91 & 1,14 \\
\hline & & 3,5 & 84,746 & 1,91 & 1,14 \\
\hline & \multirow{3}{*}{12} & 3,0 & 85,958 & 1,91 & 1,14 \\
\hline & & 3,5 & 85,263 & 1,91 & 1,14 \\
\hline & & 4,0 & 84,427 & 1,91 & 1,14 \\
\hline & \multirow{3}{*}{14} & 3,5 & 85,370 & 1,91 & 1,14 \\
\hline & & 4,0 & 84,858 & 1,91 & 1,14 \\
\hline & & 4,5 & 84,052 & 1,91 & 1,14 \\
\hline
\end{tabular}


Tabla 7.13: Eficacia de combustión de mezclas de aceite de aceite vegetal usado y gasóleo.

\begin{tabular}{|c|c|c|c|c|c|}
\hline Mezcla & $\begin{array}{l}\text { Presión de } \\
\text { inyección } \\
\text { (bar) }\end{array}$ & $\begin{array}{l}\text { Posición } \\
\text { rejilla de aire }\end{array}$ & $\begin{array}{c}\text { Eficiencia } \\
(\%)\end{array}$ & $\begin{array}{c}\mathrm{CO}_{2} \text { Fósil } \\
(\mathrm{kg} / \mathrm{kg} \text { de } \\
\text { combustible) }\end{array}$ & $\begin{array}{c}\mathrm{CO}_{2} \text { no Fósil } \\
(\mathrm{kg} / \mathrm{kg} \text { de } \\
\text { combustible) }\end{array}$ \\
\hline \multirow{9}{*}{ AVU-10 } & \multirow{3}{*}{10} & 2,5 & 86,588 & 2,86 & 0,28 \\
\hline & & 3,0 & 86,004 & 2,86 & 0,28 \\
\hline & & 3,5 & 85,076 & 2,86 & 0,28 \\
\hline & \multirow{3}{*}{12} & 3,0 & 85,920 & 2,86 & 0,28 \\
\hline & & 3,5 & 85,319 & 2,86 & 0,28 \\
\hline & & 4,0 & 84,579 & 2,86 & 0,28 \\
\hline & \multirow{3}{*}{14} & 3,5 & 85,214 & 2,86 & 0,28 \\
\hline & & 4,0 & 84,690 & 2,86 & 0,28 \\
\hline & & 4,5 & 83,962 & 2,86 & 0,28 \\
\hline \multirow{9}{*}{ AVU-20 } & \multirow{3}{*}{10} & 2,5 & 86,616 & 2,54 & 0,57 \\
\hline & & 3,0 & 85,963 & 2,54 & 0,57 \\
\hline & & 3,5 & 85,476 & 2,54 & 0,57 \\
\hline & \multirow{3}{*}{12} & 3,0 & 86,227 & 2,54 & 0,57 \\
\hline & & 3,5 & 85,364 & 2,54 & 0,57 \\
\hline & & 4,0 & 84,635 & 2,54 & 0,57 \\
\hline & \multirow{3}{*}{14} & 3,5 & 85,471 & 2,54 & 0,57 \\
\hline & & 4,0 & 84,917 & 2,54 & 0,57 \\
\hline & & 4,5 & 84,382 & 2,54 & 0,57 \\
\hline \multirow{9}{*}{ AVU-30 } & \multirow{3}{*}{10} & 2,5 & 86,909 & 2,22 & 0,85 \\
\hline & & 3,0 & 86,646 & 2,22 & 0,85 \\
\hline & & 3,5 & & & \\
\hline & \multirow{3}{*}{12} & 3,0 & 86,950 & 2,22 & 0,85 \\
\hline & & 3,5 & 86,179 & 2,22 & 0,85 \\
\hline & & 4,0 & 85,159 & 2,22 & 0,85 \\
\hline & \multirow{3}{*}{14} & 3,5 & 85,731 & 2,22 & 0,85 \\
\hline & & 4,0 & 85,274 & 2,22 & 0,85 \\
\hline & & 4,5 & 84,688 & 2,22 & 0,85 \\
\hline \multirow{9}{*}{ AVU-40 } & \multirow{3}{*}{10} & 2,5 & 86,933 & 1,91 & 1,13 \\
\hline & & 3,0 & 85,857 & 1,91 & 1,13 \\
\hline & & 3,5 & & & \\
\hline & \multirow{3}{*}{12} & 3,0 & 86,179 & 1,91 & 1,13 \\
\hline & & 3,5 & 85,486 & 1,91 & 1,13 \\
\hline & & 4,0 & & & \\
\hline & \multirow{3}{*}{14} & 3,5 & 85,665 & 1,91 & 1,13 \\
\hline & & 4,0 & 84,905 & 1,91 & 1,13 \\
\hline & & 4,5 & & & \\
\hline
\end{tabular}




\subsection{INTRODUCCIÓN.}

En el siguiente estudio se pretende caracterizar el comportamiento de mezclas de gasoil con los seis tipos de aceite mencionados y en los porcentajes descritos. Esto se hará a través de la medida directa de parámetros de la combustión y los cálculos derivados de esas medidas.

Los parámetros que se medirán/calcularán son los siguientes:

- Rendimiento

- Emisiones de CO

- Emisiones de NOx

Se controlarán cuatro parámetros, a saber:

Tipo de aceite (T): los aceites que se incluyen en el estudio son aceite de colza crudo, aceite vegetal usado, aceite de girasol crudo, aceite de girasol refinado, aceite de soja crudo y aceite de soja refinado.

Porcentaje de mezcla $(\mathrm{X})$ : se variará el porcentaje de mezcla en peso entre el $10,20,30$ y $40 \%$.

Presión de inyección de combustible (P): variará entre 10, 12 y 14 bar. 
Posición de la admisión de aire (A): este parámetro ha de tomar tres valores en las mediciones. Las medidas hubieron de ser realizadas de modo que cada presión tomó un valor distinto de posición de admisión de aire (para $P=10$ bar, $A=2,5,3$ y 3,5 ; para $P=12$ bar, $A=3,3,5$ y 4 ; y para $P=14$ bar, $A=3,5$, 4 y 4,5$)$.

El hecho de que cada presión tomara unos valores de admisión del aire obligaba a que la matriz de diseño del experimento no fuese "normal", impidiendo un análisis global de los datos, de modo que los análisis realizados han sido a presión constante variando la posición de la admisión del aire siempre entre los mismos valores.

A mayores se ha realizado un estudio a posición de admisión de aire constante $(A=3,5)$, ya que era viable y el planteamiento era lógico desde un punto de vista estadístico. Además, los resultados que se obtuviesen de él podrían llevar consigo una interpretación que tendría una base para llevar a cabo otros razonamientos.

Un hipotético estudio con todos los valores obtenidos, clasificando las posiciones de admisión del aire en bajas, medias y altas, podría ser factible desde el punto de vista práctico, pero sería poco riguroso desde el punto de vista técnico, ya que la posición "baja" de uno correspondería con la "alta" de otro. De este modo, aunque los resultados serían perfectamente tratables, las posibles interpretaciones y conclusiones sacadas de un estudio de este tipo serían, cuanto menos, discutibles.

\subsection{DESCRIPCIÓN DEL ANÁLISIS ANOVA}

Se va a emplear en el estudio la notación siguiente:

\section{Variables:}

- P: presión de inyección

- A: posición de la admisión del aire

- $\quad$ T: tipo de aceite que se mezcla con el gasoil en el combustible

- $\quad$ X: porcentaje (en masa) en la mezcla aceite-gasoil

Tipos de aceite (con tipos de aceite, se denotarán también las mezclas de los mismos con gasoil, es decir: ACC al $40 \%$ será aceite de colza crudo al $40 \%$ en peso y el resto, gasoil). 
- ACC: aceite de colza

- AGC: aceite de girasol crudo

- AGR: aceite de girasol refinado

- ASC: aceite de soja crudo

- ASR: aceite de soja refinado

- AVU: aceite vegetal usado.

\section{Descripción:}

Tomando como ejemplo la tabla del primer análisis que se va a realizar, se contemplan los factores contemplados y sus interacciones. Se tiene también el error y la contribución total.

Tabla 8.1 Factores contemplados, interacciones. Error y contribución total

\begin{tabular}{|l|c|c|c|c|c|c|c|}
\hline FACTOR & GdL & SS & MS & F & VC al 5\% & Influye & G. C. Crítica \\
\hline A & 2 & 43,59301 & 21,79650 & 239,23341 & 3,31583 & SI & $3,65493 \mathrm{E}-19$ \\
\hline T & 5 & 2,98808 & 0,59762 & 6,55929 & 2,53355 & SI & 0,000311729 \\
\hline $\mathbf{X}$ & 3 & 0,73861 & 0,24620 & 2,70228 & 2,92228 & NO & 0,06316526 \\
\hline AxT & 10 & 0,79699 & 0,07970 & 0,87476 & 2,16458 & NO & 0,565846121 \\
\hline AxX & 6 & 0,71264 & 0,11877 & 1,30363 & 2,42052 & NO & 0,285822777 \\
\hline TxX & 15 & 5,12161 & 0,34144 & 3,74757 & 2,01480 & SI & 0,001010775 \\
\hline Error & 30 & 2,733294 & 0,091110 & & & & \\
\hline Total & 71 & 56,684227 & & & & & \\
\hline
\end{tabular}

Por columnas, se tiene en la primera el factor correspondiente; en la segunda se tienen los grados de libertad de cada aportación; en la tercera se tiene la suma de cuadrados de cada aportación; en la cuarta tenemos la varianza o cuadrado medio, calculada como cociente entre la suma de cuadrados y los grados de libertad; en la quinta columna se tiene el estadístico F, el cual se obtiene como cociente entre la varianza de cada factor y la varianza del error (este estadístico será el responsable final del análisis); en la sexta columna se tiene el valor máximo que tendría que tener el estadístico $\mathrm{F}$, a un nivel de confianza del $5 \%$, para que la variable no fuese determinante en el análisis; en la séptima se evalúa si dicho estadístico interviene o no (para hacerlo, su estadístico $\mathrm{F}$ tiene que ser mayor que el valor crítico al $5 \%$ en este caso); y en la octava columna se expone el grado de confianza que tendría que tener el análisis para que el valor crítico, con ese nivel de confianza, alcanzara el valor del estadístico F obtenido. 


\subsection{ESTUDIO DEL RENDIMIENTO.}

El rendimiento se calcula a través de las pérdidas por inquemados y las pérdidas por chimenea de la siguiente forma:

$$
\begin{gathered}
\mathrm{P}_{\mathrm{inq}}=\mathrm{K} \cdot \frac{\mathrm{CO}(\mathrm{ppm}) \cdot \mathrm{V}_{\mathrm{H}}^{1} \cdot \mathrm{PCl}_{\mathrm{Co}} \cdot \mathrm{P}_{\mathrm{amb}} /\left(\mathrm{T}_{\mathrm{amb}} \cdot \mathrm{R}_{\mathrm{co}}\right)}{\mathrm{PCl}_{\mathrm{comb} .}} \\
\mathrm{P}_{\text {chim }}=100 \cdot \frac{\mathrm{M}_{\mathrm{H}}^{1} \cdot \mathrm{C}_{\mathrm{Phum}} \cdot\left(\mathrm{T}_{\text {hum }}-\mathrm{T}_{\mathrm{amb}}\right)}{\mathrm{PCl} \mathrm{c}_{\text {comb. }}} \\
\eta_{\text {comb }}=1-\mathrm{P}_{\text {inq }}-\mathrm{P}_{\text {chim }}
\end{gathered}
$$

En la que $\mathrm{K}$ un factor de conversión debido a las unidades utilizadas.

\subsubsection{Análisis del rendimiento para $p=10$ bar}

Se muestra a continuación la matriz de resultados obtenida:

Tabla 8.2:Matriz de resultados para $\mathrm{P}=10 \mathrm{bar}$

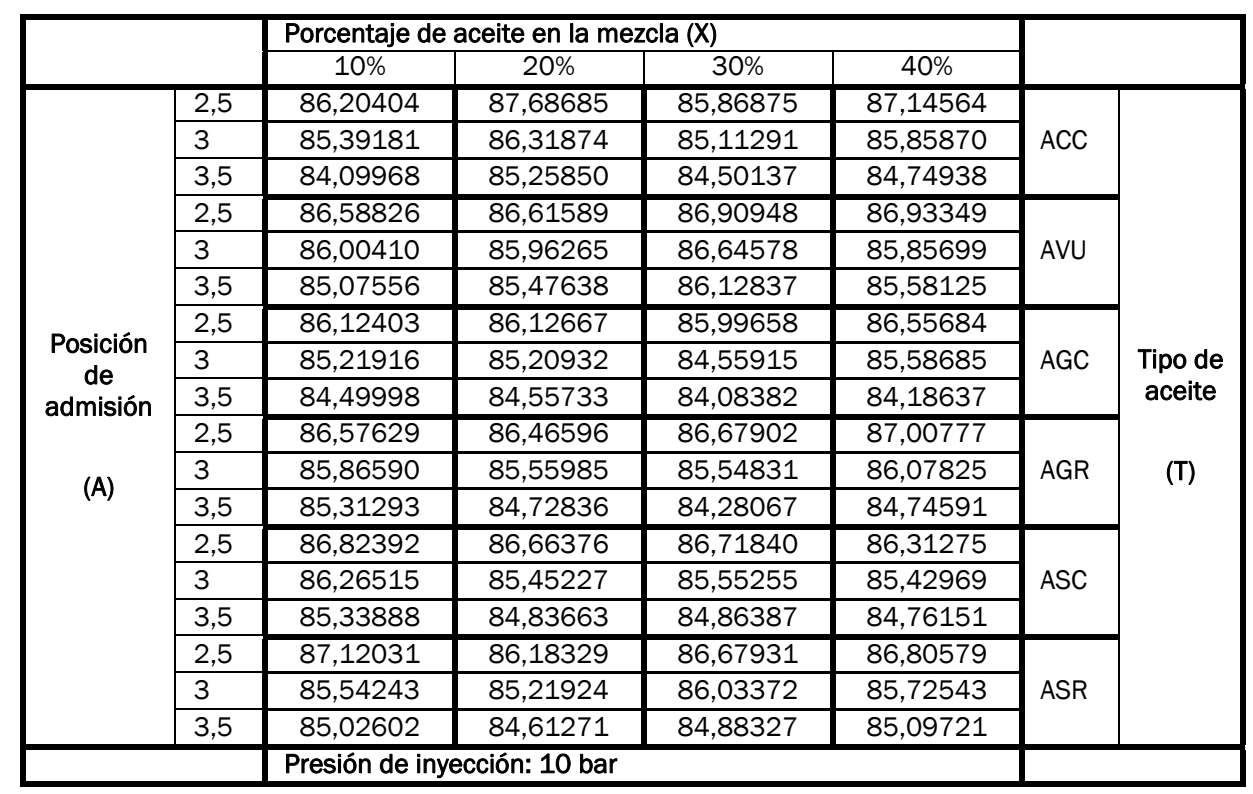


Con estos datos, lo primero que se plantea es un análisis de varianza (ANOVA), mediante el cual se determinará si las tres variables influyen (admisión del aire, tipo de aceite y porcentaje de aceite en peso) o no y de qué manera.

Tabla 8.3:Análisis ANOVA para $\mathrm{P}=10 \mathrm{bar}$

\begin{tabular}{|l|l|l|l|l|l|l|l|}
\hline FACTOR & GdL & \multicolumn{1}{|c|}{ SS } & \multicolumn{1}{c|}{ MS } & F & VC al 5\% & Influye & G. C. Crítica \\
\hline A & 2 & 36,01435 & 18,00718 & 244,61336 & 3,31583 & SI & $2,66971 \mathrm{E}-19$ \\
\hline T & 5 & 5,90060 & 1,18012 & 16,03100 & 2,53355 & SI & $1,06488 \mathrm{E}-07$ \\
\hline X & 3 & 0,30857 & 0,10286 & 1,39721 & 2,92228 & NO & 0,262840955 \\
\hline AxT & 10 & 1,57548 & 0,15755 & 2,14016 & 2,16458 & NO & 0,052515291 \\
\hline AxX & 6 & 0,15193 & 0,02532 & 0,34399 & 2,42052 & NO & 0,90779543 \\
\hline TxX & 15 & 6,59287 & 0,43952 & 5,97060 & 2,01480 & SI & $1,68839 \mathrm{E}-05$ \\
\hline Error & 30 & 2,208445 & 0,073615 & & & & \\
\hline Total & 71 & 52,752245 & & & & & \\
\hline
\end{tabular}

Una vez hecha la descripción de la tabla, la interpretación es la siguiente: con un análisis al $5 \%$ de confiabilidad, se tiene que las variables influyentes sobre el rendimiento de la combustión son la admisión del aire, el tipo de aceite y la interacción tipo de aceite-porcentaje de la misma. Como puede apreciarse, el grado de confianza que tendría que tener el análisis para que la variable X (porcentaje de aceite en la mezcla) sería del 5,25\%, valor ligeramente superior al utilizado: en un análisis con un nivel de significación más amplio el valor sería tomado como decisivo.

Puede concluirse que el factor más determinante, con diferencia, del análisis a presión constante e igual a 10 bar, es la posición de la admisión de aire. El valor del nivel de significación es muy inferior al del resto (del orden de 10-14).

Se representan a continuación los valores obtenidos para la variable rendimiento en función de las variables T, A y X. 
Representaciones gráficas del rendimiento para el aceite de colza crudo $(\mathrm{T}=\mathrm{ACC})$

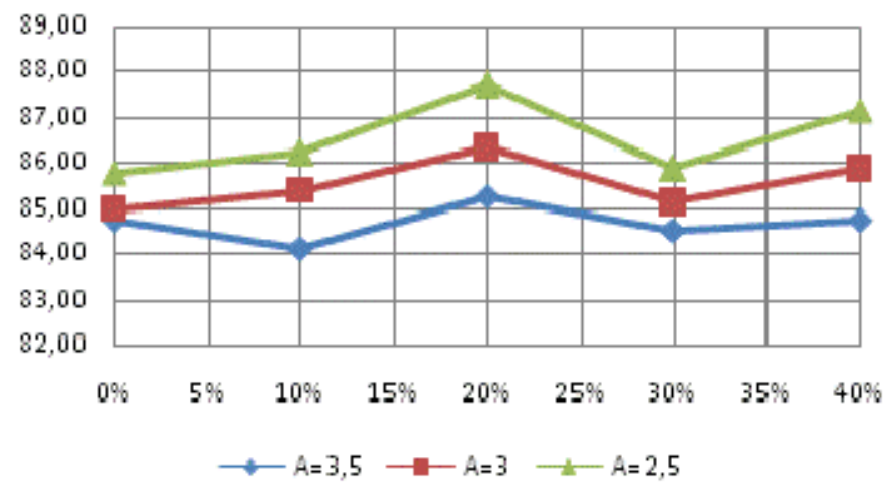

\begin{tabular}{|c|c|c|c|c|c|}
\hline$A C C, P=10 b a r$ & $X=0 \%$ & $X=10 \%$ & $X=20 \%$ & $X=30 \%$ & $X=40 \%$ \\
\hline$A=2,5$ & 85,78101 & 86,20404 & 87,68685 & 85,86875 & 87,14564 \\
\hline$A=3$ & 84,95782 & 85,39181 & 86,31874 & 85,11291 & 85,85870 \\
\hline$A=3,5$ & 84,75750 & 84,09968 & 85,25850 & 84,50137 & 84,74938 \\
\hline
\end{tabular}

Figura 8.1:Rendimiento para $\mathrm{P}=10$ bar y $\mathrm{ACC}$

Se observa, tal y como el análisis ANOVA predijo, la influencia de la posición de admisión de aire en el rendimiento. A medida que introducimos más aire $(A=3$ y $A=3,5)$, el rendimiento baja. Esto es debido a que el exceso de aire que introducimos sale arrastrando calor, aumentando las pérdidas por chimenea (hay más caudal de humos saliente y a mayor temperatura). Además, se observa en los datos que las pérdidas por inquemados también aumentan (las ppm de CO aumentan). De este modo, el rendimiento se ve influenciado por ambas pérdidas. También ha de tenerse en cuenta que el PCI del combustible disminuye al aumentar la proporción de aceite. 
Representaciones gráficas del rendimiento para el aceite vegetal usado ( $\mathrm{T}=\mathrm{AVU})$

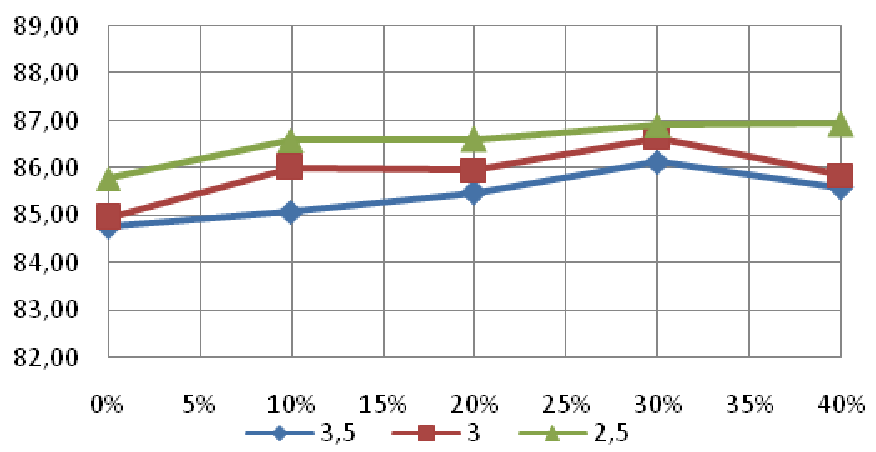

\begin{tabular}{|lccccc|}
\hline AVU,P=10bar & $\mathrm{X}=\mathbf{0} \%$ & $\mathrm{X}=\mathbf{1 0} \%$ & $\mathrm{X}=\mathbf{2 0} \%$ & $\mathrm{X}=\mathbf{3 0} \%$ & $\mathrm{X}=\mathbf{4 0} \%$ \\
\hline $\mathrm{A}=\mathbf{2 , 5}$ & 85,78101 & 86,58826 & 86,61589 & 86,90948 & 86,93349 \\
\hline $\mathrm{A}=\mathbf{3}$ & 84,95782 & 86,00410 & 85,96265 & 86,64578 & 85,85699 \\
\hline $\mathrm{A}=3,5$ & 84,75750 & 85,07556 & 85,47638 & 86,12837 & 85,58125 \\
\hline
\end{tabular}

Figura 8.2: Rendimiento para $\mathrm{P}=10$ bar y AVU

Para $A=2,5$ la tendencia es al alza cuanta más proporción de aceite hay, mientras que para las otras dos posiciones se registra un pico en el $30 \%$. No se puede decir que ninguno de los dos comportamientos sea el esperado. 
Representaciones gráficas del rendimiento para el aceite girasol crudo ( $T=A G C)$

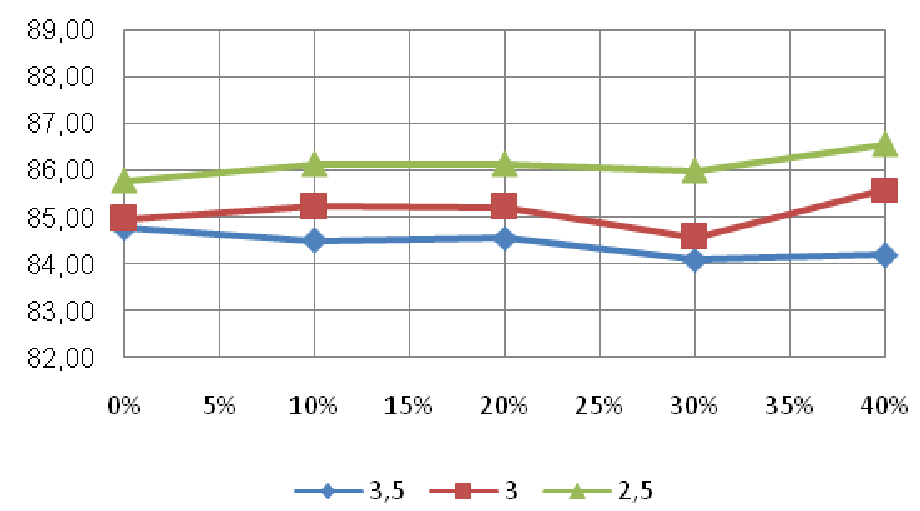

\begin{tabular}{|llllll|} 
& $\mathrm{X}=\mathbf{0} \%$ & $\mathrm{X}=10 \%$ & $\mathrm{X}=\mathbf{2 0} \%$ & $\mathrm{X}=\mathbf{3 0 \%}$ & $\mathrm{X}=\mathbf{4 0 \%}$ \\
$\mathrm{AGC}, \mathrm{P}=$ 10bar & & & & & \\
\hline $\mathrm{A}=\mathbf{2 , 5}$ & 85,78101 & 86,12403 & 86,12667 & 85,99658 & 86,55684 \\
\hline $\mathrm{A}=3$ & 84,95782 & 85,21916 & 85,20932 & 84,55915 & 85,58685 \\
\hline $\mathrm{A}=3,5$ & 84,75750 & 84,49998 & 84,55733 & 84,08382 & 84,18637 \\
\hline
\end{tabular}

Figura 8.3: Rendimiento para $\mathrm{P}=10$ bar y AGC

La tendencia seguida con la composición es a la baja a partir del $20 \%$ de aceite, salvo dos picos producidos al $40 \%$ en las posiciones de admisión bajas. 
Representaciones gráficas del rendimiento para el aceite girasol refinado ( $\mathrm{T}=\mathrm{AGR}$ )

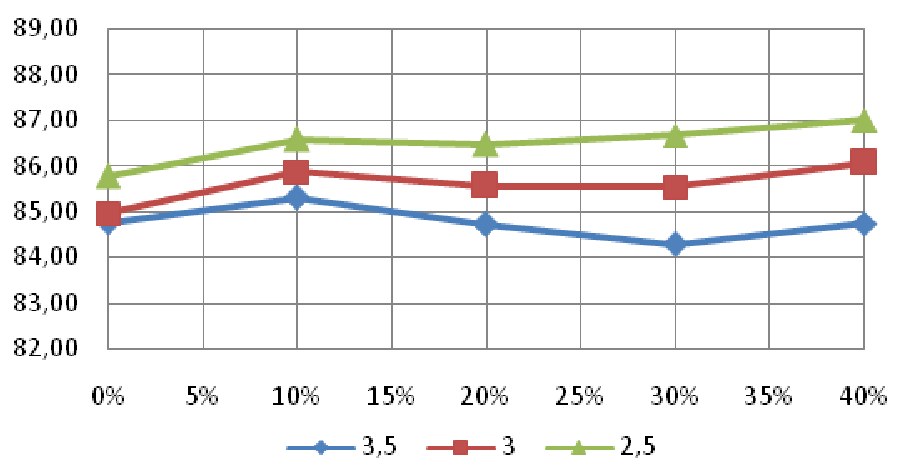

\begin{tabular}{|llllll|}
\hline AGR,P=10bar & $X=0 \%$ & $X=10 \%$ & $X=20 \%$ & $X=30 \%$ & $X=40 \%$ \\
\hline$A=2,5$ & 85,78101 & 86,57629 & 86,46596 & 86,67902 & 87,00777 \\
\hline$A=3$ & 84,95782 & 85,86590 & 85,55985 & 85,54831 & 86,07825 \\
\hline$A=3,5$ & 84,75750 & 85,31293 & 84,72836 & 84,28067 & 84,74591 \\
\hline
\end{tabular}

Figura 8.4: Rendimiento para $P=10$ bar y AGR

El comportamiento adoptado para el aceite de girasol refinado da como resultado algo parecido a los anteriores, con picos intermedios al $20 \%$ de proporción de aceite en peso y un pico final al $40 \%$ en todas. La posición de admisión de aire que más rendimiento ofrece sigue siendo la menor.

Puede compararse también el comportamiento del mismo aceite (girasol) estando crudo o refinado. Un análisis visual a ambas gráficas da como conclusión un comportamiento similar en ambos, pero con valores un poco por encima del aceite refinado. Esto se corrobora al observar la matriz de datos. Será interesante ver si dicha tendencia se cumple también entre el aceite de soja crudo y el refinado. 
Representaciones gráficas del rendimiento para el aceite soja crudo ( $\mathrm{T}=\mathrm{ASC}$ )

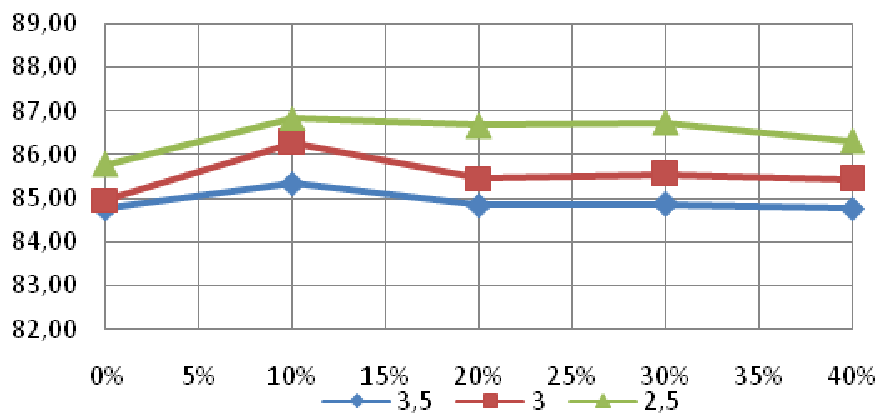

\begin{tabular}{|llllll|}
\hline $\mathrm{ASC}, \mathrm{P}=\mathbf{1 0 b a r}$ & $\mathrm{X}=\mathbf{0} \%$ & $\mathrm{X}=\mathbf{1 0} \%$ & $\mathrm{X}=\mathbf{2 0} \%$ & $\mathrm{X}=\mathbf{3 0} \%$ & $\mathrm{X}=\mathbf{4 0} \%$ \\
\hline $\mathrm{A}=\mathbf{2 , 5}$ & 85,78101 & $\mathbf{8 6 , 8 2 3 9 2}$ & 86,66376 & 86,71840 & 86,31275 \\
\hline $\mathrm{A}=3$ & 84,95782 & 86,26515 & 85,45227 & 85,55255 & 85,42969 \\
\hline $\mathrm{A}=3,5$ & 84,75750 & 85,33888 & 84,83663 & 84,86387 & 84,76151 \\
\hline
\end{tabular}

Figura 8.5: Rendimiento para $\mathrm{P}=10$ bar y ASC

El comportamiento de este tipo de aceite se caracteriza, por tener mejores valores de rendimiento cuanto menor es la posición de la admisión del aire (como en los casos anteriores un pico en la composición10\%)). 
Representaciones gráficas del rendimiento para el aceite soja refinado ( $\mathrm{T}=\mathrm{ASR}$ )

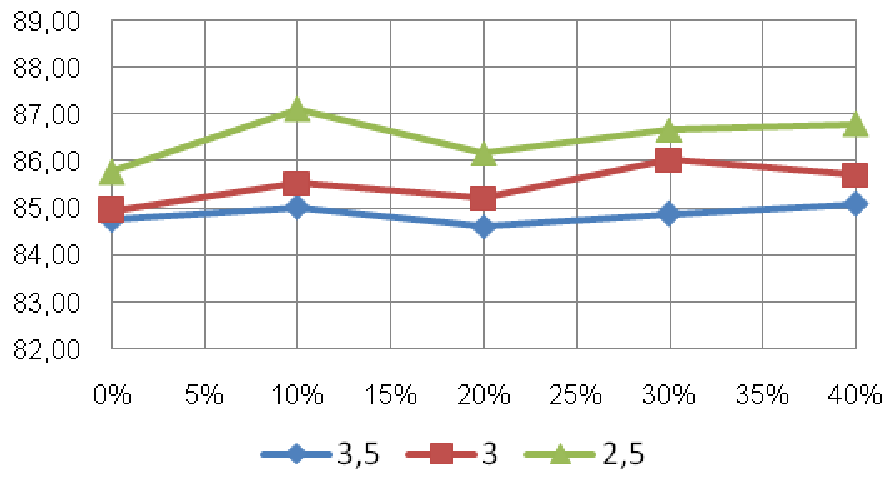

\begin{tabular}{|llllll|}
\hline ASR,P=10bar & $\mathrm{X}=\mathbf{0} \%$ & $\mathrm{X}=\mathbf{1 0} \%$ & $\mathrm{X}=\mathbf{2 0} \%$ & $\mathrm{X}=\mathbf{3 0} \%$ & $\mathrm{X}=\mathbf{4 0 \%}$ \\
\hline $\mathrm{A}=\mathbf{2 , 5}$ & 85,78101 & $\mathbf{8 7 , 1 2 0 3 1}$ & 86,18329 & 86,67931 & 86,80579 \\
\hline $\mathrm{A}=\mathbf{3}$ & 84,95782 & 85,54243 & 85,21924 & 86,03372 & 85,72543 \\
\hline $\mathrm{A}=3,5$ & 84,75750 & 85,02602 & 84,61271 & 84,88327 & 85,09721 \\
\hline
\end{tabular}

Figura 8.6: Rendimiento para $\mathrm{P}=10$ bar y ASR

En este caso el comportamiento alcanza picos ligeros al 10\%, para después seguir una tendencia positiva para todas las posiciones de admisión. Asimismo, se obtienen mejores rendimientos cuanto menor es la admisión de aire.

Respecto al comportamiento frente al aceite crudo, se puede decir que el pico en el $10 \%$ de composición se mantiene, pero el comportamiento en las composiciones posteriores es al alza y no tan estable. 
Representación gráfica del rendimiento para la admisión de aire 2,5 $(A=2,5)$

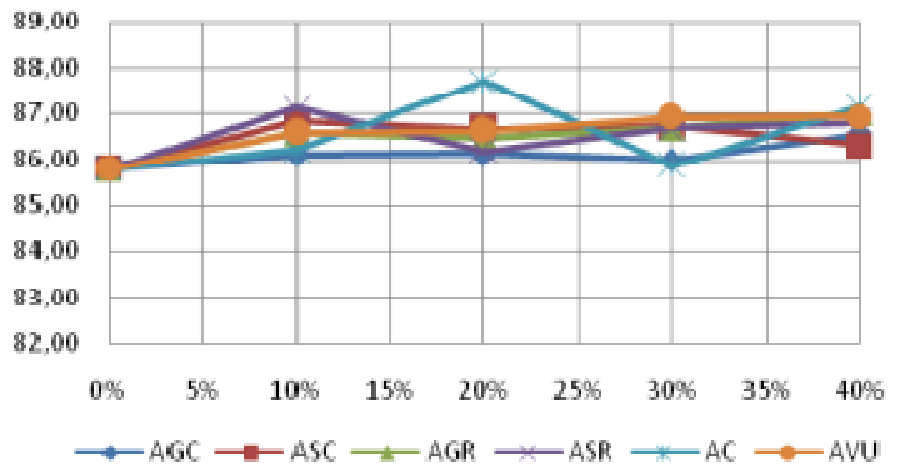

\begin{tabular}{|llllll|}
\hline A=2,5,P=10bar & $\mathbf{X = 0 \%}$ & $\mathbf{X = 1 0} \%$ & $\mathrm{X}=\mathbf{2 0} \%$ & $\mathrm{X}=\mathbf{3 0} \%$ & $\mathrm{X}=\mathbf{4 0} \%$ \\
\hline ACC & 85,78101 & 86,20404 & 87,68685 & 85,86875 & 87,14564 \\
\hline AVU & 85,78101 & 86,58826 & 86,61589 & 86,90948 & 86,93349 \\
\hline AGC & 85,78101 & 86,12403 & 86,12667 & 85,99658 & 86,55684 \\
\hline AGR & 85,78101 & 86,57629 & 86,46596 & 86,67902 & 87,00777 \\
\hline ASC & 85,78101 & 86,82392 & 86,66376 & 86,71840 & 86,31275 \\
\hline ASR & 85,78101 & 87,12031 & 86,18329 & 86,67931 & 86,80579 \\
\hline
\end{tabular}

Figura 8.7: Rendimiento para $P=10$ bar y $A=2,5$

En este gráfico puede comprobarse la tendencia según composición y tipo de aceite. Se observan "comportamientos extraños" en el ASR y en el AC, con picos seguidos de grandes valles, en lo que pudieron ser alteraciones en las medidas. La tendencia general es al alza en función del porcentaje de aceite, en contra de la idea inicial. 
Representación gráfica del rendimiento para la admisión de aire $3(A=3)$

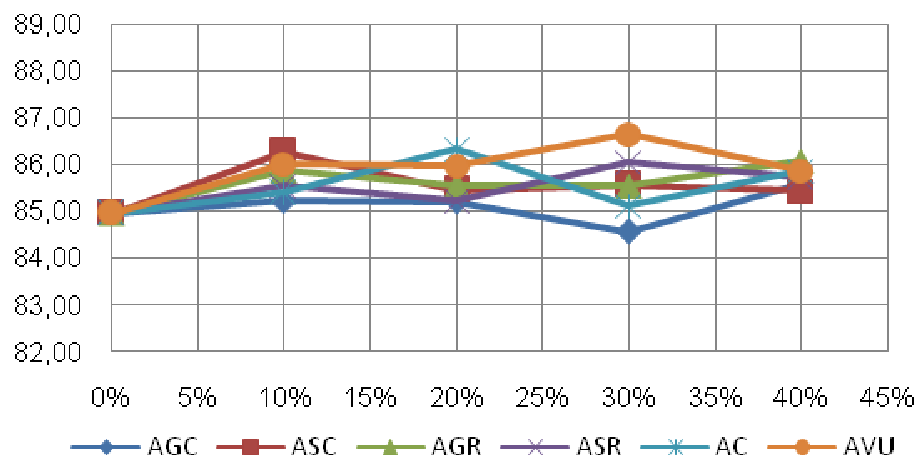

\begin{tabular}{|llllll|}
\hline A=3,P=10bar & $X=0 \%$ & $X=10 \%$ & $X=20 \%$ & $X=30 \%$ & $X=40 \%$ \\
\hline ACC & 84,95782 & 85,39181 & 86,31874 & 85,11291 & 85,85870 \\
\hline AVU & 84,95782 & 86,00410 & 85,96265 & 86,64578 & 85,85699 \\
\hline AGC & 84,95782 & 85,21916 & 85,20932 & 84,55915 & 85,58685 \\
\hline AGR & 84,95782 & 85,86590 & 85,55985 & 85,54831 & 86,07825 \\
\hline ASC & 84,95782 & 86,26515 & 85,45227 & 85,55255 & 85,42969 \\
\hline ASR & 84,95782 & 85,54243 & 85,21924 & 86,03372 & 85,72543 \\
\hline
\end{tabular}

Figura 8.8: Rendimiento para $P=10$ bar y $A=3$

En este caso pueden observarse picos de rendimiento para el $40 \%$ en varios aceites. No es posible hacer una descripción de la tendencia global seguida, no se ve una relación descriptible. A priori, es el aceite vegetal usado el que ofrece un rendimiento mayor en proporciones entre el $10 \mathrm{y}$ el $30 \%$. 
Representación gráfica del rendimiento para la admisión de aire 3,5 $(A=3,5)$

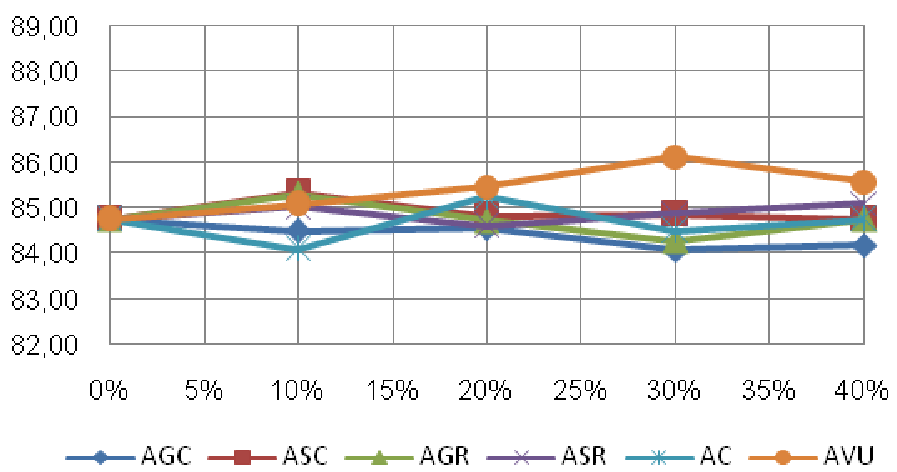

\begin{tabular}{|llllll|}
\hline A=3,5,P=10bar & $\mathrm{X}=\mathbf{0} \%$ & $\mathrm{X}=\mathbf{1 0} \%$ & $\mathrm{X}=\mathbf{2 0} \%$ & $\mathrm{X}=\mathbf{3 0} \%$ & $\mathrm{X}=\mathbf{4 0} \%$ \\
\hline ACC & 84,75750 & 84,09968 & 85,25850 & 84,50137 & 84,74938 \\
\hline AVU & 84,75750 & 85,07556 & 85,47638 & 86,12837 & 85,58125 \\
\hline AGC & 84,75750 & 84,49998 & 84,55733 & 84,08382 & 84,18637 \\
\hline AGR & 84,75750 & 85,31293 & 84,72836 & 84,28067 & 84,74591 \\
\hline ASC & 84,75750 & 85,33888 & 84,83663 & 84,86387 & 84,76151 \\
\hline ASR & 84,75750 & 85,02602 & 84,61271 & 84,88327 & 85,09721 \\
\hline
\end{tabular}

Figura 8.9: Rendimiento para $P=10$ bar y $A=3,5$

Como en el caso anterior, el rendimiento más alto corresponde al aceite vegetal usado. El rendimiento del resto de aceites se mantiene en unos valores entre el 84 y el $85 \%$. 
Representación gráfica del rendimiento para porcentaje de aceite del $10 \%$ $(X=10 \%)$

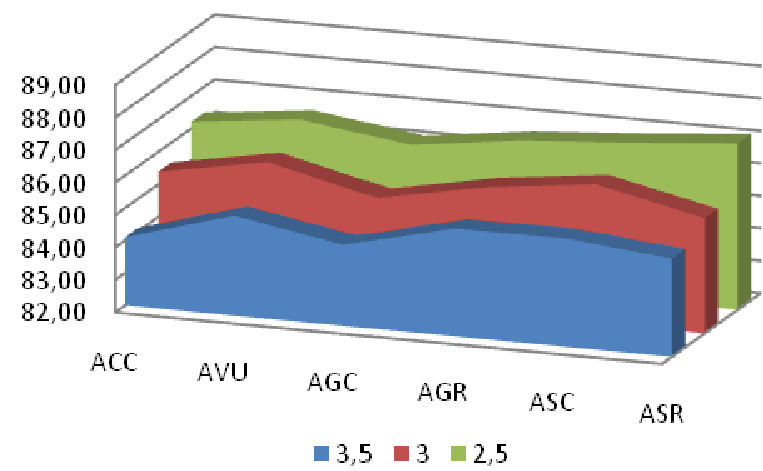

\begin{tabular}{|llll|lll|}
\hline $\mathrm{X}=\mathbf{1 0} \%, \mathrm{P}=10 \mathrm{bar}$ & ACC & AVU & AGC & AGR & ASC & ASR \\
\hline $\mathrm{A}=\mathbf{2 , 5}$ & 86,20404 & 86,58826 & 86,12403 & 86,57629 & 86,82392 & 87,12031 \\
\hline $\mathrm{A}=\mathbf{3}$ & 85,39181 & 86,00410 & 85,21916 & 85,86590 & 86,26515 & 85,54243 \\
\hline $\mathrm{A}=\mathbf{3 , 5}$ & 84,09968 & 85,07556 & 84,49998 & 85,31293 & 85,33888 & 85,02602 \\
\hline
\end{tabular}

Figura 8.10: Rendimiento para $P=10$ bar y $X=10 \%$

Puede observarse, para este porcentaje de aceite, que el AVU, el ASC y el ASR tienen rendimientos mayores. Para esta proporción, los peores aceites son con diferencia el ACC y el AGC. El AGR, sin embargo, tiene un rendimiento superior (casi 0,5\% más en cada posición de aire).

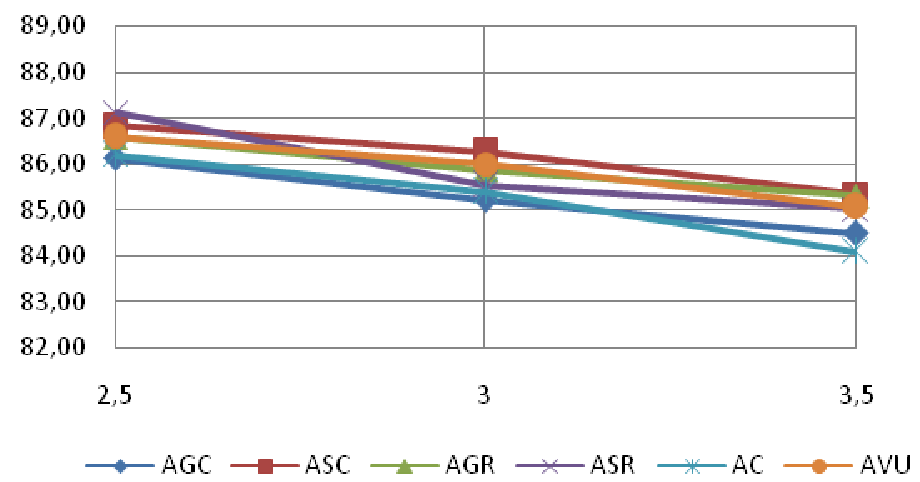

Figura 8.11: Rendimiento para $P=10$ bar y $X=10 \%$

Se ha variado la disposición de los ejes respecto a la gráfica anterior para poder apreciar mejor el comportamiento de cada combustible frente a la variación de la admisión de aire. Vuelve a quedar de manifiesto el peor comportamiento de ACC y AGC. No hay diferencia significativas en el resto (la conclusión es la misma de antes). 
El comportamiento es lógico: la admisión de más aire provoca una caída (en algunos casos mayores y en otros menores) en el rendimiento.

Representación gráfica del rendimiento para porcentaje de aceite del $20 \%$ $(X=20 \%)$

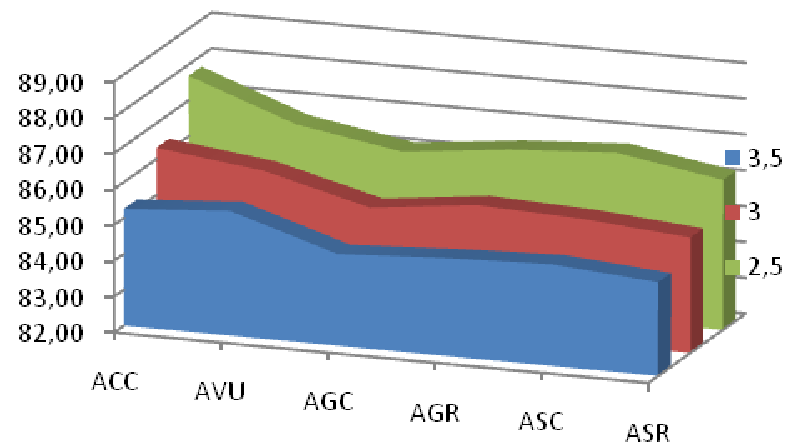

\begin{tabular}{|lllllll|}
\hline $\begin{array}{l}\mathrm{X}=\mathbf{2 0} \%, \\
\mathrm{P}=\mathbf{1 0 \text { bar }}\end{array}$ & ACC & AVU & AGC & AGR & ASC & ASR \\
\hline $\mathrm{A}=\mathbf{2 , 5}$ & $\mathbf{8 7 , 6 8 6 8 5}$ & 86,61589 & 86,12667 & 86,46596 & 86,66376 & 86,18329 \\
\hline $\mathrm{A}=3$ & 86,31874 & 85,96265 & 85,20932 & 85,55985 & 85,45227 & 85,21924 \\
\hline $\mathrm{A}=3,5$ & 85,25850 & 85,47638 & 84,55733 & 84,72836 & 84,83663 & 84,61271 \\
\hline
\end{tabular}

Figura 8.12: Rendimiento para $P=10$ bar y $X=20 \%$

Al contrario que en la proporción $10 \%$, en la de $20 \%$ el mejor comportamiento parece tenerlo el AC con diferencia. El rendimiento del resto de combustibles se mantiene en la horquilla de 84,5 y $86,6 \%$, manteniéndose el del ACC por encima salvo en $A=3,5$. Los peores rendimientos, para todas las posiciones de admisión, vienen dados para el AGC seguido de cerca por el ASR. Al contrario que la teoría inicial, en este caso el ASR obtiene peores valores que el ASC. 


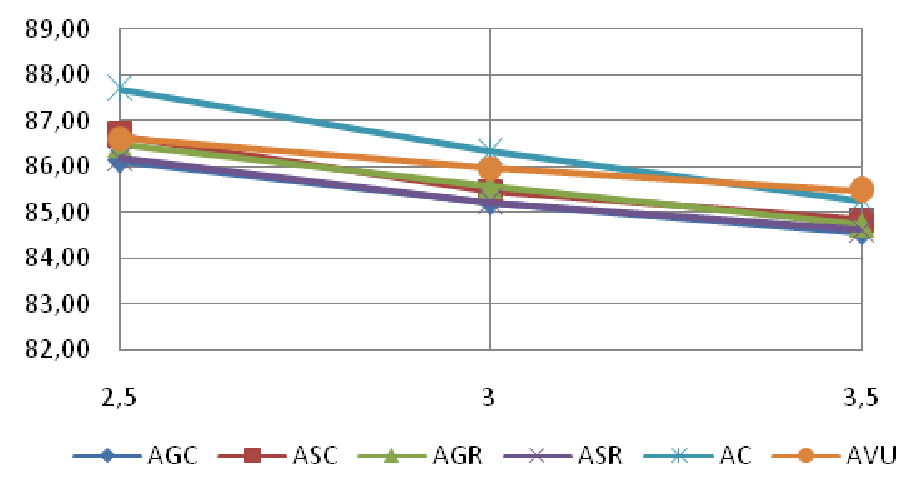

Figura 8.13: Rendimiento para $P=10$ bar y $X=20 \%$

Al igual que en la gráfica anterior se observa como el aceite de colza supera en rendimiento a los demás y la tendencia de disminución del rendimiento al aumentar el aire.

Representación gráfica del rendimiento para porcentaje de aceite del 30\% $(X=30 \%)$

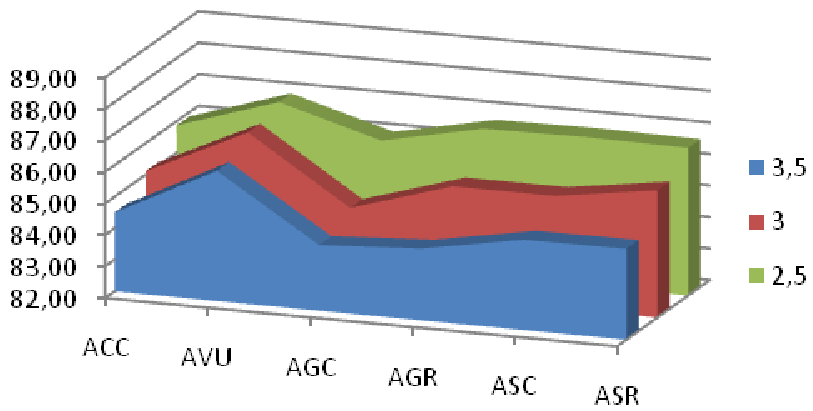

\begin{tabular}{lllllll|}
$\begin{array}{l}\mathrm{X}=\mathbf{3 0} \%, \\
\mathrm{P}=\mathbf{1 0 b a r}\end{array}$ & ACC & AVU & AGC & AGR & ASC & ASR \\
\hline $\mathrm{A}=\mathbf{2 , 5}$ & 85,86875 & 86,90948 & 85,99658 & 86,67902 & 86,71840 & 86,67931 \\
\hline $\mathrm{A}=3$ & 85,11291 & 86,64578 & 84,55915 & 85,54831 & 85,55255 & 86,03372 \\
\hline $\mathrm{A}=3,5$ & 84,50137 & 86,12837 & 84,08382 & 84,28067 & 84,86387 & 84,88327 \\
\hline
\end{tabular}

Figura 8.14: Rendimiento para $P=10$ bar y $X=30 \%$

\section{Comentario:}

En este caso se ve claramente como el AGC ofrece peores valores para cualquier posición de aire, superado para mal por el AC para $A=2,5$ 
(únicamente en ese valor, en el resto el ACC cumple). Estos valores son superados por el AVU claramente, sobre todo para las posiciones de admisión $A=3$ y $A=3,5$.

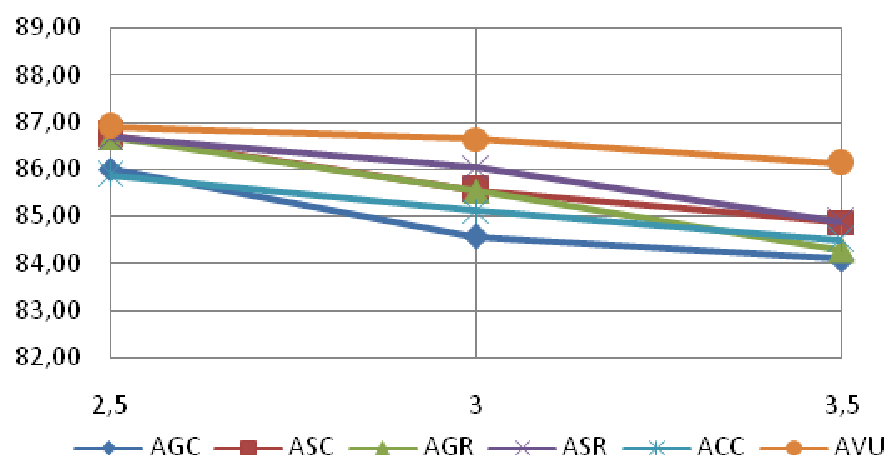

Figura 8.15: Rendimiento para $\mathrm{P}=10$ bar $\mathrm{y} X=30 \%$

Nuevamente se constatan los resultados anteriores, con un rendimiento superior del AVU en cada posición del aire. En este gráfico se aprecia mejor el buen comportamiento del ASR, y el mal comportamiento del AGC y del ACC cuando aumentamos el valor de las admisiones de aire.

Representación gráfica del rendimiento para porcentaje de aceite del $40 \%$ $(X=40 \%)$

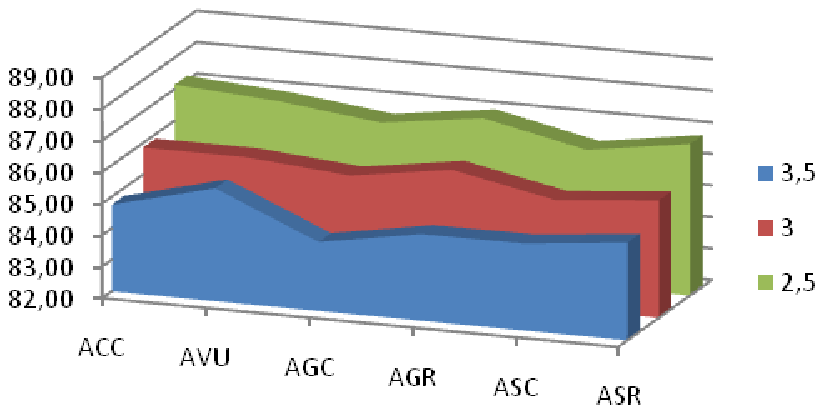

\begin{tabular}{|lllllll|}
$\begin{array}{l}\mathrm{X}=40 \%, \\
\mathrm{P}=\mathbf{1 0 b a r}\end{array}$ & ACC & AVU & AGC & AGR & ASC & ASR \\
\hline $\mathrm{A}=\mathbf{2 , 5}$ & $\mathbf{8 7 , 1 4 5 6 4}$ & 86,93349 & 86,55684 & 87,00777 & 86,31275 & 86,80579 \\
\hline $\mathrm{A}=\mathbf{3}$ & 85,85870 & 85,85699 & 85,58685 & 86,07825 & 85,42969 & 85,72543 \\
\hline $\mathrm{A}=3,5$ & 84,74938 & 85,58125 & 84,18637 & 84,74591 & 84,76151 & 85,09721 \\
\hline
\end{tabular}

Figura 8.16: Rendimiento para $P=10$ bar $y=40 \%$ 
Al contrario que en las proporciones anteriores, los valores de rendimiento no ofrecen grandes diferencias de un aceite a otro: para $A=2,5$, los valores están repartidos entre 86,3 y $87 \%$, para $A=3$ entre 85,4 y $86 \%$. Se tiene sin embargo que para $A=3,5$ los valores registrados ofrecen unos picos mayores (llega a haber $1,4 \%$ de diferencia entre el mayor y el menor).

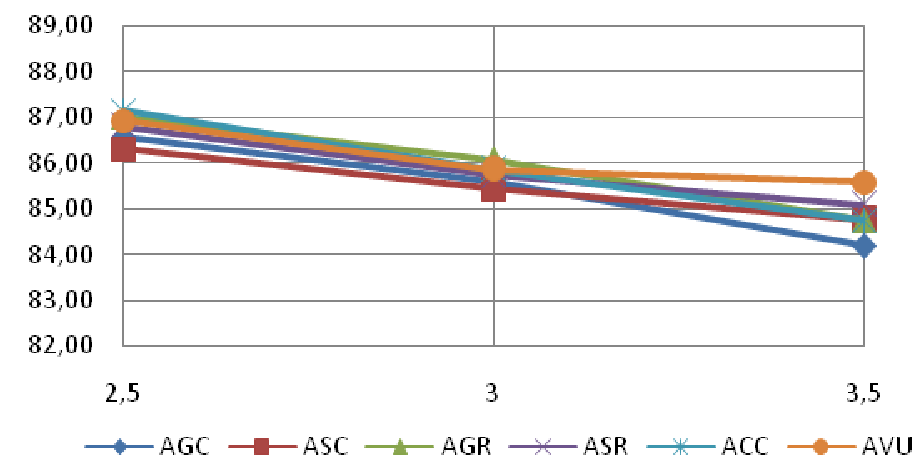

Figura 8.17: Rendimiento para $P=10$ bar y $X=40 \%$

Por aceites, queda claro que el AVU, tal y como se veía en los picos de la gráfica anterior, ofrece un mejor rendimiento cuando varía la admisión de aire. Puede apreciarse, a su vez, que los aceites crudos (girasol y soja), ofrecen peor comportamiento para esta concentración.

\subsubsection{Conclusiones}

Una vez analizado el comportamiento de cada aceite, puede decirse que el mejor rendimiento ofrecido en conjunto se da para el aceite de colza al $20 \%(87,686 \%)$. Los mejores rendimientos se dan, en todos los casos, para la posición de aire inferior, siendo éste el factor más determinante en todas las gráficas, por encima del tipo de aceite y de su porcentaje, tal y como anunciaba el ANOVA.

Los máximos registrados están todos por encima del 86,5\%, siendo los mínimos registrados todos superiores al 84\%. El rango de variación por tanto, entre condiciones tan distintas como las que se han estudiado, es del $2,5 \%$ entre unas y otras.

Las gráficas mostradas anteriormente denotan comportamientos heterogéneos entre aceites. En algunos casos, el aumento en la 
proporción de aceite da como resultado un aumento del rendimiento (ASR y AGR muestran esta tendencia claramente), y en otros casos se tiene un comportamiento opuesto (AC a partir del $20 \%$ y ASC). El comportamiento lógico, a priori, sería el de la disminución del rendimiento cuanto más aceite contuviese la mezcla. Sin embargo, tal y como mostraba el ANOVA, existe una influencia grande de la interacción TxX, la cual hace que la tendencia no sea única y dependa de qué aceite y en qué proporción.

Casi todos los valores del rendimiento para $A=2,5$ están por encima de $86 \%$, siendo el mínimo de $85,868 \%$ ( $T=A C$ y $X=30 \%$ ) y el máximo de $87,68 \%$ ( $T=A C$ y $X=20 \%$ ). Para $A=3$, los valores disminuyen alrededor de un $1 \%$, siendo el mínimo de $84,55 \%$ (T=AGC y $X=30 \%$ ) y el máximo de $86,64 \%$ ( $T=A V U$ y $X=30 \%$ ). Para $A=3,5$, los valores vuelven lógicamente a disminuir, con pocos valores superando el $85 \%$; el máximo está en $86,12 \%(\mathrm{~T}=\mathrm{AVU}$ y $\mathrm{X}=30 \%$ ), valor muy por encima del resto de la tabla, y el mínimo está en 84,08\% (T=AGC y $X=30 \%)$

\subsubsection{Análisis del rendimiento para $p=12$ bar}

Se muestra a continuación la matriz de resultados obtenidos:

Tabla 8.4 Matriz de resultados

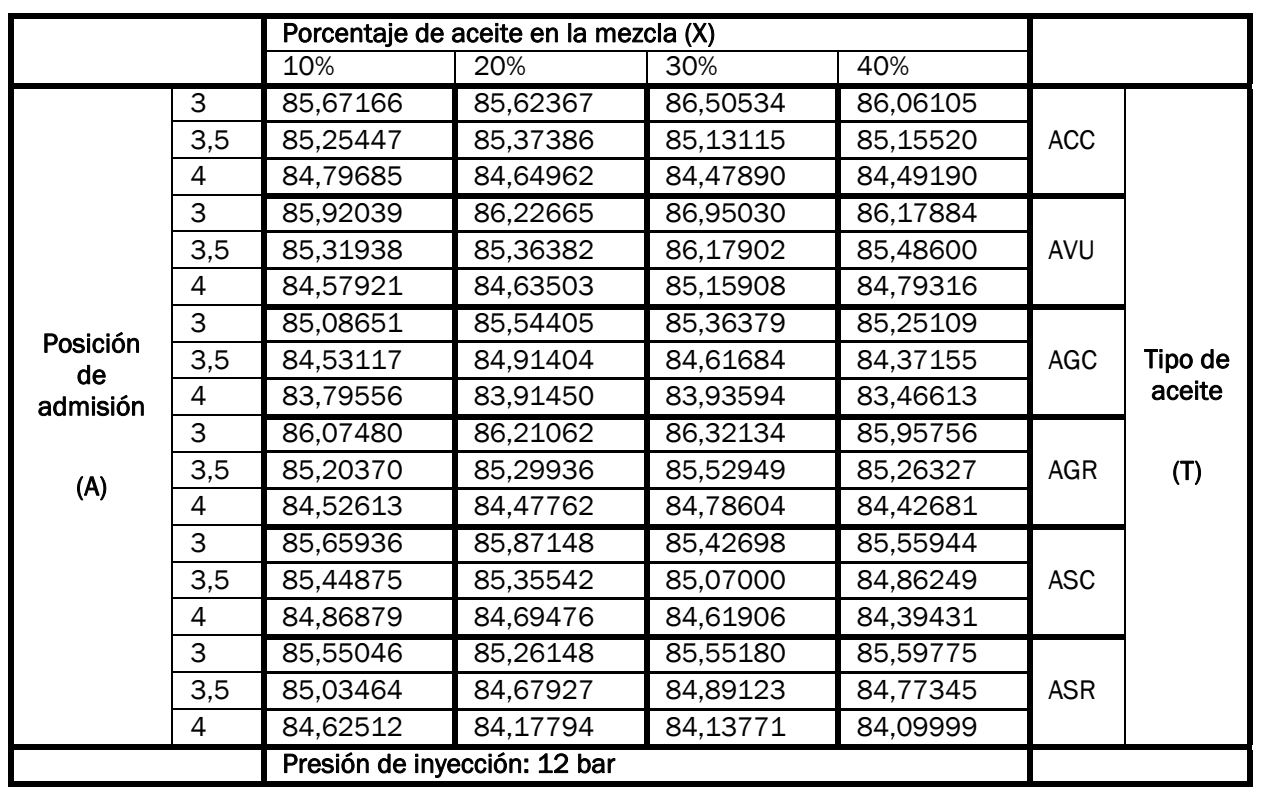


Se plantea el análisis de varianza como se planteó en el estudio de $\mathrm{P}=10$ bar. La tabla de los resultados es la siguiente:

Tabla 8.6Análisis ANOVA

\begin{tabular}{|c|c|c|c|c|c|c|c|}
\hline FACTOR & GdL & SS & MS & F & VC al 5\% & Influye & G. C. Crítica \\
\hline A & 2 & 22,54554 & 11,27277 & 502,64949 & 3,31583 & SI & $8,5277 \mathrm{E}-24$ \\
\hline T & 5 & 7,69568 & 1,53914 & 68,62960 & 2,53355 & SI & $1,65986 \mathrm{E}-15$ \\
\hline $\mathrm{X}$ & 3 & 0,56190 & 0,18730 & 8,35162 & 2,92228 & $\mathrm{SI}$ & 0,000347139 \\
\hline AxT & 10 & 0,56405 & 0,05640 & 2,51507 & 2,16458 & $\mathrm{SI}$ & 0,024808364 \\
\hline AxX & 6 & 0,29625 & 0,04937 & 2,20161 & 2,42052 & $\mathrm{NO}$ & 0,070540265 \\
\hline TxX & 15 & 1,73000 & 0,11533 & 5,14268 & 2,01480 & $\mathrm{SI}$ & $6,92604 \mathrm{E}-05$ \\
\hline Error & 30 & 0,672801 & 0,022427 & & & & \\
\hline Total & 71 & 34,066214 & & & & & \\
\hline
\end{tabular}

La interpretación es la siguiente: con un análisis al 5\% de confiabilidad, tenemos que la única variable que ha sido rechazada en el análisis ANOVA es la interacción entre la admisión del aire y el porcentaje de aceite en la mezcla. Sin embargo, se tiene que el grado de confiabilidad crítica para el estadístico $\mathrm{F}$ que nos ha resultado sería del 7\%: se puede decir que no está tan lejos de ser una variable significativa.

Sin embargo, aunque se diga que menos una el resto de variables son significativas, no lo son en la misma medida. En este caso, el grado de admisión de aire vuelve a ser la variable más significativa, con un grado de confiabilidad del orden de 10-22; en este caso además se tiene que la variable $\mathrm{T}$ o tipo de aceite de la mezcla también tiene un grado de confiabilidad muy bajo, del orden de 10-13. En orden, la siguiente variable más significativa es la interacción TxX, luego X y por último AxT.

A priori, serán las variables A y T las que marquen principalmente el comportamiento dentro de las gráficas que a continuación se exponen. 
Representaciones gráficas del rendimiento para el aceite de colza crudo ( $\mathrm{T}=\mathrm{ACC})$

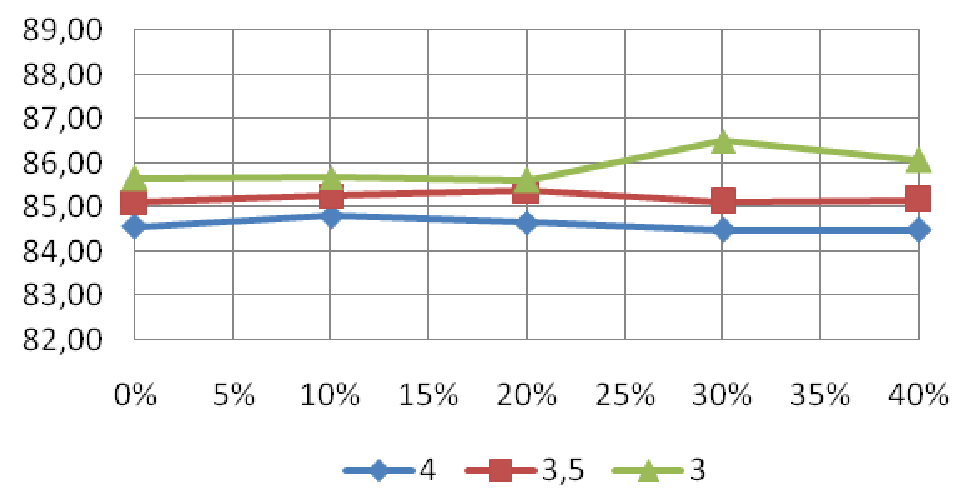

\begin{tabular}{|llllll|} 
AC, $P=12$ bar & $X=0 \%$ & $X=10 \%$ & $X=20 \%$ & $X=30 \%$ & $X=40 \%$ \\
\hline$A=3$ & 85,78101 & 85,67166 & 85,62367 & 86,50534 & 86,06105 \\
\hline$A=3,5$ & 84,95782 & 85,25447 & 85,37386 & 85,13115 & 85,15520 \\
\hline$A=4$ & 84,75750 & 84,79685 & 84,64962 & 84,47890 & 84,49190 \\
\hline \multicolumn{7}{r}{} \\
\hline
\end{tabular}

Figura 8.18: Rendimiento para $\mathrm{P}=12$ bar $\mathrm{y} T=\mathrm{ACC}$

Vuelve a observarse la tendencia existente en cuanto a la posición de admisión de aire. En este caso, los valores resultantes apenas varían poco, teniéndose un pico para la posición de admisión más favorable al $30 \%(86,5 \%)$. 
Representaciones gráficas del rendimiento para el aceite vegetal usado ( $\mathrm{T}=\mathrm{AVU})$

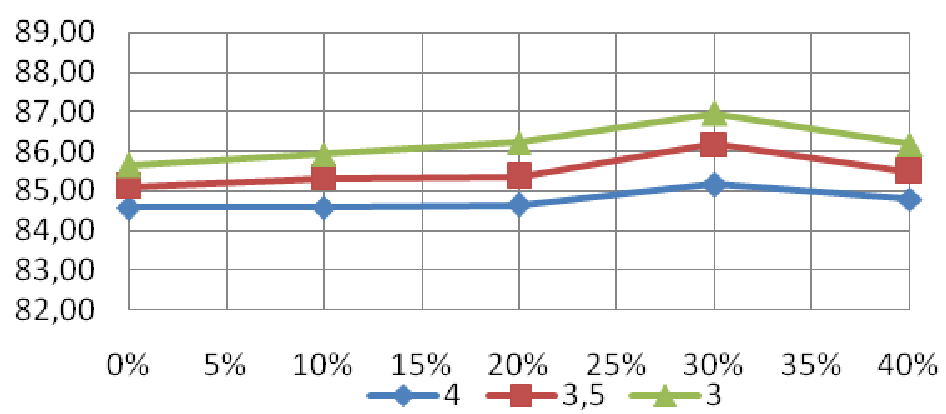

\begin{tabular}{|llllll|}
$\begin{array}{l}\text { AVU, } \\
P=12 \text { bar }\end{array}$ & $X=0 \%$ & $X=10 \%$ & $X=20 \%$ & $X=30 \%$ & $X=40 \%$ \\
\hline$A=3$ & 85,78101 & 85,92039 & 86,22665 & 86,95030 & 86,17884 \\
\hline$A=3,5$ & 84,95782 & 85,31938 & 85,36382 & 86,17902 & 85,48600 \\
\hline$A=4$ & 84,75750 & 84,57921 & 84,63503 & 85,15908 & 84,79316 \\
\hline
\end{tabular}

Figura 8.19: Rendimiento para $\mathrm{P}=12$ bar y $\mathrm{T}=\mathrm{AVU}$

Se observa una tendencia al alza hasta el 30\%, observándose una caída en los valores de rendimiento para más cantidad de aceite 
Representaciones gráficas del rendimiento para el aceite de girasol crudo ( $\mathrm{T}=\mathrm{AGC})$

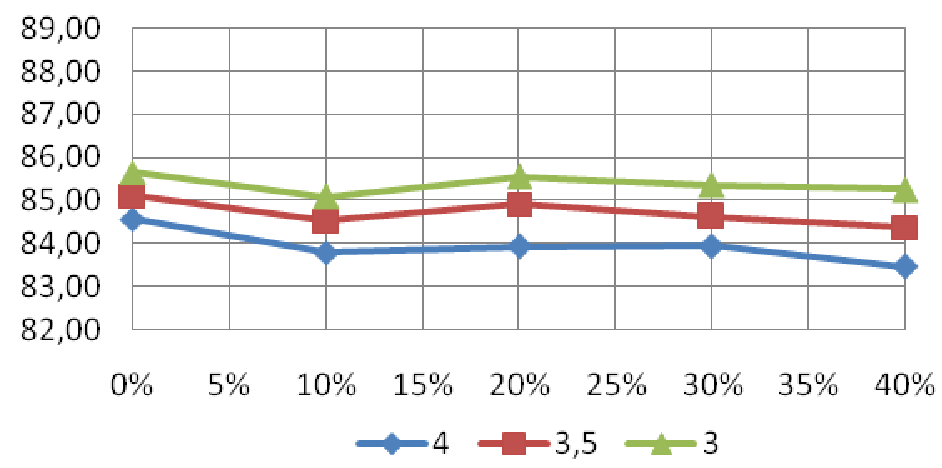

\begin{tabular}{|llllll|}
$\begin{array}{l}\text { AGC, } \\
P=12 \text { bar }\end{array}$ & $\mathrm{X}=\mathbf{0} \%$ & $\mathrm{X}=\mathbf{1 0} \%$ & $\mathrm{X}=\mathbf{2 0} \%$ & $\mathrm{X}=\mathbf{3 0} \%$ & $\mathrm{X}=\mathbf{4 0 \%}$ \\
\hline $\mathrm{A}=\mathbf{3}$ & 85,78101 & 85,08651 & 85,54405 & 85,36379 & 85,25109 \\
\hline $\mathrm{A}=3,5$ & 84,95782 & 84,53117 & 84,91404 & 84,61684 & 84,37155 \\
\hline $\mathrm{A}=4$ & 84,75750 & 83,79556 & 83,91450 & 83,93594 & 83,46613 \\
\hline
\end{tabular}

Figura 8.20: Rendimiento para $\mathrm{P}=12$ bar $\mathrm{y} \mathrm{T}=\mathrm{AGC}$

Se tiene un pico de rendimiento en $X=20 \%$, descendiendo los valores aunque no de manera muy significativa. En este caso, la tabla de datos muestra bien escalonados los valores de rendimiento obtenidos, con valores de 85, 84 y $83 \%$ para las sucesivas posiciones de la admisión de aire. 
Representaciones gráficas del rendimiento para el aceite de girasol refinado $(T=A G R)$

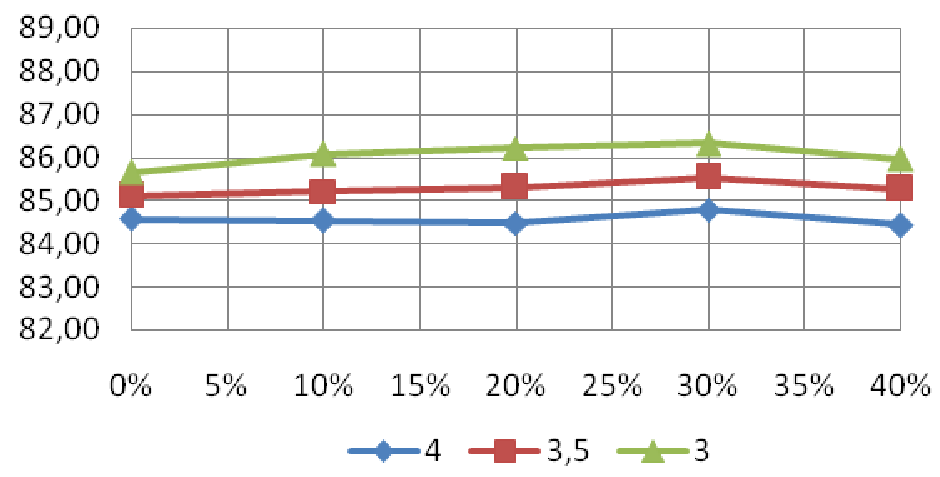

\begin{tabular}{|llllll}
$\begin{array}{l}\text { AGR, } \\
P=12 \text { bar }\end{array}$ & $\mathrm{X}=\mathbf{0} \%$ & $\mathrm{X}=\mathbf{1 0} \%$ & $\mathrm{X}=\mathbf{2 0} \%$ & $\mathrm{X}=\mathbf{3 0} \%$ & $\mathrm{X}=\mathbf{4 0 \%}$ \\
\hline $\mathrm{A}=\mathbf{3}$ & 85,78101 & 86,07480 & 86,21062 & 86,32134 & 85,95756 \\
\hline $\mathrm{A}=\mathbf{3 , 5}$ & 84,95782 & 85,20370 & 85,29936 & 85,52949 & 85,26327 \\
\hline $\mathrm{A}=\mathbf{4}$ & 84,75750 & 84,52613 & 84,47762 & 84,78604 & 84,42681 \\
\hline
\end{tabular}

Figura 8.21: Rendimiento para $P=12$ bar y $T=A G R$

Por otro lado, los valores que se obtienen variando $X$ del $10 \%$ al $40 \%$ apenas difieren un $0,4 \%$ en el rendimiento, resultando por tanto poca diferencia al aumentar el porcentaje de aceite. 
Representaciones gráficas del rendimiento para el aceite de soja crudo ( $\mathrm{T}=\mathrm{ASC}$ )

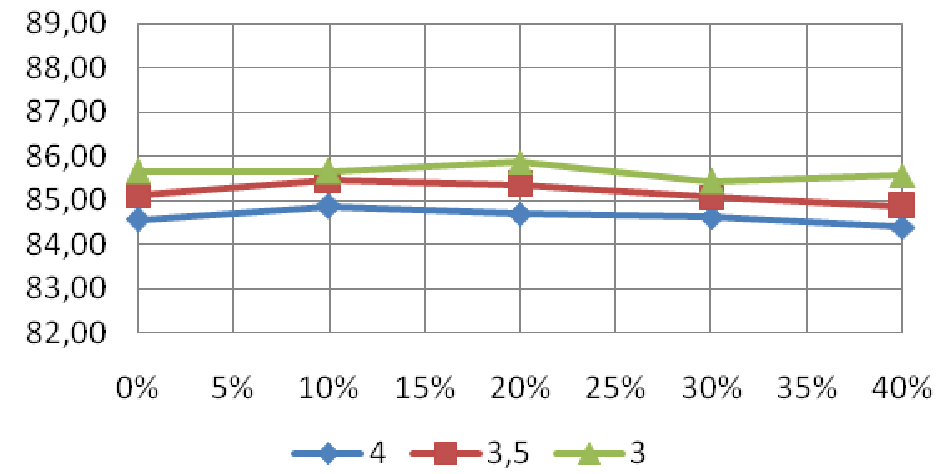

\begin{tabular}{llllll}
$\begin{array}{l}\text { ASC, } \\
\mathrm{P}=\mathbf{1 2 \text { bar }}\end{array}$ & $\mathrm{X}=\mathbf{0} \%$ & $\mathrm{X}=\mathbf{1 0} \%$ & $\mathrm{X}=\mathbf{2 0 \%}$ & $\mathrm{X}=\mathbf{3 0 \%}$ & $\mathrm{X}=\mathbf{4 0 \%}$ \\
\hline $\mathrm{A}=\mathbf{3}$ & 85,78101 & 85,65936 & 85,87148 & 85,42698 & 85,55944 \\
\hline $\mathrm{A}=\mathbf{3 , 5}$ & 84,95782 & 85,44875 & 85,35542 & 85,07000 & 84,86249 \\
\hline $\mathrm{A}=\mathbf{4}$ & 84,75750 & 84,86879 & 84,69476 & 84,61906 & 84,39431 \\
\hline
\end{tabular}

Figura 8.22: Rendimiento para $\mathrm{P}=12$ bar y $\mathrm{T}=\mathrm{ASC}$

Vuelven a mostrarse pocas diferencias entre valores de $X$ (para $A=3$, apenas varía 3 décimas). Comportamiento opuesto con la variable admisión de aire, diferenciándose claramente en el gráfico el escalonamiento existente (en la tabla de datos no resulta tan evidente). 
Representaciones gráficas del rendimiento para el aceite de soja crudo ( $\mathrm{T}=\mathrm{ASR}$ )

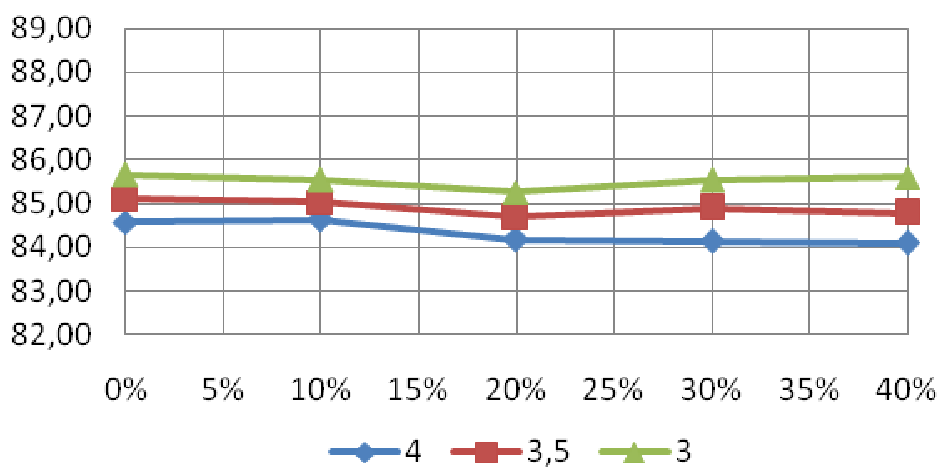

\begin{tabular}{|llllll}
$\begin{array}{l}\text { ASR, } \\
\mathrm{P}=\text { 12bar }\end{array}$ & $\mathrm{X}=\mathbf{0} \%$ & $\mathrm{X}=\mathbf{1 0} \%$ & $\mathrm{X}=\mathbf{2 0 \%}$ & $\mathrm{X}=\mathbf{3 0 \%}$ & $\mathrm{X}=\mathbf{4 0 \%}$ \\
\hline $\mathrm{A}=\mathbf{3}$ & 85,78101 & 85,55046 & 85,26148 & 85,55180 & 85,59775 \\
\hline $\mathrm{A}=\mathbf{3 , 5}$ & 84,95782 & 85,03464 & 84,67927 & 84,89123 & 84,77345 \\
\hline $\mathrm{A}=4$ & 84,75750 & 84,62512 & 84,17794 & 84,13771 & 84,09999 \\
\hline
\end{tabular}

Figura 8.23: Rendimiento para $\mathrm{P}=12$ bar y $\mathrm{T}=\mathrm{ASR}$

Puede observarse un bajón en todos los rendimientos para la concentración $X=20 \%$. Sin embargo, aparte de dichos datos para $X=20 \%$, para $A=3$ y $A=3,5$ los datos apenas varían de una concentración alta a una baja. En el caso de $A=4$, el bajón existe pero se mantiene en esos valores para $\mathrm{X}=30$ y $40 \%$. 
Representaciones gráficas del rendimiento para la posición del aire $A=3$

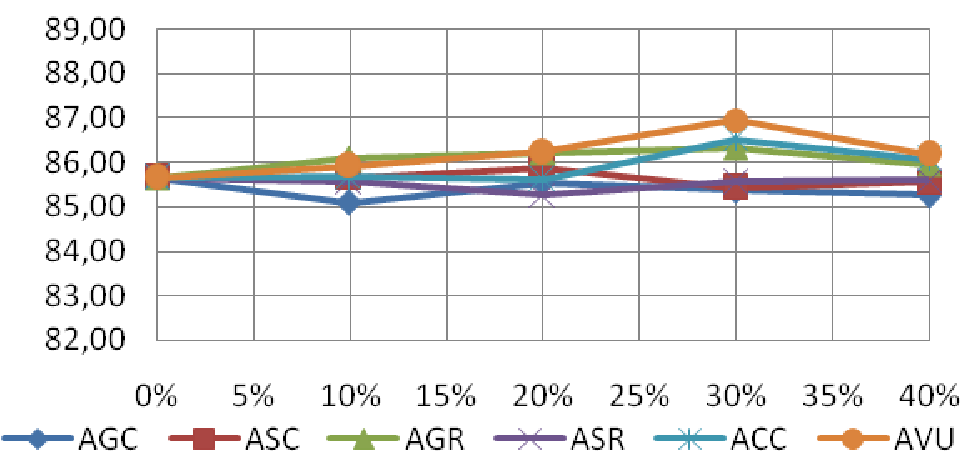

\begin{tabular}{|llllll|}
$\begin{array}{l}\text { A=3, } \\
P=12 \text { bar }\end{array}$ & $X=0 \%$ & $X=10 \%$ & $X=20 \%$ & $X=30 \%$ & $X=40 \%$ \\
\hline ACC & 85,78101 & 85,67166 & 85,62367 & 86,50534 & 86,06105 \\
\hline AVU & 85,78101 & 85,92039 & 86,22665 & 86,95030 & 86,17884 \\
\hline AGC & 85,78101 & 85,08651 & 85,54405 & 85,36379 & 85,25109 \\
\hline AGR & 85,78101 & 86,07480 & 86,21062 & 86,32134 & 85,95756 \\
\hline ASC & 85,78101 & 85,65936 & 85,87148 & 85,42698 & 85,55944 \\
\hline ASR & 85,78101 & 85,55046 & 85,26148 & 85,55180 & 85,59775 \\
\hline
\end{tabular}

Figura 8.24: Rendimiento para $P=12$ bar y $A=3$

Viendo los gráficos y los datos se aprecia que los aceites de soja, ASC y ASR, y el AGC, obtienen los peores rendimientos en estas condiciones, dando el AVU los mejores de nuevo. 
Representaciones gráficas del rendimiento para la posición del aire $A=3,5$

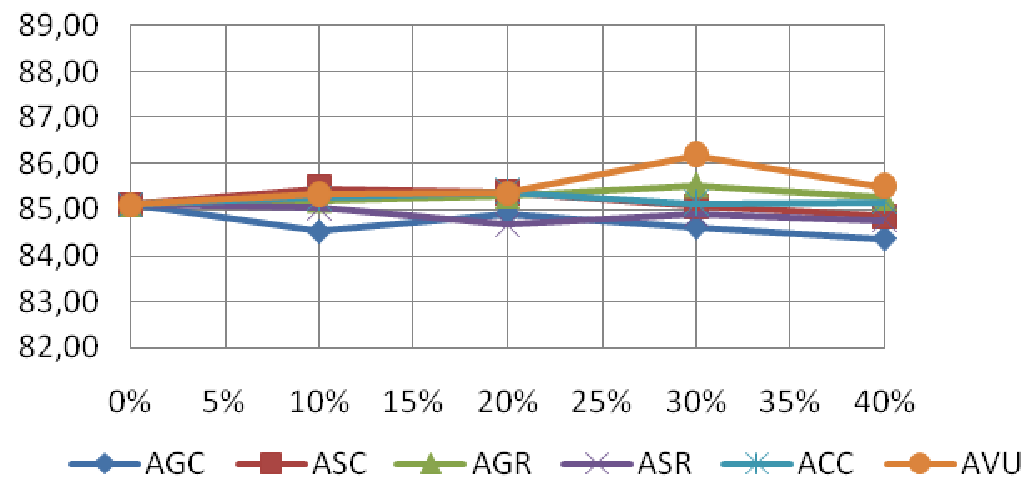

\begin{tabular}{|llllll|}
$\begin{array}{l}\text { A=3,5, } \\
P=12 \text { bar }\end{array}$ & $\mathrm{X}=\mathbf{0} \%$ & $\mathrm{X}=\mathbf{1 0} \%$ & $\mathrm{X}=\mathbf{2 0} \%$ & $\mathrm{X}=\mathbf{3 0} \%$ & $\mathrm{X}=\mathbf{4 0} \%$ \\
\hline ACC & 84,95782 & 85,25447 & 85,37386 & 85,13115 & 85,15520 \\
\hline AVU & 84,95782 & 85,31938 & 85,36382 & 86,17902 & 85,48600 \\
\hline AGC & 84,95782 & 84,53117 & 84,91404 & 84,61684 & 84,37155 \\
\hline AGR & 84,95782 & 85,20370 & 85,29936 & 85,52949 & 85,26327 \\
\hline ASC & 84,95782 & 85,44875 & 85,35542 & 85,07000 & 84,86249 \\
\hline ASR & 84,95782 & 85,03464 & 84,67927 & 84,89123 & 84,77345 \\
\hline
\end{tabular}

Figura 8.25: Rendimiento para $\mathrm{P}=12$ bar y $\mathrm{A}=3,5$

La tendencia con respecto al caso anterior es a la baja, tal y como se esperaba. Vuelve a ser el AVU el que ofrece el máximo, si bien puede decirse que se trata de un máximo aislado. El AGC ofrece los peores valores de rendimiento en general, seguido por el ASR. 


\section{Representaciones gráficas del rendimiento para la posición del aire $A=4$}

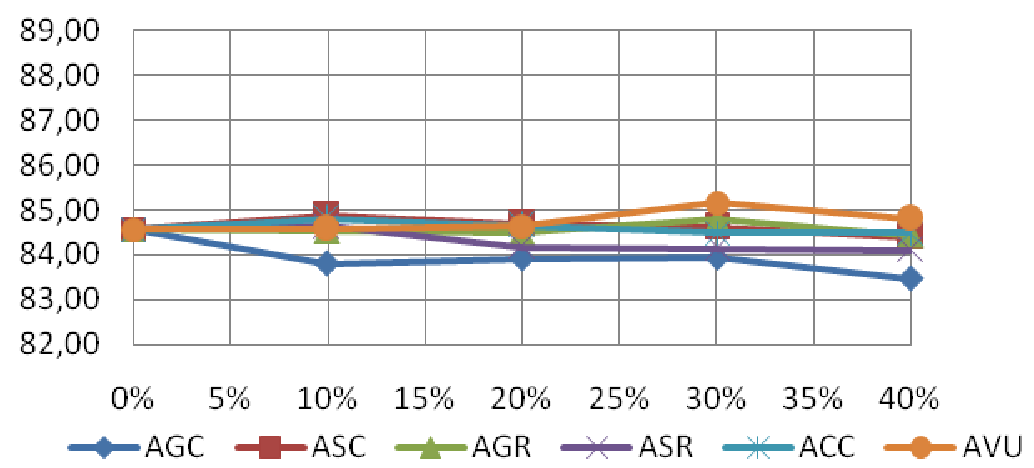

\begin{tabular}{|llllll|}
$\begin{array}{l}\mathrm{A}=4, \\
\mathrm{P}=12 \text { bar }\end{array}$ & $\mathrm{X}=\mathbf{0} \%$ & $\mathrm{X}=10 \%$ & $\mathrm{X}=\mathbf{2 0 \%}$ & $\mathrm{X}=\mathbf{3 0 \%}$ & $\mathrm{X}=\mathbf{4 0 \%}$ \\
\hline AC & 84,75750 & 84,79685 & 84,64962 & 84,47890 & 84,49190 \\
\hline AVU & 84,75750 & 84,57921 & 84,63503 & 85,15908 & 84,79316 \\
\hline AGC & 84,75750 & 83,79556 & 83,91450 & 83,93594 & 83,46613 \\
\hline AGR & 84,75750 & 84,52613 & 84,47762 & 84,78604 & 84,42681 \\
\hline ASC & 84,75750 & 84,86879 & 84,69476 & 84,61906 & 84,39431 \\
\hline ASR & 84,75750 & 84,62512 & 84,17794 & 84,13771 & 84,09999 \\
\hline
\end{tabular}

Figura 8.26: Rendimiento para $P=12$ bar y $A=4$

Se observa una caída general en el rendimiento en comparación con los dos anteriores gráficos (y tablas). Se llega al 83\% en el AGC, cuando para $A=3$ ningún valor para dicho aceite bajaba del $85 \%$. El peor comportamiento vuelve a darlo el AGC, seguido por el ASR. 
Representaciones gráficas del rendimiento para el porcentaje en peso de aceite $X=10 \%$

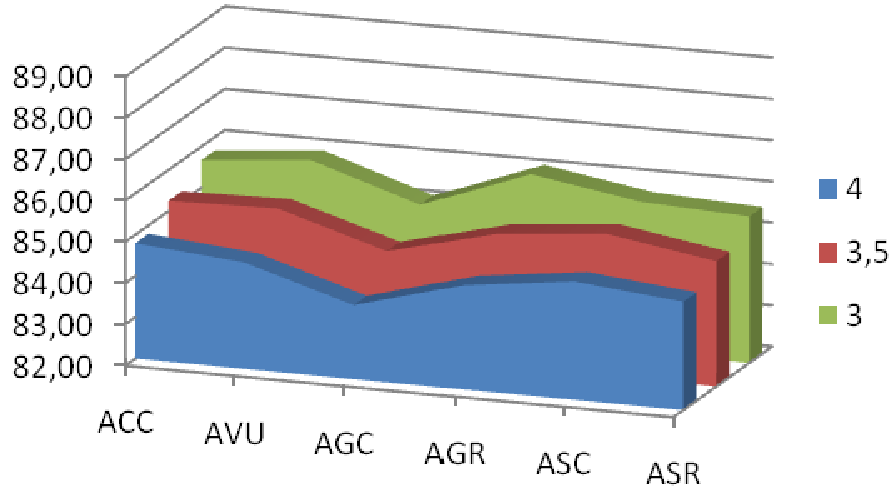

\begin{tabular}{|lllllll|}
\hline $\begin{array}{l}\mathrm{X}=\mathbf{1 0} \%, \\
\mathrm{P}=12 \mathrm{bar}\end{array}$ & AC & AVU & AGC & AGR & ASC & ASR \\
\hline $\mathrm{A}=3$ & 85,67166 & 85,92039 & 85,08651 & 86,07480 & 85,65936 & 85,55046 \\
\hline $\mathrm{A}=3,5$ & 85,25447 & 85,31938 & 84,53117 & 85,20370 & 85,44875 & 85,03464 \\
\hline $\mathrm{A}=4$ & 84,79685 & 84,57921 & 83,79556 & 84,52613 & 84,86879 & 84,62512 \\
\hline
\end{tabular}

Figura 8.27: Rendimiento para $P=12$ bar y $X=10 \%$

Se ve la tendencia seguida por todos los aceites y la dependencia con la posición de admisión del aire. Queda claro que, para este porcentaje, el AGC ofrece los peores rendimientos.

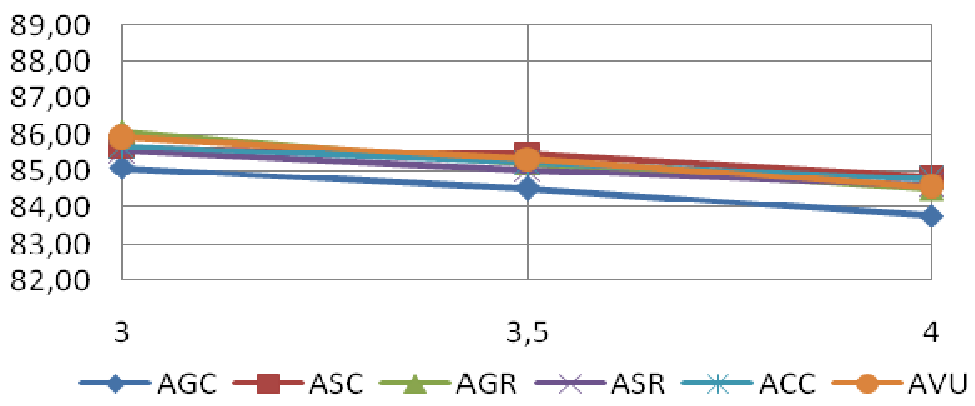

Figura 8.28: Rendimiento para $P=12$ bar y $X=10 \%$

Como demostraba el gráfico anterior, éste demuestra que los mejores rendimientos los ofrecen AGR y AVU, con valores alrededor del $86 \%$. El resto de aceites siguen todas unas tendencias similares con valores entre el 85,5 y el $84,5 \%$. 
Representaciones gráficas del rendimiento para el porcentaje en peso de aceite $X=20 \%$

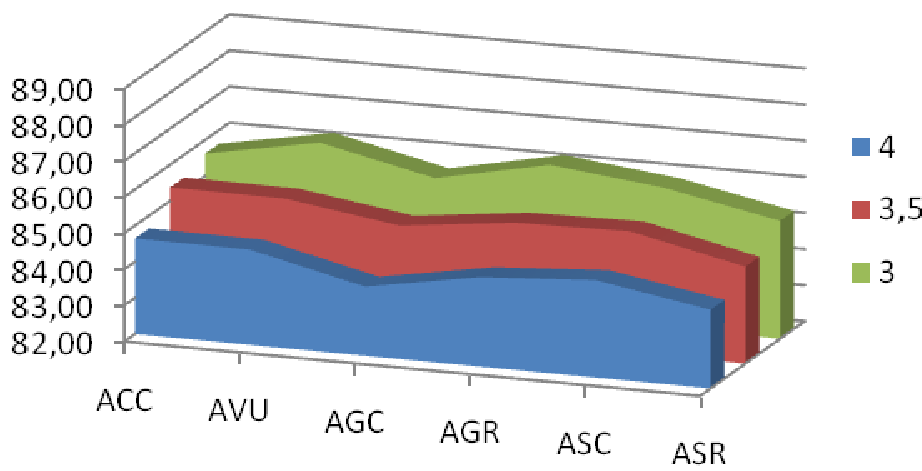

\begin{tabular}{|lllllll|}
$\begin{array}{l}\mathrm{X}=\mathbf{2 0} \%, \\
\mathrm{P}=\mathbf{1 2} \text { bar }\end{array}$ & ACC & AVU & AGC & AGR & ASC & ASR \\
\hline $\mathrm{A}=\mathbf{3}$ & 85,62367 & $\mathbf{8 6 , 2 2 6 6 5}$ & 85,54405 & 86,21062 & 85,87148 & 85,26148 \\
\hline $\mathrm{A}=\mathbf{3 , 5}$ & 85,37386 & 85,36382 & 84,91404 & 85,29936 & 85,35542 & 84,67927 \\
\hline $\mathrm{A}=4$ & 84,64962 & 84,63503 & 83,91450 & 84,47762 & 84,69476 & 84,17794 \\
\hline
\end{tabular}

Figura 8.29: Rendimiento para $P=12$ bar y $X=20 \%$

Como en el gráfico anterior, queda demostrado que el AGC es la que peores rendimientos ofrece. También el ASR ofrece rendimientos bajos, peores incluso que su equivalente cruda. Los picos obtenidos corresponden al AVU y al AGR.

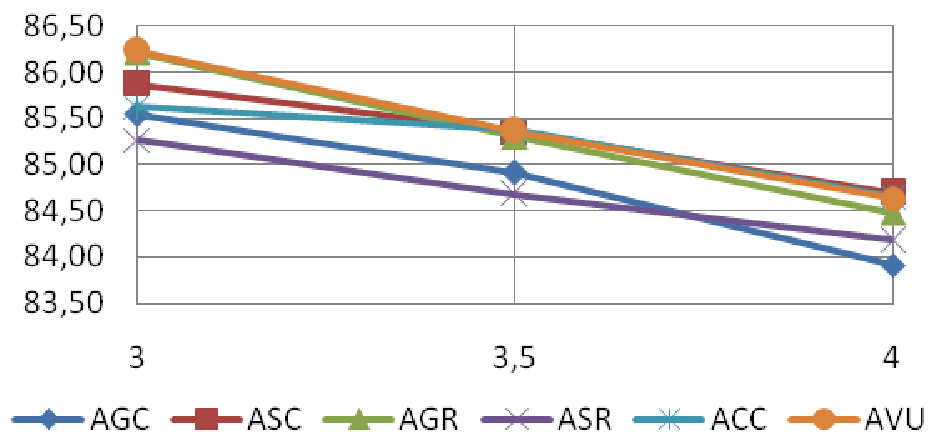

Figura 8.30: Rendimiento para $P=12$ bar y $X=20 \%$ 
Representaciones gráficas del rendimiento para el porcentaje en peso de aceite $\mathrm{X}=30 \%$

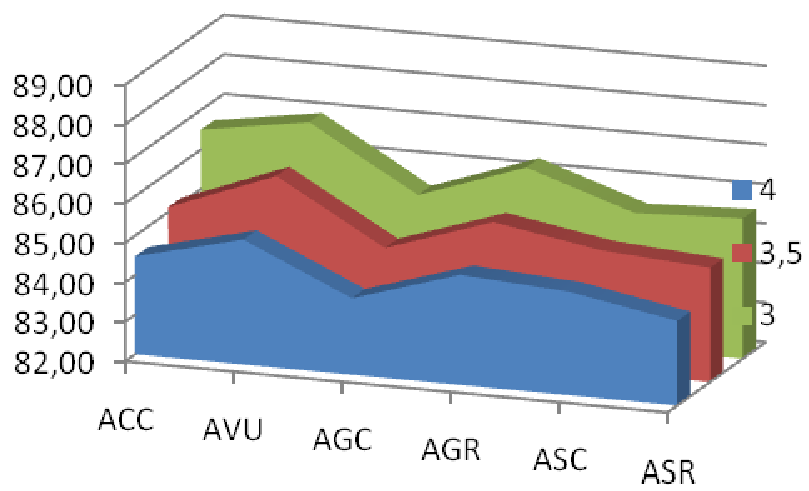

\begin{tabular}{|lllllll|}
\hline $\begin{array}{l}\mathrm{X}=30 \%, \\
\mathrm{P}=\mathbf{1 2 \text { bar }}\end{array}$ & ACC & AVU & AGC & AGR & ASC & ASR \\
\hline $\mathrm{A}=3$ & 86,50534 & 86,95030 & 85,36379 & 86,32134 & 85,42698 & 85,55180 \\
\hline $\mathrm{A}=3,5$ & 85,13115 & 86,17902 & 84,61684 & 85,52949 & 85,07000 & 84,89123 \\
\hline $\mathrm{A}=4$ & 84,47890 & 85,15908 & 83,93594 & 84,78604 & 84,61906 & 84,13771 \\
\hline
\end{tabular}

Figura 8.31: Rendimiento para $\mathrm{P}=12$ bar y $\mathrm{X}=30 \%$

Como antes, el AGC ofrece los peores resultados, seguido de cerca por el ASR. EI AVU vuelve a registrar los mejores rendimientos.

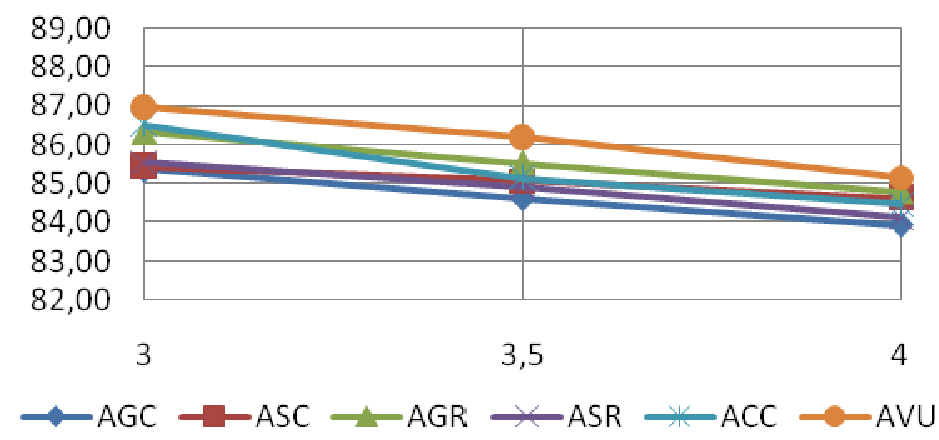

Figura 8.32: Rendimiento para $\mathrm{P}=12$ bar y $\mathrm{X}=30 \%$

Esta gráfica lo muestra muy claramente: mejores valores en el AVU, valores muy inferiores en el AGC y el ASR. 
Representaciones gráficas del rendimiento para el porcentaje en peso de aceite $X=40 \%$

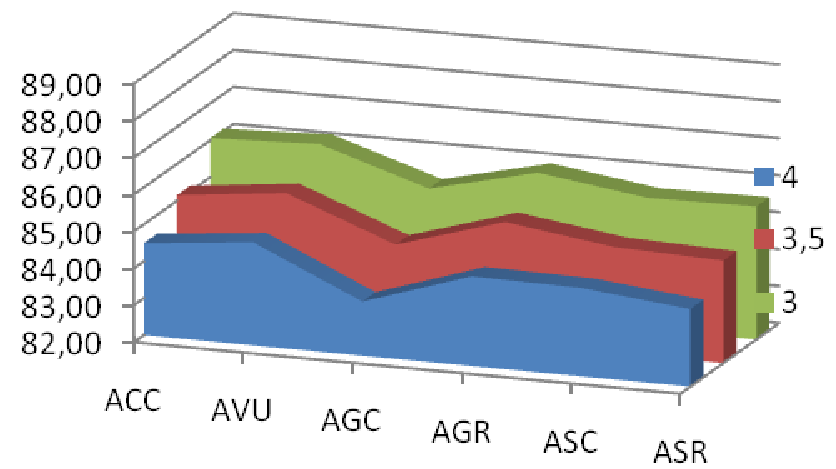

\begin{tabular}{|lllllll|}
\hline $\begin{array}{l}\mathrm{X}=40 \%, \\
\mathrm{P}=12 \text { bar }\end{array}$ & AC & AVU & AGC & AGR & ASC & ASR \\
\hline $\mathrm{A}=3$ & 86,06105 & 86,17884 & 85,25109 & 85,95756 & 85,55944 & 85,59775 \\
\hline $\mathrm{A}=3,5$ & 85,15520 & 85,48600 & 84,37155 & 85,26327 & 84,86249 & 84,77345 \\
\hline $\mathrm{A}=4$ & 84,49190 & 84,79316 & 83,46613 & 84,42681 & 84,39431 & 84,09999 \\
\hline
\end{tabular}

Figura 8.33: Rendimiento para $\mathrm{P}=12$ bar $\mathrm{y} X=40 \%$

Sigue la tendencia de los porcentajes anteriores: el AGC ofrece los peores rendimientos y el AVU y el AGR los mejores.

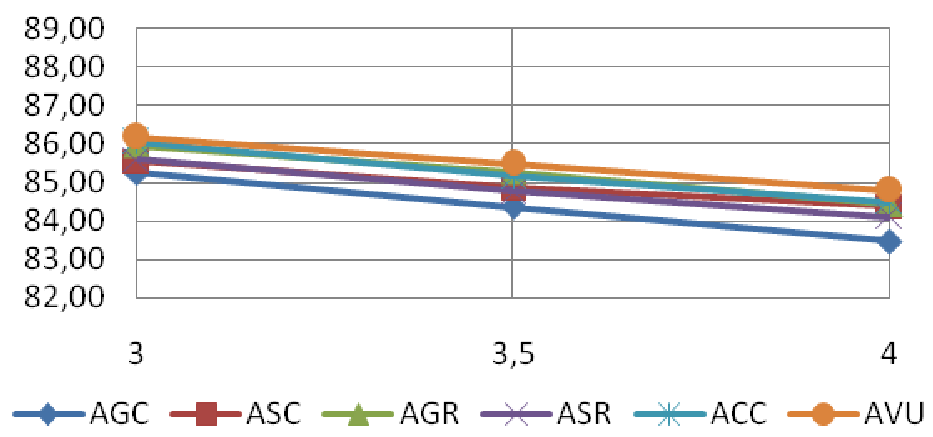

Figura 8.34: Rendimiento para $P=12$ bar y $X=40 \%$ 


\subsubsection{Conclusiones}

Las gráficas para todos los tipos de aceite muestran el comportamiento anunciado anteriormente (ya visto para $\mathrm{P}=10$ bar): cae el rendimiento a medida que aumenta la posición de la admisión de aire. El máximo obtenido es $86,95 \%$ y se tiene para AVU, $X=30 \%$ y $A=3$. El mínimo es $83,46 \%$ y se consigue para $A G C, X=40 \%$ y $A=4$.

Los máximos obtenidos para cada tipo de aceite son 86,5\% (ACC), 86,95\% (AVU), 85,44\% (AGC), 86,32\% (AGR), 85,87\% (ASC) y $85,59 \%$ (ASR), siendo la mayoría obtenidos para un porcentaje del $30 \%$ y en $A=3$. Los mínimos globales se obtienen para el AGC y la posición más desfavorable de admisión del aire, siendo los únicos valores de este ensayo por debajo del $84 \%$.

Vista la serie de gráficas para $A=$ constante, queda contrastada la caída que sufre el rendimiento cuando aumenta el caudal de aire que se introduce en la caldera. Los valores obtenidos para $A=3$ están alrededor del $86 \%$, para $A=3,5$ alrededor del $85,5 \%$ y para $A=4$ alrededor del $85 \%$.

La primera gráfica de cada análisis a $X=$ constante muestra de nuevo la importancia de la posición de la admisión del aire: no se tiene, ni en este ni en otro estudio, ningún máximo en ninguna posición de admisión de aire que no sea la mínima. La segunda gráfica de cada análisis es más interesante ya que muestra la evolución de cada tipo de combustible con el aire de admisión (no en vano, el tipo de combustible es la segunda variable más significativa). Cada tipo de aceite merece un estudio individual:

- El AVU vuelve a mostrar el mejor comportamiento del estudio, ofreciendo los máximos para casi todos los porcentajes de sustitución y posiciones de admisión del aire. Así, la conclusión es que se trata del combustible más valido.

- El AGR se revela como un buen combustible también. No da tan buenos rendimientos como el AVU, pero se queda cerca, siendo su comportamiento ligeramente inferior.

- El AGC, sin embargo, es el combustible que peor rendimiento ofrece a lo largo de todo este estudio. En el caso del aceite de girasol queda comprobado el efecto del refino, ya que mejora claramente las prestaciones que ofrece como combustible.

- La diferencia en el refino para el aceite de soja no es tan acusada como lo es para el de girasol. De hecho, los valores registrados son mejores en algunos casos para el aceite sin refinar.

- El AC da buenos resultados con la posición mínima de admisión de aire: prestando atención a los segundos gráficos para cada porcentaje, 
y observando los datos en las tablas, se ve que sufre un descenso de rendimiento acusado, pasando de tener un rendimiento cerca de los mejores para $\mathrm{A}=3$ a estar lejos de los mismos para $\mathrm{A}=4$.

\subsubsection{Análisis del rendimiento para $p=14$ bar.}

Se muestra a continuación la matriz de resultados obtenidos:

Tabla 8.7 Matriz de resultados para $\mathrm{P}=14 \mathrm{bar}$

\begin{tabular}{|c|c|c|c|c|c|c|c|}
\hline & \multicolumn{4}{|c|}{ Porcentaje de aceite en la mezcla $(X)$} & & \\
\hline & & $10 \%$ & $20 \%$ & $30 \%$ & $40 \%$ & & \\
\hline \multirow{18}{*}{$\begin{array}{l}\text { Posición } \\
\text { de } \\
\text { admisión }\end{array}$} & 3,5 & 85,35376 & 85,31776 & 85,21601 & 85,09748 & \multirow{3}{*}{ ACC } & \multirow{18}{*}{$\begin{array}{l}\text { Tipo de } \\
\text { aceite }\end{array}$} \\
\hline & 4 & 84,83856 & 84,69706 & 84,53334 & 84,41408 & & \\
\hline & 4,5 & 84,16441 & 83,90645 & 83,66133 & 83,60630 & & \\
\hline & 3,5 & 85,21401 & 85,47098 & 85,73066 & 85,66534 & \multirow{3}{*}{ AVU } & \\
\hline & 4 & 84,69014 & 84,91730 & 85,27404 & 84,90528 & & \\
\hline & 4,5 & 83,96161 & 84,38237 & 84,68806 & 84.99401 & & \\
\hline & 3,5 & 84,37523 & 84,96797 & 84,62167 & 84,64092 & \multirow{3}{*}{ AGC } & \\
\hline & 4 & 83,70988 & 84,09857 & 84,12224 & 83,95744 & & \\
\hline & 4,5 & 83,22246 & 83,41445 & 83,26727 & 83,07591 & & \\
\hline & 3,5 & 85,28721 & 85,46820 & 85,61041 & 85,36982 & \multirow{3}{*}{ AGR } & \\
\hline & 4 & 84,40975 & 84,51075 & 85,04085 & 84,85789 & & \\
\hline & 4,5 & 83,82135 & 83,84999 & 84,12749 & 84,05208 & & \\
\hline & 3,5 & 85,41063 & 85,20037 & 85,22901 & 84,57592 & \multirow{3}{*}{ ASC } & \\
\hline & 4 & 84,80435 & 84,60657 & 84,58320 & 84,11409 & & \\
\hline & 4,5 & 84,21353 & 83,98145 & 83,99638 & 83,63639 & & \\
\hline & 3,5 & 85,15540 & 84,96268 & 85,06103 & 84,70187 & \multirow{3}{*}{ ASR } & \\
\hline & 4 & 84,25931 & 84,36741 & 84,34485 & 84,18875 & & \\
\hline & 4,5 & 83,70127 & 83,67866 & 83,48797 & 83,43769 & & \\
\hline & & \multicolumn{4}{|c|}{ Presión de inyección: 14 bar } & & \\
\hline
\end{tabular}

Se plantea el análisis de varianza como se planteó en el estudio de $\mathrm{P}=10$ bar. La tabla de los resultados es la siguiente:

Tabla 8.8 Análisis ANOVA para $\mathrm{P}=14 \mathrm{bar}$

\begin{tabular}{|l|l|l|l|l|l|l|l|}
\hline FACTOR & GdL & SS & MS & F & VC al 5\% & Influye & G. C. Crítica \\
\hline A & 2 & 20,510231 & 10,255116 & 718,09703 & 3,31583 & SI & $4,61261 \mathrm{E}-26$ \\
\hline T & 5 & 7,576134 & 1,515227 & 106,10118 & 2,53355 & SI & $3,86453 \mathrm{E}-18$ \\
\hline X & 3 & 0,347284 & 0,115761 & 8,10599 & 2,92228 & SI & 0,000421868 \\
\hline AxT & 10 & 0,363858 & 0,036386 & 2,54785 & 2,16458 & NO & 0,023246008 \\
\hline AxX & 6 & 0,092286 & 0,015381 & 1,07703 & 2,42052 & NO & 0,398138093 \\
\hline TxX & 15 & 2,134959 & 0,142331 & 9,96646 & 2,01480 & SI & $7,15199 \mathrm{E}-08$ \\
\hline Error & 30 & 0,428429 & 0,014281 & & & & \\
\hline Total & 71 & 31,453181 & & & & & \\
\hline
\end{tabular}


La interpretación es la siguiente: con un análisis al 5\% de confiabilidad, tenemos que las variables rechazadas por el análisis ANOVA son las interacciones aire-tipo de aceite y aire-porcentaje de aceite. Dichas variables son rechazadas ampliamente por el análisis (el grado de confiabilidad sería altísimo, del orden del $79 \%$ uno y del $47 \%$ otro, muy lejos del $5 \%$ que se elige habitualmente).

Las medidas, como en los análisis anteriores, no dan un mismo grado de significación. Se vuelve a tener que la variable más significativa es la posición de la admisión del aire (orden de 10-24), seguida del tipo de aceite (orden de 10-16). También es muy grande la influencia de la interacción T-X (orden de 10-6).Las siguiente en orden de importancia es el porcentaje de aceite, pero es de un orden de influencia mucho menor que las anteriores.

Al igual que en el análisis anterior, serán las variables A y $\mathrm{T}$ las que marquen la diferencia en el comportamiento de la combustión. 
Representaciones gráficas del rendimiento para el aceite de colza crudo $(\mathrm{T}=\mathrm{ACC})$

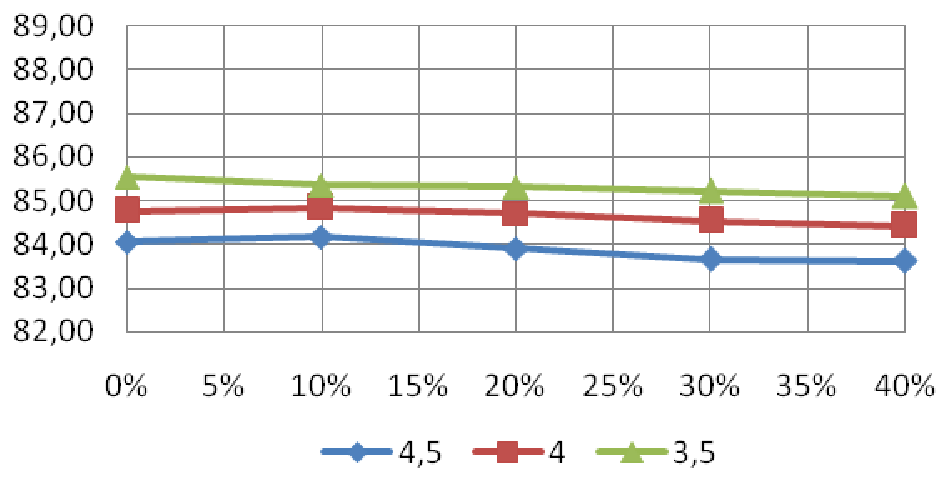

\begin{tabular}{|llllll|}
\hline $\mathrm{AC}, \mathrm{P}=$ 14bar & $\mathrm{X}=\mathbf{0} \%$ & $\mathrm{X}=\mathbf{1 0} \%$ & $\mathrm{X}=\mathbf{2 0} \%$ & $\mathrm{X}=\mathbf{3 0} \%$ & $\mathrm{X}=\mathbf{4 0 \%}$ \\
\hline $\mathrm{A}=\mathbf{3 , 5}$ & 85,78101 & $\mathbf{8 5 , 3 5 3 7 6}$ & 85,31776 & 85,21601 & 85,09748 \\
\hline $\mathrm{A}=4$ & 84,95782 & 84,83856 & 84,69706 & 84,53334 & 84,41408 \\
\hline $\mathrm{A}=4,5$ & 84,75750 & 84,16441 & 83,90645 & 83,66133 & 83,60630 \\
\hline
\end{tabular}

Figura 8.35: Rendimiento para $\mathrm{P}=14$ bar y $\mathrm{ACC}$

Se aprecia una tendencia a la baja, tanto con la apertura de la admisión de aire como con el aumento del porcentaje de aceite. Se aprecia que el descenso de rendimiento es casi lineal a posición de admisión constante. 
Representaciones gráficas del rendimiento para el aceite vegetal usado ( $T=A V U)$.

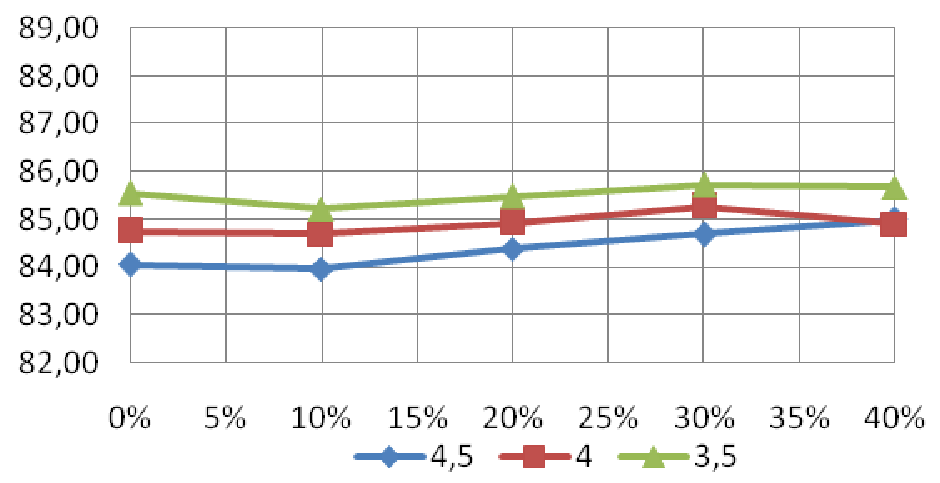

\begin{tabular}{|llllll|}
$\begin{array}{l}\text { AVU, } \\
\mathrm{P}=\mathbf{1 4 \text { bar }}\end{array}$ & $\mathrm{X}=\mathbf{0} \%$ & $\mathrm{X}=10 \%$ & $\mathrm{X}=\mathbf{2 0 \%}$ & $\mathrm{X}=\mathbf{3 0} \%$ & $\mathrm{X}=\mathbf{4 0} \%$ \\
\hline $\mathrm{A}=\mathbf{3 , 5}$ & 85,78101 & 85,21401 & 85,47098 & 85,73066 & 85,66534 \\
\hline $\mathrm{A}=4$ & 84,95782 & 84,69014 & 84,91730 & 85,27404 & 84,90528 \\
\hline $\mathrm{A}=4,5$ & 84,75750 & 83,96161 & 84,38237 & 84,68806 & 84,99401 \\
\hline
\end{tabular}

Figura 8.36: Rendimiento para $\mathrm{P}=14$ bar y $\mathrm{AVU}$

Como en los análisis anteriores, el rendimiento del AVU sufre una subida hasta $X=30 \%$, en el cual se tienen los picos de rendimiento para las tres posiciones de admisión. 
Representaciones gráficas del rendimiento para el aceite de girasol crudo ( $T=A G C)$

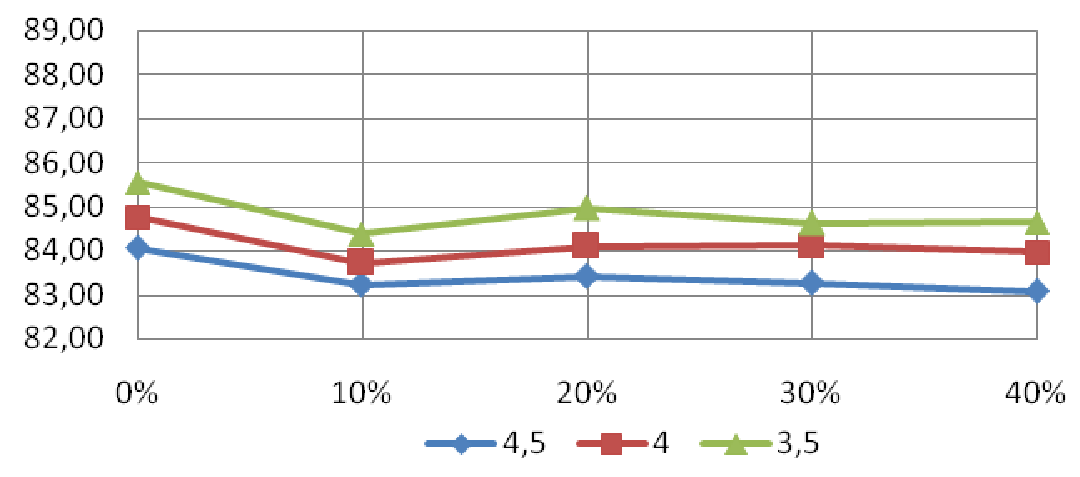

\begin{tabular}{|llllll|}
\hline $\begin{array}{l}\text { AGC, } \\
P=14 \text { bar }\end{array}$ & $X=0 \%$ & $X=10 \%$ & $X=20 \%$ & $X=30 \%$ & $X=40 \%$ \\
\hline$A=3,5$ & 85,78101 & 84,37523 & 84,96797 & 84,62167 & 84,64092 \\
\hline$A=4$ & 84,95782 & 83,70988 & 84,09857 & 84,12224 & 83,95744 \\
\hline$A=4,5$ & 84,75750 & 83,22246 & 83,41445 & 83,26727 & 83,07591 \\
\hline
\end{tabular}

Figura 8.37: Rendimiento para $\mathrm{P}=14$ bar y $\mathrm{AGC}$

En este caso, el pico se alcanza para $X=20 \%$, si bien la tendencia es bastante constante para todas las posiciones de admisión de aire para $X^{\prime}$ 's mayores a ese $20 \%$. 
Representaciones gráficas del rendimiento para el aceite de girasol refinado ( $T=A G R)$.

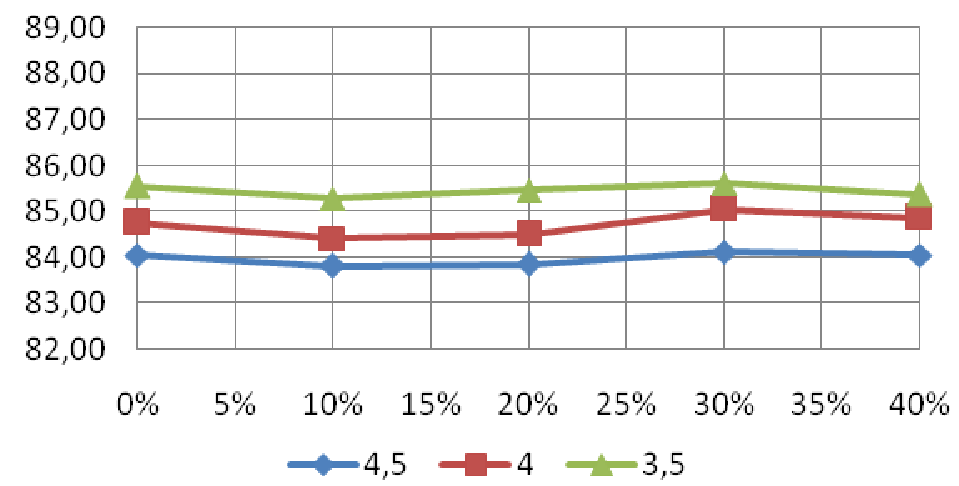

\begin{tabular}{|llllll|}
$\begin{array}{l}\text { AGR, } \\
P=14 \text { bar }\end{array}$ & $\mathrm{X}=\mathbf{0} \%$ & $\mathrm{X}=\mathbf{1 0} \%$ & $\mathrm{X}=\mathbf{2 0} \%$ & $\mathrm{X}=\mathbf{3 0} \%$ & $\mathrm{X}=\mathbf{4 0} \%$ \\
\hline $\mathrm{A}=\mathbf{3 , 5}$ & 85,78101 & 85,28721 & 85,46820 & 85,61041 & 85,36982 \\
\hline $\mathrm{A}=4$ & 84,95782 & 84,40975 & 84,51075 & 85,04085 & 84,85789 \\
\hline $\mathrm{A}=4,5$ & 84,75750 & 83,82135 & 83,84999 & 84,12749 & 84,05208 \\
\hline
\end{tabular}

Figura 8.38: Rendimiento para $\mathrm{P}=14$ bar y $\mathrm{AGR}$

El AGR sigue un comportamiento parecido al AGC, con un pico intermedio en la posición $X=20 \%$. Tal y como hemos visto hasta ahora, las prestaciones que ofrece el aceite refinado son superiores a la del crudo. 
Representaciones gráficas del rendimiento para el aceite de soja crudo ( $\mathrm{T}=\mathrm{ASC}$ ).

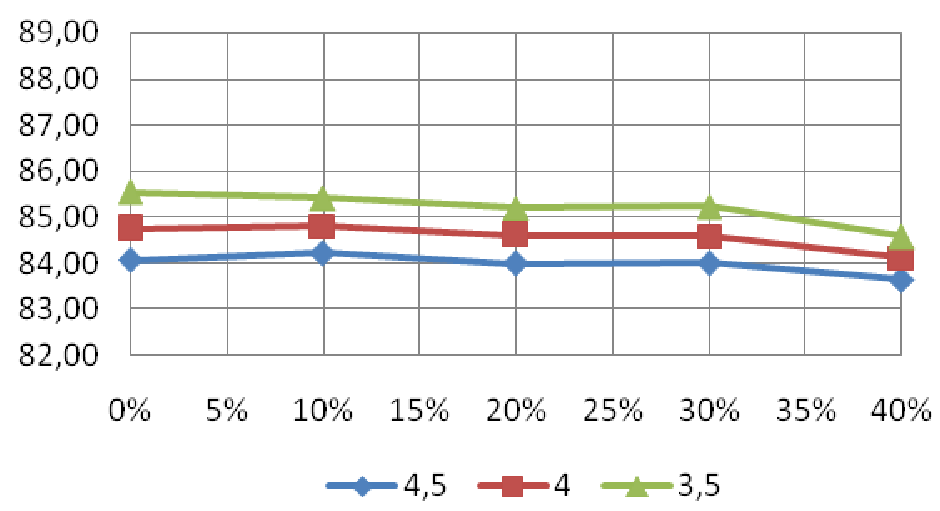

\begin{tabular}{|llllll|}
$\begin{array}{l}\text { ASC, } \\
\mathrm{P}=\mathbf{1 4 \text { bar }}\end{array}$ & $\mathrm{X}=\mathbf{0} \%$ & $\mathrm{X}=10 \%$ & $\mathrm{X}=\mathbf{2 0} \%$ & $\mathrm{X}=\mathbf{3 0} \%$ & $\mathrm{X}=\mathbf{4 0} \%$ \\
\hline $\mathrm{A}=\mathbf{3 , 5}$ & 85,78101 & 85,41063 & 85,20037 & 85,22901 & 84,57592 \\
\hline $\mathrm{A}=4$ & 84,95782 & 84,80435 & 84,60657 & 84,58320 & 84,11409 \\
\hline $\mathrm{A}=4,5$ & 84,75750 & 84,21353 & 83,98145 & 83,99638 & 83,63639 \\
\hline
\end{tabular}

Figura 8.39: Rendimiento para $\mathrm{P}=14$ bar y ASC

El máximo se obtiene en este caso para el porcentaje mínimo de aportación de aceite (no se considera el $0 \%$ ya que es gasoil puro). Se sigue una tendencia negativa a medida que aumenta el porcentaje de aceite para todas las posiciones de admisión del aire, si bien las diferencias entre el 20 y el $30 \%$ de aceite son apenas imperceptibles. 
Representaciones gráficas del rendimiento para el aceite de soja crudo ( $\mathrm{T}=\mathrm{ASC}$ ).

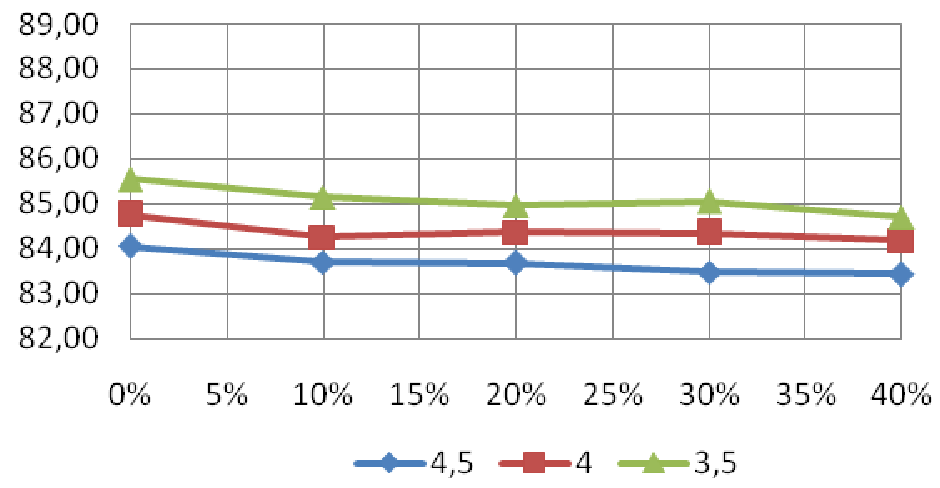

\begin{tabular}{|llllll|}
\hline $\begin{array}{l}\text { ASR, } \\
P=14 \text { bar }\end{array}$ & $\mathrm{X}=\mathbf{0} \%$ & $\mathrm{X}=\mathbf{1 0} \%$ & $\mathrm{X}=\mathbf{2 0 \%}$ & $\mathrm{X}=\mathbf{3 0 \%}$ & $\mathrm{X}=\mathbf{4 0} \%$ \\
\hline $\mathrm{A}=\mathbf{3 , 5}$ & 85,78101 & 85,15540 & 84,96268 & 85,06103 & 84,70187 \\
\hline $\mathrm{A}=4$ & 84,95782 & 84,25931 & 84,36741 & 84,34485 & 84,18875 \\
\hline $\mathrm{A}=4,5$ & 84,75750 & 83,70127 & 83,67866 & 83,48797 & 83,43769 \\
\hline
\end{tabular}

Figura 8.40: Rendimiento para $\mathrm{P}=14$ bar y ASR

Para el ASR, tenemos el máximo en el 10\% de aceite. Siendo éste el máximo, el comportamiento del aceite varía muy levemente del $10 \%$ al $40 \%$ (no llega al 0,5\%) para las tres posiciones de admisión de aire. Por otra parte, vuelve a darse el comportamiento inverso al conocido hasta ahora: el aceite crudo vuelve a dar mejores resultados que el refinado. 
Representaciones gráficas del rendimiento para la admisión del aire $A=3,5$

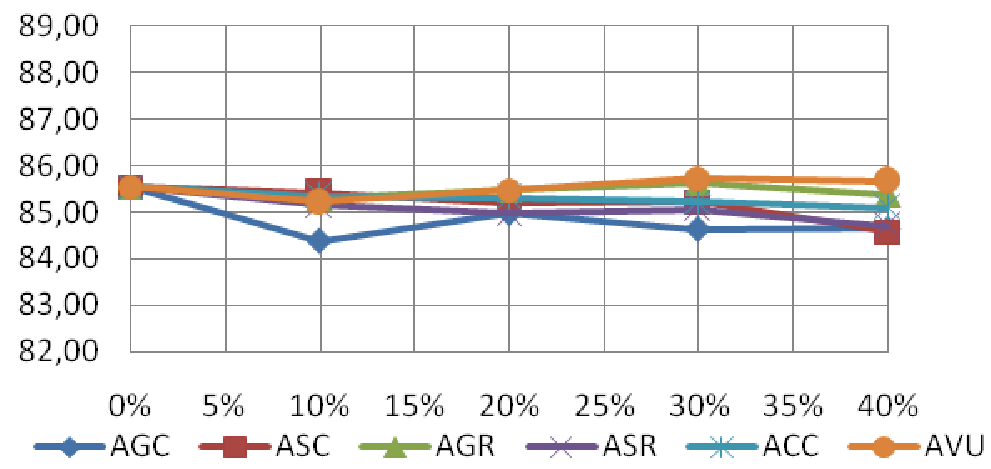

\begin{tabular}{|llllll|}
$\begin{array}{l}\text { A=3,5, } \\
P=14 \text { bar }\end{array}$ & $X=0 \%$ & $X=10 \%$ & $X=20 \%$ & $X=30 \%$ & $X=40 \%$ \\
\hline AC & 85,78101 & 85,35376 & 85,31776 & 85,21601 & 85,09748 \\
\hline AVU & 85,78101 & 85,21401 & 85,47098 & 85,73066 & 85,66534 \\
\hline AGC & 85,78101 & 84,37523 & 84,96797 & 84,62167 & 84,64092 \\
\hline AGR & 85,78101 & 85,28721 & 85,46820 & 85,61041 & 85,36982 \\
\hline ASC & 85,78101 & 85,41063 & 85,20037 & 85,22901 & 84,57592 \\
\hline ASR & 85,78101 & 85,15540 & 84,96268 & 85,06103 & 84,70187 \\
\hline
\end{tabular}

Figura 8.41: Rendimiento para $\mathrm{P}=14$ bar y $\mathrm{A}=3,5$

El gráfico y la tabla de datos muestran los mejores rendimientos posibles para esta presión. Como hemos visto en el análisis anterior, el máximo lo consigue el AVU. Podíamos decir que es la que mejores prestaciones tiene junto con el AGR. Vuelve a destacar la inferioridad en rendimiento del ASR frente al ASC. Por otra parte, y como se observa en primer término en la gráfica, el peor comportamiento vuelve a tenerle el AGC. 
Representaciones gráficas del rendimiento para la admisión del aire $A=4$

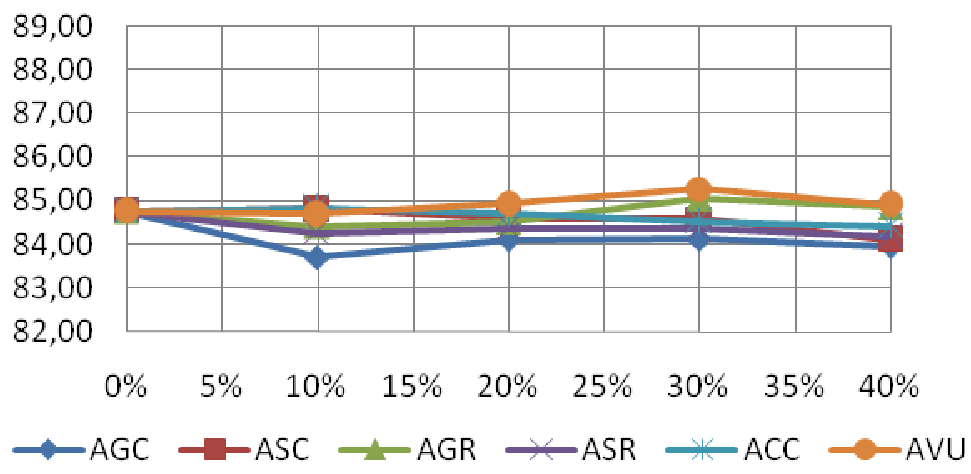

\begin{tabular}{|llllll|}
$\begin{array}{l}\text { A=4, } \\
P=14 \text { bar }\end{array}$ & $X=0 \%$ & $X=10 \%$ & $X=20 \%$ & $X=30 \%$ & $X=40 \%$ \\
\hline AC & 84,95782 & 84,83856 & 84,69706 & 84,53334 & 84,41408 \\
\hline AVU & 84,95782 & 84,69014 & 84,91730 & 85,27404 & 84,90528 \\
\hline AGC & 84,95782 & 83,70988 & 84,09857 & 84,12224 & 83,95744 \\
\hline AGR & 84,95782 & 84,40975 & 84,51075 & 85,04085 & 84,85789 \\
\hline ASC & 84,95782 & 84,80435 & 84,60657 & 84,58320 & 84,11409 \\
\hline ASR & 84,95782 & 84,25931 & 84,36741 & 84,34485 & 84,18875 \\
\hline
\end{tabular}

Figura 8.42: Rendimiento para $P=14$ bar y $A=4$

El comentario es esencialmente el mismo que para $A=3,5$. 
Representaciones gráficas del rendimiento para la admisión del aire $A=4,5$

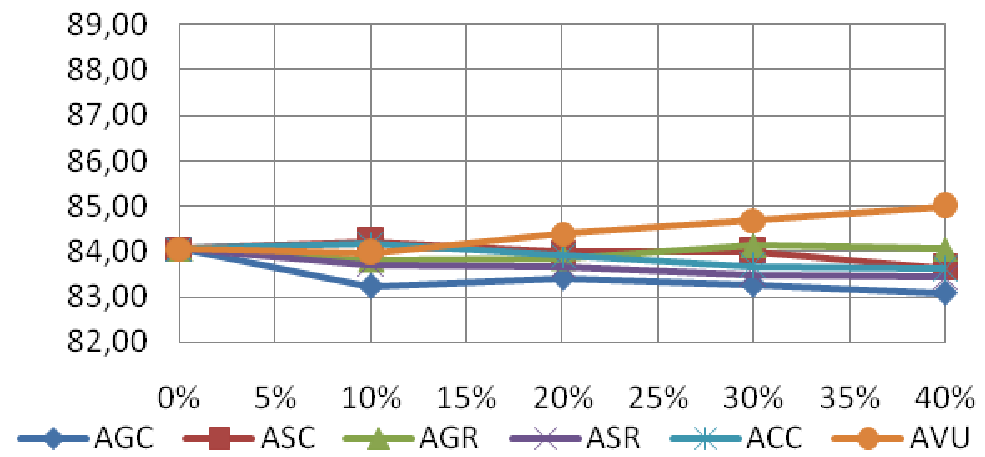

\begin{tabular}{|llllll|}
$\begin{array}{l}\text { A=4, } \\
P=14 b a r\end{array}$ & $X=0 \%$ & $X=10 \%$ & $X=20 \%$ & $X=30 \%$ & $X=40 \%$ \\
\hline AC & 84,75750 & 84,16441 & 83,90645 & 83,66133 & 83,60630 \\
\hline AVU & 84,75750 & 83,96161 & 84,38237 & 84,68806 & 84,99401 \\
\hline AGC & 84,75750 & 83,22246 & 83,41445 & 83,26727 & 83,07591 \\
\hline AGR & 84,75750 & 83,82135 & 83,84999 & 84,12749 & 84,05208 \\
\hline ASC & 84,75750 & 84,21353 & 83,98145 & 83,99638 & 83,63639 \\
\hline ASR & 84,75750 & 83,70127 & 83,67866 & 83,48797 & 83,43769 \\
\hline
\end{tabular}

Figura 8.43: Rendimiento para $P=14$ bar y $A=4,5$

El rendimiento del AVU da su máximo para el porcentaje mayor, en un comportamiento que se sale de lo normal tanto en el plano particular del AVU como en la tendencia que han marcado el resto de aceites. El mínimo, y con creces, lo da el AGC. 
Representaciones gráficas del rendimiento para el porcentaje de aceite de $X=10 \%$

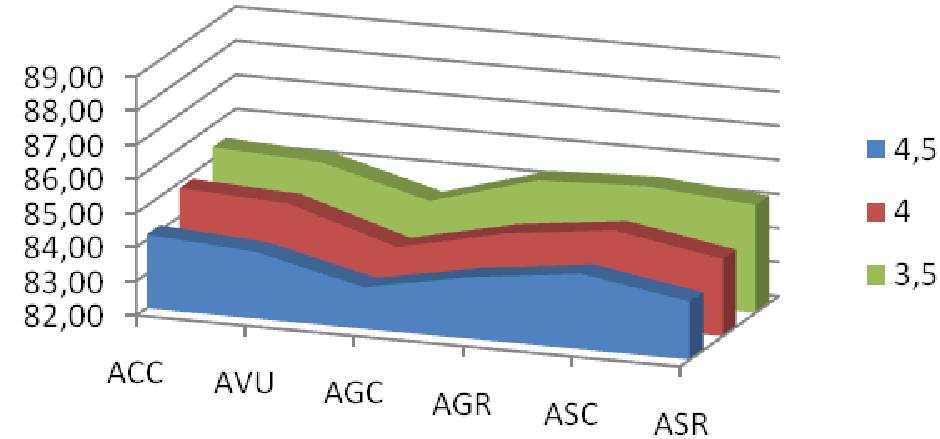

\begin{tabular}{|lllllll|}
$\begin{array}{l}\mathrm{X}=\mathbf{1 0} \%, \\
\mathrm{P}=\mathbf{1 4 \text { bar }}\end{array}$ & AC & AVU & AGC & AGR & ASC & ASR \\
\hline $\mathrm{A}=3,5$ & 85,35376 & 85,21401 & 84,37523 & 85,28721 & 85,41063 & 85,15540 \\
\hline $\mathrm{A}=4$ & 84,83856 & 84,69014 & 83,70988 & 84,40975 & 84,80435 & 84,25931 \\
\hline $\mathrm{A}=4,5$ & 84,16441 & 83,96161 & 83,22246 & 83,82135 & 84,21353 & 83,70127 \\
\hline
\end{tabular}

Figura 8.44: Rendimiento para $P=14$ bar $y=10 \%$

En este caso el máximo le da el ASC para las posiciones extremas de admisión de aire. Aún así, tanto el ACC, como el AVU como los dos aceites de soja están en valores similares. El AGC, sin embargo, está lejos de todos ellos (a un 1\% de distancia).

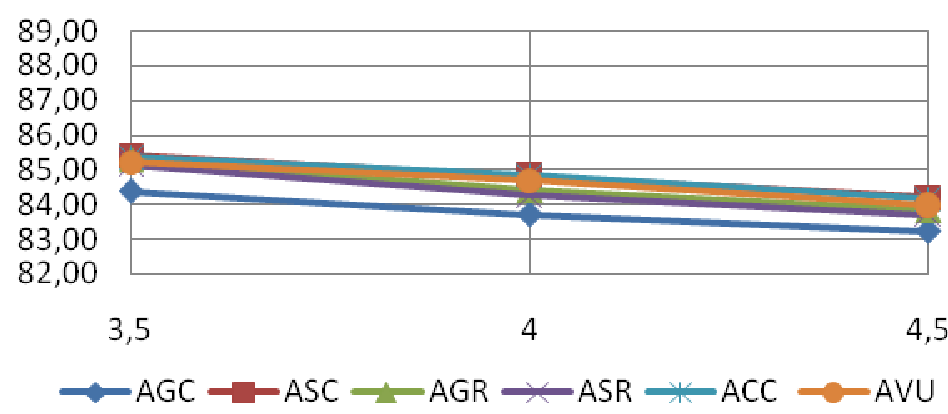

Figura 8.45: Rendimiento para $P=14$ bar $y \mathrm{X}=10 \%$

En este gráfico es muy apreciable que AVU, ACC y ASC ofrecen un comportamiento bastante similar. AGR y ASR ofrecen un rendimiento parecido a los anteriores para $A=3,5$, pero para las sucesivas posiciones caen más abruptamente. Se ve además lo inferior que es el AGC. 
Representaciones gráficas del rendimiento para el porcentaje de aceite de $X=20 \%$

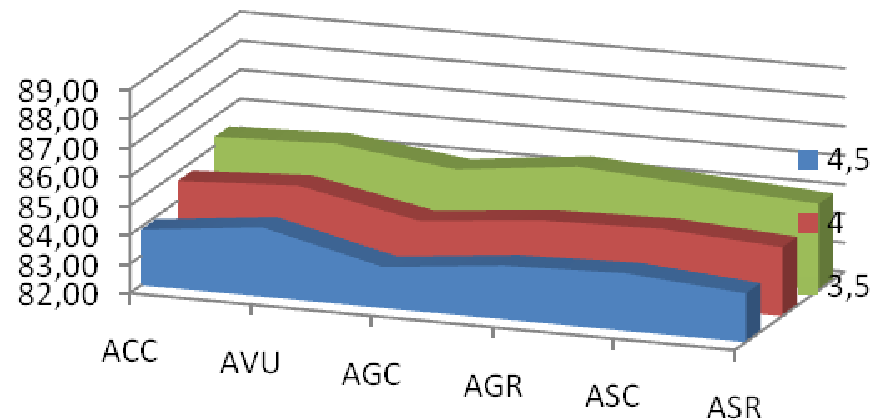

\begin{tabular}{|lllllll|}
\hline $\begin{array}{l}\mathrm{X}=\mathbf{2 0} \%, \\
\mathrm{P}=\mathbf{1 4 \text { bar }}\end{array}$ & AC & AVU & AGC & AGR & ASC & ASR \\
\hline $\mathrm{A}=3,5$ & 85,31776 & 85,47098 & 84,96797 & 85,46820 & 85,20037 & 84,96268 \\
\hline $\mathrm{A}=4$ & 84,69706 & 84,91730 & 84,09857 & 84,51075 & 84,60657 & 84,36741 \\
\hline $\mathrm{A}=4,5$ & 83,90645 & 84,38237 & 83,41445 & 83,84999 & 83,98145 & 83,67866 \\
\hline
\end{tabular}

Figura 8.46: Rendimiento para $P=14$ bar y $X=20 \%$

AVU y AGR ofrecen los mejores rendimientos para $A=3,5$, pero $A V U$ es superior en el resto de posiciones. La gráfica y las tablas muestran que tanto ASR como AGC ofrecen los peores rendimientos.

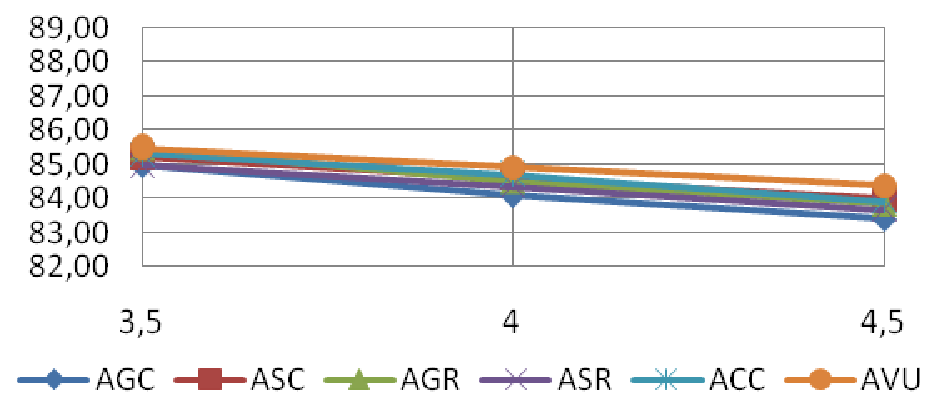

Figura 8.47: Rendimiento para $\mathrm{P}=14$ bar y $\mathrm{X}=20 \%$ 
Este gráfico denota, por partes, la inferioridad tanto de AGC como del ASR. Por otro lado, se aprecia mejor el buen rendimiento del AVU, y lo similares que son el comportamiento del AC, ASV y AGR.

Representaciones gráficas del rendimiento para el porcentaje de aceite de $X=30 \%$

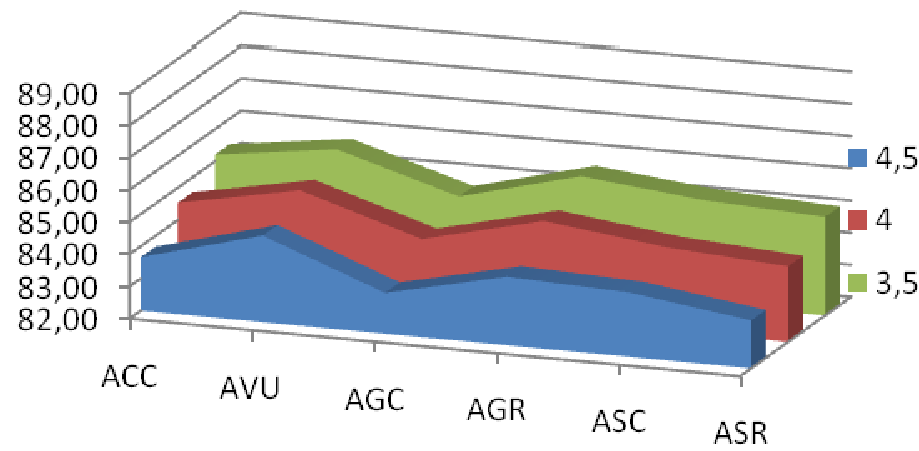

\begin{tabular}{|lllllll|}
$\begin{array}{l}\mathrm{X}=30 \%, \\
\mathrm{P}=\mathbf{1 4 \text { bar }}\end{array}$ & AC & AVU & AGC & AGR & ASC & ASR \\
\hline $\mathrm{A}=3,5$ & 85,21601 & 85,73066 & 84,62167 & 85,61041 & 85,22901 & 85,06103 \\
\hline $\mathrm{A}=4$ & 84,53334 & 85,27404 & 84,12224 & 85,04085 & 84,58320 & 84,34485 \\
\hline $\mathrm{A}=4,5$ & 83,66133 & 84,68806 & 83,26727 & 84,12749 & 83,99638 & 83,48797 \\
\hline
\end{tabular}

Figura 8.48: Rendimiento para $P=14$ bar y $X=30 \%$

Tanto la gráfica como la tabla de datos muestran que tanto AVU como AGR ofrecen los mejores rendimientos. El AGC vuelve a ofrecer el menor rendimiento.

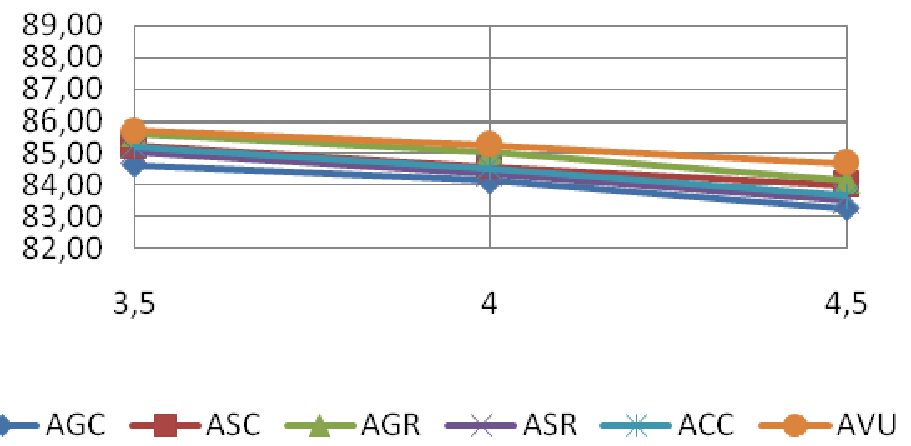

Figura 8.49: Rendimiento para $P=14$ bar y $X=30 \%$ 
Los peores rendimientos los registran en este caso tanto AGC como ASR. El AGR y ASC muestran unos rendimientos intermedios. Destaca, como en análisis anteriores, la diferencia de comportamiento con respecto al refino del aceite de soja y el aceite de girasol, por lo menos para estos casos.

Representaciones gráficas del rendimiento para el porcentaje de aceite de $X=40 \%$

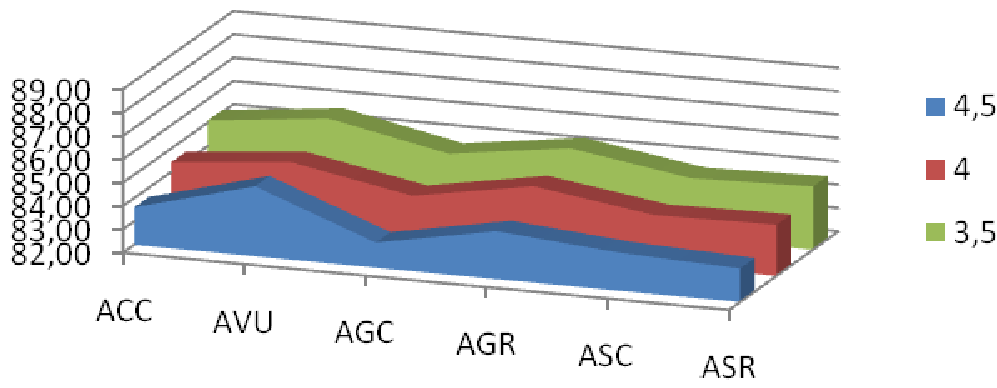

\begin{tabular}{|lllllll|}
$\begin{array}{l}\mathrm{X}=40 \%, \\
\mathrm{P}=14 \mathrm{bar}\end{array}$ & AC & AVU & AGC & AGR & ASC & ASR \\
\hline $\mathrm{A}=3,5$ & 85,09748 & 85,66534 & 84,64092 & 85,36982 & 84,57592 & 84,70187 \\
\hline $\mathrm{A}=4$ & 84,41408 & 84,90528 & 83,95744 & 84,85789 & 84,11409 & 84,18875 \\
\hline $\mathrm{A}=4,5$ & 83,60630 & 84,99401 & 83,07591 & 84,05208 & 83,63639 & 83,43769 \\
\hline
\end{tabular}

Figura 8.50: Rendimiento para $P=14$ bar y $X=40$

El mejor rendimiento vuelve a ser conseguido por el AVU, seguido por el AGR. Salvo el AC, con un rendimiento en el nivel del $85 \%$, el resto ofrecen rendimientos similares para la posición $A=3,5$. La tendencia es la misma para las mismas posiciones de la admisión de aire.

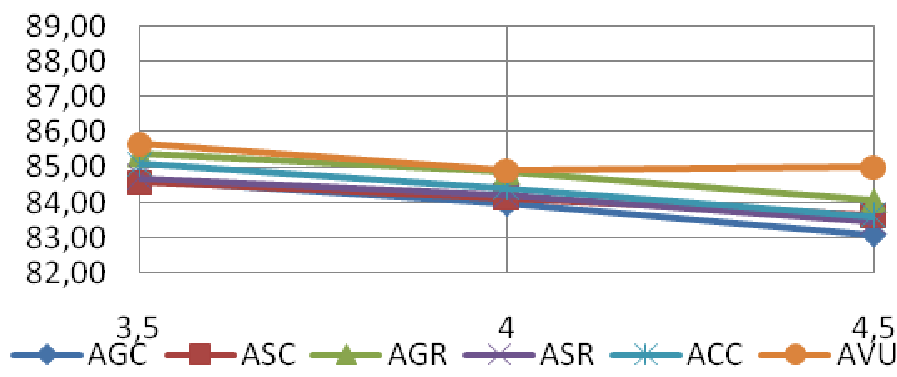

Figura 8.51: Rendimiento para $\mathrm{P}=14$ bar $\mathrm{y} X=40$ 


\subsubsection{Conclusiones}

Como en los análisis anteriores, volvemos a tener una caída bien visible en el rendimiento según aumenta la variable $A$. Se ve en todas las gráficas, sobre todo en la primera gráfica de cada análisis a $X=$ constante.

Los máximos se alcanzan en el mínimo porcentaje de aceite en tres casos (ACC, ASR y ASC), mientras que el AVU y el AGR vuelven a obtener máximos en el porcentaje 30\%. El AGC lo hace en el 20\%. En cualquier caso, los valores ya no sobrepasan el $86 \%$ como en el análisis a $\mathrm{P}=12$ bar, ni mucho menos los valores alcanzados para el análisis a $P=10$ bar (el máximo alcanzado aquí es $85,73 \%$ ). Esto se verá más adelante en el análisis para $\mathrm{A}=$ constante que se verá al terminar el de $\mathrm{P}=14$ bar.

La influencia de la variable tipo de aceite queda también clara en todas las gráficas (es un resultado que conocíamos del análisis ANOVA). En la segunda gráfica de los análisis a $X=$ constante se muestran las tendencias que ya han sido comentadas para cada gráfico, pero que merecen un análisis individual para cada aceite:

- $\quad$ ACC: su tendencia es dar buenos rendimientos para valores de X y de A bajos. Cumpliendo esto, se sitúa cerca del mejor valor de la comparativa.

- $\quad$ AVU: su tendencia es dar buenos valores cuanto más crece la variable $X$. La variable $A$ no le afecta tanto, y para $A=4$ y $A=4,5$ sigue dando los mejores valores. Da los mejores rendimientos para $X=20 \%, X=30 \%$ y $X=40 \%$.

- AGC: ofrece los peores rendimientos del estudio, independientemente de los valores de $X$ y de A. No pasa del $85 \%$ de rendimiento, cuando otros aceites rozan el $86 \%$.

- $\quad$ AGR: tomando como referencia el comportamiento del AVU, se le acerca mucho para valores de A bajos, pero se aleja para valores altos de $\mathrm{A}$.

- $\quad$ ASC: ofrece el mejor comportamiento para $X=10 \%$, pero su rendimiento cae cuanto más proporción de aceite hay en la mezcla de combustible.

- $\quad$ ASR: sorprendentemente, su rendimiento está por debajo de su equivalente sin refinar, luego puede decirse que si las condiciones de combustión fuesen éstas, el refino, no sólo sería inútil, sería perjudicial 


\subsubsection{Análisis del rendimiento para $A=3,5$}

A continuación se exponen la matriz de resultados para este análisis:

Tabla 8.9 Matriz de resultados para $A=3,5$

\begin{tabular}{|c|c|c|c|c|c|c|c|}
\hline & & \multicolumn{4}{|c|}{ Porcentaje de aceite en la mezcla $(\mathrm{X})$} & & \\
\hline & & $10 \%$ & $20 \%$ & $30 \%$ & $40 \%$ & & \\
\hline \multirow{18}{*}{$\begin{array}{l}\text { Presión } \\
\text { de } \\
\text { inyección } \\
\text { (P) }\end{array}$} & 10 & 84,09968 & 85,25850 & 84,50137 & 84,74938 & \multirow{3}{*}{$\mathrm{AC}$} & \multirow{18}{*}{$\begin{array}{l}\text { Tipo de } \\
\text { aceite } \\
\text { (T) }\end{array}$} \\
\hline & 12 & 85,25447 & 85,37386 & 85,13115 & 85,15520 & & \\
\hline & 14 & 85,35376 & 85,31776 & 85,21601 & 85,09748 & & \\
\hline & 10 & 85,07556 & 85,47638 & 86,12837 & 85,58125 & \multirow{3}{*}{ AVU } & \\
\hline & 12 & 85,31938 & 85,36382 & 86,17902 & 85,48600 & & \\
\hline & 14 & 85,21401 & 85,47098 & 85,73066 & 85,66534 & & \\
\hline & 10 & 84,49998 & 84,55733 & 84,08382 & 84,18637 & \multirow{3}{*}{ AGC } & \\
\hline & 12 & 84,53117 & 84,91404 & 84,61684 & 84,37155 & & \\
\hline & 14 & 84,37523 & 84,96797 & 84,62167 & 84,64092 & & \\
\hline & 10 & 85,31293 & 84,72836 & 84,28067 & 84,74591 & \multirow{3}{*}{ AGR } & \\
\hline & 12 & 85,20370 & 85,29936 & 85,52949 & 85,26327 & & \\
\hline & 14 & 85,28721 & 85,46820 & 85,61041 & 85,36982 & & \\
\hline & 10 & 85,33888 & 84,83663 & 84,86387 & 84,76151 & \multirow{3}{*}{ ASC } & \\
\hline & 12 & 85,44875 & 85,35542 & 85,07000 & 84,86249 & & \\
\hline & 14 & 85,41063 & 85,20037 & 85,22901 & 84,57592 & & \\
\hline & 10 & 85,02602 & 84,61271 & 84,88327 & 85,09721 & \multirow{3}{*}{ ASR } & \\
\hline & 12 & 85,03464 & 84,67927 & 84,89123 & 84,77345 & & \\
\hline & 14 & 85,15540 & 84,96268 & 85,06103 & 84,70187 & & \\
\hline & & \multicolumn{4}{|c|}{ Grado de apertura de aire constante $(A=3,5)$} & & \\
\hline
\end{tabular}

Con los datos ya dispuestos, se plantea un análisis de varianza (ANOVA), mediante el cual se determinará si las tres variables influyen (presión de inyección, tipo de aceite y porcentaje de aceite en peso) o no y de qué manera.

Tabla 8.10 Análisis ANOVA para A=3,5

\begin{tabular}{|l|l|l|l|l|l|l|l|}
\hline FACTOR & GdL & SS & MS & F & VC al 5\% & Influye & G. C. Crítica \\
\hline P & 2 & 1,26180 & 0,63090 & 12,50018 & 3,31583 & SI & 0,000112548 \\
\hline T & 5 & 6,77429 & 1,35486 & 26,84415 & 2,53355 & SI & $3,13015 \mathrm{E}-10$ \\
\hline X & 3 & 0,26188 & 0,08729 & 1,72954 & 2,92228 & NO & 0,182079947 \\
\hline PxT & 10 & 1,06949 & 0,10695 & 2,11901 & 2,16458 & NO & 0,05479703 \\
\hline PxX & 6 & 0,20513 & 0,03419 & 0,67737 & 2,42052 & NO & 0,668880785 \\
\hline TxX & 15 & 2,30271 & 0,15351 & 3,04162 & 2,01480 & SI & 0,004614874 \\
\hline Error & 30 & 1,51414 & 0,05047 & & & & \\
\hline Total & 71 & 13,38944 & & & & & \\
\hline
\end{tabular}


Vistos los resultados de la tabla ANOVA generada, se tiene que las variables influyentes son la presión de inyección, el tipo de aceite y la interacción tipo de aceite-porcentaje de la misma en la mezcla para un nivel de significación del $5 \%$. Tanto la interaccion presión de inyecciónporcentaje en mezcla (ésta en mayor medida) como la variable porcentaje de aceite en la mezcla son rechazadas con un margen relativamente amplio. Sin embargo, la interacción presión de inyección-tipo de aceite ha sido rechazada con apenas un $0,4 \%$ de margen. Esto quiere decir que, si se hubiese hecho el análisis para un nivel de significancia del $6 \%$, la variable entraría a ser representativa.

Dentro de las variables significativas, el tipo de aceite es la más determinante (orden de 10-8\%), teniendo después en orden de importancia a la presión de inyección y por último, como última variable significativa la interacción tipo de aceite-porcentaje en mezcla.

A priori, será la variable tipo de aceite T la que marque, principalmente, el comportamiento de la variable rendimiento.

Representaciones gráficas del rendimiento para el aceite de colza crudo ( $\mathrm{T}=\mathrm{ACC})$

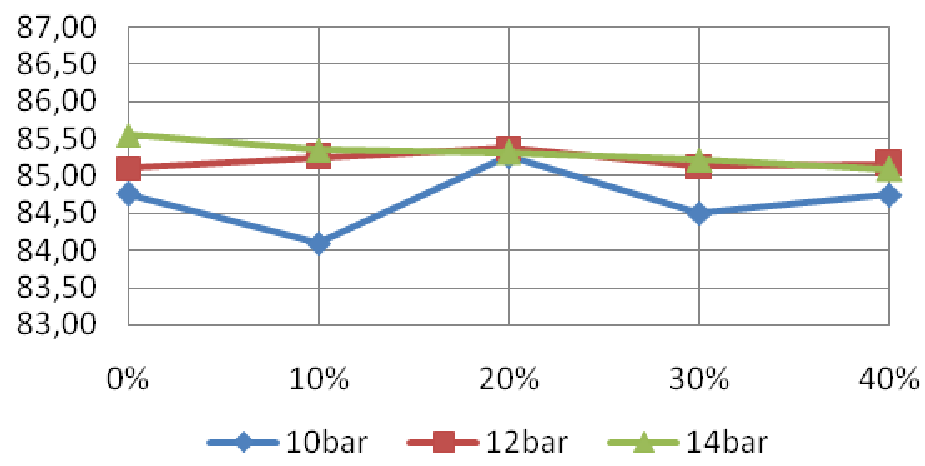

\begin{tabular}{|llllll|}
\hline AC, & $X=0 \%$ & $X=10 \%$ & $X=20 \%$ & $X=30 \%$ & $X=40 \%$ \\
$A=3,5$ & & & & & \\
\hline$P=10$ bar & 84,75750 & 84,09968 & 85,25850 & 84,50137 & 84,74938 \\
\hline$P=12$ bar & 85,10567 & 85,25447 & 85,37386 & 85,13115 & 85,15520 \\
\hline$P=14$ bar & 85,54939 & 85,35376 & 85,31776 & 85,21601 & 85,09748 \\
\hline
\end{tabular}

Figura 8.52: Rendimiento para $A=3,5$ y $\mathrm{T}=\mathrm{ACC}$ 
El análisis muestra un mayor rendimiento cuanto mayor es la presión de inyección. Salvo el valor para $\mathrm{X}=20 \%$, el rendimiento para $\mathrm{P}=10$ bar es bastante inferior. No hay mucha diferencia entre los valores recogidos para $\mathrm{P}=12$ bar y $\mathrm{P}=14$ bar, de hecho, el máximo valor lo da $\mathrm{P}=12$ bar.

Representaciones gráficas del rendimiento para el aceite vegetal usado ( $\mathrm{T}=\mathrm{AVU}$ )

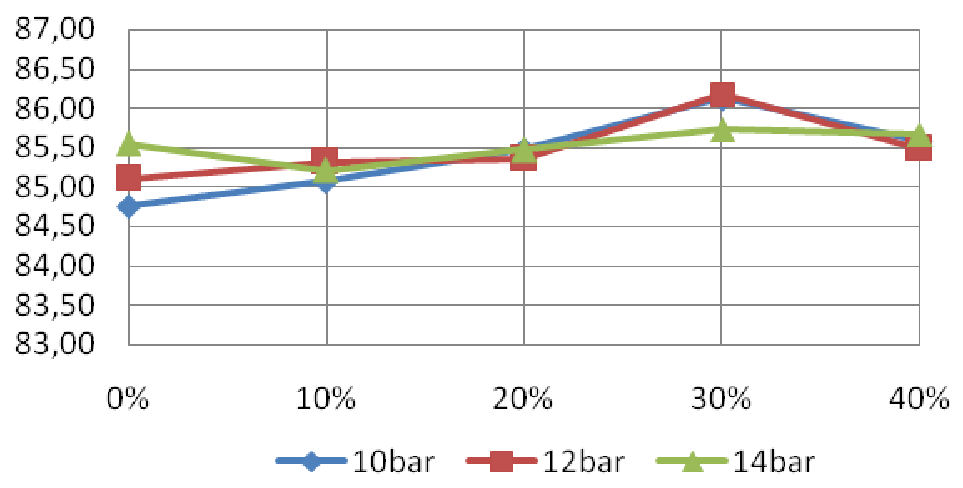

\begin{tabular}{|llllll|}
\hline AVU, & $X=0 \%$ & $X=10 \%$ & $X=20 \%$ & $X=30 \%$ & $X=40 \%$ \\
A=3,5 & & & & & \\
\hline$P=10$ bar & 84,75750 & 85,07556 & 85,47638 & 86,12837 & 85,58125 \\
\hline$P=12$ bar & 85,10567 & 85,31938 & 85,36382 & 86,17902 & 85,48600 \\
\hline$P=14$ bar & 85,54939 & 85,21401 & 85,47098 & 85,73066 & 85,66534 \\
\hline
\end{tabular}

Figura 8.53: Rendimiento para $A=3,5$ y $T=A V U$

Para el AVU, la tendencia es difícil de calibrar. Para porcentajes pequeños, sigue la tendencia del caso anterior, pero para porcentajes altos los rendimientos se igualan para las distintas presiones. El máximo vuelve a darlo la $\mathrm{P}=12$ bar a $\mathrm{X}=30 \%$, con un $86 \%$. 
Representaciones gráficas del rendimiento para el aceite de girasol crudo ( $\mathrm{T}=\mathrm{AGC}$ )

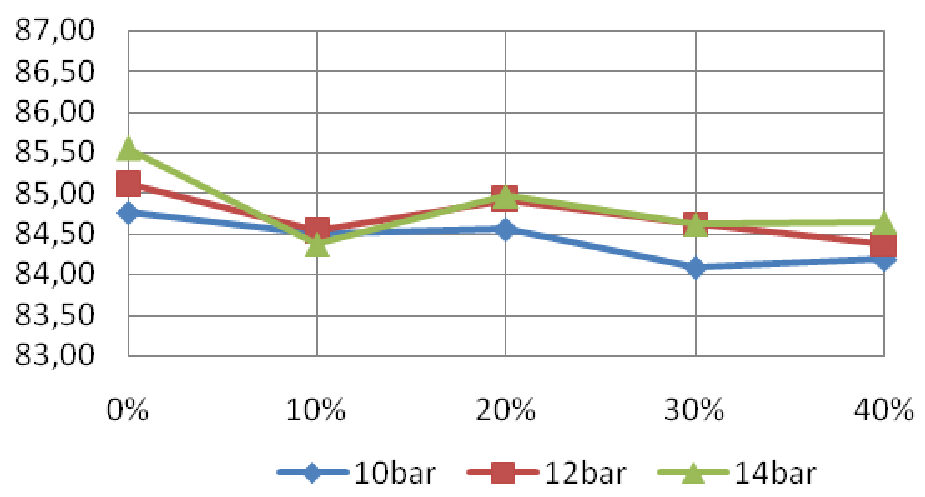

\begin{tabular}{|llllll|}
\hline AGC, & $X=0 \%$ & $X=10 \%$ & $X=20 \%$ & $X=30 \%$ & $X=40 \%$ \\
$A=3,5$ & & & & & \\
\hline$P=10$ bar & 84,75750 & 84,49998 & 84,55733 & 84,08382 & 84,18637 \\
\hline$P=12$ bar & 85,10567 & 84,53117 & 84,91404 & 84,61684 & 84,37155 \\
\hline$P=14$ bar & 85,54939 & 84,37523 & 84,96797 & 84,62167 & 84,64092 \\
\hline
\end{tabular}

Figura 8.54: Rendimiento para $A=3,5$ y $T=A G C$

Para el AGC, los valores descienden con respecto a los dos casos anteriores. La tendencia es que el rendimiento aumenta con la presión, si bien el máximo se alcanza en $X=20 \%$, lo cual corrobora que no existe dependencia con el porcentaje de aceite. 
Representaciones gráficas del rendimiento para el aceite de girasol refinado ( $T=A G R)$

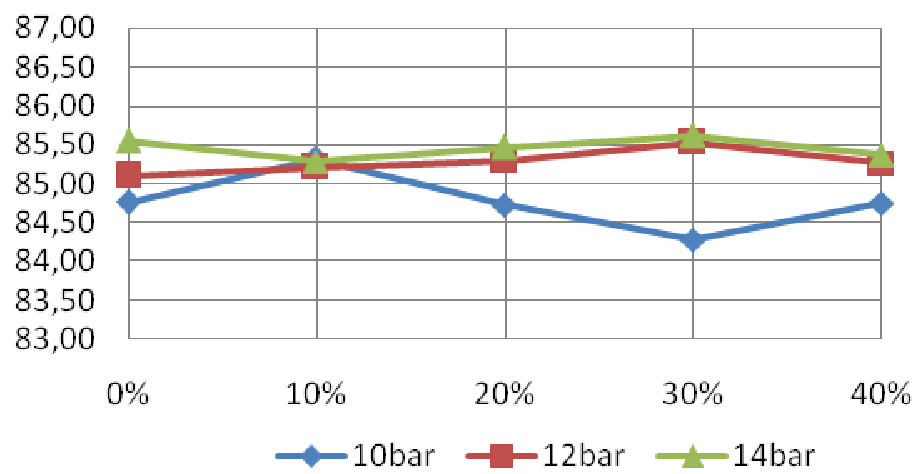

\begin{tabular}{|llllll|}
\hline $\begin{array}{l}\text { AGR, } \\
\text { A=3,5 }\end{array}$ & $X=0 \%$ & $X=10 \%$ & $X=20 \%$ & $X=30 \%$ & $X=40 \%$ \\
\hline$P=10$ bar & 84,75750 & 85,31293 & 84,72836 & 84,28067 & 84,74591 \\
\hline$P=12$ bar & 85,10567 & 85,20370 & 85,29936 & 85,52949 & 85,26327 \\
\hline$P=14$ bar & 85,54939 & 85,28721 & 85,46820 & 85,61041 & 85,36982 \\
\hline
\end{tabular}

Figura 8.55: Rendimiento para $A=3,5$ y $T=A G R$

En este caso, la influencia de la presión está más clara, y el rendimiento aumenta con la presión para todos los porcentajes. El máximo se alcanza para $X=30 \%$, y es del $85,61 \%$. 
Representaciones gráficas del rendimiento para el aceite de soja crudo ( $\mathrm{T}=\mathrm{ASC}$ )

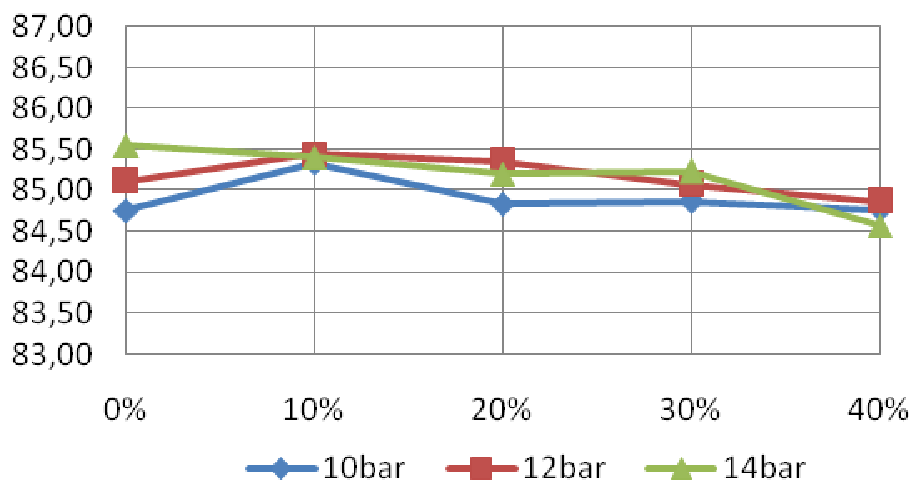

\begin{tabular}{|llllll|}
\hline ASC, & $X=0 \%$ & $X=10 \%$ & $X=20 \%$ & $X=30 \%$ & $X=40 \%$ \\
A=3,5 & & & & & \\
\hline$P=10$ bar & 84,75750 & 85,33888 & 84,83663 & 84,86387 & 84,76151 \\
\hline$P=12$ bar & 85,10567 & 85,44875 & 85,35542 & 85,07000 & 84,86249 \\
\hline$P=14$ bar & 85,54939 & 85,41063 & 85,20037 & 85,22901 & 84,57592 \\
\hline
\end{tabular}

Figura 8.56: Rendimiento para $A=3,5$ y $T=A S C$

En este caso, el máximo se da para la presión intermedia. La tendencia no está clara en este caso, ya que, si bien la presión menor da rendimientos menores, la presión intermedia y la mayor se reparten los máximos por cada porcentaje. 
Representaciones gráficas del rendimiento para el aceite de soja refinado ( $\mathrm{T}=\mathrm{ASR}$ )

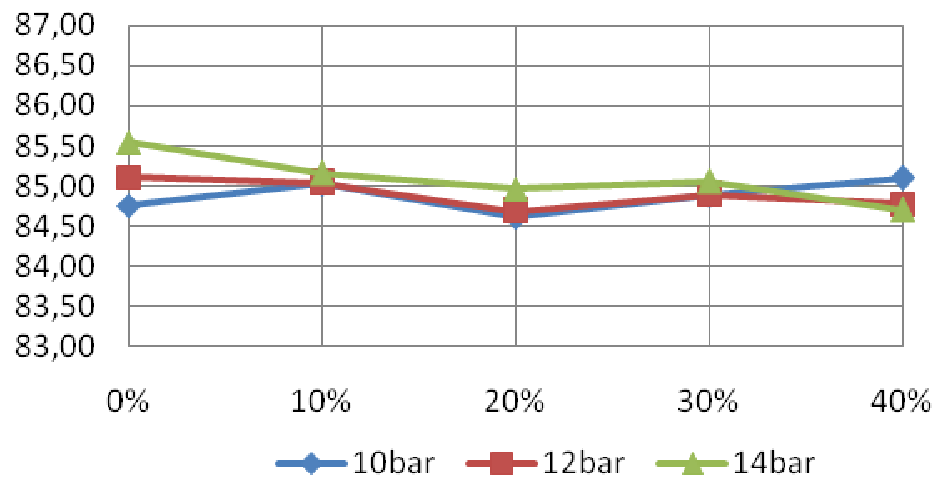

\begin{tabular}{|llllll|}
\hline ASR, & $X=0 \%$ & $X=10 \%$ & $X=20 \%$ & $X=30 \%$ & $X=40 \%$ \\
$A=3,5$ & & & & & \\
\hline$P=10$ bar & 84,75750 & 85,02602 & 84,61271 & 84,88327 & 85,09721 \\
\hline$P=12$ bar & 85,10567 & 85,03464 & 84,67927 & 84,89123 & 84,77345 \\
\hline$P=14$ bar & 85,54939 & 85,15540 & 84,96268 & 85,06103 & 84,70187 \\
\hline
\end{tabular}

Figura 8.57: Rendimiento para $A=3,5$ y $T=A S R$

En este último caso, la tendencia de aumento de rendimiento con la presión se sigue hasta el último porcentaje, si bien es reseñable que no existe mucha diferencia de la presión menor a la intermedia. 
Representaciones gráficas del rendimiento para la presión de inyección $\mathrm{P}=10$ bar

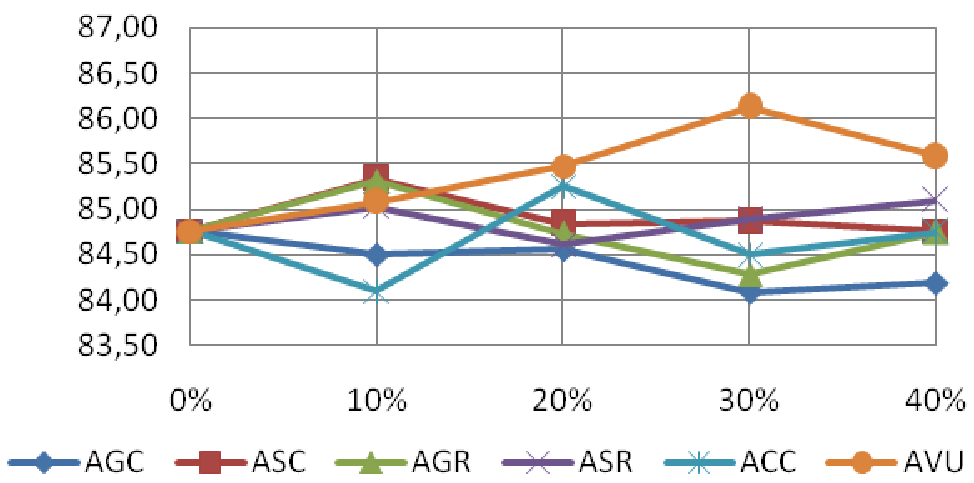

\begin{tabular}{|llllll|}
\hline $\begin{array}{l}\text { P=10bar, } \\
\text { A=3,5 }\end{array}$ & $X=0 \%$ & $X=10 \%$ & $X=20 \%$ & $X=30 \%$ & $X=40 \%$ \\
\hline ACC & 84,75750 & 84,09968 & 85,25850 & 84,50137 & 84,74938 \\
\hline AVU & 84,75750 & 85,07556 & 85,47638 & 86,12837 & 85,58125 \\
\hline AGC & 84,75750 & 84,49998 & 84,55733 & 84,08382 & 84,18637 \\
\hline AGR & 84,75750 & 85,31293 & 84,72836 & 84,28067 & 84,74591 \\
\hline ASC & 84,75750 & 85,33888 & 84,83663 & 84,86387 & 84,76151 \\
\hline ASR & 84,75750 & 85,02602 & 84,61271 & 84,88327 & 85,09721 \\
\hline
\end{tabular}

Figura 8.58 Rendimiento para $A=3,5$ y $P=10$ bar

Se observa que el mayor rendimiento lo ofrece el AVU. El AGC ofrece menores rendimientos como se puede ver en la gráfica. 
Representaciones gráficas del rendimiento para la presión de inyección $\mathrm{P}=12$ bar

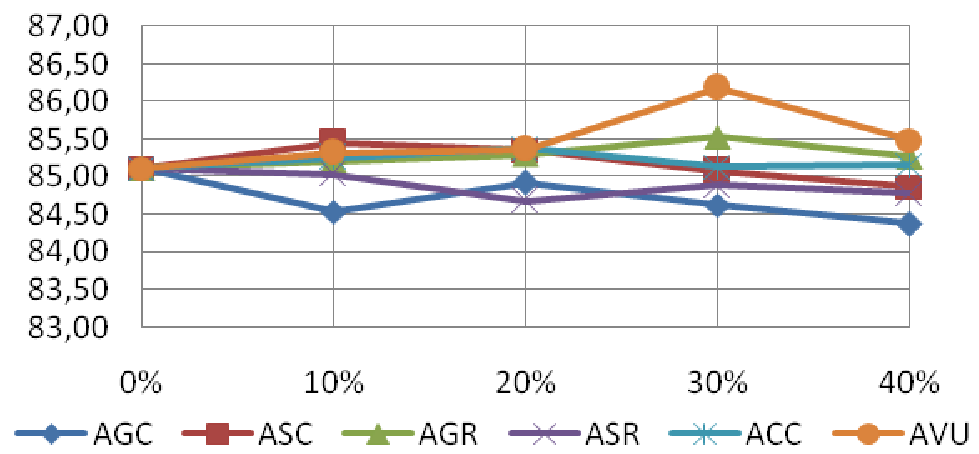

\begin{tabular}{|llllll|}
$\begin{array}{l}P=12 b a r, \\
\text { A=3,5 }\end{array}$ & $X=0 \%$ & $X=10 \%$ & $X=20 \%$ & $X=30 \%$ & $X=40 \%$ \\
\hline ACC & 85,10566 & 85,25446 & 85,37385 & 85,13114 & 85,15520 \\
\hline AVU & 85,10566 & 85,31938 & 85,36381 & 86,17902 & 85,48600 \\
\hline AGC & 85,10566 & 84,53117 & 84,91403 & 84,61683 & 84,37154 \\
\hline AGR & 85,10566 & 85,20369 & 85,29936 & 85,52948 & 85,26326 \\
\hline ASC & 85,10566 & 85,44874 & 85,35541 & 85,06999 & 84,86249 \\
\hline ASR & 85,10566 & 85,03463 & 84,67926 & 84,89123 & 84,77344 \\
\hline
\end{tabular}

Figura 8.59: Rendimiento para $A=3,5$ y $P=12$ bar

Puede notarse como aumentan los valores del rendimiento con respecto al análisis anterior. El AVU vuelve a dar el máximo para $X=30 \%$. El AGC da el mínimo para $X=40 \%$. AC, ASC y AGR dan resultados por encima del $85 \%$. Cabe destacar que el aceite de soja ofrece mejores resultados sin refino que con él. 
Representaciones gráficas del rendimiento para la presión de inyección $\mathrm{P}=14$ bar.

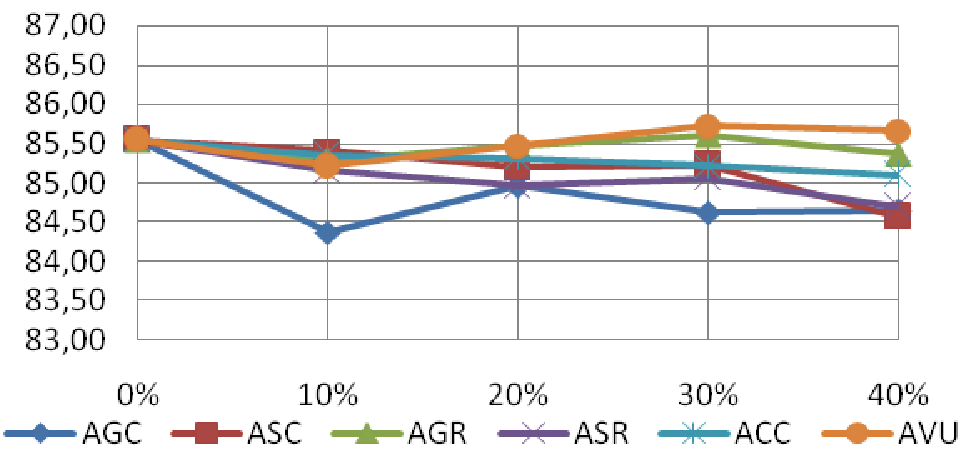

\begin{tabular}{|llllll|}
\hline $\begin{array}{l}P=14 b a r, \\
\text { A=3,5 }\end{array}$ & $X=0 \%$ & $X=10 \%$ & $X=20 \%$ & $X=30 \%$ & $X=40 \%$ \\
\hline ACC & 85,54939 & 85,35376 & 85,31776 & 85,21601 & 85,09748 \\
\hline AVU & 85,54939 & 85,21401 & 85,47098 & 85,73066 & 85,66534 \\
\hline AGC & 85,54939 & 84,37523 & 84,96797 & 84,62167 & 84,64092 \\
\hline AGR & 85,54939 & 85,28721 & 85,46820 & 85,61041 & 85,36982 \\
\hline ASC & 85,54939 & 85,41063 & 85,20037 & 85,22901 & 84,57592 \\
\hline ASR & 85,54939 & 85,15540 & 84,96268 & 85,06103 & 84,70187 \\
\hline
\end{tabular}

Figura 8.60: Rendimiento para $A=3,5$ y $P=14$ bar

El AVU ofrece el máximo al 30\% de composición. Tanto AVU como AGR dan rendimientos altos. El AGC y el ASR dan los resultados más bajos. 
Representaciones gráficas del rendimiento para el porcentaje de aceite de $X=10 \%$

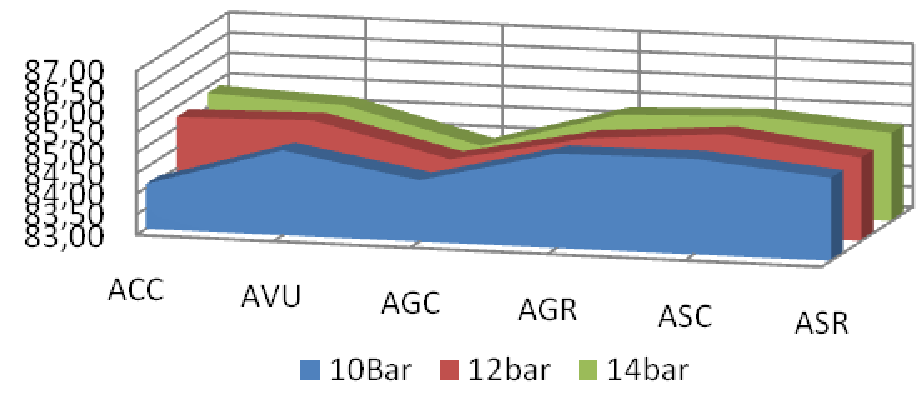

\begin{tabular}{|lllllll|}
\hline $\begin{array}{l}\mathrm{X}=10 \% \\
\mathrm{~A}=\mathbf{3}, \mathbf{5}\end{array}$ & ACC & AVU & AGC & AGR & ASC & ASR \\
\hline $\mathrm{P}=10$ bar & 84,099684 & 85,075564 & 84,499976 & 85,312927 & 85,338880 & 85,026015 \\
\hline $\mathrm{P}=12$ bar & 85,254469 & 85,319382 & 84,531170 & 85,203698 & 85,448745 & 85,034638 \\
\hline $\mathrm{P}=14$ bar & 85,353756 & 85,21400 & 84,375234 & 85,287211 & 85,4106253 & 85,1554004 \\
\hline
\end{tabular}

Figura 8.61: Rendimiento para $A=3,5$ y $X=10 \%$

Se ve claramente que el AGC ofrece un rendimiento bastante inferior al resto. El ASC ofrece los máximos para este X (máximo de $85,44 \%$ para $\mathrm{P}=12 \mathrm{bar}$ ). Destaca que mientras el refinado de girasol da mucho mejor rendimiento que el crudo, el refinado de soja da peores rendimientos (gran diferencia de comportamiento).

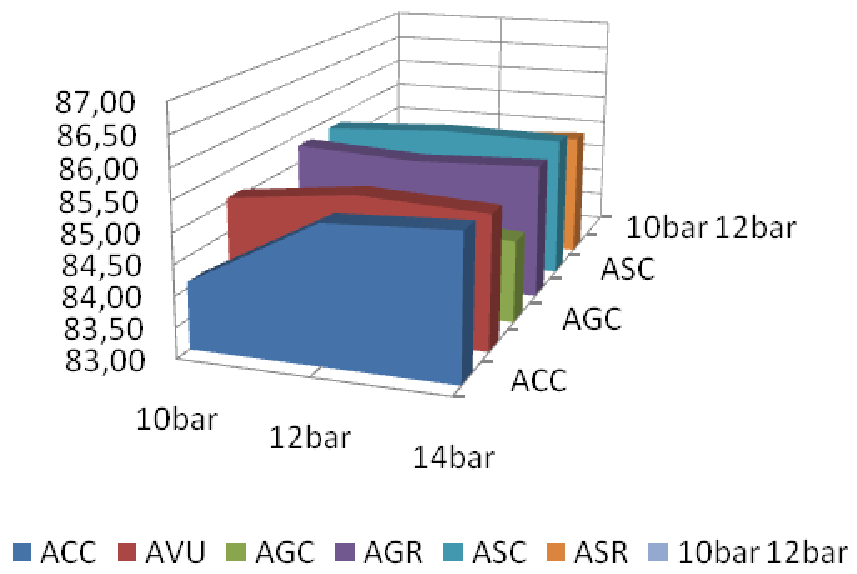

Figura 8.62: Rendimiento para $A=3,5$ y $X=10 \%$. 
Representaciones gráficas del rendimiento para el porcentaje de aceite de $X=20 \%$

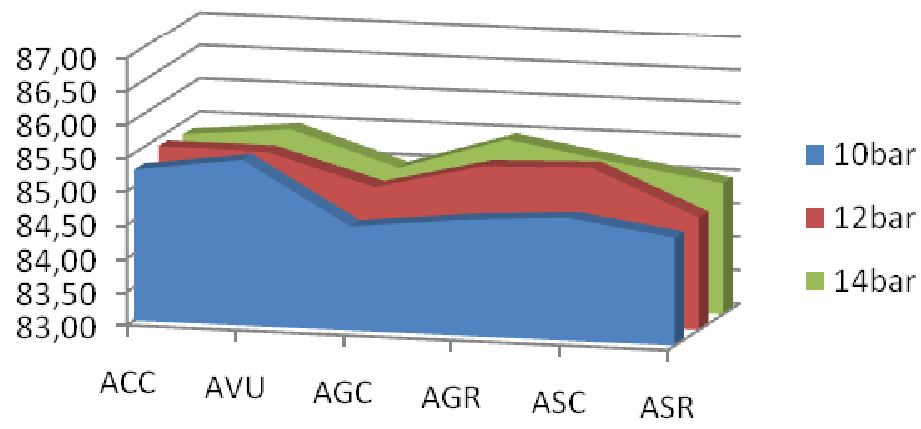

\begin{tabular}{|lllllll|}
$\begin{array}{l}\mathrm{X}=\mathbf{2 0} \%, \\
\mathrm{~A}=3,5\end{array}$ & AC & AVU & AGC & AGR & ASC & ASR \\
\hline $\mathrm{P}=10$ bar & 85,25850 & 85,47638 & 84,55733 & 84,72836 & 84,83663 & 84,61271 \\
\hline $\mathrm{P}=12 \mathrm{bar}$ & 85,37386 & 85,36382 & 84,91404 & 85,29936 & 85,35542 & 84,67927 \\
\hline $\mathrm{P}=14 \mathrm{bar}$ & 85,31776 & 85,47098 & 84,96797 & 85,46820 & 85,20037 & 84,96268 \\
\hline
\end{tabular}

Figura 8.63: Rendimiento para $A=3,5$ y $X=20 \%$

Vuelve a darse que el AGC da malos rendimientos. Los mayores rendimientos se consiguen con el AVU para todas las presiones. Destaca que para $\mathrm{P}=10 \mathrm{bar}$, el $\mathrm{AGR}$ y el ASC tienen un rendimiento muy inferior a los de las presiones superiores.

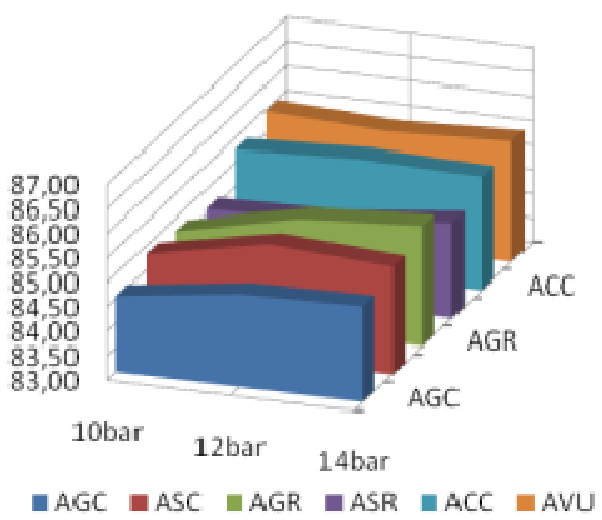

Figura 8.64: Rendimiento para $A=3,5$ y $X=20 \%$ 
Representaciones gráficas del rendimiento para el porcentaje de aceite de $X=30 \%$

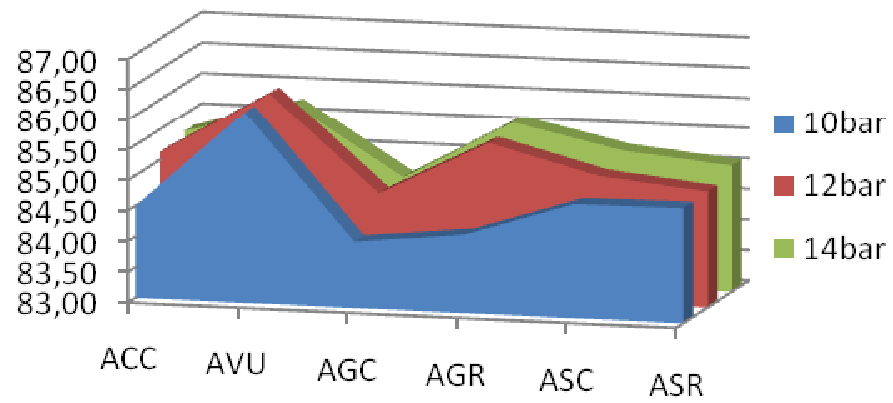

\begin{tabular}{|lllllll|}
\hline $\begin{array}{l}\mathrm{X}=30 \%, \\
\mathrm{~A}=3,5\end{array}$ & AC & AVU & AGC & AGR & ASC & ASR \\
\hline $\mathrm{P}=10 \mathrm{bar}$ & 84,50137 & 86,12837 & 84,08382 & 84,28067 & 84,86387 & 84,88327 \\
\hline $\mathrm{P}=12 \mathrm{bar}$ & 85,13115 & 86,17902 & 84,61684 & 85,52949 & 85,07000 & 84,89123 \\
\hline $\mathrm{P}=14 \mathrm{bar}$ & 85,21601 & 85,73066 & 84,62167 & 85,61041 & 85,22901 & 85,06103 \\
\hline
\end{tabular}

Figura 8.65: Rendimiento para $A=3,5$ y $X=20 \%$

El máximo se consigue con el $\mathrm{AVU}$ a $\mathrm{P}=12 \mathrm{bar}$, siendo los valores ofrecidos por el AVU los máximos globales. Para $\mathrm{P}=10$ bar, ambos aceites de girasol dan malos rendimientos, aunque para las presiones superiores el AGR dio una medición alta.La tendencia que muestra el AVU difiere de la del resto de combustibles. La tendencia de estos es de aumentar, en mayor o menor medida, con la presión.

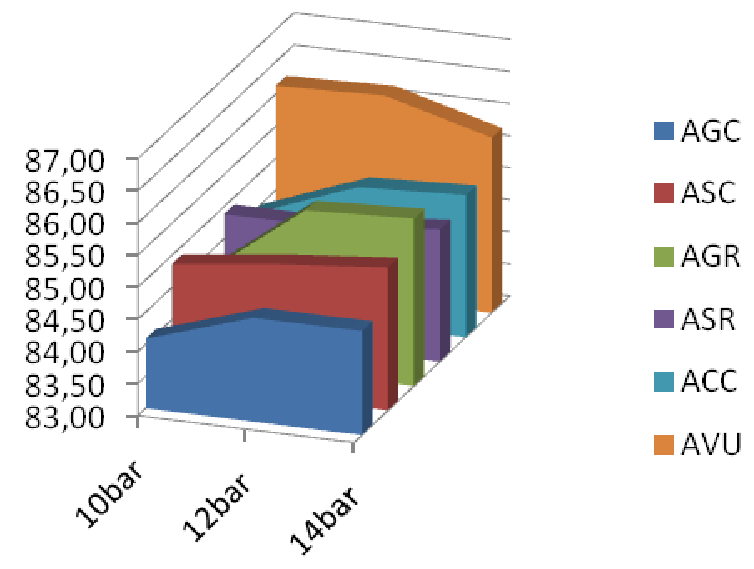

Figura 8.66: Rendimiento para $A=3,5$ y $X=30 \%$ 
Representaciones gráficas del rendimiento para el porcentaje de aceite de $X=40 \%$

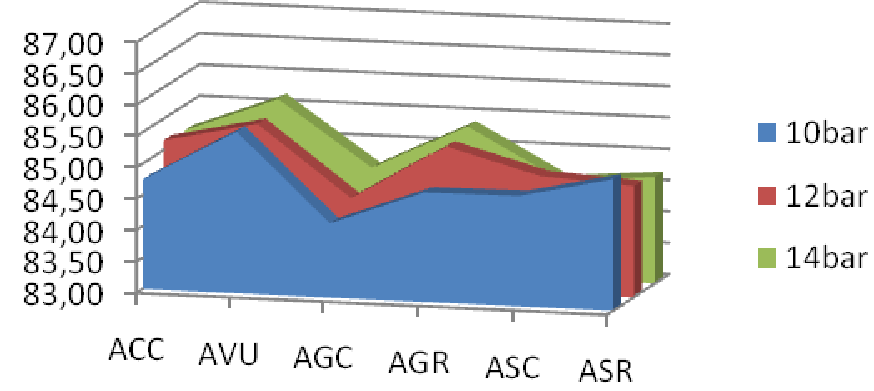

\begin{tabular}{|lllllll|}
$\begin{array}{l}\mathrm{X}=40 \%, \\
\mathrm{~A}=\mathbf{3}, \mathbf{5}\end{array}$ & AC & AVU & AGC & AGR & ASC & ASR \\
\hline $\mathrm{P}=10$ bar & 84,74938 & 85,58125 & 84,18637 & 84,74591 & 84,76151 & 85,09721 \\
\hline $\mathrm{P}=12$ bar & 85,15520 & 85,48600 & 84,37155 & 85,26327 & 84,86249 & 84,77345 \\
\hline $\mathrm{P}=14$ bar & 85,09748 & 85,66534 & 84,64092 & 85,36982 & 84,57592 & 84,70187 \\
\hline
\end{tabular}

Figura 8.67: Rendimiento para $A=3,5$ y $X=40 \%$

El AVU vuelve a dar los valores máximos, y el AGC los mínimos. Destaca que el ASR muestra un comportamiento inverso al normal, dando la medida que el rendimiento disminuye cuando aumenta la presión.Es en esta gráfica donde se ve que cada aceite sigue una tendencia distinta, alejándose de la esperada. AVU y AGR parecen ofrecer los valores más altos.

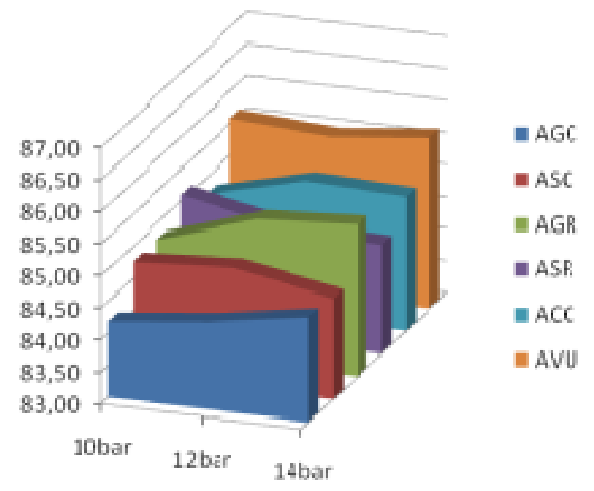

Figura 8.68: Rendimiento para $A=3,5$ y $X=40 \%$ 


\subsubsection{Conclusiones}

Tal y como se anunció en el análisis ANOVA, la variable más influyente en los datos de rendimiento que se tienen es el tipo de aceite. El comportamiento del rendimiento respecto a la variable presión de inyección del combustible $(\mathrm{P})$, a pesar de ser determinante, no lo es tanto como la variable $\mathrm{T}$, además de mostrar un comportamiento irregular en algunas condiciones. Esto queda demostrado en la segunda gráfica de cada análisis a $\mathrm{X}=$ constante, en los que puede verse que se tienen tendencias al alta y a la baja con la presión.

El máximo alcanzado es $86,18 \%$ y se consigue con el AVU para $X=30 \%$ y $\mathrm{P}=12$ bar. El mínimo es $84,08 \%$ y lo consigue el AGC para $\mathrm{X}=30 \%$ y $\mathrm{P}=10$ bar. Los mínimos de cada análisis se consiguen para $\mathrm{P}=10 \mathrm{bar}$; sin embargo los máximos no siempre se consiguen con la presión superior, siendo de hecho el máximo registrado para la presión intermedia.

Los análisis de cada aceite por separado muestran comportamientos muy diferenciados:

- $\quad$ ACC: a presiones altas, el rendimiento se mantiene dentro de unos valores cuando variamos X (entre 85 y $85,4 \%$ ). No ocurre lo mismo a la mínima presión, con fluctuaciones.

- $\quad$ AVU: al aumentar $X$, las presiones inferiores consiguen un pico de rendimiento para $X=30 \%(86,18 \%$ para $P=12$ bar $)$. Aún teniendo el máximo en este porcentaje, el rendimiento a $\mathrm{P}=14$ bar no sufre un pico tan acusado.

- $\quad$ AGC: el comportamiento seguido para las tres presiones del ensayo es equivalente, con un pico en $X=20 \%$. Aún así, no se supera el $85 \%$.

- $\quad$ AGR: a las presiones superiores se tiene un pico en $X=30 \%$ (85,61\%). El comportamiento a la presión inferior es distinto, con el pico a $X=10 \%$, único valor de esa serie que consigue superar el $85 \%$.

- $\quad$ ASC: la presión de inyección $\mathrm{P}=12$ bar da mejores rendimientos que la presión superior. Las tres siguen una tendencia similar, con el máximo en $85,4 \%$.

- $\quad$ ASR: la tendencia que siguen es la misma, salvo un pico registrado para $\mathrm{P}=10$ bar y $\mathrm{X}=40 \%$. Los valores están siempre entre 84,6 y $85 \%$. 


\subsection{ESTUDIO DE LAS EMISIONES DE CO.}

Se estudian a continuación las emisiones de CO (en ppm) medidas con el medidor Testo modelo 342-3. Se realizan los análisis a presión constante (10, 12 y 14 bar) y a posición de admisión de aire constante.

\subsubsection{Análisis a de las emisiones de $\mathrm{CO}$ a P=10 BAR}

Se presentan a continuación la matriz de resultados de las emisiones de $\mathrm{CO}$

Tabla 8.11 Matriz de resultados de Emisiones de CO

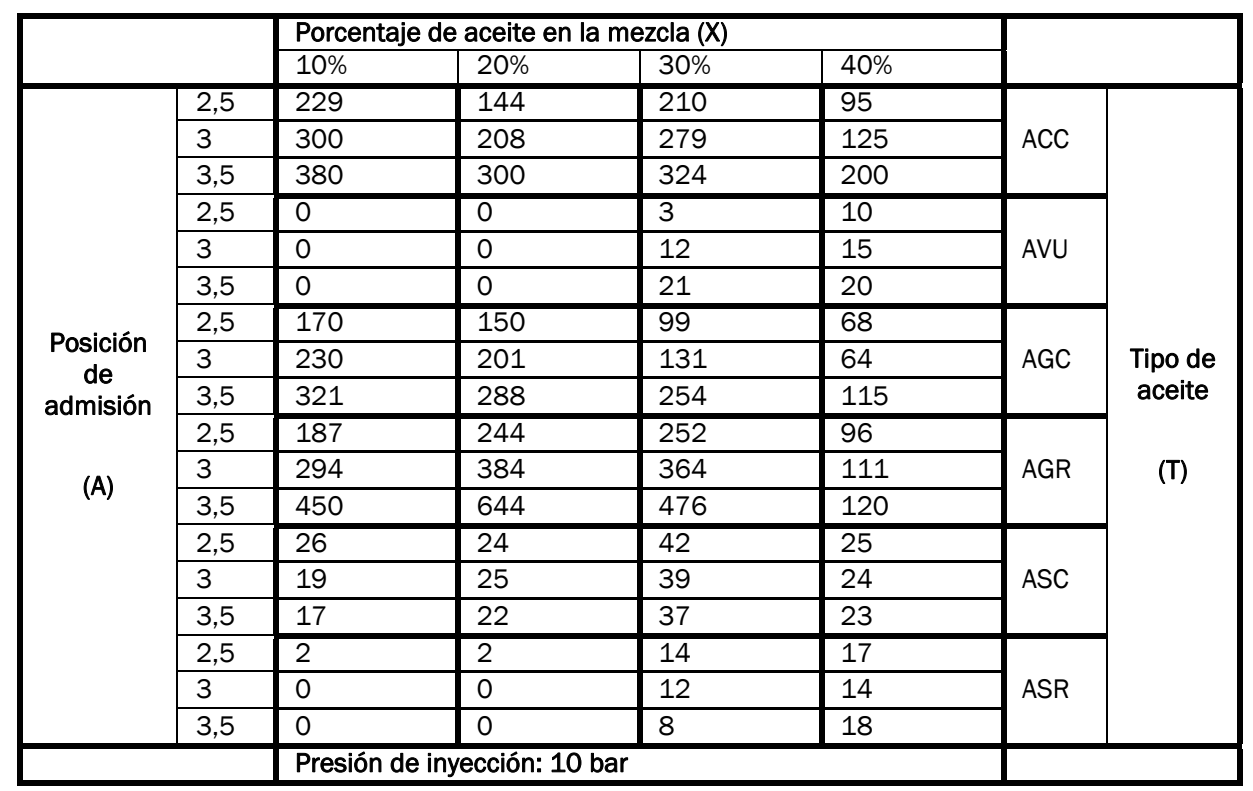

Con estos datos, lo primero que se plantea es un análisis de varianza (ANOVA), mediante el cual se determinará si las tres variables influyen (admisión del aire, tipo de aceite y porcentaje de aceite en peso) o no y de qué manera. 
Tabla 8.12:Análisis ANOVA

\begin{tabular}{|l|l|l|l|l|l|l|l|}
\hline FACTOR & GdL & SS & MS & F & VC al 5\% & Influye & G. C. Crítica \\
\hline A & 2 & 78896,861 & 39448,431 & 36,796 & 3,316 & SI & $8,45021 \mathrm{E}-09$ \\
\hline T & 5 & 993504,944 & 198700,989 & 185,343 & 2,534 & SI & $1,31267 \mathrm{E}-21$ \\
\hline X & 3 & 88036,056 & 29345,352 & 27,373 & 2,922 & SI & $1,0002 \mathrm{E}-08$ \\
\hline AxT & 10 & 92852,639 & 9285,264 & 8,661 & 2,165 & SI & $1,84387 \mathrm{E}-06$ \\
\hline AxX & 6 & 11620,361 & 1936,727 & 1,807 & 2,421 & NO & 0,13148662 \\
\hline TxX & 15 & 171024,944 & 11401,663 & 10,635 & 2,015 & SI & $3,37042 \mathrm{E}-08$ \\
\hline Error & 30 & 32162,139 & 1072,071 & & & & \\
\hline Total & 71 & 1468097,944 & & & & & \\
\hline
\end{tabular}

La interpretación del análisis es la siguiente: para un análisis con un 5\% de confiabilidad, se tiene que la única variable rechazada para el análisis ANOVA es la interacción de la posición de admisión de aire junto con el porcentaje de aceite en peso en la mezcla $(A x X)$. Se trata de la única variable que tiene un grado de confiabilidad crítica del orden de décimas, ya que el resto de variables se mueven varios órdenes de magnitud por debajo de ella.

Se puede sacar la conclusión de que la variable más significativa es el tipo de aceite, con un orden de confiabilidad crítico del orden de 10-19 (en términos porcentuales, en términos absolutos en tanto por 1 es 10-21). A continuación, en orden de importancia, se sitúa la variable A y a continuación la X, ambas con órdenes de magnitud del orden de $10^{-6}$. También la interacción TxX está en esos órdenes, mientras que la interacción AxT está en un orden de 10-4 por ciento.

A priori, será la variable T la más significativa. Sin embargo, los valores críticos obtenidos para el resto de variables y sus interacciones hacen que la única variable que de verdad sea claramente no influyente sea AxX.

Se representan a continuación los valores obtenidos para las emisiones de $\mathrm{CO}$ en función de las variables $\mathrm{A}, \mathrm{X}$ y $\mathrm{T}$. 
Representaciones gráficas de las emisiones de $\mathrm{CO}$ para el aceite de colza crudo $(\mathrm{T}=\mathrm{ACC})$

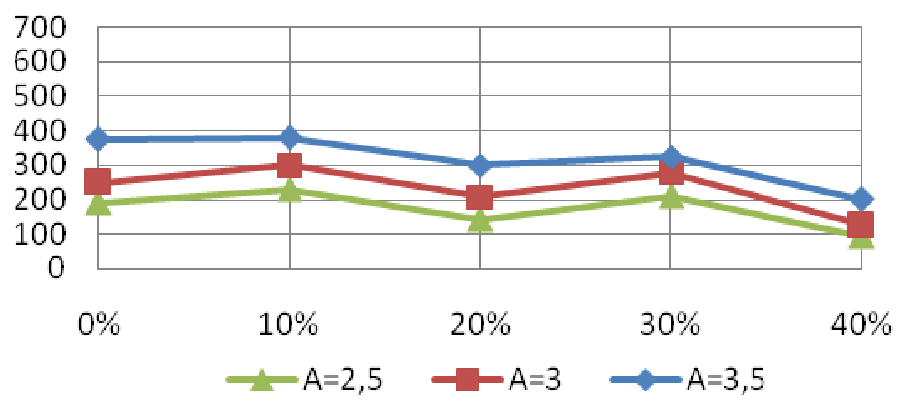

\begin{tabular}{|llllll|}
$\begin{array}{l}\text { AC, } \\
P=10 \text { bar }\end{array}$ & $X=0 \%$ & $X=10 \%$ & $X=20 \%$ & $X=30 \%$ & $X=40 \%$ \\
\hline$A=2,5$ & 192 & 229 & 144 & 210 & 95 \\
\hline$A=3$ & 250 & 300 & 208 & 279 & 125 \\
\hline$A=3,5$ & 376 & 380 & 300 & 324 & 200 \\
\hline
\end{tabular}

Figura 8.69: Emisiones para $\mathrm{P}=10$ bar y $\mathrm{T}=\mathrm{ACC}$

La tendencia observada es que el mayor exceso de aire provoca mayores emisiones. Las máximas emisiones se producen para dicha posición $(A=3,5)$ y $X=10 \%$. 
Representaciones gráficas de las emisiones de CO para el aceite vegetal usado ( $\mathrm{T}=\mathrm{AVU}$ )

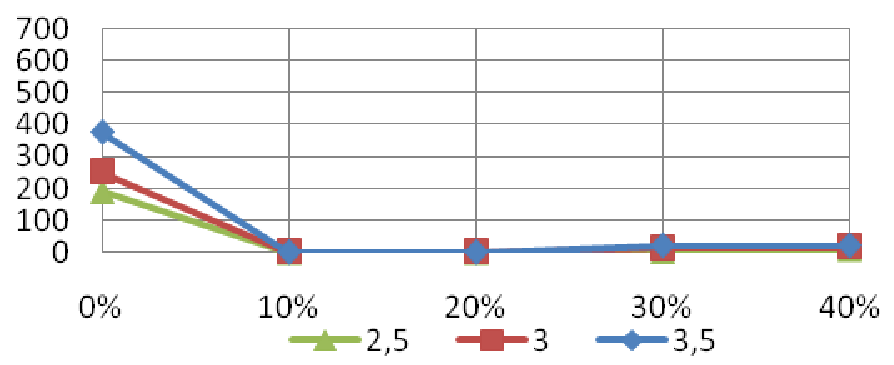

\begin{tabular}{|llllll|}
\hline $\begin{array}{l}\text { AVU, } \\
P=10 \text { bar }\end{array}$ & $X=0 \%$ & $X=10 \%$ & $X=20 \%$ & $X=30 \%$ & $X=40 \%$ \\
\hline$A=2,5$ & 192 & 0 & 0 & 3 & 10 \\
\hline$A=3$ & 250 & 0 & 0 & 12 & 15 \\
\hline$A=3,5$ & 376 & 0 & 0 & 21 & 20 \\
\hline
\end{tabular}

Figura 8.70: Emisiones para $P=10$ bar y $T=A V U$

Las medidas obtenidas para este tipo de aceite son extremadamente bajas, dando los porcentajes $X=10 \%$ y $X=20 \%$ valores nulos. Los otros porcentajes dan también valores bajos. 
Representaciones gráficas de las emisiones de CO para el aceite girasol crudo ( $T=A G C)$

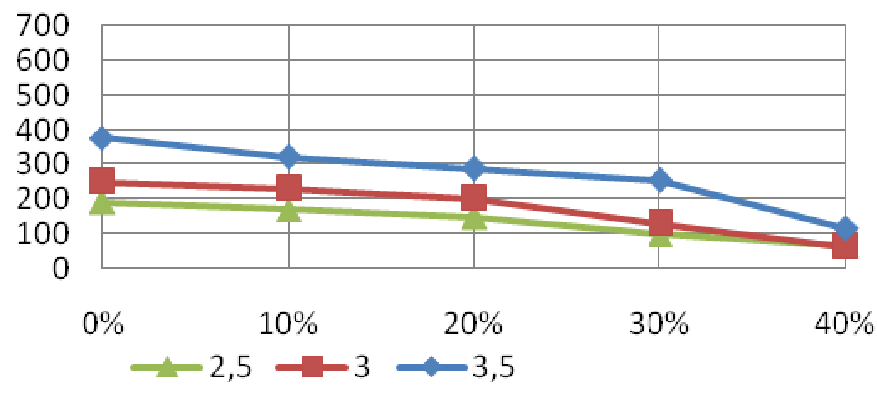

\begin{tabular}{|llllll|}
$\begin{array}{l}\text { AGC, } \\
P=10 \text { bar }\end{array}$ & $X=0 \%$ & $X=10 \%$ & $X=20 \%$ & $X=30 \%$ & $X=40 \%$ \\
\hline$A=2,5$ & 192 & 170 & 150 & 99 & 68 \\
\hline$A=3$ & 250 & 230 & 201 & 131 & 64 \\
\hline$A=3,5$ & 376 & 321 & 288 & 254 & 115 \\
\hline
\end{tabular}

Figura 8.71: Emisiones para $P=10$ bar y $T=A G C$

Los valores obtenidos muestran la misma tendencia que en el ACC, dando más emisiones a mayor exceso de aire. Además, queda patente también que el porcentaje de aceite influye, daño menores emisiones a menores porcentajes. 
Representaciones gráficas de las emisiones de CO para el aceite girasol refinado $(T=A G R)$

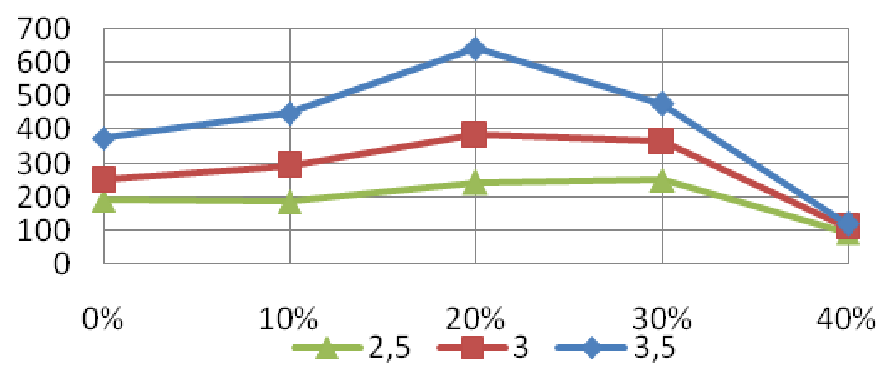

\begin{tabular}{|llllll|}
$\begin{array}{l}\text { AGR, } \\
P=10 \text { bar }\end{array}$ & $X=0 \%$ & $X=10 \%$ & $X=20 \%$ & $X=30 \%$ & $X=40 \%$ \\
\hline$A=2,5$ & 192 & 187 & 244 & 252 & 96 \\
\hline$A=3$ & 250 & 294 & 384 & 364 & 111 \\
\hline$A=3,5$ & 376 & 450 & 644 & 476 & 120 \\
\hline
\end{tabular}

Figura 8.72: Emisiones para $\mathrm{P}=10$ bar y $\mathrm{T}=\mathrm{AGR}$

Se observa una tendencia distinta de la de las anteriores gráficas, teniendo picos para porcentajes intermedios, si bien el mínimo sigue obteniéndose para el porcentaje mayor de aceite. 
Representaciones gráficas de las emisiones de CO para el aceite soja crudo ( $\mathrm{T}=\mathrm{ASC}$ )

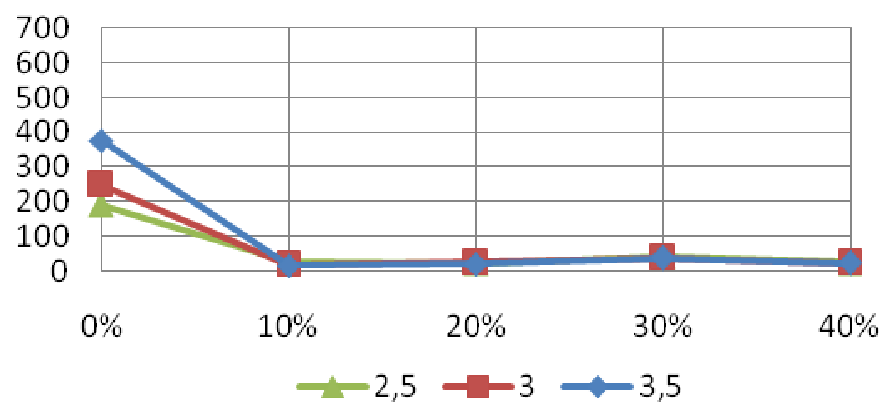

\begin{tabular}{|llllll|}
$\begin{array}{l}\text { ASC, } \\
P=10 \text { bar }\end{array}$ & $X=0 \%$ & $X=10 \%$ & $X=20 \%$ & $X=30 \%$ & $X=40 \%$ \\
\hline$A=2,5$ & 192 & 26 & 24 & 42 & 25 \\
\hline$A=3$ & 250 & 19 & 25 & 39 & 24 \\
\hline$A=3,5$ & 376 & 17 & 22 & 37 & 23 \\
\hline
\end{tabular}

Figura 8.73: Emisiones para $\mathrm{P}=10$ bar y $\mathrm{T}=\mathrm{ASC}$

La tendencia es muy parecida a la que teníamos en el AVU, con valores muy bajos para todos los porcentajes y posiciones de admisión de aire. 
Representaciones gráficas de las emisiones de CO para el aceite soja refinado $(\mathrm{T}=\mathrm{ASR})$

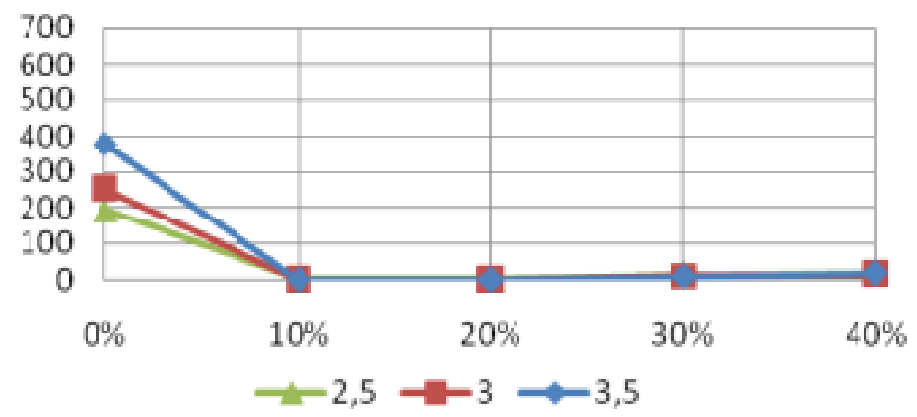

\begin{tabular}{|llllll|}
$\begin{array}{l}\text { ASC, } \\
P=1 \text { bbar }\end{array}$ & $X=0 \%$ & $X=10 \%$ & $X=20 \%$ & $X=30 \%$ & $X=40 \%$ \\
\hline$A=2,5$ & 192 & 2 & 2 & 14 & 17 \\
\hline$A=3$ & 250 & 0 & 0 & 12 & 14 \\
\hline$A=3,5$ & 376 & 0 & 0 & 8 & 18 \\
\hline
\end{tabular}

Figura 8.74: Emisiones para $\mathrm{P}=10$ bar y $\mathrm{T}=\mathrm{ASR}$

Misma tendencia que el aceite sin refinar, con valores si puede ser más pequeño todavía. 
Representaciones gráficas de las emisiones de CO para la posición del aire $A=2,5$

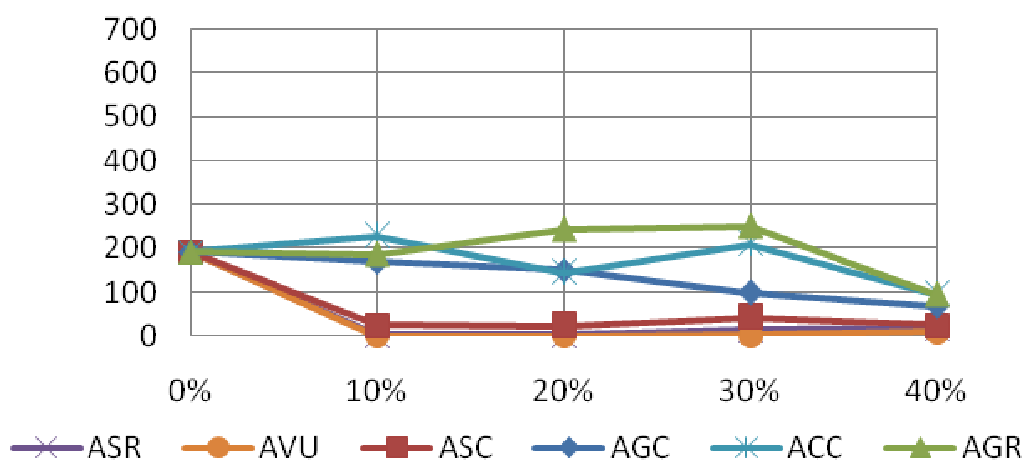

\begin{tabular}{|llllll|}
$\begin{array}{l}\text { A=2,5, } \\
P=10 \text { bar }\end{array}$ & $X=0 \%$ & $X=10 \%$ & $X=20 \%$ & $X=30 \%$ & $X=40 \%$ \\
\hline AC & 192 & 229 & 144 & 210 & 95 \\
\hline AVU & 192 & 0 & 0 & 3 & 10 \\
\hline AGC & 192 & 170 & 150 & 99 & 68 \\
\hline AGR & 192 & 187 & 244 & 252 & 96 \\
\hline ASC & 192 & 26 & 24 & 42 & 25 \\
\hline ASR & 192 & 2 & 2 & 14 & 17 \\
\hline
\end{tabular}

Figura 8.75: Emisiones para $P=10$ bar y $A=2,5$

Puede observarse lo ya visto en el análisis de cada aceite: se tienen tres tipos de mezcla (AGR, AGC y ACC) los cuales dan unos valores de emisión de $\mathrm{CO}$ altos, siendo el máximo de 252 ppm obtenido para AGC y $\mathrm{X}=30 \%$. Por otro lado, los dos aceites de soja y el vegetal usado dan unos valores muy inferiores a los otros, dando los mínimos el aceite vegetal usado (AVU). 
Representaciones gráficas de las emisiones de CO para la posición del aire $A=3$

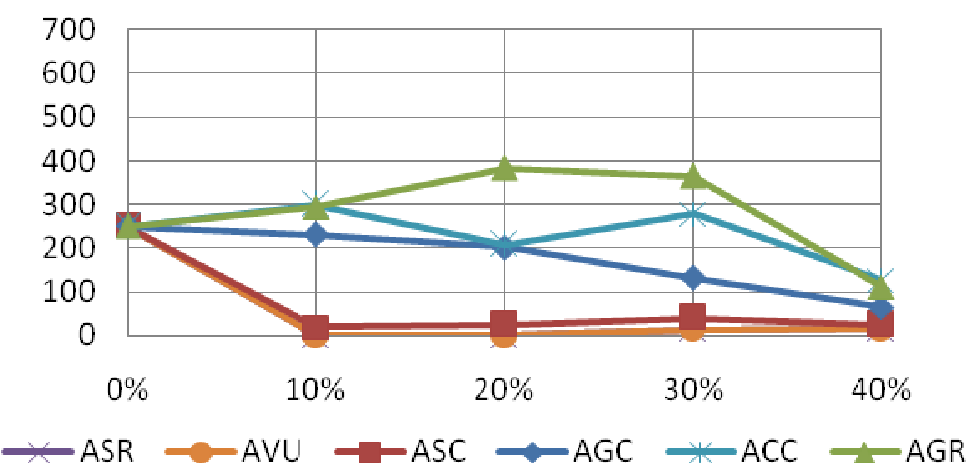

\begin{tabular}{|llllll|}
$\begin{array}{l}\text { A=3, } \\
P=10 \text { bar }\end{array}$ & $X=0 \%$ & $X=10 \%$ & $X=20 \%$ & $X=30 \%$ & $X=40 \%$ \\
\hline AC & 250 & 300 & 208 & 279 & 125 \\
\hline AVU & 250 & 0 & 0 & 12 & 15 \\
\hline AGC & 250 & 230 & 201 & 131 & 64 \\
\hline AGR & 250 & 294 & 384 & 364 & 111 \\
\hline ASC & 250 & 19 & 25 & 39 & 24 \\
\hline ASR & 250 & 0 & 0 & 12 & 14 \\
\hline
\end{tabular}

Figura 8.76: Emisiones para $\mathrm{P}=10$ bar y $\mathrm{A}=3$

Misma tendencia que antes (incluso la forma de los gráficos es idéntica), pero valores de emisión mayores. El aceite de girasol refinado da unos valores excesivamente altos para $X=20 \%$ y $X=30 \%$ (384 y 364 ppm respectivamente). También el ACC y el AGC dan valores altos, pero inferiores al AGR. Es destacable el hecho de que el aceite refinado da más emisiones que el crudo. El comportamiento es el inverso en el aceite de soja, dando los valores mínimos el refinado. Tanto AVU, como ASR como ASC dan valores muy por debajo de los obtenidos con los otros tipos de 
Representaciones gráficas de las emisiones de CO para la posición del aire $A=3,50$.

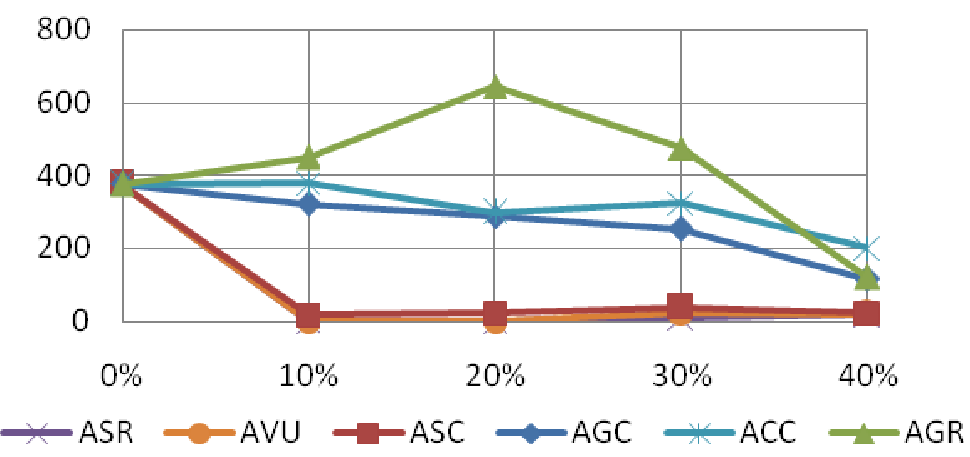

\begin{tabular}{|llllll|}
$\begin{array}{l}\text { A=3,5, } \\
P=10 \text { bar }\end{array}$ & $X=0 \%$ & $X=10 \%$ & $X=20 \%$ & $X=30 \%$ & $X=40 \%$ \\
\hline AC & 376 & 380 & 300 & 324 & 200 \\
\hline AVU & 376 & 0 & 0 & 21 & 20 \\
\hline AGC & 376 & 321 & 288 & 254 & 115 \\
\hline AGR & 376 & 450 & 644 & 476 & 120 \\
\hline ASC & 376 & 17 & 22 & 37 & 23 \\
\hline ASR & 376 & 0 & 0 & 8 & 18 \\
\hline
\end{tabular}

Figura 8.77: Emisiones para $\mathrm{P}=10$ bar y $\mathrm{A}=3,5$

Comportamiento bastante parecido a los anteriores. Los grupos de aceite con grandes emisiones y con pequeñas emisiones están bien diferenciados. Los valores obtenidos para el AGR siguen siendo los más altos, con un pico para $\mathrm{X}=20 \%$ de $644 \mathrm{ppm}$. El ASR vuelve a ofrecer los mínimos. 
Representaciones gráficas de las emisiones de CO para el porcentaje en peso de aceite $X=10 \%$

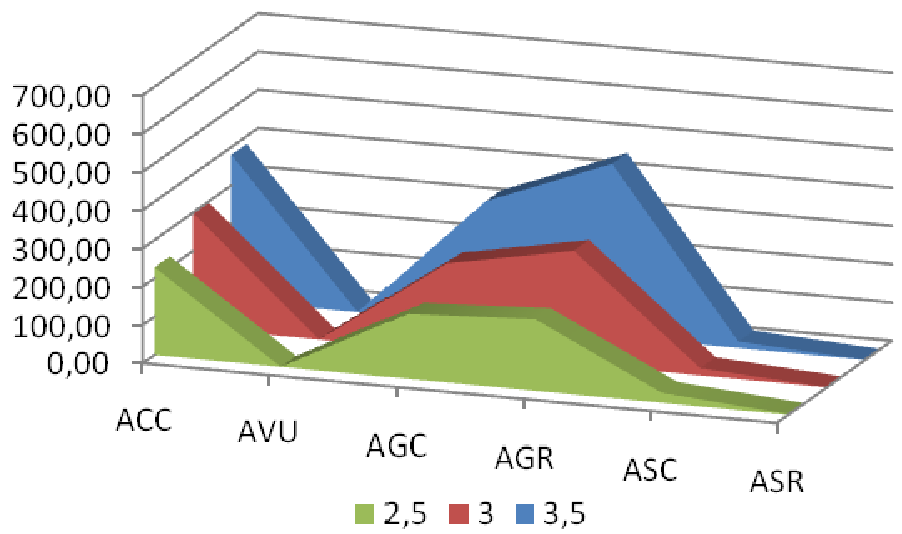

\begin{tabular}{|lllllll|}
\hline $\begin{array}{l}X=10 \%, \\
P=10 \text { bar }\end{array}$ & ACC & AVU & AGC & AGR & ASC & ASR \\
\hline$A=2,5$ & 229 & 0 & 170 & 187 & 26 & 2 \\
\hline$A=3$ & 300 & 0 & 230 & 294 & 19 & 0 \\
\hline$A=3,5$ & 380 & 0 & 321 & 450 & 17 & 0 \\
\hline
\end{tabular}

Figura 8.78: Emisiones para $\mathrm{P}=10$ bar y $\mathrm{X}=10 \%$

En el primer gráfico puede observarse qué aceites dan valores altos de emisión y cuáles dan emisiones casi nulas (se ve también en la tabla). La segunda gráfica no ofrece mucho más. La tendencia es al alza con el aumento de la admisión del aire.

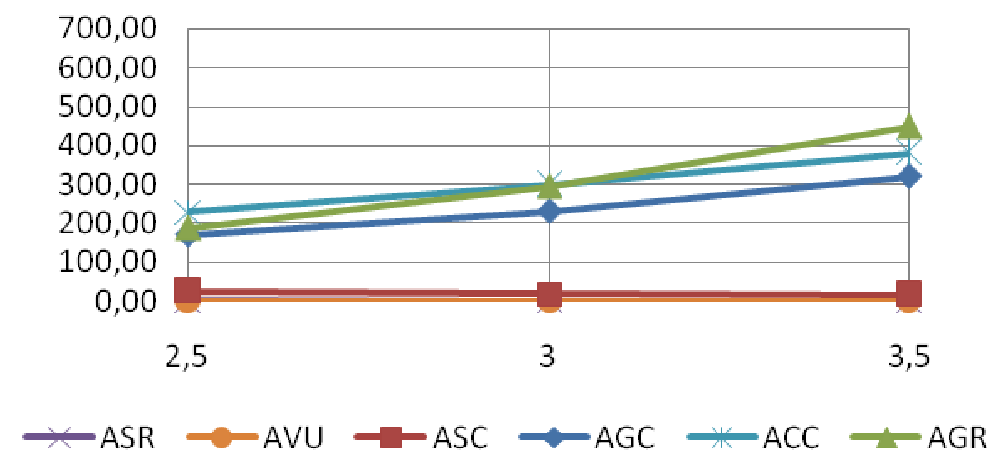

Figura 8.79: Emisiones para $\mathrm{P}=10$ bar y $\mathrm{X}=10 \%$ 
Representaciones gráficas de las emisiones de CO para el porcentaje en peso de aceite $X=20 \%$

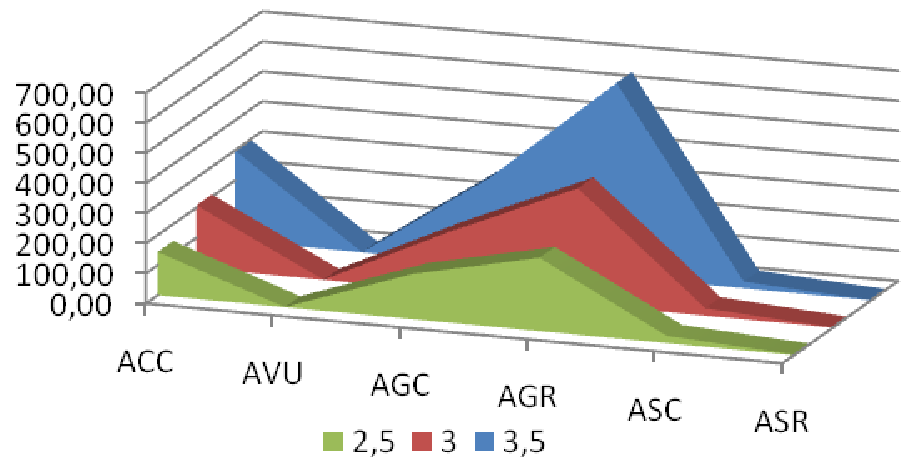

\begin{tabular}{|lllllll|}
\hline $\begin{array}{l}X=20 \%, \\
P=10 \text { bar }\end{array}$ & ACC & AVU & AGC & AGR & ASC & ASR \\
\hline$A=2,5$ & 144 & 0 & 150 & 244 & 24 & 2 \\
\hline$A=3$ & 208 & 0 & 201 & 384 & 25 & 0 \\
\hline$A=3,5$ & 300 & 0 & 288 & 644 & 22 & 0 \\
\hline
\end{tabular}

Figura 8.80: Emisiones para $\mathrm{P}=10$ bar $\mathrm{y} \mathrm{X}=20 \%$

Se obtienen un valor muy alto para $A=3,5$ y $A G R$. Resultados nulos de nuevo en AVU y casi nulos en ASR.

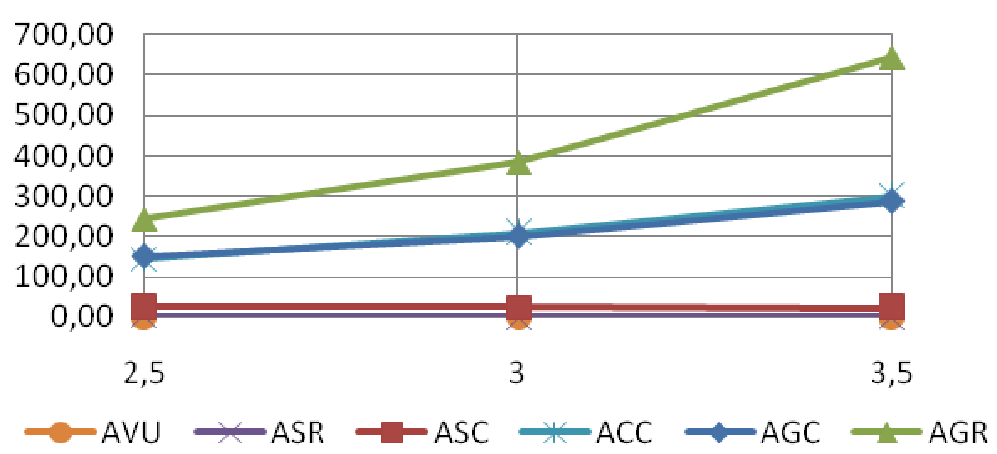

Figura 8.81: Emisiones para $\mathrm{P}=10$ bar y $\mathrm{X}=20 \%$ 
Representaciones gráficas de las emisiones de CO para el porcentaje en peso de aceite $X=30 \%$

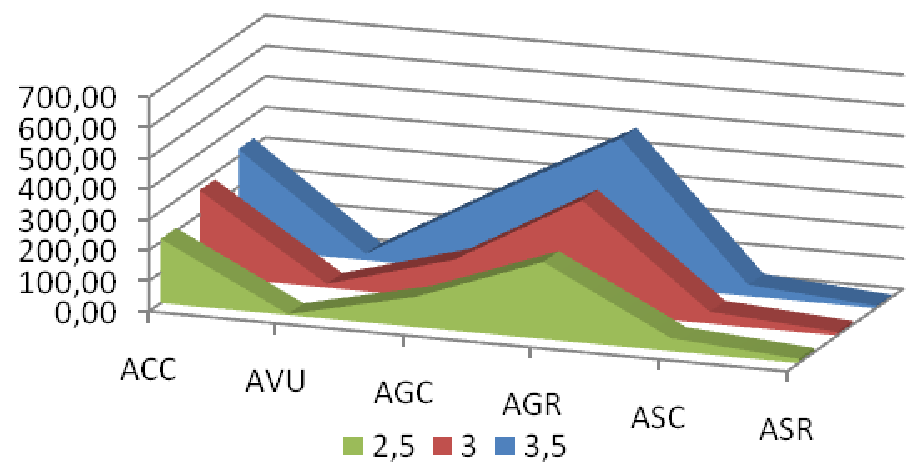

\begin{tabular}{|lllllll|}
\hline $\begin{array}{l}X=30 \%, \\
P=10 \text { bar }\end{array}$ & ACC & AVU & AGC & AGR & ASC & ASR \\
\hline$A=2,5$ & 210 & 3 & 99 & 252 & 42 & 14 \\
\hline$A=3$ & 279 & 12 & 131 & 364 & 39 & 12 \\
\hline$A=3,5$ & 324 & 21 & 254 & 476 & 37 & 8 \\
\hline
\end{tabular}

Figura 8.82: Emisiones para $\mathrm{P}=10$ bar y $\mathrm{X}=30 \%$

Aún siguiéndose la tendencia de los gráficos anteriores, los valores de AVU, ASC y ASR aumentan con respecto a porcentajes inferiores. Por otro lado, se estabilizan las emisiones en el resto de aceite, disminuyendo sus valores y el máximo obtenido. La segunda gráfica muestra que la tendencia al alta del valor de las emisiones con la admisión del aire.

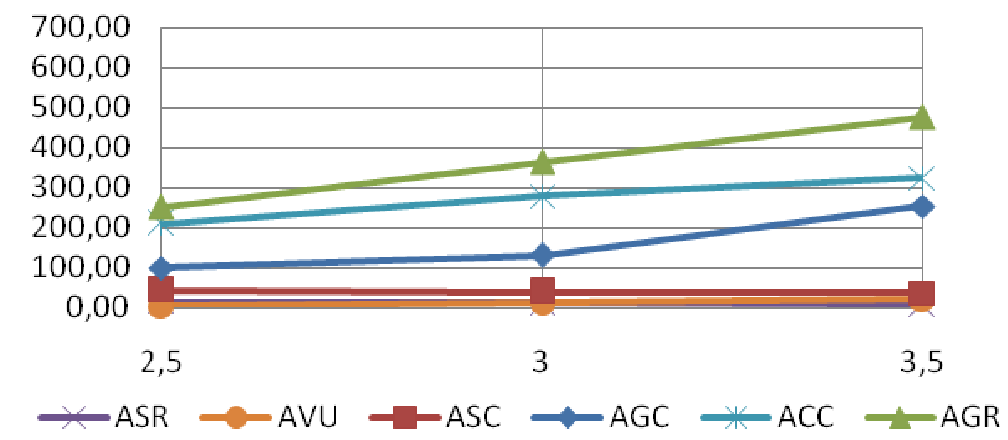

Figura 8.83: Emisiones para $\mathrm{P}=10$ bar y $\mathrm{X}=30 \%$ 
Representaciones gráficas de las emisiones de CO para el porcentaje en peso de aceite $X=40 \%$.

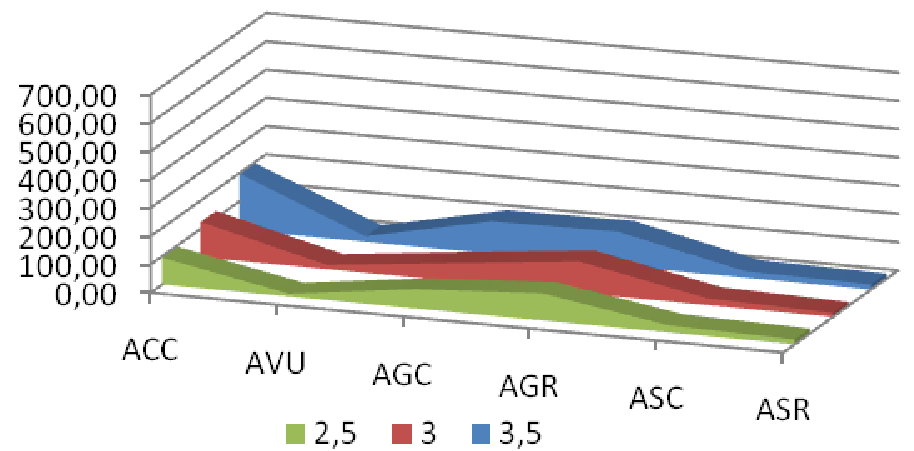

\begin{tabular}{|lllllll|}
\hline $\begin{array}{l}\mathrm{X}=40 \%, \\
\mathrm{P}=10 \mathrm{bar}\end{array}$ & ACC & AVU & AGC & AGR & ASC & ASR \\
\hline $\mathrm{A}=\mathbf{2 , 5}$ & 95 & 10 & 68 & 96 & 25 & 17 \\
\hline $\mathrm{A}=3$ & 125 & 15 & 64 & 111 & 24 & 14 \\
\hline $\mathrm{A}=3,5$ & 200 & 20 & 115 & 120 & 23 & 18 \\
\hline
\end{tabular}

Figura 8.84: Emisiones para $\mathrm{P}=10$ bar y $\mathrm{X}=40 \%$

El aumento de aceite en la mezcla de combustible "suaviza" el valor de las emisiones, si bien los aceites con emisiones altas en otros porcentajes siguen siendo las mismas. El máximo es de nuevo menor. El mínimo lo obtiene el AVU a $A=2,5$. En este caso, las emisiones del ACC fueron las más altas.

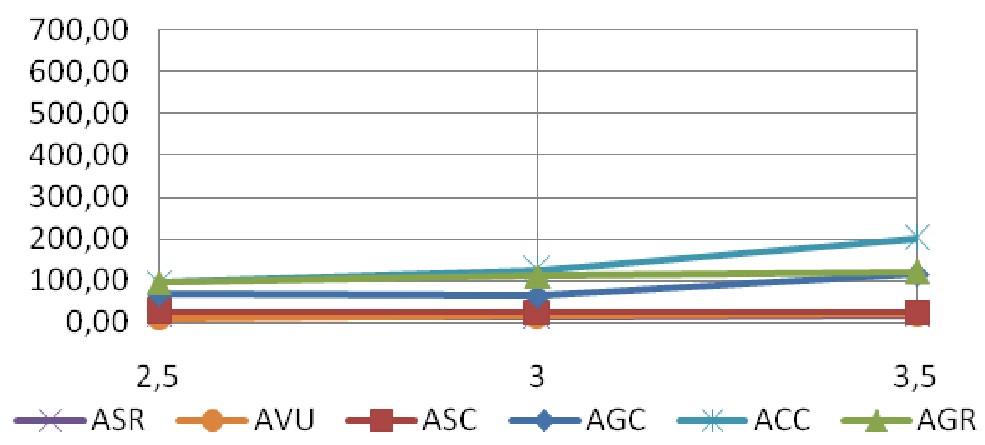

Figura 8.85: Emisiones para $\mathrm{P}=10$ bar y $\mathrm{X}=40 \%$ 


\subsubsection{Conclusiones}

El análisis tanto del ANOVA como de las representaciones gráficas da como conclusiones las siguientes:

- La variable más influyente del análisis es el tipo de aceite (T). Se han distinguido dentro de los tipos de aceite dos grupos: por un lado, el AGR, el AGC y el ACC nunca obtienen valores de emisión por encima de 100 ppm, llegando a superar los 400 ppm con asiduidad. El otro grupo está formado por el AVU, el ASC y el ASR, siendo el máximo de estos en todo el análisis $42 \mathrm{ppm}$. Se tiene, por tanto, que estos aceites serían, desde el punto de vista de reducción de emisiones, los mejores del análisis, con el ASR y el AVU por delante del ASC.

- Además, los tres aceites de mayores emisiones ofrecen una tendencia a la baja clara cuando aumenta el porcentaje de aceite en la mezcla (influencia de la interacción TxX). En el resto de aceites, al ser valores tan bajos en la emisión, no se aprecia tanto la tendencia. Para $X=20 \%$ y $A=2,5$, tanto AVU como ASR tienen emisiones cero, mientras que el para $X=40 \%$ y $A=2,5$ se tienen 10 y $17 \mathrm{ppm}$. Esto comparado con la caída que experimenta, por ejemplo, el AGR de 244 a 96 ppm para las mismas condiciones, ofrece como conclusión que este aceite sufre más (para bien, ya que las emisiones son inferiores) el aumento de $X$.

- $\quad$ El máximo obtenido es 644 ppm y se obtiene para $A G R, X=20 \%$ y $A=3,5$. Los mínimos obtenidos son $0 \mathrm{ppm}$ para las posiciones $A V U$ ( $X=10$ y $20 \%$, para todos los $A^{\prime}$ 's) y AGR ( $X=10$ y $20 \%$ con $A=3$ y 3,5).C

- La tendencia seguida por el aceite refinado para la soja y el girasol es contraria: con la soja refinada, las emisiones disminuyen, mientras que con el girasol refinado aumentan. 


\subsubsection{Análisis a de las emisiones de $\mathrm{CO}$ a P=12 BAR}

Se muestra a continuación la matriz de resultados obtenidos:

Tabla 8.13:Matriz de resultados de emisiones de CO

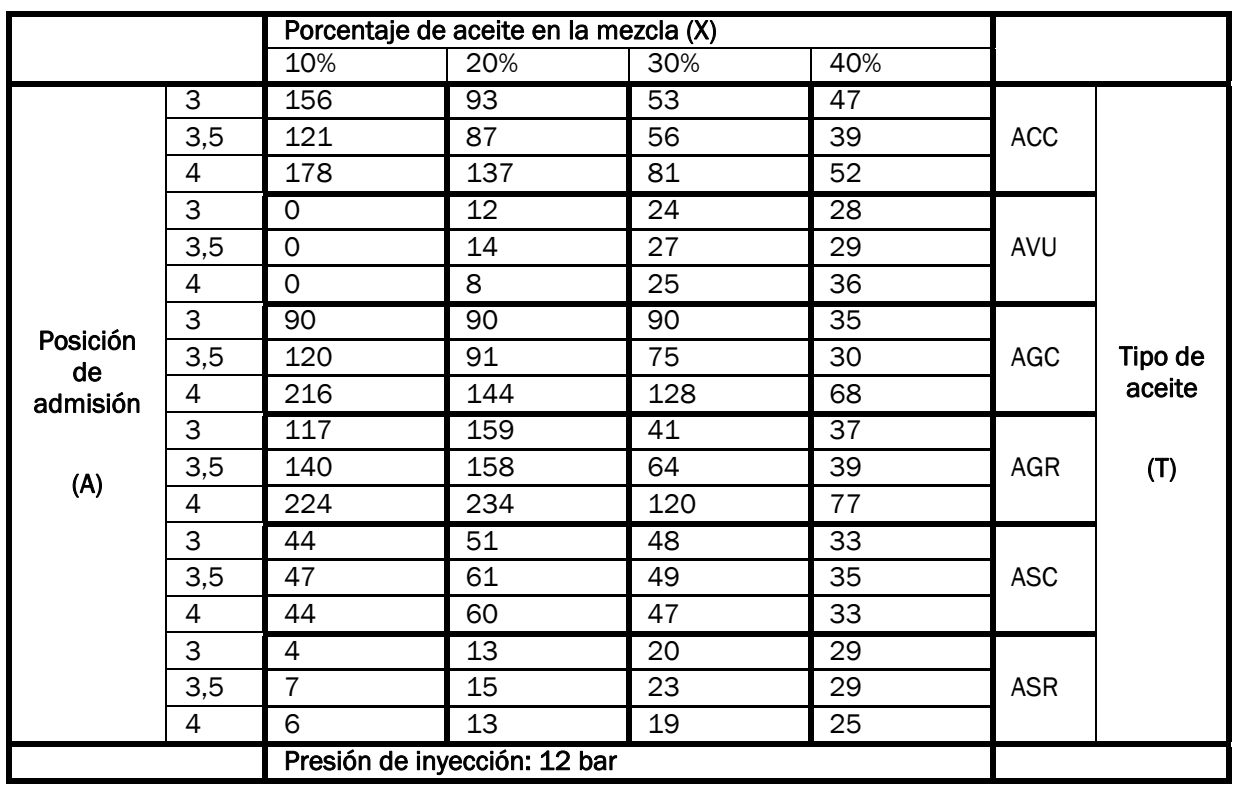

Con los datos ya dispuestos, se plantea un análisis de varianza (ANOVA), mediante el cual se determinará si las tres variables influyen (presión de inyección, tipo de aceite y porcentaje de aceite en peso) o no y de qué manera.

Tabla 8.14: Análisis ANOVA emisiones de CO

\begin{tabular}{|l|l|l|l|l|l|l|l|}
\hline FACTOR & GdL & SS & MS & F & VC al 5\% & Influye & G. C. Crítica \\
\hline A & 2 & 11414,528 & 5707,264 & 46,000 & 3,316 & SI & $7,26833 \mathrm{E}-10$ \\
\hline T & 5 & 114545,569 & 22909,114 & 184,645 & 2,534 & SI & $1,38644 \mathrm{E}-21$ \\
\hline X & 3 & 24627,264 & 8209,088 & 66,164 & 2,922 & SI & $2,49073 \mathrm{E}-13$ \\
\hline AxT & 10 & 14554,639 & 1455,464 & 11,731 & 2,165 & SI & $7,15006 E-08$ \\
\hline AxX & 6 & 1551,361 & 258,560 & 2,084 & 2,421 & NO & 0,08491808 \\
\hline TxX & 15 & 50934,486 & 3395,632 & 27,368 & 2,015 & SI & $1,99346 E-13$ \\
\hline Error & 30 & 3722,139 & 124,071 & & & & \\
\hline Total & 71 & 221349,986 & & & & & \\
\hline
\end{tabular}

La interpretación del análisis es la siguiente: para un análisis con un $5 \%$ de confiabilidad, se tiene que la única variable rechazada para el análisis ANOVA es la interacción de la posición de admisión de aire junto con el porcentaje de aceite en peso en la mezcla (AxX). Se tiene, sin embargo, 
que con un análisis al 8,5\% la variable pasaría a ser significativa, de modo que no está tan lejos como la misma variable en el análisis a $\mathrm{P}=10$ bar.

Se puede sacar la conclusión de que la variable más significativa es el tipo de aceite, con un orden de confiabilidad crítico del orden de 10-19 (en términos porcentuales, en términos absolutos en tanto por 1 es 10-21). A continuación, en orden de importancia, se sitúa la variable $X$ y a continuación la interacción TXX, ambas con órdenes de magnitud del orden de 10-11. La variable A tiene un valor crítico de la confiabilidad de $10^{-8}$ y la interacción AxT de 10-6.

A priori, será la variable T la más significativa. Sin embargo, los valores críticos obtenidos para el resto de variables y sus interacciones hacen que la única variable que de verdad sea claramente no influyente sea AxX (misma conclusión que en el anterior análisis).

Representaciones gráficas de las emisiones de CO para el aceite de colza crudo $(\mathrm{T}=\mathrm{ACC})$

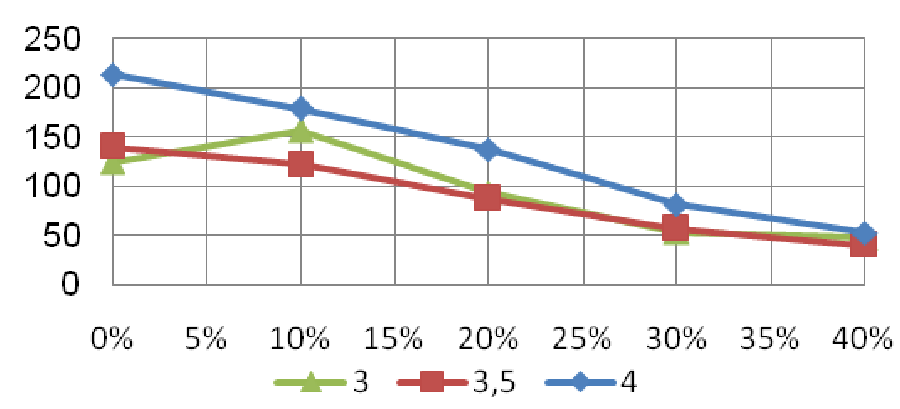

\begin{tabular}{|llllll|}
\hline $\begin{array}{l}\text { ACC, } \\
P=12 \text { bar }\end{array}$ & $X=0 \%$ & $X=10 \%$ & $X=20 \%$ & $X=30 \%$ & $X=40 \%$ \\
\hline$A=3$ & 124 & 156 & 93 & 53 & 47 \\
\hline$A=3,5$ & 139 & 121 & 87 & 56 & 39 \\
\hline$A=4$ & 213 & 178 & 137 & 81 & 52 \\
\hline
\end{tabular}

Figura 8.86: Emisiones para $\mathrm{P}=12$ bar y $\mathrm{T}=\mathrm{ACC}$

Se observa tendencia descendente con el aumento de porcentaje en la mezcla. Además, las emisiones para la posición intermedia de la admisión del aire son inferiores a las de la posición mínima en algunos valores. 
Representaciones gráficas de las emisiones de CO para el aceite vegetal usado ( $\mathrm{T}=\mathrm{AVU}$ )

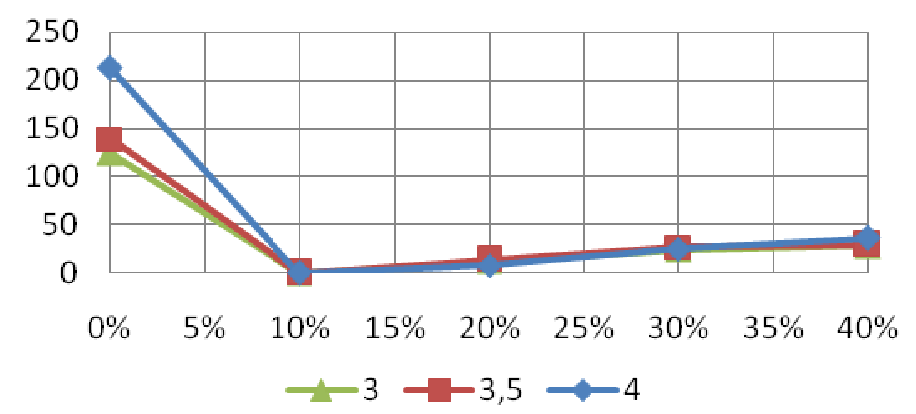

\begin{tabular}{|llllll|}
\hline $\begin{array}{l}\text { AVU, } \\
P=12 \text { bar }\end{array}$ & $X=0 \%$ & $X=10 \%$ & $X=20 \%$ & $X=30 \%$ & $X=40 \%$ \\
\hline$A=3$ & 124 & 0 & 12 & 24 & 28 \\
\hline$A=3,5$ & 139 & 0 & 14 & 27 & 29 \\
\hline$A=4$ & 213 & 0 & 8 & 25 & 36 \\
\hline
\end{tabular}

Figura 8.87: Emisiones para $\mathrm{P}=12$ bar y $\mathrm{T}=\mathrm{AVU}$

Emisiones menores que en ACC, y con una tendencia inversa a la de ésta: las emisiones de $\mathrm{CO}$ aumentan con el porcentaje de aceite en la mezcla. No puede describirse una tendencia clara en el comportamiento con la variación de A. 
Representaciones gráficas de las emisiones de CO para el aceite girasol crudo $(\mathrm{T}=\mathrm{AGC})$

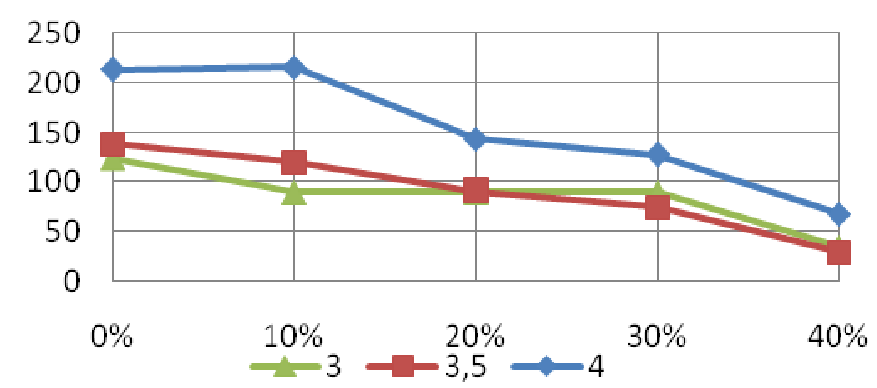

\begin{tabular}{|llllll|}
\hline $\begin{array}{l}\text { AGC, } \\
P=12 \text { bar }\end{array}$ & $X=0 \%$ & $X=10 \%$ & $X=20 \%$ & $X=30 \%$ & $X=40 \%$ \\
\hline$A=3$ & 124 & 90 & 90 & 90 & 35 \\
\hline$A=3,5$ & 139 & 120 & 91 & 75 & 30 \\
\hline$A=4$ & 213 & 216 & 144 & 128 & 68 \\
\hline
\end{tabular}

Figura 8.88: Emisiones para $\mathrm{P}=12$ bar y $\mathrm{T}=\mathrm{AGC}$

Tendencia muy parecida a la del AC: las emisiones decrecen con X. Vuelve a no hacerse distinguible el comportamiento con la variable $A$ : para $A=4$ tenemos los máximos, pero los mínimos se los reparten $A=3$ y $A=3,5$. 
Representaciones gráficas de las emisiones de $\mathrm{CO}$ para el aceite girasol refinado $(T=A G R)$

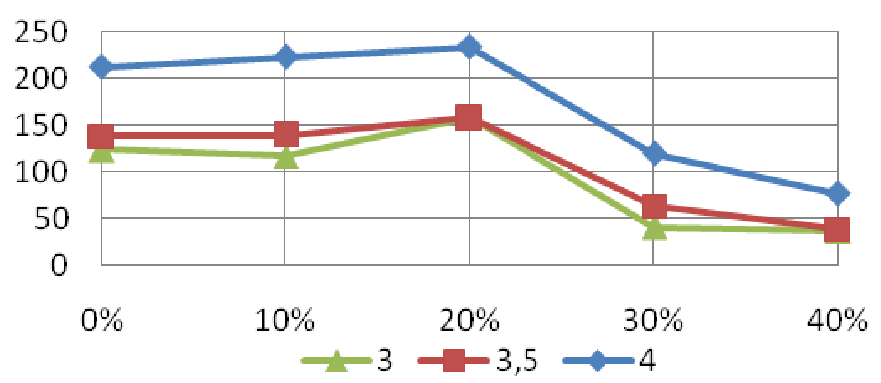

\begin{tabular}{|llllll|}
\hline $\begin{array}{l}\text { AGR, } \\
P=12 \text { bar }\end{array}$ & $X=0 \%$ & $X=10 \%$ & $X=20 \%$ & $X=30 \%$ & $X=40 \%$ \\
\hline$A=3$ & 124 & 117 & 159 & 41 & 37 \\
\hline$A=3,5$ & 139 & 140 & 158 & 64 & 39 \\
\hline$A=4$ & 213 & 224 & 234 & 120 & 77 \\
\hline
\end{tabular}

Figura 8.89: Emisiones para $\mathrm{P}=12$ bar y $\mathrm{T}=\mathrm{AGR}$

En este caso, se tiene un pico para $X=20 \%$ y luego las emisiones descienden. Además, se ve que para posiciones de admisión de aire mayores las emisiones son mayores. 
Representaciones gráficas de las emisiones de CO para el aceite de soja crudo ( $\mathrm{T}=\mathrm{ASC}$ )

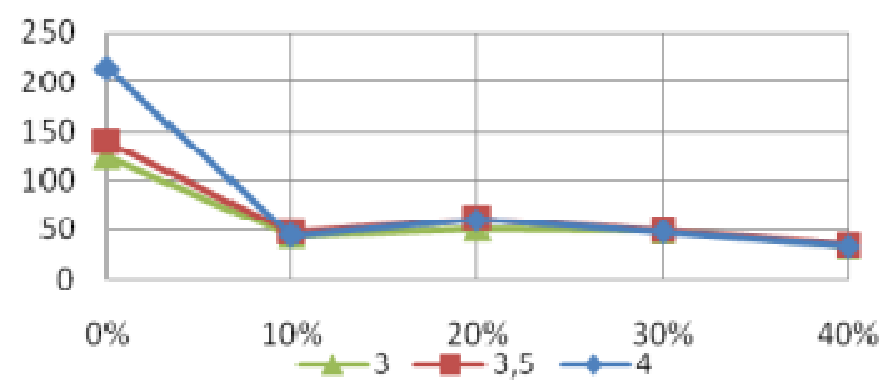

\begin{tabular}{|llllll|}
\hline $\begin{array}{l}\text { ASC, } \\
P=12 \text { bar }\end{array}$ & $X=0 \%$ & $X=10 \%$ & $X=20 \%$ & $X=30 \%$ & $X=40 \%$ \\
\hline$A=3$ & 124 & 44 & 51 & 48 & 33 \\
\hline$A=3,5$ & 139 & 47 & 61 & 49 & 35 \\
\hline$A=4$ & 213 & 44 & 60 & 47 & 33 \\
\hline
\end{tabular}

Figura 8.90: Emisiones para $\mathrm{P}=12$ bar y $\mathrm{T}=\mathrm{ASC}$

Las emisiones vuelven a alcanzar un máximo para $X=20 \%$. El mínimo se obtiene para el porcentaje mayor del estudio (40\%). No se obtiene, a priori, mucha diferencia con la variación de la posición de la admisión de aire. 
Representaciones gráficas de las emisiones de CO para el aceite de soja refinado $(T=A S R)$

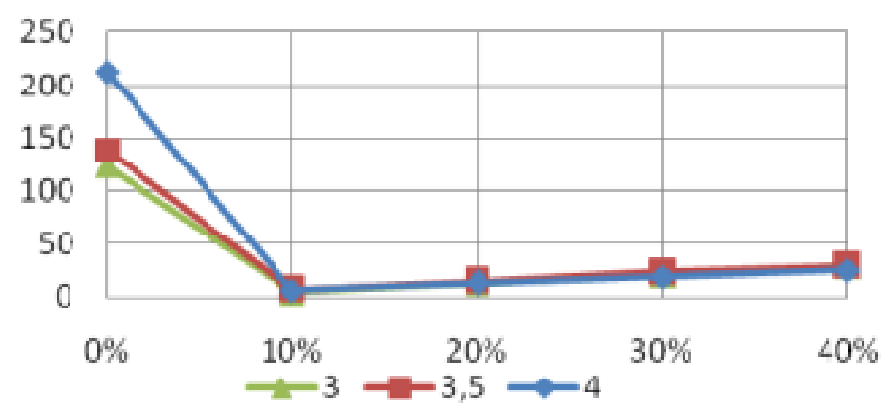

\begin{tabular}{|llllll|}
\hline $\begin{array}{l}\text { ASR, } \\
P=12 \text { bar }\end{array}$ & $X=0 \%$ & $X=10 \%$ & $X=20 \%$ & $X=30 \%$ & $X=40 \%$ \\
\hline$A=3$ & 124 & 4 & 13 & 20 & 29 \\
\hline$A=3,5$ & 139 & 7 & 15 & 23 & 29 \\
\hline$A=4$ & 213 & 6 & 13 & 19 & 25 \\
\hline
\end{tabular}

Figura 8.91: Emisiones para $\mathrm{P}=12$ bar y $\mathrm{T}=\mathrm{ASR}$

Se observan emisiones bajas para todos los porcentajes de aceite en la mezcla. La tendencia es al alza con el porcentaje de aceite, y no se observa cambio alguno en el comportamiento variando la admisión de aire. 
Representaciones gráficas de las emisiones de CO para la posición del aire $A=3$

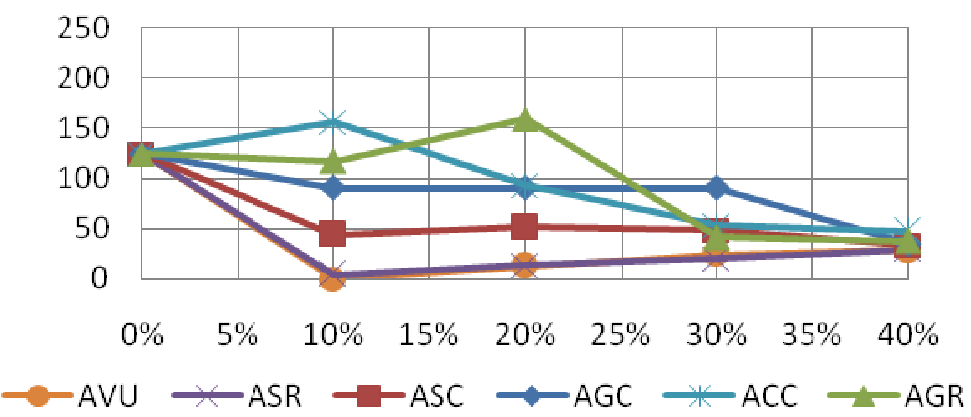

\begin{tabular}{|llllll|}
$\begin{array}{l}\text { A=3, } \\
P=12 \text { bar }\end{array}$ & $X=0 \%$ & $X=10 \%$ & $X=20 \%$ & $X=30 \%$ & $X=40 \%$ \\
\hline ACC & 124 & 156 & 93 & 53 & 47 \\
\hline AVU & 124 & 0 & 12 & 24 & 28 \\
\hline AGC & 124 & 90 & 90 & 90 & 35 \\
\hline AGR & 124 & 117 & 159 & 41 & 37 \\
\hline ASC & 124 & 44 & 51 & 48 & 33 \\
\hline ASR & 124 & 4 & 13 & 20 & 29 \\
\hline
\end{tabular}

Figura 8.92: Emisiones para $P=12$ bar y $A=3$

Se observan las distintas tendencias que adoptan los diferentes tipos de aceite con el porcentaje en mezcla. AGR, AGC y AC descienden, con X, mientras que AVU y ASR ascienden, y ASC se mantiene dentro de unos valores. Obviando la tendencia a la alta o a la baja, se observa que las emisiones para $X=40 \%$ son bastante parecidas, con valores acotados entre 47 y 28 ppm (las diferencias en otros valores de $X$ son mucho más abultadas: para $X=10 \%$, de 0 a $156 \mathrm{ppm}$ ). 
Representaciones gráficas de las emisiones de CO para la posición del aire $A=3,5$

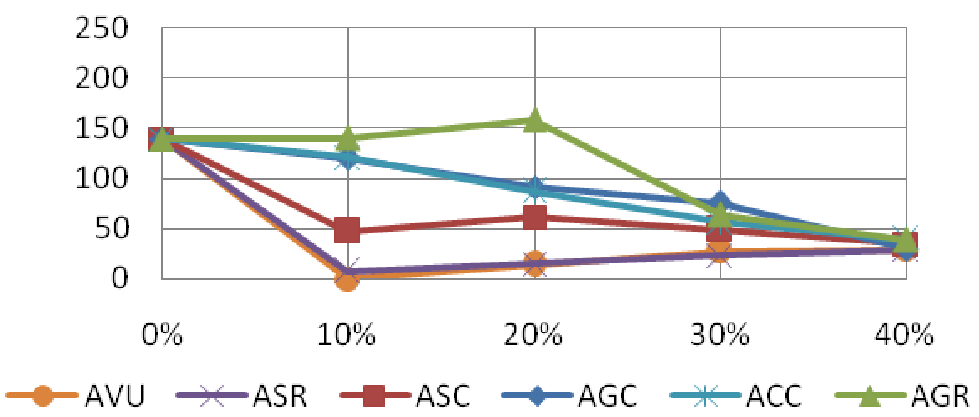

\begin{tabular}{|llllll|}
$\begin{array}{l}\text { A=3,5, } \\
P=12 \text { bar }\end{array}$ & $X=0 \%$ & $X=\mathbf{1 0} \%$ & $X=\mathbf{2 0} \%$ & $X=30 \%$ & $X=40 \%$ \\
\hline ACC & 139 & 121 & 87 & 56 & 39 \\
\hline AVU & 139 & 0 & 14 & 27 & 29 \\
\hline AGC & 139 & 120 & 91 & 75 & 30 \\
\hline AGR & 139 & 140 & 158 & 64 & 39 \\
\hline ASC & 139 & 47 & 61 & 49 & 35 \\
\hline ASR & 139 & 7 & 15 & 23 & 29 \\
\hline
\end{tabular}

Figura 8.93: Emisiones para $\mathrm{P}=12$ bar y $\mathrm{A}=3,5$

El análisis hecho para $A=3$ vuelve a ser válido. Los valores para $X=40 \%$ tienden más si cabe a valores constantes, siendo el máximo 39 y el mínimo 29 ppm. Tanto AVU como ASR tienen ofrecen unas emisiones muy contenidas. 
Representaciones gráficas de las emisiones de CO para la posición del aire $A=4$

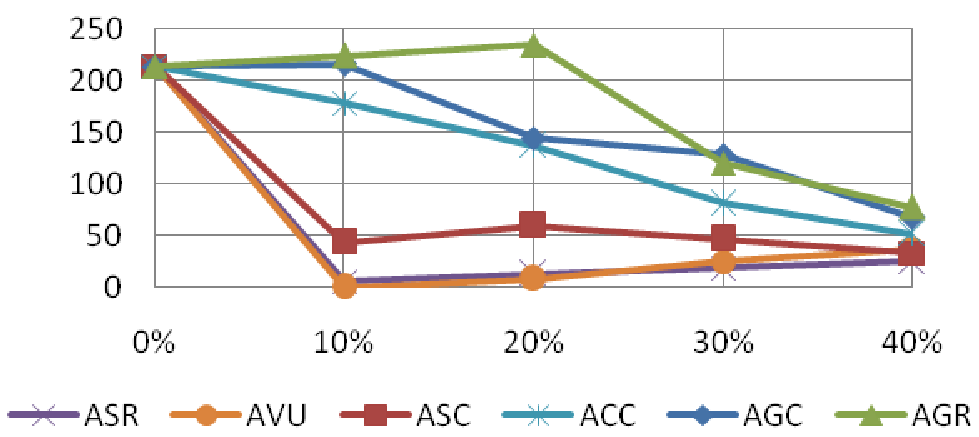

\begin{tabular}{|llllll|}
$\begin{array}{l}\text { A=4, } \\
P=12 \text { bar }\end{array}$ & $X=0 \%$ & $X=10 \%$ & $X=20 \%$ & $X=30 \%$ & $X=40 \%$ \\
\hline ACC & 213 & 178 & 137 & 81 & 52 \\
\hline AVU & 213 & 0 & 8 & 25 & 36 \\
\hline AGC & 213 & 216 & 144 & 128 & 68 \\
\hline AGR & 213 & 224 & 234 & 120 & 77 \\
\hline ASC & 213 & 44 & 60 & 47 & 33 \\
\hline ASR & 213 & 6 & 13 & 19 & 25 \\
\hline
\end{tabular}

Figura 8.94: Emisiones para $\mathrm{P}=12$ bar y $\mathrm{A}=4$

Se distingue, por un lado, la tendencia de AGC, AGR y AC: valores altos y descendentes con el porcentaje de aceite en mezcla; por otro lado ASR y AVU tendencia contraria, y valores mucho más pequeños. Entre medias, el ASC no tiene las variaciones de los otros. Los valores para el valor más alto de $X$, si bien son los más cercanos entre sí, tienen una diferencia mayor entre ellos que en los dos estudios anteriores. 
Representaciones gráficas de las emisiones de CO para el porcentaje de aceite en peso de $X=10 \%$

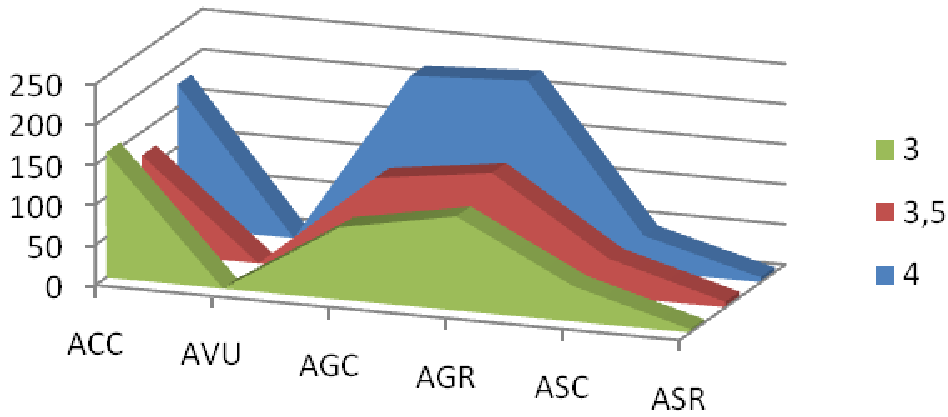

\begin{tabular}{|lllllll|}
\hline $\begin{array}{l}X=10 \%, \\
P=12 \text { bar }\end{array}$ & ACC & AVU & AGC & AGR & ASC & ASR \\
\hline$A=3$ & 156 & 0 & 90 & 117 & 44 & 4 \\
\hline$A=3,5$ & 121 & 0 & 120 & 140 & 47 & 7 \\
\hline$A=4$ & 178 & 0 & 216 & 224 & 44 & 6 \\
\hline
\end{tabular}

Figura 8.95: Emisiones para $\mathrm{P}=12$ bar y $\mathrm{X}=10 \%$

Las emisiones de CO aumentan con la admisión de aire. Además, se tiene que AVU y después ASR ofrecen unas emisiones mínimas. El siguiente nivel de emisiones sería el ASC, y en el siguiente se encontrarían los aceites de girasol y el de colza. La segunda gráfica lo muestra más claramente.

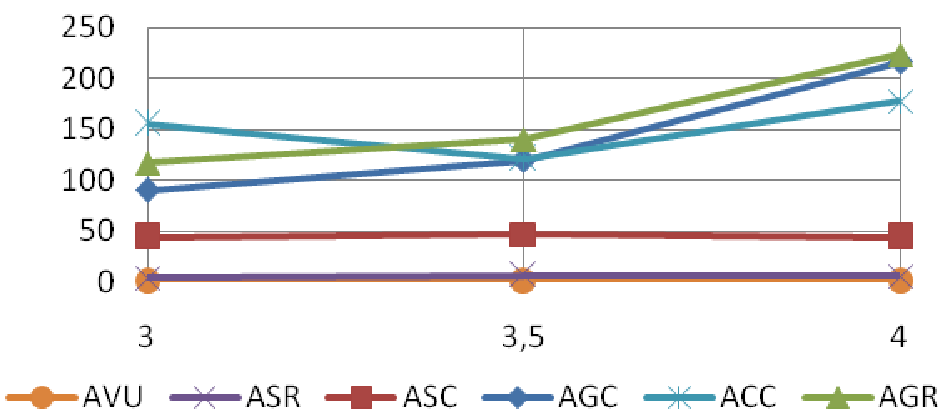

Figura 8.96: Emisiones para $\mathrm{P}=12$ bar y $\mathrm{X}=20 \%$

Representaciones gráficas de las emisiones de CO para el porcentaje de aceite en peso de $X=20 \%$ 


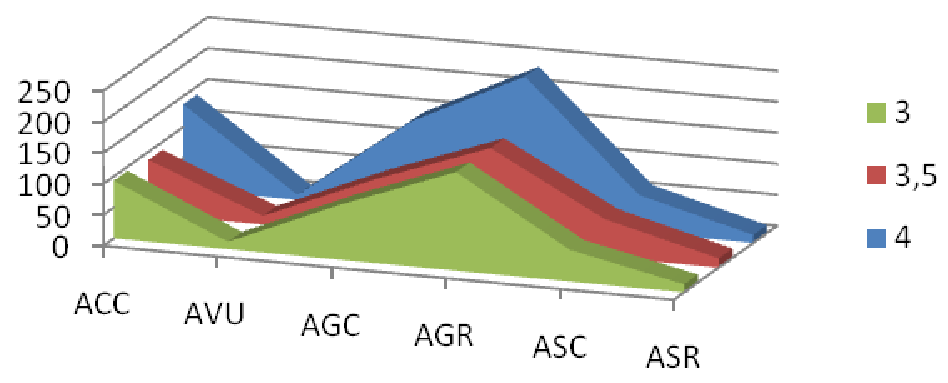

\begin{tabular}{|lllllll|}
\hline $\begin{array}{l}X=20 \%, \\
P=12 b a r\end{array}$ & ACC & AVU & AGC & AGR & ASC & ASR \\
\hline$A=3$ & 93 & 12 & 90 & 159 & 51 & 13 \\
\hline$A=3,5$ & 87 & 14 & 91 & 158 & 61 & 15 \\
\hline$A=4$ & 137 & 8 & 144 & 234 & 60 & 13 \\
\hline
\end{tabular}

Figura 8.97: Emisiones para $\mathrm{P}=12$ bar y $\mathrm{X}=20 \%$

Puede observarse una tendencia similar a la anterior, si bien es cierto que para $A=3$ y $A=3,5$ los valores obtenidos apenas difieren. Para $A=4$ sí que hay diferencia. El máximo nivel de emisiones corresponde al AGR, cuyo refinado parece ir en contra de las emisiones de CO. ASR y AVU ofrecen las mínimas emisiones. En el siguiente gráfico pueden observarse mejor los distintos niveles de emisiones existentes para esta X.

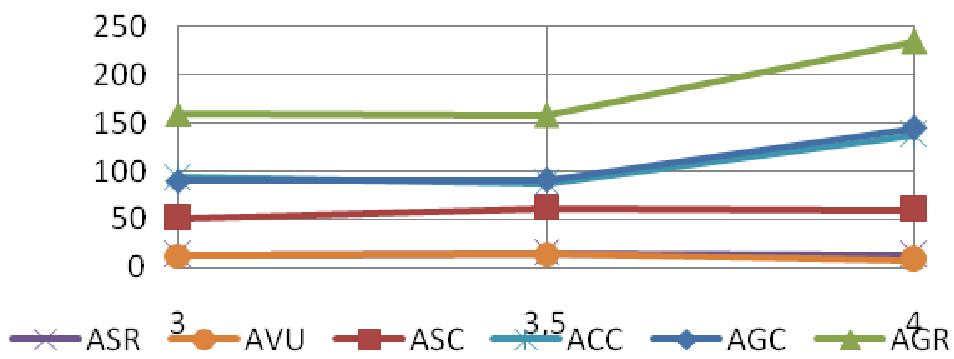

Figura 8.98: Emisiones para $\mathrm{P}=12$ bar y $\mathrm{X}=20 \%$

Representaciones gráficas de las emisiones de CO para el porcentaje de aceite en peso de $X=30 \%$ 


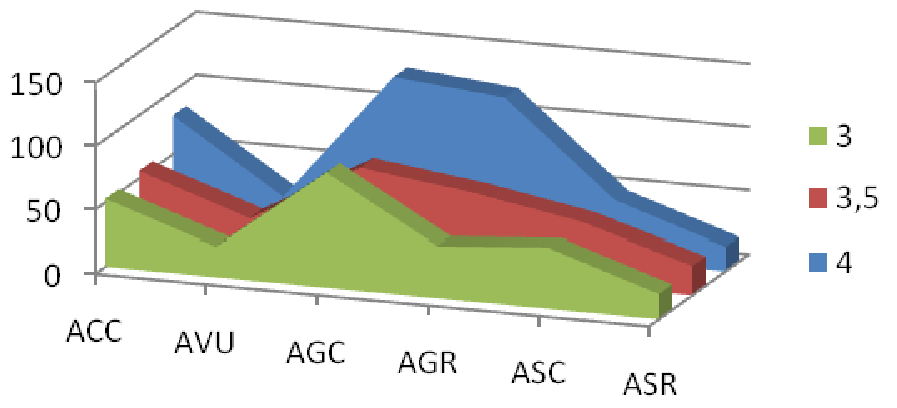

\begin{tabular}{|lllllll|}
\hline $\begin{array}{l}X=30 \%, \\
P=12 \text { bar }\end{array}$ & ACC & AVU & AGC & AGR & ASC & ASR \\
\hline$A=3$ & 53 & 24 & 90 & 41 & 48 & 20 \\
\hline$A=3,5$ & 56 & 27 & 75 & 64 & 49 & 23 \\
\hline$A=4$ & 81 & 25 & 128 & 120 & 47 & 19 \\
\hline
\end{tabular}

Figura 8.99: Emisiones para $\mathrm{P}=12$ bar y $\mathrm{X}=30 \%$

En el primer gráfico puede apreciarse la influencia de la posición de la admisión de aire, si bien esta influencia es clara, más que nada, para la posición mayor. Esta gráfica ha sufrido una estabilización con respecto a las de los análisis $X=10 \%$ y $X=20 \%$ : si bien las diferencias en las emisiones son altas, no puede obviarse que son mucho menores. Esto se aprecia mucho mejor en la siguiente gráfica. Tanto AVU como ASR dan los mínimos valores. Los peores valores los da el AGC. Además, destaca la influencia tan acusada que la variable A tiene para el AGR. En términos globales, los aceites de girasol ofrecen los peores niveles de emisiones.

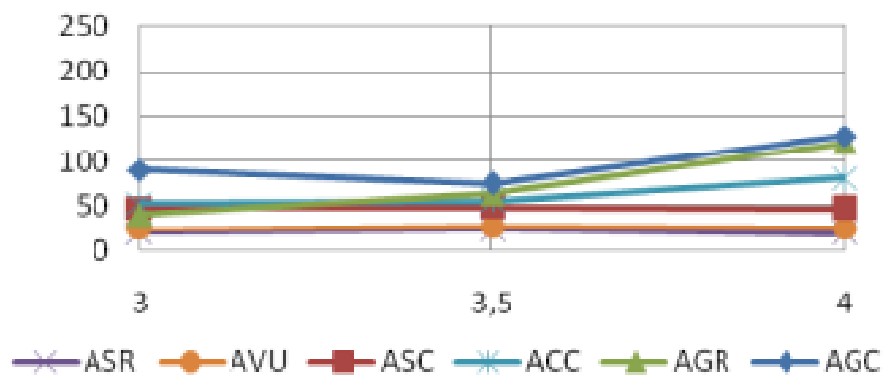

Figura 8.100: Emisiones para $\mathrm{P}=12$ bar y $\mathrm{X}=30 \%$

Representaciones gráficas de las emisiones de CO para el porcentaje de aceite en peso de $X=40 \%$ 


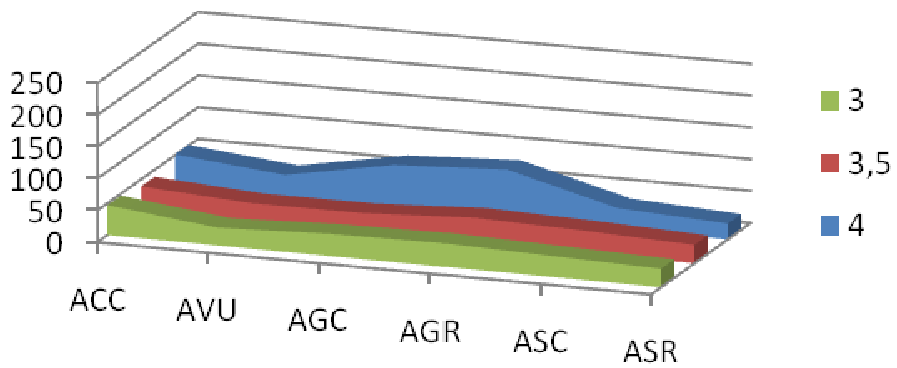

\begin{tabular}{|lllllll|}
\hline $\begin{array}{l}X=40 \%, \\
P=12 \text { bar }\end{array}$ & ACC & AVU & AGC & AGR & ASC & ASR \\
\hline$A=3$ & 47 & 28 & 35 & 37 & 33 & 29 \\
\hline$A=3,5$ & 39 & 29 & 30 & 39 & 35 & 29 \\
\hline$A=4$ & 52 & 36 & 68 & 77 & 33 & 25 \\
\hline
\end{tabular}

Figura 8.101: Emisiones para $P=12$ bar y $X=40 \%$

Como se anunciaba en el análisis de gráficas anteriores, para $X=40 \%$ los valores parecían estabilizarse e igualarse. Únicamente se tienen dos picos considerables para los aceites de girasol en la posición más desfavorable de admisión de aire, y aún así dichos picos son del orden de 30 o 40 ppm superiores al resto: ya no se tienen unas diferencias de 200 ppm. Los valores mínimos los dan de nuevo AVU y ASR. Es destacable que para $A=3$, los valores permanecen dentro de un rango reducido. Puede destacarse también que para ASR el valor de emisión para $A=4$ es menor que los otros dos, una tendencia que a priori no cuadra con lo visto hasta ahora.

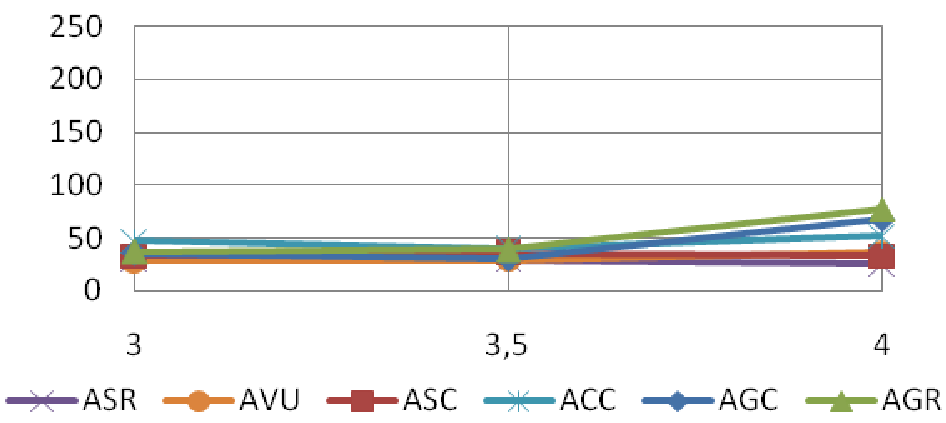

Figura 8.102: Emisiones para $\mathrm{P}=12$ bar y $\mathrm{X}=40 \%$ 


\subsubsection{Conclusiones}

El estudio a $\mathrm{P}=12$ bar constante nos ofrece las siguientes conclusiones:

- La variable más influyente es el tipo de aceite (T), resultado predicho por el análisis ANOVA y contrastado con las gráficas anteriores. Por orden, son AVU y ASR los tipos de aceite que menores niveles de emisiones tienen. A continuación se tiene que el ASC también tiene unos valores contenidos, pero mayores. Varios niveles por detrás se tienen las emisiones producidas por los aceites de girasol y el de colza. Esta tendencia se ve, principalmente, para $A=3$.

- La influencia de la posición de admisión del aire (A), aún siendo menor que en otros análisis, existe. Tras lo observado en las anteriores gráficas, la tendencia es que los máximos niveles de emisión se tienen para $A=4$ (posición máxima de apertura de admisión en este estudio), con una diferencia considerable con los $A=3,5$. Los valores para $A=3$ son menores que los de $A=3,5$, pero no existe una diferencia como la citada con los de $A=4$.

- La variable porcentaje de aceite en la mezcla $(X)$ tiende a igualar los niveles de emisión al aumentar X, notándose en todos los gráficos esta influencia.

- Destaca de nuevo la tendencia inversa en el refino del aceite de girasol y el de soja, con unos resultados similares a los del estudio anterior, esto es: para la soja, el refino es beneficioso en cuanto a emisiones de $\mathrm{CO}$, mientras que para el girasol es perjudicial.

- Vuelven a obtenerse emisiones 0, las cuales corresponden para AVU al $10 \%$ y todos los valores de A. El máximo se obtiene para AGC, $X=20 \%$ y $A=4$. 


\subsubsection{Análisis de las emisiones de $\mathrm{CO}$ a P=14 BAR}

Se muestra a continuación la matriz de resultados obtenidos:

Tabla 8.15: Matriz e resultados para emisiones de CO

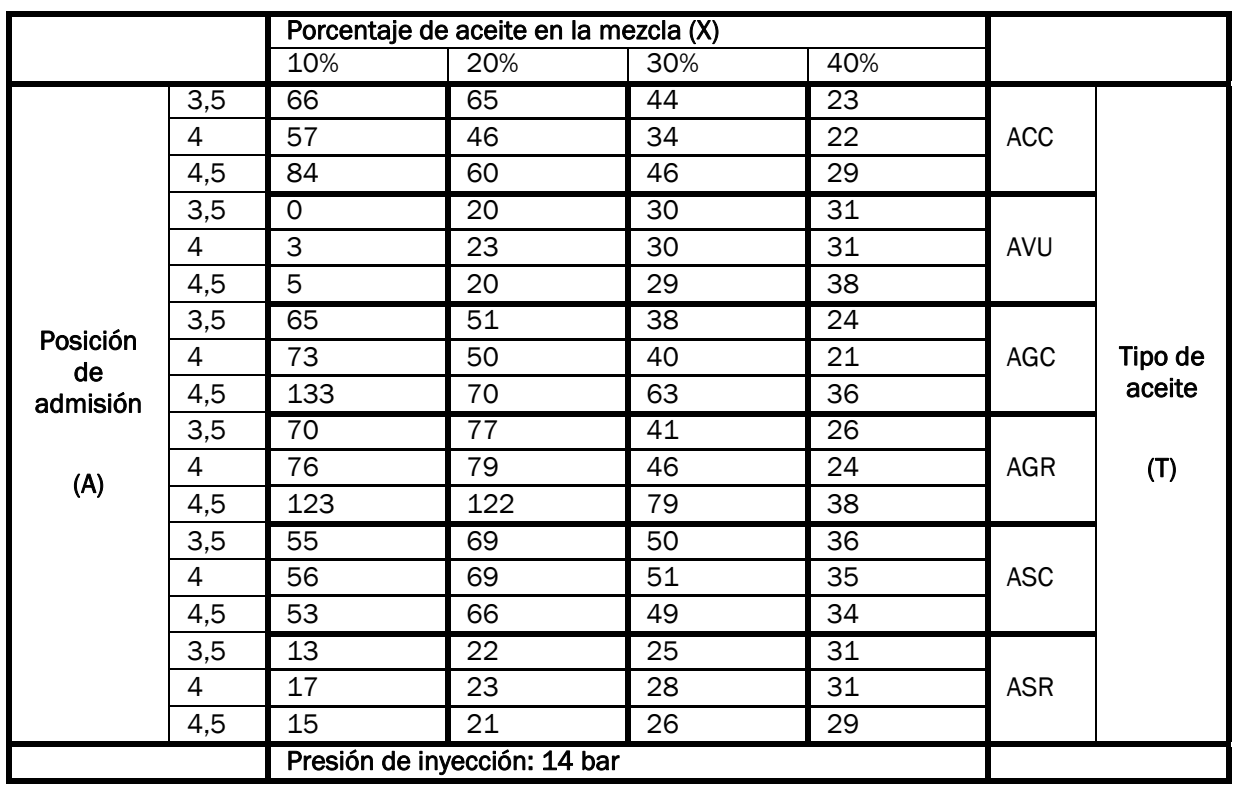

Con los datos ya dispuestos, se plantea un análisis de varianza (ANOVA), mediante el cual se determinará si las tres variables influyen (presión de inyección, tipo de aceite y porcentaje de aceite en peso) o no y de qué manera.

Tabla 8.16: Análisis ANOVA emisiones CO para 14 bar

\begin{tabular}{|l|l|l|l|l|l|l|l|}
\hline FACTOR & GdL & SS & MS & F & VC al 5\% & Influye & G. C. Crítica \\
\hline A & 2 & 2492,694 & 1246,347 & 30,417 & 3,316 & SI & $6,06813 \mathrm{E}-08$ \\
\hline T & 5 & 19746,569 & 3949,314 & 96,383 & 2,534 & SI & $1,4946 \mathrm{E}-17$ \\
\hline X & 3 & 6723,375 & 2241,125 & 54,695 & 2,922 & SI & $2,84491 \mathrm{E}-12$ \\
\hline AxT & 10 & 3852,972 & 385,297 & 9,403 & 2,165 & SI & $7,87672 \mathrm{E}-07$ \\
\hline AxX & 6 & 665,750 & 110,958 & 2,708 & 2,421 & SI & 0,03194129 \\
\hline TxX & 15 & 14831,375 & 988,758 & 24,131 & 2,015 & SI & $1,08796 \mathrm{E}-12$ \\
\hline Error & 30 & 1229,250 & 40,975 & & & & \\
\hline Total & 71 & 49541,986 & & & & & \\
\hline
\end{tabular}

La interpretación del análisis es la siguiente: para un análisis con un 5\% de confiabilidad, se tiene que todas las variables contempladas en el estudio son influyentes. Como en estudios anteriores, medimos el grado de influencia de las mismas por el valor crítico del grado de confiabilidad. En este caso, el grado de confiabilidad más "discutible" sería el de la 
interacción AxX, la cual estaría en un 3,2\%. Ya en los ANOVAS anteriores, esta variable había sido la que menos influencia había tenido.

Se puede sacar la conclusión de que la variable más significativa es el tipo de aceite, con un orden de confiabilidad crítico del orden de 10-15 (en términos porcentuales, en términos absolutos en tanto por 1 es 10-17). A continuación, en orden de importancia, se sitúa la variable $X$ junto con la interacción TxX, ambas con órdenes de magnitud del orden de 10-10\%. Después iría la variable A (10-6 \%), luego AxT (10-3\%), y por último AxX (3\%).

En un principio, volvería a ser T la variable más influyente del estudio seguida por el porcentaje de aceite en la mezcla. La influencia de la posición de admisión del aire es menor. 
Representaciones gráficas de las emisiones de $\mathrm{CO}$ para el aceite de colza crudo $(\mathrm{T}=\mathrm{ACC})$

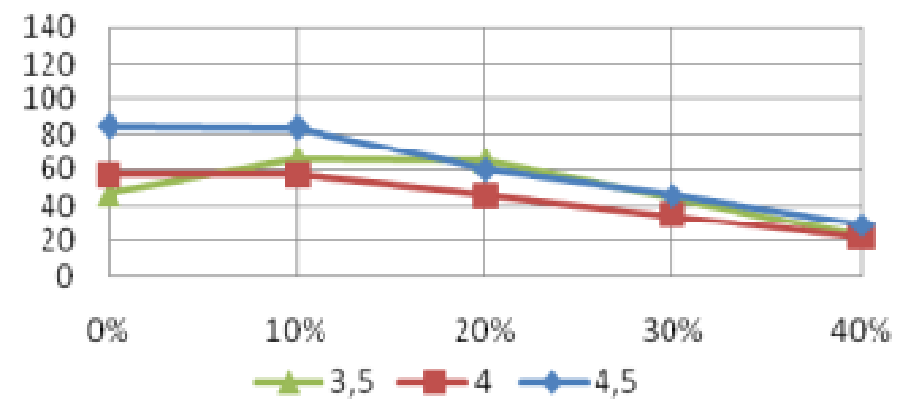

\begin{tabular}{|llllll|}
$\begin{array}{l}\text { ACC, } \\
P=14 \text { bar }\end{array}$ & $X=0 \%$ & $X=10 \%$ & $X=20 \%$ & $X=30 \%$ & $X=40 \%$ \\
\hline$A=3,5$ & 47 & 66 & 65 & 44 & 23 \\
\hline$A=4$ & 57 & 57 & 46 & 34 & 22 \\
\hline$A=4,5$ & 85 & 84 & 60 & 46 & 29 \\
\hline
\end{tabular}

Figura 8.103: Emisiones para $\mathrm{P}=14$ bar y $\mathrm{T}=\mathrm{ACC}$

Se observa tendencia al descenso de las emisiones de CO con el aumento de X. Además, puede verse que al contrario de lo esperado, las emisiones para $A=3,5$ son mayores que las obtenidas para $A=4$. 
Representaciones gráficas de las emisiones de CO para el aceite vegetal usado ( $\mathrm{T}=\mathrm{AVU}$ )

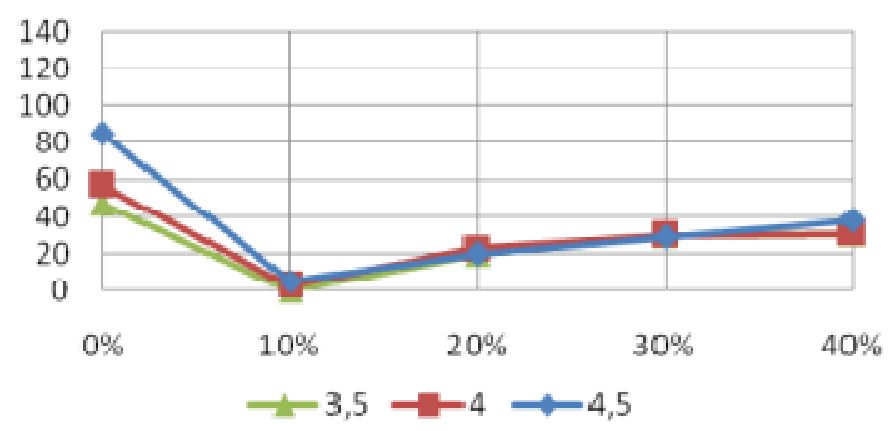

\begin{tabular}{|llllll|}
$\begin{array}{l}\text { AVU, } \\
P=14 \text { bar }\end{array}$ & $X=0 \%$ & $X=10 \%$ & $X=20 \%$ & $X=30 \%$ & $X=40 \%$ \\
\hline$A=3,5$ & 47 & 0 & 20 & 30 & 31 \\
\hline$A=4$ & 57 & 3 & 23 & 30 & 31 \\
\hline$A=4,5$ & 85 & 5 & 20 & 29 & 38 \\
\hline
\end{tabular}

Figura 8.104: Emisiones para $\mathrm{P}=14$ bar y $\mathrm{T}=\mathrm{AVU}$

Tendencia al alza con el valor de $\mathrm{X}$, al contrario que lo que ocurría con el ACC. Valores bastante acotados, no superando las 38 ppm. Además, se tiene poca variación con los distintos grados de admisión de aire. 
Representaciones gráficas de las emisiones de CO para el aceite de girasol crudo ( $\mathrm{T}=\mathrm{AGC})$

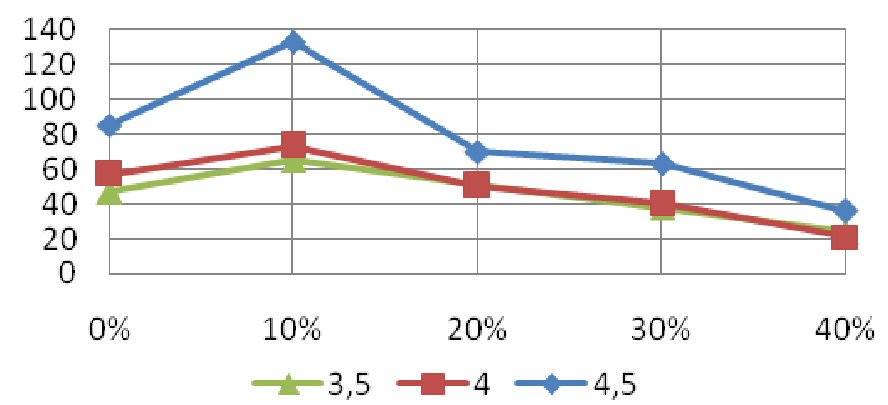

\begin{tabular}{|llllll|}
$\begin{array}{l}\text { AGC, } \\
P=14 \text { bar }\end{array}$ & $X=0 \%$ & $X=10 \%$ & $X=20 \%$ & $X=30 \%$ & $X=40 \%$ \\
\hline$A=3,5$ & 47 & 65 & 51 & 38 & 24 \\
\hline$A=4$ & 57 & 73 & 50 & 40 & 21 \\
\hline$A=4,5$ & 85 & 133 & 70 & 63 & 36 \\
\hline
\end{tabular}

Figura 8.105: Emisiones para $\mathrm{P}=14$ bar y $\mathrm{T}=\mathrm{AGC}$

Misma tendencia a la baja, con picos para $X=10 \%$. Puede verse además la influencia de la variable A (mayores emisiones para los A altos). 
Representaciones gráficas de las emisiones de CO para el aceite de girasol refinado $(\mathrm{T}=\mathrm{AGR})$

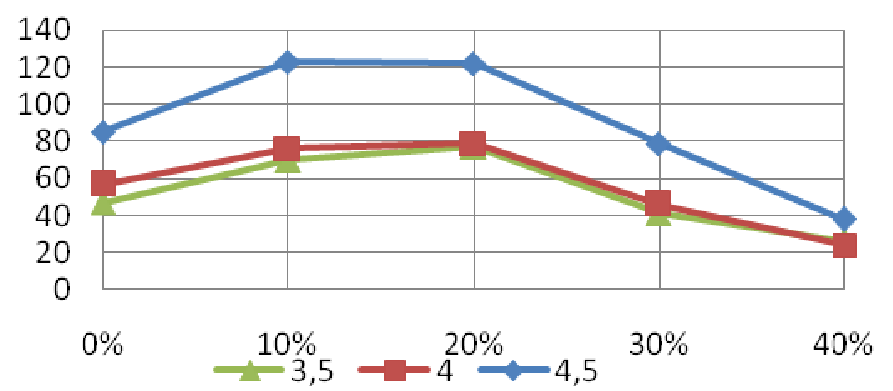

\begin{tabular}{|llllll|}
\hline $\begin{array}{l}\text { AGR, } \\
P=14 \text { bar }\end{array}$ & $X=0 \%$ & $X=10 \%$ & $X=20 \%$ & $X=30 \%$ & $X=40 \%$ \\
\hline$A=3,5$ & 47 & 70 & 77 & 41 & 26 \\
\hline$A=4$ & 57 & 76 & 79 & 46 & 24 \\
\hline$A=4,5$ & 85 & 123 & 122 & 79 & 38 \\
\hline
\end{tabular}

Figura 8.106: Emisiones para $\mathrm{P}=14$ bar y $\mathrm{T}=\mathrm{AGR}$

En este caso, se tienen picos para $X=10$ y $X=20 \%$. La tendencia a partir de ahí es a la baja. Para $A=4,5$ se tienen los valores de emisiones más altos. No se aprecian grandes diferencias entre las otras dos posiciones de admisión de aire. 
Representaciones gráficas de las emisiones de CO para el aceite de soja crudo ( $\mathrm{T}=\mathrm{ASC}$ )

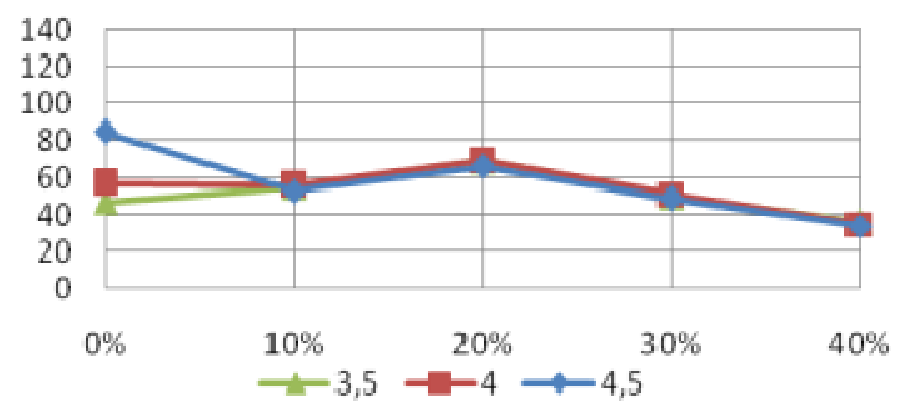

\begin{tabular}{|llllll|}
$\begin{array}{l}\text { ASC, } \\
P=14 \text { bar }\end{array}$ & $X=0 \%$ & $X=10 \%$ & $X=20 \%$ & $X=30 \%$ & $X=40 \%$ \\
\hline$A=3,5$ & 47 & 55 & 69 & 50 & 36 \\
\hline$A=4$ & 57 & 56 & 69 & 51 & 35 \\
\hline$A=4,5$ & 85 & 53 & 66 & 49 & 34 \\
\hline
\end{tabular}

Figura 8.107: Emisiones para $\mathrm{P}=14$ bar y $\mathrm{T}=\mathrm{ASC}$

Tendencia a la baja para valores a partir de $X=20 \%$, porcentaje para el cual se tienen picos en las emisiones, pero picos menos altos que en aceites anteriores. La influencia de la variable A es nula. 
Representaciones gráficas de las emisiones de CO para el aceite de soja refinado $(T=A S R)$

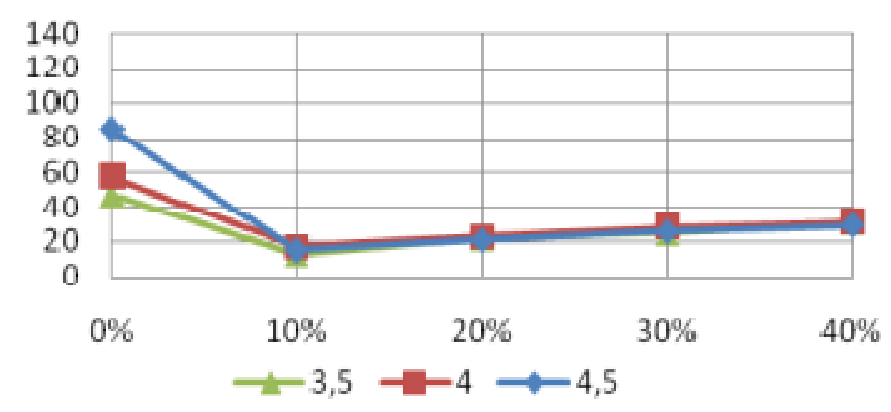

\begin{tabular}{|llllll|}
$\begin{array}{l}\text { ASR, } \\
P=14 \text { bar }\end{array}$ & $X=0 \%$ & $X=10 \%$ & $X=20 \%$ & $X=30 \%$ & $X=40 \%$ \\
\hline$A=3,5$ & 47 & 13 & 22 & 25 & 31 \\
\hline$A=4$ & 57 & 17 & 23 & 28 & 31 \\
\hline$A=4,5$ & 85 & 15 & 21 & 26 & 29 \\
\hline
\end{tabular}

Figura 8.108: Emisiones para $\mathrm{P}=14$ bar y $\mathrm{T}=\mathrm{ASR}$

Tendencia al alta con el aumento del porcentaje de aceite en mezcla, si bien puede apreciarse que el aumento es muy ligero. La influencia de la posición de la admisión del aire es de nuevo nula. Los valores obtenidos son los mejores que en los aceites anteriores. 
Representaciones gráficas de las emisiones de CO para la posición de aire $A=3,5$

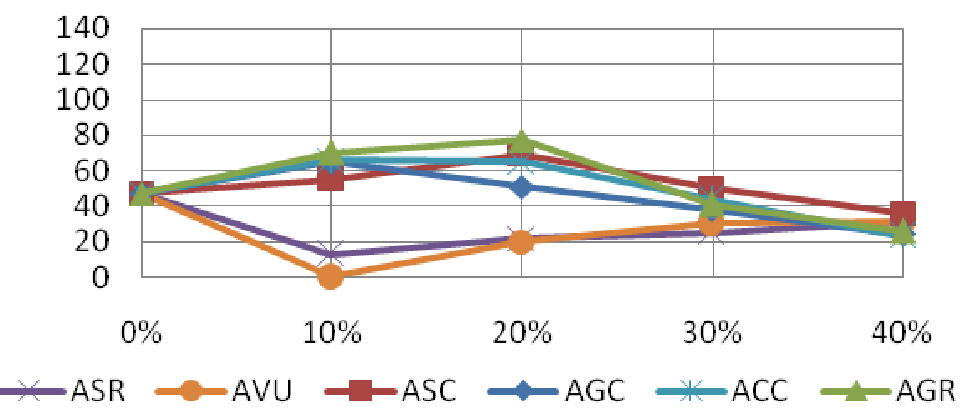

\begin{tabular}{|llllll|}
$\begin{array}{l}\text { A=3,5, } \\
P=14 \text { bar }\end{array}$ & $X=0 \%$ & $X=10 \%$ & $X=20 \%$ & $X=30 \%$ & $X=40 \%$ \\
\hline ACC & 47 & 66 & 65 & 44 & 23 \\
\hline AVU & 47 & 0 & 20 & 30 & 31 \\
\hline AGC & 47 & 65 & 51 & 38 & 24 \\
\hline AGR & 47 & 70 & 77 & 41 & 26 \\
\hline ASC & 47 & 55 & 69 & 50 & 36 \\
\hline ASR & 47 & 13 & 22 & 25 & 31 \\
\hline
\end{tabular}

Figura 8.109: Emisiones para $\mathrm{P}=14$ bar y $\mathrm{A}=3,5$

Puede observarse la distinta tendencia que sufren ASR y AVU para la zona entre 10 y 20\%: estas aceites tienen menores emisiones mientras que el resto de aceites obtienen sus mayores valores. Para $X=40 \%$, los valores se igualan. 
Representaciones gráficas de las emisiones de CO para la posición de aire $A=4$

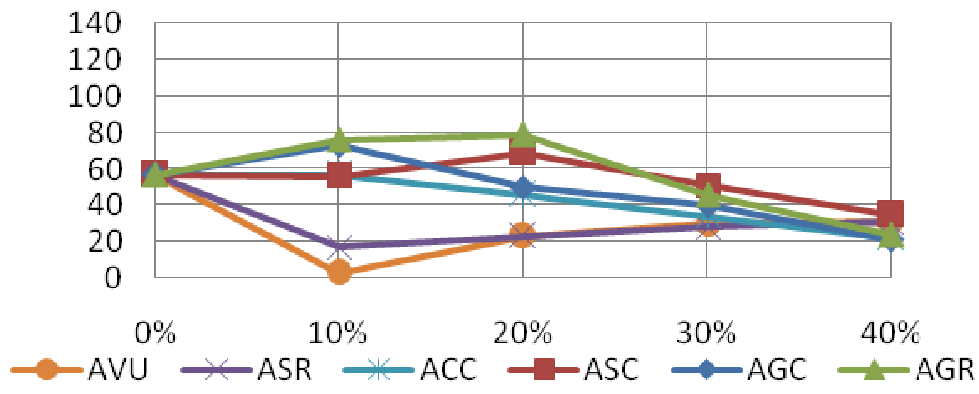

\begin{tabular}{|llllll|}
$\begin{array}{l}\text { A=4, } \\
P=14 \text { bar }\end{array}$ & $X=0 \%$ & $X=10 \%$ & $X=20 \%$ & $X=30 \%$ & $X=40 \%$ \\
\hline AC & 57 & 57 & 46 & 34 & 22 \\
\hline AVU & 57 & 3 & 23 & 30 & 31 \\
\hline AGC & 57 & 73 & 50 & 40 & 21 \\
\hline AGR & 57 & 76 & 79 & 46 & 24 \\
\hline ASC & 57 & 56 & 69 & 51 & 35 \\
\hline ASR & 57 & 17 & 23 & 28 & 31 \\
\hline
\end{tabular}

Figura 8.110: Emisiones para $P=14$ bar y $A=4$

Nuevamente se tiene que la tendencia de AVU y ASR son contrarias a la de las demás. Valores cercanos en las emisiones para $X=40 \%$. 
Representaciones gráficas de las emisiones de CO para la posición de aire $A=4,5$

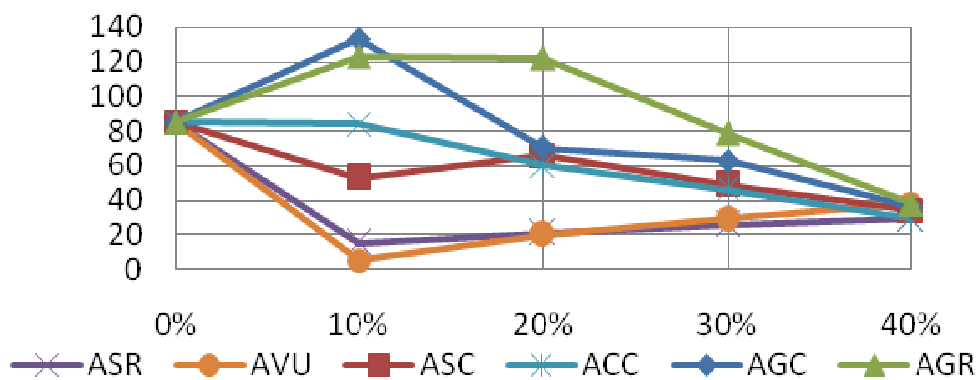

\begin{tabular}{|llllll|}
$\begin{array}{l}\text { A=4,5, } \\
P=14 \text { bar }\end{array}$ & $X=0 \%$ & $X=10 \%$ & $X=20 \%$ & $X=30 \%$ & $X=40 \%$ \\
\hline AC & 85 & 84 & 60 & 46 & 29 \\
\hline AVU & 85 & 5 & 20 & 29 & 38 \\
\hline AGC & 85 & 133 & 70 & 63 & 36 \\
\hline AGR & 85 & 123 & 122 & 79 & 38 \\
\hline ASC & 85 & 53 & 66 & 49 & 34 \\
\hline ASR & 85 & 15 & 21 & 26 & 29 \\
\hline
\end{tabular}

Figura 8.111: Emisiones para $P=14$ bar y $A=4,5$

Comportamiento parecido pero no similar a los anteriores. AGR y AGC ofrecen los mayores niveles de emisión (los mayores del estudio se obtienen aquí), si bien para porcentajes altos de aceite vuelven a acercarse unos a otros. Las emisiones de ASR y AVU vuelven a ser las menores. 
Representaciones gráficas de las emisiones de CO para el porcentaje de aceite en peso de $X=10 \%$

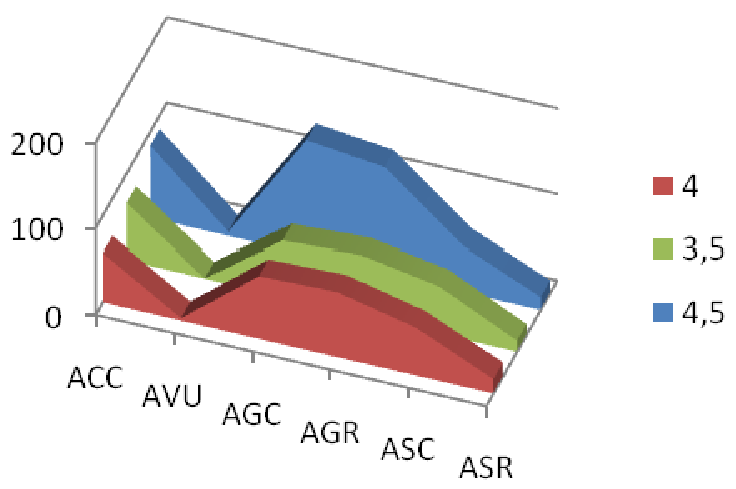

\begin{tabular}{|lllllll|}
\hline $\begin{array}{l}X=10 \%, \\
P=14 \text { bar }\end{array}$ & ACC & AVU & AGC & AGR & ASC & ASR \\
\hline$A=3,5$ & 66 & 0 & 65 & 70 & 55 & 13 \\
\hline$A=4$ & 57 & 3 & 73 & 76 & 56 & 17 \\
\hline$A=4,5$ & 84 & 5 & 133 & 123 & 53 & 15 \\
\hline
\end{tabular}

Figura 8.112: Emisiones para $\mathrm{P}=14$ bar $\mathrm{y} X=10 \%$

Las menores emisiones de CO las consigue el AVU, seguido por el ASR. Ambos aceites de girasol obtienen los peores resultados. La influencia de la posición de admisión de aire es clara para la máxima admisión, sin embargo el efecto entre $A=3,5$ y $A=4$ no es tan clara. En la segunda gráfica puede observarse que tanto AVU como ASR emiten bastante menos que las demás. Además, se aprecia un gran aumento de las emisiones para el aceite de girasol cuando A crece.

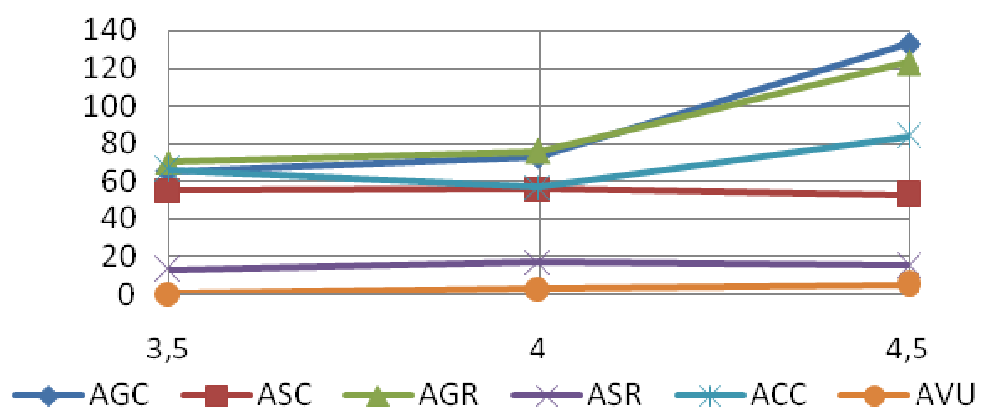

Figura 8.113: Emisiones para $P=14$ bar y $X=10 \%$ 
Representaciones gráficas de las emisiones de CO para el porcentaje de aceite en peso de $X=20 \%$

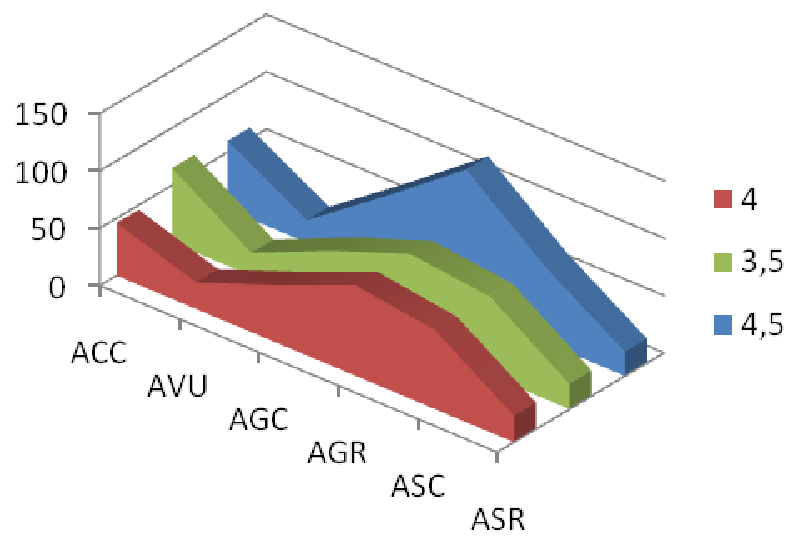

\begin{tabular}{|lllllll|}
\hline $\begin{array}{l}X=20 \%, \\
P=14 b a r\end{array}$ & ACC & AVU & AGC & AGR & ASC & ASR \\
\hline$A=3,5$ & 65 & 20 & 51 & 77 & 69 & 22 \\
\hline$A=4$ & 46 & 23 & 50 & 79 & 69 & 23 \\
\hline$A=4,5$ & 60 & 20 & 70 & 122 & 66 & 21 \\
\hline
\end{tabular}

Figura 8.114: Emisiones para $P=14$ bar $y \mathrm{X}=20 \%$

Se observa que el mayor nivel de emisiones se obtiene para el AGR. AVU y ASR obtienen los menores niveles de emisiones, mientras que ASC, ACC y AGC se mueven en niveles bastante parecidos. La influencia del aire sólo se hace notar en los aceites de girasol.

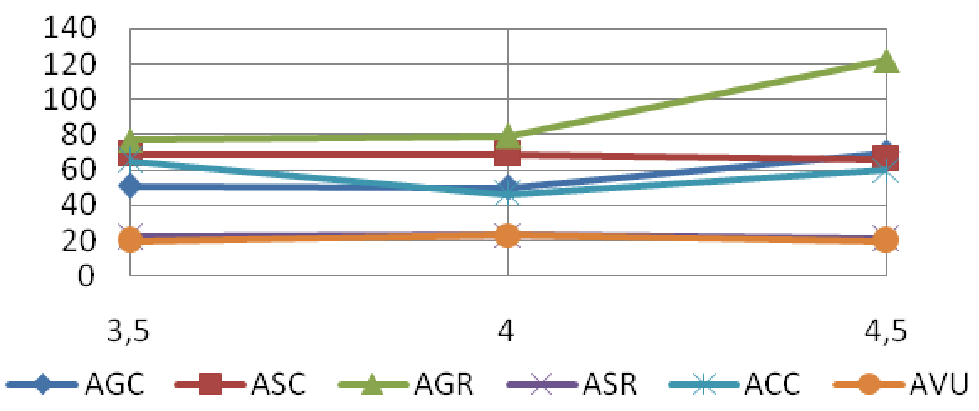

Figura 8.115: Emisiones para $\mathrm{P}=14$ bar y $\mathrm{X}=20 \%$ 
Representaciones gráficas de las emisiones de CO para el porcentaje de aceite en peso de $X=30 \%$

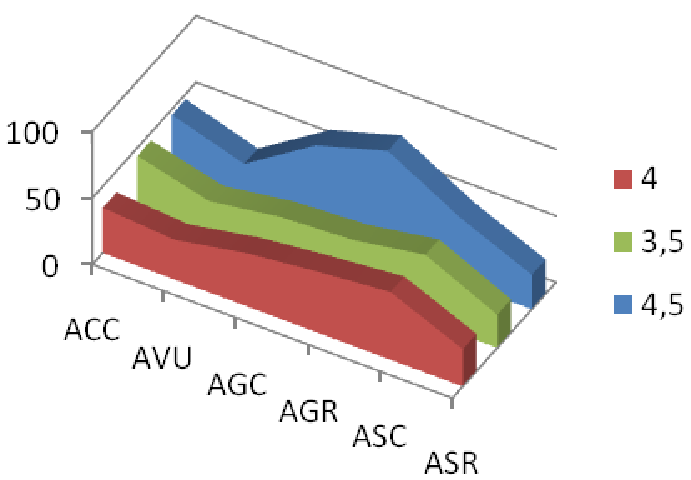

\begin{tabular}{|lllllll|}
$\begin{array}{l}X=30 \%, \\
P=14 \text { bar }\end{array}$ & AC & AVU & AGC & AGR & ASC & ASR \\
\hline$A=3,5$ & 44 & 30 & 38 & 41 & 50 & 25 \\
\hline$A=4$ & 34 & 30 & 40 & 46 & 51 & 28 \\
\hline$A=4,5$ & 46 & 29 & 63 & 79 & 49 & 26 \\
\hline
\end{tabular}

Figura 8.116: Emisiones para $\mathrm{P}=14$ bar y $\mathrm{X}=30 \%$

Como se había observado en otras gráficas, los niveles de emisiones van homogeneizándose cuando aumenta el porcentaje de aceite en la mezcla. Se tiene un máximo de nuevo en AGR, sin embargo no es tan alto. Los mínimos que teníamos antes, tanto AVU como ASR, siguen siéndolo pero las emisiones aumentan. La influencia del aire no es tan clara de ver como en otras gráficas.

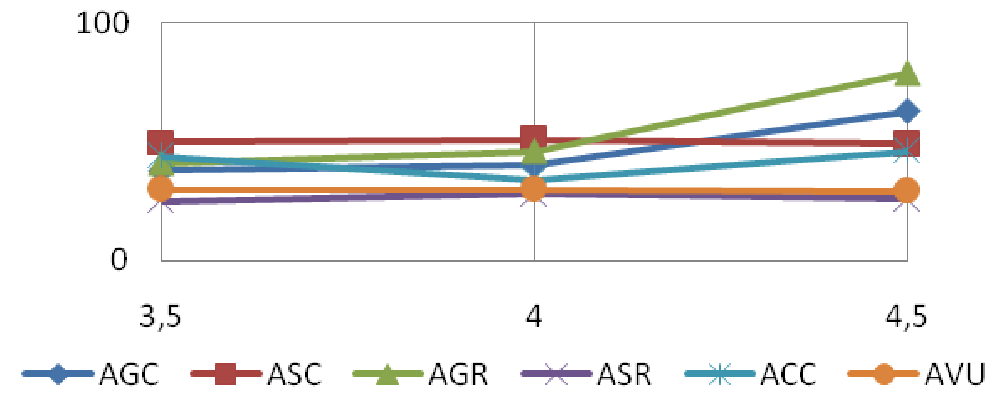

Figura 8.117: Emisiones para $\mathrm{P}=14$ bar y $\mathrm{X}=30 \%$ 
Representaciones gráficas de las emisiones de CO para el porcentaje de aceite en peso de $X=40 \%$

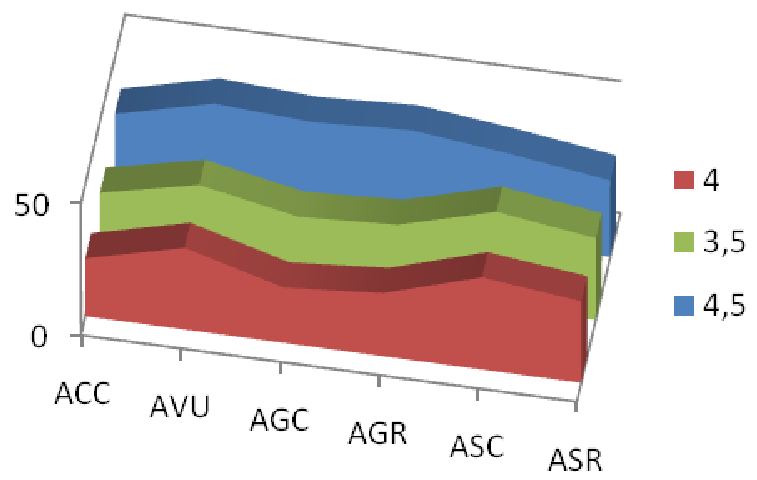

\begin{tabular}{|lllllll|}
\hline $\begin{array}{l}X=40 \%, \\
P=14 b a r\end{array}$ & AC & AVU & AGC & AGR & ASC & ASR \\
\hline$A=3,5$ & 23 & 31 & 24 & 26 & 36 & 31 \\
\hline$A=4$ & 22 & 31 & 21 & 24 & 35 & 31 \\
\hline$A=4,5$ & 29 & 38 & 36 & 38 & 34 & 29 \\
\hline
\end{tabular}

Figura 8.118: Emisiones para $P=14$ bar y $X=40 \%$

Los niveles de emisiones para la máxima concentración de aceite en la mezcla son menores que los vistos hasta ahora. La tendencia que siguen tanto ASR como AVU sigue siendo a la alta, y en este caso el nivel de emisiones que presentan es mayor que el de otros aceites. De hecho, los mínimos son conseguidos por el grupo de aceites que daba mayor nivel de emisiones a porcentajes bajos. La influencia de la posición de admisión de aire es clara para la máxima posición, pero no lo es tanto para las dos menores, con valores muy parecidos.

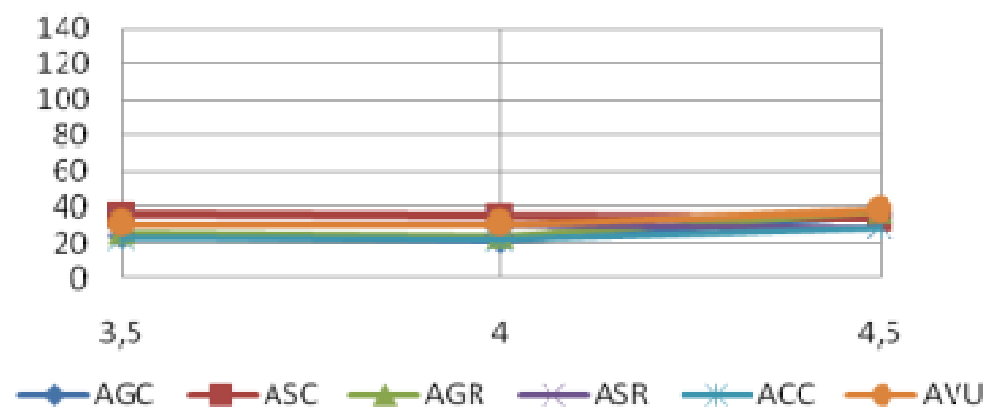

Figura 8.119: Emisiones para $P=14$ bar y $X=40 \%$ 


\subsubsection{Conclusiones}

El análisis tanto del ANOVA como de las representaciones gráficas da como conclusiones las siguientes:

- Como primera conclusión del estudio, destaca la diferencia en el comportamiento que ofrecen el AVU y el ASR frente al resto de aceites. Se tiene que estos dos aceites presentan más emisiones cuanto más aceite hay en la mezcla, partiendo de valores cercanos a cero para llegar a valores sobre las 30-40 ppm.

- $\quad$ Por otro lado, el ASC y el ACC se mantienen en valores intermedios y sufren un pico en torno a $X=20 \%$ uno y a $10 \%$ el otro, para después descender.

- Por último, los aceites de girasol ofrecen un descenso en las emisiones según el porcentaje de aceite va aumentando. Las mínimas emisiones se consiguen con $X=40 \%$.

- Siendo como son las tendencias que se han comentado, cabe destacar que las ppm obtenidas para $X=40 \%$ son, en conjunto, las más bajas. Sólo las citadas AVU y ASR no se encuentran en este porcentaje en su mínimo.

- Resulta difícil hacer una distinción clara en lo que a posición de admisión de aire se refiere. El comportamiento observado ofrece mayores emisiones para $A=4,5$, pero no se llega a distinguir con claridad si la posición $A=4$ o la posición $A=3,5$ son las que ofrecen menores emisiones, ya que se resparten los mínimos.

- Dependiendo del tipo de aceite que se usase para sustituir al gasoil, se tendrían, según se acaba de comentar, que para dos de los aceites la estrategia sería un porcentaje mínimo de sustitución, con lo cual mejoraríamos las emisiones del gasoil puro; para el resto de aceites, la combustión mejora cuanto más aceite tenemos en la mezcla. 


\subsubsection{Análisis de las emisiones de CO para $a=3,5$}

A continuación se exponen los datos registrados para este análisis:

Tabla 8.17 Matriz de datos de emisiones de CO

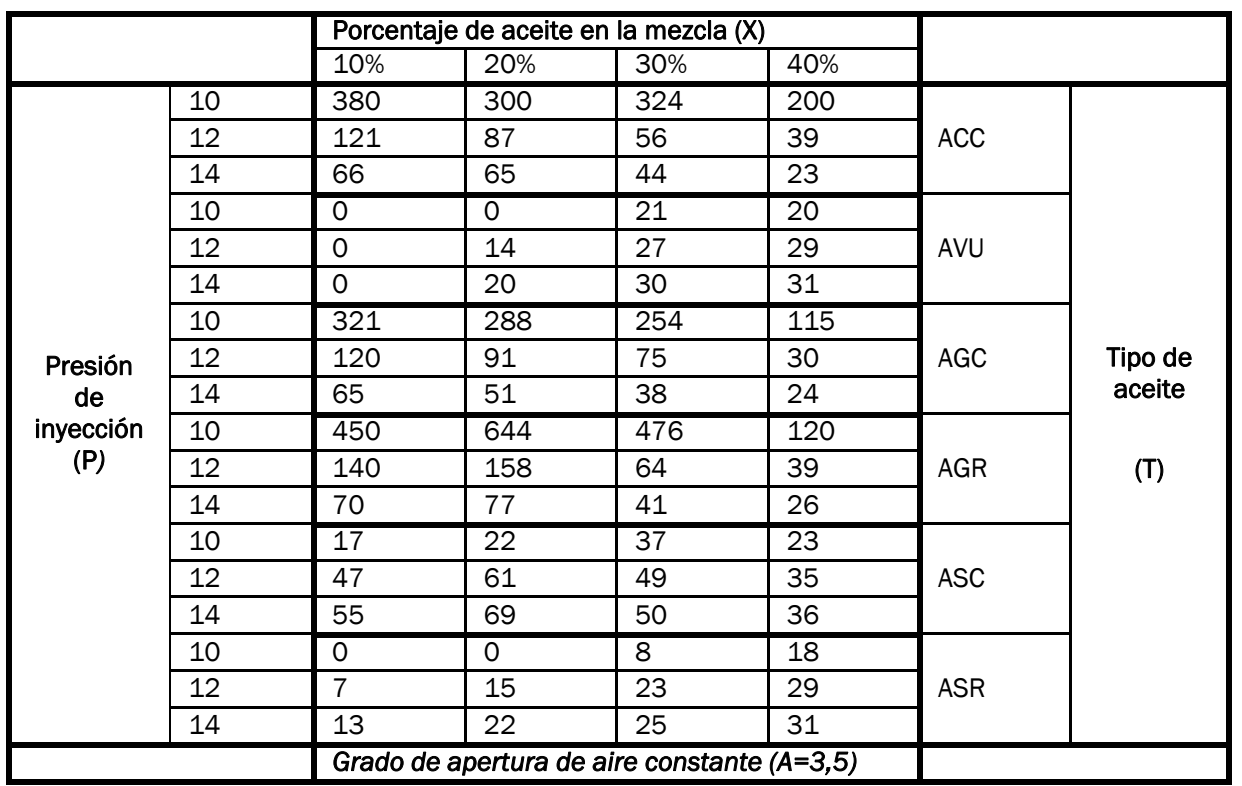

Con los datos ya dispuestos, se plantea un análisis de varianza (ANOVA), mediante el cual se determinará si las tres variables influyen (presión de inyección, tipo de aceite y porcentaje de aceite en peso) o no y de qué manera.

Tabla 8.18: Análisis ANOVA

\begin{tabular}{|l|l|l|l|l|l|l|l|}
\hline FACTOR & GdL & SS & MS & F & $\begin{array}{l}\text { VC al } \\
5 \%\end{array}$ & Influye & G. C. Crítica \\
\hline P & 2 & 232513,000 & 116256,500 & 56,287 & 3,316 & SI & $7,01728 \mathrm{E}-11$ \\
\hline T & 5 & 329737,833 & 65947,567 & 31,930 & 2,534 & SI & $3,76322 \mathrm{E}-11$ \\
\hline $\mathrm{X}$ & 3 & 42152,167 & 14050,722 & 6,803 & 2,922 & SI & 0,00123818 \\
\hline PxT & 10 & 337311,167 & 33731,117 & 16,331 & 2,165 & SI & $1,508 \mathrm{E}-09$ \\
\hline PxX & 6 & 25923,667 & 4320,611 & 2,092 & 2,421 & NO & 0,08386236 \\
\hline TxX & 15 & 81133,500 & 5408,900 & 2,619 & 2,015 & SI & 0,012064153 \\
\hline Error & 30 & 61962,167 & 2065,406 & & & & \\
\hline Total & 71 & & & & & & \\
\hline
\end{tabular}


Vistos los resultados de la tabla ANOVA generada, se tiene que la única variable rechazada por el análisis ANOVA para un nivel de significación del $5 \%$ es la interacción PxX (presión y porcentaje en mezcla). Sin embargo, y como se ha dicho en otros análisis, viendo el valor crítico del grado de significación de esta variable, se queda cerca, con un 8,38\%. Además, se tiene también que la interacción TxX ofrece un nivel de significación crítico del 1,2\%, valor que si bien es aceptado en el análisis, probablemente no ofrezca la influencia que los demás ofrecen.

Como variables más significativas se tienen la presión de inyección $(\mathrm{P})$ y el tipo de aceite $(\mathrm{T})$, ambas con un nivel de significación crítico del orden de $10^{-9} \%$. A continuación, la interacción de ambas (PxT) con un nivel del 10-7 $\%$. Por último, la variable porcentaje en peso $(X)$ con un $0,12 \%$, además de la ya citada $\mathrm{TXX}$ con un $1,2 \%$.

Por tanto, viendo el análisis, queda claro que la variable $X$ es la que menos influencia tiene en el estudio: ni ella misma ni sus interacciones ofrecen grandes niveles de significación. Es destacable además el gran nivel que la interacción PxT ofrece.

Se representan a continuación los valores obtenidos para la variable rendimiento en función de las variables $\mathrm{P}, \mathrm{X}$ y T. 
Representaciones gráficas de emisiones de CO para el aceite de colza crudo $(T=A C C)$ con $A=3,5$

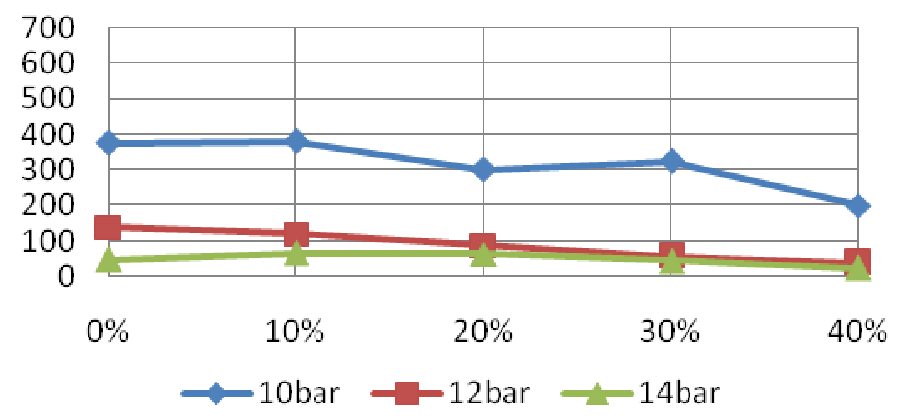

\begin{tabular}{|llllll|}
\hline $\begin{array}{l}\text { ACC, } \\
A=3,5\end{array}$ & $X=0 \%$ & $X=10 \%$ & $X=20 \%$ & $X=30 \%$ & $X=40 \%$ \\
\hline$P=10$ bar & 376 & 380 & 300 & 324 & 200 \\
\hline$P=12$ bar & 139 & 121 & 87 & 56 & 39 \\
\hline$P=14$ bar & 47 & 66 & 65 & 44 & 23 \\
\hline
\end{tabular}

Figura 8.120: Emisiones de $\mathrm{CO}$ para $\mathrm{A}=3,5$ y $\mathrm{T}=\mathrm{ACC}$

El análisis para el AC denota mucho cambio en lo que a comportamiento con la presión se refiere: la presión más baja ofrece unos niveles de emisión más altos. Después, la diferencia en las emisiones entre las dos presiones menores no es tan amplia, aunque existe. Como se vio en el análisis anterior, el ACC es de los aceites cuyo comportamiento en lo que a emisiones se refiere se ve mejorado con el aumento del porcentaje en mezcla. 
Representaciones gráficas de emisiones de CO para el aceite vegetal usado ( $\mathrm{T}=\mathrm{AVU}$ ) con $\mathrm{A}=3,5$

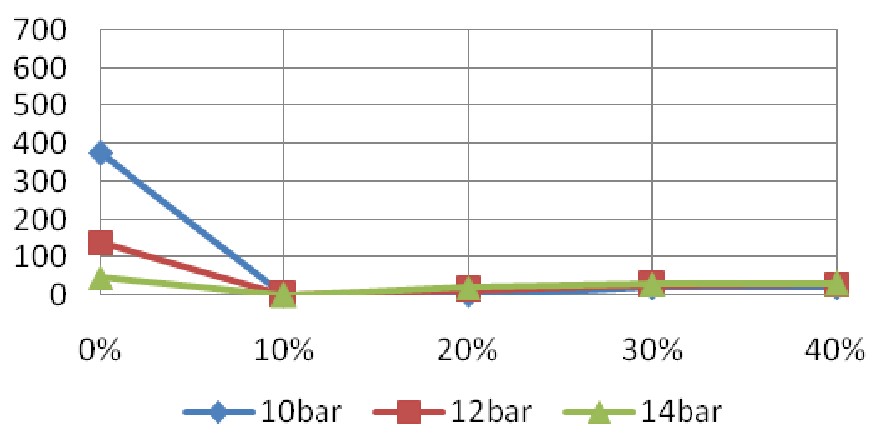

\begin{tabular}{|llllll|}
\hline AVU, $A=3,5$ & $X=0 \%$ & $X=10 \%$ & $X=20 \%$ & $X=30 \%$ & $X=40 \%$ \\
\hline$P=10$ bar & 376 & 0 & 0 & 21 & 20 \\
\hline$P=12$ bar & 139 & 0 & 14 & 27 & 29 \\
\hline$P=14$ bar & 47 & 0 & 20 & 30 & 31 \\
\hline
\end{tabular}

Figura 8.121: Emisiones de CO para $A=3,5$ y $T=A V U$

Se observa poca influencia con la presión (únicamente en los valores de referencia $0 \%$ se ve claramente diferencia, y ese no es el estudio). Además, como se vio antes, el AVU es de los aceites cuyas emisiones aumentan aumentando su porcentaje en mezcla. 
Representaciones gráficas de emisiones de CO para el aceite de girasol crudo $(T=A G C)$ con $A=3,5$

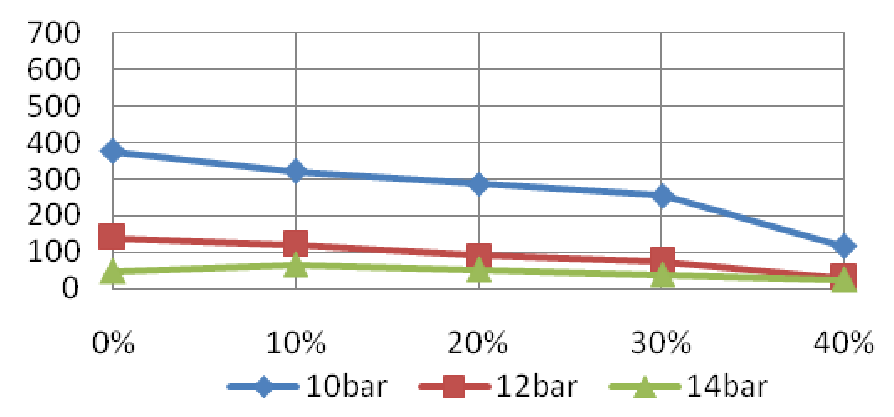

\begin{tabular}{|llllll|}
\hline $\begin{array}{l}\text { AGC, } \\
A=3,5\end{array}$ & $X=0 \%$ & $X=10 \%$ & $X=20 \%$ & $X=30 \%$ & $X=40 \%$ \\
\hline$P=10$ bar & 376 & 321 & 288 & 254 & 115 \\
\hline$P=12$ bar & 139 & 120 & 91 & 75 & 30 \\
\hline$P=14$ bar & 47 & 65 & 51 & 38 & 24 \\
\hline
\end{tabular}

Figura 8.122: Emisiones de $C O$ para $A=3,5$ y $T=A G C$.

Se nota la influencia de la presión, con mayores emisiones a menores presiones. Se ve además la tendencia a disminuir dichas emisiones con el aumento del porcentaje en mezcla. 
Representaciones gráficas de emisiones de CO para el aceite de girasol refinado ( $T=A G R$ ) con $A=3,5$

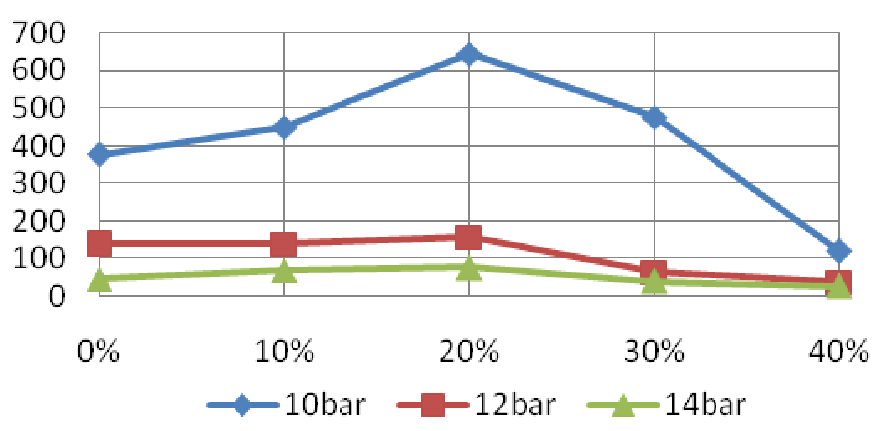

\begin{tabular}{|llllll|}
\hline $\begin{array}{l}\text { AGR, } \\
A=3,5\end{array}$ & $X=0 \%$ & $X=10 \%$ & $X=20 \%$ & $X=30 \%$ & $X=40 \%$ \\
\hline$P=10$ bar & 376 & 450 & 644 & 476 & 120 \\
\hline$P=12$ bar & 139 & 140 & 158 & 64 & 39 \\
\hline$P=14$ bar & 47 & 70 & 77 & 41 & 26 \\
\hline
\end{tabular}

Figura 8.123: Emisiones de CO para $A=3,5$ y $T=A G R$

El AGR ofrece un pico de emisiones para todas las presiones a $X=20 \%$, para después disminuir éstas. Se aprecia la influencia de la presión claramente en la gráfica (y en la tabla). 
Representaciones gráficas de emisiones de CO para el aceite de soja crudo $(\mathrm{T}=\mathrm{ASC}$ ) con $\mathrm{A}=3,5$

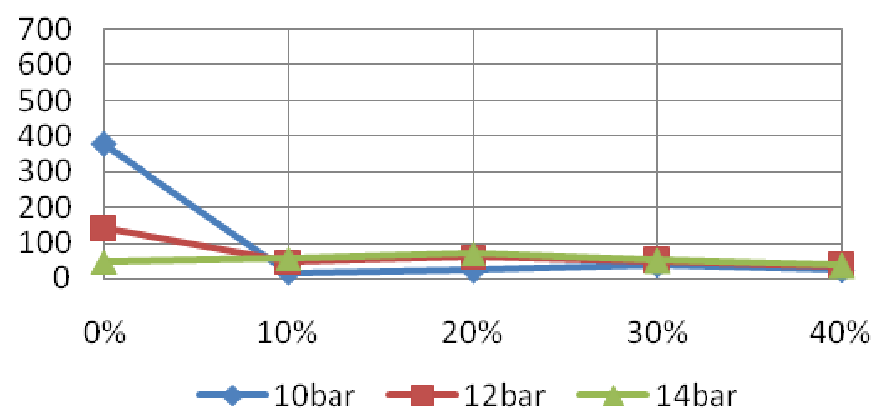

\begin{tabular}{|llllll|}
$\begin{array}{l}\text { ASC, } \\
\text { A=3,5 }\end{array}$ & $X=0 \%$ & $X=10 \%$ & $X=20 \%$ & $X=30 \%$ & $X=40 \%$ \\
\hline$P=10$ bar & 376 & 17 & 22 & 37 & 23 \\
\hline$P=12$ bar & 139 & 47 & 61 & 49 & 35 \\
\hline$P=14$ bar & 47 & 55 & 69 & 50 & 36 \\
\hline
\end{tabular}

Figura 8.124: Emisiones de $\mathrm{CO}$ para $\mathrm{A}=3,5$ y $\mathrm{T}=\mathrm{ASC}$

El ASC ofrece picos para $X=20 \%$ y da su mínimo para $X=40 \%$. Resulta curioso el comportamiento con la presión, ya que es el inverso al visto hasta ahora: se tienen las mínimas emisiones para la presión mínima, si bien las máximas las ofrece la presión intermedia. 
Representaciones gráficas de emisiones de CO para el aceite de soja refinado ( $T=A S R$ ) con $A=3,5$

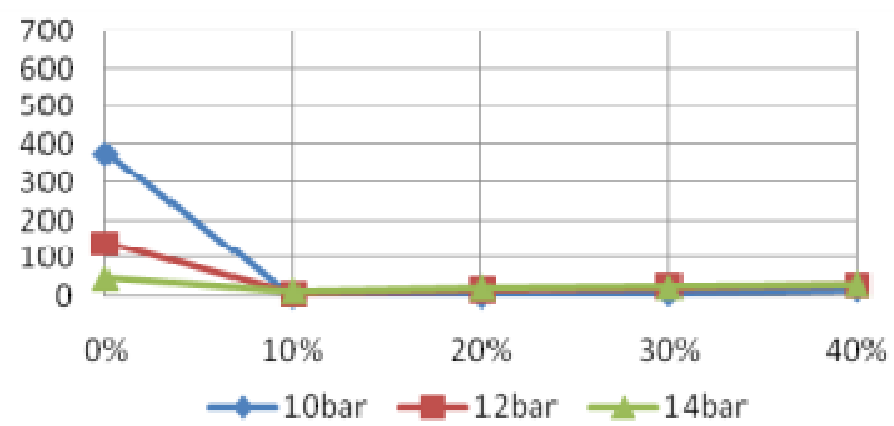

\begin{tabular}{|llllll|}
$\begin{array}{l}\text { ASR, } \\
\text { A=3,5 }\end{array}$ & $X=0 \%$ & $X=10 \%$ & $X=20 \%$ & $X=30 \%$ & $X=40 \%$ \\
\hline$P=10$ bar & 376 & 0 & 0 & 8 & 18 \\
\hline$P=12$ bar & 139 & 7 & 15 & 23 & 29 \\
\hline$P=14$ bar & 47 & 13 & 22 & 25 & 31 \\
\hline
\end{tabular}

Figura 8.125: Emisiones de $\mathrm{CO}$ para $\mathrm{A}=3,5$ y $\mathrm{T}=\mathrm{ASR}$

Se tiene un nivel bajo de emisiones en el ASR. La tendencia es positiva tanto con el aumento del porcentaje de aceite en mezcla como con el aumento de presión (tal y como pasaba en AVU). Se consiguen emisiones cero a baja presión y bajo porcentaje. 
Representaciones gráficas de emisiones de CO para la presión de inyección $P=10$ bar con $A=3,5$

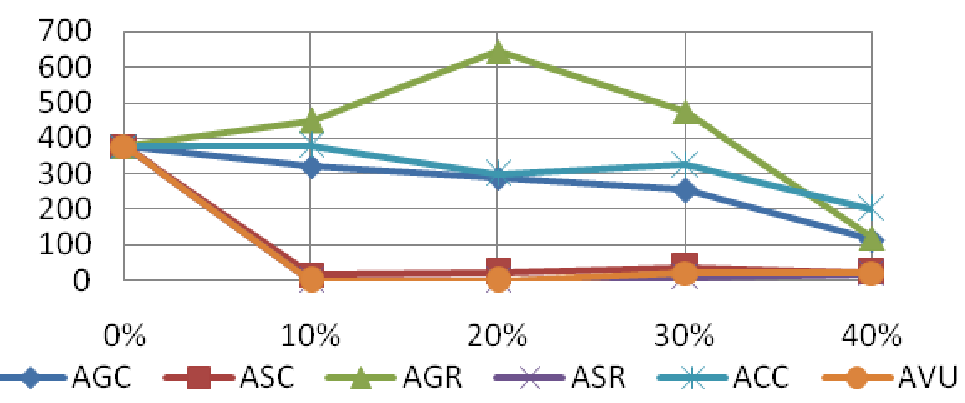

\begin{tabular}{|llllll|}
$\begin{array}{l}\text { P=10bar, } \\
\text { A=3,5 }\end{array}$ & $X=0 \%$ & $X=10 \%$ & $X=20 \%$ & $X=30 \%$ & $X=40 \%$ \\
\hline ACC & 376 & 380 & 300 & 324 & 200 \\
\hline AVU & 376 & 0 & 0 & 21 & 20 \\
\hline AGC & 376 & 321 & 288 & 254 & 115 \\
\hline AGR & 376 & 450 & 644 & 476 & 120 \\
\hline ASC & 376 & 17 & 22 & 37 & 23 \\
\hline ASR & 376 & 0 & 0 & 8 & 18 \\
\hline
\end{tabular}

Figura 8.126: Emisiones de $C O$ para $A=3,5$ y $P=10$ bar

Se observa en el gráfico que tanto AVU como los aceites de soja ofrecen uno nivele mucho menor de emisión para esta presión. 
Representaciones gráficas de emisiones de CO para la presión de inyección $P=12$ bar con $A=3,5$

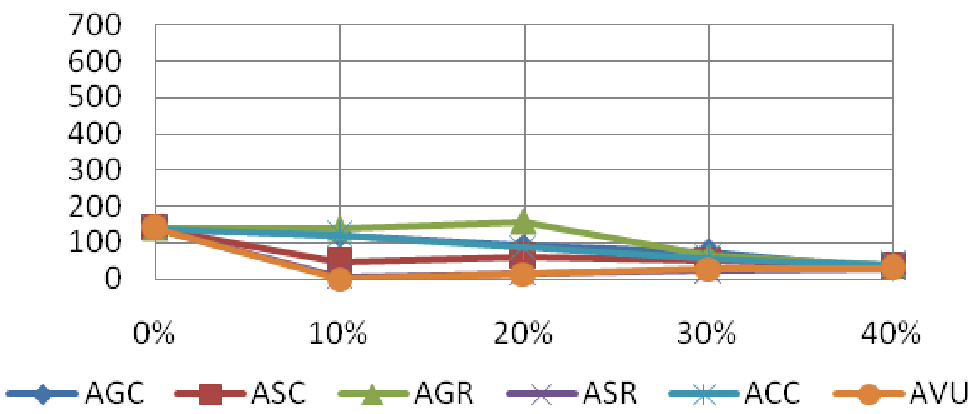

\begin{tabular}{|llllll|}
\hline $\begin{array}{l}P=12 \text { bar, } \\
\text { A=3,5 }\end{array}$ & $X=0 \%$ & $X=10 \%$ & $X=20 \%$ & $X=30 \%$ & $X=40 \%$ \\
\hline ACC & 139 & 121 & 87 & 56 & 39 \\
\hline AVU & 139 & 0 & 14 & 27 & 29 \\
\hline AGC & 139 & 120 & 91 & 75 & 30 \\
\hline AGR & 139 & 140 & 158 & 64 & 39 \\
\hline ASC & 139 & 47 & 61 & 49 & 35 \\
\hline ASR & 139 & 7 & 15 & 23 & 29 \\
\hline
\end{tabular}

Figura 8.127: Emisiones de $\mathrm{CO}$ para $\mathrm{A}=3,5$ y $\mathrm{P}=12$ bar

Para $\mathrm{P}=12$ bar, se observan tres tendencias distintas: por un lado, una en la que las emisiones disminuyen cuando $X$ aumenta (AGR, AGC y ACC); por otro lado, AVU y ASR, con una tendencia contraria a la anterior; y por último, la de ASC, que es intermedia entre las dos, tanto por valores como por tendencia, ya que alcanza un pico en $20 \%$ (hasta ahí aumenta) y después disminuye. 
Representaciones gráficas de emisiones de CO para la presión de inyección $P=14$ bar con $A=3,5$

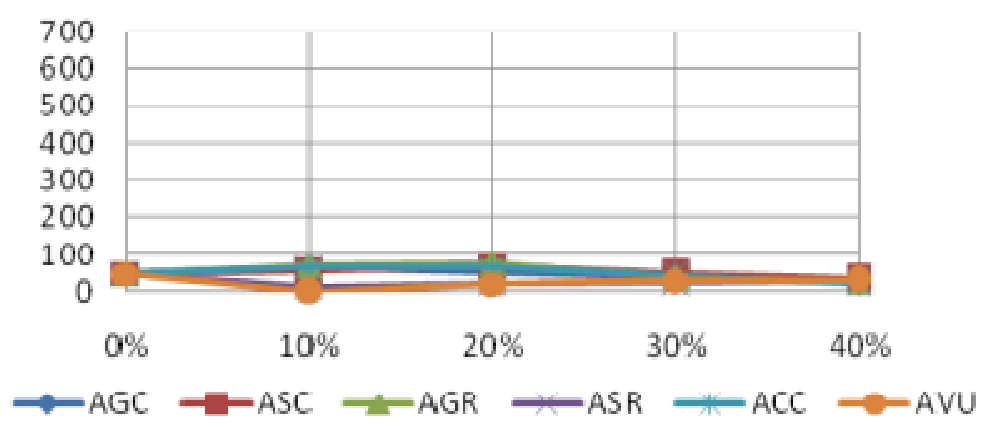

\begin{tabular}{|llllll|}
\hline $\begin{array}{l}\text { P=14bar, } \\
\text { A=3,5 }\end{array}$ & $X=0 \%$ & $X=10 \%$ & $X=20 \%$ & $X=30 \%$ & $X=40 \%$ \\
\hline ACC & 47 & 66 & 65 & 44 & 23 \\
\hline AVU & 47 & 0 & 20 & 30 & 31 \\
\hline AGC & 47 & 65 & 51 & 38 & 24 \\
\hline AGR & 47 & 70 & 77 & 41 & 26 \\
\hline ASC & 47 & 55 & 69 & 50 & 36 \\
\hline ASR & 47 & 13 & 22 & 25 & 31 \\
\hline
\end{tabular}

Figura 8.128: Emisiones de $\mathrm{CO}$ para $\mathrm{A}=3,5$ y $\mathrm{P}=14$ bar

La tendencia es la misma que la que vimos en el análisis anterior, pero con valores más homogéneos y más bajos. De esta forma, las emisiones llegan a converger en un rango relativamente estrecho para $X=40 \%$ : unas porque han aumentado y otras porque han disminuido. 
Representaciones gráficas de emisiones de CO para el porcentaje de aceite en peso $X=10 \% \operatorname{con} A=3,5$

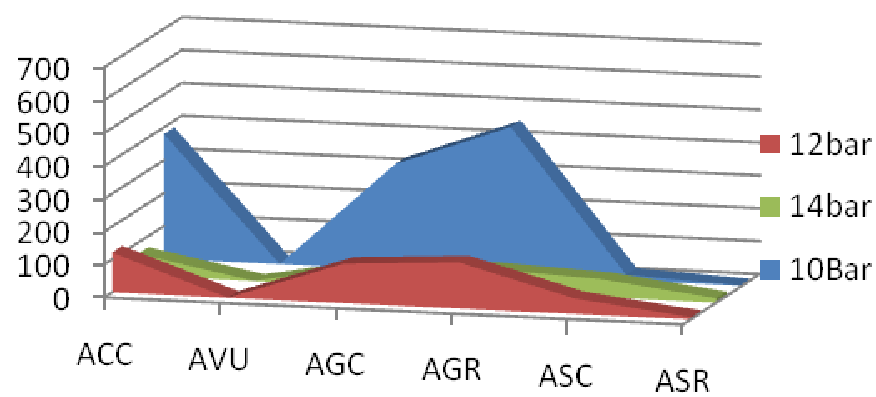

\begin{tabular}{|lllllll|}
\hline $\begin{array}{l}\mathrm{X}=\mathbf{1 0} \%, \\
\mathrm{~A}=\mathbf{3}, \mathbf{5}\end{array}$ & ACC & AVU & AGC & AGR & ASC & ASR \\
\hline $\mathrm{P}=10$ bar & 380 & 0 & 321 & 450 & 17 & 0 \\
\hline $\mathrm{P}=12$ bar & 121 & 0 & 120 & 140 & 47 & 7 \\
\hline $\mathrm{P}=14$ bar & 66 & 0 & 65 & 70 & 55 & 13 \\
\hline
\end{tabular}

Figura 8.129: Emisiones de CO para $A=3,5$ y $X=10 \%$

Se ve clara la tendencia: tres aceites con muy bajas emisiones (ASC, ASR y AVU) y tres aceites con emisiones mayores (AGC, AGR y ACC). El máximo lo consigue el AGR (450 ppm).

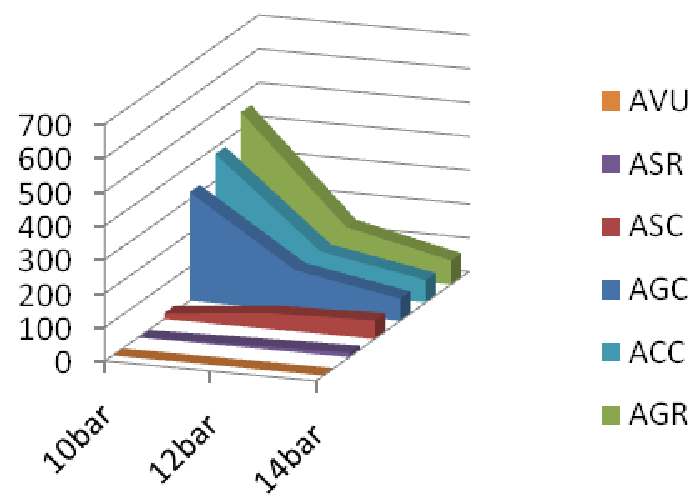

Figura 8.130: Emisiones de CO para $A=3,5$ y $X=10 \%$ 
Representaciones gráficas de emisiones de CO para el porcentaje de aceite en peso $X=20 \% \operatorname{con} A=3,5$

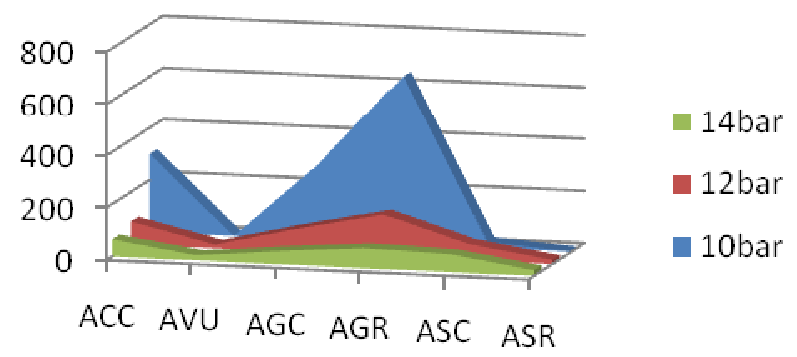

\begin{tabular}{|lllllll|}
\hline $\begin{array}{l}\mathrm{X}=\mathbf{2 0} \%, \\
\mathrm{~A}=\mathbf{3}, \mathbf{5}\end{array}$ & ACC & AVU & AGC & AGR & ASC & ASR \\
\hline $\mathrm{P}=10$ bar & 300 & 0 & 288 & 644 & 22 & 0 \\
\hline $\mathrm{P}=12$ bar & 87 & 14 & 91 & 158 & 61 & 15 \\
\hline $\mathrm{P}=14$ bar & 65 & 20 & 51 & 77 & 69 & 22 \\
\hline
\end{tabular}

Figura 8.131: Emisiones de $\mathrm{CO}$ para $A=3,5$ y $X=20 \%$

Las emisiones que da el AGR son las mayores del estudio: aumentan consiguiendo un pico para $X=20 \%$, mientras que ACC y AGC no sufren este acusado pico. AVU y ASR tienen mínimos para $\mathrm{P}=10 \mathrm{bar}$ (0 ppm).

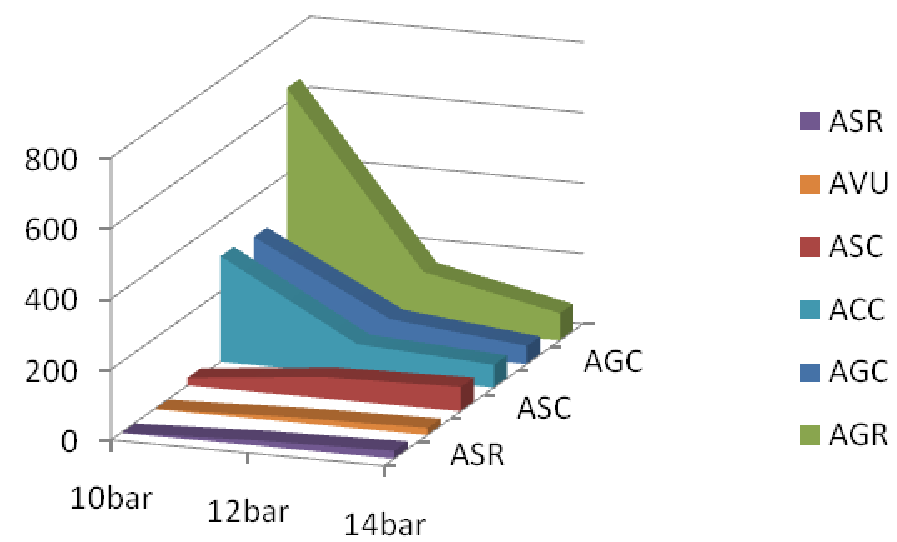

Figura 8.132: Emisiones de $\mathrm{CO}$ para $\mathrm{A}=3,5$ y $\mathrm{X}=20 \%$ 
Representaciones gráficas de emisiones de CO para el porcentaje de aceite en peso $X=30 \% \operatorname{con} A=3,5$

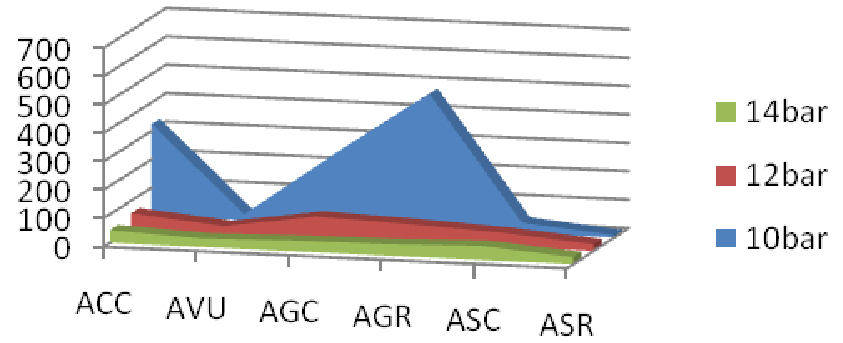

\begin{tabular}{|lllllll|}
\hline $\begin{array}{l}\mathrm{X}=30 \%, \\
\mathrm{~A}=\mathbf{3}, \mathbf{5}\end{array}$ & ACC & AVU & AGC & AGR & ASC & ASR \\
\hline $\mathrm{P}=10$ bar & 324 & 21 & 254 & 476 & 37 & 8 \\
\hline $\mathrm{P}=12$ bar & 56 & 27 & 75 & 64 & 49 & 23 \\
\hline $\mathrm{P}=14$ bar & 44 & 30 & 38 & 41 & 50 & 25 \\
\hline
\end{tabular}

Figura 8.133: Emisiones de $\mathrm{CO}$ para $A=3,5$ y $X=30 \%$

En este caso, las emisiones producidas son menores que las anteriores, pero están situadas en los mismos puntos (son los mismos aceites). Aumentan las emisiones de los aceites que antes daban menos, camino esto hacia la homogeneización que se anunciaba antes. Máximo: 476 ppm para $A G C$ y $P=10$ bar.

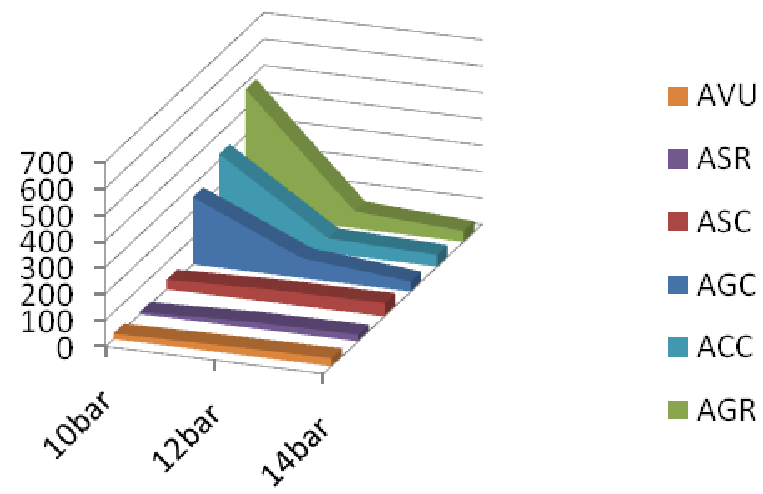

Figura 8.134: Emisiones de $\mathrm{CO}$ para $\mathrm{A}=3,5$ y $\mathrm{X}=30 \%$

Representaciones gráficas de emisiones de CO para el porcentaje de aceite en peso $X=30 \% \operatorname{con} A=4$ 


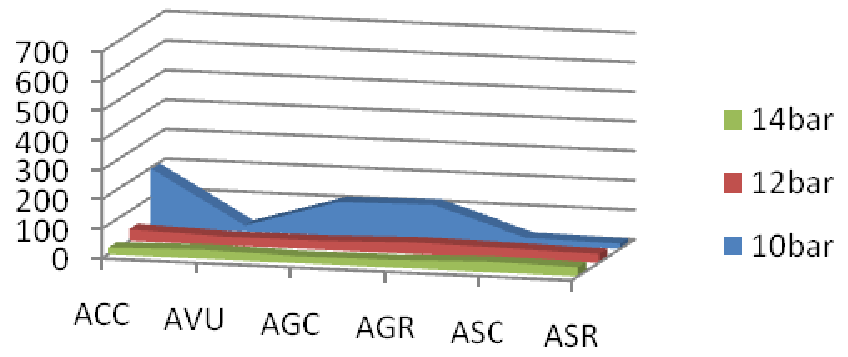

\begin{tabular}{|lllllll|}
\hline $\begin{array}{l}X=40 \%, \\
A=3,5\end{array}$ & ACC & AVU & AGC & AGR & ASC & ASR \\
\hline$P=10$ bar & 200 & 20 & 115 & 120 & 23 & 18 \\
\hline$P=12$ bar & 39 & 29 & 30 & 39 & 35 & 29 \\
\hline$P=14$ bar & 23 & 31 & 24 & 26 & 36 & 31 \\
\hline
\end{tabular}

Figura 8.135: Emisiones de CO para $A=3,5$ y $X=40 \%$

Se tiene en este caso un máximo anormalmente alto (vista la tendencia) en ACC y $\mathrm{P}=10$ bar. Se obtienen también máximos relativos para esa presión y los aceites de girasol. Cabe también destacar el comportamiento estable que muestran los aceites de soja y el vegetal usado, con valores todos entre 18 y $36 \mathrm{ppm}$. La influencia de la presión depende del tipo de aceite (interacción PxT).

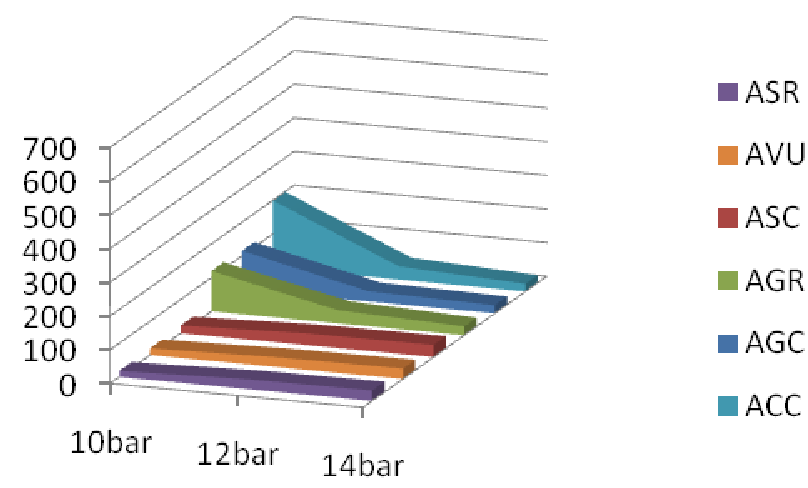

Figura 8.136: Emisiones de $C O$ para $A=3,5$ y $X=40 \%$ 


\subsubsection{Conclusiones}

El análisis tanto del ANOVA como de las representaciones gráficas da como conclusiones las siguientes:

- La influencia de la interacción PxT, ya comentada en el análisis ANOVA, queda refrendada después de ver las gráficas y las tablas expuestas. Por un lado, se tiene que para AVU, ASC y ASR las emisiones aumentan cuando aumenta la presión de inyección del combustible, mientras que disminuyen para el resto de aceites.

- Dentro del análisis de cada aceite, se tiene que las que tienen una interacción positiva con la presión (aumentan las emisiones cuando ésta aumenta) presentan también un comportamiento con el aumento del porcentaje en mezcla, de modo que las emisiones aumentan cuanto más aceite hay en la mezcla. El ASC no ofrece una tendencia tan clara, con picos de emisiones en el $20 \%$. Asimismo, también el AGR ofrece picos de emisiones para el $20 \%$, pero estos picos son de valores mucho mayores. Los aceites de girasol no ofrecen picos, sino tendencias negativas con el porcentaje de aceite en mezcla, de modo que la comparativa para el porcentaje mayor (40\%) ofrece unos resultados bastante homogéneos dentro de todos los tipos de aceite.

- Queda patente también lo diferente del resultado del refino en girasol y soja: el ASR ofrece los mejores resultados (junto con el AVU), mientras que el AGR no sólo es peor que el AGC, si no que es el peor en una buena cantidad de condiciones de ensayo.

Como conclusión final a este análisis, puede decirse que, a caudal de aire constante, dependerá de la presión de inyección el aceite a elegir. Normalmente elegiríamos siempre AVU y ASR, pero para altos porcentajes de sustitución se podría valorar el elegir cualquiera de los otros aceites por delante de estos. 


\subsection{ESTUDIO DE LAS EMISIONES DE NOx}

Se estudian a continuación las emisiones de NOx (en ppm) medidas con el medidor Testo modelo 342-3. Se realizan los análisis a presión constante $(10,12$ y 14 bar) y a posición de admisión de aire constante para las distintas mezclas.

\subsubsection{Análisis de las emisiones de NOx para $\mathrm{P}=10 \mathrm{bar}$}

Tabla 8.19 Matriz de resultados para $\mathrm{P}=10 \mathrm{bar}$

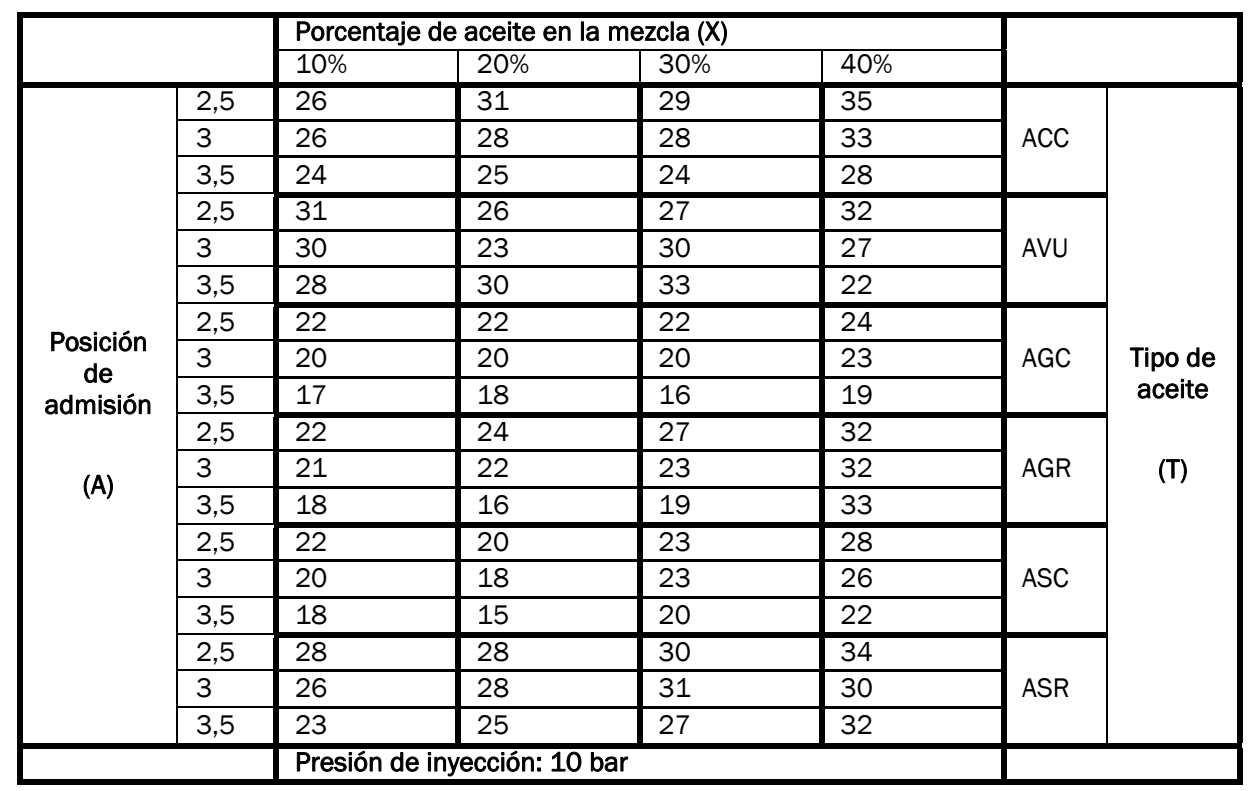

Con estos datos, lo primero que se plantea es un análisis de varianza (ANOVA), mediante el cual se determinará si las tres variables influyen (admisión del aire, tipo de aceite y porcentaje de aceite en peso) o no y de 
Tabla 8.20 Matriz de resultados para $\mathrm{P}=10 \mathrm{bar}$

\begin{tabular}{|l|l|l|l|l|l|l|l|}
\hline FACTOR & GdL & SS & MS & F & VC al 5\% & Influye & G. C. Crítica \\
\hline A & 2 & 182,694 & 91,347 & 19,356 & 3,316 & SI & $3,99415 \mathrm{E}-06$ \\
\hline T & 5 & 837,069 & 167,414 & 35,473 & 2,534 & SI & $1,0077 \mathrm{E}-11$ \\
\hline X & 3 & 310,375 & 103,458 & 21,922 & 2,922 & SI & $1,03345 \mathrm{E}-07$ \\
\hline AxT & 10 & 35,639 & 3,564 & 0,755 & 2,165 & NO & 0,66879327 \\
\hline AxX & 6 & 8,083 & 1,347 & 0,285 & 2,421 & NO & 0,93927647 \\
\hline TxX & 15 & 255,208 & 17,014 & 3,605 & 2,015 & SI & 0,00136102 \\
\hline Error & 30 & 141,583 & 4,719 & & & & \\
\hline Total & 71 & 1770,653 & & & & & \\
\hline
\end{tabular}

Vistos los resultados de la tabla ANOVA generada, se tiene que tanto la interacción AxT como la interacción AxX son rechazadas por el análisis ANOVA para un nivel de significación del 5\%. Los valores críticos de significación de ambas interacciones son además valores muy altos, con lo que la conclusión es clara e indiscutible. La interacción sobrante, TxX, supera el análisis con un grado de confiabilidad crítico de 0,136\%, lejos de los niveles de influencia que ofrecía esta misma interacción en análisis anteriores.

Como variables más significativas se tienen el tipo de aceite $(T)\left(10^{-9} \%\right)$ y porcentaje de aceite en la mezcla $(X)\left(10^{-5}\right)$, con lo cual las emisiones de $\mathrm{NO}_{x}$ las marcarán las características del combustible que introduzcamos en la caldera. Sin embargo, la posición de la admisión del aire (A) también es una variable muy importante dentro del análisis $\left(3 * 10^{-4} \%\right)$, lo cual se verá a continuación.

Como conclusión del análisis ANOVA, se puede decir que a priori lo que marcará la cantidad de emisiones será la naturaleza del combustible por encima de las condiciones de admisión de aire.

Se representan a continuación los valores obtenidos para la variable rendimiento en función de las variables $\mathrm{A}, \mathrm{X}$ y T. 
Representaciones gráficas de la emisión de NOx para el aceite de colza crudo $(\mathrm{T}=\mathrm{ACC})$

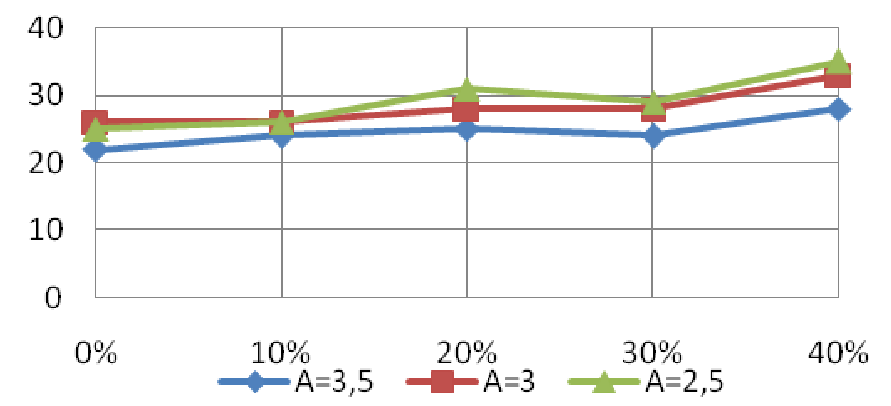

\begin{tabular}{|llllll|}
$\begin{array}{l}\text { ACC, } \\
P=1 \text { bbar }\end{array}$ & $X=0 \%$ & $X=10 \%$ & $X=20 \%$ & $X=30 \%$ & $X=40 \%$ \\
\hline$A=2,5$ & 25 & 26 & 31 & 29 & 35 \\
\hline$A=3$ & 26 & 26 & 28 & 28 & 33 \\
\hline$A=3,5$ & 22 & 24 & 25 & 24 & 28 \\
\hline
\end{tabular}

Figura 8.137: Emisiones para $\mathrm{P}=10$ bar y $\mathrm{T}=\mathrm{ACC}$

La gráfica muestra una ligera tendencia al alta cuando aumenta el porcentaje de aceite en mezcla. En cuanto a la posición de admisión de aire, se tienen menores emisiones con la posición más abierta (A mayor). 
Representaciones gráficas de la emisión de NOx para el aceite vegetal usado ( $\mathrm{T}=\mathrm{AVU}$ )

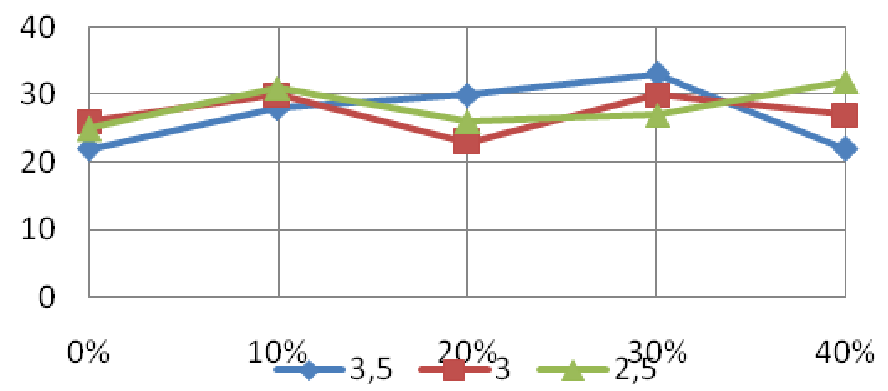

\begin{tabular}{|llllll|}
$\begin{array}{l}\text { AVU, } \\
P=10 \text { bar }\end{array}$ & $X=0 \%$ & $X=10 \%$ & $X=20 \%$ & $X=30 \%$ & $X=40 \%$ \\
\hline$A=2,5$ & 25 & 31 & 26 & 27 & 32 \\
\hline$A=3$ & 26 & 30 & 23 & 30 & 27 \\
\hline$A=3,5$ & 22 & 28 & 30 & 33 & 22 \\
\hline
\end{tabular}

Figura 8.138: Emisiones para $\mathrm{P}=10$ bar y $\mathrm{T}=\mathrm{AVU}$

Cada posición de admisión de aire sigue un comportamiento, teniéndose el mínimo para $A=3,5$ y $X=40 \%$. Dependiendo del porcentaje, las emisiones crecen o decrecen con la posición de aire. 
Representaciones gráficas de la emisión de NOx para el aceite de girasol crudo ( $\mathrm{T}=\mathrm{AGC}$ )

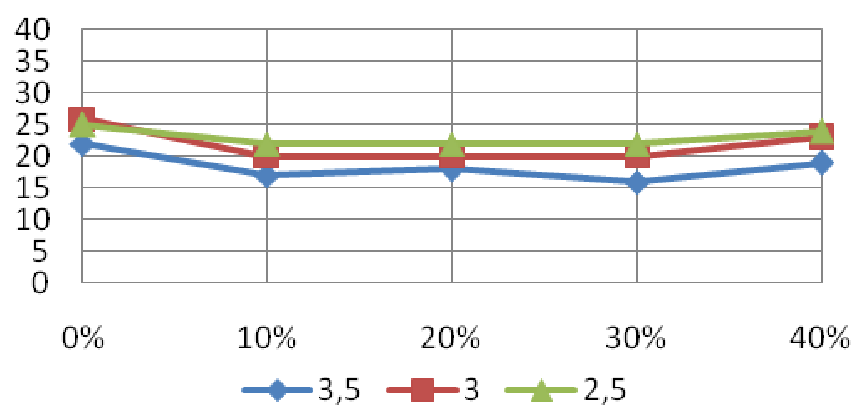

\begin{tabular}{|llllll|}
$\begin{array}{l}\text { AGC, } \\
P=10 \text { bar }\end{array}$ & $X=0 \%$ & $X=10 \%$ & $X=20 \%$ & $X=30 \%$ & $X=40 \%$ \\
\hline$A=2,5$ & 25 & 22 & 22 & 22 & 24 \\
\hline$A=3$ & 26 & 20 & 20 & 20 & 23 \\
\hline$A=3,5$ & 22 & 17 & 18 & 16 & 19 \\
\hline
\end{tabular}

Figura 8.139: Emisiones para $\mathrm{P}=10$ bar y $\mathrm{T}=\mathrm{AGC}$

Tendencia al alza en las emisiones con el porcentaje de aceite en mezcla, y a la baja con la posición de admisión de aire. Se registra, sin embargo, máximos para $X=40 \%$. 
Representaciones gráficas de la emisión de NOx para el aceite de girasol refinado $(T=A G R)$

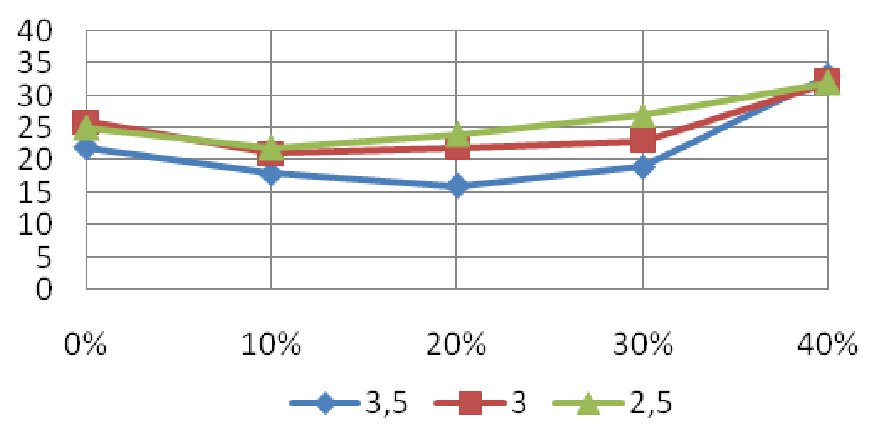

\begin{tabular}{|llllll|}
$\begin{array}{l}\text { AGR, } \\
P=10 \text { bar }\end{array}$ & $X=0 \%$ & $X=10 \%$ & $X=20 \%$ & $X=30 \%$ & $X=40 \%$ \\
\hline$A=2,5$ & 25 & 22 & 24 & 27 & 32 \\
\hline$A=3$ & 26 & 21 & 22 & 23 & 32 \\
\hline$A=3,5$ & 22 & 18 & 16 & 19 & 33 \\
\hline
\end{tabular}

Figura 8.140: Emisiones para $\mathrm{P}=10$ bar y $\mathrm{T}=\mathrm{AGR}$

Se tienen máximos para $X=40 \%$ tal y como ocurría en el aceite sin refinar, y tendencia a la baja con la posición de aire. 
Representaciones gráficas de la emisión de NOx para el aceite de soja crudo ( $\mathrm{T}=\mathrm{ASC}$ )

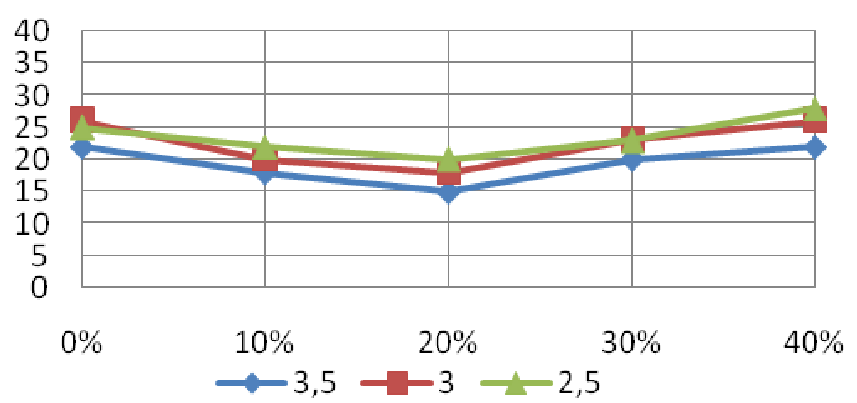

\begin{tabular}{|llllll|}
$\begin{array}{l}\text { ASC, } \\
P=10 \text { bar }\end{array}$ & $X=0 \%$ & $X=10 \%$ & $X=20 \%$ & $X=30 \%$ & $X=40 \%$ \\
\hline$A=2,5$ & 25 & 22 & 20 & 23 & 28 \\
\hline$A=3$ & 26 & 20 & 18 & 23 & 26 \\
\hline$A=3,5$ & 22 & 18 & 15 & 20 & 22 \\
\hline
\end{tabular}

Figura 8.141: Emisiones para $\mathrm{P}=10$ bar y $\mathrm{T}=\mathrm{ASC}$

El gráfico muestra mínimos para el porcentaje $X=20 \%$ en todas las posiciones de admisión de aire. Tendencia a la baja con el aumento de la posición de admisión de aire. 
Representaciones gráficas de la emisión de NOx para el aceite de soja refinado $(\mathrm{T}=\mathrm{ASR})$

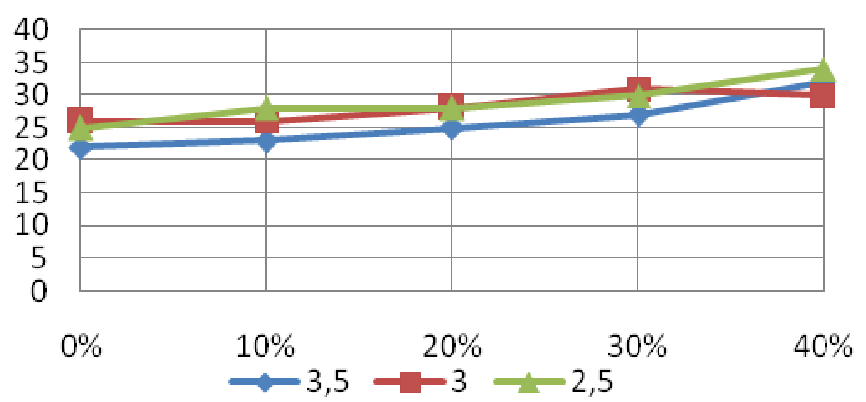

\begin{tabular}{|llllll|}
$\begin{array}{l}\text { ASR, } \\
P=10 \text { bar }\end{array}$ & $X=0 \%$ & $X=10 \%$ & $X=20 \%$ & $X=30 \%$ & $X=40 \%$ \\
\hline$A=2,5$ & 25 & 28 & 28 & 30 & 34 \\
\hline$A=3$ & 26 & 26 & 28 & 31 & 30 \\
\hline$A=3,5$ & 22 & 23 & 25 & 27 & 32 \\
\hline
\end{tabular}

Figura 8.142: Emisiones para $\mathrm{P}=10$ bar y $\mathrm{T}=\mathrm{ASR}$

Poco tiene que ver la tendencia del aceite refinado con la del aceite sin refinar: el nivel de emisiones crece desde $X=10 \%$ ininterrumpidamente para cada posición de admisión de aire. 
Representaciones gráficas de la emisión de NOx para la posición de aire $A=2,5$

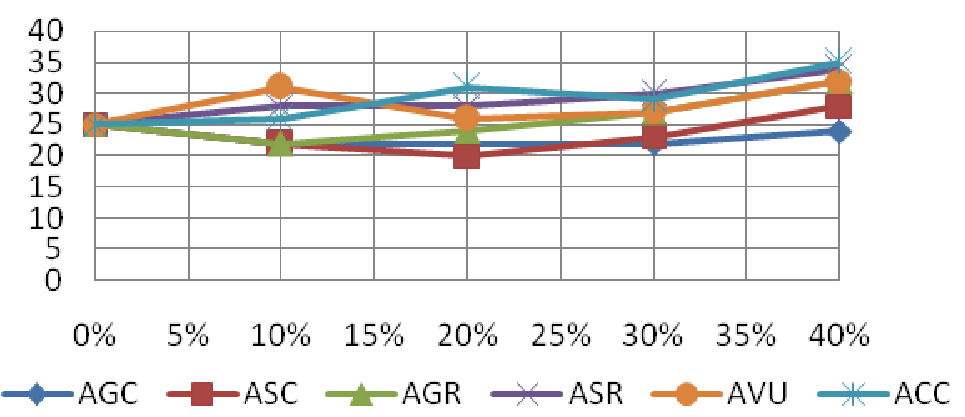

\begin{tabular}{|llllll|}
$\begin{array}{l}\text { A=2,5, } \\
P=10 \text { bar }\end{array}$ & $X=0 \%$ & $X=10 \%$ & $X=20 \%$ & $X=30 \%$ & $X=40 \%$ \\
\hline ACC & 25 & 26 & 31 & 29 & 35 \\
\hline AVU & 25 & 31 & 26 & 27 & 32 \\
\hline AGC & 25 & 22 & 22 & 22 & 24 \\
\hline AGR & 25 & 22 & 24 & 27 & 32 \\
\hline ASC & 25 & 22 & 20 & 23 & 28 \\
\hline ASR & 25 & 28 & 28 & 30 & 34 \\
\hline
\end{tabular}

Figura 8.143: Emisiones para $\mathrm{P}=10$ bar y $\mathrm{A}=2,5$

Ambos aceites crudos, AGC y ASC, ofrecen menores niveles de emisiones que los aceites refinados. El que peor nivel de emisiones presenta es el ACC, sobre todo en porcentajes altos en mezcla tiene un comportamiento peor que el de los demás. Destaca el pico que presenta el AVU para $X=10 \%$. 
Representaciones gráficas de la emisión de NOx para la posición de aire $A=3$

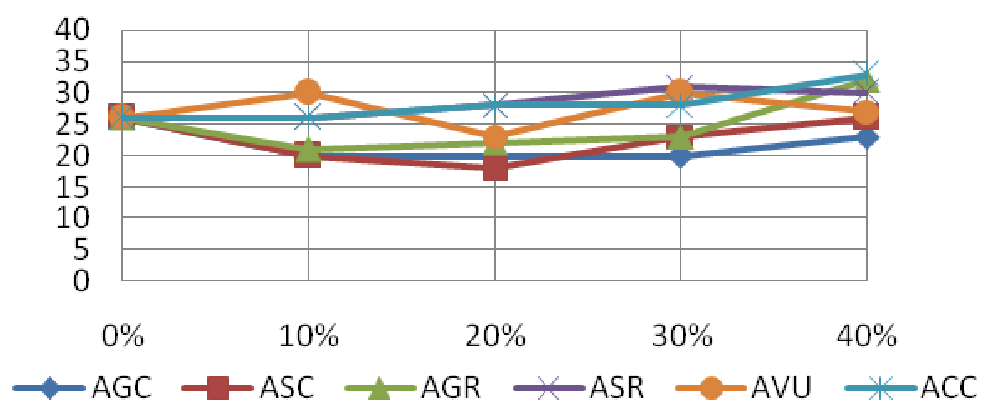

\begin{tabular}{|llllll|}
$\begin{array}{l}\text { A=3, } \\
P=10 \text { bar }\end{array}$ & $X=0 \%$ & $X=10 \%$ & $X=20 \%$ & $X=30 \%$ & $X=40 \%$ \\
\hline ACC & 26 & 26 & 28 & 28 & 33 \\
\hline AVU & 26 & 30 & 23 & 30 & 27 \\
\hline AGC & 26 & 20 & 20 & 20 & 23 \\
\hline AGR & 26 & 21 & 22 & 23 & 32 \\
\hline ASC & 26 & 20 & 18 & 23 & 26 \\
\hline ASR & 26 & 26 & 28 & 31 & 30 \\
\hline
\end{tabular}

Figura 8.144: Emisiones para $\mathrm{P}=10$ bar y $\mathrm{A}=3$

De nuevo destaca el menor nivel de emisiones de los aceites crudos con respecto a los aceites refinados de la misma especie (en primer término en la gráfica). Sin embargo, el AGR no da malos niveles de emisión, aunque estén por debajo del AGC. ACC, AVU y ASR dan más emisiones que los aceites citados anteriormente. 
Representaciones gráficas de la emisión de NOx para la posición de aire $A=3,5$

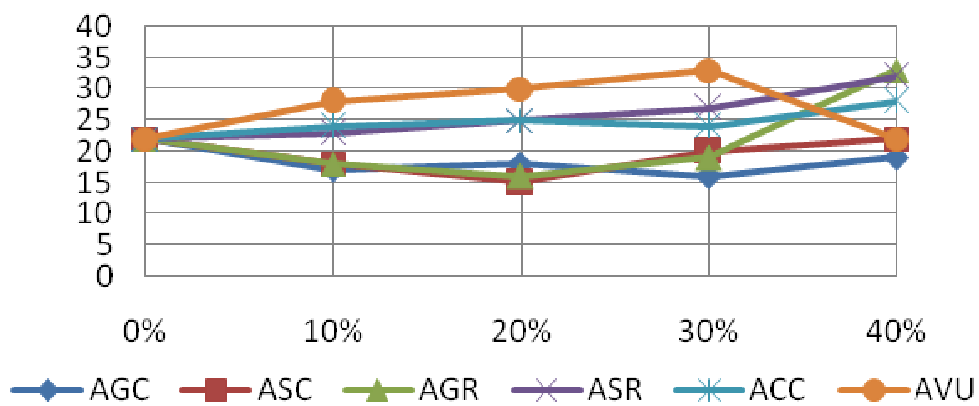

\begin{tabular}{|llllll|}
$\begin{array}{l}\text { A=3,5, } \\
P=10 \text { bar }\end{array}$ & $X=0 \%$ & $X=10 \%$ & $X=20 \%$ & $X=30 \%$ & $X=40 \%$ \\
\hline ACC & 22 & 24 & 25 & 24 & 28 \\
\hline AVU & 22 & 28 & 30 & 33 & 22 \\
\hline AGC & 22 & 17 & 18 & 16 & 19 \\
\hline AGR & 22 & 18 & 16 & 19 & 33 \\
\hline ASC & 22 & 18 & 15 & 20 & 22 \\
\hline ASR & 22 & 23 & 25 & 27 & 32 \\
\hline
\end{tabular}

Figura 8.145: Emisiones para $\mathrm{P}=10$ bar y $\mathrm{A}=3,5$

ASC y AGC vuelven a dar los mínimos. Los máximos los da el AVU, aunque para el máximo porcentaje ofrece un nivel de emisiones aceptable comparado con el de los demás. También da un nivel aceptable el AGR, no siendo así para el otro aceite refinado. 
Representaciones gráficas de la emisión de NOx para el porcentaje en peso de aceite $X=10 \%$

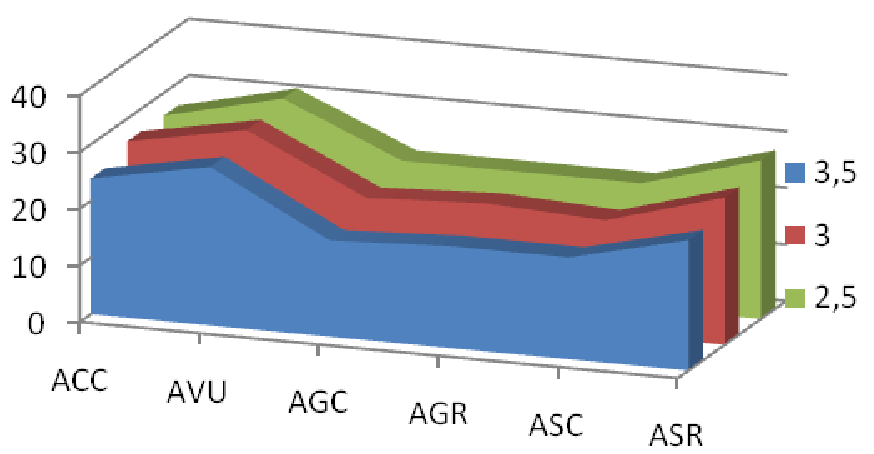

\begin{tabular}{|lllllll|}
$\begin{array}{l}X=10 \%, \\
P=10 \text { bar }\end{array}$ & ACC & AVU & AGC & AGR & ASC & ASR \\
\hline$A=2,5$ & 26 & 31 & 22 & 22 & 22 & 28 \\
\hline$A=3$ & 26 & 30 & 20 & 21 & 20 & 26 \\
\hline$A=3,5$ & 24 & 28 & 17 & 18 & 18 & 23 \\
\hline
\end{tabular}

Figura 8.146: Emisiones para $P=10$ bar y $X=10 \%$

En la primera gráfica se observa que, para $X=10 \%$, el AVU da el peor nivel de emisiones, seguido por ASR y ACC. A su vez, se ve que las menores emisiones las dan los aceites de girasol y ASC. La segunda gráfica muestra que, en mayor o menor medida, el aumento de la apertura de la posición de aire disminuye las emisiones.

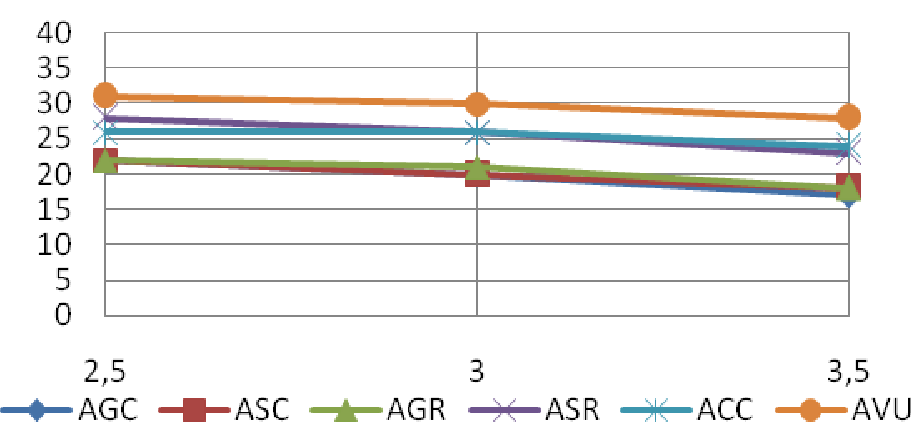

Figura 8.147: Emisiones para $P=10$ bar y $X=10 \%$

Representaciones gráficas de la emisión de NOx para el porcentaje en peso de aceite $X=20 \%$ 


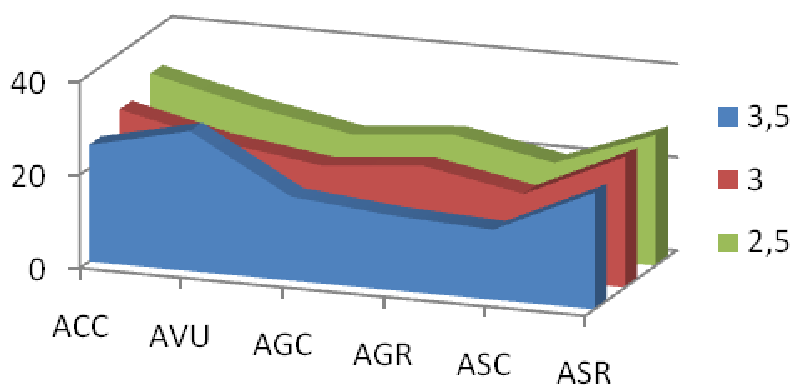

\begin{tabular}{|lllllll|}
\hline $\begin{array}{l}X=20 \%, \\
P=10 \text { bar }\end{array}$ & ACC & AVU & AGC & AGR & ASC & ASR \\
\hline$A=2,5$ & 31 & 26 & 22 & 24 & 20 & 28 \\
\hline$A=3$ & 28 & 23 & 20 & 22 & 18 & 28 \\
\hline$A=3,5$ & 25 & 30 & 18 & 16 & 15 & 25 \\
\hline
\end{tabular}

Figura 8.148: Emisiones para $P=10$ bar y $X=20 \%$

Para este porcentaje de aceite, el ASC da las menores emisiones para cualquier posición del aire. La mayoría de aceites tienen tendencia a la disminución de emisiones cuando aumenta la posición de admisión de aire (salvando el pico del AVU para $A=3,5$ ). El segundo gráfico muestra claramente la existencia de dos niveles bien diferenciados: ACC, AVU y ASR dan emisiones altas, y AGC, AGR y ASC dan emisiones más bajas.

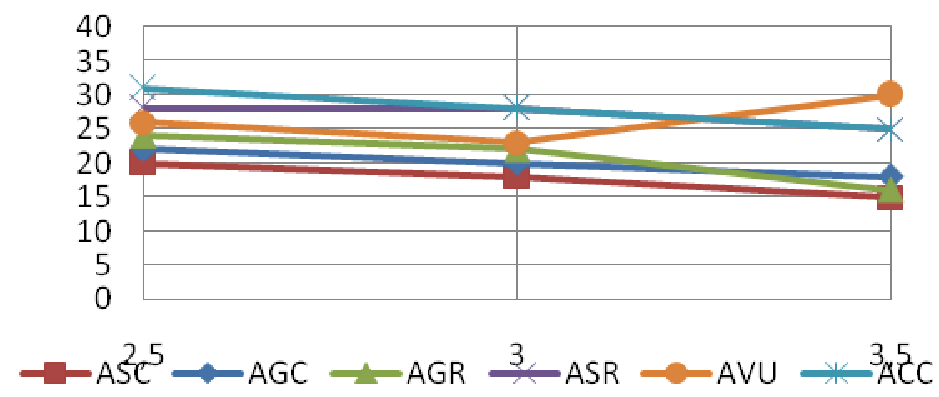

Figura 8.149: Emisiones para $P=10$ bar y $X=20 \%$

Representaciones gráficas de la emisión de NOx para el porcentaje en peso de aceite $X=30 \%$ 


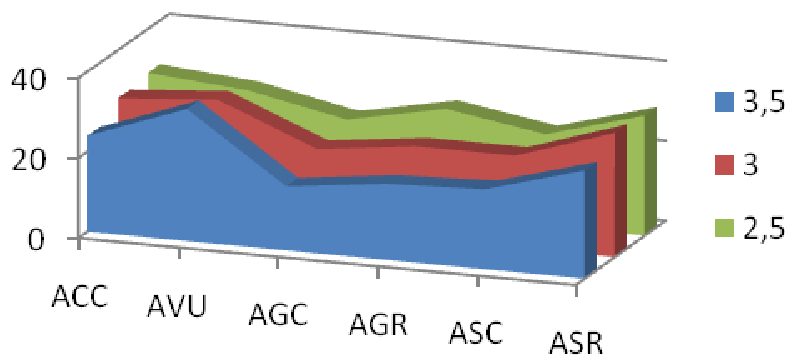

\begin{tabular}{|lllllll|}
$\begin{array}{l}X=30 \%, \\
P=10 \text { bar }\end{array}$ & ACC & AVU & AGC & AGR & ASC & ASR \\
\hline$A=2,5$ & 29 & 27 & 22 & 27 & 23 & 30 \\
\hline$A=3$ & 28 & 30 & 20 & 23 & 23 & 31 \\
\hline$A=3,5$ & 24 & 33 & 16 & 19 & 20 & 27 \\
\hline
\end{tabular}

Figura 8.150: Emisiones para $\mathrm{P}=10$ bar y $\mathrm{X}=30 \%$

En este caso, los menores niveles de emisión de $\mathrm{NO}_{x}$ los da el AGC. El AGR tiene un comportamiento muy progresivo (a la baja) con la apertura de la admisión de aire. El ASC tiene un comportamiento bastante constante con la variación de A. Por último, tanto ASR, como ACC como AVU dan valores mayores, destacando que éste da, al contrario que los otros aceites, mayores emisiones a mayor posición de admisión de aire. Esto se aprecia claramente en la segunda gráfica.

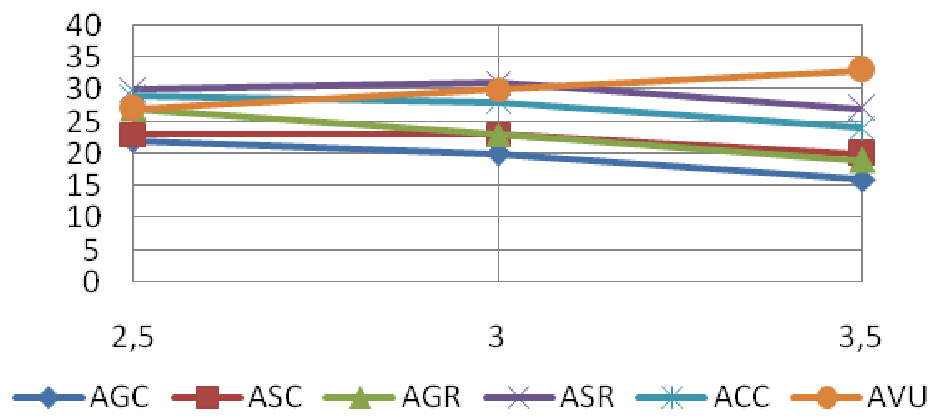

Figura 8.151: Emisiones para $P=10$ bar y $X=30 \%$

Representaciones gráficas de la emisión de NOx para el porcentaje en peso de aceite $X=40 \%$ 


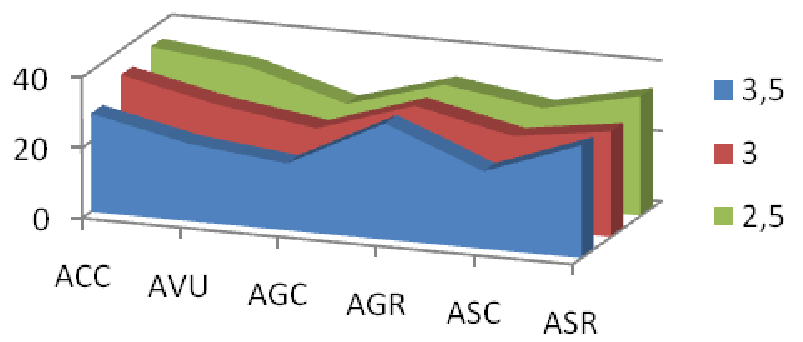

\begin{tabular}{|lllllll|}
\hline $\begin{array}{l}X=40 \%, \\
P=10 \text { bar }\end{array}$ & ACC & AVU & AGC & AGR & ASC & ASR \\
\hline$A=2,5$ & 35 & 32 & 24 & 32 & 28 & 34 \\
\hline$A=3$ & 33 & 27 & 23 & 32 & 26 & 30 \\
\hline$A=3,5$ & 28 & 22 & 19 & 33 & 22 & 32 \\
\hline
\end{tabular}

Figura 8.152: Emisiones para $P=10$ bar y $X=40 \%$

El AGC ofrece los menores niveles de emisiones para cada posición de admisión de aire. A continuación, ASC y AVU. Tanto ACC, como AGR y ASR están un nivel por encima. Salvo el AGR, todos los aceites ofrecen un comportamiento inversamente proporcional al aumento en $A$.

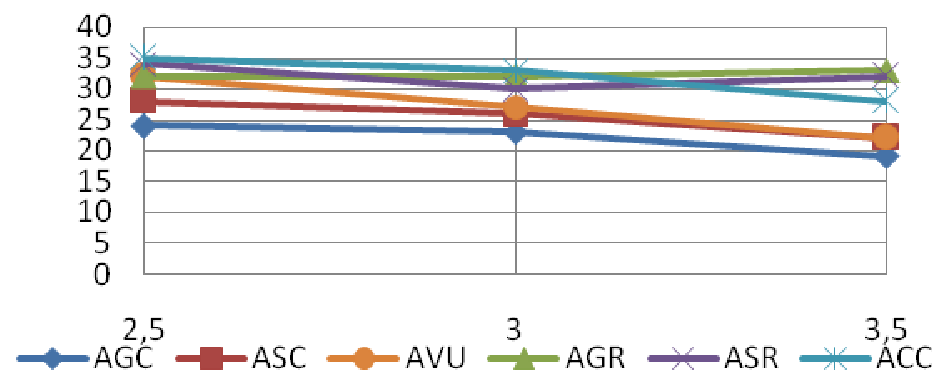

Figura 8.153: Emisiones para $\mathrm{P}=10$ bar y $\mathrm{X}=40 \%$ 


\subsubsection{Conclusiones}

El análisis tanto del ANOVA como de las representaciones gráficas da como conclusiones las siguientes:

- $\quad$ El hecho de que la variable con mayor influencia en el análisis ANOVA sea el tipo de aceite (T) queda demostrado viendo la representación gráfica para cada tipo de aceite, no por valores, si no por la tendencia y las curvas que describen. Caso a caso:

o ACC: valores bastante estables con subida al final para porcentajes altos.

o AVU: comportamiento difícilmente explicable.

o AGC: ligera tendencia al alta con el aumento del porcentaje de aceite en mezcla, pero con un comportamiento muy, muy estable.

o AGR: estabilidad, con picos para el porcentaje alto.

o ASC: mínimas emisiones para el $20 \%$ en mezcla.

o ASR: ligera tendencia al alza con el aumento de X.

- La tendencia que tienen las emisiones de $\mathrm{NO}_{x}$ con el aumento de la posición de admisión de aire es inversamente proporcional a ésta: a mayor posición, menores emisiones. Cabe destacar que el AVU contradice esta ley para dos porcentajes de aceite en mezcla (20 y $30 \%)$.

- Las gráficas a posición de aire constante demuestran que para la gran mayoría de casos, cuando $X=40 \%$ se tiene el mayor nivel de emisiones, consiguiendo los máximos en estos puntos. Si bien esto es cierto, también se puede decir que el patrón no es claro, con picos intermedios en algunos casos y un ascenso/descenso en los valores poco pronunciado.

- $\quad$ Claramente se ha ido viendo durante el análisis que AVU, AC y ASR son los tres aceites que peores niveles de emisiones ofrecen. A continuación, AGR, y por último, los aceites con menores niveles de emisiones son AGC y ASC, los aceites crudos.

- $\quad$ En cuanto al grado de afectación que sufren las emisiones de $\mathrm{NO}_{x}$ con el refino, puede decirse que éste afecta para mal. Sobre todo en aceite de soja (en menor medida en girasol) se tiene un aumento considerable del nivel de emisiones.

- Viendo los valores críticos de confiabilidad que nos da el análisis ANOVA, puede concluirse que, comparando este análisis con los de emisiones de $\mathrm{CO}$ o con los de rendimiento, no se tiene una influencia tan claramente distinguible de una variable como en aquellos análisis. La razón para que esto ocurra puede venir dada por el hecho de que entre los grados de confiabilidad críticos que ofrecen las tres variables (las interacciones no son tampoco tan 
representativas) no exista uno dominante. De esta forma, pese a existir tendencia, la descripción resulta más complicada.

\subsubsection{Análisis a de las emisiones de NOxa P=12 BAR}

Se estudian a continuación las emisiones de $\mathrm{NO}_{x}$ (en ppm) medidas con el medidor Testo modelo 342-3. Se realizan los análisis a presión constante de 12 bar y a posición de admisión de aire constante.

Tabla 8.21 Matriz de emisiones de NOx

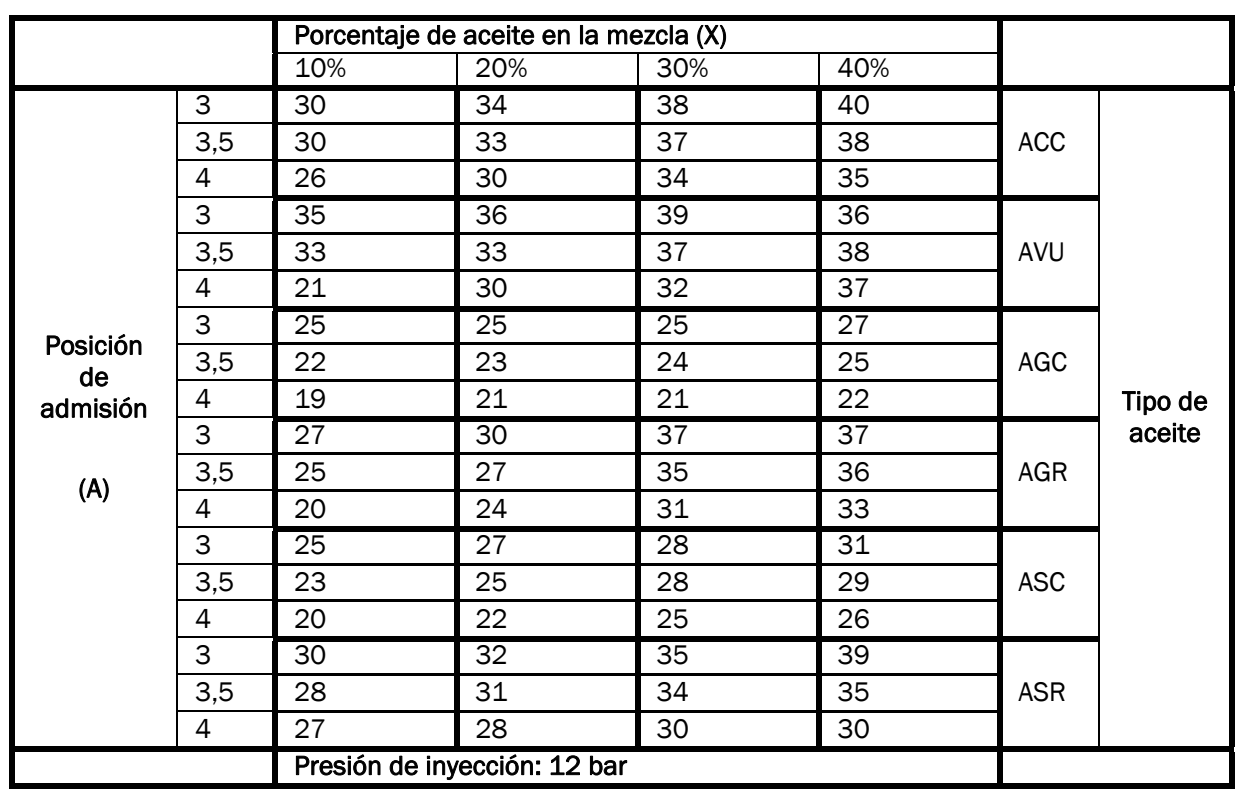

Con estos datos, lo primero que se plantea es un análisis de varianza (ANOVA), mediante el cual se determinará si las tres variables influyen (admisión del aire, tipo de aceite y porcentaje de aceite en peso) o no y de qué manera.

Tabla 8.22 Análisis ANOVA emisiones de NOx

\begin{tabular}{|l|l|l|l|l|l|l|l|}
\hline FACTOR & GdL & SS & MS & F & VC al 5\% & Influye & G. C. Crítica \\
\hline A & 2 & 335,02778 & 167,51389 & 66,43959 & 3,31583 & SI & $9,52435 \mathrm{E}-12$ \\
\hline T & 5 & 1141,73611 & 228,34722 & 90,56739 & 2,53355 & SI & $3,57465 \mathrm{E}-17$ \\
\hline X & 3 & 557,93056 & 185,97685 & 73,76239 & 2,92228 & SI & $6,02016 \mathrm{E}-14$ \\
\hline AxT & 10 & 11,47222 & 1,14722 & 0,45501 & 2,16458 & NO & 0,90550943 \\
\hline AxX & 6 & 9,86111 & 1,64352 & 0,65185 & 2,42052 & NO & 0,68833347 \\
\hline TxX & 15 & 110,31944 & 7,35463 & 2,91700 & 2,01480 & SI & 0,00610283 \\
\hline Error & 30 & 75,638889 & 2,521296 & & & & \\
\hline Total & 71 & 2241,986111 & & & & & \\
\hline
\end{tabular}


Vistos los resultados de la tabla ANOVA generada, se tiene que tanto la interacción AxT como la interacción AxX son rechazadas por el análisis ANOVA para un nivel de significación del 5\%. Los valores críticos de significación de ambas interacciones son valores bastante altos, de modo que la conclusión es que no afectan. En orden ascendente de importancia se tiene que la interacción TxX está en un nivel de confianza del 0,6\%, de modo que pasa el análisis con un margen amplio, siendo la variable menos influyente dentro de las que lo son.

El resto de variables significativas, que son las variables simples $A, X$ y $T$, tienen valores bastante alejados del valor de la confiabilidad del análisis: $10^{-10}(\%)$ la variable $\mathrm{A}, 1^{-12}(\%)$ la variable X y $10^{-15}(\%)$ la variable T.

La conclusión del análisis ANOVA tendrá que ser, primero, que las tres variables simples son variables influyentes con un alto nivel de confiabilidad. A priori la más importante deberá ser la variable T, a continuación la $\mathrm{X}$ y después la $\mathrm{A}$, pero sus niveles de confiabilidad son tan altos que se hará difícil distinguir cuál es la variable que más influye en según qué caso. Dentro de las interacciones, la más influyente será la TxX, mientras que el resto no aportarán significancia al análisis. 
Representaciones gráficas de las emisiones de NOx para el aceite de colza crudo $(\mathrm{T}=\mathrm{ACC})$

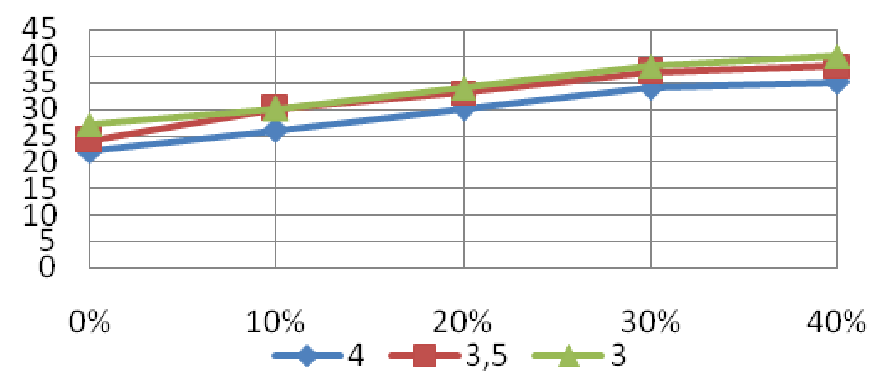

\begin{tabular}{|llllll|}
$\begin{array}{l}\text { ACC, } \\
P=12 \text { bar }\end{array}$ & $X=0 \%$ & $X=10 \%$ & $X=20 \%$ & $X=30 \%$ & $X=40 \%$ \\
\hline$A=3$ & 27 & 30 & 34 & 38 & 40 \\
\hline$A=3,5$ & 24 & 30 & 33 & 37 & 38 \\
\hline$A=4$ & 22 & 26 & 30 & 34 & 35 \\
\hline
\end{tabular}

Figura 8.154: Emisiones de NOx para para $\mathrm{P}=12$ bar y $\mathrm{T}=\mathrm{ACC}$

La tendencia es la siguiente: cuanto mayor es la posición de aire y menor el porcentaje de aceite en mezcla, menores son las emisiones. Tendencia igual en todas las posiciones. 
Representaciones gráficas de las emisiones de NOx para el aceite vegetal usado ( $\mathrm{T}=\mathrm{AVU}$ )

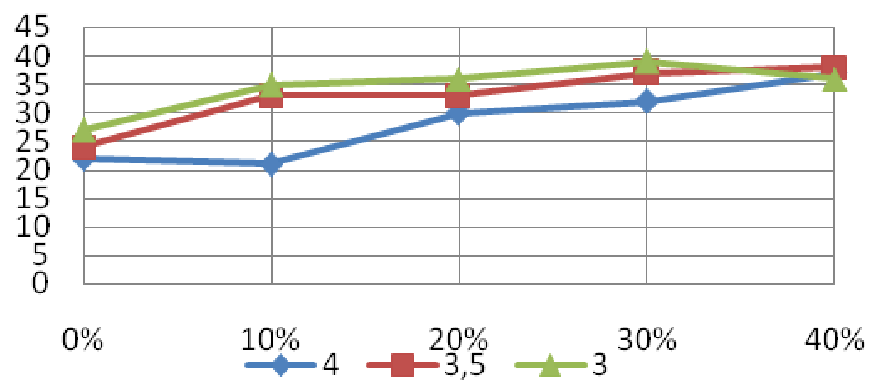

\begin{tabular}{|llllll|}
$\begin{array}{l}\text { AVU, } \\
P=12 \text { bar }\end{array}$ & $X=0 \%$ & $X=10 \%$ & $X=20 \%$ & $X=30 \%$ & $X=40 \%$ \\
\hline$A=3$ & 27 & 35 & 36 & 39 & 36 \\
\hline$A=3,5$ & 24 & 33 & 33 & 37 & 38 \\
\hline$A=4$ & 22 & 21 & 30 & 32 & 37 \\
\hline
\end{tabular}

Figura 8.155: Emisiones de NOx para para $\mathrm{P}=12$ bar y $\mathrm{T}=\mathrm{AVU}$

Misma tendencia: a mayor porcentaje de aceite y mayor posición de aire, menores emisiones, salvo para $X=40 \%$, porcentaje en el cual no se sigue la tendencia. Destaca el mínimo tan acusado que hay para $X=10 \%$ y $A=4$. 
Representaciones gráficas de las emisiones de NOx para el aceite de girasol crudo ( $T=A G C)$

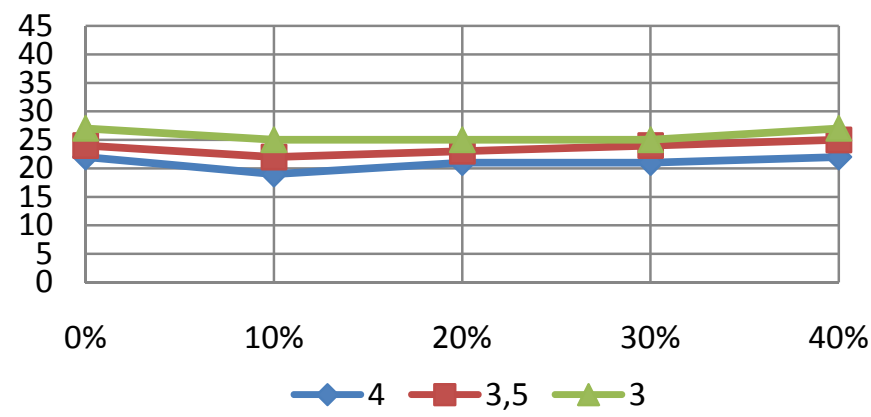

\begin{tabular}{|c|c|c|c|c|c|}
\hline $\begin{array}{l}\text { AGC, } \\
P=12 \text { bar }\end{array}$ & $X=0 \%$ & $x=10 \%$ & $X=20 \%$ & $X=30 \%$ & $X=40 \%$ \\
\hline$A=3$ & 27 & 25 & 25 & 25 & 27 \\
\hline$A=3,5$ & 24 & 22 & 23 & 24 & 25 \\
\hline$A=4$ & 22 & 19 & 21 & 21 & 22 \\
\hline
\end{tabular}

Figura 8.156: Emisiones de NOx para $\mathrm{P}=12$ bar y $\mathrm{T}=\mathrm{AGC}$

Este aceite sigue la tendencia de los anteriores pero con un nivel de emisiones mucho más constante que en aquellos. 
Representaciones gráficas de las emisiones de NOx para el aceite de girasol refinado $(T=A G R)$

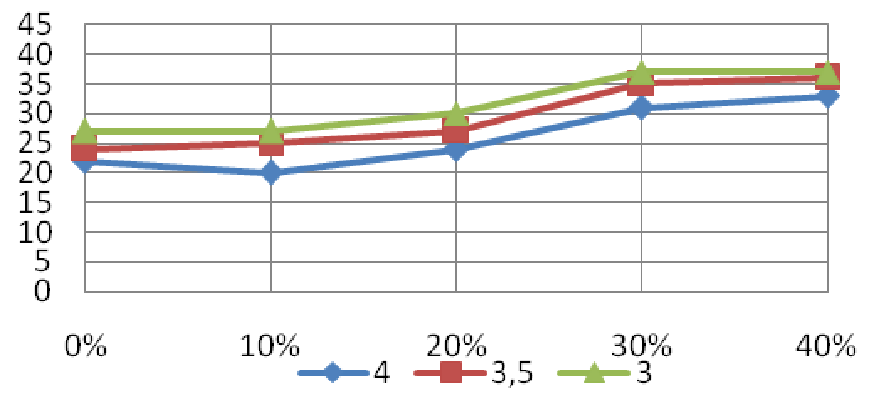

\begin{tabular}{|llllll|}
$\begin{array}{l}\text { AGR, } \\
P=12 \text { bar }\end{array}$ & $X=0 \%$ & $X=10 \%$ & $X=20 \%$ & $X=30 \%$ & $X=40 \%$ \\
\hline$A=3$ & 27 & 27 & 30 & 37 & 37 \\
\hline$A=3,5$ & 24 & 25 & 27 & 35 & 36 \\
\hline$A=4$ & 22 & 20 & 24 & 31 & 33 \\
\hline
\end{tabular}

Figura 8.157: Emisiones de NOx para $\mathrm{P}=12$ bar y $\mathrm{T}=\mathrm{AGR}$

Misma tendencia que las anteriores, tendencia más acusada que en el aceite crudo anterior, y con mayores emisiones: el refino provoca ese efecto, sobre todo con altos niveles de participación en la mezcla. 
Representaciones gráficas de las emisiones de NOx para el aceite de soja crudo ( $\mathrm{T}=\mathrm{ASC}$ )

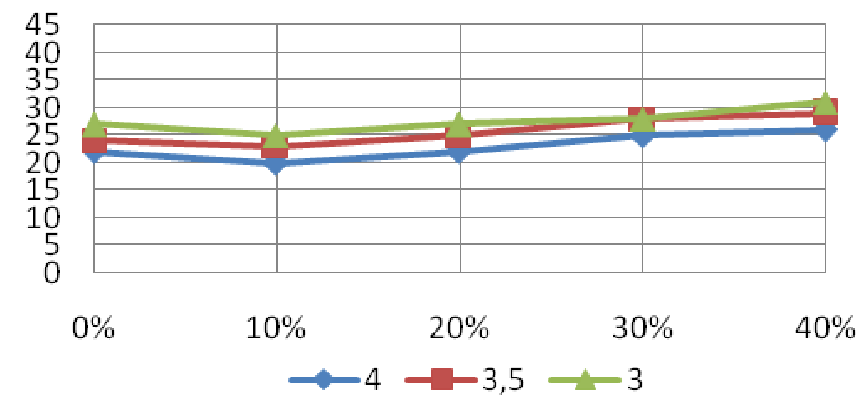

\begin{tabular}{|llllll|}
$\begin{array}{l}\text { ASC, } \\
P=12 \text { bar }\end{array}$ & $X=0 \%$ & $X=10 \%$ & $X=20 \%$ & $X=30 \%$ & $X=40 \%$ \\
\hline$A=3$ & 27 & 25 & 27 & 28 & 31 \\
\hline$A=3,5$ & 24 & 23 & 25 & 28 & 29 \\
\hline$A=4$ & 22 & 20 & 22 & 25 & 26 \\
\hline
\end{tabular}

Figura 8.158: Emisiones de NOx para $\mathrm{P}=12$ bar y $\mathrm{T}=\mathrm{ASC}$

De nuevo la misma tendencia: mayores emisiones a mayor posición de admisión de aire y a mayor porcentaje en mezcla. 
Representaciones gráficas de las emisiones de NOx para el aceite de soja refinado $(\mathrm{T}=\mathrm{ASR})$

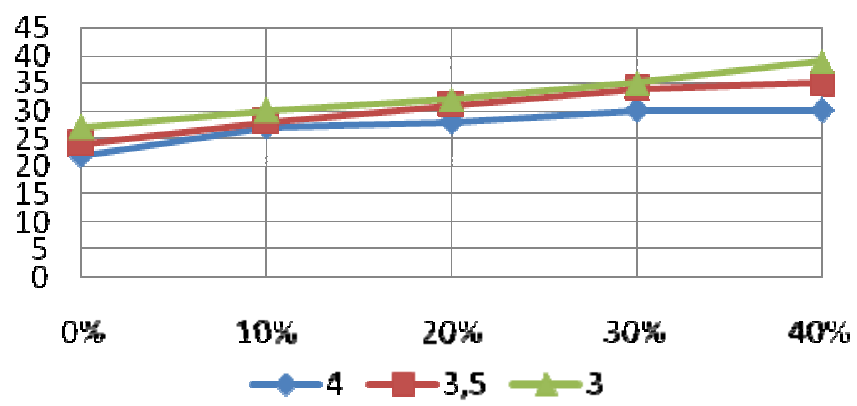

\begin{tabular}{|llllll|}
$\begin{array}{l}\text { ASR, } \\
P=12 \text { bar }\end{array}$ & $X=0 \%$ & $X=10 \%$ & $X=20 \%$ & $X=30 \%$ & $X=40 \%$ \\
\hline$A=3$ & 27 & 30 & 32 & 35 & 39 \\
\hline$A=3,5$ & 24 & 28 & 31 & 34 & 35 \\
\hline$A=4$ & 22 & 27 & 28 & 30 & 30 \\
\hline
\end{tabular}

Figura 8.159: Emisiones de NOx para $\mathrm{P}=12$ bar y $\mathrm{T}=\mathrm{ASR}$

Como ocurría en el aceite de girasol, aún permaneciendo casi inalterable la tendencia, el efecto del refino ha sido aumentar los niveles de emisiones entre 5 y 7 ppm del aceite sin refinar al refinado. 
Representaciones gráficas de las emisiones de NOx para la posición de aire $A=3$

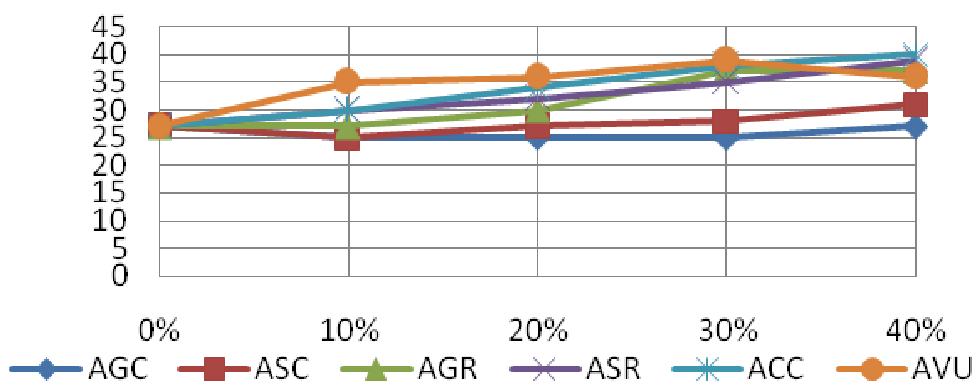

\begin{tabular}{|llllll|}
$\begin{array}{l}\text { A=3, } \\
P=12 \text { bar }\end{array}$ & $X=0 \%$ & $X=10 \%$ & $X=20 \%$ & $X=30 \%$ & $X=40 \%$ \\
\hline ACC & 27 & 30 & 34 & 38 & 40 \\
\hline AVU & 27 & 35 & 36 & 39 & 36 \\
\hline AGC & 27 & 25 & 25 & 25 & 27 \\
\hline AGR & 27 & 27 & 30 & 37 & 37 \\
\hline ASC & 27 & 25 & 27 & 28 & 31 \\
\hline ASR & 27 & 30 & 32 & 35 & 39 \\
\hline
\end{tabular}

Figura 8.160: Emisiones de NOx para $\mathrm{P}=12$ bar y $\mathrm{A}=3$

Ambos aceites crudos, girasol y soja, ofrecen los mejores niveles de emisiones del estudio (algo mejor el de girasol). Salvo dos picos ofrecidos por AVU y AGR en X=30\%, el resto de aceites ofrecen todos la tendencia al alza cuando aumenta el porcentaje de aceite en mezcla. La tendencia más clara se aprecia en el ACC, con un aumento casi lineal de las emisiones. El AGR es el tercer mejor comportamiento, mientras que los otros tres (AVU, AC y ASR) ofrecen los peores datos, siendo bastante similares entre ellos. 
Representaciones gráficas de las emisiones de NOx para la posición de aire $A=3,5$

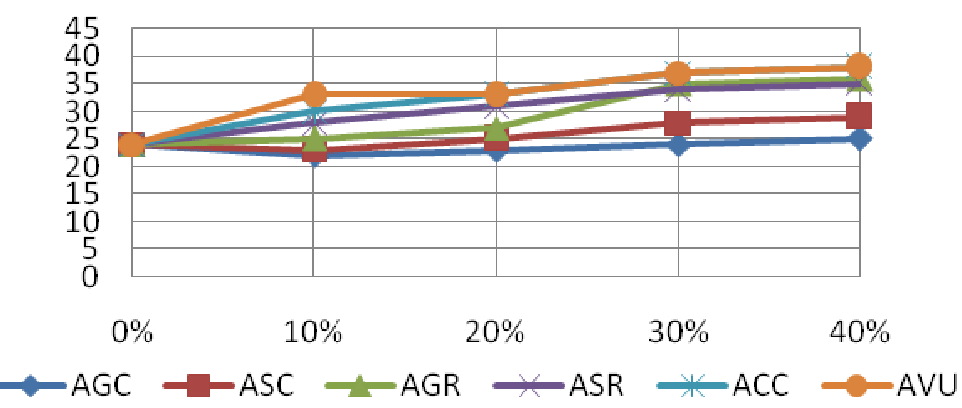

\begin{tabular}{|llllll|}
$\begin{array}{l}\text { A=3,5, } \\
P=12 \text { bar }\end{array}$ & $X=0 \%$ & $X=10 \%$ & $X=20 \%$ & $X=30 \%$ & $X=40 \%$ \\
\hline ACC & 24 & 30 & 33 & 37 & 38 \\
\hline AVU & 24 & 33 & 33 & 37 & 38 \\
\hline AGC & 24 & 22 & 23 & 24 & 25 \\
\hline AGR & 24 & 25 & 27 & 35 & 36 \\
\hline ASC & 24 & 23 & 25 & 28 & 29 \\
\hline ASR & 24 & 28 & 31 & 34 & 35 \\
\hline
\end{tabular}

Figura 8.161: Emisiones de NOx para $\mathrm{P}=12$ bar y $\mathrm{A}=3,5$

El AGC ofrece los menores niveles de emisiones para todos los porcentajes de aceite en mezcla. A continuación el ASC y el AGR. Estos tres aceites, tal y como se vio en el anterior estudio, son los que para esta presión de inyección ofrecen las menores emisiones (falta por validar esta teoría con el último ensayo para $A=4$ ). EL AGR, sin embargo, da buenos valores para porcentajes pequeños de participación en la mezcla, pero para valores altos da valores tan malos como los que más. 
Representaciones gráficas de las emisiones de NOx para la posición de aire $A=4$

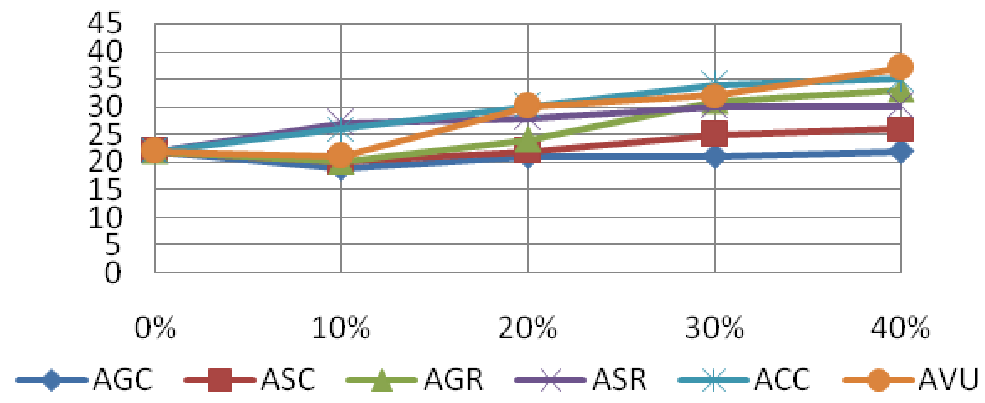

\begin{tabular}{|llllll|}
$\begin{array}{l}\text { A=4, } \\
P=12 \text { bar }\end{array}$ & $X=0 \%$ & $X=10 \%$ & $X=20 \%$ & $X=30 \%$ & $X=40 \%$ \\
\hline ACC & 22 & 26 & 30 & 34 & 35 \\
\hline AVU & 22 & 21 & 30 & 32 & 37 \\
\hline AGC & 22 & 19 & 21 & 21 & 22 \\
\hline AGR & 22 & 20 & 24 & 31 & 33 \\
\hline ASC & 22 & 20 & 22 & 25 & 26 \\
\hline ASR & 22 & 27 & 28 & 30 & 30 \\
\hline
\end{tabular}

Figura 8.162: Emisiones de NOx para $\mathrm{P}=12$ bar y $\mathrm{A}=4$

El nivel de las emisiones cae para todos los aceites del estudio cuando aumenta la posición de admisión de aire. Como se adelantaba en la gráfica anterior, la tendencia es que los aceites de girasol y el de soja crudo ofrecen los menores niveles de emisiones. El AVU también ofrece un buen resultado para $X=10 \%$, pero se trata de un error aislado o un error de medida casi con total seguridad, ya que después da los mayores niveles de emisiones de toda la tabla. Es destacable también que el ASR tiene menos emisiones para $X$ altas que el AGR, sin embargo para $X$ bajas es mejor este último. 
Representaciones gráficas de las emisiones de NOx para el porcentaje en peso de aceite $X=10 \%$

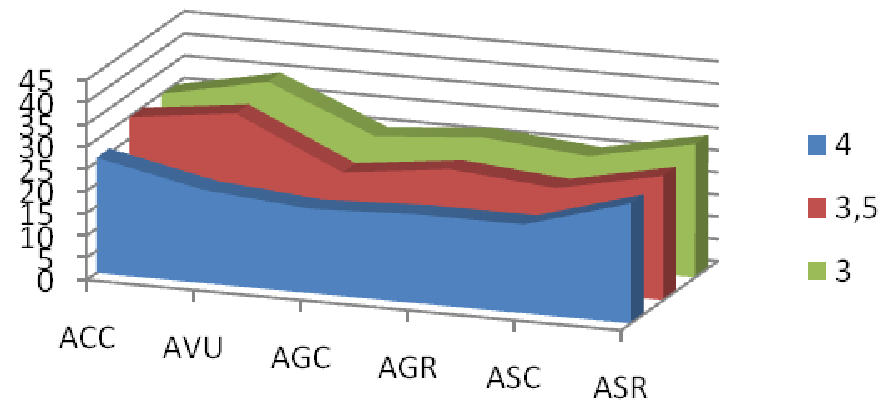

\begin{tabular}{|lllllll|}
\hline $\begin{array}{l}X=10 \%, \\
P=12 \text { bar }\end{array}$ & ACC & AVU & AGC & AGR & ASC & ASR \\
\hline$A=3$ & 30 & 35 & 25 & 27 & 25 & 30 \\
\hline$A=3,5$ & 30 & 33 & 22 & 25 & 23 & 28 \\
\hline$A=4$ & 26 & 21 & 19 & 20 & 20 & 27 \\
\hline
\end{tabular}

Figura 8.163: Emisiones de NOx para $\mathrm{P}=12$ bar y $\mathrm{X}=10 \%$

La primera gráfica muestra que para todas las A's tanto AGC, como AGR y ASC tienen menores niveles de emisiones, amén de que la posición de admisión del aire resulta determinante en los resultados de emisiones. Todos los aceites obtienen sus mínimos para $A=4$, y conociendo de las gráficas anteriores que los menores niveles de emisiones se dan para $X=10 \%$, entonces estos resultados son los mejores del estudio $P=12$ bar.

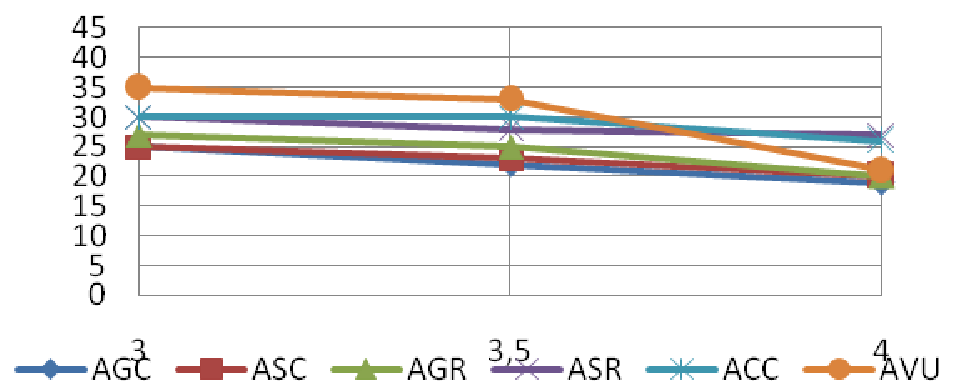

Figura 8.164: Emisiones de NOx para $\mathrm{P}=12$ bar y $\mathrm{X}=10 \%$ 
Representaciones gráficas de las emisiones de NOx para el porcentaje en peso de aceite $X=20 \%$

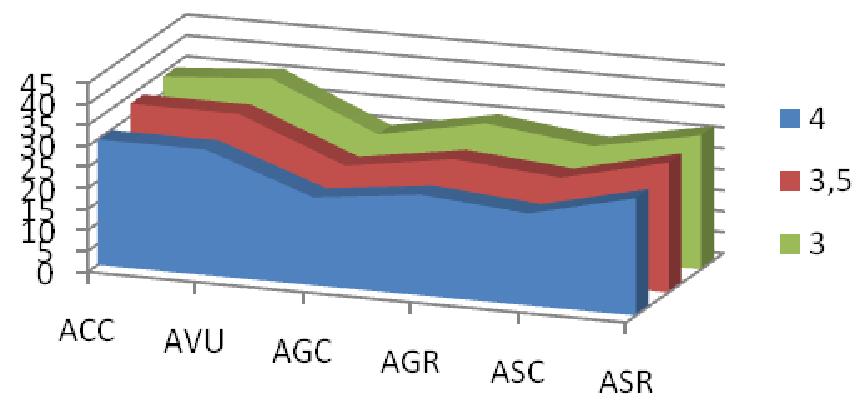

\begin{tabular}{|lllllll|}
\hline $\begin{array}{l}X=20 \%, \\
P=12 \text { bar }\end{array}$ & ACC & AVU & AGC & AGR & ASC & ASR \\
\hline$A=3$ & 34 & 36 & 25 & 30 & 27 & 32 \\
\hline$A=3,5$ & 33 & 33 & 23 & 27 & 25 & 31 \\
\hline$A=4$ & 30 & 30 & 21 & 24 & 22 & 28 \\
\hline
\end{tabular}

Figura 8.165: Emisiones de NOx para $\mathrm{P}=12$ bar y $\mathrm{X}=20 \%$

La primera gráfica muestra una tendencia más marcada en el comportamiento de las emisiones de $\mathrm{NO}_{x}$. El mejor comportamiento lo vuelve a dar el AGC, teniendo todas las gráficas un valle en dicho aceite. Después: ASC, AGR, ASR, ACC y AVU. Con respecto a $X=10 \%$, se aprecia un aumento en las emisiones de entre 2 y $4 \mathrm{ppm}$. La segunda gráfica vuelve a mostrar la tendencia que muestran todos los aceites con respecto a la posición de admisión de aire.

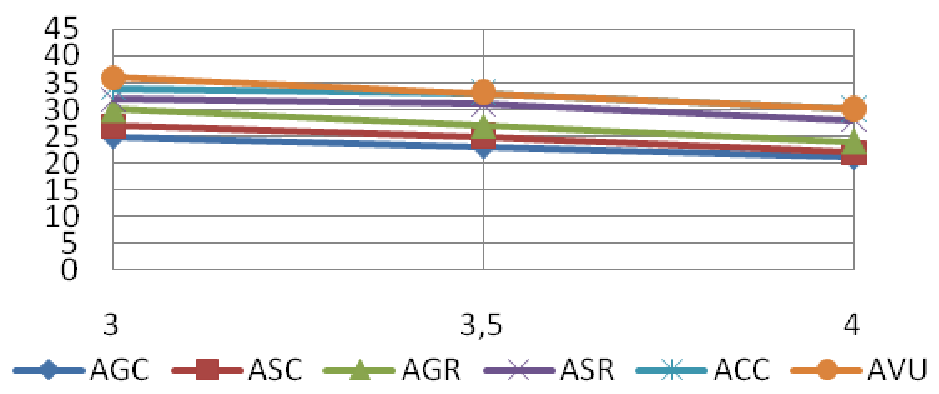

Figura 8.166: Emisiones de NOx para $\mathrm{P}=12$ bar y $\mathrm{X}=20 \%$ 
Representaciones gráficas de las emisiones de NOx para el porcentaje en peso de aceite $X=30 \%$

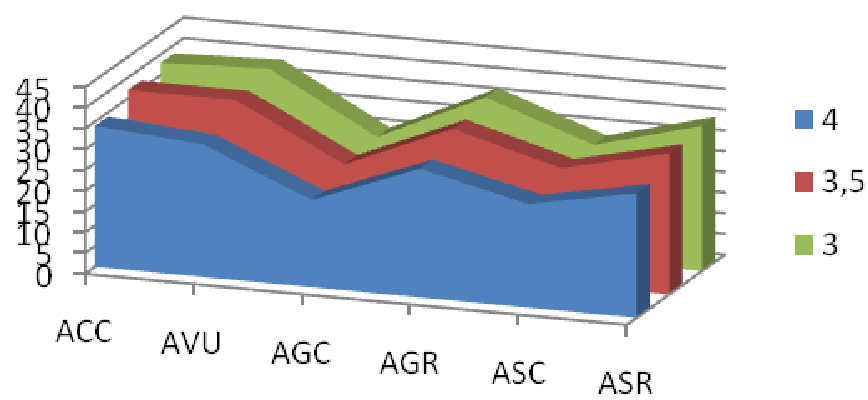

\begin{tabular}{|lllllll|}
\hline $\begin{array}{l}X=30 \%, \\
P=12 \text { bar }\end{array}$ & ACC & AVU & AGC & AGR & ASC & ASR \\
\hline$A=3$ & 38 & 39 & 25 & 37 & 28 & 35 \\
\hline$A=3,5$ & 37 & 37 & 24 & 35 & 28 & 34 \\
\hline$A=4$ & 34 & 32 & 21 & 31 & 25 & 30 \\
\hline
\end{tabular}

Figura 8.167: Emisiones de NOx para para $\mathrm{P}=12$ bar $\mathrm{y} \mathrm{X}=30 \%$

Con respecto a $X=20 \%$, los picos y valles de la primera gráfica vuelven a remarcarse, siendo más alta la diferencia entre los máximos y mínimos. Destaca que las emisiones de AGC apenas han variado: el resto lo han hecho en una cantidad entre las 3 y las $5 \mathrm{ppm}$. En cuanto a la dependencia con $A$, parece más marcada entre la posición intermedia $A=3,5$ y $A=4$ que entre $A=3$ y $A=3,5$. Este hecho es observable en la segunda gráfica.

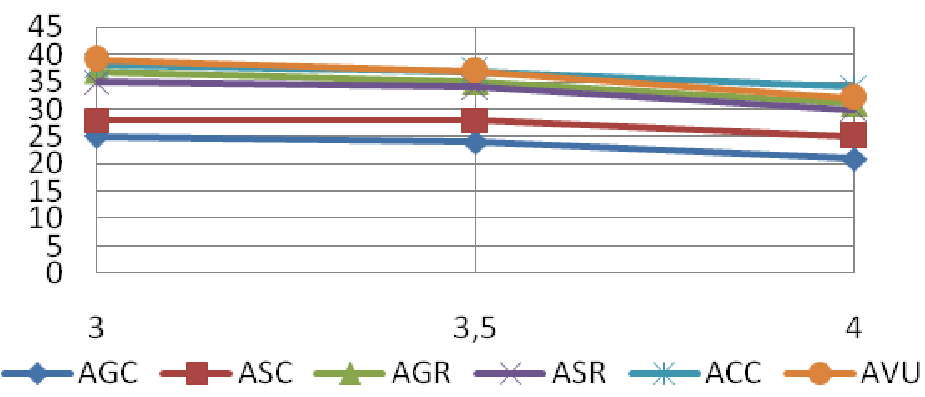

Figura 8.168: Emisiones de NOx para $\mathrm{P}=12$ bar y $\mathrm{X}=30 \%$

Representaciones gráficas de las emisiones de NOx para el porcentaje en peso de aceite $X=40 \%$ 


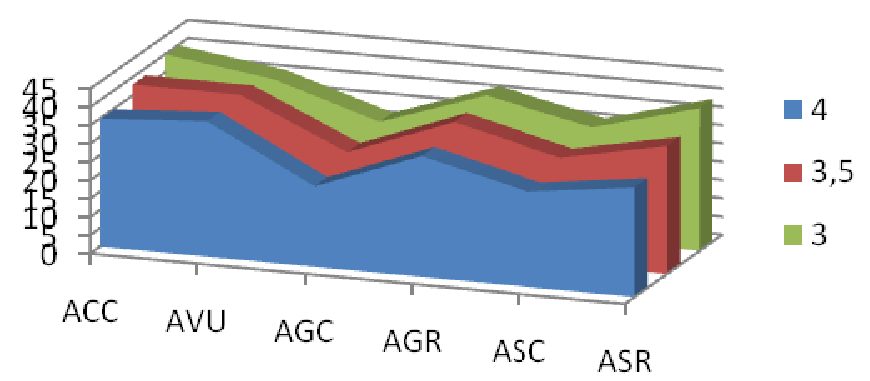

\begin{tabular}{|lllllll|}
\hline $\begin{array}{l}X=40 \%, \\
P=12 \text { bar }\end{array}$ & ACC & AVU & AGC & AGR & ASC & ASR \\
\hline$A=3$ & 40 & 36 & 27 & 37 & 31 & 39 \\
\hline$A=3,5$ & 38 & 38 & 25 & 36 & 29 & 35 \\
\hline$A=4$ & 35 & 37 & 22 & 33 & 26 & 30 \\
\hline
\end{tabular}

Figura 8.169: Emisiones de NOx para $\mathrm{P}=12$ bar y $\mathrm{X}=40 \%$

La diferencia con respecto al $\mathrm{X}$ anterior no parece a priori tan abultada como en los estudios anteriores: entre las 2 y 3 ppm. De nuevo las menores emisiones las da el AGC, tendencia que se ve clarísima en la gráfica. Se puede ver una tendencia que se empezó a ver en el estudio de $X=30 \%$ : el AGR da bastantes más emisiones que el ASC para estos porcentajes. Queda por tanto demostrada la influencia del refino del aceite en las emisiones de $\mathrm{NO}_{\mathrm{x}}$. AC, AVU, AGR y ASR muestran niveles de emisiones bastante mayores a los otros dos tipos de aceite.

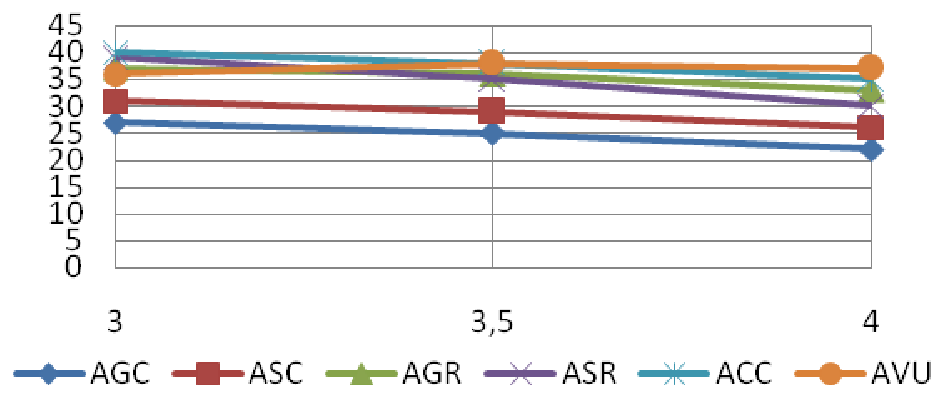

Figura 8.170: Emisiones de NOx para para $\mathrm{P}=12$ bar y $\mathrm{X}=40 \%$ 


\subsubsection{Conclusiones}

El análisis tanto del ANOVA como de las representaciones gráficas da como conclusiones las siguientes:

- $\quad$ Como predijo el análisis ANOVA, el tipo de aceite (variable T) es la variable más determinante del estudio, dando unos resultados muy diferenciados unos aceites y otros.

- La variable X, porcentaje de aceite en mezcla, es la segunda variable en orden de importancia según el ANOVA. Esto ha quedado demostrado en las gráficas realizadas, siendo la tendencia sin ninguna duda la de aumento de las emisiones de $\mathrm{NO}_{\mathrm{x}}$ al aumentar el contenido de aceite en la mezcla.

- Por último, la variable $\mathrm{A}$, posición de admisión del aire, influye también de manera bastante evidente, ya que los mínimos conseguidos son todos con la posición $A=4$, la mayor.

- $\quad$ El mejor aceite del estudio en cuanto a emisiones de $\mathrm{NO}_{x}$ es sin duda el AGC, y después el ASC, ambos aceites crudos, lo cual indica que el tratamiento del refino empeora el comportamiento de las emisiones de $\mathrm{NO}_{\mathrm{x}}$.

- Puede concluirse, por tanto, que las mejores condiciones observadas para evitar las emisiones de $\mathrm{NO}_{x}$ son bajos porcentajes de aceite en mezcla, posición de admisión de aire alta y aceite crudo.

- $\quad$ El aceite de colza (ACC) y el aceite vegetal usado (AVU) son, gráfica a gráfica y tabla a tabla, los peores indicados para tener bajos niveles de emisiones.

- $\quad$ Como en el análisis a $\mathrm{P}=10$ bar, y comparando este análisis con los realizados para las emisiones de $\mathrm{CO}$ o el rendimiento, puede decirse que no existe una variable que domine a las demás en cuanto a importancia se refiere. En este estudio en concreto, son las tres variables controladas las que marcan la influencia de una manera difícil de describir, ya que todas tienen un grado de significancia alto. 


\subsubsection{Análisis de las emisiones de NOxa P=14 BAR}

Se estudian a continuación las emisiones de $\mathrm{NO}_{x}$ (en ppm) medidas con el medidor Testo modelo 342-3. Se realizan los análisis a presión constante de 14 bar y a posición de admisión de aire constante.

Tabla 8.23 Matriz de resultados de emisiones de NOx

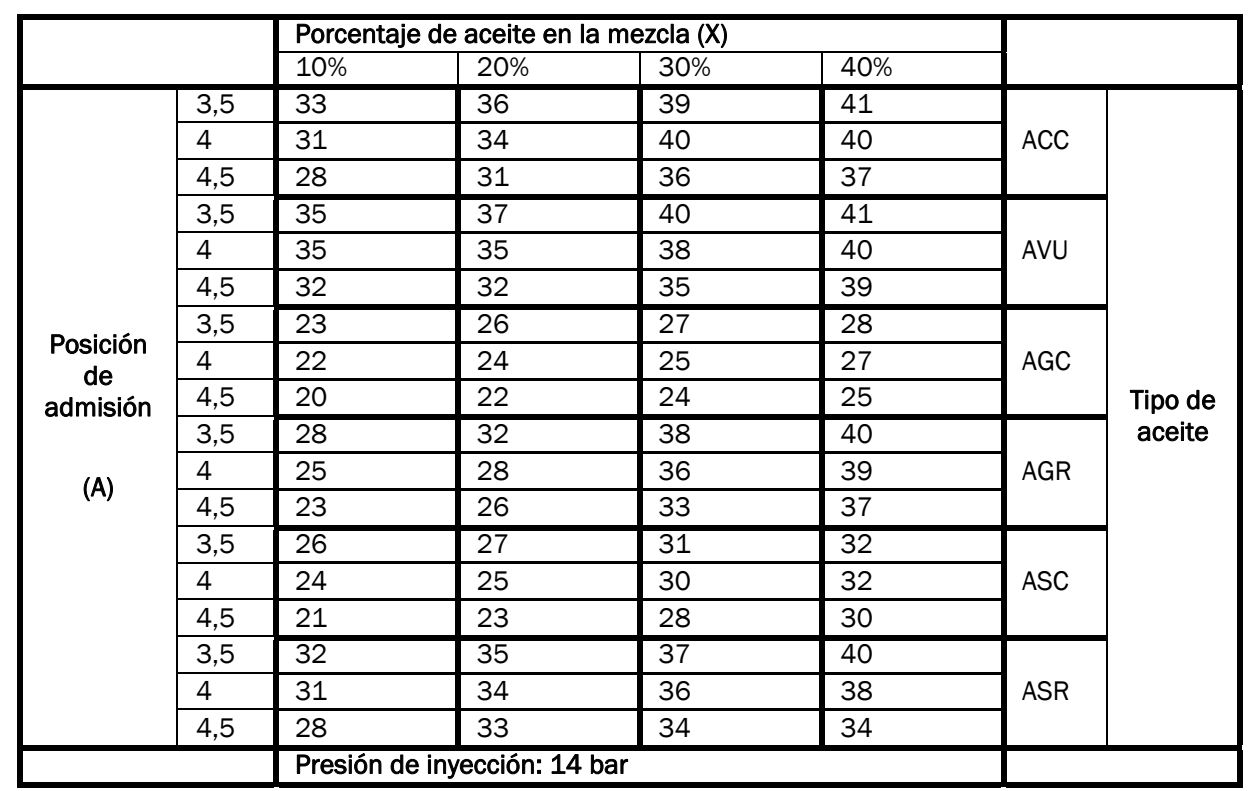

Con estos datos, lo primero que se plantea es un análisis de varianza (ANOVA), mediante el cual se determinará si las tres variables influyen (admisión del aire, tipo de aceite y porcentaje de aceite en peso) o no y de qué manera.

Tabla 8.24 Análisis ANOVA

\begin{tabular}{|l|l|l|l|l|l|l|l|}
\hline FACTOR & GdL & SS & MS & F & VC al 5\% & Influye & G. C. Crítica \\
\hline A & 2 & 183,861111 & 91,930556 & 170,30017 & 3,31583 & SI & $4,1998 \mathrm{E}-17$ \\
\hline T & 5 & 1401,111111 & 280,222222 & 519,10806 & 2,53355 & SI & $3,5812 \mathrm{E}-28$ \\
\hline X & 3 & 694,111111 & 231,370370 & 428,61063 & 2,92228 & SI & $1,0357 \mathrm{E}-24$ \\
\hline AxT & 10 & 5,472222 & 0,547222 & 1,01372 & 2,16458 & NO & 0,45508473 \\
\hline AxX & 6 & 3,138889 & 0,523148 & 0,96913 & 2,42052 & NO & 0,46273734 \\
\hline TxX & 15 & 106,555556 & 7,103704 & 13,15952 & 2,01480 & SI & $2,6395 \mathrm{E}-09$ \\
\hline Error & 30 & 16,194444 & 0,539815 & & & & \\
\hline Total & 71 & 2410,444444 & & & & & \\
\hline
\end{tabular}


Vistos los resultados de la tabla ANOVA generada, se tiene que tanto la interacción AxT como la interacción AxX son rechazadas por el análisis ANOVA para un nivel de significación del 5\%. Los valores críticos de significación de ambas interacciones son valores altos, de modo que la conclusión es que no afectan.

En este caso se tiene que la interacción TxX sí influye, y con un grado de confiabilidad crítico del orden de $10^{-7} \%$, el cual está bastante bien teniendo en cuenta que se trata de una interacción. Sin embargo, como se va a comentar ahora, los valores de confiabilidad críticos mostrados por el resto de variables (las simples) hacen que la "influencia absoluta" que a priori parecía importante de la interacción, en términos relativos quedará en clara muy por debajo.

La variable más influyente del estudio es el tipo de aceite, T, con una grado de confiabilidad crítico del orden de 10-26 \%. A continuación en orden de importancia estaría el porcentaje de aceite en mezcla $(X)$, con un grado de confiabilidad crítico del orden de 10-22 \%. Por último, se tiene que el factor posición de admisión del aire (A) tiene un grado de confiabilidad crítico del orden de 10-15\%.

La conclusión del análisis ANOVA realizado a los datos del análisis a $\mathrm{P}=14$ bar es que la variable tipo de aceite es, si cabe, más importante que en cualquier análisis que se haya visto hasta ahora. El grado de confiabilidad crítico obtenido es ínfimo. Destaca la influencia de la variable $X$ también, y también la de la variable A: a priori se tendrán caracteres muy marcados dentro de las gráficas, pero al ser las tres variables principales tan significativas, resultará difícil una descripción exacta de estos.

Se representan a continuación los valores obtenidos para la variable emisiones de NOx en función de las variables A, X y T. 
Representaciones gráficas de las emisiones de NOx para el aceite de colza crudo $(\mathrm{T}=\mathrm{ACC})$

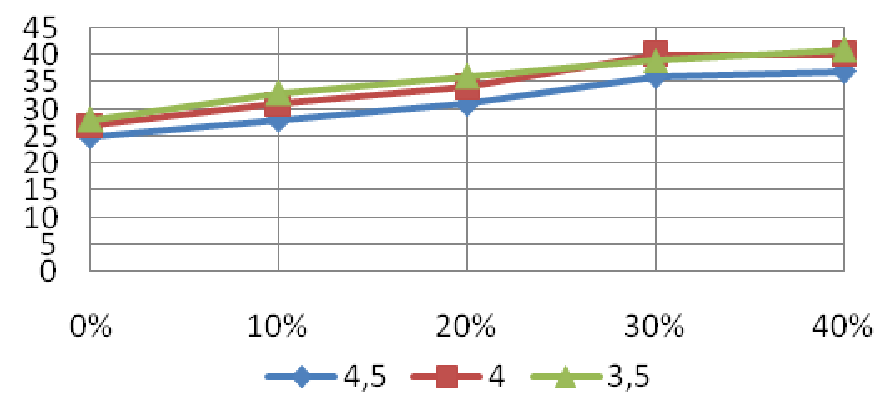

\begin{tabular}{|llllll|}
$\begin{array}{l}\text { ACC, } \\
P=14 \text { bar }\end{array}$ & $X=0 \%$ & $X=10 \%$ & $X=20 \%$ & $X=30 \%$ & $X=40 \%$ \\
\hline$A=3,5$ & 28 & 33 & 36 & 39 & 41 \\
\hline$A=4$ & 27 & 31 & 34 & 40 & 40 \\
\hline$A=4,5$ & 25 & 28 & 31 & 36 & 37 \\
\hline
\end{tabular}

Figura 8.171: Emisiones de NOx para 14 bar y ACC

Se observa claramente que el aumento de porcentaje de aceite en la mezcla provoca un aumento de las emisiones. Además, se ve la influencia de la posición del aire, de modo que para $A=4,5$ las emisiones son menores que para el resto de posiciones. 
Representaciones gráficas de las emisiones de NOx para el aceite vegetal usado ( $\mathrm{T}=\mathrm{AVU}$ )

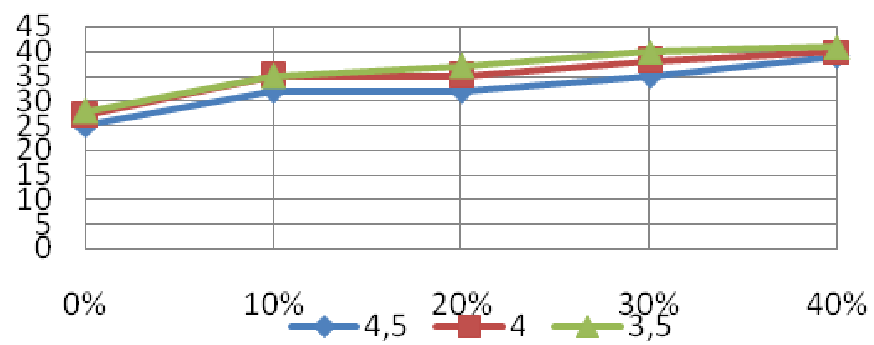

\begin{tabular}{|llllll|}
$\begin{array}{l}\text { AVU, } \\
P=14 \text { bar }\end{array}$ & $X=0 \%$ & $X=10 \%$ & $X=20 \%$ & $X=30 \%$ & $X=40 \%$ \\
\hline$A=3,5$ & 28 & 35 & 37 & 40 & 41 \\
\hline$A=4$ & 27 & 35 & 35 & 38 & 40 \\
\hline$A=4,5$ & 25 & 32 & 32 & 35 & 39 \\
\hline
\end{tabular}

Figura 8.172: Emisiones de NOx para 14 bar y AVU

Mayores emisiones cuanto mayor es el porcentaje de aceite en la mezcla y menor cuanto mayor es la posición de admisión de aire. Tendencia uniforme. 
Representaciones gráficas de las emisiones de NOx para el aceite de girasol crudo ( $T=A G C)$

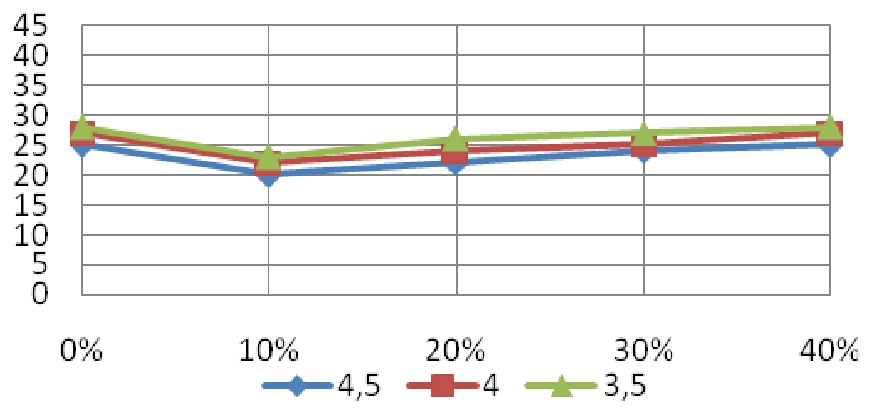

\begin{tabular}{|llllll|}
$\begin{array}{l}\text { AGC, } \\
P=14 \text { bar }\end{array}$ & $X=0 \%$ & $X=10 \%$ & $X=20 \%$ & $X=30 \%$ & $X=40 \%$ \\
\hline$A=3,5$ & 28 & 23 & 26 & 27 & 28 \\
\hline$A=4$ & 27 & 22 & 24 & 25 & 27 \\
\hline$A=4,5$ & 25 & 20 & 22 & 24 & 25 \\
\hline
\end{tabular}

Figura 8.173: Emisiones de NOx para 14 bar y AGC

Misma tendencia que las dos anteriores, pero con valores menores. En los dos análisis anteriores, el comportamiento del AGC con las emisiones de NOx era peor que éste. 
Representaciones gráficas de las emisiones de NOx para el aceite de girasol refinado $(T=A G R)$

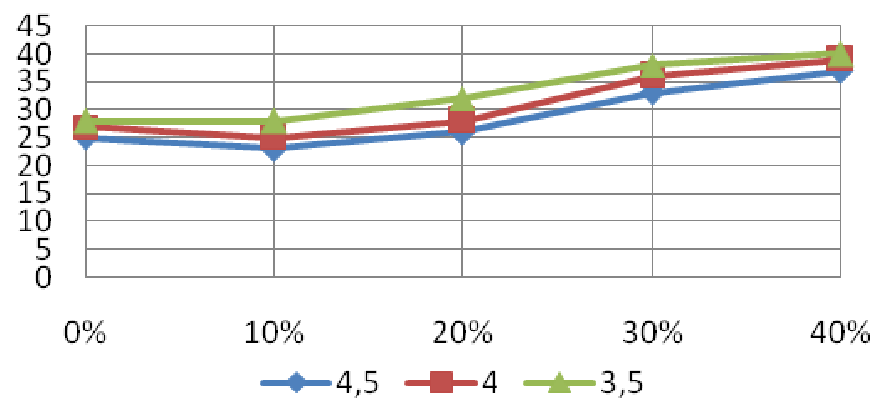

\begin{tabular}{|llllll|}
$\begin{array}{l}\text { AGR, } \\
P=14 \text { bar }\end{array}$ & $X=0 \%$ & $X=10 \%$ & $X=20 \%$ & $X=30 \%$ & $X=40 \%$ \\
\hline$A=3,5$ & 28 & 28 & 32 & 38 & 40 \\
\hline$A=4$ & 27 & 25 & 28 & 36 & 39 \\
\hline$A=4,5$ & 25 & 23 & 26 & 33 & 37 \\
\hline
\end{tabular}

Figura 8.174: Emisiones de NOx para 14 bar y AGR

Valores más altos en las emisiones de $\mathrm{NO}_{x}$ en el AGR que en el AGC. La tendencia al alza crece más de lo esperado para $X>20 \%$. Comportamiento esperado en cuanto a la dependencia de A. 
Representaciones gráficas de las emisiones de NOx para el aceite de soja crudo ( $\mathrm{T}=\mathrm{ASC}$ )

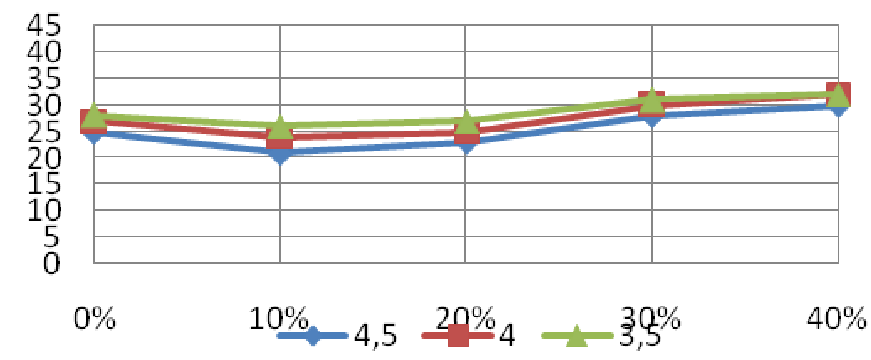

\begin{tabular}{|llllll|}
\hline $\begin{array}{l}\text { ASC, } \\
P=14 \text { bar }\end{array}$ & $X=0 \%$ & $X=10 \%$ & $X=20 \%$ & $X=30 \%$ & $X=40 \%$ \\
\hline$A=3,5$ & 28 & 26 & 27 & 31 & 32 \\
\hline$A=4$ & 27 & 24 & 25 & 30 & 32 \\
\hline$A=4,5$ & 25 & 21 & 23 & 28 & 30 \\
\hline
\end{tabular}

Figura 8.175: Emisiones de NOx para 14 bar y ASC

El ASC, como se vio en los análisis para otras presiones, registra buenos valores de emisiones, pero siempre un escalón por debajo del AGC. EI comportamiento es el mismo que se describió para los aceites anteriores. 
Representaciones gráficas de las emisiones de NOx para el aceite de soja refinado $(\mathrm{T}=\mathrm{ASR})$

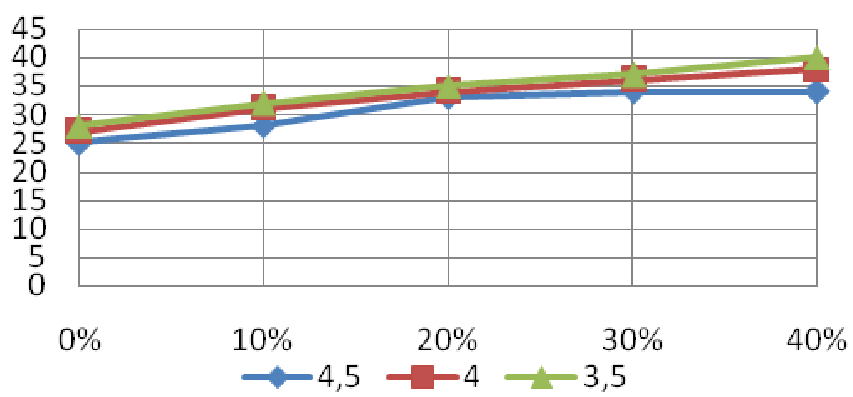

\begin{tabular}{|llllll|}
\hline $\begin{array}{l}\text { ASR, } \\
P=14 \text { bar }\end{array}$ & $X=0 \%$ & $X=10 \%$ & $X=20 \%$ & $X=30 \%$ & $X=40 \%$ \\
\hline$A=3,5$ & 28 & 32 & 35 & 37 & 40 \\
\hline$A=4$ & 27 & 31 & 34 & 36 & 38 \\
\hline$A=4,5$ & 25 & 28 & 33 & 34 & 34 \\
\hline
\end{tabular}

Figura 8.176: Emisiones de NOx para 14 bar y ASR

La tendencia es la explicada en los gráficos anteriores. Los valores que da son bastante más altos que los del ASC, de modo que queda comprobado el comportamiento anteriormente mencionado de que el refino provoca un aumento considerable de las emisiones de $\mathrm{NO}_{\mathrm{x}}$. 
Representaciones gráficas de las emisiones de NOx para la admisión de aire $A=3,5$

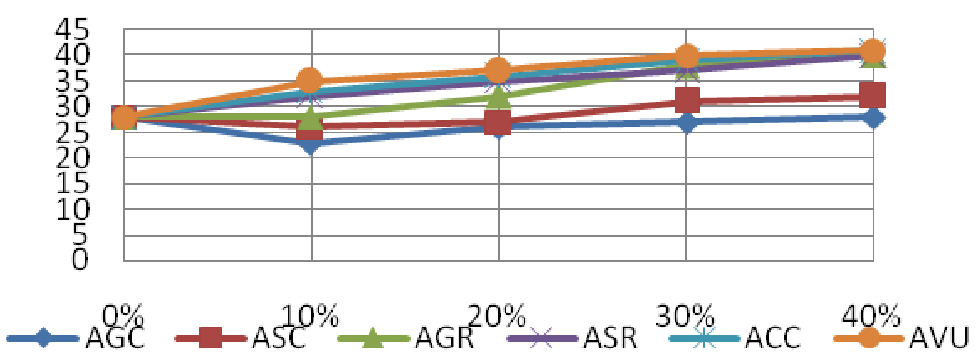

\begin{tabular}{|llllll|}
$\begin{array}{l}\text { A=3,5, } \\
P=14 \text { bar }\end{array}$ & $X=0 \%$ & $X=10 \%$ & $X=20 \%$ & $X=30 \%$ & $X=40 \%$ \\
\hline ACC & 28 & 33 & 36 & 39 & 41 \\
\hline AVU & 28 & 35 & 37 & 40 & 41 \\
\hline AGC & 28 & 23 & 26 & 27 & 28 \\
\hline AGR & 28 & 28 & 32 & 38 & 40 \\
\hline ASC & 28 & 26 & 27 & 31 & 32 \\
\hline ASR & 28 & 32 & 35 & 37 & 40 \\
\hline
\end{tabular}

Figura 8.178: Emisiones de NOx para 14 bar y $A=3,5$

El análisis para una posición de admisión fija muestra un comportamiento al alza de las emisiones con respecto a la variable X. En el gráfico se observa que AVU, ACC y ASR están un nivel por encima del resto. Además, puede verse como para $X>20 \%$, el AGR también muestra unos niveles similares a los anteriores. Los dos aceites crudos dan los mejores resultados, siendo mejores los del aceite de girasol que los del aceite de soja. 
Representaciones gráficas de las emisiones de NOx para la admisión de aire $A=4$

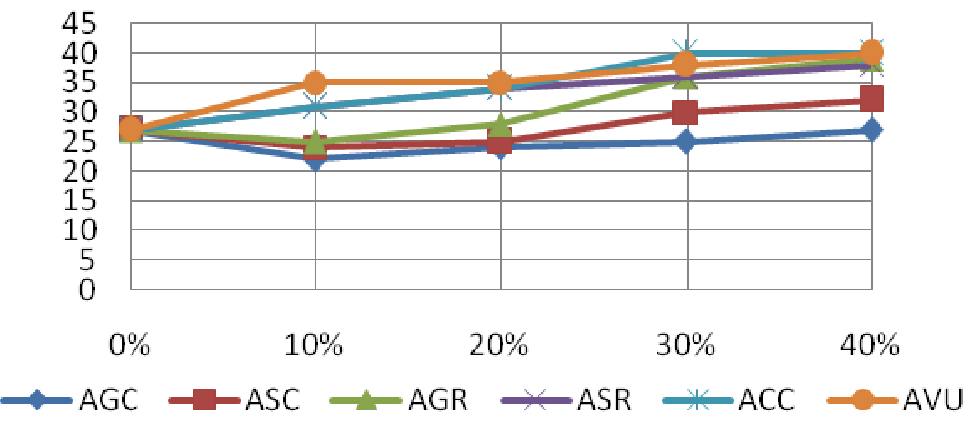

\begin{tabular}{|llllll|}
$\begin{array}{l}\text { A=4, } \\
P=14 \text { bar }\end{array}$ & $X=0 \%$ & $X=10 \%$ & $X=20 \%$ & $X=30 \%$ & $X=40 \%$ \\
\hline ACC & 27 & 31 & 34 & 40 & 40 \\
\hline AVU & 27 & 35 & 35 & 38 & 40 \\
\hline AGC & 27 & 22 & 24 & 25 & 27 \\
\hline AGR & 27 & 25 & 28 & 36 & 39 \\
\hline ASC & 27 & 24 & 25 & 30 & 32 \\
\hline ASR & 27 & 31 & 34 & 36 & 38 \\
\hline
\end{tabular}

Figura 8.179: Emisiones de NOx para 14 bar y $A=4$

El comportamiento es similar al de la posición $A=3,5$, aunque con matices. En el AVU, destaca las elevadas emisiones que registra para porcentajes bajos de aceite en mezcla, mayores incluso que los de los aceites crudos para $X=40 \%$. Tanto ACC como AGR sufren una subida "inesperada" a partir de $X=20 \%$, cosa que no le ocurre al ASR, cuyo comportamiento es casi perfectamente lineal. AGC, ASC y AGR registran emisiones menores con el mínimo porcentaje de la mezcla que con un porcentaje nulo, lo cual queda plasmado en el pequeño valle que muestran los 3 aceites para ese valor de X. El menor nivel de emisiones, de nuevo, para AGC. 
Representaciones gráficas de las emisiones de NOx para la admisión de aire $A=4,5$

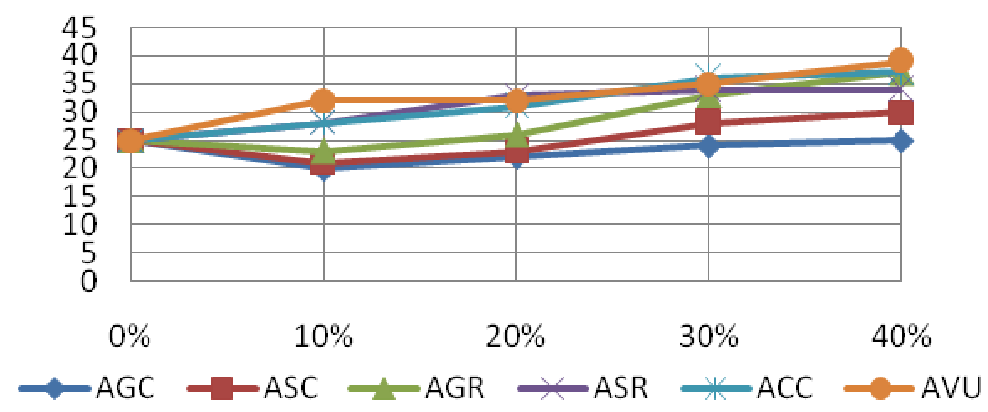

\begin{tabular}{|llllll|}
$\begin{array}{l}\text { A=4,5, } \\
P=14 \text { bar }\end{array}$ & $X=0 \%$ & $X=10 \%$ & $X=20 \%$ & $X=30 \%$ & $X=40 \%$ \\
\hline ACC & 25 & 28 & 31 & 36 & 37 \\
\hline AVU & 25 & 32 & 32 & 35 & 39 \\
\hline AGC & 25 & 20 & 22 & 24 & 25 \\
\hline AGR & 25 & 23 & 26 & 33 & 37 \\
\hline ASC & 25 & 21 & 23 & 28 & 30 \\
\hline ASR & 25 & 28 & 33 & 34 & 34 \\
\hline
\end{tabular}

Figura 8.180: Emisiones de NOx para 14 bar y $A=4,5$

Comparados con los datos de las dos últimas gráficas, estos son claramente menores, lo cual confirma el hecho de que la posición de aire más recomendable para reducir emisiones es la mayor posible. El gráfico muestra de nuevo como los valores para $X=10 \%$ son menores que los de $X=0 \%$ para AGC, AGR y ASC, incluso los del $20 \%$ en AGC y ASC, no llegando a superarse en el AGC. El comportamiento del ASC no es tan lineal, creciendo más las emisiones para aumentos de X. El AVU y el ACC, en ese orden, son los aceites que peores niveles de emisiones ofrecen. Destaca también que por una vez, las emisiones del aceite de soja son menores que las del aceite de girasol en el apartado de refinados. 
Representaciones gráficas de las emisiones de NOx para el porcentaje en peso de aceite $X=10 \%$

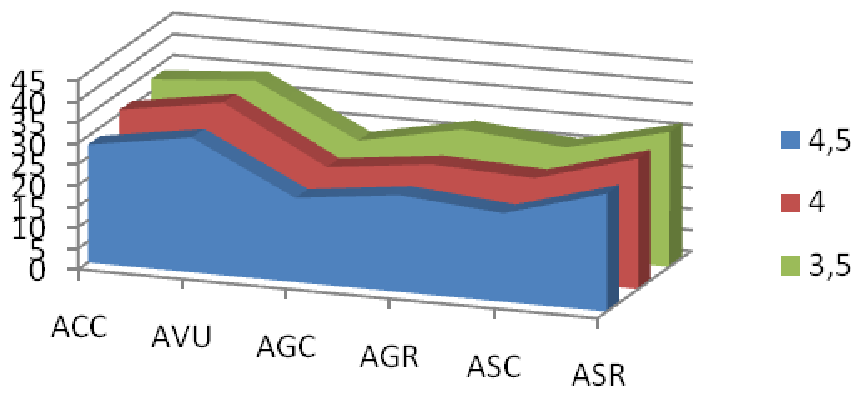

\begin{tabular}{|lllllll|}
\hline $\begin{array}{l}X=10 \%, \\
P=14 \text { bar }\end{array}$ & ACC & AVU & AGC & AGR & ASC & ASR \\
\hline$A=3,5$ & 33 & 35 & 23 & 28 & 26 & 32 \\
\hline$A=4$ & 31 & 35 & 22 & 25 & 24 & 31 \\
\hline$A=4,5$ & 28 & 32 & 20 & 23 & 21 & 28 \\
\hline
\end{tabular}

Figura 8.181: Emisiones de NOx para 14 bar y $X=10 \%$

La primera gráfica muestra, por un lado, que AGC y ASC son las mejores para este porcentaje. Destaca que el AVU tiene el mayor nivel de emisiones. De nuevo se ve que la posición de admisión de aire más favorable es la mayor $(A=4,5)$. En la segunda gráfica puede verse, además, la diferencia existente entre AVU, ACC, ASR y el resto.

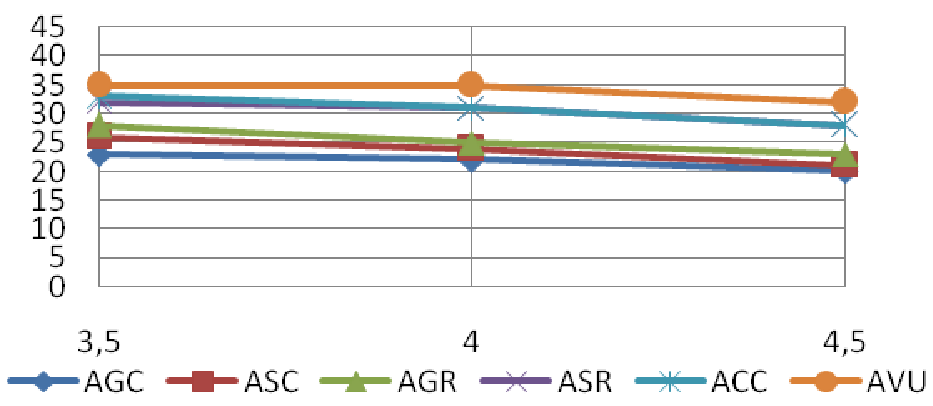

Figura 8.182: Emisiones de NOx para 14 bar y $X=10 \%$ 
Representaciones gráficas de las emisiones de NOx para el porcentaje en peso de aceite $X=20 \%$

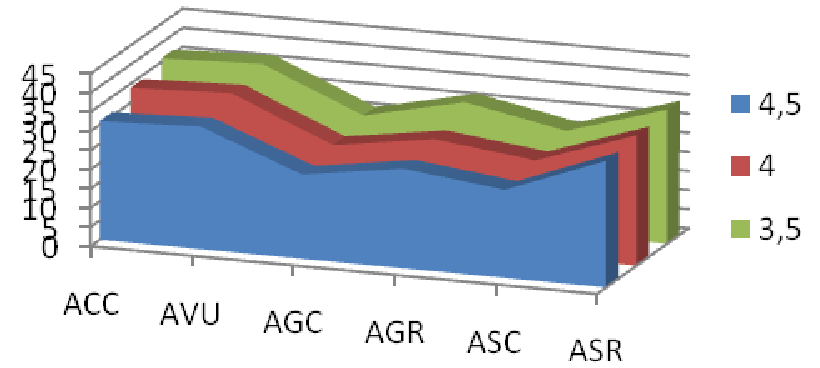

\begin{tabular}{|lllllll|}
\hline $\begin{array}{l}X=20 \%, \\
P=14 \text { bar }\end{array}$ & ACC & AVU & AGC & AGR & ASC & ASR \\
\hline$A=3,5$ & 36 & 37 & 26 & 32 & 27 & 35 \\
\hline$A=4$ & 34 & 35 & 24 & 28 & 25 & 34 \\
\hline$A=4,5$ & 31 & 32 & 22 & 26 & 23 & 33 \\
\hline
\end{tabular}

Figura 8.183: Emisiones de NOx para 14 bar y $X=20 \%$

Las diferencias para este porcentaje parecen estar más suavizadas que en el anterior. Para este porcentaje de mezcla los aceites crudos tienen un comportamiento casi igual (siempre un poco mejor el AGC. ACC, AVU y ASR muestran un comportamiento bastante peor, y entre medias se tiene el AGR. En la segunda gráfica se aprecia cómo tanto en ACC como en AVU el aumento de la posición de admisión de aire las beneficia más.

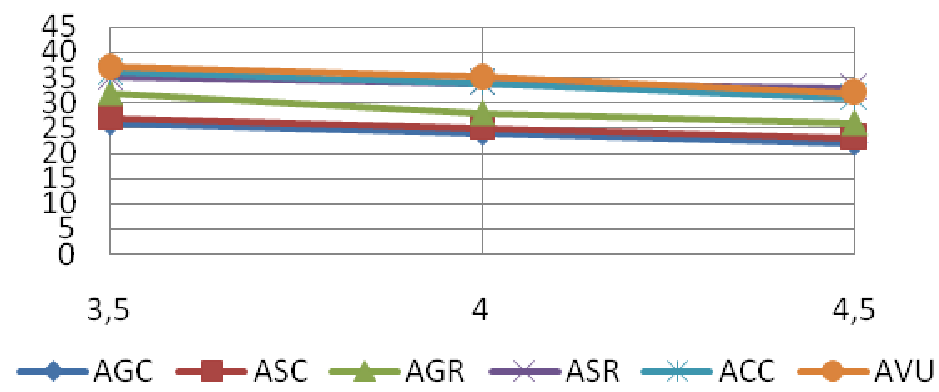

Figura 8.184: Emisiones de NOx para 14 bar y $X=20 \%$ 
Representaciones gráficas de las emisiones de NOx para el porcentaje en peso de aceite $X=30 \%$

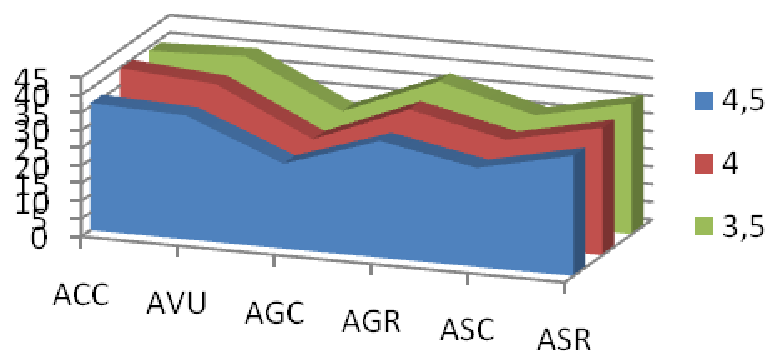

\begin{tabular}{|lllllll|}
\hline $\begin{array}{l}X=30 \%, \\
P=14 \text { bar }\end{array}$ & ACC & AVU & AGC & AGR & ASC & ASR \\
\hline$A=3,5$ & 39 & 40 & 27 & 38 & 31 & 37 \\
\hline$A=4$ & 40 & 38 & 25 & 36 & 30 & 36 \\
\hline$A=4,5$ & 36 & 35 & 24 & 33 & 28 & 34 \\
\hline
\end{tabular}

Figura 8.185: Emisiones de NOx para 14 bar y $X=30 \%$

El AGC provoca la aparición de un pronunciado valle en la primera gráfica. ACC, AVU, AGR y ASR vuelven a dar niveles similares de emisiones, mucho más altos que los obtenidos con los aceites crudos. La segunda gráfica muestra esto claramente, amén de la influencia de la variable $\mathrm{A}$. El único "punto extraño" es el registrado para $A C$ en $A=4$, el cual da mayores emisiones que $A=3,5$.

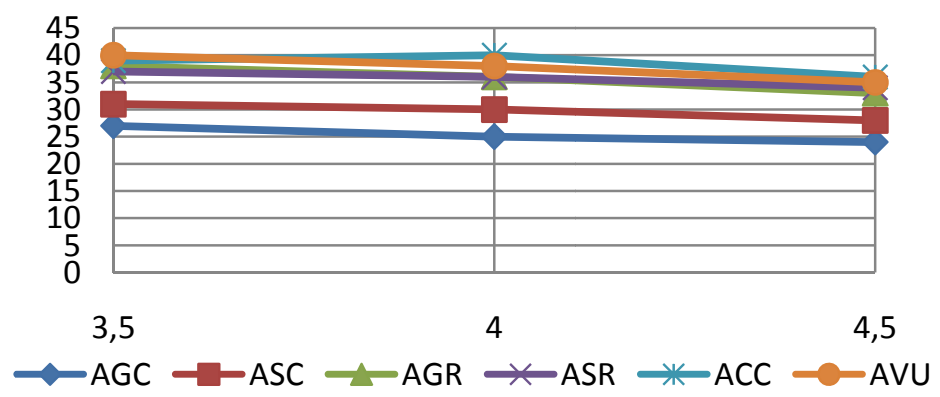

Figura 8.186: Emisiones de NOx para 14 bar y $X=30 \%$ 
Representaciones gráficas de las emisiones de NOx para el porcentaje en peso de aceite $X=40 \%$

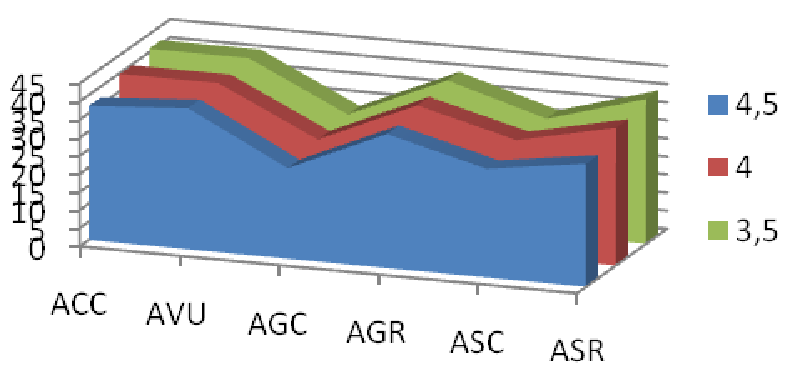

\begin{tabular}{|lllllll|}
\hline $\begin{array}{l}X=40 \%, \\
P=14 \text { bar }\end{array}$ & ACC & AVU & AGC & AGR & ASC & ASR \\
\hline$A=3,5$ & 41 & 41 & 28 & 40 & 32 & 40 \\
\hline$A=4$ & 40 & 40 & 27 & 39 & 32 & 38 \\
\hline$A=4,5$ & 37 & 39 & 25 & 37 & 30 & 34 \\
\hline
\end{tabular}

Figura 8.187: Emisiones de NOx para 14 bar y $X=40 \%$

AVU, ACC y AGR dan valores muy similares para el porcentaje máximo de estudio en todas las posiciones de admisión de aire. ASR da valores menores, sobre todo para $A=4,5$, mientras que $A S C$ da valores todavía menores. De nuevo vuelve a ser el AGC el aceite que menor nivel de emisiones ofrece, marcando el mínimo para la posición de mayor admisión de aire. La segunda gráfica muestra esto más claramente.

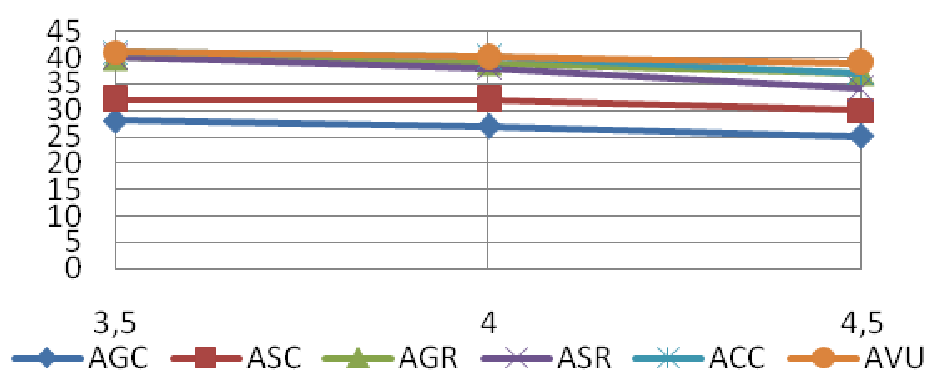

Figura 8.188: Emisiones de NOx para 14 bar y $X=40 \%$ 


\subsubsection{Conclusiones}

El análisis tanto del ANOVA como de las representaciones gráficas da como conclusiones las siguientes:

- $\quad$ Como predijo el análisis ANOVA, el tipo de aceite (variable T) es la variable más determinante del estudio y con diferencia.

- La variable X, porcentaje de aceite en mezcla, es la segunda variable en orden de importancia según el ANOVA. La influencia que tiene el aumento del porcentaje de aceite en mezcla es bastante clara, sufriendo esto todos los combustibles casi por igual.

- Los mínimos vuelven a conseguirse para la mayor posición de admisión de aire posible, $A=4,5$ en este caso. Pese a no ser la variable más influyente en teoría, la inmensa mayoría de las series de datos vistas en este análisis cumplen esto.

- $\quad$ El mejor aceite del estudio en cuanto a emisiones de $\mathrm{NO}_{x}$ es sin duda el AGC, y después el ASC, ambos aceites crudos, lo cual indica que el tratamiento del refino empeora el comportamiento de las emisiones de $\mathrm{NO}_{x}$.

- Puede concluirse, por tanto, que las mejores condiciones observadas para evitar las emisiones de $\mathrm{NO}_{x}$ son bajos porcentajes de aceite en mezcla, posición de admisión de aire alta y aceite crudo.

- $\quad$ El aceite de colza (ACC) y el aceite vegetal usado (AVU) son, gráfica a gráfica y tabla a tabla, los peores indicados para tener bajos niveles de emisiones.

- Debido al ínfimo grado de confiabilidad crítico obtenido en el ANOVA, y al igual que se dijo en el análisis anterior, no cabe establecer que una variable es la que "somete" a las demás en este estudio. 


\subsubsection{Análisis de las emisiones de NOxpara A=3,5}

A continuación se exponen los datos registrados para este análisis:

Tabla 8.25 Matriz de resultados de emisiones de NOx

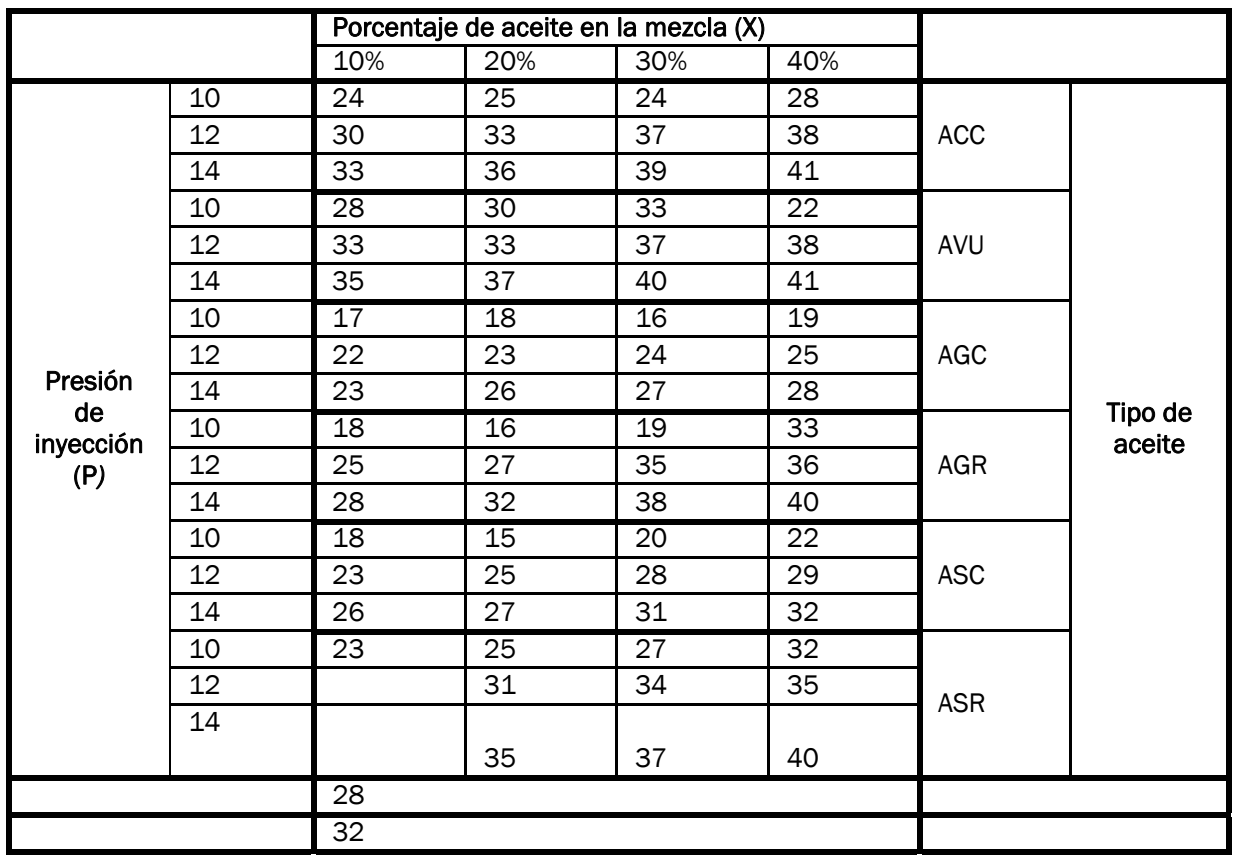

Con los datos ya dispuestos, se plantea un análisis de varianza (ANOVA), mediante el cual se determinará si las tres variables influyen (presión de inyección, tipo de aceite y porcentaje de aceite en peso) o no y de qué manera.

Tabla 8.26 Análisis ANOVA

\begin{tabular}{|l|l|l|l|l|l|l|l|}
\hline FACTOR & GdL & SS & MS & F & VC al 5\% & Influye & G. C. Crítica \\
\hline P & 2 & 1395,2500 & 697,6250 & 152,36299 & 3,31583 & SI & $1,93409 \mathrm{E}-16$ \\
\hline T & 5 & 1262,1250 & 252,4250 & 55,13023 & 2,53355 & SI & $3,22156 \mathrm{E}-14$ \\
\hline X & 3 & 430,15278 & 143,3842 & 31,31547 & 2,92228 & SI & $2,25698 \mathrm{E}-09$ \\
\hline PxT & 10 & 39,75000 & 3,97500 & 0,86815 & 2,16458 & NO & 0,571401465 \\
\hline PxX & 6 & 32,97222 & 5,49537 & 1,20020 & 2,42052 & NO & 0,333234368 \\
\hline TxX & 15 & 169,26389 & 11,28426 & 2,46451 & 2,01480 & SI & 0,017273716 \\
\hline Error & 30 & 137,36111 & 4,57870 & & & & \\
\hline Total & 71 & 3466,87500 & & & & & \\
\hline
\end{tabular}


Los resultados generados en la tabla ANOVA muestran que las interacciones PxT y PxX son rechazadas en un estudio con un grado de confiabilidad al $5 \%$. Además, la interacción TxX pasa el test pero no con un valor excesivamente bajo, $1,72 \%$, de modo que la influencia que pueda llegar a tener será bastante menor a la que tengan las variables simples.

Como variables más significativas se tienen la presión de inyección $(\mathrm{P})$ (orden de 10-14 \%) y el tipo de aceite (T) (orden de 10-12 \%). El grado de confiabilidad crítica que ofrece la variable X es del orden de $10^{-7} \%$.

A priori las variables que más van a influir en el análisis son $\mathrm{P}$ y $\mathrm{T}$. $\mathrm{X}$ influirá pero estará en un escalón inferior, mientras que, a pesar de haber pasado el test una de ellas, ninguna interacción mostrará una influencia excesiva dentro del estudio.

Se representan a continuación los valores obtenidos para la variable emisión de NOx en función de las variables $\mathrm{P}, \mathrm{X}$ y T. 
Representaciones gráficas de las emisiones de NOx para el aceite de colza crudo ( $\mathrm{T}=\mathrm{ACC})$

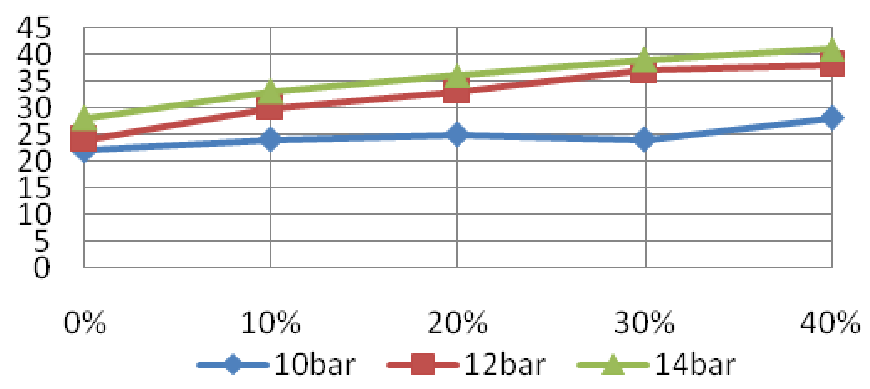

\begin{tabular}{|llllll|}
\hline $\begin{array}{l}\text { ACC, } \\
\text { A=3,5 }\end{array}$ & $X=0 \%$ & $X=10 \%$ & $X=20 \%$ & $X=30 \%$ & $X=40 \%$ \\
\hline$P=10$ bar & 22 & 24 & 25 & 24 & 28 \\
\hline$P=12$ bar & 24 & 30 & 33 & 37 & 38 \\
\hline$P=14$ bar & 28 & 33 & 36 & 39 & 41 \\
\hline
\end{tabular}

Figura 8.189: Emisiones de NOx para $A=3,5$ y $\mathrm{T}=\mathrm{ACC}$

Se observa que las emisiones crecen cuanto más aumenta la presión de inyección del combustible, y además puede verse que cuanto más porcentaje de aceite se tiene en la mezcla las emisiones son mayores. 
Representaciones gráficas de las emisiones de NOx para el aceite vegetal usado ( $\mathrm{T}=\mathrm{AVU}$ )

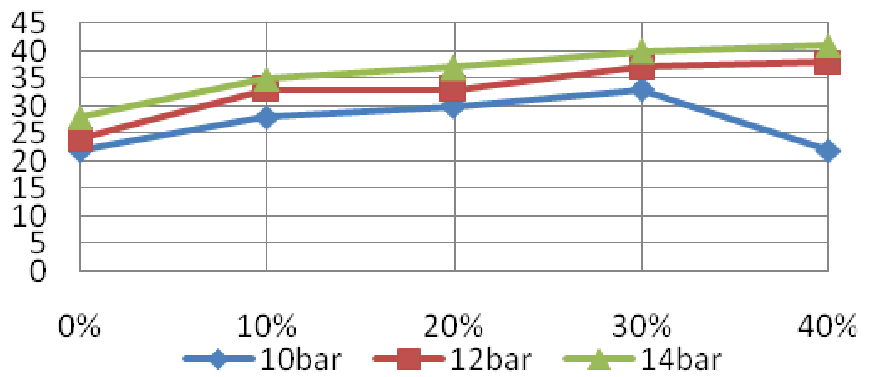

\begin{tabular}{|llllll|}
\hline $\begin{array}{l}\text { AVU, } \\
\text { A=3,5 }\end{array}$ & $X=0 \%$ & $X=10 \%$ & $X=20 \%$ & $X=30 \%$ & $X=40 \%$ \\
\hline$P=10$ bar & 22 & 28 & 30 & 33 & 22 \\
\hline$P=12$ bar & 24 & 33 & 33 & 37 & 38 \\
\hline$P=14$ bar & 28 & 35 & 37 & 40 & 41 \\
\hline
\end{tabular}

Figura 8.190: Emisiones de NOx para $A=3,5$ y $T=A V U$

De nuevo, y salvo el valor registrado para $\mathrm{P}=10$ bar y $\mathrm{X}=40 \%$, la tendencia es al alza con el porcentaje de aceite en mezcla y la presión. Los valores obtenidos son mayores en este caso que en el anterior para valores bajos de $\mathrm{X}$, pero para valores altos están muy igualados. 
Representaciones gráficas de las emisiones de NOx para el aceite de girasol crudo ( $T=A G C)$

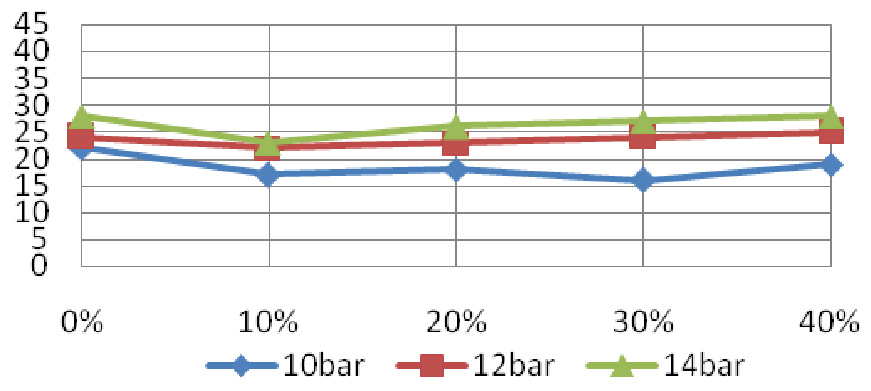

\begin{tabular}{|llllll|}
\hline $\begin{array}{l}\text { AGC, } \\
A=3,5\end{array}$ & $X=0 \%$ & $X=10 \%$ & $X=20 \%$ & $X=30 \%$ & $X=40 \%$ \\
\hline$P=10$ bar & 22 & 17 & 18 & 16 & 19 \\
\hline$P=12$ bar & 24 & 22 & 23 & 24 & 25 \\
\hline$P=14$ bar & 28 & 23 & 26 & 27 & 28 \\
\hline
\end{tabular}

Figura 8.191: Emisiones de NOx para $A=3,5$ y $T=A G C$

Puede apreciarse un comportamiento bastante más "suave" de las gráficas, de manera que los valores no aumentan tanto con X (pero aumentan). Los mínimos se registran a la menor presión y menor porcentaje en mezcla. Los valores obtenidos con este aceite están bastante por debajo de los obtenidos con los dos anteriores. 
Representaciones gráficas de las emisiones de NOx para el aceite de girasol refinado $(T=A G R)$

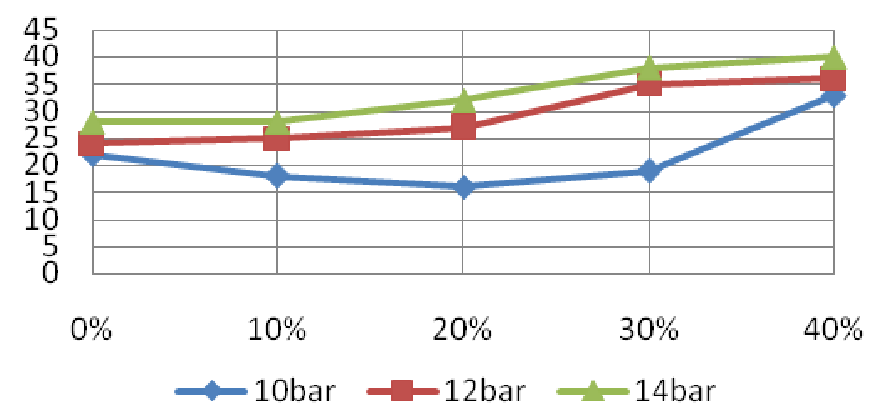

\begin{tabular}{|llllll|}
\hline $\begin{array}{l}\text { AGR, } \\
A=3,5\end{array}$ & $X=0 \%$ & $X=10 \%$ & $X=20 \%$ & $X=30 \%$ & $X=40 \%$ \\
\hline$P=10$ bar & 22 & 18 & 16 & 19 & 33 \\
\hline$P=12$ bar & 24 & 25 & 27 & 35 & 36 \\
\hline$P=14$ bar & 28 & 28 & 32 & 38 & 40 \\
\hline
\end{tabular}

Figura 8.192: Emisiones de NOx para $A=3,5$ y $T=A G R$

Las emisiones obtenidas con el AGR son bastante más radicales que las obtenidas anteriormente. Para $\mathrm{P}=10$ bar, el comportamiento es difícilmente descriptible, con un pico final que no se adapta a la serie pero si a la lógica del resto de la gráfica. En cuanto a los valores registrados para $\mathrm{P}=12$ bar y $\mathrm{P}=14$ bar, son más razonables, con mayores emisiones cuanto mayor porcentaje de aceite en mezcla hay y menores para presión menor. 
Representaciones gráficas de las emisiones de NOx para el aceite de soja crudo ( $\mathrm{T}=\mathrm{ASC}$ )

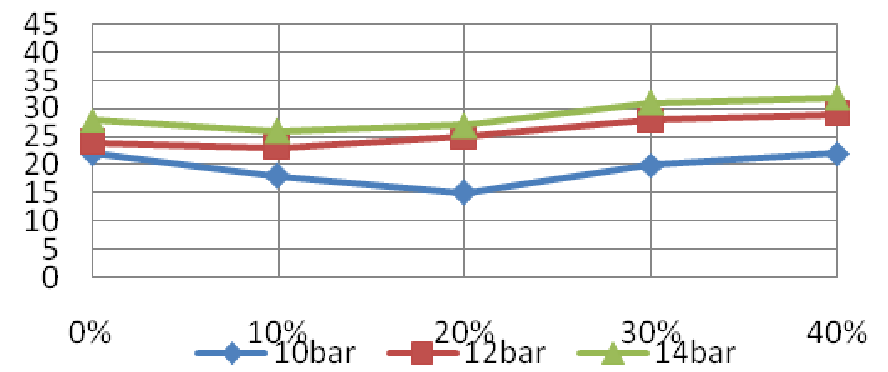

\begin{tabular}{|llllll|}
$\begin{array}{l}\text { ASC, } \\
\text { A=3,5 }\end{array}$ & $X=0 \%$ & $X=10 \%$ & $X=20 \%$ & $X=30 \%$ & $X=40 \%$ \\
\hline$P=10$ bar & 22 & 18 & 15 & 20 & 22 \\
\hline$P=12$ bar & 24 & 23 & 25 & 28 & 29 \\
\hline$P=14$ bar & 28 & 26 & 27 & 31 & 32 \\
\hline
\end{tabular}

Figura 8.193: Emisiones de NOx para $A=3,5$ y $T=A S C$

Las emisiones obtenidas para $\mathrm{P}=10$ bar muestran un mínimo para $\mathrm{X}=20$ $\%$, un suceso extraño ya que el mínimo ha venido dado siempre por el mínimo porcentaje de aceite en mezcla. Los valores para $\mathrm{P}=12$ bar y $\mathrm{P}=14$ bar siguen una tendencia casi exacta, con una emisión de 3 ppm superior en $\mathrm{P}=14$ bar. 
Representaciones gráficas de las emisiones de NOx para el aceite de soja refinado $(\mathrm{T}=\mathrm{ASR})$

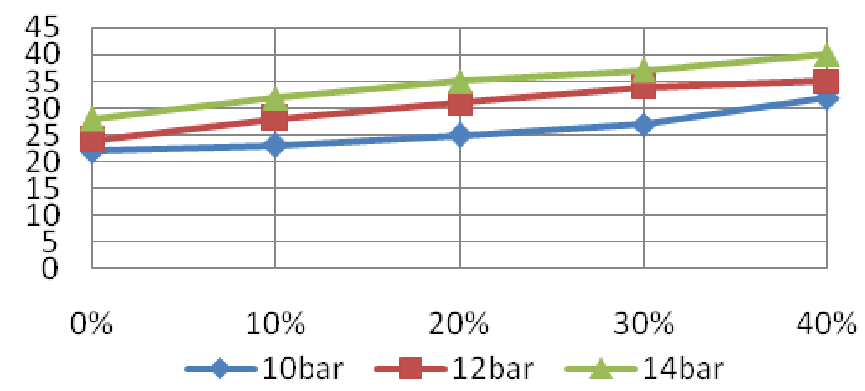

\begin{tabular}{|llllll|}
$\begin{array}{l}\text { ASR, } \\
A=3,5\end{array}$ & $X=0 \%$ & $X=10 \%$ & $X=20 \%$ & $X=30 \%$ & $X=40 \%$ \\
\hline$P=10$ bar & 22 & 23 & 25 & 27 & 32 \\
\hline$P=12$ bar & 24 & 28 & 31 & 34 & 35 \\
\hline$P=14$ bar & 28 & 32 & 35 & 37 & 40 \\
\hline
\end{tabular}

Figura 8.194: Emisiones de NOx para $A=3,5$ y $T=A S R$

Al contrario que el crudo, el aceite de soja refinado sigue la tendencia "lógica" vista hasta ahora: el aumento de la presión provoca aumento de emisiones, y el aumento de aceite en la mezcla también. 
Representaciones gráficas de las emisiones de NOx para la presión de inyección $\mathrm{P}=10$ bar

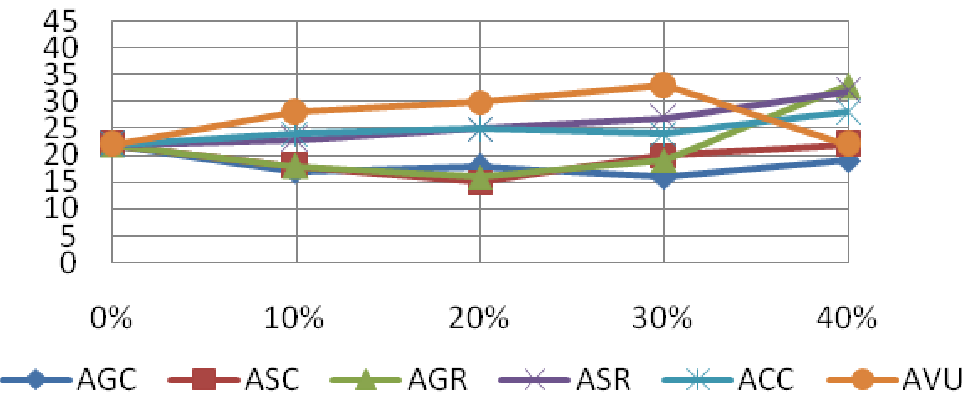

\begin{tabular}{|c|c|c|c|c|c|}
\hline $\begin{array}{l}P=10 \text { bar, } \\
A=3,5\end{array}$ & $X=0 \%$ & $X=10 \%$ & $X=20 \%$ & $X=30 \%$ & $X=40 \%$ \\
\hline ACC & 22 & 24 & 25 & 24 & 28 \\
\hline$\overline{A V U}$ & 22 & 28 & 30 & 33 & 22 \\
\hline AGC & 22 & 17 & 18 & 16 & 19 \\
\hline$\overline{\text { AGR }}$ & 22 & 18 & 16 & 19 & 33 \\
\hline ASC & 22 & 18 & 15 & 20 & 22 \\
\hline ASR & 22 & 23 & 25 & 27 & 32 \\
\hline
\end{tabular}

Figura 8.195: Emisiones de NOx para $A=3,5$ y $P=10$ bar

El dato comentado anteriormente para ASC, $X=20 \%$ y $P=10$ bar vuelve a ser el mínimo. Sin embargo, en esta tabla se ve claramente que a posición de admisión de aire constante, también el AGR tiene su mínimo en $X=20 \%$. Por lo general puede decirse que todos los aceites muestran subidas bastante comedidas en sus emisiones de $X=10 \%$ a $X=20 \%$ en mezcla. Por lo demás, queda claro que el AVU tiene las emisiones más altas para todos los porcentajes (salvo en $X=40 \%$ en un probable fallo de medida), lo cual lo coloca como el peor en este estudio. Tanto el gráfico como los datos muestran claramente que los dos aceites crudos muestran los mejores niveles de emisiones. También muestra el AGR unos buenos niveles, salvo para $X=40 \%$, donde el comportamiento mostrado extraña por la subida tan pronunciada que representa. 
Representaciones gráficas de las emisiones de NOx para la presión de inyección $\mathrm{P}=12 \mathrm{bar}$

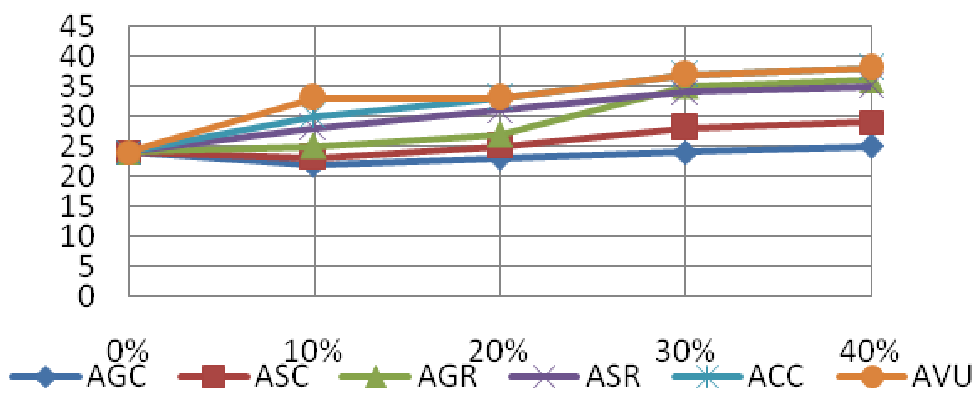

\begin{tabular}{|llllll|}
$\begin{array}{l}P=12 \\
\text { A=3,5 }\end{array}$ & $X=0 \%$ & $X=10 \%$ & $X=20 \%$ & $X=30 \%$ & $X=40 \%$ \\
\hline ACC & 24 & 30 & 33 & 37 & 38 \\
\hline AVU & 24 & 33 & 33 & 37 & 38 \\
\hline AGC & 24 & 22 & 23 & 24 & 25 \\
\hline AGR & 24 & 25 & 27 & 35 & 36 \\
\hline ASC & 24 & 23 & 25 & 28 & 29 \\
\hline ASR & 24 & 28 & 31 & 34 & 35 \\
\hline
\end{tabular}

Figura 8.196: Emisiones de NOx para $A=3,5$ y $P=12$ bar

Al contrario que en el ensayo a $\mathrm{P}=10$ bar, en éste el comportamiento seguido es más familiar ya que es el que se ha ido describiendo en otros ensayos. La tendencia mostrada es que al aumentar el porcentaje de aceite en mezcla aumenta el nivel de emisiones. En cuanto a los distintos aceites, puede verse que AGC y ASC muestran un comportamiento parecido, mejor en el AGC para todos los niveles. El AGR tiene también un comportamiento bueno, pero a partir de $X=20 \%$ sufre un aumento, y a partir de ahí se iguala con el ASR. Por su parte, tanto AC como AVU ofrecen las mayores emisiones del apartado. 
Representaciones gráficas de las emisiones de NOx para la presión de inyección $\mathrm{P}=14$ bar

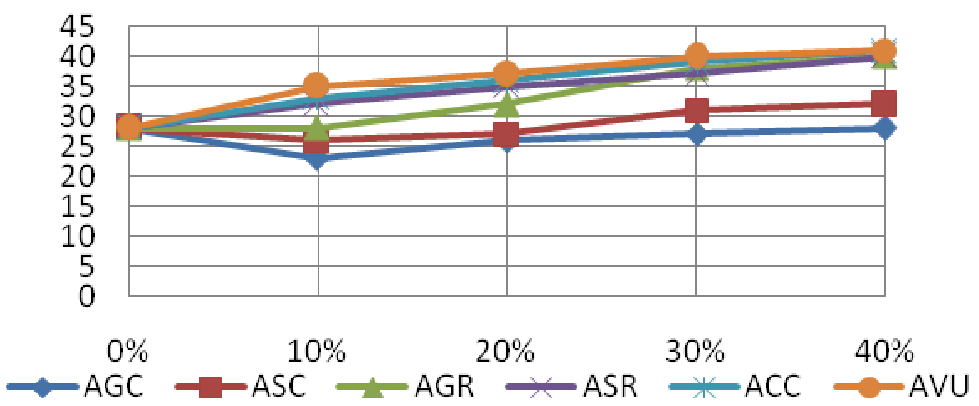

\begin{tabular}{|llllll|}
$\begin{array}{l}P=14 \\
\text { A=3,5 }\end{array}$ & $X=0 \%$ & $X=10 \%$ & $X=20 \%$ & $X=30 \%$ & $X=40 \%$ \\
\hline ACC & 28 & 33 & 36 & 39 & 41 \\
\hline AVU & 28 & 35 & 37 & 40 & 41 \\
\hline AGC & 28 & 23 & 26 & 27 & 28 \\
\hline AGR & 28 & 28 & 32 & 38 & 40 \\
\hline ASC & 28 & 26 & 27 & 31 & 32 \\
\hline ASR & 28 & 32 & 35 & 37 & 40 \\
\hline
\end{tabular}

Figura 8.197: Emisiones de NOx para $A=3,5$ y $P=14$ bar

El último estudio a presión constante ofrece unos resultados en cuanto a valores de las emisiones superiores a los anteriores; sin embargo, la tendencia seguida se asemeja bastante al estudio a $\mathrm{P}=12$ bar. Vuelve a tenerse que los mínimos los da el AGC, seguido por el ASC y el AGR: la conclusión que se extrae de aquí es que el aceite de girasol ofrece menores emisiones de $\mathrm{NO}_{\mathrm{x}}$ en estas condiciones ( $\mathrm{y}$ en todas las vistas hasta ahora) y que el no refinado también hace que las emisiones sean menores (es más importante el hecho de no refinarse a que sea de girasol). AVU, ASR y ACC tienen valores del orden de $10 \mathrm{ppm}$ superiores al AGC. Vuelve a destacar el aumento repentino en las emisiones del AGR, que pasa de ser el tercero menos emisor a estar en cabeza en el camino que va de $10 \%$ a $40 \%$. Por otra parte, destaca el hecho de que las emisiones del AGC no llegan a superar a las del gasoil puro en todo el estudio, y las del ASC sólo lo hacen a partir del 30\%. 
Representaciones gráficas de las emisiones de NOx para el porcentaje en peso de aceite $X=10 \%$

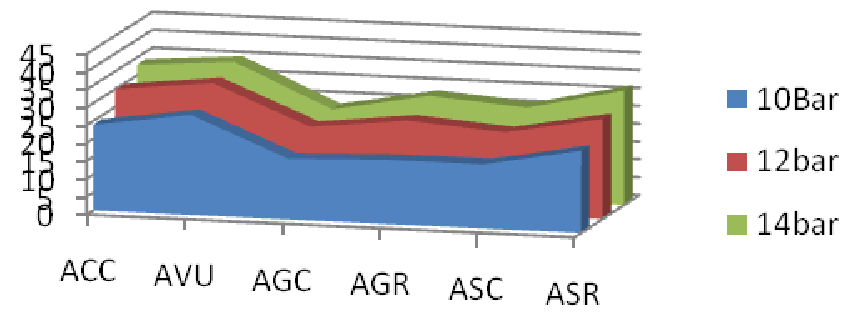

\begin{tabular}{|lllllll|}
\hline $\begin{array}{l}X=10 \%, \\
A=3,5\end{array}$ & ACC & AVU & AGC & AGR & ASC & ASR \\
\hline$P=10$ bar & 24 & 28 & 17 & 18 & 18 & 23 \\
\hline$P=12$ bar & 30 & 33 & 22 & 25 & 23 & 28 \\
\hline$P=14$ bar & 33 & 35 & 23 & 28 & 26 & 32 \\
\hline
\end{tabular}

Figura 8.198: Emisiones de NOx para $A=3,5$ y $X=10 \%$

En la primera gráfica se observa que para todas las presiones el AVU es el que más emite, seguido por el AC y el ASR. El AGC mantiene un nivel bastante bajo para las tres presiones. Tanto AGR como ASC aumentan mucho su nivel de emisiones al aumentar la presión. La segunda gráfica muestra más claramente el "ranking" descrito y sus tendencias.

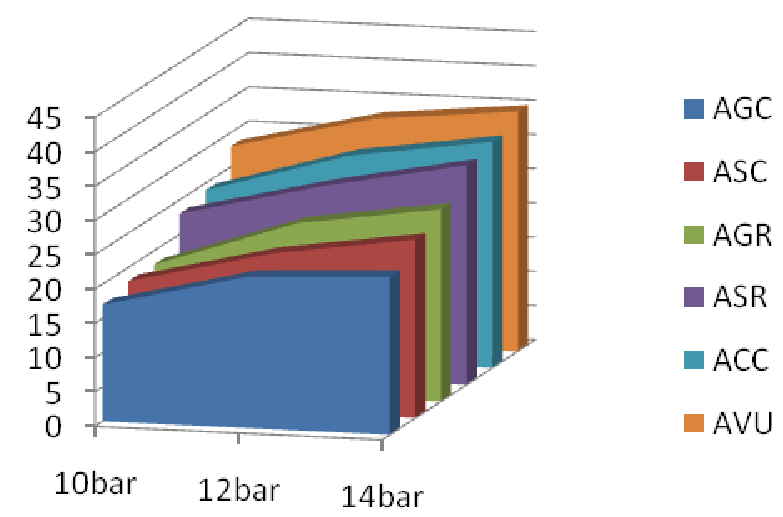

Figura 8.199: Emisiones de NOx para $A=3,5$ y $X=10 \%$ 
Representaciones gráficas de las emisiones de NOx para el porcentaje en peso de aceite $X=20 \%$

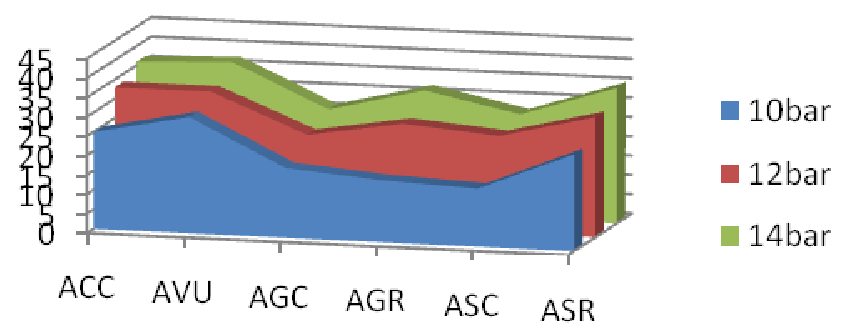

\begin{tabular}{|lllllll|}
\hline $\begin{array}{l}\mathrm{X}=\mathbf{2 0} \%, \\
\mathrm{~A}=3,5\end{array}$ & ACC & AVU & AGC & AGR & ASC & ASR \\
\hline $\mathrm{P}=10$ bar & 25 & 30 & 18 & 16 & 15 & 25 \\
\hline $\mathrm{P}=12$ bar & 33 & 33 & 23 & 27 & 25 & 31 \\
\hline $\mathrm{P}=14$ bar & 36 & 37 & 26 & 32 & 27 & 35 \\
\hline
\end{tabular}

Figura 8.200: Emisiones de NOx para $A=3,5$ y $X=20 \%$

La primera gráfica muestra que para alta presión la tendencia de todos los aceites es la misma. Destaca que es el ASC el que consigue el mínimo, para $\mathrm{P}=10$ bar (en las otras presiones es el AGC el que lo consigue). En la segunda gráfica se aprecia que el aumento en la presión influye de manera más grande tanto al ASC como al AGR (pendiente más alta desde 10 hasta 12 bar).

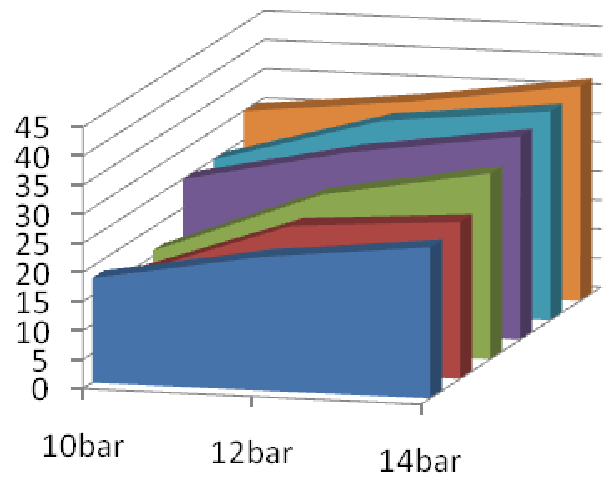

Figura 8.201: Emisiones de NOx para $A=3,5$ y $X=20 \%$ 
Representaciones gráficas de las emisiones de NOx para el porcentaje en peso de aceite $X=30 \%$

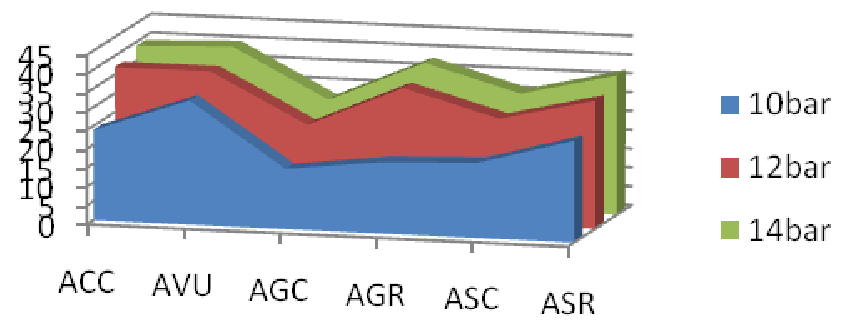

\begin{tabular}{|lllllll|}
$\begin{array}{l}\mathrm{X}=30 \%, \\
\mathrm{~A}=3,5\end{array}$ & ACC & AVU & AGC & AGR & ASC & ASR \\
\hline $\mathrm{P}=10$ bar & 24 & 33 & 16 & 19 & 20 & 27 \\
\hline $\mathrm{P}=12$ bar & 37 & 37 & 24 & 35 & 28 & 34 \\
\hline $\mathrm{P}=14$ bar & 39 & 40 & 27 & 38 & 31 & 37 \\
\hline
\end{tabular}

Figura 8.202: Emisiones de NOx para $A=3,5$ y $X=30 \%$

El AGC marca los mínimos para todas las presiones. Destaca que el AGR marca unas emisiones muy bajas con la presión mínima, pero después "se desmadra" en sus valores estando al nivel de los más contaminantes. En la segunda gráfica se ve la estratificación existente. Vuelve a ser el peor el AVU, a todas las presiones.

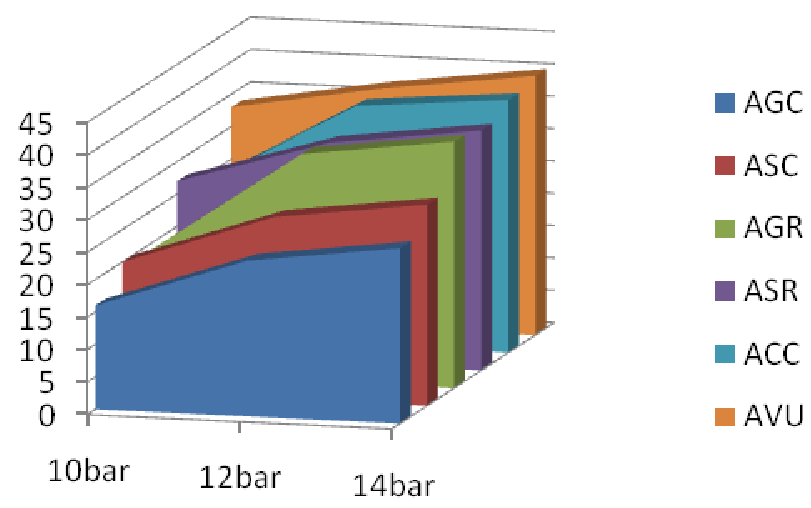

Figura 8.203: Emisiones de NOx para $A=3,5$ y $X=30 \%$ 
Representaciones gráficas de las emisiones de NOx para el porcentaje en peso de aceite $X=40 \%$

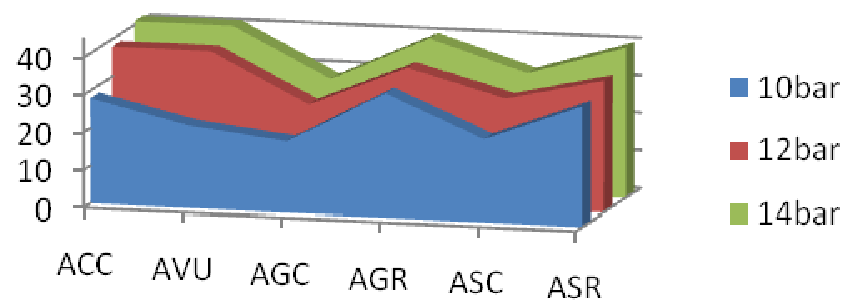

\begin{tabular}{|lllll|ll|}
\hline $\begin{array}{l}\mathrm{X}=40 \%, \\
\mathrm{~A}=3,5\end{array}$ & ACC & AVU & AGC & AGR & ASC & ASR \\
\hline $\mathrm{P}=10$ bar & 28 & 22 & 19 & 33 & 22 & 32 \\
\hline $\mathrm{P}=12$ bar & 38 & 38 & 25 & 36 & 29 & 35 \\
\hline $\mathrm{P}=14$ bar & 41 & 41 & 28 & 40 & 32 & 40 \\
\hline
\end{tabular}

Figura 8.204: Emisiones de NOx para $A=3,5$ y $X=40 \%$

Destaca el bajo valor del AVU a $\mathrm{P}=10$ bar, ya que en todo el estudio ha dado valores tan bajos, y lo hace con el porcentaje en mezcla a priori más desfavorable. Sin embargo luego vuelve a dar valores altos (los que más). El AGC vuelve a ser el que menos emisiones produce, con un mínimo a $\mathrm{P}=10$ bar al que ni AVU, ni ACC, ni ASR han conseguido acercarse en todo este último estudio. Destaca el mal comportamiento que ambos aceites refinados ofrecen con la participación al 40\%. En la segunda gráfica puede verse como llegan a solapar las emisiones de AVU y ACC, algo que todavía no había ocurrido en el estudio.

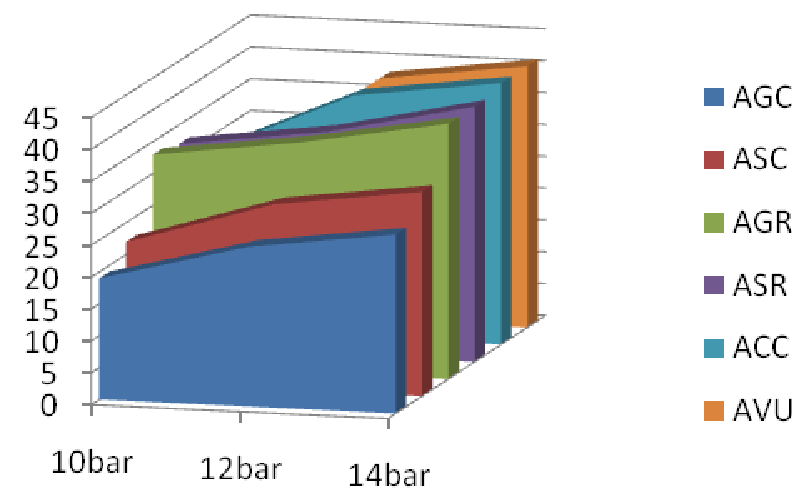

Figura 8.205: Emisiones de NOx para $A=3,5$ y $X=40 \%$ 


\subsubsection{Conclusiones}

El análisis tanto del ANOVA como de las representaciones gráficas da como conclusiones las siguientes:

.Como predijo el análisis ANOVA, la presión de inyección $(\mathrm{P})$ y el tipo de aceite $(\mathrm{T})$ son las variables más significativas del estudio. Puede parecer que destaca más el tipo de aceite, pero la estratificación del nivel de emisiones según la presión de inyección elegida puede verse en todas y cada una de las gráficas.

,La variable $X$, porcentaje de aceite en mezcla es importante tal y como rebela el ANOVA, pero no tanto como las dos mencionadas anteriormente. Los valores de emisión tienen la tendencia a crecer cuando aumenta X; sin embargo, en el AGC la tendencia no es tan clara y se mantiene en niveles más o menos constantes (bajos).

.Los mínimos se consiguen para la menor presión de inyección posible, $\mathrm{P}=10$ bar en este caso. La presión de inyección es la variable más determinante del estudio.

.El mejor aceite del estudio en cuanto a emisiones de NOx es sin duda el AGC, y después el ASC, ambos aceites crudos, lo cual indica que el tratamiento del refino empeora el comportamiento de las emisiones de NOx. Cabe destacar que en algunas condiciones otros aceites, como el AVU o el ASR, ofrecen unos valores de emisiones también muy bajos, pero más que una tendencia puede llegar a parecer un error de medida.

.Puede concluirse, por tanto, que las mejores condiciones observadas para evitar las emisiones de NOx son bajos porcentajes de aceite en mezcla, presión baja y aceite crudo (AGC o ASC).

.El aceite de colza (AC) y el aceite vegetal usado (AVU) son, gráfica a gráfica y tabla a tabla, los peores indicados para tener bajos niveles de emisiones. También el ASR ofrece valores muy altos en algunos de los estudios.

.Destaca que para AGC (todas las presiones), ASC ( $\mathrm{P}=10$ bar $\mathrm{y}$ valores sueltos) y AGR (valores sueltos) se obtienen valores de emisión menores que con el gasoil puro $(X=0 \%)$. 
.Las emisiones de los aceites refinados crecen con el porcentaje de aceite en mezcla en mayor medida que lo que lo hacen el resto de aceites. 


\section{$9.1 \quad$ INTRODUCCIÓN.}

Se fijaba como objetivo general de la presente tesis, el estudio de la combustión en un generador convencional, en una cámara a presión constante y con un quemador de pulverización mecánica por presión, de mezclas de aceites vegetales con gasóleo, logrando una combustión eficiente con la consiguiente reducción en la emisión de gases de efecto invernadero. La consecución de dicho objetivo principal queda reflejada en la serie de datos correspondientes a los distintos ensayos que se han realizado y que se presentan en el capítulo 8.

Al margen del objetivo principal se caracterizaban otros objetivos cuyo alcance se presenta a continuación en forma de conclusiones ordenadas conforme a los siguientes apartados:

a) Los biocombustibles como recurso energético, recursos disponibles, aspectos sociales y económicos.

b) Caracterización de los distintos aceites y mezclas como biocombustibles.

c) Adecuación de los aceites para su uso con fines térmicos.

d) Combustión de las mezclas con distintos parámetros de funcionamiento del quemador.

e) Análisis de resultados, estudiando rendimiento, emisiones de $\mathrm{CO}$ y emisiones de NOx. 


\subsection{CONCLUSIONES}

Seguimos para presentar las conclusiones el orden que hemos determinado en el apartado anterior

\subsubsection{Los biocombustibles como recurso energético.}

La utilización de aceites vegetales en mezcla con combustibles fósiles como el gasóleo en M.C.I. (Biodiesel) para obtención de energía mecánica está en este momento condicionando enormemente el uso de los aceites para la obtención de biodiesel, por los fuertes compromisos establecidos por la CEE, aunque paradójicamente factores económicos internacionales han llevado a las empresas de trasformación españolas y de otros países europeos a no producir biodiesel. En el caso de España las plantas de producción de biodiesel están al 14\% de la producción después de las fuertes inversiones realizadas. El biodiesel importado de Argentina y de Indonesia representa el $89 \%$ del consumo108. El actual conflicto con Argentina, por la expropiación de YPF, puede modificar esta situación.

Este problema de precios con las importaciones de biodiesel no es el único conflicto de intereses en el sector. El difícil equilibrio entre el uso como recurso energético de los aceites y el uso para el consumo humano añaden nuevas incertidumbres a su desarrollo.

Las fuertes exigencias requeridas a los combustibles de automoción (biodiesel) lo que origina un porcentaje de rechazos significativo, el coste del proceso de transformación (transesterificación), la utilización de aceites usados de difícil reciclaje para biodiesel, excedentes de producción, etc. garantizan la disponibilidad de aceites que pueden ser utilizados como combustibles para fines térmicos en calderas de pequeña y mediana potencia con quemadores convencionales sin ninguna transformación, contribuyendo a los objetivos de diversificación, sostenibilidad y reducción de GEl.

\subsubsection{Caracterización de los biocmbustibles}

La caracterización de los distintos tipos de aceite que se estudian permite observar que no existen grandes diferencias con el gasóleo.

Las diferencias más notables son la densidad, ligeramente mayor que la del gasóleo, la viscosidad, sensiblemente mayor, el contenido de C

${ }^{108}$ APPA Biocarburantes. Datos biodiesel 2011 
ligeramente menor lo que hace que el $\mathrm{PCl}$ sea menor y el contenido en $\mathrm{O}$ mayor lo que permite el empleo de un dosado relativo menor.

La diferencia más notable es pues la viscosidad. La influencia de esta característica se pone de manifiesto en la dificultad de pulverización o atomización del combustible, el aumento de la temperatura del combustible y el aumento de la presión de inyección compensan el aumento de viscosidad. A la vista de los resultados, vemos como en casi todos los casos el aumento de presión de inyección aumenta el rendimiento de la combustión pero en valores muy poco significativos incluso en algunos disminuye.

$\mathrm{El} \mathrm{PCl}$ en todos los casos tiene valores inferiores al del gasóleo al tener un contenido en Carbono inferior, esta disminución del $\mathrm{PCl}$ queda en parte compensada con el aumento de 0 en el combustible que permite la utilización de menor aire de exceso y por lo tanto un aumento en el rendimiento de la combustión al haber menores perdidas en los humos.

\subsubsection{Adecuación del combustible}

Los procesos de obtención del aceite de semillas varían según la naturaleza y el origen de la semilla pero en términos generales se recogen en el apartado 2.6 de una forma genérica. Hay que señalar los mejores resultados que proporcionan los aceites refinados frente a los crudos sobre todo en el caso del aceite de girasol.

Esta adecuación de los aceites podría simplificarse para el uso del aceite como combustible, limitándose a procesos de prensado mecánico y filtrado obteniéndose como subproducto harinas para consumo animal o bien procediendo a la extracción con solventes que aumentan la producción de aceite, con mayor inversión.

En resumen es un equilibrio económico con distintas soluciones para distintos casos. Aunque en líneas generales el rendimiento aumenta al utilizar aceites refinados tampoco el aumento es demasiado significativo.

La composición de las mezclas de aceite y gasóleo no presenta problemas de solubilidad y la mezcla es totalmente homogénea a temperatura ambiente.

\subsubsection{Combustión de las mezclas}

El proceso de combustión que se ha desarrollado ha permitido observar el comportamiento de las distintas mezclas aceite-gasóleo para distintos aceites con modificaciónde los parámetros de la combustión: admisión de 
aire y la presión de inyección. El $\mathrm{n}^{\mathrm{a}}$ total de experimentos que se han efectuado ha sido de 216.

Los factores que intervienen en el análisis son, como ya se ha indicado en Capítulo 6, el tipo de aceite, el porcentaje de mezcla, la presión de inyección y el caudal de aire.

El objetivo de los ensayos no era encontrar el punto óptimo de cada una de las muestras ensayadas sino ver el comportamiento frente a los cambios de los parámetros de la combustión lo que permitirá un uso en equipos convencionales en los que las condiciones de funcionamiento no corresponden a las de laboratorio..

Los datos correspondientes a los productos de la combustión y el rendimiento de la misma se calculan partiendo de la composición elemental del combustible para cada una de las mezclas y de los datos obtenidos en el analizador de humos utilizado en los experimentos. Los datos se tratan en una hoja de cálculo desarrollada a tal efecto.

\subsubsection{Análisis de los resultados}

El análisis de resultados se estructura en los tres parámetros que se consideran los más significativos del proceso de combustión que son el rendimiento, las emisiones en humos de $\mathrm{CO}$ y NOx.

La conclusión en resumen del análisis del Rendimiento es que la variable más influyente es el tipo de aceite, que el parámetro de presión de inyección tiene un comportamiento en algunos casos irregular, no siempre aumenta el rendimiento con el aumento de la presión de inyección.

El comportamiento para cada tipo de aceite varía sensiblemente y es necesario analizar separadamente los distintos tipos de aceite.

En el análisis de las emisiones de CO, tal y como predecía el análisis ANOVA la mayor interacción entre factores se da en la interacción AceitePresión de inyección, aunque su comportamiento difiere según el tipo de aceite, para el aceite de soja Crudo y refinado y para el aceite vegetal usado (ASC, ASR, AVU) las emisiones de CO aumentan con la presión, mientras que para el resto de los aceites disminuyen. También en el grupo de aceites con interacción positiva las emisiones aumentan al aumentar el porcentaje de aceite. En el resto de los aceites presentan en unos casos picos de emisiones y en otros tendencias negativas con el aumento de porcentaje. 
En el caso de las emisiones de NOx también se predecía que las variables más significativas eran el tipo de aceite y la presión de inyección.

Con respecto al porcentaje de aceite en la mezcla, las emisiones tienden a crecer en general al aumentar dicho porcentaje, aumenta el nivel de Nitrógenoy sobre todo el contenido en 0 del combustible lo que hace que aumente la temperatura de combustión, mecanismo fundamental para la generación de NOx.

Los mínimos de emisión se producen a las presiones de inyección más bajas.

En cuanto al tipo de aceite las emisiones aumentan al utilizar aceites refinados frente a los crudos. Las tendencias de todos ellos pueden observarse en las gráficas correspondientes donde se han comentado cada una de ellas.

\subsection{DESARROLLOS FUTUROS}

La experiencia obtenida en la presente tesis y en otras desarrolladas en el mismo laboratorio del Departamento de Ingeniería Energética y Fluidomecánica puede aplicarse al estudio de la combustión de otros tipos de residuos líquidos que permita además de la valorización de dichos residuos, la capacidad de deshacerse de ellos sin perjuicio medioambiental. La variedad de residuos que se generan hace que sea necesaria su destrucción de una forma segura con el mínimo coste, valorizarlos energéticamente puede ser una de las formas de eliminación. La Lista Europea de Residuos (LER) ${ }^{109}$ contiene una amplia clasificación de residuos y su valoración.

Desde el punto de vista experimental el disponer de un equipo de combustión que permita la medición de los caudales de aire de forma precisa podría aportar datos más elaborados sobre el proceso de combustión y sobre las condiciones óptimas de maniobra.

El disponer de analizadores más completos que permitan la obtención directa de más parámetros de la combustión, no teniendo que calcularlos teóricamente, y con mayor precisión, puede aportarnos la explicación a algunos resultados que parecen contradecir los pronósticos teóricos.

109 LER (Lista Europea de Residuos) MAM/304/2002de 8 de Febrero 
Para el ensayo de fluidos más viscosos sería necesario profundizar en los procesos de atomización, incluso ensayos de atomización con fluido auxiliar que permitan asimismo el uso de equipos convencionales de combustión. 


\section{BIBLIOGRAFÍA CAPÍTULO 9}

108) APPA Biocarburantes. Datos biodiesel 2011

109) LER (Lista Europea de Residuos) MAM/304/2002de 8 de Febrero 


\section{A1. ANÁLISIS DE LOS ACEITES}

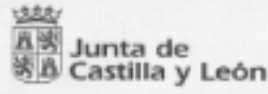

\section{DATOS ADMINISTRATIVOS}

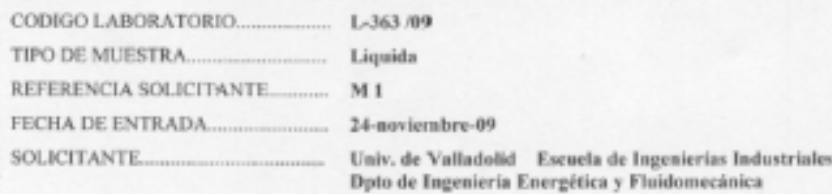

RESULTADOS

\begin{tabular}{|c|c|c|c|}
\hline Densidad a $15^{\circ} \mathrm{kakj}$ & 920 & $\mathrm{Kg}_{\mathrm{m}} \mathrm{m}^{\prime}$ & CNESMIII \\
\hline Dewsidas a $35^{\circ} \ldots \ldots \ldots$ & 907,5 & $K=m^{\prime}$ & ENe $\sin 6$ \\
\hline Densidad a $60^{\circ} \ldots$ & 891 & $\mathrm{Kg} \mathrm{m}^{\mathrm{T}}$ & ENESHIV \\
\hline Viscosidad einemleica a $4 \bar{\circ} \mathrm{C}$ & 41,22 & $\mathrm{~mm}^{2} / \mathrm{s}$ & CAEST/NA \\
\hline Viscosidad cinemitika a loorc. & 8,87 & $\operatorname{mon}^{2} / \mathrm{s}$ & LNESThes \\
\hline Carbono...... & 773 & Sind in & 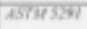 \\
\hline 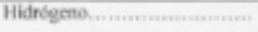 & 113 & $\mathrm{Sm} / \mathrm{m}$ & ASTh 5801 \\
\hline Nitrogeno....................., & 4,05 & Somin & ASTMEN \\
\hline 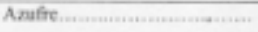 & 4.02 & Nomim & 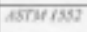 \\
\hline Cenizas & 0,000 & Somint & ENETH \\
\hline AgGua......... & 469 & $m e \mathrm{ke}$ & ATMNITH \\
\hline Oxigeno issim por def .......... & 113 & Simint & \\
\hline Poder calorifico superior........... & 9990 & Keal Kg & 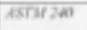 \\
\hline Poder calonifico inferior.......... & 8817 & Keal $K_{g}$ & सरामानक \\
\hline
\end{tabular}

Lecha. 23 de dicifffore de 200

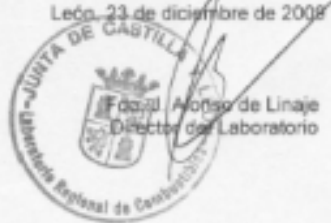

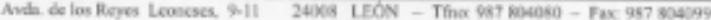

Análisis del aceite vegetal usado 


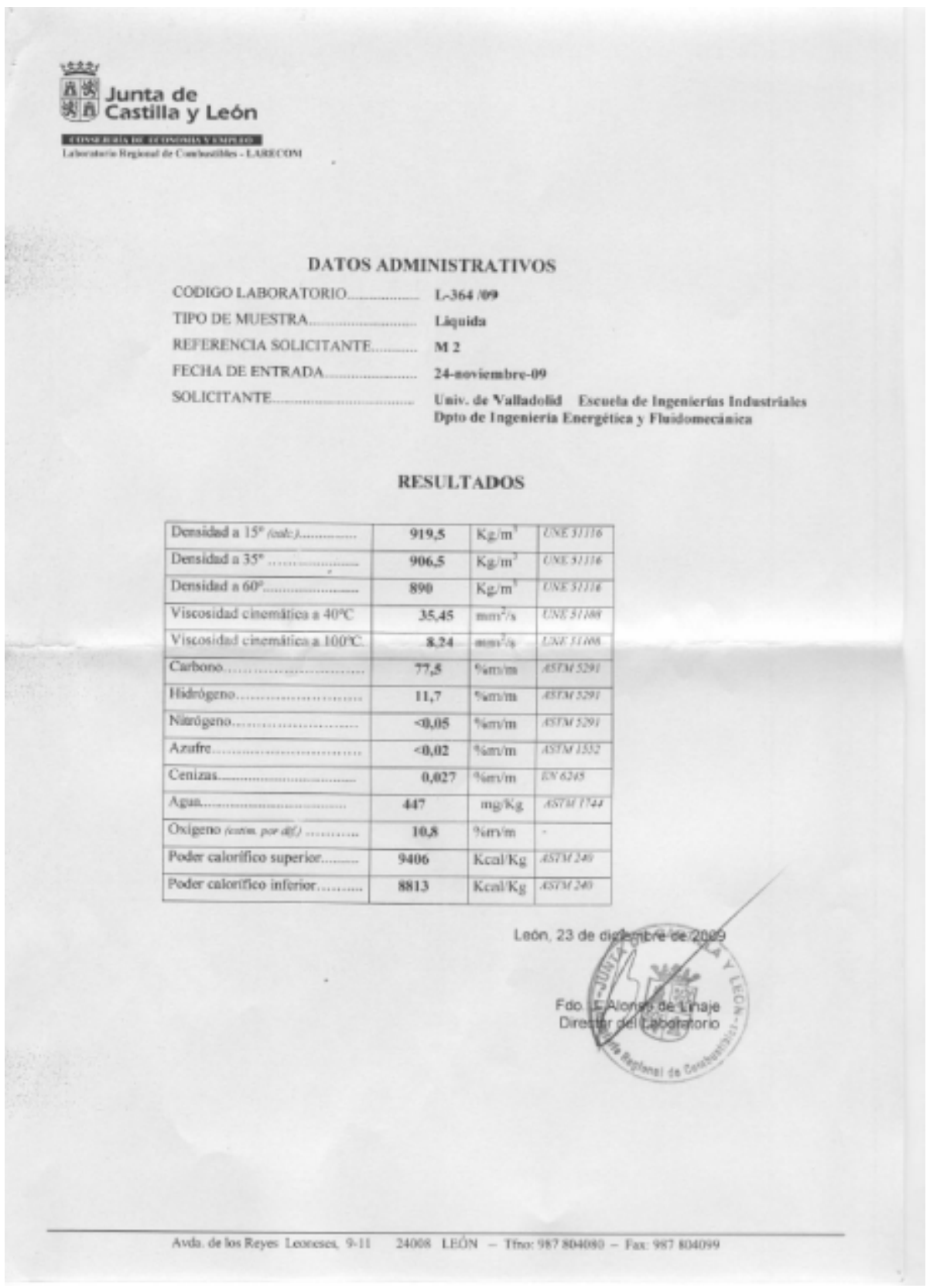

Análisis del aceite de colza crudo 
ares

A Junta de

8) Castilla y León

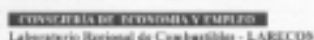

\section{DATOS ADMIVISTRATIVOS}

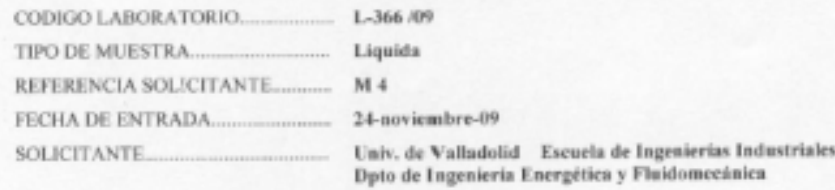

RESULTADOS

\begin{tabular}{|c|c|c|c|}
\hline Densidad a $15^{\circ}$ fodt li.............. & 9225 & $\mathrm{Kg} \mathrm{m}^{\prime}$ & 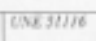 \\
\hline Densidad a $35^{\prime \prime} \ldots \ldots \ldots$ & 9095 & $\mathrm{Kg} / \mathrm{m}^{2}$ & We: 11116 \\
\hline Densidad a $60^{\circ}$ & 894 & $\mathrm{~K} g \mathrm{~m}^{\prime}$ & Covग5ा \\
\hline Viscosidad cinemática a $40^{\circ} \mathrm{C}$ & 31,96 & $\min ^{2} / \mathrm{s}$ & CAE गास \\
\hline Viscosidad cincmatica a $100 \mathrm{C}$. & 7,67 & $\min \operatorname{mis}^{2}$ & बतशाल \\
\hline Carbono. & 77,4 & Simim & 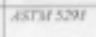 \\
\hline Hidrógeno ..................... & 115 & $5 \mathrm{~km} / \mathrm{at}$ & 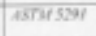 \\
\hline 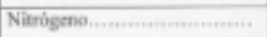 & as & $\mathrm{sm} / \mathrm{m}$ & Asrusal \\
\hline Azafre & 102 & STnim & ASTMTS52 \\
\hline Cenizas... & 0,069 & $\sin m / m$ & Evoves \\
\hline Agva & 494 & $m g / \mathrm{Kg}$ & 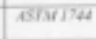 \\
\hline Onizeno kuin por difo .............. & 11,0 & Simm & 15 \\
\hline Poder calortitico superior....... & 9397 & Keal Ks & ESTM:200 \\
\hline 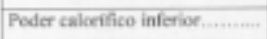 & 8814 & Keal/Kg & \\
\hline
\end{tabular}

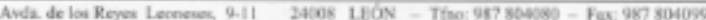

Análisis del aceite de soja crudo 


\section{Ator Junta de \\ * A Castilla y León

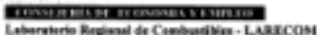

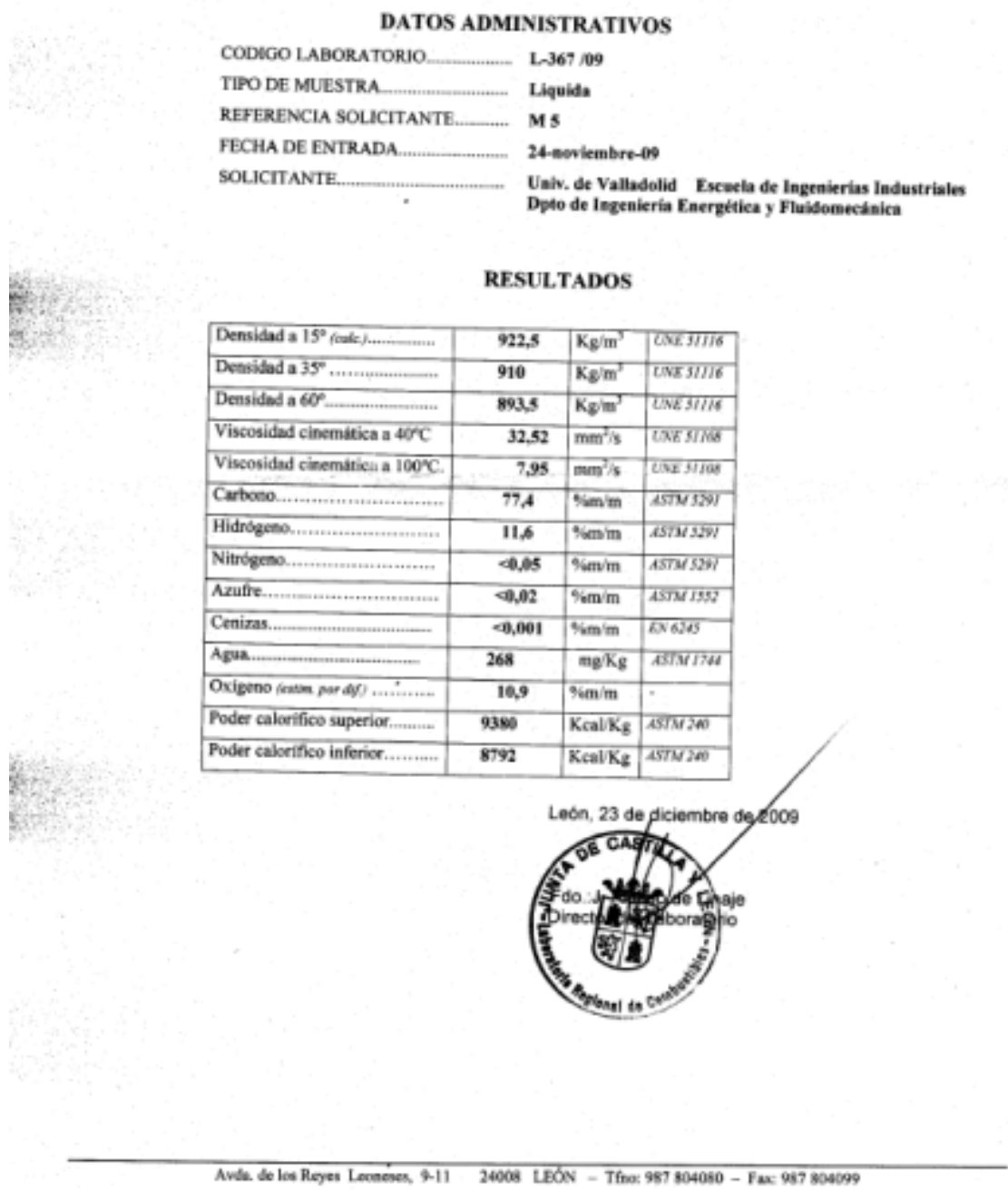

Análisis del aceite soja refinado 


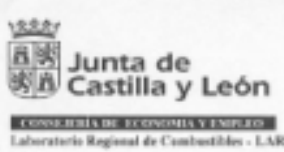

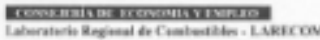

DATOS ADMINISTRATIVOS

CODICO LABORATORIO
TIPO DE MUESTRA
REFERENCLA SOLICITANTE
FECHA DE ENTRADA
SOLICITANTE
L-368 ie9

Liquida

M6

24-neviembre-09

Univ. de Valladolid Escuela de Ingeaierias Industriales

Dpto de Iageaieria Eanergética y Fluidomecaaica

RESULTADOS

\begin{tabular}{|c|c|c|c|}
\hline Densidad a $15^{*}$ fouct-h................. & 922,5 & $\mathrm{Kg} / \mathrm{m}^{\prime}$ & ENE शान \\
\hline Densidad a $35^{n}$. & 9005 & $\mathrm{Kg} / \mathrm{m}^{\prime}$ & एज्ञाया \\
\hline Dencidad a $60^{\circ} \ldots$ & $8 \$ 3$ & $\mathrm{Kg} / \mathrm{m}^{\prime}$ & एAESTIT \\
\hline Viseosidad cinemática a $40^{\circ} \mathrm{C}$ & 33.68 & $\operatorname{man}^{2} / s$ & WESMTOS \\
\hline Visonsidad cinemática a $100{ }^{\circ} \mathrm{C}$. & 8.25 & $\mathrm{~mm}^{2} / \mathrm{s}$ & Lacsitas \\
\hline Cartoce & 77,5 & $5 \mathrm{sanm}$ & 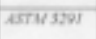 \\
\hline Hidrógeno.... & 11,5 & Nanm & ASAM SEN \\
\hline Nitrogeno ............................. & $-0,08$ & Sarim & 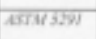 \\
\hline Axufre............... & 0,03 & Gavie & ASTM/ 159 \\
\hline 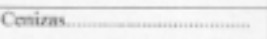 & 0,004 & $\operatorname{San}=$ & $2 \times 6245$ \\
\hline 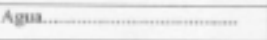 & 287 & $m g / g$ & $=$ \\
\hline 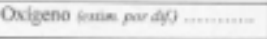 & 10,9 & 4 tanim & \\
\hline Poder caloritice superiof ............... & 9355 & Keal/Kg & $A 5 T M 225$ \\
\hline Poder ca & 8772 & KealKg & wo \\
\hline
\end{tabular}

León, 23 degdiciembre de 2009 जTA DE of

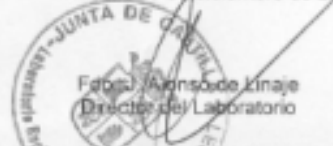

30

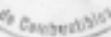

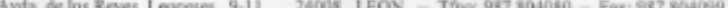

Análisis del aceite de girasol refinado 


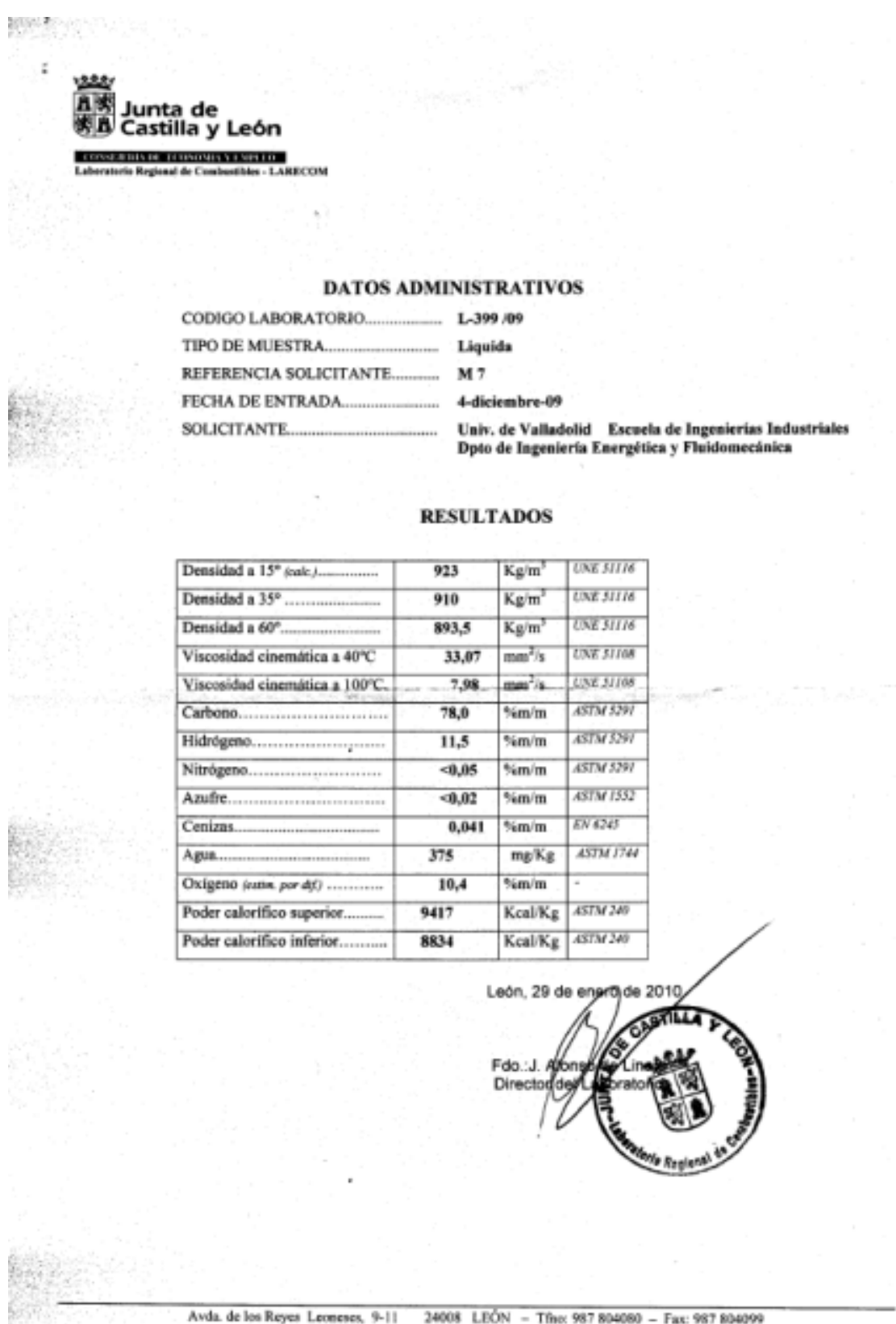

Análisis del aceite de girasol crudo 


\section{A2. CALIBRACIÓN DEL ANALIZADOR}

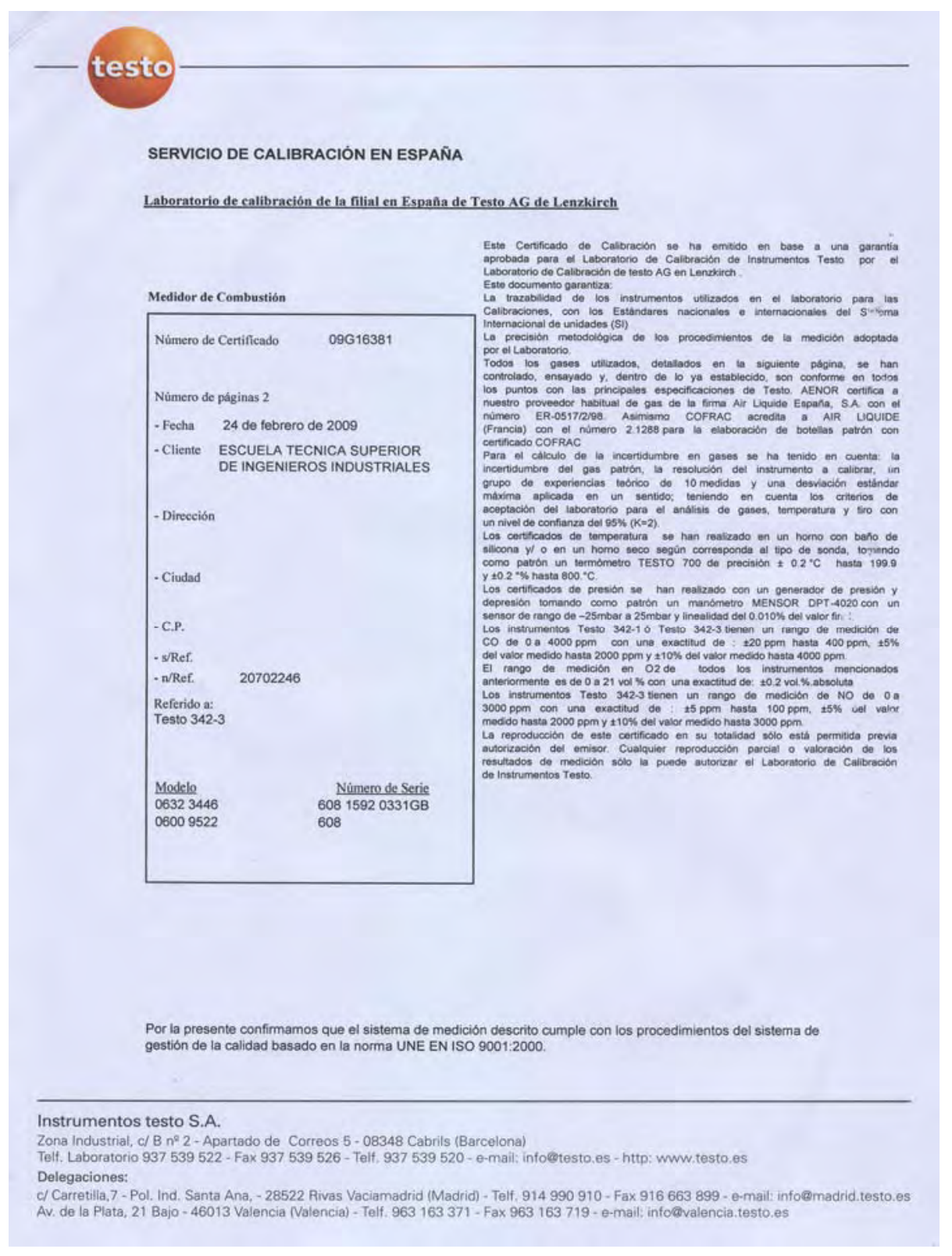


testo

CERTIFICADO DE CALIBRACION

\begin{tabular}{|c|c|c|c|}
\hline \multicolumn{4}{|c|}{ CONDICIONES AMBIENTALES } \\
\hline Parametro & $\begin{array}{c}\text { Unidad } \\
\text { Medicion }\end{array}$ & $\begin{array}{c}\text { Valores } \\
\text { limites }\end{array}$ & $\begin{array}{c}\text { Valores al } \\
\text { inicio de la }\end{array}$ \\
\hline Temperatura & ${ }^{\circ} \mathrm{C}$ & $18 . . .26$ & 21.7 \\
\hline Humedad relativa & $\%$ & $<70$ & 28.4 \\
\hline Presión & $\mathrm{hPa}$ & $860 . .1080$ & 946 \\
\hline
\end{tabular}

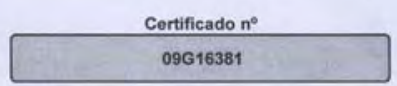

Fabricante: Testo AG

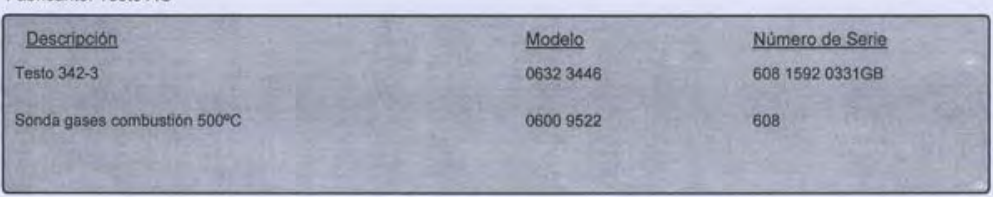

TABLA DE VALORES DE LA CALIBRACION

\begin{tabular}{|c|c|c|c|c|c|c|c|c|}
\hline Parámetro & $\begin{array}{l}\text { Unidad } \\
\text { medición }\end{array}$ & $\begin{array}{l}\text { Valor } \\
\text { nominal }\end{array}$ & $\begin{array}{l}\text { Valor } \\
\text { medido }\end{array}$ & $\begin{array}{l}\text { Limite } \\
\text { minimo }\end{array}$ & $\begin{array}{l}\text { Limite } \\
\text { máximo }\end{array}$ & $\begin{array}{l}\text { incentisumbre on } \\
\text { in mescion }\end{array}$ & $n^{n}$ Certificado del patron & $\begin{array}{l}\text { Laboratorio que ha } \\
\text { emitio ol cortificado }\end{array}$ \\
\hline co & ppm & 994 & 989 & 945 & 1043 & 19 & 160300A COFRAC & AIR LQUIDE \\
\hline 02 & \% & 1.4304 & 1.3 & 1,2 & 1.6 & 0.1 & 160308A COFRAC & AIR LQUIDE \\
\hline No & ppm & 79.5 & 79 & 74 & 24 & 2 & 5484 SCS & CARBAGAS \\
\hline Temp, Gas & *c & 100,12 & 100,1 & 98,5 & 101,7 & 0.7 & T17314 OKD-K-11201 2008-02 & TESTOAG \\
\hline Tiro & mbar & $-0,9096$ & 0.908 & $-0,0396$ & $-0,8796$ & 0.01 & D2819 DKD-K-05301 07-08 & TESTOAG \\
\hline
\end{tabular}

Comentarios:

Comentarios:
Los valores positivos del tiro indican que no hay revoco.

- Las valores positivos del tiro indican que no hay revocalizada según el procedimiento PR-15.

24 de febrero de 2009

Técnico de Calibración

Roveo.

Marco Campillejo 